

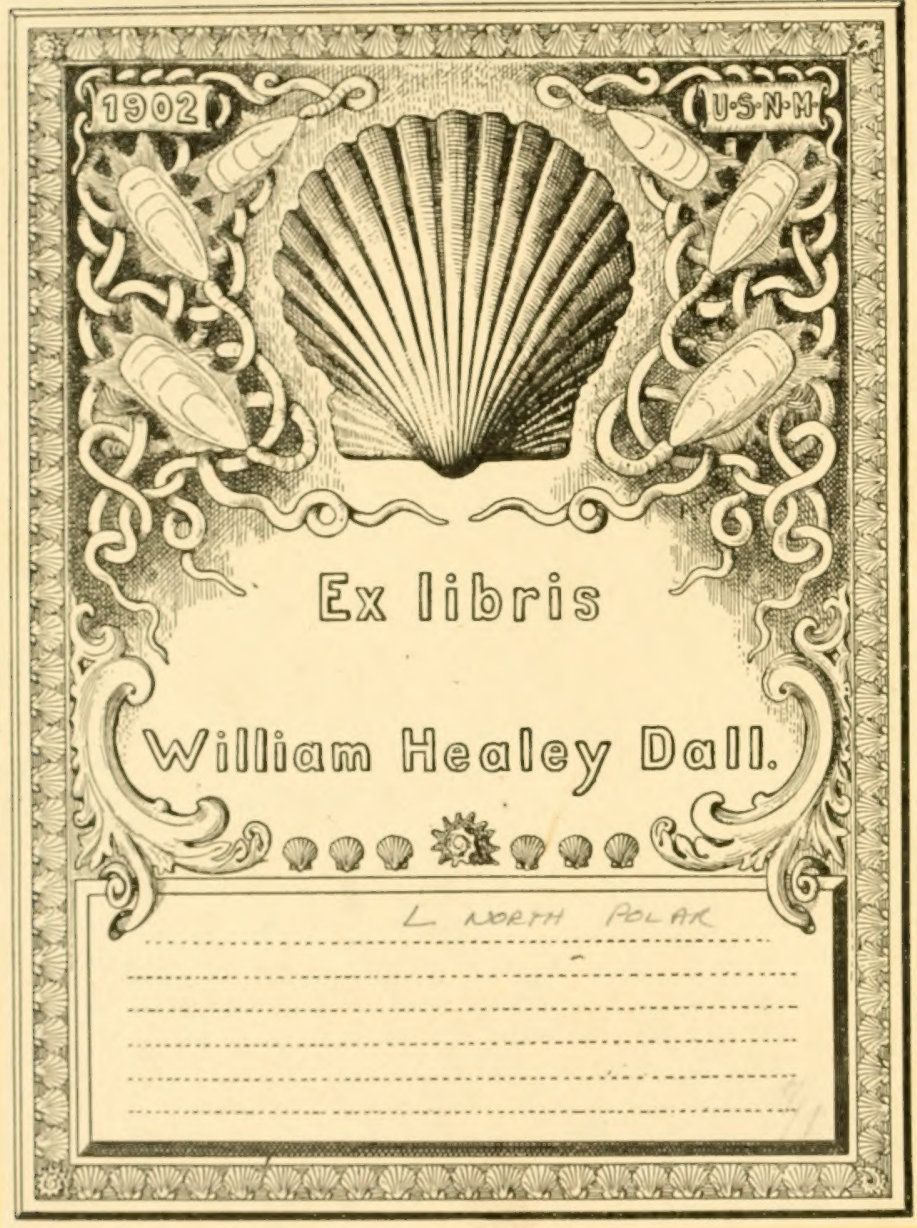


Division of Mollueles Sectional Librory 



Division of Mollusks Sectional Library

\section{DIE ZWEITE \\ DEUTSCHE NORDPOLARFAHRT}

Z W E I T E R B A N D.

WISSENSCHAFTLICHE ERGEBNISSE. 



\title{
DIE ZWEITE
}

\section{DEUTSCHE NORDPOLARFAHRT}

\author{
IN DEN JAHREN 1869 UND $18 \% 0$
}

UNTER FÜHRUNG DES KAPITÄN KARL KOLDEWEY.

\author{
HERAUSGEGEBEN
}

VON DEM

VEREIN FÜR DIE DEUTSCHE NORDPOLARFAHRT IN BREMEN.

ZWEITER BAND.

WISSENSCHAFTLICHE ERGEBNISSE.

MIT 31 TAFELN IN LITHOGRAPHIE UND KUPFERSTICH

UND 3 LITHOGRAPHIRTEN KAR'TEN.

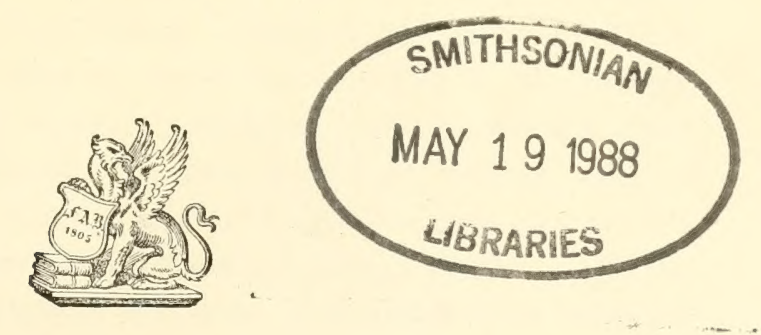

LEIPZIG :

F. A. B R O C K H A U S.

1874. 
Das Recht der Uebersetzung ist vorbehalten. 


\section{Vor W 0 I. t.}

Als der Verein für die Dentsche Nordpolarfahrt mit der IIerausgabe des officiellen Hauptwerkes iiber die zweite Deutsche Nordpolarexpedition zugleich auch die der wissenschaftlichen Ergebnisse iibernahm, war er sich der erhöhten Schwierigkeiten dieses 'Theiles wol bewnsst, durfte aber bei der Wichtigkeit des Gegenstandes von Seiten der Gelchrtenwelt auf kräftige Unterstiitzung rechnen. Dieselbe ist ihm dem auch in der erfreulichsten Weise reichlich zutheil geworden, wie der vorliegende Band genügend zeigen wird, den der Verein sich beehrt hiermit der Oeffentlichkeit zu iibergeben.

Er fühlt sich dabei gedrungen allen Denen ron Herzen Dank zu sagen, die das Zustandekommen des schönen Werkes in so würdiger Weise möglich machten, zunächst also den Bearbeitern des von der Expedition heimgebrachten wissenschaftlichen Materials, den Hexten: l'rofessor Dr. A. Bauer in Wien, Regimentsarzt Dr. H. F. Bonorden in Herford, Dr. C. Börgen in Leipzig, Professor Dr. Franz Buchenau in Bremen, Professor Dr. Rudolf Buchholz, zur Zeit in Westafrika, Dr. Ralph Copeland in Parsonstown (Irland), Geheimrath Professor' Dr. C. G. Ehrenberg in Berlin, Dr. Otto Finsch in Bremen, Dr. Wr. O. Focke in Bremen, L. Fuckel in Oesterich im Rheingau, Dr. A. Gerstäcker in Berlin, P'rofessor Dr. E. Hrekel in Jena, Professor Dr. Oswald Heer in Ziirich, Hauptmann Alexander von Homeyer in Schweidnitz, Bürgermeister Dr. G. H. Kirchenpaner in Iamburg, Dr. Louis Koch in Nürnberg, Kapitän Karl Koldewey in Hamburg, Professor Dr. G. W. Körber in Breslau, Professor Dr. Gregor Kraus in Erlangen, Professor Dr. C. Kupffer in Kiel, Dr. Oskar Lenz in Wien, Professor Dr. Karl Möbius in Kiel, Professor Dr. Karl Müller in Halle, Hermann ron Nathusius in Hundisburg, P'rofessor Dr. Alfred Newton 


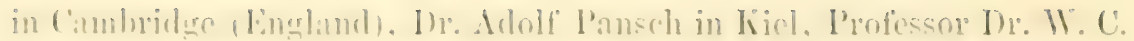

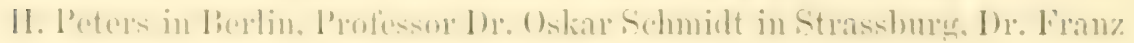

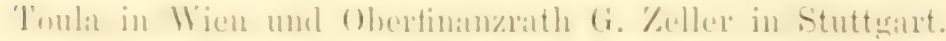

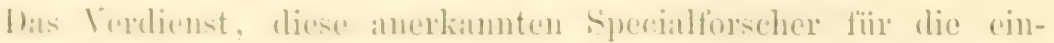

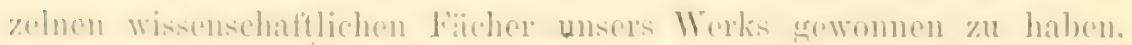

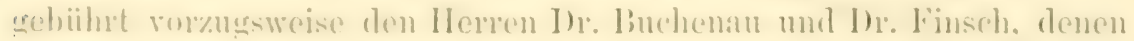

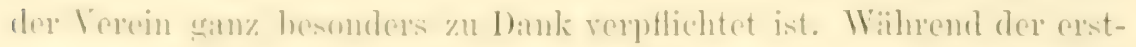

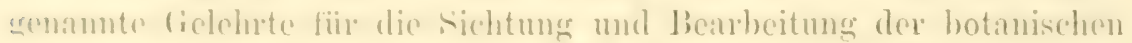

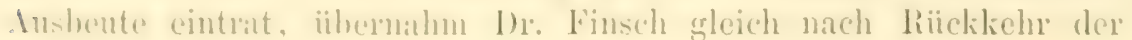
Lxperlition die Sorge fïr die bei Weitem umfangreicheren zoologiselsen simmlungen. sowie später die Ilauptredaction des wissenschattlichen 'Theils, zu dessen Herausarabe el den ersten Anstoss gab und die er dureh seine lirfihrungen und mermüdliche Thaitigkeit wesentlich trimilem hall:

Die wissenschaftliche Verwerthung der geologischen und mineraIngischen sammlungen verdankt der Verein der ansgezeichneten Vermittolung des Herm I'rofessor I)r. Ferdinand ron Hochstetter in Wien.

liesonders dankend muss hier noch der L'nterstitzung der Kïnierlichen Akutemie der Wissenschaften in lierlin wedacht werden, welche in antmunternder Weise \%ur Iferstellung der Crustaceentafeln die schüne summe von joot Thalern anwies, mu dadurch das lebhatte Interense an der wiurdigen IIerausgale des nationalen Werkes kräitign zit herthiitigens.

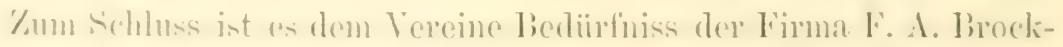
hans in Lajprig die wohlverdiente Anerkemnung iffentlich auszusprechen

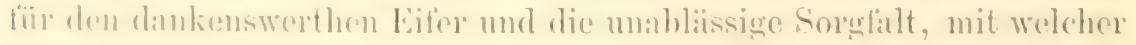
in dreren riihmlichst hekannten typographisch-atristischen Anstalten die

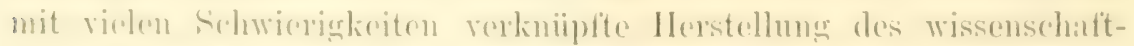

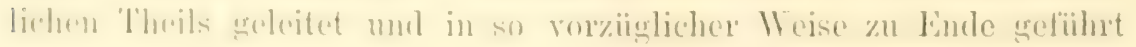
murale.

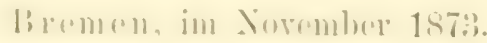

lor. Vorein fïr die Dentsche Xorlpolarfihnt.

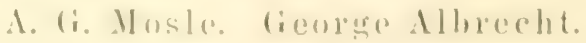




$$
\text { B } 0 \text { T A N I K. }
$$





\section{Vorbemerkung.}

Die botanischen Sammlungen der zweiten deutschen Nordpol-Expedition gewähren sowohl durch ihren änssern Umfang, als durch ihre Mannichfaltigkeit ein ganz besonderes Interesse. Bis zu dieser Expedition waren unsere Kemntnisse der Flora des arktischen Ostgrönland nux mangelhaft; sie beschränkten sich auf die von W. Scoresby und General Sabine angelegten Sammlungen, welche beide yon W. J. Hooker bearbeitet wurden. Scoresby sammelte während seiner kurzen Aufenthalte an der Küste (1822) 37 Gefäss- und einige wenige Zellenpflanzen, Sabine dagegen brachte (1823) obwohl durch astronomische und physikalische Beobachtungen vielfach in Anspruch genommen, doch eine Sammlung von 57 Gefäss- und 4 Zellenpflanzen zusammen, so dass die Gesammtzahl der aus dem arktischen Ostgrönland nachgewiesenen Arten von Gefässpflanzen nunmehr 61 betrug. - Unsere Experlition erweiterte die botanische Kenntniss des östlichen Grönland in sehr erfrenlicher Weise. Natiirlich war es den wissenschaftlichen Begleitem der Hansa nicht möglich, in dieser Richtung etwas zu thuen, da es ihnen nicht gelang, die Ostküste zu erreichen; desto erfreulichere liesultate lieferte die Thätigkeit der Herren Dr. Panseh und Dr. Copeland anf der Germania, welche sich nach besten Kräften bemiihten, msere Kienntniss der ostgrönländischen Pflanzenwelt allseitig zu erweitern.

Die botanischen Sammlungen bestanden im wesentlichen aus einer Anzahl Packen regelrecht getrockneter P'flanzen (meist I'hanerogamen und Gefässkryptogamen, aber auch cinige Algen), zwei Kisten mit Rasen und Einzelexemplaren von P'flanzen, welche ohne Pressung verpackt waren, zwei Kisten Flechten und Moose, sïmmtlich gleichfalls ungepresst, einer Anzahl von Birken- und Weidenstimmen, einer Sammlung Treibholz (theils grosse Stämme, theils kleinere Stiicke), und endlich einigen Büichsen und Kruken mit Hutpilzen und Algen in Spiritus. Hierzu kamen dann noch einige Pflanzen, welche die HansaMänner nach ihrer Landung im südlichen Grönland gesammelt hatten.

Alle diese Gegenstände wurden mir bald nach der Rückkehr der Expedition zur Präparation uibergeben. Es hatte sich nicht ganz rermeiden lassen, dass manche derselben, namentlich die in Löschpapier eingelegten und die in Kisten verpackten Pflanzen während der stiirmischen Rückreise einige Feuchtigkeit angezogen hatten und in Folge 


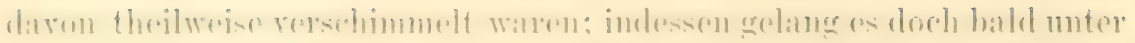

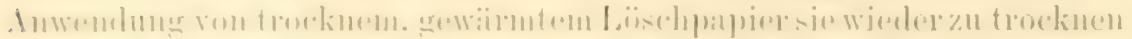

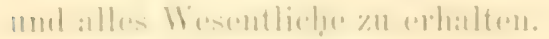

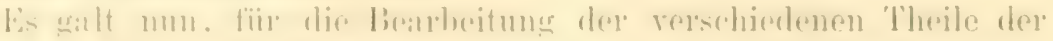

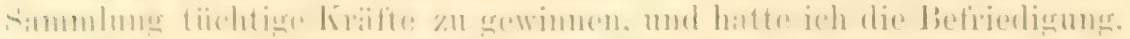

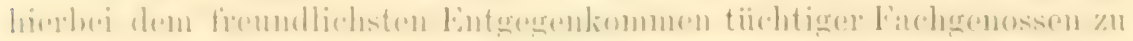

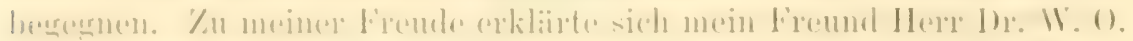

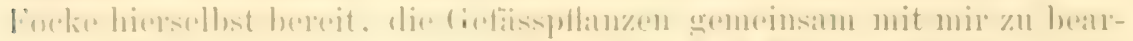

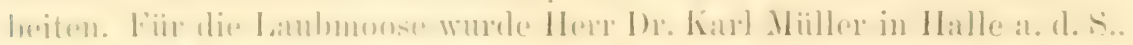

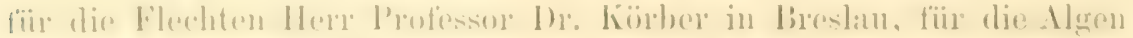

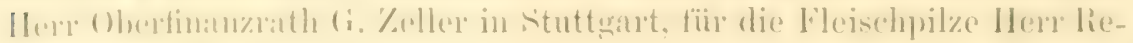

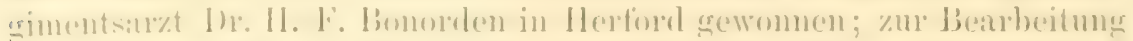

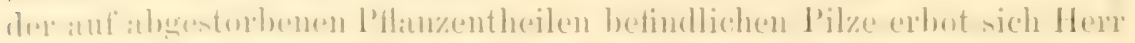

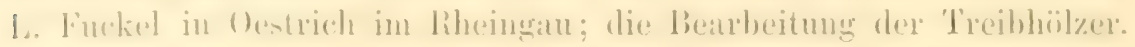

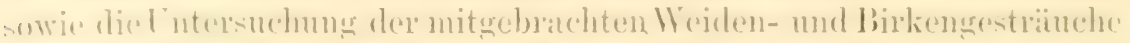

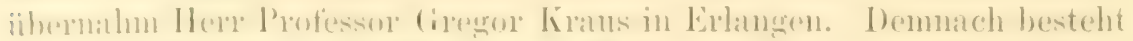

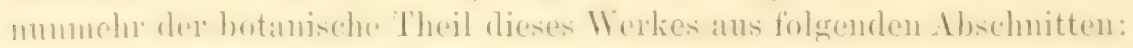

1) lilinil und P'llanzenleben ant Ostgrönland, ron 1)r. Ad. Pausch (bereits ab)redruckt in der liroschüre: ,Dic zweite Deutsehe Nordpolarexpedition

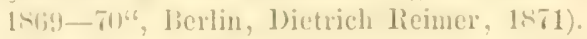

2) Ciefissptlanzen Ostgrönlands, nebst einer Einleitung und Discussion der his jetzt üher die Filora Ostgrünlands bekamnten 'Thatsachen, bearbeitet von Profeson I)r. Franz linchenau mul Dr. Wilhelm Olbers Focke.

ii) Tatubnoose, brarheitet von Dr. Liarl Müller.

1) Filechen. learlicitet von Professor I)r. Kïrber.

5) Algen, bearbeitef von Olertimamzrath (i. Zeller.

(i) J'ilze: a) l'leischpilze, hearbeitet von I)r. II. F. Bonorden,

b) endophytische Pilze, bearbeitet ron L. Fuckel.

i) Treibhölzer von del ostgrünländischen hïste und aus dem F.jort, bearbeitet von l'rofessor Dr. Gregor liraus.

s) Finige Bomerkungen über Alter und Wachsthumsverhïlnisse ostgrönlïndischer Ilolzerewächse, ron demselben.

Ilit Iliilfe der tiichtigen, vorstehend genamenten Gelehrten ist es

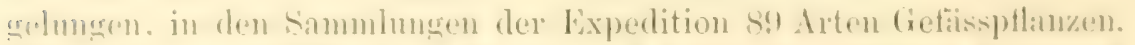

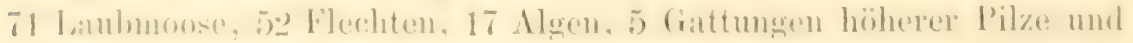
1:; Aten endophytischer P'ilze nochzuweisen, sowie den beweis fïr die

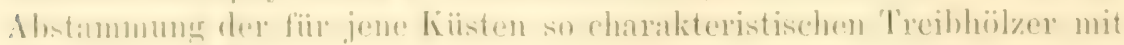

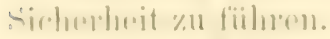

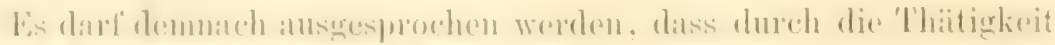

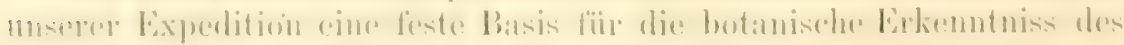

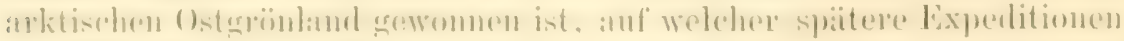
mit bifule forthancol kimment.

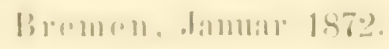

Franz Buchenau. 
1.

\title{
Klima und Pflanzenleben auf Ostgrönland,
}

\author{
Von \\ Adolf Panseh \\ in Kiel.
}

Wan ist ron vornherein allzu leicht geneigt, sich die arktischen Lïnder den ganzen Sommer hindurch unter einer Schneedecke begraben zu denken; man hat dic Vorstellung, als ob aus diesen weissen Einerlei nur hier und da eine schroffe, glatte Felswant oder Zacke herrorrage, oder, durch gïnstige Verhältnisse hervorgerufen, im Hochsommer einzelne schneefreie Flecken einer kümmerlichen Vegetation Raum bieten.

Diese Vorstellung, wenn sie auch bei den meisten eine iibertriebene war, ist doch durch die Erfahrung aus andern arktischen Gegenden einigermassen gerechtfertigt. Wem, jene Länder, unter hoher Breite gelegen, von vielen Nebehn umflossen, mu mit sparsamer und schwacher Somnenwarme beglïckt werden, so genügt dieselbe nicht, die Menge Schnee eines Winters, der im Sommer noch oft genug durch neven Niederschlag vermeht wird, zu vernichten, um so weniger, wenn thanendes Küsteneis alle Wärme dämpft.

Auch wir hatten solche Vorstellungen an die ostgrönländische Küste mitgebracht, $u m$ so mehr, da ein ewiger Eisstrom, und dazu noch ein Strom kalten Wassers die Küste bestreicht. Und was fanden wir? Ein vollständig schmeefreies Land und zwar nicht nur im Hochsommer, sondern während drei voller Monate; ich sage schneefreies Land, denn Anhäufungen von vereistem Schnee und Eis bleiben selbstrerständlich an Hängen und in Schluchten stets vorhanden. Fragen wir aber nun weiter, wie es denn der Natur möglich wird. schon im Juni einen schneefreien Boden zu schaflen und denselben 


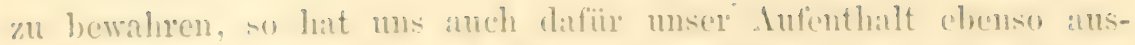

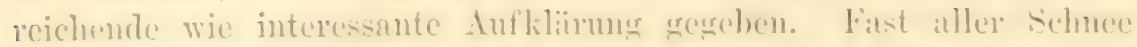

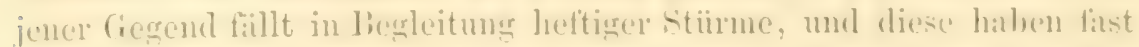

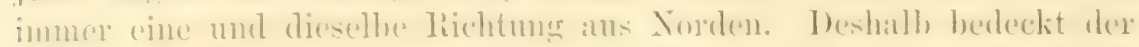

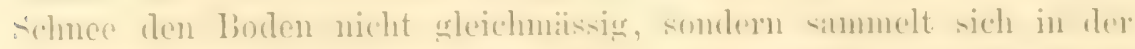

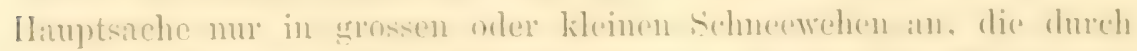

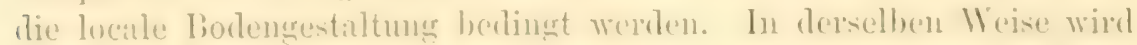

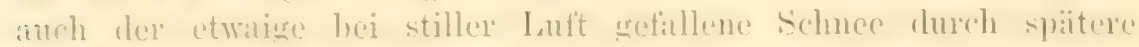

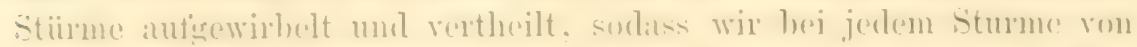

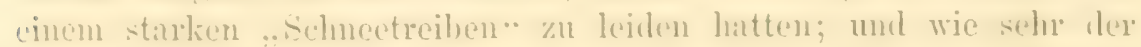

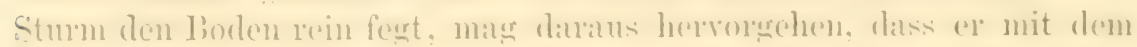
Felnee noch eine beträ̈chtliche Jenge lirde. Sinnd und steine rom andirnemen linelen weit hinans durch die Laft fortjagt, sodlass meilen-

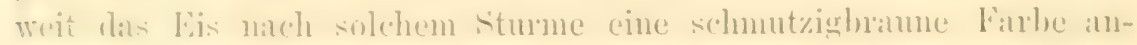
nimunt. Inf diese Woise erklärt sich demn anch die sonst anffallende Thatsache, ditss wir eigentlich nur einmal (es war bule Juni) eine

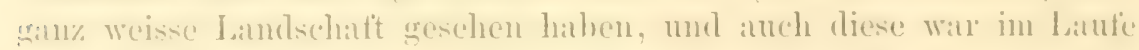
ron 2-; Theren wieder vollstïndig geschwmulen. So also h]ciben

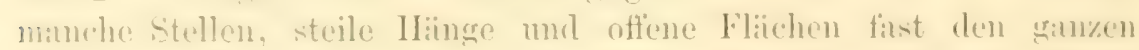
Winter von schnee entblösst; alles ïln'ige Land bedeckt eine diime 1-3ziillige sehneedecke, und in grösstem und kleinstem Missstalle finden sich ïherall zerstrent die Schneewehen. So wie num im lirüh-

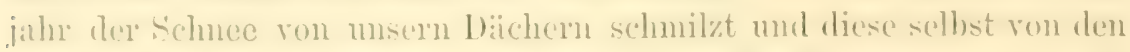

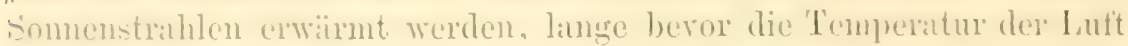
chtsprechend wïrmer wirk, so geschieht es in jenem (iebirgshonde in

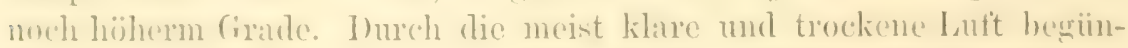

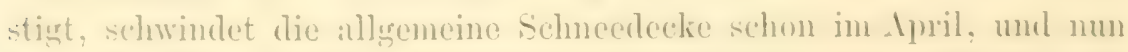

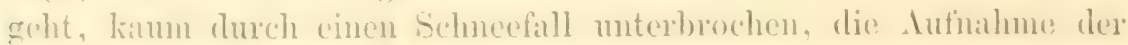
Waime, welche die jetzt nicht mehr mutergehende some ansstrahlt, in den dunkeln felsigen boden in hëchat ïherraschender Wrese vor sich. Wibhrend bis geenen Eule Mai die Luftemperatur noch stets

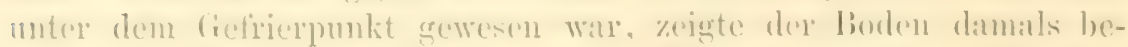

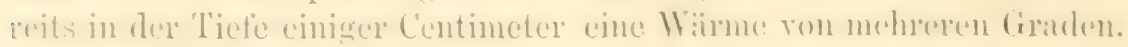

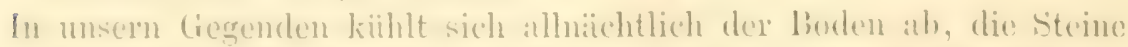

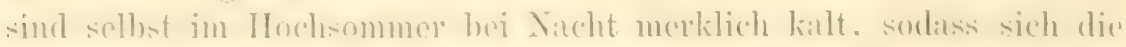

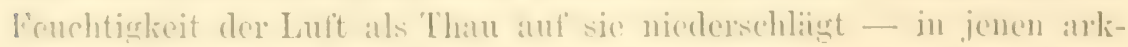
tischen fiefenden eribt e's im hohen sommer nur cine geringe nä̈cht-

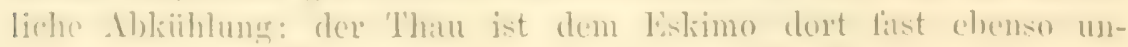

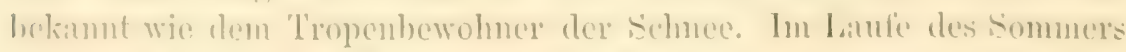
wirel um froilich die Evwirmung des liodens etwas gemaissignt, indem

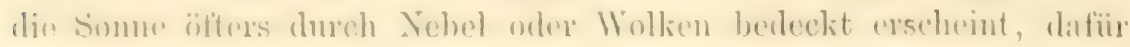


strahlt dann aber der Borlen auch nicht so stark aus. Der Boden thaut je nach Verhïltniss auf $1-1 \frac{1}{2}$. Fuss Tiefe auf und besitzt eine Wärme, die wohl geeignet ist, die Wurzeln der vorhandenen PHanzen energisch zu treiben. Und ebenso ist es cine bedeutende Wäme, die selhst bei kalter Luft den überirdischen Theilen der Pflanzen zuströmen muss, ebensowol von der strahlenden Wärme des Bodens als durch die Strahlen der allseitig lenchtenden nicht untergehenden Some. Die Erwärmung des Bodens ist so bedentend, dass bei Tage durch die aufsteigende warme Strömung die Luft iiberall in zitternder, wallender liewegung ist, so dass man sich genöthigt sieht. alle genanen trigonometrischen Messmgen bei Nacht zu machen, und das Auge selbst die Spitzen der höchsten Berge zuweilen in Kerrbildern erblickt. Diese massenhaft anfsteigende warme Luft folgt natugemäss dem Hange der Berge bis zu ihren höchsten Spitzen und wird hier anstatt abzukiihlen noch erwärmt durch die reinern, länger und meist senkrechter auffallenden Somnenstrahlen. Nimmt man dazu, dass selbst bei den dichtesten Nebeln, die das Land bedeckten, die (iipfel meist hervor'agten, so begreift es sich leicht, dass auf den bereren (ich spreche zunäichst nur von den beobachteten Höhen von $1-3000$ Inss), wo die ïbrigen Umstiunde es zulassen, die Yegetation vollstiundig dieselbe sein kamn wie in der Ebene, dass es also keine eigentlichen Höhengrenzen der P'thanzen hier gibt. Auf den Gipfeln der nicdrigern Berge fanden wix die Saxifragac, die Silene, Dryas und andere Gewächse oft in schönerer Entwickelung als in dev Ebene; und ist es nicht eine wunderbare Thatsache, dass auf einem Gipfel ron 7000 Fuss ausser schönen Flechten noch dicke Polster eines mehrere Zoll langen Mooses wachsen? Es her'scht in dem ganzen Walten und Wirken des arktischen Sommers sowie jedes einzelnen sommertages eine durchgehende Verschiedenheit von demjenigen, den man aus den Eisregionen der Alpen kennt. Dort in den $\Lambda$ pen ist Tag fü 'Tag ein Wechsel zwischen Kälte und Hitze, Dunkelheit und Helligkeit, Winter und Sommer, und auf beiden Seiten reschieht der Wechsel schnell und plötzlich, es wirken die einzehnen Factoren mit Lebhattigkeit, Nachdruck und augenblicklichem Erfolge. Hier im Norken gibt es eigentlich keinen Kreislauf von 24 Stunden: dex 'Jag zerfällt nicht in Licht nnd Dunkelheit, Wärme und Käle, sondern jeder dieser Gegensätze hat scine Herrschaft über einen ganzen Jahrestheil; sie treten nicht mit Siegesbewusstsein und schmellen bifolgen atuf, aber sie gleichen durch Ausuntzung aller vorhandenen Vortheile reichlich aus, was ihnen an grossen Mitteln abgeht. So macht diese langsam be- 


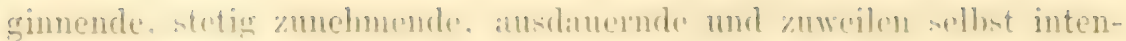

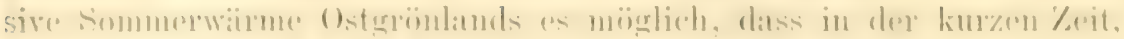

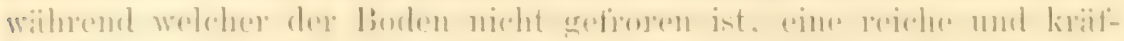

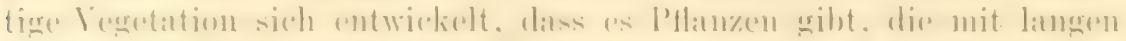

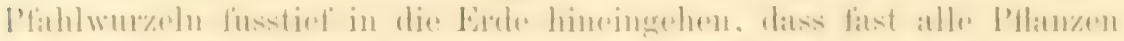

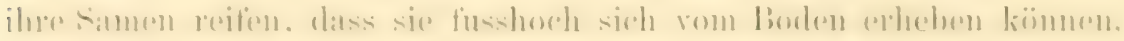

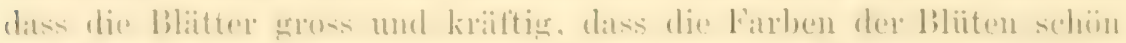
mul loblatt sind.

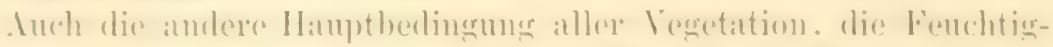

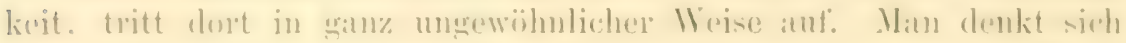

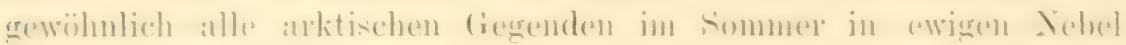

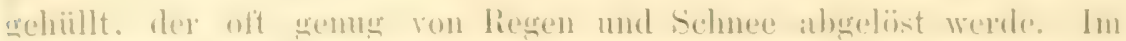

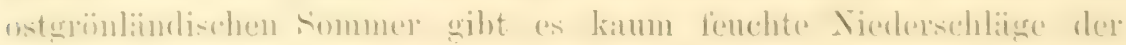

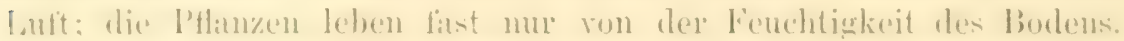

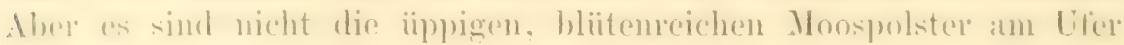

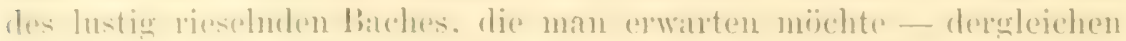

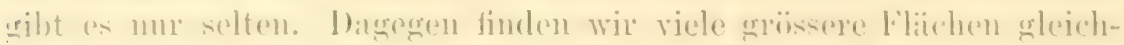

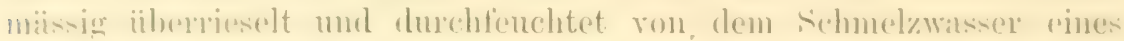

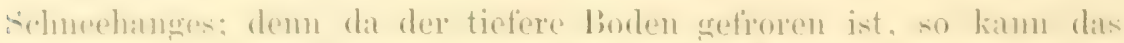

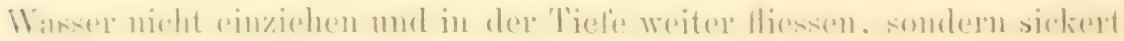

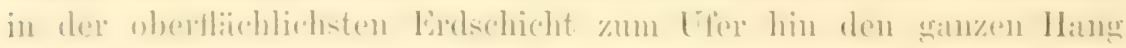

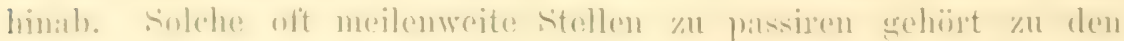

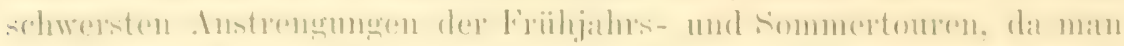

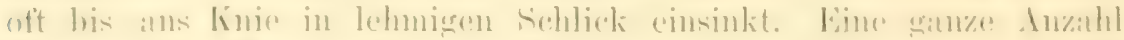

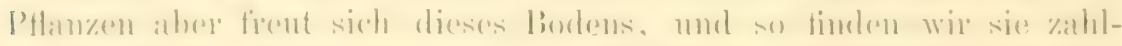

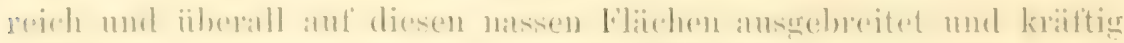

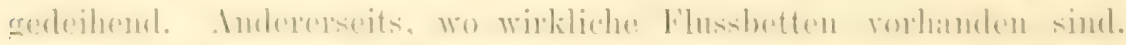

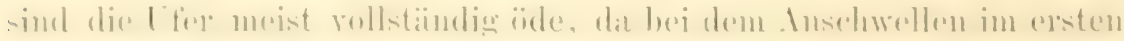

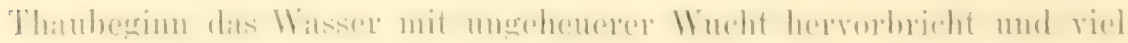

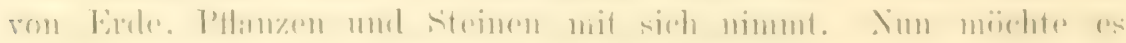

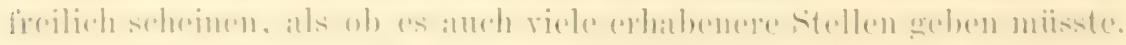

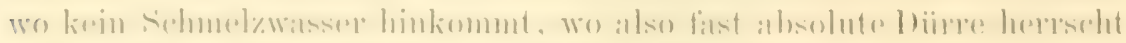

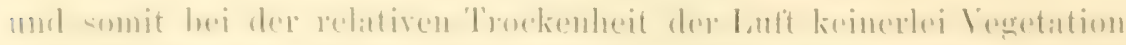

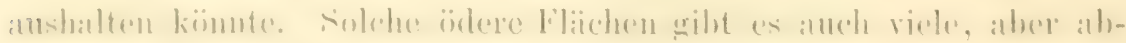

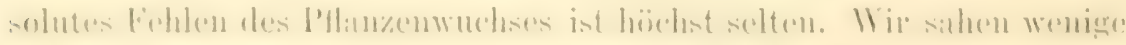

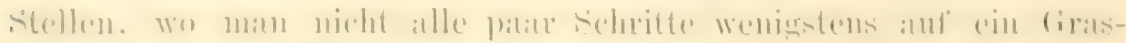

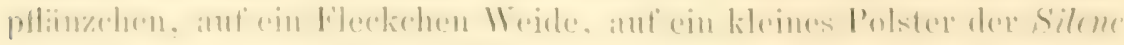

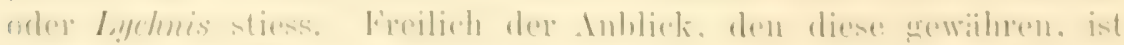

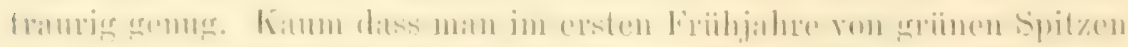

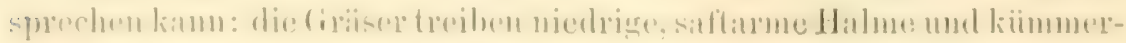

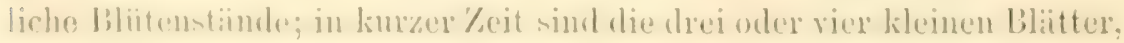


welche bei Kråutern und Sträuchern jeder Schössling treibt, blassbraum gefäbt wie die nicht abgefallenen vorjährigen; die Polster weisen sparsame, kurzstengelige, kleine Blüten auf - und der Jahreslauf ist heendet. Ist es nicht wunderbar? Wie der Wanderer auf winterlichen Fahrten an nichts mehr zu leiden hat als an Durst, so finden wir hier ein Pflanzenlehen auf ein Minimum reducirt, nicht durch Kälte und Nässe, sonder'n durch Diire und sengende Gilut! Diese V'erhältnisse sind es anch, die dem Gedeihen von Flechten und Moosen so hinderlich sind, dass wir in jenem "Reich der Moose und Flechten" oft erst lange suchen mussten, ehe wir eine Localitit funden, die dieser Bezeichmung nu einigermassen entsprach, und während Rennthiere himreichend vorhanden sind, ist die Rennthierflechte eine der seltensten Pflanzen.

Bedeutend höher aber steht die Vegetation des mit intensiverer Sommenwärme bedachten Festlandes. Da sieht man grosse gleichmässig griüne Flächen, auf rlenen Heerden von Rennthieren und Ochsen weiden, nicht nux am Fusse der Berge, sondern auch an den Gehängen derselben bis ïber 1000 Fuss hoch hinauf. Da findet man an manchen Stellen den dichtesten schönsten Rasen, den wie bei uns die gelben Köpfe des Löwenzahns zieren, da erreichen dic Hahme mit dichten Aehren besetzt die Höhe von 1-2 Fuss, da stellt sich neben der AnAromeda die Heidelbeere ein und iiberzieht wie anf msern moorigen IIeiden grosse Strecken des Bodens; in den fenchten Klüften der Felsen gedeiht das rierliche Farnnkraut, breiten sich die sïnerlichen Blätter des Ampfer's zu seltener Grösse aus; an den somnigen Halden nickt auf hohem Stengel die tiefblane Campanula, entziickt uns die zarte, immergrüne Pyrola mit den mamorweissen Bliiten. In Schutgeröll der Biche und des Strandes entfaltet das Epilobium seine grossen Bliiten, die mit ihrem prachtvoll glänzenden Roth von weit her selbst den Gleichgïltigsten locken. Und zwischen den ödesten Felsen hat sich das merkwürdige Polemonium in grossen Mengen angresiedelt und erhebt aus dem stark duftenden, feingefiederten Blaitterkreise die dichten Büschel der grossen, rein hellblaten Blumen. Wie Fremdlinge erscheinen diese so ganz heimisch gekleideten l'thazen in der arktischen Natur. Und dort jene eigenthümliche 'Färloung des Berghanges, sie wird, wie wir zu unserm Erstannen finden, von kleinem, aber kräftigem -Birkengestrüpp gebildet, das, obgleich es jedes Jahr nur wenig zunimme, sich dennoch hier wohl zu tühlen scheint, denn es hat Bliten und Fuichte gereift. Daneben stehen Heidelbeerbiische mit reifen, ansnehmend süssen lrüichten, die nit kindlicher Freude geptliickt und genossen werden, und endlich trimmphirt der 


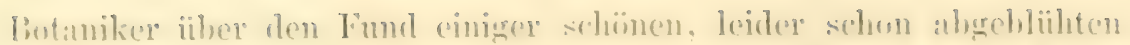

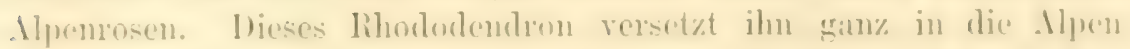

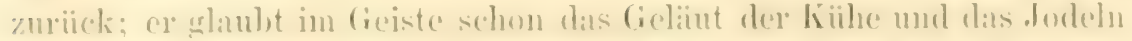

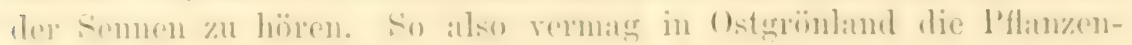

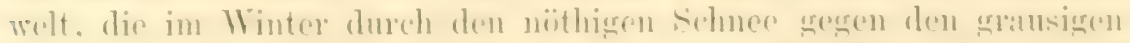

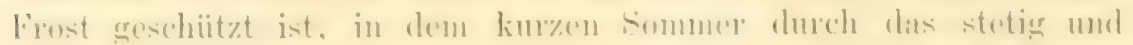

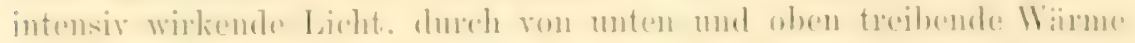

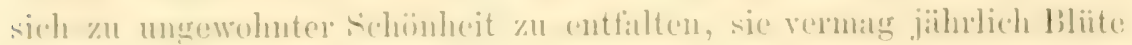
und fincht zin reifens.

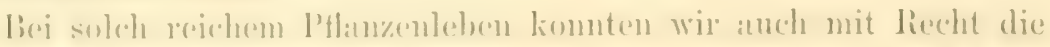
Gerenwant mancher pilinzenfressenden thiere rermuthen, und zwan' sirher des liemuthiers und des rein weissen Polarhasen, die iiberall

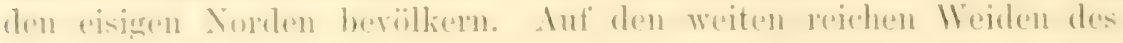

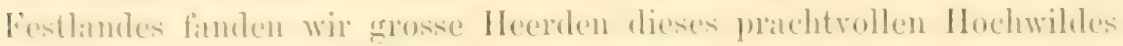

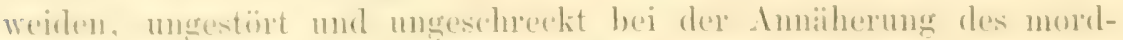
Instien Mensehen. Ther es war noreh ein anderes chenso wichtiges

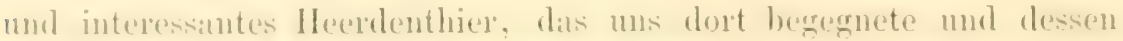

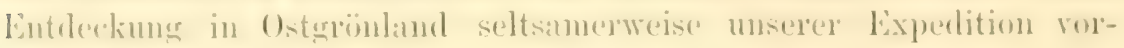
hehalten wall. Es ist das der anktische (behse, jener von den Fanklin-kxpertitionen her bekanto Moschusoche mit seiner niedrigen

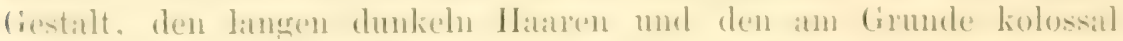
dieken und schweren Ilïnern. Anch dieses seltsame Thier leht in

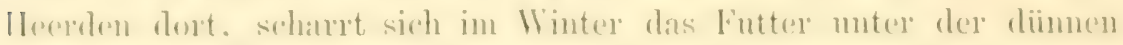

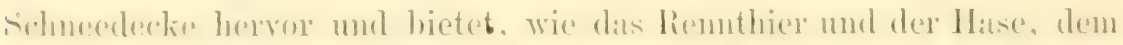
Irenschen eine ansezeichnete mol gesmule Nahrung. Auch kileinere Thiere leben von l'flanzen: der kleine sratue Lemming wräbt den feinen Wurzeln nach, und unter den Vögeln sahen wir die diämse and den Wiesen wejden und die reizenden Schnedhilhner von den jungen Sidrïslingen der Wriden sich nïhren. Aber wie in der sanzen Natur, so hathen anch hiog die Thiene ihne besondern Fende. Dats zwischen den

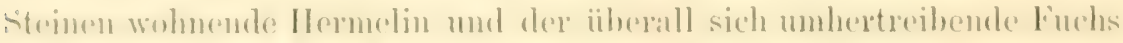
stollen ihment ant dem bande chenso nareh, whe ans hoher Laft herah die bule und der lialke. Aber dessenumgeachet zwitschert und singt

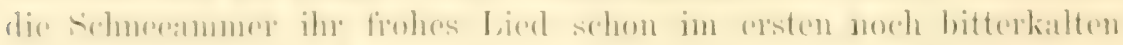

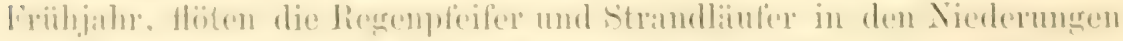
des strandes mol stellen den kleinen datrven. Maideken und filiegen mach. die: anch dort ihr stilles lathen fristem.

line rejehere Xathmugspuetle för Vïgel und simgethiere bietet

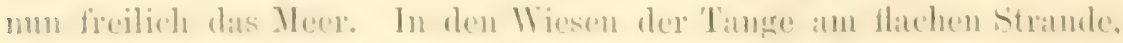
in don Wailden der riesigen Laminaria treiben Millionen ron hrebsthierehen ihr Wesen, and dureh die jahraus jahrein gleiche 'Tem- 
peratur des Wassers begïnstigt, erreichen sie eine ungewöhnliche Grösse; an den Steinen und am Boden des Grundes leben Vuschehn und Schnecken - es sind theilweise dieselben wie in unserer Ostsee, aber sie zeigen meist kräftigern Bau. Und diese Krebsthiere nebst einigen kleinen Fischchen dienen dem Heere der Wasservögel zur Nahrung, den Eidergänsen, den Möven und Tauchern, den Seeschwalben und andern. An den hohen Klippen nistend, kreisen diese Vögel unıhing und schreiend Tag und Nacht in der Luft, oder tummeh sich auf dem stillen Wasser umher. Auch sie haben ihre Jungen zu vertheidigen gegen die genannten Raubvögel, deren Zahl noch durch die grosse Möve und namentlich den schwarzen Raben vermehrt wird. Aber so angenehm das Fleisch und die Eier, die Felle und Federn dieser Vierfüssler und Vögel dem europäischen Eindringling sind, ihr Nutzen für den Ureinwohner ist verschwindend gegenüber dem, den das Walross und der Sechund gewährt. Es sind dieses die wichtigsten Thiere aller Eiskiisten; auf dem Dasein und der Ausnutzung derselben basirt eigentlich das ganze Leben der dortigen Eskimos. Doch auch sie haben keinen ungestörten Genuss ihrer Jagd: das mächtigste Raubthier, der Eisbär, erhebt dieselben Anspriiche an Seehunde, Walrosse und Riemnthiere, und zwischen der Kraft und Schlauheit des Thieres und der Intelligenz des ärmsten Menschen entsteht der wunderbarste Wettstreit and Krieg. 


\title{
9. \\ Gefässpflanzen.
}

\author{
Bearbeitet von \\ Franz Buchenau und Wilhelm Olbers Focke
}

in Bremen.

Durch die wenigen Reisenden, welche bisher das arktische Ostgrönland besucht haben, ist bereits Eniges iiber die Tegetation dieses Landstrichs bekament geworden. Im Jahre 1822 wurden von Scoresby

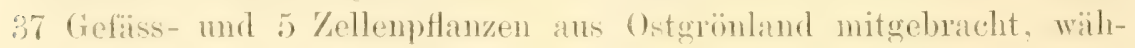
rend sabine, der die Clavering sche lixperlition hegleitete, 1823 in denselben fregenden, 57 Gefäsphtanzen sammelte. W. J. Hooker, einer der ausgezeichnetsten botaniker der damaligen 'zeit, bearbeitete das ron diesen beiden Reisenden zusammengebrachte Material in zwei gesonderten Mbhandlungen. Die Gesammtzahl der aus den arktischen

1 Uebersicht der wichtigsten Literatur über die Flora des östichen Grönland:

William Scoresby, des Jüngern, Tagebuch auf einer Reise auf den Walfischfang. Uebersetzt ron Friedrich Kries (IIamburg 1825). Darin S. 385: W. J. Hooker, Verzeichniss von P'flanzen ron der östlichen Küste von Grönland.

IV. J. Hooker, Some Account of a collection of Aretic plants formed by Edward Sabine, during a Voyage in the arctic Seas in Transact. Linn. Soc., 1825, XIV, 1). 360.

IV. 1. Graah, Narrat. of an Expedition to the East coast of Greenland; translat. by G. G. Macdougall, 1837, p. 177 (dic Pflanzen bestimmt von Hornemann).

J. D. Hooker, Outlines of the distribution of Aretic plants in 'Transact. Linn. Soc., 1862, XX111, p. 251.

Siid- Ind Westgrönland sind in botanischer Beziehung besonders durch die Thätigkeit danischer Missionare und Naturforscher relativ recht gut bekannt und findet sich eine vollständige Zusammenstellung der von dort bekanten P'tanzen aus der Feder von Prof. Joh. Lange in dem Werke von II. Rink: Gronland geographisk og statistisk bescrevet, 1557, welches in dentscher Uebersetzung unter dem 'litel: A. v. litzel, Gröland geographisch und statistisch beschrieben, als 44. Lie- 
Ostgrönland seit der Publication dieser Hooker'schen Arbeiten genaner bekannten Gefasspflanzen belief sich auf etwa 61 Arten, wenn man die völlig zweifelhaften Fomen unberiicksichtigt lässt. 26 Arten maren sowol ton Scoresby als ron Sabine aulgefunden worden.

Nahezu ein halbes Jahrhundert verfloss, ohne dass msere Kienntnisse ïber die nördlichen Gegenden Ostgrönlands irgendwie bereichert worden wären. Der zweiten Dentschen Nordpolexpedition war es rorbehalten, weiteres Licht iiber diese entlegenen Gestade zu rerbreiten. Das ron unsem Reisenden mitgebrachte, grösstentheils ron Dr. Pansch gesammelte Material lieferte uns s? Arten ron Gefäspflanzen (darunter zmei zweifelhafte), sodass die Lahl der aus dem arktischen Grönland bekannten Pflanzen nummehr ansehnlich gewachsen ist, nämlich, abgesehen von den zweifelhaften Formen, bis zu 96 Arteñ. Fir die Kemntniss der Zellenpflanzen der Gegend wrole fener eine erste Grundlage geromen, da die wenigen Arten Scoresby's kamm in Betracht kommen können. Man darf indess nicht glauben, dass nummelir die Flora Ostgrönlands einigemassen rollständig exforscht sei. Wenn man sich die Schwierigkeiten rergegenwärigt, mit welchen alle wissenschaftlichen Untersuchungen in den mwirthlichen Polargegenden zu kämpfen haben, wenn man sich erinnert, wie z. B. unsere Funde ïber die Flora ron Spitzbergen Schritt fuir Schritt durch jerte Expedition um einige Arten bereichert worden ist, so wird man die Ueberzeugung gewimnen, dass in Ostgrönland noch viele Gerächse roxkommen dürften, deren Auffindung spätern Reisenden rorbehalten ist. Namentlich gilt dies von den Moosen, Flechten und sonstigen Zellenpflanzen, sowie ron den Gräsern und Halbgräsern. Die bedentendsten Entdeckungen diurte das nu flïchtig besuchte Innere des Laudes rersprechen, welches ungleich reicher und fruchtbarer zu sein scheint, als die stets ron Eis mmlagerten Kïistengegenden. Es rerdient indess hervorgehoben zu werden, dass der wissenschaftliche Gewinn, welchen die bedeutenden Sammhngen der zweiten Deutschen Nordpolexpedition lieferten, nicht allein in der Vermehrung der Zahl der aus Ostgrönland bekannten Pflanzenformen besteht. Das mitgebrachte Material ermöglicht vielmehr ausserdem theils eine bessere Kiemntniss mancher Arten, theils liefert es treftliche Belege zu den rorstehenden, der unmittelbaren Anschaumg entsprungenen, lebenstrischen Schilde-

ferung der Hauff und Peschel'schen Sammlung von Reisen- und Länderbeschreibungen erschienen ist. Wir verdanken den naturhistorischen Theil des dänischen Originalwerks, welcher auch als Separatabdruck erschienen ist, der Güte des Herrn Prof. Joh. Lange in Kopenhagen. 
rungen der Vegetationsrerhïltnisse ()stgrönlands, welche wir Dr. Adolf Pansch rerdanken.

Einige der mitgebrachten Pflanzen sind bereits im Herbst 1869 auf der Sabine-Insel, Klein-Pendulum und am Cap Philip Broke gesammelt. Da indess. Dr. Pansch das Ungliick hatte, sich bald nach der Ankunft an der grönländischen Küste erheblich zu verwunden, so ist die Zahl der damals eingelegten Arten eine geringe. Auf der Winterreise bis zum 77. Grade nördl. Br. konnten natürlich keine Pflanzen gesammelt werden, doch wurden ron einem der nördlichsten Punkte Proben der Saxifraga oppositifotia L. mitgebracht. Der grösste Theil der Pflanzenvorräthe stammt von der Sabine-Insel und aus den Monaten Juni und Juli 1870. Klein-Pendulum wurde am 29. Juni md am 23.-24. Juli, die Shannon-Insel rom 24.-26. Juli besucht. Die Pflanzen ron der Clavering-Insel sind am 16. und 17. Juli, die ron der Jackson-Insel am 1. und 2. August, die von Cap Broer Ruys mnd der Mackenzie-Bucht am 3.-5. August, die aus dem Kaiser-FranzJosephs-Fjord am 11. und 12. August gesammelt. Die grosse Mehrzahl der Exemplare ist von Dr. Pansch eingelegt, indess haben sich anch Dr. Copeland und andere Nitglieder der Expedition in anerkennenswerther Weise gelegentlich beim Sammeln betheiligt.

Die rorstehenden Angaben ïber den Besuch der einzelnen Oertlichkeiten erweisen schon, dass eine gründliche Untersuchung der südlichern Standorte, namentlich im Fijord und am Cap Broer liuys, wegen der Kürze des Aufenthalts völlig unmöglich war. Die Vegetation zeigte an den Ufern des Kaiser-Franz-Josephs-Fjord eine ungleich reichere Entwiekelung als auf den Inseln der Aussenkïste. Folgende Arten sind ron der Expedition nur am Fjord angetroffen worden:

Ranumenlus auricomes L., Vesicaria aretica R. Br., Saxifraga aizoides L., Campamela rotundifotia L., Avctostaplyglos alpina Spreng., Pyrola rotundifolia L., Betula nana L., Juncus trighumis L., Juncus castancus Sm., Carex subspathacea Wormsk., Kobresia caricina Willd., Culamagrostis mupurascens R. Br., Woodsia itvensis R. Br.

Ausserdem sind folgende Arten nur von den siidlichern der besuchten Localitäten mitgebracht worden, nämlich von der ClaveringInsel, Jackson-Insel, dem Fiord und Cap Broer Ruys:

Draba rupestris R. Br., Saxifraga rivularis L., S. hieracifolia IT. K., Erigeron criocephalus J. Vahl, Enphrasia officinalis L., Carex mestris All., C. nardina li., C. rigida Good., Elyna spricata Schrad., Eriophorum Scheuchacri IIopp., Poa abbreviata R. Br., Catabrosa latifolic Fir.

Linige dieser Arten erreichen vielleicht in der Breite des 74. Grades 
die Nordgrenze ihres Torkommens in Ostgrönland. Es darf indess kein grosser Unterschied in der Vegetation der verschiedenen, ron der Expedition botanisch untersuchten Punkte in Folge der nördlichern oder südlichern Lage erwartet werden, da die siidlichste erreichte Landungsstelle im Fjord nur etwa um zwei Grade ferner rom Pol liegt als die Shamnon-Insel, der nördlichste Fundort der mitgebrachten Pflanzen.

Für die Vegetationsverhältnisse Ostgrönlands scheint die grössere oder geringere Entfernung der Standorte ron dem Eisgiirtel der Aussenkïste bedeutungsvoller zu sein als eine etwas siidlichere Lage. Der Pflanzenwuchs an den Berglehnen des Kaiser-Franz-Josephs-Fjord ist nach den Schilderungen unserer Reisenden (rgl. die vorstehenden Schilderungen von Adolf Pansch auf S. 9) ein ansserordentlich iippiger, und geben auch die von dort mitgebrachten trockenen Exemplare Zeugniss ron dem treftlichen Gedeihen der Vegetation in jener Gegend. Besonders bemerkenswerth sind die starken Birken- und Weidenstämme, das dichte Heidelbeergestrüpp und die hohen Gräser sowie die dichtbuschigen, vielverzweigten Exemplare von Epitobium latifotium L., welche die Abhänge des Fjord bewohnen. Diese bessere Entwickelung der Flora im Innern des Landes kann indess bei näherer' Prüfung der Verhältnisse keineswegs auffallen. Das organische Leben in den arktischen Gegenden wird bedingt und ermöglicht durch die bedeutende Wärmeabsorption der Bodenoberfläche, während das eisbedeckte Meer wenigstens im Sommer nur abkiihlend wirken kann. Die klimatischen Terhältnisse müssen sich daher für jeden Ort Ostgrönlands im Sommer um so gïnstiger gestalten, je grösser die ron Schnee und Eis freien Flächen in der Umgebung dieses Punktes sind. und je weiter der abkiihlende Eisgürtel der Aussenkiuste von ihm entfernt liegt. Der unguinstige Einfluss der Nähe des Meeres auf die Vegetation der Polarländer zeigt sich iiberall bei Betrachtung der Polargrenze des Baumwuchses. Während in dem continentalen Sibirien trotz einer mittlern Jahrestemperatur von $-12^{\circ} \mathrm{r}$. die Baumgrenze an der Lena und Chatanga bis zu $72 \frac{1}{2}$ Grad hinaufreicht, hat das in klimatischer Hinsicht so vielfach begïnstigte mittlere Island unter dem 65. Grade und der Isotherme ron $+1^{\circ}$ schon keine Wälder mehr aufzuweisen. Die meerumflossene Südspitze Grönlands hat unter dem 60. Grade nördl. Br. nur Spuren von Baumwuchs. Somit steht die Thatsache, dass im Innern Ostgrönlands die Pflanzenwelt reicher und üppiger entwickelt ist als an der Küiste, im Einklange mit den in andern arktischen Gegenden gesammelten Erfahrungen, und ist dieses bessere Gedeihen der Vegetation im Innern durch eine im Vergleich zu den 
Aussenkiisten höhere Sommertemperatur zu crklären. Die aus dem Fjord mitgebrachten Exemplare mancher Pflanzen zeigen eine autfallend reichlichere Fruchtbildung als die der Inseln, was wenigstens zim Theil Folge der ginstigern Lage sein dirfte, zum Theil aber anch wol nur auf Rechnumg des Einsammelis wähend einer rorgeritickten Jahreszeit zu setzen ist.

Die Zellemptlanzen scheinen in Ostgrönland keinestegs eine so bedentende Rolle zn spiclen wie in vielen andern arktischen Gegenden. Der felsige Boden und die trockene Luft sind ihren Gedeihen menig giunstig. Vegetationsformen, welche an die Noos- und Flechtentindren erinnern, fehlen, soweit bekannt, in Ostgrönland ganz. Für das phaneroganische Pflamenleben erscheint dagegen die dünnere Schneedecke und die im Terhältniss zu Westgrönland geringere dusdehmung der Gletscher entschieden vortheilhaft. Nur durch den geringen Betrag der Niederschläge ist die Ausdehmung der eisfreien Gelände in Ostgrönland zu erklïien. Wegen des Zuriicktretens der Zellenpflanzen kömnen wir uns hei Besprechung des allgemeinen Charakters der ostgrönländischen Flora anf die Gefässpflanzen beschränken. Die Terbreitung dieser Gewächse in den übrigen arkischen Ländem ist ziemhich gut bekannt und gestattet manche lehreiche Vergleichungen.

Die Flora des arktischen Ostgrönland zeigt im allgemeinen alle Merkmale der hochnordischen Tegetation. Unter denjenigen Pflanzenfamilien, welche in der gemässigten /one reich entwickelt sind und einzelne Vertreter his in die artischen Gegenden senden, sind z. B. rie Leominosen, Timbelliferen, Labiaten und Orchideen in den bisherigen Sammlungen nordostgrönländischer Pflanzen gar nicht mehr rertreten. Es fehlen in denselben alle Knollen- und Zwiebelgewächse anie alle phanerogamischen Wasserpflanzen.

Ton IOlzgew ächsen zählt die arktisch-ostgrönländische Flora, orveit bekannt, nem Arten, nämlich: Dryas octopetala L., Taccinim alininosm L., Aratostaphylos alpina Spreng., Rihododendron Tapponicum L., Ledum pulustre L., Amdromeda tetragona L., Emmetrum nigrum j.. Satix ardica P'all., Betula nana L. Ton diesen Arten gehören zwei, nämlich Botula und Salix, trotz ihres niedrigen Wruchses zu den starkern Stranchern, inden sie Stämme von mehr als $1^{\mathrm{cm}}$ Dicke bilden. Einige andere Arten sind schwächere heideartige Gesträuche, nämlich Fracinium, Rhododcndron, Ledum und Empotrum, denen sich anch noch die niedrige Aretostaphylos amreihen lïsst. Die beiden letzten Arten, Dryas und Andromeda, bilden nur sehr dimne fädliche Holzzweige. Unter diesen newn Holzptlanzen sind fünf Arten (Dryas, Rhododendron, Ledum, Andromeda, Empetrum) immexgriin, vier dagegen 
blattwechselnd. Drei Arten (Vaccinium, Arctostaphylos, Empetrum) tragen Beerenfriichte, drei (Betula, Salix, Dryas) besitzen Samen, welche mit Flugapparaten versehen sind; ihnen schliesst sich Ledum mit sehr kleinen feilspanförmigen Samen (deren Kern von einer lockern, weissen Haut umgeben ist) an; die beiden letzten (Rhododendron, Andromeda) haben feine, staubartige Samen.

Unter den Stauden Nordostgrönlands ist nur eine Art (Pyrola) mit immergrünen Blättern vorhanden, aber keine einzige rankende, windende oder kletternde Form. Es fehlen alle Kräuter mit Beerenfriichten. dagegen findet sich eine nicht mubetrïchtliche Zahl von Arten, welche samen mit Federkronen oder sonstigen Flugapparaten besitzen (Epilobium, Amica, Erigeron, Taraxacum, Armeria, Eriophorum, Calamagrostis). Daran reihen sich noch manche Gräser und Halbgräser mit Samen, die durch anhaftende Schlïuche und Spelzen befihigt sind, eine grössere Strecke rom Winde fortgefiihrt zu werden. Die iibrigen Arten erzeugen meistens feine, manchmal staubartige Samen. Eine Ausnahme macht Halianthus; die verhältnissmässig grossen Samen dieser Pflanze sind $7 u$ ihrer Verbreitung nicht auf einen Transport durch die Luft, sondern durch die Meereswellen angewiesen.

Die einjährigen Gewächse sind bekanntlich sowol in den arktischen Gegenden als in den Hochgebirgen selten. Von unzweifelhaft annuellen Pflanzen ist Koenigia islandica L. die einzige im arktischen Ostgrönland gefundene Art; das Pflänzchen ist von Sabine, aber nicht ron unserer deutschen Expedition mitgebracht worden. Daran würde sich als eine fernere einjührige Art Poa amma L. anschliessen, falls sich ihr Vorkommen in Ostgrönland bestätigen sollte (s. unten bei der Aufzählung der einzelnen Pflanzen). Ob dagegen Rammoulus pygmacus Wahlnbg. zu den einjährigen Gewächsen zu rechnen ist, dürfte mindestens zweifelhaft sein. Diese Art wird zwar von Wahlenberg fiir einjährig gehalten und anch Kerner (Die Abhängigkeit der P'tanzen-Gestalt von Klima und Boden, Festschrift zur Versammlung der deutschen Naturforscher und Aerzte in Innsbruck 1869, S. 36 des Separatabdruckes) spricht dieselbe Ansicht aus, dagegen geben Hartmann in seiner Flora Scandinaviens, Pursh in der Flora of NorthAmerica, Ledebour in der Flora des russischen Reiches und De Candolle im Prodromus an. dass sie ausdauernd sei. Wahrscheinlich ist diese letzte Ansicht die richtige.

Die Blattform der arktischen Pflanzen ist in der Regel sehr einfach. Es finden sich in Nordostgrönland nur 6 Arten mit zusammengesetzten Blättern, nïmlich Polemonium, Ramunculus glacialis L.. Pedicularis und die drei Potentillen. Mehr oder weniger tief gelappte 
Blätter haben namentlich noch die drei andern Ranunkeln. Einige Pflanzen, welche in der gemässigten Zone meist tief getheilte oder eingeschnittene Blätter besitzen, wie Saxifraga caespitosa L. und Taraxacum bringen im hohen Norden meistens ganz einfache Blattformen hervor. Vorherrschend sind unter den arktischen Pflanzen einfache linealische. spatelige ode! elliptische Blatter. IDickblatterig ist Sedum Rhodiolu DC.. in geringerm Grade sind es auch Ramunculus glacialis L. und Halianthus peplödes Fr.; letztere Art ist indess in Grönland durch weniger fleischige Blätter ausgezeichnet als in der gemässigten Zone.

Die Beharrung der Pflanzen des arktischen Ostgrönland ist häutig eine spärliche; viele Arten sind ganz kahl oder besitzen nur zerstreute Haare oder Wimpern. Indess schliesst das Vorwiegen der kahlen Gewächse keineswegs das Vorkommen dicht behaarter Arten aus. Insbesondere in den Gattungen Draba, Vesicaria, Melandryum, Epilobium, Potentilla und Pedicular is findet sich auch in Grönland theils dichter Sternfilz, theils eine aus zahlreichen längern Haaren gebildete Bekleidung an Stengeln und Blättern. Zwei an somnigen, steinigen Plätzen wachsende Rosaceen, nämlich Potentilla nivea L. und Dryas octopetala L., haben verschiedenfarbige Blätter, indem deren Oberseite ziemlich kahl und dunkelgrün, die Unterfläche dagegen dicht weissfilzig ist. Zerstreute längere Haare finden sich bei manchen Arten, so bei Papaver, Cerastium, Erigeron, Amica, Polemonium, Salix, wie demn solche längere Haare auffallend häufig unter den arktischen Arten zu sein scheinen. - Stachelige, sowie mit Widerhaken und anhaftenden Borsten besetzte Pflanzen fehlen in Ostgrönland, was wol mit der geringen Entwickelung des Thierlebens in Verbindung stehen diurfte.

Die Bliiten der arktischen Pflanzen zeigen einige Eigenthümlichkeiten. Bemerkenswerth ist, dass Pflanzen mit zygomorphen Bliten im arktischen Ostgrönland selten sind. Zwei Scrofularineen (Euphrasia und Pedicularis) und ein Taraxacum scheinen die einzigen Vertreter dieser Blütenform zu sein. Im Westen und Siiden Grönlands ' sind solche Blüten viel häufiger; das Verhältniss der Arten mit zygomorphen Blumenkronen zu denen mit actinomorphen stellt sich für ganz Grönland etwa wie 1:6, für Nordostgrönland dagegen wie 1: 18 .

Die Blumen einer riemlichen Zahl von Pflanzen des nordöstlichen Grönland sind sehr ansehnlich. Als die schönste Blume des Landes

1 Westgrönlands Flora enthält 2 Papitionaceae, 3 Violarieae, \& Cichoraceae, 12 Scrofularineae, 1 Labiata, 1 Lentibulariea, 4 Orchideae. 
schildern monere Reisenden das Enilobium latifolium L., dessen präichtige, scharlachrothe Blüten weithin leuchten. Ferner hat Polemonium ziemlich zahlreiche, grosse, schön blau gefärbte Blïten. Unter den gelben Blumen sind die des Alpenmohns, unter den weissen die der Dryas durch Grösse ausgezeichnet. Sehr zierlich sind die Blitentrauben der Pyrola rotundifolia L. Auch kleine Blüten bringen oft durch ihre grosse Zahl, ihre lebhafte Färbung und ihre niedlichen Formen eine bedeutende Wirkung herror. So Andromeda tetragona L., Saxifraga oppositifolia L. und namentlich Silene acaulis L. Diese drei Arten blïhen roth. Die übrigen Saxifragen, die Ranunkeln und Potentillen haben meist lebhaft gelb oder weiss gefärbte Blumen. Was, abgesehen von Grösse und Schönheit der Blumen, die Färbung derselben betriftt, so ist das Blau im nordöstlichen Grönland am spärlichsten rertreten. Nur das prächtige Polemonium und die beiden Campanula-Arten kleiden sich in reines Blau; vorwiegend dürfte diese Farbe auch bei der kleinen seltenen Euphrasia sein. Eine viel bedentendere Rolle, sowol durch die Zahl als die Häufigkeit der Arten, spielen die rothen Blumen. Roth blïhen Epilobium, Rhododendron, Andromeda, Pedicularis, Armeria, Silene, Saxifraga oppositifolia L., sowie die unscheinbaren Melandryen und Wahlbergella. Gelh blühen drei Rammkeln, drei Potentillen, drei Saxifragen (S. Hivculus L., S. aizoüdes L., S. flagellaris L.), Draba alpina L., Papaver, Sedum, Arnica und Taraxacum. Die iibrigen Arten, insbesondere Ranunculus glaciatis L., Dryas, Vaccinium, Arctostaphylos, Pyrola, Polygonum, sowie die meisten Cruciferen, Alsineen und Saxifragen haben weisse Bliiten.

Die Zahl der Dikotyledonen und Monokotyledonen Nordostgrönlands mit einander zu vergleichen, ist nach dem bis jetzt vorhandenen Materiale nicht anlissig, weil die betreftenden monokotyledonischen Pflanzen weniger vollständig gesammelt sind als die dikotyledonischen. Von den eimzelnen Pflanzenfamilien sind die Gramineen, Cyperaceen, Caryophylleen, Saxifrageen und Cruciferen vorher'rschend. Bei genanerer Durchforschung des Landes wird sich ohne Zweifel ein bedeutendes Uebergewicht der Gramineen und namentlich der Cyperaceen herausstellen. Nach den genamnten Familien sind noch die Ranunculaceen, Rosaceen, Ericineen und Juncaceen durch je 4-5 Arten verhältnissmässig gut vertreten, während die grosse Familie der Compositen in unserer Sammlung nur in drei Arten erscheint. Alle andern Familien sind nur durch je 1-2 meist ganz isolirt dastehende Arten repräsentirt. Unter den einzelnen Gattungen sind Carex, Saxifraga und Draba die artenreichsten, ferner treten Ranunculus, 
Metantrym (incl. Wablbergetla), Potentilla, Juncus und Poa in je 3-4 Arten auf.

Die Lebensbedingungen der arktischen Pflanzen sind für viele Arten nur ungenügend bekannt. Unter den Pflanzen Ostgrönlands finden sich zwei Wurzelschmarotzer'. Eupherasin und Pediculuris: blattlose Schmarotzer kommen in ganz Grönland nicht vor. Linige Arten scheinen einen wewissen (iehalt von Humus oder organischer Substanz. im Boden zu verlangen, insbesondere Saxifraga Hirculus L., Pyrola, Rhododendron, Andromeda und Tacrinum. Grösser scheint die Zahl derjenigen Gewächse zu sein, welche einen kalireichen, rerwitterten Felsboden zu ihrem Gedeihen erfordern. Diese Arten lassen sich aber noch nicht mit einiger Sicherheit ausscheiden. Als Halophyten lassen sich nur vier Arten der Flora des nordöstlichen Grönland bezeichnen, nämlich Cochlearia, Halianthus, Armeria und die ron Sabine gefundene Glyceria (Poa) angustata (R. Br.) Fr.

Die Vegetation des arktischen Ostgrönland stimmt in allen wesentlichen Zïgen mit der wohlbekannten Flora Westgrönlands iiberein. An der südlichen Kïiste (Ostgrönlands ist die unter 6.3 $37^{\prime}$ nördl. Br. gelegene Insel Kemisak, welche ron Graah besucht wurde, der nördlichste Punkt, über dessen Vegetation genauere Angaben rorhanden sind. Zwichen Kemisak und dem Kaiser Frany-Josephs-Fjord liegen fast neun Breitengrade unerforschten Landes. Nur an einer dazwischen gelegenen Stelle landete Scoreshy; aher selbst wem man die Gegend des nach ihm benamnten Sundes den bekamnten Küistenstrecken des Nordens zurechnet, bleibt eine Lücke von sieben Breitengraden zwischen den äussersten Punkten, welche durch die von Norden und von Süden vordringenden Reisenden erreicht worden sind. Es versteht sich daher von selbst, dass die hekannte Vegetation des südlichen und die des nördlichen ()stgrönland beträchtlich ron einander abweichen. Ob irgend eine Grenzscheide zwischen beiden Florengebieten worhanden ist, oder ob auf jener Strecke ron sieben, resp. nem Graden ein allmählicher Cebergang stattfindet,

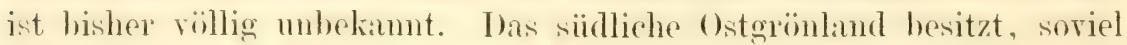
wir wissen, keine Pflanzen, welche der Westküste fehlen. Die Flora des nördlichen Ostgrönland zeichnet sich dagegen durch einige bemerkenswerthe Eigenthiimlichkeiten ans. Bis jetzt sind nämlich an der Nordostkiiste folgende P'flanzenformen gefunden, welche dem Süden und Westen fehlen:

Ramunculus glacialis L. (für Westgrönland sehr zweifelhaft!), - auricomes $\mathrm{L}$.,

Dryas octopetala L. (form. typica!),

Saxifraga hieracifolia W. K., 
Saxifraga Hirculus L.,

Pyrola rotundifolia L., var. arenaria Koch.,

Polemonium humile Willd.,

Juncus trighumis L., var. Copelandi Buchenau,

Deschampsia brevifolia $\mathrm{R}$. Br.

Von diesen Pflanzenformen werden einige in Westgrönland durch sehr ähnliche Arten oder Varietäten vertreten, nämlich:

Ranunculus glacialis L.' durch R. alpinus L.,

Dryas octopetala L. ", Dr. integrifolia J. Vahl,

Pyrola rotundifolia L. $\quad$ P. rotundifolia L.,

var. arenaria Koch, var. grandiflora Radde,

Juncus trighumis L. "J.triglumis L. typicus. var. Copelandi Buchen.

Ton den für Nordostgrönland charakteristischen PHanzen wachsen auf Spitzbergen, also der nächstgelegenen Inselgruppe:

Ramunculus glacialis $\mathrm{L}$.,

Dryas octopetala L.,

Saxifraga Tieracifolia W. K.,

- Hirculus L.,

Polemonium humile Willd.

Im Westen ron Grönland auf der Melvil-Insel im arktisch-amerikanischen Archipel kommen vor:

Ramunculus auricomus $\mathrm{L}$.,

Saxifraga hieracifolia W. K.,

- Hirculus L.,

Deschampsia brevifolia $\mathrm{R}$. Br.

Alle diese Arten finden sich auch im arktischen Europa. Ramunculus auricomus L., Saxifraga hieracifolia W. K., S. Hirculus L., Polemonium humile Willd. und Deschampsia brevifolic R. Br. sind als weitverbreitete arktische Pflanzen zu bezeichnen, deren Fehlen in Westgrönland auffälliger erscheint, als ihr Torkommen in (Dstgrönland. Dagegen ist Ramunculus glacialis L. eine europäisch-alpine und skandinavisch-spitzbergische Art, deren Verbreitung sich bis über Nordostgrönland, aber nicht über die andern arktischen Regionen erstreckt. Dryas octopetaln L. ist im arktisch-amerikanischen Archipel in Westgrönland und manchen andern nördlichen Standorten durch Dr. integrifolia J. Vahl vertreten, welche in Europa fehlt. Wenn sich das Vorkommen der Dr. integrifolic auf Spitzbergen während der postpliocänen Periode (vgl. Heer, Fl. foss. arct. II, 2, p. 91, tab. 16, fig. 69) bestätigen sollte, so würde die $D r$ octopetala als eine von Europa aus einwandernde, die $D r$ integrifolia verdrängende Rasse aufgefasst werden müssen. 
Die zerstreut im mittlern Europa auf Sanddinen (an der Meeresküste und im Wallis in der Schweiz in Gesellschaft ron Küstenpflanzen) rorkommende var. arenaria der Pyrola rotundifotia L. ist bisher noch nirgends in den arktischen Gegenden unterschieden, ebenso wenig wie die neu aufgefundene Varietät des Junous trighmis L. Diese beiden Varietäten, die Draba muricella, var. Panschii nob. und die Saxifraga 7ieracifolia W. K. sind auch der einzige Zuwachs, welchen die Phancrogamen-Flora von Gesammtgrönland durch die zweite Deutsche Nordpolexpedition erfahren hat.

Diesen Bemerkungen über die ron der zweiten Deutschen Nordpolexpedition mitowathen I'Hanzen diurte sich naturgemais ein Ceberhlick iiber die allgemeinen Verhältnisse der Flora Grönlands anreihen. Da indess ein näheres Eingehen in Specialforschungen, soweit sie nicht direct die Arbeiten der Expedition berihhren, an diesem Orte unthunlich sein würde, so mag hier eine kurze Charakteristik der neuern Ansichten über die Veränderungen der Flora in den arktischen Gegenden folgen, wodurch zugleich auf die Tragweite der Forschungen uiber die arktische Flora hingewiesen werden wird.

Während der Tertiärperiode erfreute sich Nordgrönland des Schmuckes eincr reichen und höchentwickeiten Vegetation. Insbesondere war dieselbe durch das Vorkommen zahlreicher immergrüner Bäume und Sträucher ansgezeichnet. Vergleicht man die tertiären Versteinerungen von Atanekerdluk in Nordwestgrönland mit der lebenden Pflanzenwelt, so gelangt man zu dem Schlusse, dass jetzt nur Länder mit einem so milden Klima, wie es der wärmern gemässigten Zone eigen ist, eine ähnliche aus immergrünen und laubwechselnden Holzarten gemischte Waldflora zu ernähren in Stande sind. Länder wie lortugal, Griechenland oder Nippon erimnern gegenwärtig am meisten an das Nordgrönland der Tertiärzeit. Viele der zu Atanekerdluk und in der Nähe gefundenen tertiären P'tanzenreste stimmen genau iiberein mit Niocänptlanzen Nitteleuropas. Nordwestamerikas und anderer Länder. Nan muss aus diesem Vorkommen den Schluss ziehen, dass entweder während einer gewissen Epoche der Erdgeschichte viele Pflanzenarten so ziemlich über die ganze jetzige kalte und kühlere gemässigte Kone der nördlichen Halbkugel verbreitet gewesen sind, oder dass Arten, welche urspringlich vielleicht im hohen Norden heimisch waren, sich später über weite Strecken der gemässigten Zone ansbreiteten. In dem ersten Falle ist die Gleichaltrigkeit der Schichten, in welchen die betreffenden I'flanzen in den verschiedenen Ländern vorkommen, vorausgesetzt; im zweiten wiurde das Auftreten derselben Art an verschiedenen Localitïten nach und nach zu verschie- 
denen Zeiten erfolgt sein. Welche von beiden Amnahmen genauer der Wirklichkeit entspricht, muss vorläufig unentschieden bleiben. Die Tertiärflora Islands und spitzhergens zeigt manche Achnlichkeiten mit der Nordgrönlands, lässt aber jene merkwürdigen immergrïnen Laubbäume vermissen, so dass dadurch die Vermuthung gerechtfertigt wird, es habe sich Nordwestgrönland, vielleicht in Folge einer offenen Seeverbindung zwischen der Hudsonsbai und dem mexicanischen Golf. zur Tertiürzeit eines aussergewöhnlich milden oceanischen Klimas erfreut. Im Grossen und Ganzen lässt sich die Niocän- (mittlere 'Tertiür-)Flora der ganzen nördlichen Ilalbkugel rom Pol bis zum $45^{\circ}$ nördl. Br. als ein zusammenhängendes Florengebiet auffassen, imnerhalb dessen natirlich ein weiter Spielraum für örtliche und zeitliche Terschiedenheiten angenommen werden muss. Von den Pflanzenarten der Miocänperiode haben sich einzelne anscheinend völlig unverändert bis zur Gegenwart erhalten, andere scheinen ihre Gestalt etwas modificirt und sich in mehrere geographisch gesonderte Rassen gespalten zu haben. Die Mehrzahl der Arten ist aber stärker verändert oder ganz ausgestorben; riele Typen scheinen röllig verschwunden zu sein; manche tertiäre Pflanzen zeigen nur eine allgemeine Analogie mit lebenden Formen. Wenn wir nun wissen, dass die arktischen Länder zur Niocänzeit ein mildes Klima genossen, und dass während derselben Periode in Nordwestamerika unter dem 50. Breitengrade nnd ebenso in Mitteleuropa, z. B. am jetzigen Bodensee, ein subtropisehes Kilima herrschte, so werden wir uns uiber das Schicksal dor Vegetation, welche damals jene Länder bewohnte, nicht wundern. Der Unterschied zwischen jener P'eriode und der Gegenwart ist so ausserordentlich gross, dass in den nördlichern Gegenden gewiss keine eimzige Pflanze den gewaltigen Wechsel an ihrem ursprünglichen Wohnorte zu überdauern vermochte. Nur wenn die Arten wandern konnten. waren sie im Stande, sich in solchen Gegenden zu erhalten, die weniger als ihre ehemalige Heimat unter der Ungunst der veränderten klimatischen Verhältnisse zu leiden hatten. Bei den umfangreichen Ueberschwemmungen der Tertiüzeit waren es rorzüglich die in nordsuidlicher Richtung verlaufenden Bergketten, lïngs deren sich die Pflanzen des Nordens in wärmere Gegenden zuriickzuziehen rermochten, während Meere, Wiisten und hohe Gebirgsketten von ostwestlicher Erstreckung ihnen jede Flucht versperren mussten. In Californien, Japan, Persien und Syrien treffen wir daher die Reste der Niocänflora des Nordens etwa unter dem 35.-40. Breitengrade an. Für die Zwischenstufen von der Miocïnzeit bis zur Gegenwart fehlt es uns in den arktischen Gegenden an geologischen Anhaltspunkten. Das Klima muss allmählich 
rauher geworden sein; während die zartern Arten num südwärts wanderten oder ausstarben, drangen von den Gebirgen her neue Arten in die Ebenen der Polarländer ein. Auf den Alpen Grönlands und Spitzbergens wird schon zur Miocänzeit eine an Frost und Schnee gewöhnte Vegetation ansinsig geweren sein; die Erkaltung der Ebenen ermöglichte ferner einen rielfachen Austausch zwischen den Pflanzen der Polarländer und der Hochgebirgstlora der gemäsiggten Zone. Der Yorden wird auf diese Weise allmählich mehrfach seine Ptlanzendecke gewechselt haben. Es ist num eine auf die vielseitigste Weise begründete Thatsache, dass der Gegenwart eine Periode rorausging, in welcher es in den aussertropischen Gegenden der Erde noch kälter war als jetzt. Bevor diese Periode eintrat, müssen sich aus den arktischen Ländern diejenigen drten narh den kiihlern Gegenden Europas, Asiens und Nordamerikas zurickgezogen haben, welche jetzt noch diesen verschiedenen Erdtheilen, inshendere Luropa und Ostanerika, gemeinsam angehören. Während der Kälteperiode, der sogenannten Eiszeit, herrschte his zum 45. Breitengrade eine subarktiche Florat. Wämere und kältere Perioden mögen sewechselt haben; jedenfalls besserte sich schliesslich das Klima wieder, die Eiszeit schwand aus den mittlern Breiten. Nun drangen anch die arktischen l'Hanzen wieder nordwärts ror, isolirte Colonien in den Gebirgen der gemässigten Zone zuriicklassend.

Ein Blick auf die geographische Gestaltung der den Nordpol umgebenden Länder zeigt, dass sich hier bis etwa zum 45. Grade nicht nur in Amerika, sondern auch in Europa und Asien zahlreiche Rückzugslinien für die Gewächse finden. Erst in der Nähe des 45. Grades und siddlich davon beginnen die ostwestlichen Gebirge, Meere und Wüsten. Die arktischen und subarktischen Arten der spätern Tertiärperiode und der Eiszeit fanden somit Wege genug, um sich je nach dem Wechsel des Klimas mehr nordwärts oder mehr siidwärts auszıbreiten. Ein Wandern der Gebirgsgewichse nach dem Norden und umgekehrt wurde durch die Richtung der Bergketten sehr beginstigt. Von allen subarktischen Ländern hat nur Südgrönland eine besonders unvortheilhafte Lage. Seit langen P'erioden der Erdgeschichte eine Halbinsel, hat dies Land wïhrend und nach der Tertiärzeit wahrscheinlich nur iiber Nordgrönland zeitweise mit den andern Continenten in Verbindung gestanden. Grönland bot nun für die sïdwärts zuriickwejchenden ehemaligen alpinen nud hochmodischen Pthanzen zunädhat

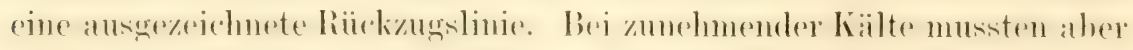

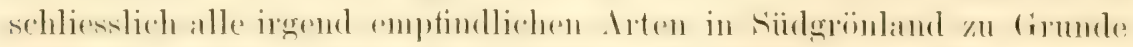
gehen, weil ihmen dort jede Flucht nach Suiden abgeschnitten war. Es blieben daher in jenem Lande nur solche Arten zurück, welche 
im Stande waren, dort das Klima der Eiszeit zu ertragen. Nach der Eiszeit konnte jedoch keine Finwanderung von Sirden her stattfinden, während z. B. skandinavien reich durch mitteleuropäische Arten bevölkert wurde. Dieser schon von J. D. Hooker hervorgehobene Umstand bedingt die Eigenthümlichkeit der gegenwärtigen grönlindischen Vegetation. Wir finden in Grönland noch die unvermischte Flora der Eiszeit vor.

Von diesem Gesichtspunkte aus erhalten auch die einzelnen die Flora Grönlands betreffenden Thatsachen eine bestimmtere Bedeutung. Grönland besitzt keine nur diesem Lande eigenthïmlichen Pflanzenarten; dieser Erfahrungssatz bedeutet: Alle PHanzenarten der präglacialen Polarflora, welche sich während der Eiszeit in Grönland erhalten haben, sind auch an irgend einem Punkte Europas, Asiens oder Amerikas erhalten geblieben. Die meisten grönländischen P'tlanzen kommen sowol in Europa als in Amerika vor; daraus folgt, dass diese Arten sich bei Beginn der Eiszeit aus den Polargegenden sowol nach Grönland als nach den beiden benachbarten Continenten zuriickziehen konnten. Grönland besitzt weit mehr europäische Arten, welche in Amerika fehlen, als amerikanische Arten, welche nicht in Europa rorkommen. Diese Thatsatche heweist, dass die präglacialen Polarptlanzen meln Chancen gehatbt haben, sich zugleich nach Europa und Grönland. als nach Amerika und Grönland zuriekzuziehen. Trotz der geographischen Lage gehört Grönland rom naturhistorischen Standpunkte aus nicht zu Amerika, da es nur sechs amerikanische Pflanzenarten besitzt, welche nicht in Europa oder Asien vorkommen.

Die PHanzenwelt Grönlands hat nach dieser Auffassung ein eigenthümliches historisches Interesse; sie ist die Vegetation, welche die jetzigen arktischen und subarktischen Länder während der Eiszeit bedeckte und ist zugleich ein fast unvermischter Rest der eigentlichen Polarflora, welche während der voreiszeitlichen (pliocänen) Periode den höchsten Norden bewohnte. Es mag indess, um irrthümliche Folgerungen zu verhüten, noch erwähnt sein, dass die Polargegenden nicht als die ursprüngliche Heimat aller dieser Gewächse angesehen werden dürfen. Die Stätte, auf welcher sie entstanden, d. h. ihre jetzige Gestalt erhielten, liegt für weitaus die meisten dieser uralten Polbewohner wahrscheinlich ferm vom Pol in den Hochgebirgen der gemässigten Zone.

Professor Grisebach sucht in seinem kürzlich ę̧schienenen ausgezeichneten Werke' die nahe Verwandtschaft der grönländischen Flora

${ }^{1}$ Die Vegetation der Erde nach ihrer klimatischen Anordnung, von A. Grisebach (Leipzig 1872). 
mit der des arktinchen I-ien und Europa durch den Transport der I'flanzensamen mittels Treibeis zu erklären. Mit Huilfe der Sammlungen der zweiten Deutschen Nordpolexpedition ist, wie durch Herrn Professor Kraus nachgewiesen werden wird, die Thatsache festgestellt worden, dass sibirische Hölzer in grosser Menge an Grönlands Ostküste angetrieben werden. Durch die Strömung, welche diesen Transport vermittelt, kömnen auch Eisschollen mit Pflanzensamen aus Sibiriens Flïssen nach Grönland gelangen, sie können dort stranden und die mitgebrachten Samen dem Lande mittheilen. So anerkennenswerth nun auch Grisebach's Bestreben ist, die Verbreitung der Arten durch Vorgänge zu erklären, welche noch gegenwärtig wirksam sind, so darf man doch die Bedeutung der Eiswanderungen von Sibirien nach Grönland nicht iiberschätzen. Einige Pflanzenarten mögen allerdings auf dem angedeuteten Wege nach Grönland gelangt sein, so vielleicht namentlich mehrere der dem Osten des Landes eigenthümlichen Arten. Die Hauptmasse der Vegetation kamn indess wol nicht auf diese Weise in Grönland angesiedelt sein, auch wird man nicht annehmen wollen, dass ein so grosses Land ehemals ohne alle Vegetation gewesen sei. Ohne den durch Grisebach gegebenen bedeutsamen Wink unbeachtet zu lassen. werden wir wol auch in Zukunft an der Auffassung festhalten miissen, dass die arktiche Flora ebenso gut und ebenso lange in Grönland heimisch ist wie in den andern Polarländern, dass sie aber dort weniger durch neuere Einwanderungen rerändert worden ist als auf den grossen Continenten.

Vorstehende Bemerkungen mögen auf einige der Zielpunkte arktischer Pflanzenforschung hinweisen. Der Norden bietet dem Systematiker nicht leicht eine wirklich neue Art, wie sie der Pflanzensammler in den Tropen fast überall mit verhältnissmässig geringer Nühe zu Dutzenden und Hunderten erlangen kinn. Dagegen bietet das Studium der hochnordischen Vegetation reichen Stoff für physiologische Untersuchumgen und für Forschungen über die Vorgeschichte der Pflanzenlecke unserer Erde.

Indem wir nach diesen einleitenden Bemerkungen zu einer Aufzählung und Besprechung der von der Expedition gesammelten Ptlanzen übergehen, wgllen wir zunächst hervorheben, dass wir trotz mancher Bedenken die in De Candolle's l'rodromus und Hooker's Distrib. of aretic plants befolgte Anordnung der P'flanzen im Wesentlichen beibehalten haben, 1 m eine leichtere Vergleichung mit der letztgenannten Arbeit zu ermöglichen; nur Empetrum haben wir, den nenern 
Forschungen folgend, in die Nähe semer natiurlichen Verwandten. der Ericaceen, gebracht.

In Beziehung auf die Ausarbeitung bemerken wir, dass wir bei jeder Pflanzenart hervorgehoben haben, ob sie bereits von Scoresby und von Sabine gefunden wurde; auch die von diesen Mämmern gefundenen Pflanzen, welche in der Sammlung unserer Expedition fehlen, sind in Petitschrift an den betreffenden stellen eingeschaltet. Ex wird dadurd die folgende Zusammenstellung zu einer vollständigen Aufaihlung allev bisjetzt aus dem fraglichen Gebiete (von der Shannon-Insel bis zum Scoresby-Sund) bekannten Gefässptlanzen. - Graah's Beobachtungen sind dagegen nicht iiberall erwähnt, da, wie bereits oben bemerkt, zwischen dem nördlichsten von Graah besuchten Punkte und dem Scoresby-Sund ein völlig unbekannter Raum von etwa sieben Breitengraden liegt und die von Graah besuchten Localitäten dem südlichen Grönland; nicht aber dem arktischen Ostgrönland angehören.

Noch duirfen wir bemerken, dass wir uns bei der Bestimmung der mitgebrachten P'Hanzen mehrseitiger fremallicher Iseihülte zu erfrenen hatten. Herr Dr. A. Engler in Breslau (jetzt in München) revidirte die von uns bestimmten Saxifragen, Herr Professor Dr. J. Milde, der inzwischen bereits der Wissenschaft durch den 'Tod entrissen wurde, die Equiseten, Herr Dr. Max Kuhn in Berlin die Farrn. Herr Professor Grisebach in Göttingen hatte die (xïte, einzelne kritische sachen mit den reichen Schätzen seines Herbariums zu vergleichen und unsere Bestimmungen der in schönen Reihen vorhandenen Poa-Formen zu revidiren. - Durch reiche Sendungen arktischer PHanzen unterstiitzten uns bei diesen Studien die Herren Professor Joh. Lange zu Kopenhagen und Professor C. J. Maximowicz in Petersburg. Allen diesen Herren sprechen wir hier für ihr freundliches Entgegenkommen den wämsten Dank aus.

\section{1) Ranumenlaceae.}

1) Ranunculus glacialis $\mathbf{L}$.

Auf zahlreichen feuchten Stellen der Inseln; aus dem Fjord nicht vorhanden. Bereits ron Scoresby 1 und Sabine gefunden.

2) Ramunculus auricomus L.

An den Abhängen des Kaiser-Franz-Josephs-Fjord, ziemlich hoch hinauf, namentlich auf feuchtem Boden zwischen Felsblöcken;

1 R. nivalis in der Hooker'schen Aufzählung der von Scoresby gesammelten Pflanzen ist in Wahrheit Ranunculus glacialis L., wie Hooker selbst Linn. Transact. XII, 1. 362 hervorhebt. 
auch von Sabine gesammelt, während unsere Expedition ihn von den Inseln nicht mitgebracht hat; fehlt dagegen in der Lange'schen Flora von Grönland gänzlich. Die Wurzelblätter unserer Exemplare sind bis zur Mitte eingeschnitten; rundlich-nierenförmige ungetheilte Wurzelblätter sind an denselben nicht vorhanden. Unter einer grössern Zahl ron Exemplaren aus den verschiedensten Gegenden Europas fanden wir an den meisten nur getheilte Wurzelblätter. Es lässt sich somit nach diesem Merkmal kein arktischer R. affinis R. Br. rom R. auricomus unterscheiden.

3) Ramunculus nivalis L.

Auf nassen Wiesen und an schlickigen, oft uiberrieselten Stellen weit verbreitet. Sabine-Insel, Clavering-Insel, Klein-PendulumInsel, Jackson-Insel, Cap Broer Ruys. Auch vou Sabine gesammelt.

An den vorliegenden Pflanzen sind die Wurzelblätter fast durchgängig an der Basis mehr oder weniger keilfömig; die Einschnitte reichen nicht bis zur Mitte des Blattes hinab. Hiernach wïrden diese Formen dem $R$. sulphureus Soland. zuzurechmen sein. Fine Ausnahme machen jedoch einige Exemplare von Klein-Pendulum, welche einen etwas zartern Wuchs haben und deren Wurzelblätter breiter, fast nierenförmig und tiefer getheilt sind. Fs scheint aher nicht statthaft, nach diesen offenbar sehr variabeln Merkmalen bestimmte Varietäten oder gar Arten zu unterscheiden. Auch von dem lappländischen $R$. nivalis ist unsere Pflanze nicht merklich verschieden. Das Merkmal der grössern Breite der Basis der Blattlappen ist durchaus unbeständig.

4) Ranunculus pygmacus Wahlnbg.

Klein-Pendulum und Jackson-Insel. Fehlt bei Scoresby, Sabine und Graah; nach Lange im westlichen Grönland vom $60^{\circ} 43^{\prime}$ $-72^{\circ} 48^{\prime}$.

Eine sehr niedliche, kleine Art. Ueber ihre Daner ist die Bemerkumg in der Einleitung zu diesem Abschnitt (s. oben S. 17) zu vergleichen.

\section{2) Papaveraceac.}

5) Papavor mudicaule L.

Von fast allen besuchten l'unkten mitgebracht; besonders massenhaft auf der Sabine-Insel. wo einzelne Stellen von dem leuchtenden Gelb der Bliiten ganz gefïrbt und schon ans der Eerne zu erkennen sind. Dr. Copeland theilte uns muindlich mit, dass einzelne Exemplare mit 16 gleichzeitig geöffneten Blïten gefunden wurden. Seltener im Fjord; hier erreichen einzelne Exemplare auf Felshalden die Höhe von $25^{\mathrm{cm}}$. - Scoresby, Sabine. 
Die Blätter der vorliegenden Pflanzen sind einfach-, selten doppelt-fiederspaltig, in der Breite äusserst variabel, sodass die Segmente bald linealisch-lanzettlich, bald eiförmig und dabei entweder spitz oder stumpf sind. Die Narbe ist gewöhnlich 6-7-, seltener 5 strahlig, die Staubgefässe sind etwas länger als der Fruchtknoten der blühenden Blume. Die meisten Exemplare sind ziemlich stark behaart.

\section{3) Cruciferae.}

(i) Arabis petraca Lam.

Leider nur ein einziges Exemplar dieser interessanten Pflanze, dessen Fundort sich ïberdies nicht mehr sicher ermitteln lässt; wahrscheinlich aber stammt es aus dem Franz-Josephs-Fjord.

Auf einer starken Hauptwurzel sitzt eine dichte Blattrosette, aus der sich vier Stengel erheben. Ausläufer fehlen. Die Stengel, Fruchtstiele und Früchte sind mit weissen Gabelharen dicht besetzt; die linealisch-spatelförmigen, entfernt-gesägten Laubblätter besitzen nur gegen die Spitze hin einige Gabelhaare. Die Stengel (von etwa $8^{\mathrm{cm}}$ Höhe) tragen 1-2 Laubblätter; alle übrigen Blätter sind grundständig; zwei Trauben haben an den untersten Blüten lanbige Deckblätter. Die Friichte sind kurz gestielt (die Stiele etwa ein Viertel so lang als die Frïchte), aufrecht-abstehend, linealisch und meist etwas gekrümmt. - Herr Professor Grisebach, der die Freundlichkeit hatte, diese Pflanze zu untersuchen, glaubte eine eigenthümliche Form ron Arabis ciliata R. Br. mit behaarter Schote und etwas verlängertem Griffel darin zu erkennen. Nach sorgfältiger Vergleichung können wir indess dieser Ansicht nicht beipflichten, zweifeln vielmehr durchaus nicht an der Richtigkeit unserer obigen Bestimmung.

Arabis alpina L. wurde von Scoresby gefunden.

7) Cardamine bellidifolia L.

Sabine-Insel, Klein-Pendulum-Insel. Fehlt bei Scoresby, Sabine und Graah; nach J. Lange im westlichen Grönland rom $60^{\circ}-$ $72^{\circ} 48^{\prime}$.

Nur wenige kleine Exemplärchen mit Bliiten und Früchten rorhanden. Die Blätter sind meist zu einer grundständigen Rosette vereinigt, aus welcher sich die Blüten und Fruchtstände nur wenig erheben; seltener sind Exemplare mit weitläufiger rerzweigten Stengeln, deren Blätter nicht zu einer wirklichen Rosette zusammenschliessen. Die Figur der Flora danica, Tab. 20, entspricht in dex Blattform den ms rorliegenden Exemplaren nicht; viel ähnlicher 
sind die Blätter anf der 'Taf. 33506 der Engl. Bot. An unsern Exemplaren sind die Blätter allmïhlich in den Blattstiel verschmälert. 8) Tesicaria aretica R. Br.

"Heidelbeerberg" am Fjord, 4-800 Fuss hoch, einzeln. Nur mit halbreifen oder reifen Friichten beobachtet. Fehlt bei Scoresby, Sabine und Graah. Nach J. Lange in Westgrönland ron $69^{\circ} 40^{\prime}$ $-70^{\circ} 41^{\prime}$, also nur sehr local.

Alle oberirdischen Theile der Pflanze mit Ausnahme der aufgeblasenen Fruchtklappen sind mit ausgezeichnet schönen schülfrigen Sternhaaren bedeckt.

\section{9-13) Draba.}

Von allen Gattungen der arktischen Flora ist die Gattung Draba unbestritten die schwierigste, und wir können nur Hooker's Bemerkung (Distribution of arctic plants, S. 315) bestätigen, dass man bei ihrer Bearbeitung zu keinem befriedigenden Abschlusse kommt. Die Schwierigkeiten liegen zum grossen Theil in der Sache selbst. Die Draben sind äusserst veränderliche Pflanzen. Die Höhe des Wuchses, die Reichblitigkeit des Blïtenstanders, die Form und (iröisse der Blätter, das Vortreten von deren Mittelrippe anf der untern Seite, die Anoder Abwesenheit von Blättern am Stengel, der Grad der Behaarung, die Länge des Griffels sind äusserst variabel; am constantesten scheint uns noch die Form der Haare, der Umriss des Bliitenstandes, die Gestalt der Friichte und die lockere oder dichte Anordnung der Samen zu sein. Dazu weicht das Aussehen der blühenden Pflanzen oft wesentlich ron dem der fruchttragenden ab, und es ist daher nicht selten schwierig. in einer Sammlung die zusammengehörigen Formen zu identificiren. Anch die Blitenfarbe ist bei getrocknetem Materiale nicht zuverlässig, da mehrere weissblïtige Arten, z. B. Dr. Wahlenbergii Hartm. und Dr.arctica Vahl beim 'Trocknen mehr oder weniger gelb werden. Durchmustert man ein reicheres Material, wie es uns vorlag, iilutr dessen Kusammengehörigkeit und Wachsthunsrerhältnisse aber keine speciellen Beobachtungen angestellt sind, so wird man anfangs dadurch förmlich rerwirt, dass kein Complex von Merkmalen durch grössere Reihen von Pflanzen getreu bleibt. Fast jedes Merkmal ist fuir sich unabhängig variabel, sodass die Anordnung der P'flanzen verschieden ausfällt, je nachdem man sie nach einem derselben, z. B. der Kahlheit oder Behar theit der Friichte, der Höhe des Wuchses u. s. w. ordnet. Bildet man, was wol der naturgemässeste Weg ist, nach der Blitenfarbe, der Form der Frïchte, dem Umriss des Blïtenstandes und der Gestalt der Haare die Hauptgruppen, so bleiben doch immer einige Exemplare zurïck, welche zu Zweifeln Veranlassung geben 
und die scharfen Grenzen zwischen den Gruppen verwischen. Offenbar spielt auch die Bastardbildung eine bedentende Rolle in dieser (rattung.

Es kommt nun noch hinzu, dass die Literatur ïber diese Pflanzen eine äusserst verwirrte ist. Es hat dies (natuirlich neben der Variabilität der Pflanzen selbst) besonders seinen Grund darin, dass man die in den Alpen, Pyrenäen u. s. w. erkamnten Arten in andern Gegenden ohme Weiteres wiederzutinden glaubte, währoul die Pflanzen sich eben in verschiedenen Gegenden verschieden rerhalten.

Unter diesen Umständen wird an eine genügende Erkenntniss der arktischen Draben wol erst damn zu denken sein, wenn sie zum Gegenstand eines eigenen Studiums an Ort und Stelle gemacht werden, wozu aber vorläufig wenig Aussicht sein diurfte.

Für die grönländischen Arten sind natïrlich die Abbildungen und Beschreibungen der Flora danica besonder's wichtig, und haben wir daher die Tafeln derselben möglichst häufig citirt.

Hooker führt aus der Sammlung von Scoresby nur Draba hirta und auf Grund der von Sabine gesammelten Materialien Draba alpina, a major, $\beta$ intermedia, $\gamma$ nana, Dr. hirta, muricella, incana(?) auf; natiirlich bleibt es aber dabei zweifelhaft, ob er die Benemungen in demselben Sinne braucht wie wir. Graah hat auf der Insel Kemisak Draba muricella Whlnbg. gesammelt; Lange gibt für Grönland überhaupt Dr. corymbose R. Br., arctica J. Vahl, crassifolia Grah., lapponica DC., lactea Adams (Wahlenbergii Hn.), nivalis Liljebl., rupestris R. Br., hirta L., alpina L., aurea M. Vahl, ineana L. an und bezeichnet von diesen Dr. corymbosa R. Br. und nivalis Liljebl. als im östlichen Grönland rorkommend.

Wir gehen nummehr zur Aufzählung der einzelnen Arten über.

9) Draba arctica Vahl (Flor. dan., 'Taf. 2294).

Pendulum-Insel, Clavering-Insel, Jackson-Insel, Sabine-Insel, Fjord.

Eine weissblütige Art. Die Stengel stehen gedrängt zu zwei bis vier. Die oberirdischen Theile der Pflanze (auch die Fribchte) sind dicht mit weissen Sternhaaren bedeckt und dadurch grau gefärbt. Grundständige Blätter verlängert-spatelförmig, ganzrandig orler sehr spärlich gezähnt. Der Stengel trägt ein orler mehrere Laubblätter (zuweilen ist das oberste die Bractee der untersten Bliite); sie sind schmal- oder breit-lanzettlich, mit breiter Basis sitzend. An den Blättern tritt die Mittelrippe wenig hervor. Die Traube ist ziemlich reichblütig. Die Fruchtstiele sind nahezu so lang wie die Friichte selbst; diese letztern sind elliptisch und besitzen einen sehr kurzen Griffel (bei den Exemplaren aus dem Fjord ist derselbe aber länger, bis zu $1^{\mathrm{mm}}$ lang). 
Es reiht sich hieran eine Anzahl von Exemplaren von der Clavering-Insel, welche durch besonders ïppiges Wachsthum in feuchtem Schlamm verändert zu sein scheinen. Bei ihnen sind die Stämmchen verlängert und die Behaarung ist bedeutend verändert. Die Sternhaare sind rermindert; Gabelhaare und einfache Haare treten vielfach an ihre Stelle; die Friichte sind kahl. Die Blütenfarbe, der Besitz ron Stengelblättern und die Form der Frucht nähern sie aber der Hauptform, mit der sie auch durch Uebergänge verbunden sind.

10) Draba Wahlenbergii Hartm. (Flor. dan., Taf. 1420).

Sabine-Insel, Clavering-Insel; Fjord.

Eine weissblühende Pflanze, deren Bliiten aber (wie schon Wahlenberg, Flora lapponica, S. 174 bemerkt) beim 'Trocknen leicht gelb werden. Die Blïten der vorliegenden Pflanzen sind sämmtlich blassgelb gefirirbt.

Die Pflanze bildet meist dichte Rosetten, die Blätter sind klein. borstig-gewimpert und sehr spärlich gabelhaarig, die Nittelrippe stark herrortretend. Die Stengel sind bei den fruchttragenden Exemplaren entweder völlig kahl oder doch nur sehr schwach gabelhaarig; Fruchtstiele und Friichte kahl; die letztern sind schmal eilanzettförmig, der (iriffel selten mehr als $1 / 2 \mathrm{~mm}$ lang. Kelchblätter kahl oder doch nur sehr selten einzelne Borsten tragend. - Bei den blitentragenden Exemplaren, welche wir hierher ziehen, sind die Stengel meist nicht kahl, sondern in verschiedenem Grade mit Gabelhaaren besetzt; doch finden sich darin in einem und demselben Rasen sehr rerschiedene Abstufungen, und es ist wol wahrscheinlich, dass die Kahlheit der Stengel, auf welche Wahlenberg in der Flora lapponica und die Flora danica so grossen Werth legen, erst im Laufe der Entwickelung durch Verschwinden der Haare auftritt. Da unsere bliitentragenden Exemplare allgemein stärker behart sind als die fruchttragenden, so wagen wir nicht, hierauf eine eigene form zu grïnden. Durch die Beharung des Stengels wird eine Annäherung an die nächste Art hergestellt, sodass man bei blihhenden Exemplaren oft sehr zweifelhaft sein kann, zu welcher Art man sie rechnen soll. Exemplare aus der GydeTundra: Draba Wahlenbergii Flor.'Taim., stimmen mit unsern Pflanzen sehr wohl überein, haben aber anch einzelne Haare an den Stengeh.

11) Draba alpina L.

Sabine-Insel, Clavering-Insel, Shannon-Insel, Jackson-Insel; Cap Broer Ruys; Fjord.

Eine Art mit schön dunkelgelben Blüten. Stark rerzweigte Rasen 
bildend; die Blätter grösser als bei đer vorigen Art, verlängert spatelförmig-lanzettlich; der Mittelnerv nur in der untern Hälfte hervortretend. Blätter am Rande stark borstig-gewimpert, auf der Fläche mehr oder weniger mit Gabelharren besetzt; die Stengel sind stark gabelhaarig, die Kelche borstig-haarig; Früchte kahl oder behaart. Die Traube ist kurz und gedrängt, im Umriss fast doldig; die Fruchtstiele sind abstehend. Die Früchte dieser Art sind eiförmig oder eilanzettlich (stets bemerklich breiter als bei Draba Wahlenbergii Hartm.), der Griffel entweder sehr kurz oder bis $1^{\mathrm{mm}}$ lang. Die Samen sind gross, dunkelbraun gefärbt und von einander entfernt (d. h. sie liegen auf jeder Seite der Scheidewand nicht dicht aneinander, sondern lassen Liicken zwischen sich).

Die fruchttragenden Pflanzen stimmen fast rollständig mit der Abbildung der Draba corymbosa R. Br. in der Flora danica (Taf. 2418) iiberein.

Nach der Behaarung oder Kahlheit der Früchte sind bei dieser Art (wie dies auch schon von Hooker u. A. geschehen ist) zwei Varietïten zu unterscheiden.

12) Draba mestris R. Br. (Flora danica, Taf. 2421).

(Draba hirta L., $\beta$ alpicola Wahlenbg. [Flor. lapp., S. 175].)

Kaiser-Franz-Josephs-Fjord; Clavering-Insel, Jackson-Insel.

Die charakteristischste Form ist die aus dem Franz-JosephsFjord, wo die Pflanze auf grasigen Halden und kahlen Abhängen wächst. Die Exemplare sind die höchsten von allen gesammelten Drabaformen, $16-20^{\mathrm{cm}}$ hoch; das Wachsthum ist nicht dichtrasig, sondern locker, indem die Exemplare nur ein, zwei oder drei Stengel besitzen. Die Stengel tragen 1-3 kleine Laubblätter und endigen mit einer 4- blütigen (seltener reichblütigern) Traube. Die Blätter und der untere Theil des Stengels sind stern- und gabelharig, der obere Theil kahl. Die Blätter sind ziemlich kurz, spatelförmig und haben eine unterwärts sehr stark hervortretende Mittelrippe. Die Friichte sind elliptisch-lanzettlich, 7-10 $\mathrm{mm}$ lang, Griffel sehr kurz; die Stiele etwas kürzer als die Frucht. Die Klappen der Frucht sind im reifen Zustande gelbgrün gefärbt. Die kleinen hellbraunen Samen sind auf beiden Seiten dichtgedrängt. Diese Form entspricht der oben citirten Abbildung der Flora danica sehr mohl, auch stehen ihnen russische und sibirische Exemplare, welche wir als Dr. hirta, Dr. hirta, var. foliosa und Dr. rupestris aus dem Petersburger Herbarium erhielten, sehr nahe. - Hieran schliessen sich, sehr wohl mit ihnen übereinstimmend, aber durch blattlosen Stengel und geringere Höhe $\left(12-13^{\mathrm{cm}}\right)$ verschieden, die Exem- 
plare rom Suidostabhang der Jackson-Insel. Noch kleiner $(5-10 \mathrm{~cm}$ hoch) sind endlich Exemplare ron der Clavering-Insel; auch sie entbehren meistens der Laubblätter am Stengel, stimmen aber in der Beharung, der lockern 'Traube, und der charakteristischen Fruchtform mit den erstbeschriebenen Formen überein. Sie bilden den Uebergang zu der gleichfalls schmalfruichtigen Dr. Wahlenbergii, welche hauptsächlich durch den zur Fruchtreifezeit kahlen (oder doch nahezu kahlen) Stengel und die borstig-gewimperten Blätter von ihmen verschieden ist. Bei einzelnen Exemplaren ist man aber zweifelhaft, wohin man sie rechnen soll.

13) Draba murcella Wahlnbg. (nivalis Liljebl. nec DC.)

Sabine-Insel.

Kleine Drabaformen (meist $4-6^{\mathrm{cm}}$ hoch) von dichtrasigem Wachsthum. Die ganze Pflanze mit Ausnahme der Früchte mit schönen weissen Sternhaaren bedeckt; Früchte kahl. Die Blätter sind klein, ganzrandig, der Mittelnery auf der untern Seite nur wenig hervortretend. Die Stengel sind blattlos, die Traube ziemlich locker; die F'ruchtstiele sind aufrecht. Friichte länger als die Fruchtstiele, lanzettlich, oder selbst linealisch-lanzettlich, Griffel sehr kurz. Samen klein, hellbram, dichtgedrängt. Stengel und Frichte meist eigenthümlich roth überlanfen; die Blätter sind filzig - grau.

Diese Exemplare stimmen durchaus mit der Abbildung und Beschreibung von Wahlenberg (Flor. lapp., S. 174, Taf. XI, Fig. 2) iiberein. Die Sternhaare sind angedriickt. In den Herbarien findet man vielfach Exemplare mit gestielten und mehrfach rerzweigten Gabelhaaren unter diesem Namen.

Ausser den kahlfrïchtigen Exemplaren befinden sich in unserer Sammlung num aber auch noch Exemplare einer Varietät mit behaarten Schötchen, die wir als var. Panschii unterscheiden wollen. Charakteristische Pflanzen dieser Form ron etwa $5^{\mathrm{cm}}$ Höhe wurden auf der Jackson-Insel und am Cap Broer Ruys gesammelt. Die Schötchen sind bei ihnen auffallend breit, die Fruchtklappen mit zwei- oder dreispaltigen Haaren besetzt. Die ganze Pflanze ist stärker als bei der Hauptart. Einzelne Exemplare haben ein ganz kleines Laubblatt am Stengel. - Hierher duirften auch zwei grosse Exemplare (von 10 und $14^{\mathrm{cm}}$ Höhe) von der Sabine-Insel zu ziehen sein. Sie sind nicht vielköpfig, sondern haben nur einen Stengel; die Traube ist sehr verlängert, sodass der Wruchs ganz an die grossen Exemplare der Draba rupestris R. Br. erinnert. In der Fruchtform, sowie der Behaarung stimmen sie aber ganz 
mit den eben erwähnten Exemplaren der Draba muricella Whlnbg., var. Panschii ïberein.

14) Cochlearia fenestrata R. Br.(?)

Walross-Insel (October 1869 bereits so gut wie völlig abgestorben), Sabine-Insel, Klein-P'endulum-Insel. Hooker gibt bei Scoresby C. anglica et C. - ?, bei Sabine Cochl. fenestrata? an. Wir geben die obige Benenumg nur mit Widerstreben, da die Abgrenzung der Species in der Gattung Cochlearia eine höchst unsichere ist, und die Gattung in dieser Beziehung dringend einer Revision bedarf. Um eine Idee zu erhalten, welche Confusion in ihr her'scht, muss man Hooker's Auseinandersetzung in seiner oben citirten Arbeit: On the distribution of aretic plants, S. 317 lesen. Wir geben daher, statt uns in das Labyrinth der Synonymie zu begeben, lieber eine Beschreibung der vorliegenden Pflanzen.

Oberhalb der kräftigen Hauptwuzel befindet sich eine dichte Rosette langgestielter Blätter. Die Stiele derselben erreichen eine Läinge von $5-8^{\mathrm{cm}}$; die Blattscheibe ist klein (selten grösser als $1^{\mathrm{cm}}$ im Durchmesser), im Umriss kreisrund, fast nierenförmig oder rund-eiförmig, rund-dreieckig oder rund-rautenförmig; die Basis ist stets abgestutzt, die Spitze abgerundet stumpf, der Rand ganzrandig. In der Mitte der Blattrosette erblickt man fruiheitig einen dichten Ḱnäuel ron Bliitenknospen, der aus der terminalen und den lateralen Bliitentrauben besteht. Dic letztern entwickeln sich bedeutend frïher und auch stärker als der Hauptstengel; dabei sind die Seitenäste anfangs steil, später horizontal abstehend und geben daher der Pflanze ein ungemein sparriges Ansehen. Der Hauptstengel erreicht an den grössten Exemplaren eine Höhe ron 5-. $6^{\mathrm{cm}}$, während die /weige schon an mittelgrossen Exemplaren diese Länge, an besonders starken aber $8-10^{\mathrm{cm}}$ erreichen; die 'Zweige sind nur höchst spärlich und gewöhnlich erst dicht unter rer Bliitentraube beblättert. Mit dem Eintritt der Blïtezeit beginnen die grundständigen Blätter zu welken und sind zur Zeit der Fruchtreife gewöhnlich ganz abgestorben. Die stengelmul zweigständigen Blitter sind lanzettlich-spatelfömig, allmählidh in den ziemlich breiten Blattstiel verschmälert, die Spitze ziemlich spitz oder stumpflich, der Rand entfernt gezähnt. An den Blütenständen sind die untern Bliitenstiele gewöhnlich stärker verlängert als die obern, so dass mahezu eine Doldentraube gebildet wird. Die Bliitenstiele sind unter den Blüten keulig rerdickt. Die Früchte sind ziemlich gross (4-7mm lang), kugelig-eifömig oder elliptisch, der Griffel gewöhnlich sehr kurz. Unter den Exemplaren von der 
Sabine-Insel befinden sich ein paar kleine Pflanzen mit sehr kleinen, wenig über $1^{\mathrm{mm}}$ im Durchmesser haltenden Früchten, wei denen der Griffel fast so lang ist als die Frucht. Einen Nerr konnten wir auf den Fruchtklappen nicht entdecken. Die Scheidewand ist an den uns vorliegenden (nicht sehr zahlreichen) reifen Friichten entweder gar nicht durchbohrt oder unregelmässig und in sehr verschiedenem Grade zerrissen; sie behält anch nach dem Abfallen der Klappen ihre breit-elliptische Form bei ohne zusammenzufallen. Die ganze Pflanze ist kahl und fleischig.

\section{5) Silene acantis $\mathrm{L}$.}

\section{4) Caryophylleac.}

In dichten Rasenpolstern wachsend und weit verbreitet: SabineInsel, Klein-Pendulum-Insel, Jackson-Insel (von hier mit ganz reifen Frïchten), Cap Broer Ruys. Anch von Scoreshy und Sabine gesammelt. - Unter dem lediglich getrockneten, nicht gepressten Material an Pflanzen, welches unsere Expedition in Kisten verpackt mitgebracht hat, befinden sich einige Rasenpolster, welche bis zur. Unkenntlichkeit abgeweidet sind; die einzelnen Stïmmchen des Rasens bilden damn auf der Oberfläche rosettenartige Figuren.

16) Wahlbergella (Lychnis) apetala (L.) Fries.

Im fenchten Rasen und zwischen nassen Moosbüscheln: SabineInsel, Clavering-Insel, Jackson-Insel, Cap Broer Ruys (von den beiden letzten Standorten besonders fructificirende Exemplare). Bereits von Sabine gefunden.

Bei den meisten Exemplaren haben nur die Kelchrippen eine violette Farbe, die dazwischen liegenden Flächen sind blassgrün gefärbt; eine Reihe von Exemplaren der Sabine-Insel besitzt aber Kelche, welche in ihrer ganzen Fläche tief violett gefïrbt sind. Die Blumenblätter überragen entweder den bauchigen Kelch ein wenig, oder sind von ihm eingeschlossen. Die Samen sind noch grösser als die der folgenden Art und von einem breiten häutigen Flügel umzogen.

17) Melandrium affine Vahl.

Auf grasigen Felshalden spärlich gefunden: Sabine-Insel, Clavering-Insel, Kaiser-Franz-Josephs-Fjord. (hange gibt die Pflanze für Westgrönland vom $65^{\circ} 38^{\prime}-72^{\circ} 48^{\prime}$ an. Wahrscheinlich ist auch mit: Iychnis dioica, var. nana von Hooker in der Sabine'schen Sammlung dieselbe Pflanze gemeint.) - Einzelne Stengel sind nur einbliitig. Die Samen sind etwas kleiner als die der vorigen Art, dabei von einem häutigen Flügel umzogen und im Umrisse gewöhnlich dreieckig. 
18) Melandrium triflorum (R. Br.) Vahl.

Von der Shamnon-Insel und der Sabine-Insel vorliegend. Fehlt bei Scoresby, Sabine und Graah; von Joh. Lange für das westliche Grönland vom $60^{\circ} 50^{\prime}-72^{\circ} 48^{\prime}$ angegeben. - Wie bei der vorigen Art sind die Kelche zur Bliitezeit cylindrisch und erst zur Fruchtreifezeit aufgetrieben. Sie unterscheidet sich aber leicht durch die sehr kleinen, zur Reifezeit gestachelten Samen.

19) Arenaria ciliata $\mathbf{L}$.

Auf fruchtbarem, feuchtem Schuttboden, Gletscherwällen u. dgl.: Sabine-Insel, Clavering-Insel, Jackson-Insel, Cap Broer Ruys, Ablänge vom Kaiser-Franz-Josephs-Fjord. Schon von Sabine gefunden.

Bildet meist kleinere, dichte Rasen, welche ganz mit Bliiten bedeckt sind; in dem fruchtbaren Gletscherschlamme des Fjord sind die Exemplare üppiger, die Stengel und Blütenstiele verlängerter. An den breit-spatelförmigen, sehr stumpfen, etwas fleischigen und am Rande, namentlich gegen die Basis hin gewimperten Blättern leicht zu erkemnen; die grossen weissen Blumenblätter sind um die Hälfte länger als der Kelch; dieser letztere bei manchen Exemplaren lebhaft roth gefärbt. Die Bliitenstiele sind mit kurzen, rückwärts gerichteten Haaren besetzt.

20) Alsine rubella Wahlenberg.

Die Hauptform mit kurzgestielten, die Blätter nur' wenig überragenden Bliiten liegt nur von der Sabine-Insel vor; die verlängerte Form $\gamma$ Gisckii Joh. Lange in Rink (Alsine Gisekii Hornemann, Flora danica, T'ab. 1518) dagegen von mehrern Fundorten: von der Sabine-Insel (in der Nähe der Eskimohütten), der JacksonInsel, Cap Broer Ruys; ein Exemplärchen fanden wir auch zwischen andern Pflanzen aus dem Franz-Josephs-Fjord. Hooker füht bei Sabine nur einfach Alsine mibella auf; bei Scoresby und Graah fehlt die Pflanze.

21) Alsine biflora Wahlenberg.

Nur in wenigen von der Sabine-Insel stammenden Exemplaren vorliegend. Fehlt bei Scoresby, Sabine und Graah; nach Joh. Lange im westlichen Grönland vom $60^{\circ}-72^{\circ} 48^{\prime}$ (bis 2050 Fuss Meereshöhe).

Die Pflanze mag wol ihrer Unscheinbarkeit wegen bei manchen Excursionen ibersehen worden sein. Die vorliegenden Exemplare stimmen völlig mit solchen aus Lulea-Lappmarken in unserm Herbarium überein. 
22) Hatianthus peplö̈des (L.) Fries.

var. oblongifolice J. Lange in sched.

In dichtem Rasen am Fusse steiler Klippen auf der ClaveringInsel; seltener bei Cap Borlase Warren. Von Sabine angegeben; nach Lange an der Westküste rom $60^{\circ} \div 69^{\circ} 14^{\prime}$.

Blüten etwas kleiner und grinlicher als bei der mitteleuropäischen Pflanze; Blätter weniger Heisehig.

23) Stellaria lompipes Gouldie (St. Edwardsii R. Br., St. nitida Hooker bei Scoresby).

Weitverbreitet; in trockenem Rasen und zwischen andern Pflanzen wachsend; z. B. Sabine-Insel, Clarering-Insel (auf beiden in der Nähe der Eskimohiitten häufig), Shannon-Insel, Jackson-Insel, Cap Broer Rius, Fjord (hier zwischen Felsblöcken in etwa 600 Fuss Höhe). Von Scoresby und Sabine gesammelt. - Besonders die absterbenden Theile der Pflanze haben einen lebhaften Glanz.

24) Stellaria humifusa Rottb.

Auf Wiesen, Sabine-Insel. (Unter dem in Kisten gepackten, nicht gepressten Material finden sich eine Anzahl ron sterilen und blihhenden Rasen, deren Fundort sich nicht mehr sicher ermitteln lässt; sie haben meist durch Schimmel sehr stark gelitten.) Wird von Sabine und Graah angegeben; im. westlichen Grönland nicht selten.

Stellaria cerastoides L., von Sabine mitgebracht, fehlt in unserer Sammlung.

25) Cerastium alpinum L., var. lanatum.

Allgemein verbreitet; auch ron Scoresby, Sabine, Graah gefunden.

Eine äusserst variable Pflanze. Sie bildet dichte liasen aus einer kräftigen Hauptwurzel. Die Behaarung ist sehr verschieden stark, die Dehnung der Achsenglieder gleichfalls äusserst veränderlich. Bald sind die Blätter rosettenartig zusammengedrängt und die Blïten erheben sich nur wenig uiber die Polster, bald sind (namentlich wol zwischen Felsblöcken) die Exemplare sehr gestreckt and bis $71124^{\mathrm{cm}}$ hoch.

Das Vorkommen des Cerastium latifolium, von W. J. Hooker bei Scoresby angegeben, ist wol sehr zu bezweifeln, da das echte Cer. latifolium der arktischen Flora, so viel bekannt, nicht angehört. J. D. Hooker hat es denn auch in seine Outlines of the distributions of aretic plants nicht anfgenommen.

\section{5) Rosaceac.}

26) Dryas actopetale I.

Sehr weit verbreitet und wie in den Alpen dichte, dem Boden anliegende Gebüsche bildend. An vielen Stellen nur höchst spärlich 
blühend; aus dem Fjord mit Früchten vorhanden. Von Scoresby und Sabine gefunden.

Sämmtliche Exemplare haben stark gekerbt-gesägte Blätter; die Form integrifolia Vahl fehlt unter dem gesammelten Material, obwol sie nach J. Lange's Angabe in Westgrönland allein (ohne die gesägt-blättrige Form) vorkommt; vergl. darüber auch oben S. 21.

27) Potentilla pulchella R. Br. (Flor. dan., Taf. 2234).

Nur wenige von der Clavering-Insel stammende Exemplare dieser schönen, bisher aus Ostgrönland nicht bekannten Pflanze sind in der Sammlung vorhanden.

Ausgezeichnet durch gefiederte grundständige Blätter, an denen die untern Fiedern kleiner sind als die folgenden. Junge Exemplare sind ganz mit langem, weichem, weissem Seidenfilze bedeckt, der sich aber später auf der obern Seite der Blätter mehr verliert. Ist dies vielleicht die eine Varietät von Pot. nivea L. bei Sabine oder die Pot. nivea, var.(?) von Graah? Lange gibt die Pflanze für Westgrönland rom $70^{\circ}-70^{\circ} 41^{\prime}$ an.

Unsere ostgrönländische Pflanze gehört zu der typischen Form, wie sie im arktischen Amerika und in Westgrönland vorkommt. Von Spitzbergen erhielten wir eine auffallend verschiedene Form, welche bis auf die kurzhaarigen Kelche völlig kahl ist. Diese Form, welche jedenfalls eine charakterische Varietät, wenn nicht Subspecies darstellt, haben wir bereits in den Abhandlungen des naturwissenschaftlichen Vereines zu Bremen, Band III, S. 89 als var. Friesii unterschieden. Muthmaasslich vertritt sie auf Spitzbergen die Hauptform, da das Vorkommen zweier so abweichender Varietäten sicher von den Bearbeitern der Spitzbergischen Flora hervorgehoben sein wiirde.

28) Potentilla nivea $\mathrm{L}$.

An sonnigen Abhängen: Sabine-Insel, Jackson-Insel, Ufer des Fjords. - Hooker führt nach der Sammlung von Sabine eine var. $\alpha$ und $\beta$ auf; Lange gibt sie für das westliche Grönland rom $64^{\circ}$ $-72^{\circ} 48^{\prime}$ an.

29) Potentille emarginate Pursh (Flor. dan., Tat. 2291 ; doch sind die Kelchblätter an unsern I'flanzen weit stumpfer, als diese Figur sie darstellt).

Von den meisten besuchten Orten mitgebracht; scheint überhaupt dort die häufigste dieser Arten zu sein. - Hierher gehört wol die Pot. verna L., von Hooker in Scoresby's Reise, dann wahrscheinlich eine der Varietäten von Pot. nivea bei Sabine und endlich vielleicht auch die Pot. retusa Retz von Hornemann bei Graah; nach Joh. Lange im westlichen Grönland rom $66^{\circ} 50^{\prime}-72^{\circ} 48^{\prime}$, 
Diese und die vorige Art gehören zu den Arten mit dreizähliggefiederten Blättern. Pot. emarginata hat stumpfe Kelchblätter und eine gelbliche Beharung, Pot. nivea dagegen spitze Kelchblätter und oben grüne, unten weisstilzige Laubblätter; auch sind die letztern bei Pot. nivea tiefer getheilt und die einzelnen Zipfel schmaler und spitzer als bei Pot. emarginata P'ursh.

\section{6) Onagrariaceae.}

30) Epitobium latifolium L.

In Grönland weit verbreitet, besonders auf jungem Boden, Gletscherwällen und an ähnlichen Localitäten, wohin die Pflanze vermöge ihrer mittelst der Harkirone fliegenden Samen ähnlich wie unsere Arten auf Holzlichtungen und ähnliche Standorte, leicht gelangt. Bildet dichte Büsche, von denen viele im Jahre 1870 noch die umreifen, aber abgestorbenen Kapseln des Vorjahres trugen. Auch von Scoresby, Sabine und Graah gefunden. - Eine der schönsten Blumen Grönlands.

\section{7) Crassulaceac.}

31) Sedum Rhodiola DC.

Nur auf der Clavering-Insel bei Cap Mary. Fehlt bei Scoresby, Sabine und Graah; von Lange für das westliche Grönland rom $60^{\circ}-67^{\circ}$ und auch für Ostgrönland (durch einen beigesetzten *) angegeben.

Die wenigen gesammelten Exemplare sind nur $3-4^{\mathrm{cm}}$ hoch, während die von Kapitän Hegemann (Expeditionssehift Hansa) aus dem südlichen Grönland mitgebrachten Exemplare $10-20^{\mathrm{cm}}$ messen und sich auch durch weit grössere Reichblütigkeit auszeichnen. Die Blätter, welche bei der nordischen Form mit breitem, fast herzförmigem Grunde sitzen, sind bei den Pflanzen aus Südgrönland nach unten verschmälert; doch finden sich auch einzelne Annäherungen an die Blattform der nördlichen Exemplare. Frische Rhizome vom Cap Mary, die sich unter den von der Expedition mitgebrachten Pflanzen vorfanden, trieben im Sommer 1871 Stengel, deren Blätter nicht breiter als die suidgrönländischen waren.

\section{8) Saxifragaceac.}

32) Saxifrage oppositifolia L.

Eine der verbreitetsten arktischen P'flanzen, von fast allen besuchten Punkten mitgebracht; auf der Südseite der ClaveringInsel eine Form mit sehr blassen Blumen; aus dem Fjord mit 
Friichten. - Wurde auch von Scoresby und Sabine gesammelt. Die Schlittenexpedition nach dem Norden brachte von einem der nördlichsten erreichten Punkte $\left(77^{\circ}\right.$ nördl. Br.) Proben von dieser Pflanze mit.

33) Saxifraga caespitosa L., var. gronlandica L. (als Art).

Liegt von fast allen besuchten Orten vor, jedoch nicht aus dem Fjord; auch von Scoresby, Sabine und Graah gefunden.

Von dieser sehr polymorphen Art befinden sich unter dem gesammelten Material theils grössere, mehrblütige Formen mit lockern Blattrosetten, theils kleinere, ein-bis zweiblitige Zwergformen; die letztern sind an Stengeln und Kelchen besonder's stark drïsenharrig.

34) Saxifraga cernua L.

An feuchten Stellen, zwischen Felsblöcken u. s. w. weit verbreitet, von fast allen besuchten Punkten mitgebracht; aus dem Fjord Exemplare von $25^{\mathrm{cm}}$ Höhe, welche zwischen Felsblöcken autgeschossen sind. Von Scoresby und Sabine gesammelt. - Blumen sehr häufig nicht entwickelt, sondern durch kleine Bubillen ersetzt; die gipfelständige Blüte ist dann aber meistens doch entwickelt.

35) Saxifraga rivularis $\mathrm{L}$.

Liegt nur in einigen, etwa $2^{\mathrm{cm}}$ hohen Exemplaren von der Clavering-Insel und dem Cap Broer Ruys vor; auch von Sabine gefunden. - Die kleine Pflanze dürfte wol an einigen Stellen übersehen sein.

36) Saxifraga nivalis L.

Ueberall verbreitet, namentlich an feuchten schlickigen Stellen; auch von Scoresby und Sabine gefunden. An trockenern Stellen der Sabine-Insel sind die Exemplare kaum $2^{\mathrm{cm}}$ hoch und sehr armblütig, wogegen andere Pflanzen von den Moränen des Fjord $25^{\mathrm{cm}}$ Höhe erreichen.

37) Saxifraga hieracifotia IV. et K.

Nur ein Exemplar dieser, der vorigen Art sehr nahe stehenden Pflanze mit Exemplaren derselben bei Cap Broer Ruys gefunden. Herr Dr. Engler erklärt es für zweifellose $S$. hieracifolia.

Die Pflanze ist für Grönland neu, kommt aber auf Spitzbergen und sonst im arktischen Gebiete ror.

38) Saxifraga hirculus L., var alpina Engler.

Auf schlickigem Boden und zwischen feuchten Moospolstern: Gruppe der Pendulum-Inseln, Mackenzie-Bucht; aus dem Fjord nicht vorliegend. Schon von Sabine gefunden.

Das Vorkommen dieser Art in Grönland ist, wie auch J. D. Hooker 
in seiner Arbeit iiber die arktische Flora angiebt, auf die Ostküste beschränkt; in der Lange'schen Flora von Grönland fehlt sie.

Eine ungewöhnlich gedrungene und dicht-rasige Form, deren Stengel nur selten $5^{\mathrm{cm}}$ Höhe überschreiten. Die Blïten sind ausserordentlich gross und intensiv gelb gefiribt.

39) Saxifraga flagellaris Willd.

In durchweichtem Boden, in der Niihe der Gletscherbảche u. s. w.: Gruppe der Pendulum-Inseln (wo sie auch schon von Sabine gefunden wurde), aber nicht in der Nähe von Cap Broer Ruys und aus dem Fiord. Im Siiden mud an der Westkïste von Grönland fehlt sie. (Ein kleines blühendes Exemplar dieser Art wurde vom Stenermann Hildebrand von der Hansa im Sommer 1869 auf dem Eise gefunden, wohin es wol durch einen Sturm verschlagen war.)

40) Saxifraga aizoïles $\mathrm{I}$.

Im Schutte der Gletschermorinen und auf feuchten Wiesen am Kaiser-Franz-Josephs-Fjord, grosse Rasen und Polster bildend, zum Theil mit Frichten. Scheint soust in Ostgrönland selten zu sein, da sie von unserer Expedition an keiner andern Stelle gefunden wurde und atuch von Scoresby, Sabine und Graah nicht angegeben wird. Tach Joh. Lange an der Westkiiste ron $60^{\circ}$ $70^{\circ} 41^{\prime}$.

Saxifraga stellaris L. (foliosa R. Br.), von Sabine gefunden, fehlt in unserer Sammlung.

\section{9) Compositae.}

Gnaphatium alpinum L., von Scoresby gesammelt, fehlt in unserer Sammlung. 41) Amica alpina Murr. (A. angustifotia Vahl, Flor. dan., Taf. 1524).

Auf berasten Abhängen weit verbreitet und stellenweise sehr häufig, z. B. Clavering-Insel, Jackson-Insel, Mackenzie-Bucht, Abhänge am Fjord; auch von Scoresby und Sabine angegeben. Die Exemplare von den Inseln sind $10-15^{\mathrm{cm}}$ hoch, die von der Mackenzie-Bucht und vom fijord sind bemerklich grösser (keins unter $13^{\mathrm{cm}}$, meist $20^{\mathrm{cm}}$ hoch) und dabei stärker behart; dabei sind die Blätter dieser Exemplare linealisch-lanzettlich oder selbst linealisch, nicht wie bei den Insel-Exemplaren länglich-lanzettlich. Die sämntlichen Exemplare sind stäker grautilzig als solche von Ome11ak, Westgrönland, welche wir der Güte des Herm Professor Joh. Lange verdanken.

42) Erigeron eriocephalus J. Vahl (1'lor. dan., 'Tab. 2299).

Stellenweise auf der Siidkiiste der Clavering-Insel, sonst nicht bemerkt; bereits ron Scoresby, Sabine und Graah gefunden. Die 
Exemplare sind $4-10^{\mathrm{cm}}$ hoch, der Stengel und die stengelständigen Blätter (weniger die grundständigen) sind mit langen weissen Haaren berleckt; die Huille des Köpfchens aber ist dicht wollig. Ob die specifische 'Tremung dieser Pflanze von Er. uniflorus L. sich wird aufrecht erhalten lassen, erscheint uns zweifelhaft; die vorliegenden Exemplare stimmen aber mit der Diagnose und Abbildung in der Flora danica iiberein.

Erigeron compositus Pursh ist von Sabine gefunden, wurde aber von unserer Expedition nicht mitgebracht.

43) Taraxacum phymatocarpum J. Vahl (Flor. dan., 'Tat. 2298).

Von fast allen besuchten Localitäten mitgebracht. Graah giebt Leontodon taraxacum L. var. an; bei Scoresby und Sabine fehlt merkwürdigerweise jedes T'uraxacum.

Die mitgebrachten Exemplare zeigen alle möglichen Bildungen des Blattrandes vom Ganzrandigen durch das Geschweifte, Gezähnte bis zum Schrotsägeförmigen; der Umriss wechselt vom Spatelförmigen bis Linealischen. Alle Exemplare sind unter $10^{\mathrm{cm}}$ lang, die Köpfchen sind klein; die Früchte zeigen sämmtlich die charakteristische und stark ausgeprägte Berippung, mit scharfen Sägezähnen auf den Rippen, wie sie die Originalabbildung in der Flora danica darstellt; die Stiele der Harkronen sind aber länger; als dort gezeichnet ist.

Im 15. Bande der Flora danica ist auf S. 7 und Taf. 2659 das Taraxacum ceratophorm DC. aus Grönland beschrieben und abgebildet, eine grössere Pflanze mit stark schrotsägezähnigen Blättern, welche sich durch stachelig-beharte Frïchte und einen eigenthümlichen hornfömigen Anhang auf der Aussenseite unter der Spitze der Deckblätter des Köpfchens auszeichnet. Diese Form ist unter dem rorliegenden Materiale nicht vertreten. Dr. Hooker erklärt sie (Distribution of arctic plants, S. 333) eher fur eine abnorme Form als für eine Varietät. Alle aufgestellten 'Taraxacum-Arten diuften zuletzt wol als Subspecies des $T$. officinale zu betrachten sein.

44) Campanula miflora L.

\section{0) Campanulaceae.}

Bergabhänge auf den Pendulum-Inseln; bereits ron Sabine gesammelt; in Westgrönland weit verbreitet.

45) Campanula rotundifotia L., var. arctica J. Lange (Flor. dan., Taf. 2711).

Auf den Abhängen des Fjord zerstreut, häufig in einer Höhe von 6-800 Fuss mit Pyrola zusammen; Bliiten lebhaft, aber nicht dlunkel blau. (Pansch.) 
Die Pflanze scheint in der Niahe des Fjord ihre Nordgrenze fiir Grönland zu erreichen, da sie von keinem Sammler weiter nordwärts beobachtet wurde. Graah sammelte sie unter dem $63^{\circ}$ nördl. Br.; Joh. Lange giebt sie für das westliche Grönland von 68-70 an.

\section{1) Vaceiniaceas.}

46) Vaccinum uliginosum $\mathrm{L}$.

Weitverbreitet; sowol auf den Inseln als am Fjord gesammelt, anch ron Scoresby und Sabine mitgebracht. Die Exemplare ron den Insehn und den Nordabhängen des Fjord meist kümmerlich; kräftige, dichtbelaubte Pflanzen an der Südseite der Jackson-Insel (fast $40^{\mathrm{cm}}$ hoch und mit einem $6-7^{\mathrm{mm}}$ starken Hauptstamme) und den Suidostabhängen des Fjord; hier bildet sie an manchen Stellen dichte, struppige Rasen und wurde auch fructificirend beobachtet. Einzehne Exemplare sind dam dicht mit Beeren bedeckt, während daneben andere steril und ohne Spuren ron Blüten sind. Beeren theilweise reif, meistens aber noch grün. (Pansch.) Eimzelne Exemplare aus dem Fjord haben anscheinend neben den heurigen anch noch vorjährige Blätter.

Die grönländische Form dieser Pflanze ist ausgezeichnet durch die Kleinheit ihrer Blätter, welche auch im Süden Grönlands nicht grösser zu werden scheinen. Weiter ist kein Unterschied zwischen der grönländischen und der europäischen Pflanze nachzuweisen.

Das Vace. pubescens Wormsk. ist nicht, wie gewöhnlich angenommen wird, mit dieser kleinblätterigen Abänderung identisch. Es scheint vielmehr eine ausgezeichnete Varietät des $V$. uliginosum $\mathrm{L}$. zu sein, charakterisirt durch unterseits kurzhaarig-flaumige Blätter. Es ist bisjetzt nur von Westgrönland bekannt. Unter den von Scoresby gesammelten Pflanzen befindet sich, wie Hooker ausdruicklich erwähnt, kein behaartes Vaccinum uliginosum.

\section{2) Ericaceac.}

47) Andromede tetragona L.

Eine sehr verbreitete arktische Pflanze, mitgebracht ron der Clavering-Insel, Shannon-Insel, aus dem Fiord u. s. w. (von dem letztgenannten l'undorte mit reifen Früchten); auch von Scoresby und Sabine gesamnelt; bildet niedrige, aber dichtverflochtene Gestriippe.

48) Arctostaphylos alpina Spreng.

Auf Alluvium an der Eleonoren-Bai, Kaiser-Franz-Josephs-Fjord, zwischen Gräsern, Riedgräsern, Moos und Vaccinium; einziger 
Fundort. (Pansch.) Von Scoresby, Sabine und Graah nicht beobachtet; auch in der Lange'schen Flora von Grönland, sowie auch der Hooker'schen Arbeit über die Flora ron Grönland noch nicht aufgeführt; ist aber inzwischen nach freundlicher Mittheilung des Herrn Professor Johann Lange bei Sukkertoppen im westlichen Grönland gefunden worden. Zwei der wenigen vorliegenden Exemplare besitzen anscheinend reife Früchte.

49) Rhododendron lapponicum L.

Nur sehr spärlich gefunden: auf der Kohleninsel von der geodätischen Expedition; am Kaiser-Franz-Josephs-Fjord. Von Sabine gesammelt; im westlichen Grönland anscheinend häufiger.

Ledum palustre L., welches von Sabine gefunden wurde, fehlt in der vorliegenden Sammlung.

\section{3) Pyrolaceae.}

50) Pyrola rotundifolia L., var. arenaria Koch.

Nur am Kaiser-Franz-Josephs-Fjord; dort in einer Region ron (i- - 800 Fuss Höhe auf grasigen Folshalden sehr häutig, mit Campamula rotundifolia L. zusammen; sonst nur vereinzelt. Von Scoresby, Sabine und Graah nicht gefunden; im westlichen Grönland ist eine andere Form (Pyr. grandiflora Rad., Auct.) häufiger.

Am 10. August noch in voller Blüte; Insekten wurden an den Blumen nicht bemerkt. Der Farbenton in Blättern und Bliiten ganz wie bei den deutschen Pyrola-Arten. (Pansch.)

Die vorliegenden Pflanzen sind durch niedrigen Wuchs, kleine Bliitter, kurze Bliitenstiele, wenigbliitige, ziemlich gedrungene Bliitentraube und breitere Kelchzipfel von der Hauptart rerschieden, schliessen sich der var, arenaria Koch dagegen eng an.

51) Empetrum nigrum I.

\section{4) Empetraceac.}

Von der geodätischen Expedition nach der Kohlen-Insel mitgebracht; ferner aus der Mackenzie-Bucht. Auch von Scoresby gesammelt. Auffallend ist die Spärlichkeit dieser sonst für den hohen Norden so charakteristischen Pflanze; im westlichen Grönland ist sie von $60^{\circ}-72^{\circ} 48^{\prime}$ verbreitet.

Die von Kapitän Hegemann von der Hansa aus dem südlichen Grönland mitgebrachten Exemplare ron Empetrum sind monöcisch, oder gar zwitterig; die hier erwähnten Pflanzen dagegen sind steril oder zeigen spärliche männliche Blüten.

15) Polemoniaceac.

52) Polemonium humile Willd. (P. acutiflorum Willd., P. pulchellum 
Bung., P. capitatum Eschsch., P. Richardsoni Hook. et Arn., P. pulcherimum Hook.)

Fine fuir das östliche Grönland sehr charakteristische Pflanze. die im siidlichen und westlichen Grönland fehlt; wurde auf der Sabine-Insel, Clavering-Insel und Kilein-Pendulum-Insel gesammelt, die kräftigsten Exemplare (bis $15^{\mathrm{cm}}$ hoch) in der Nähe der verlassenen Eskimowohnungen. In Jahre 1869 weit reichlicher bliihend als 1870 .

Wurde bereits ron Sabine beobachtet; fehlt in der Lange'schen Flora ron Grönland. Aus Skandinarien nicht bekannt, in andern arktischen Floren aber häufig.

\section{6) Serophulariateat.}

Veronica alpina, von Scoresby gesammelt, fehlt in unserer Sammlung.

53) Euphasia officinalis L.

Jackson-Insel: , unter den Bürgermeisterklippen an einer beschränkten Stelle als einzigem Fundorte" (Pansch.)

Ein einziges winziges, $1^{\mathrm{cm}}$ hohes Exemplar, dessen speciellere Bestimmung unmöglich ist. Es besitzt keine Dröisenhaare und scheinen die Bliiten klein gewesen zu sein; demmach dürfte es zu der Subspecies gracilis Fries zu rechnen sein. - Scoresby und Sabine haben die Pflanze nicht beobachtet; von Graah wurde sie im KöniginMarien-Thale gefunden; derselbe fügt die Bemerkung bei: $8^{\prime \prime}$ lang, an der Westküste 1-3". - Im Süden und Westen ist sie häufiger.

54) Pedicularis hirsuta L.

Auf feuchtem Boden sehr häufig und von fast allen besuchten Punkten mitgebracht. Schon von Sabine gesammelt; auch im westlichen Grönland häufig.

Nach der grössern oder geringern Fruchtbarkeit und Feuchtigkeit des Bodens verschieden an Grösse und der Stärke der Behaarumg; sonst aber kaum variirend.

\section{7) P'Imbaginaceac.}

55) Armeria maritima Willd. (A. sibrica Turez. in DC. Prodr. XII, 678 u. Flor. dan., 'Tat'. 2769 ist anscheinend nicht von der grönländischen Form rerschieden.)

Ḱleine, niedrige Exemplare; die Schäfte sehr kurz, die Blätter nicht überragend. Blätter kahl, Schäfte flaumig, Kelchröhe ringsum gleichmässig behaart. Aehnliche kahlblätterige Formen mit nu wenig höhern Schäften kommen auch an unsern deutschen Nordseeküsten ror. Die Unterscheidmg einer var. labradorica (A. labradorica Wallr.) auf Grund solcher leichten Abänderungen erscheint 
daher mangemessen. Aus Südgrönland haben wir eine höhere Form mit behaarten Blïttern erhalten.

Nur wenige Exemplare zwischen andern ungepresst getrockneten Pflanzen mitgebracht, wahrscheinlich von der Sabine-Insel; wurde anch von Sabine im nordöstlichen Grönland gesammelt.

\section{8) Polygonaceac.}

56) Oxyria digyna (L.) Campd.

Eine sehr weitverbreitete arktische Pflanze und, wie Dr. Pansch bemerkt, meist sehr gesellig; von fast allen besuchten Punkten mitgebracht, auch von Scoresby und Sabine bereits gesammelt. Aus dem Fjord liegen ausser ein paar Fruchtexemplaren noch einige sterile, unter Felsblöcken gewachsene Exemplare vor, deren Blätter ganz ungewöhnlich gross $\left(4-5^{\mathrm{cm}}\right.$ breit) sind.

57) Polygomum viviparum L.

Eine der häufigsten arktischen Pflanzen, wurde an allen besuchten Orten beobachtet und auch ron Scoresby, Sabine und Graah gesammelt. Die meisten Exemplare tragen Bulbillen. Die Höhe überschreitet selten $8-10^{\mathrm{cm}}$, doch sind einige Riesenexemplare aus dem Fjord vorhanden, welche $30-45^{\mathrm{cm}}$ Höhe erreichen.

Königia islandica L. wurde von Sabine gesammelt und ist im westlichen Grönland weiter verbreitet, fehlt aber in unserer Sammlung.

\section{9) Betulaceae.}

58) Betula nana L., var. genuina Regel.

Abhänge am Kaiser-Franz-Josephs-Fjord, stellenweise, namentlich in 800-1000 Fuss Höhe an Rande der Moräne dichtes (iestriip) bildend.

Eine Form mit in der Jugend dicht kurzhaarigen, später kahlen und glänzenden, drüsenlosen Zweigen. Die Blätter sind kahl, fast stets breiter als lang, sehr kurz gestielt und stumpf-gekerbt, oder auch wol gekerbt-gesägt. Blätter vielfach bramroth gefärbt.

Von diesem Strauche liegt eine Anzahl von Stämmen und ziemlich rollständigen Exemplaren vor, welche ein ziemlich deutliches Bild rom Wachsthume desselben geben. Danach scheinen die Birkengestrüppe meistens eine Höhe von $40--45^{\mathrm{cm}}$ zu erreichen; die grössten Exemplare sind $70^{\mathrm{cm}}$ hoch. Es bezieht sich dies aber nur auf die eigentliche Erhebung der Seitenzweige iiber den Boden; der Hauptstamm ist dem Boden angedruickt und mag wol auch eine Länge ron fast $1^{\mathrm{m}}$ erreichen. Die meisten starken Stämme haben einen Durchmesser ron $2-2 \frac{1}{\mathrm{~cm}}$, der stärkste ist 3 und $3 \frac{1}{2}{ }^{\mathrm{cm}}$ dick; die Hauptwurzeln sind an keiner Stelle dicker als $2-21 / 2{ }^{\mathrm{cm}}$. Die längste vorliegende Hauptwurzel ist (obwol abgebrochen) $65^{\mathrm{cm}}$ lang. 
Die Richtung der Wurzeln ist wol meist (wie auch einzelne Exemplare reigen) nahezu horizontal, da sie ja nicht weit in den unten immer gefrorenen Boden einzudringen vermögen. Die diesjährigen Zweige sind graubram, etwas ältere (namentlich ron $1^{\mathrm{cm}}$ Dicke) glänzend dunkelbraun gefärbt. Noch stärkere Zweige zeigen einen weissen Anflug und zuletzt löst sich die Rinde in papierartigen Fetzen ab; dabei iberwiegt aber doch immer die braune Farbe. Die Wurzel ist matt und heller rothbram gefärbt. An einzelnen Exemplaren erkemnt man deutlich die Unbilden, welche das nordische Klima ihnen zugefïgt hat. Hier und da ist die Rinde abgeschunden; an verstiimmelten Exemplaren haben sich aus Adventivknospen dichte Büschel neuer Triebe gebildet; die Stämme sind mehr oder weniger hin- und hergedreht, zuweilen sind selbst benachbarte Aeste umeinandergeflochten. Der Verlauf der Holzfasern ist nur an wenigen Stellen deutlich zu verfolgen; sie sind dam nach rechts gedreht.

\section{0) Salicaceae.}

59) Satix arctica Pallas.

An allen besuchten Localitäten beobachtet, theilweise (namentlich im Fjord) mit reifen Früchten; auch von Scoresby („Salix aff. glancae et limosae"), Sabine und Graah beobachtet.

Diese Weide ist, wie die meisten Arten, sehr variabel. Die Zweige sind in der Jugend behaart, aber nicht filzig; die Rinde später glatt, und glänzend gelb oder braun gefärbt. Die Blätter sind nach Gestalt und Grösse sehr variabel, oben lebhaft grün, unterseits bläulich-grün gefärbt, hier und am liande lange, zerstreute, filzigseidige Haare tragend, oberwärts fast kahl. Im Alter werden sie meist röllig kahl. Die Deckschuppen sind langhaarig, die Fruchtknoten dichtfilzig. Ine Friichte sind sehr kurz gestielt, kegelförmig. die Griftel lang und erst an der Spitze gespalten. Unsere Pflanze stimmt genau mit sibirischen Exemplaren (am Taimyr gesammelt) überein, welche wir durch die freundliche Vermittelung des Herru Profensor Maximowic\% aus dem botanischen Musemm deg Petersburger Akademie erhielten.

Auch von diesem Strauche wurde eine Anzahl mehr oder weniger vollständiger Exemplare mitgebracht. Nach dem Aussehen derselben scheinen die IIanptstämme der Weide bemerklich wrösiser $z$ werden als die der Birke (es liegen uns Exemplare ron $1-2^{\mathrm{m}}$ Länge vor), aber das Gestripp derselben sich doch weniger ïber den Boden zu erheben und auch nicht so dicht zu sein. Die 
Stämme liegen dem Boden angedriickt und sind vielfach schlangenartig hin- und hergebogen, offenbar durch Felsblöcke oder Steine von der geraden Richtung des Wachsthumes abgelenkt. Sie erreichen einen Durchmesser von $3^{\mathrm{cm}}$; ein einzelner, vielfach gedrehter und plattgedriickter Stamm, der durch Eis oder Steine oberwärts entrindet ist, zeigt einen Durchmesser von $5^{\mathrm{cm}}$ bei $3^{\mathrm{cm}}$ Dicke; Haufen kleiner 'Triebe sind am Rande der entrindeten Stellen entstanden. Die diesjährigen Zweige sind lebhaft gelb, die vorjährigen bram gefïlbt und beide glänzend; ältere Zweige sind weisslichbraun und matt. An den Stämmen springt die dicke Borke mit kurzen Querrissen, die eigenthïmlich wulstige Lippen haben, auf. Die Holzfasern waren an mehreren Stellen dentlich nach rechts gedreht, an andern aber auch gerade oder unbestimmt hin- und hergewunden. Die Wurzeln erreichen niemals die Dicke des Stammes; ich sah sie nie dicker als $2 \frac{1}{2}{ }^{\mathrm{cm}}$. Eine vorliegende Wurzel ist $50^{\mathrm{cm}}$ lang und dann noch an der Spitze abgebrochen; ob sie senkrecht nach unten gewachsen ist, ist nicht mehr mit Sicherheit zu beurtheilen, doch scheint es uns sehr zweifelhaft. - Ein besonder's 'schönes, festes Stuick Weidenholz von $2 \frac{1}{2}{ }^{\mathrm{cm}}$ Durchmesser wurde durch die geodätische Expedition von der Kohlen-Insel mitgehracht.

\section{1) Juncaceac.}

60) Luzula hyperborea R. Br.

Eine Charakterptlanze der arktischen Flora, die von fast allen besuchten Localitäten mitgebracht und auch von Scoresby („Luzula arcuata Hooker") und Sabine gesammelt wurde.

Wachsthum in dichten Rasen; aber die nenen Triebe seltener gerade, meist bogenförmig aufsteigend, zuweilen selbst ausläuferartig gestreckt. Meist nur eine (einfache oder zusammengesetzte) Bliitenähre, selten noch eine oder zwei gestielte Seitenähren; die Stiele der letztern gewöhnlich gerade, zuweilen aber auch so schlank gebogen, wie bei Luz. arcuatu. Die ganze Pflanze ist starrer, steifer als die letztgenannte Art, ihre Blätter breiter. Häufig zeigen alle frischen Theile der Pflanze eine bramrothe larbe, die abgestorbenen Blätter sind lebhaft strohgelb.

Wie ïberhaupt in der Gattung Luzula, so ist auch in der rein nordischen Gruppe der Luzula hyperborea die Abgrenzung der Arten ausserst schwierig. Wenn man die äussersten Formen der Luzula liyperborea R. Br. und arcuata Whlnbg. mit einander vergleicht, so ist die letztere an dem schlankern Wuchse, den rimnigen, oft fast borstlichen Blättern, den wenigblütigen Köpfchen und den ungeZweite Deutsche Nordpolfahrt. II. 
mein schlanken, stark gebogenen Stielen der Seitenköpfohen leicht zu unterscheiden. Bei Vergleichung dieser Kennzeichen an einer grössern Reihe von Exemplaren wird man aber bald gewahr, dass keims derselben völlig getren bleibt. So verbinden z. B. Lxenplare, welche von H. Mertens anf der Lütke'schen Expedition nach Sitka und den Alenten gresammelt sind, die breiten Blätter der $L$. hyperborea mit den zarten Stielen und der geringen Bliitenzahl der L. arcuata.

Das vou unserer Expedition mitgebrachte Material schliesst sich in fast allen Exemplaren den breitblätterigen 'Typus mit grossen, relativ reichblitigen Aehren an, der nnter der Bezeichnung $L$. huperborea R. Br. verstanden wird. Nur wenige sehr grosse Exemplare (das grösste misst $24^{\mathrm{cm}}$ ) nähern sich durch schmalere Bläitter, armblïtigere Köpfchen und zartere Stiele dem Typus der skandinarischen Laz. arcuata, ohne ihn aber entfernt zu erreichen. Als anderes Extrem finden sich aber auch ein par Exemplare von der Shamnon-Insel ror, welche sich der dritten aus dieser Gruppe beschriebenen Art, der Lus. arctica Blytt ansserordentlich amähern. Diese Art wird ron ihrem Autor (M. N. Blytt, Norges flora, 1861, I, p. 299) durch niedrigen Wuchs, relativ breite, Hache, an Rande nur spärlich behaarte Blätter, völlig kahle Stengelblätter, zwei bis drei an der Spitze des Stengels zusammengedrängte Köpfehen (selten ist ein seitliches gestieltes), kurz zerrissene, aber nicht gewimperte Bliitendeckblïtter und eiformige Perigonblätter charakterisirt. Hiermit stimmen die vorliegenden Exemplare fast vollständig ïberein, nur sind die stengelstïndigen Blätter nicht kahl und besitzen an der. Scheidenmiindung einen schwachen Haarbiischel; auch finde ich die Perigonblätter nicht eiförnig, sondern lanzettlich. Die charakteristischen Eigenthümlichkeiten des niedrigen Wuchses, der breiten Blätter und der nicht harig-gewimperten Deckblätter (wodurch die Köpfchen eine bedeutend dunklere Farbe zeigen als die der iibrigen Exemplare) haben unsere Pflanzen dagegen mit solchen ron Spitzbergen gemein. Lis muss weiterer Beobachtung iiberlassen bleiben, zu entscheiden, ob diese Form eine grössere Selbständigkeit zeigt, oder ob sie nur einzeln zwischen typischer L. hyperborea rorkommt.

Die Nomenclatur dieser Arten ist höchst verwirt. So führen die Schweden die beiden auf Spitzbergen rorkommenden Formen als Luz. arcuata $\beta$ confusa Lindeb. und L. Typerborea R. Br. (nach Fies) auf; die erste ist aber gerade die echte Luz. hyperborea R. Br., die zweite dagegen ist $=L$. arctica Blytt. Fs wird dies durch 
Exemplare, welche wir aus dem Stockholmer Herbarium erhielten, zweifellos festgestellt (rgl. dariuber auch Blytt a. a. O.).

61) Juncus biglumis L.

In Begleitung der vorigen Art, jedoch nur local auftretend: Sabine-Insel, Cap Broer Ruys, Fjord. Fehlt bei Scoresby, Sabine und Graah.

Lockere Lasen bildend; selten mehr als $6-7^{\mathrm{cm}}$ hoch. Blïten meistens schwarzbraun gefürbt und gewöhnlich von der untersten Bractee iiberragt.

62) Juncus trighmis L., var. Copelundi Buchenau.

Gletscherwälle am Kaiser-Franz-Josephs-Fjord. Fehlt ron allen nördlichern von unserer Expedition besuchten I'unkten; auch ron Scoresby und Sabine nicht beobachtet.

Eine sehr interessante zarte Form von J. triglumis L. mit riel schwächerm, hin- und hergebogenem Stengel und kleinern Bliten als der normale. Köpfchen vier- bis sechsbliitig, nicht von dem mntersten Deckblatte (welches nur wenig länger ist als seine Bliite) iiber'agt; die unterste Bliite oft eine kleine Strecke weit ron den iibrigen entfernt. Die (umreife) stumpfe Kapsel überragt die Kelchblätter; sie hat einen kurzen Griffel. Die Blïten sind hellkastanienbram gefinbt, nicht schwarzbram, wie bei J. biglumis.

Es liegen leider nur wenige Exemplare dieses Juncus vor, der vielleicht ron J. triglumis L. zu trennen sein diufte. Exemplare von J. triglumis aus dem südlichen und westlichen Grönland sahen wir noch nicht. Die Varietiit ist nach Dr. Copeland genannt, welcher nächst Dr. Pansch an meisten zum lieichthum der vorliegenden Pflanzensammlung beigetragen hat.

63) Juncus castaneus Sil.

Kaiser-Franz-Josephs-Fjord.

Auch ron dieser Art liegen nur sehr wenige Exemplare vor; sie scheint, wie die rorige $\lambda_{\text {rt, }}$ in der Nahe des Fjord ihre Nordgrenze zu erreichen, da sie werler von der dentschen Expedition, noch ron Scoresby und Sabine weiter nordwärts beobachtet wurde.

Die vorliegenden Exemplare sind wenig mehr als $10^{\mathrm{cm}}$ hoch. Die äussern Perigonblïtter sind bemerklich länger als die innern, beide aber um reichlich ein Drittel kiurer als die dunkelkastanienbranne (iibrigens noch nicht ganz reife) Kapsel. Die meisten Exemplare haben nur ein endständiges Köpfchen; eins jedoch hat drei Köpfchen, von denen das unterste merkwüligerweise aus der Achsel eines fast an der Basis des Stengels sitzenden Laubblattes entspringt und langgestielt ist. 


\section{2) Cyperaceae.}

64) Carex*) rupestris All.

Nur spärlich beobachtet: Jackson-Insel; Cap Broer Ruys. Fehlt bei Scoresby, Sabine und Graah; im westlichen Grönland weit rerbreitet.

Die Abbildungen von Sturm (VI, 7), Allione (Flora pedemontana, Taf. 91, Fig. 1) und der English botany stellen sämmtlich nur Einen Trieb von einer Pflanze mit verlängerten Ausläufern dar; dagegen besitzen die vorliegenden Exemplare, wie auch sämmtliche aus den Alpen stammende unsers Herbariums alle ein weit gestauchteres Ansehen und kürzere, meist bogig aufsteigende Ausläufer, wodurch ihr Habitus ein anderer wird.

65) Carex nardina Fries.

Clavering-Insel, Jackson-Insel; nur äusserst spärlich in der Sammlung vorhanden. Von Scoresby, Sabine und Graah nicht beobachtet; in Westgrönland weiter verbreitet.

Die Fruchtschlïuche sind weit stärker borstig gewimpert als nach der Abbildung der Flora danica, 'Taf. 2365, und an Exemplaren aus dem siidlichen Grönland, welche wir von Professor Joh. Lange erhielten.

66) Carex fuliginosu Sternb. et Hoppe.

Auf durchrieseltem Boden: Clavering-Insel, Sabine-Insel, KaiserFranz-Josephs-Fjord (hier mit überreifen Früchten, sodass an manchen Exemplaren alle Fruchtschläuche und Deckblätter abgefallen sind). Von Sabine gefunden.

Mittelgrosse Exemplare dieser schönen, auch in den Alpen verbreiteten Art.

67) Carex subspathacea Wormsk.

Ein einziges Exemplar von den Abhängen am Fjord.

Von Scoresby, Sabine und Graah nicht beobachtet; stimmt vollständig mit suidgrönländischen Exemplaren überein, welche wir der Güte des Herrn Professor Joh. Lange verdanken; nach der Angabe in Rink's Werk ist sie dort von 60-62 Grad verbreitet.

68) Carex rigida Good.

Gleichfalls nur ein Exemplar vorliegend, welches bei Cap Broer Ruys gefunden wurde; ron Scoresby, Sabine und Graah nicht beobachtet; im westlichen Grönland weit verbreitet.

*) Das aus dieser Gattung vorliegende Material drängt den Gedanken anf, dass bei speciellerer Beachtung gewiss noch manche Art in den besuchten Gebieten aufgefunden werden kann. 
Das Exemplar (zwei mit ihren Blättern verfochtene Stengel ohne Wurzel) ist nur $7^{\mathrm{cm}}$ hoch und noch nicht ganz entwickelt; die Bestimmung verdanken wir der Güte des Herm Professor Dr. Grisebach.

69) Kobresia caricina Willd.

Moränen am Fjord. Von Scoresby, Sabine und Graah nicht gefunden; in Westgrönland von 64-72 Grad angegeben.

Schöne Exemplare dieser Pflanze, zum Theil in Bliite, zum Theil mit abgefallenen Früchten.

70) Elyna spicata Schrad.

Cap Broer Ruys. Auch sie wurde sonst noch nicht in Ostgrönland beobachtet, während sie in Westgrönland weit verbreitet ist, und diirfte daher vielleicht in der Nähe des Fjord ihre Nordgrenze fiir die Ostkiiste erreichen.

71) Eriophorum polystachyum L.

Auf feuchten Niederungen an vielen Stellen, z. B.: Sabine-Insel, Clavering-Insel, Cap Broer Ruys, Fjord. Bereits von Salbine gesammelt.

72) Eriophorum Schenchacri Hppe. (cupitatum Host).

Mit der vorigen Art, aber nicht so allgemein verbreitet: Clavering-Insel, Cap Broer Ruys, Fjord. Von Scoresby und Sabine gesammelt.

\section{3) Gramineae.}

73) Alopecurus alpinus Sm.

Auf feuchten Niederungen häufig an allen besuchten Localitäten; auch von Scoresby und Sabine gesammelt.

Bildet ziemlich lange, horizontale Ausläufer, die sich an der Spitze mässig stark bestocken; die meisten Exemplare sind 15$20^{\mathrm{cm}}$ hoch, doch erreichen einzelne auch die Höhe von $27-28^{\mathrm{cm}}$. Die Scheide des obersten stengelständigen Blattes ist schlauchartig aufgetrieben ${ }^{1}$, die Lamina nur kurz.

74) Calamagrostis purpurascens R. Br. (Flor. dat1., Taf. 2523).

Nit Cutabrosa latifoliu Fries zusammen am Kaiser-Franz-JosephsFjord. Von Scoresloy, Sabine und Graah nicht gefunden; auch von unserer Expedition nicht weiter nördlich beobachtet; im westlichen Grönland nicht selten. Wol die höchste krautartige Pflanze Ostgrönlands, da einzelne Exemplare mehr als $1 / \mathbf{2}^{\mathrm{m}}$ hoch werden.

${ }^{1}$ Dies ist eine Eigenthümlichkeit, welche bei vielen arktischen Gräsern mehr oder weniger deutlich auftritt; sie hat wol darin ihren Grund, dass der Blütenstand zufolge der klimatischen Verhältnisse lange fertig ausgebildet in der obersten Blattscheide verweilt, bis er unmittelbar nach dem Beginne der bessern Jahreszeit aus derselben heraustritt. 
75) Hierochloa alpina li. et S.

Anf trocknern und feuchtern Stellen der Inseln, z. B.: ShamnonInsel, Sabine-Insel, Jackson-Insel. Ton Scoresby, Sabine und Graah nicht angegeben.

Eine in dichten Riasen wachsende Pflanze mit bogig anfsteigenden Trieben; die untern Blattscheiden schön violettroth iiberlaufen. Bis $20^{\mathrm{cm}}$ hoch. Angenehm duftend.

76) Deschampsia brevifolia R. Br.

Nur wenige Exemplare von Cap Philipp Broke. Bereits von Sabine gesammelt; auf den Osten beschränkt.

77) Trisetum subspicutum P. de B.

Ein ziemlich verbreitetes arktisches Gras; liegt von der JacksonInsel, der Clavering-Insel und Cap Broer Ruys ror. Von Scoresby und Sabine angegeben.

Die Exemplare meist unter $15^{\mathrm{cm}}$ hoch, während Exemplare von Godhavn im siidlichen Grönland bis $26^{\mathrm{cm}}$ hoch sind.

78) Catabrosa (Phippsia) algida (Sol.) Fries.

Sabine-Insel, Shamnon-Insel. Fehlt bei Scoresby, Sabine und Graah; im westlichen Grönland weit verbreitet.

Ein dichtrasig wachsendes Gras. Die vorliegenden Exemplare selten mehr als $2^{\mathrm{cm}}$ hoch. Exemplare von Holsteinborg im suidlichen Grönland sind weit grösser und haben massigere Stengel und Blätter; selbst dam bleibt die P'llanze aber eins der kleiusten Gräser.

79) Catabrosa (Cotpodium) latifotia (R. Br.) Fries.

Cap Broer Ruys; Fjord. Fehlt bei Scoresby, Sabine und Graah; fuir das westliche Grönland von $70-72^{\circ} 48^{\prime}$ angegeben.

Nächst Calamagrostris purpurascens wol die höchste krautartige Pflanze, da einzelne Exemplare eine Höhe ron $50^{\mathrm{cm}}$ erreichen.

80) Poa ${ }^{1}$ abbreviate R. Br.

Clavering-Insel, Kaiser-Franz-Josephs-Fjord.

Eine ausgezeichnete Art von dichtrasigem Wachsthum und niedrigem Wuchse; die Blätter sind schmal und zusammengerollt. Die Exemplare von der Clavering-Insel haben weit weniger beharte Blïtenspelzen als die aus dem Fjord; sie stimmen durchaus überein

1 Das reiche aus dieser Gattung vorliegende Naterial zeigt, dass diese Pflanzen auch im aussersten Norden sehr stark variiren. Wir haben die Freute gehabt, dass Herr Professor Grisebach, dieser ausgezeichnete Kenner der arktischen Gräser, unsere Bestimmungen revidirt und sich in allem. Wesentlichen mit ihnen cinverstanden erklärt hat. 
mit einem Exemplar, welches wir als "Poa Vahtiana Liebm." von Herrn Professor Joh. Lange in Kopenhagen erhielten. Herr Professor Grisebach macht uns aber mit Recht darauf aufmerksam, dass hier wol eine Verwechselung vorgefallen sein mïsse, da die Abbildung der Poa Vahtiana Liebm. (Flor. dan., Taf. 2401) eine andere Pflanze darstellt.

81) Poa arctien R. Br.

Diese und die folgende Art sind sehr weit verbreitet und bilden einen Hauptbestandtheil des Rasens; sie sind von fast allen besuchteu Localitäten mitgebracht und auch die abgeschnittenen Rasenstuicke, welche theilweise wegen eingebetteter Pflanzen, theilweise nur als Packmaterial mitgebracht wurden, enthalten sie meistens.

Poa arctica R. Br., eine der P. flexnosa Host nahe stehende und von ihr nicht immer leicht zu unterscheidende Art, variirt seh" stark, und unterscheiden wir an dem vorliegenden Material folgende, durch mancherlei Uebergänge verbundene Formen:

a) mit glatten Rispenästen und flaumigen Bliitenspelzen; Clavering-Insel (so nach Grisebach auch von der Eschscholtzbai);

ß) mit rauhen Rispenästen und flaumigen Bliitenspelzen; KaiserFranz-Josephs-Fjord (diese Exemplare durch grösstentheils abwärts gerichtete Rispenäste ausgezeichnet), Shannon-Insel, Cap Broer Ruys (auch hierunter einige Exemplare mit abwärts gerichteten Rispenästen; sie haben zugleich grössere Aehrchen als die meisten iibrigen Pflanzen, und die untern Spelzen sind nicht so lebhaft gefärbt - unten dunkelviolett, damm bräunlich und an der Spitze weisshäutig - wie bei der Nehrzahl der Exemplare);

$\gamma$ ) mit glatten Rispenästen und kahlen Bliitenspelzen; JacksonInsel, Sabine-Insel.

Hooker fuihrt unter den von W. Scoresby gesammelten. Pflanzen Poa. laxe und als von Sabine gesammelt: Poa angustata R. Br., aretica R. Br. und laxa Hke. an. Von diesen ist Poa angustatos 1. Br. (s. nachstehend) vielleicht ein Synonym von Glycerio maritima, M. U. K. oder eine derselben sehr nahe stehende Art, und wir irren uns wol nicht, wenn wir die Poa laxa genannte Pflanze für eine der Varietäten von Poa arctica halten, da Poa laxa eine Alpenpflanze ist, ïber deren Abgrenzung gegen arctica man friiher sehr unsicher war. - Graah hat keine Poa gesammelt.

Aus Spitzbergen erhielten wir durch die Güte des Herrn Professor Andersson in Stockholm kleine, von K. Chydenius gesammelte Pflanzen, welche mit unserer Varietät $\beta$ uibereinstimmen; sie sind bezeichnet als Poa cenisia All. 
82) Poa caesia Sm.

Wie bereits bei der rorigen Art erwähnt, ist diese Art an den besuchten Localitäten ïberall gefunden worden. Sie besitzt ein dichtrasiges Wachsthum, während Poa arctica mit horizontalen oder bogig aufsteigenden Auslänfern umherkriecht.

Diese Art variirt wesentlich nur in der Höhe des Wuchses und der grössern oder geringern Reichbliitigkeit. Einzelne kräftige Exemplare rom Kaiser-Franz-Josephs-Fjord erreichen eine Höhe ron $36-38^{\mathrm{cm}}$, während die gewöhnliche Höhe etwa $16^{\mathrm{cm}}$ beträgt. Im Schatten grosser Felsblöcke wird die Pflamze locker und schlatf und verliert ganz den Typus des Starren, Festen, der sonst der Art eigenthïmlich ist.

8.3) Poa anmu L. (?)

Einige abnorme, wahrscheinlich durch ïbermässige Feuchtigkeit (Rieselwasser?) krankhaft veränderte Pflanzen. Die Bliten sind vor der Entfaltung abgestorben und ausgebleicht, die Blätter schlaft, welk und hin- und hergebogen; nur einige Seitentriebe der Pflanzen besassen zur Zeit des Sammelns noch frisches Leben. Die Blätter sind flach. Die Bestimmung bleibt uns sowol als Herm Professor Grisebach zweifelhaft.

Glyceriu (Poa) angustata (R. Br.) Fr., eine der Glyceria maritima M. u. K. sehr nahe stehende und vielleicht mit ihr zu vereinigende Pflanze, von Sabine gefunden, fehlt in unserer Sammlung.

84) Festuca brevifolia R. Br.

Rasen bildend: Jackson-Insel, Clavering-Insel, Cap Broer Ruys (dies ist wol die Festuca ovina, var. von Hooker bei Sabine). Wird auch für Westgrönland ron mehreren Standorten angegeben.

Die Exemplare ïberschreiten selten die Höhe ron $10^{\mathrm{cm}}$.

85) Festuca (?)

Ein vivipares Gras, wahrscheinlich eine Festuca. Von der SabineInsel. Lis bildet dichte Rasen und hat borstliche Bläter wie die vorige Art. Die Stengel sind aber ziemlich hoch hinauf beblättert, während sie bei der vorigen Art nur am Grunde oder doch wenig iiber demselben Laubblätter tragen. Die Laubblätter sind bemerklich lïnger als bei $r$. brevifolia, vielleicht sind aber doch beide Pflanzen zu vereinigen. - Lange giebt für das westliche Grönland cine $F$. ovina, vivipure an; bei Scoresby ist eine Festuca vivipara ohne Autor angegeben, womit wol auch dieselbe Pflanze gemeint ist.

\section{4) Filices.}

86) Woodsin ilvensis R. Mr.

In Felsritzen und auf Felstorsprüngen, ca. 700 Fuss hoch an 
den Abhängen des Kaiser-Franz-Josephs-Fjord. Von Scoresby, Sabine und Graah nicht beobachtet.

Herr Dr. Kuhn in Berlin, dem wir die Pflanze zur Revision sandten, bemerkt über sie Folgendes:

Woodsia ilvensis R. Br. emend., var. hyperborea R. Br.

Forma pilosella (Ruprecht) Milde, Fil. Europ., p. 162 (Woodsia pilosella Ruprecht, Beitr., III, p. 54, t. spec. origin.!).

Die Exemplare stimmen trotz ihrer Kleinheit (sie sind nur $5^{\mathrm{cm}}$ hoch und $1 / 2^{\mathrm{cm}}$ breit) sehr genau mit Exemplaren aus dem Alataugehirge in Sibirien, den Originalpflanzen der Ruprecht'schen Art. Die Nervenenden sind stark verdickt und laufen gegen die Spitzen der Zähne aus. Die Sporen oblong und dicht mit Warzen bedeckt.

87) Cystopteris fragilis Bernh.

In Felsritzen und unter Felsen: Jackson-Insel, Clavering-Insel, Fiord; hier gleichfalls meist in kleinern Rasen zerstreut, unter uiberhängenden Felsen aber oft mehrere Quadratfuss in üppigem Wachsthum bedeckend. - Wurde auch von Sabine und Graah beobachtet.

M. Kuhn charakterisirt diese Pflanzen folgendermassen: Cystopteris fragilis Bernh.

Forma arctica: Lamina pinnatisecto-pimmatificla, $4^{\mathrm{cm}}$ longa, 2 lata; segmenta primaria ovata obtusa, $1^{\mathrm{cm}}$ longa; secundaria late ovata, obtuse dentata; nervi dentes adeuntes.

Eine Form dieser kosmopolitischen Art, welche wol nur ihrem Standort die geringe Grösse verdankt. Die Blattflïche ist frei von Drüsen; an einigen Exemplaren, die offenbar schon überwintert haben, dicht mit reifen Sporangien iiberdeckt. Die frischern Wedel zeigen noch nicht hinreichend entwickelte Sporangien.

Forma lobuluto-dentute. Nilde, Fil. Europ., p. 148.

Kaiser-Franz-Josephs-Fjord.

Eine Form, welche in Dentschland sich häufig in den höhern Gebirgen vorfindet und von dort auch tief hinabsteigt in die Ebene.

\section{5) Eviuisetaceae.}

88) Equisetum scirpoides Michx.

In berieseltem Schlick und unter dem Gestrüipp ron Viccinium uliginosum L.: Ostseite der Sabine-Insel, nahe dem Ufer. - Fehlt bei Scoresby, Sabine und Graah; nach J. Lange im westlichen Grönland an einigen Stellen.

Die sterilen Stengel treten nur etwa $3^{\mathrm{cm}}$ hoch iiber den boden hervor; fructificirende wurden leider nicht gefunden; einzelne 
Stengel fanden wir noch zwischen den Wurzeln eines Busches ron Vaccinium.

89) Equisetum arvense L., var. borcule Bongard (als Art).

An mehreren Stellen der Sabine-Insel, zum 'Theil in ïberieseltem Schlick, zum Theil in feuchtem Moose wathsend; bei Cap Broer Ruys auf einer sumptigen Wiese, stellenweise dichte Rasen bildend.

Nur kleine (wenige Centimeter hohe) sterile Exemplare, welche leider durch starke Ueberwucherung mit Schimmel sehr mübe geworden sind. - Die Aeste sind fast stets dreikantig, wie es die Diagnose verlangt; nur ganz einzeln fanden sich vierkantige destchen.

\section{A $n$ h a $n g$ I.}

\section{Flora der Sabine-lusel.}

Da die Sabine-Insel in Folge des längern Aufenthaltes der deutschen Expedition ${ }^{1}$ der in naturwissenschaftlicher Beziehung am genauesten gekannte l'unkt der ostgrönläudischen Küste ist, so scheint es uns von einigem Interesse zu sein, die von ihr bis jetzt bekannt gewordenen Pflanzen im Nachstehenden zusammenzustellen:

Ramunculus glacialis L.

- nivatis L.

Papuver mdicante L.

Cardamine bellidifolia $\mathrm{L}$.

Draba aretica Tahl.

- Wahlenbergii Hartm.

- alpina L.

- muricella Whlnbg.

Cochlearia spec.

Silene acaulis $\mathrm{L}$.

Wahlbergella apetala $\mathrm{Fr}$.

Melandrium affine Vahl.

- triflorum Vahl.

Arenaria ciliata L.

Alsine vubella Whlnbg.

- biflora Whlubg.

Stellaria longipes Gouldie.
Stellaria humifuse liottb.

Dryas octopetala L.

Potentilla nivea L.

- emarginata Pursh.

Epilobium latifolium L.

Saxifraga oppositifolia L.

- caespitosa L.

- cemua L.

- nivalis L.

- Hirculus L.

- Aagellaris Willd.

Taraxacum phymatocarpum

J. Vahl.

Campanula uniflora $\mathrm{L}$.

Vaccinum uliginosum L.

Andromeda tetragona L.

Polcmonium humile Willd.

1 Auch viele dex von Sabine gesammelten Pflanzen werden wol von dieser Insel herstammen, doch sind von ihm leider keine nähern Fundorte angegeben worden. 
Pedicularis hirsute $\mathrm{L}$.

Armeria maritima Willd.

Oxyria digyna Campd.

Polygomem viviparum L.

Salix aretica Pall.

Luzula hyperborea R. Br.

Juncus biglumis L.

Carex fuliginosa Sternbg et Hopp.

Eriophorem polystachyeni L.
Alopecurus alpinus Sm.

Hicrochloce alpina R. et S.

Catubrosa algida Fr.

Festuca? vivipara.

Poa aretice Ii. Br.

- caesia Sm.

Equisetum scirpoides Michx.

- arvense L., v. boreule bongard.

\section{A $n$ h a $n g$ II.}

Von Herrn Kapitän P. F. A. Hegemann erhielten wir eine Anzahl von Pflanzen, welche er selbst und andere Begleiter des Expeditionsschiffes Hansa nach ihrer Landung im suidlichen Grönland am Ende der langen Schollen- und Bootfahrt gesimmelt haben. Diese Pflanzen stammen sämmtlich aus der nächsten Umgebung der dänischen Stationen Julianshaab, Lichtenau u. s. w. her. Die Verhältnisse gestatteten aber nicht eine wirklich sorgfältige Durchmusterung der Flora jener Gegenden, welche iibrigens durch das Verdienst der dänischen Naturforscher Vahl, Rink, Hornemann, Wormskiold u. A. so genan bekannt ist, dass kaum noch Bereicherungen derselben zu erwarten sind.

Wir geben im Nachstehenden eine Aufzählung dieser von den Hansa-Männern mitgebrachten Pflanzen:

1) Thalictrum alpinem $\mathrm{L}$.

2) Ranunculus acer $\mathrm{L}$.

3) Coptis trifolia Salisb.

4) Cardamine pratensis L.

5) Draba incana L.

6) Cochlearia officinalis L., var, arctica.

7) Viola Mïhlenbergiana Ging., Bminor Hook. (Flor. dan., Tab. 2710).

8) Viscaria alpina (L.) Fries.

9) Stellaria cerastoides L.

10) Cerastium alpinum L.

11) " triviale Lk.

12) Lathyrus maritimus Fr.

13) Alchemilla alpina $\mathrm{L}$.

14) "vulgaris $\mathrm{L}$.

15) Potentilla tridentate Pursh.

16) Sedum Rikodiola DC. 
17) Saxifraga Aizoon Jacq.

18) " oppositifolia L.

19) ", caespitosa L.

20) "nivalis L.

21) Antemaria dioica (xïrtn. (lediglich ein Zweig mit grundständigen Blättern, aber ohne Blütenköpfchen).

22) Taraxacum officinale L., var. palustre DC. (als Art).

23) Vaccinium uliginosum L.

24) Andromeda Tupnoides L.

25) Azalea procumbens L.

26) Rhododendron lapponicum L.

27) Ledum Tatifolium Ait.

28) Phyllodoce cocruleu Gren. et Godron.

29) Pyrola rotundifolia L. (eine Blattrosette ohne Bliiten).

30) Thymus serpyllum L., var. boreale Joh. Lange.

31) Veronica alpina L.

32) Bartsia alpina L.

3:3) Pinguicula vulyaris L.

:34) Armeria maritima Willd.

35) Plantago borealis Lge.

36) Pumex acetose L.

37) Polygonum viviparum L. (ein Exemplar mit ausgebildeten Bliiten, eins mit Bulbillen).

3is) Empetrum niymu L. Es liegen mehrere Exemplare vor, welche monöcisch sind, also Frïchte und männliche Bliiten auf derselben Pflanze tragen. Vielleicht sind einige der fruchttragenden Bliiten sogar zwitterig gewesen.

39) Betula intermedia 'Thomas (vide Babington, A revision of the flora of Iceland; Joum. of the Limn. Society, 1870, XI, p. 46). Regel ordnet in seiner bekannten Monographie der Birken diesen Namen als Synonym seiner $B$. nuna $\delta$ alpestris Fr. (B. alpestris Fr.) unter, doch ist die vorliegende Pflanze von Betulunan sehr verschieden; sie stimmt aber mit Exemplaren aus Island, die wir der Giite des Herrn Professor Joham Lange rerdanken, sehr nahe iiberein. In seiner spätern Arbeit (De Candolle, Prodromus, XV1, 2, p. 170) führt aber Regel selbst, bezngnehmend auf die Abbildung bei leichenbach, Iconogr. fl. germ., XII, t. 624, fig. 1283, die Pflanze als eine eigene Art auf und rersetat sie sogar in eine andere Gruppe als $B$. nun . - Die neneste Abbildung der Betula intermedia Thom. gibt Professor Lange im nenesten Ifefte der Flora danica (48. Lief., 1870, Taf. 2852) nach isländischen Exemplaren. 
40) Betula nana L., $\gamma$ intermedia Rgl. (steril).

41) Salix myrsinites L.

42) Streptopus amplexifolius DC. Eine bekannte siidgrönländische Pflanze, welche aber, wie bereits J. D. Hooker in seiner mehrfach citirten Arbeit: Distribution of arctic plants (S. 274), erwähnt, den Polarkreis nicht überschreitet und deshalb in dem jenem Aufsatze angehängten Verzeichnisse der eigentlichen arktischen I'tanzen nicht mit aufgefuihrt ist.

43) Platanthera Konigii Lindl. Ein noch ziemlich unentwickeltes Exemplar.

44) Juncus trifidus L. Ein Exemplar mit zwei vorjährigen und fünf diesjährigen Stengeln; sie haben sämmtlich nur eime entwickelte Blüte, zwei der diesjälnigen Stengel aber noch ausserdem eine riemlich entwickelte Bliitenknospe.

45) Carex rariflora Sm.

46) , migritella Drejer.

47) Scirpus caespitosus L.

48) Eriophorum capitatum Host.

49) Phlerm alpinum L.

50) Poa pratensis L., var. arctica Joh. Lge.

51) Poa alpina L.

52) Aspidium Lonchitis Sw. Eine sehr ausgezeichnete Varietät mit breit dreieckig-trapezischen, stark doppeldornig-genïgten Fiedern.

53) Polystichum spimulosum DC., eine der var. dilatata sich annähernde Form.

54) Lycopodium Selago L.

55),$\quad$ annotinum L.

56) , alpinum $L$.

57) Equisetum arvense L.

A nme rkung. Einige wenige Zellenpflanzen, welche sich zwischen diesen Phanerogamen befanden, namentlich ein grosser Hutpilz, sind in den nachfolgenden Abschnitten über die Zellenpflanzen mit aufgefüht worden. 
3 .

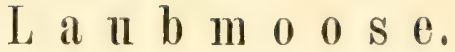

Bearbeitet von

Ki a r l M ï ll e r

in Halle a. d. Saale.

Als Kapitän Koldewey auf seiner limndreise zum Behufe einer intensivern Amregung für Nordpolfahrten auch Halle beriihrte, nahm ich Gelegenheit, demselben die Einsammlung ron Laubmoosen dringend an das Herz zu legen. Ich ging dabei von der allgemein herrschenden Ansicht aus, dass die Polargegenden, das ,Reich der Moose und Flechten", ganz und gar mit jenen schönen, wemn auch unwirthlichen Regionen der Alpen zusammenfallen, wo in der Nähe der Gletscher und Schneefelder, der schmelzenden Schneemassen, Bäche, Wasserfïlle und 'Torfmoore nicht allein die reichste Abwechselung von Moosarten, sondern auch nicht selten ein wahrer Moosteppich angetroffen wird, der über der Grenze der Alpenkräuter diese ablöst und dem Alpengelände seinen Charakter aufdriickt.

Wie aber war ich erstaunt, aus den Nittheilungen des Herru Dr. Pansch zu vernehmen, dass die ostgrönländische Küiste höchst arm an Moosen sei! Ich begrift das um so weniger, als doch die Herrnhuter Missionare in Süd- und Westgrönland, als J. Vahl u. a., ebendaselbst eine :ihnliche Moosflor antrafen, wie man sie im polarischen Skandinavien liingst gewohnt ist. Das Saftige, frische dieser Moose ist allbekannt und ebenso ihre Schönheit, die ja bekanntlich in den beiden schönsten Moosen der Erde, in Splachmum rubum und Spl. huteum alles iibertrifft, was man von Laubmoosen iiberhaupt erwarten kam. Um so gespannter war ich anf die von Herrn Dr. Pansch gesammelten Moose.

Selten jedoch ist mir eine solche Enttiunschung geworden, wie ich

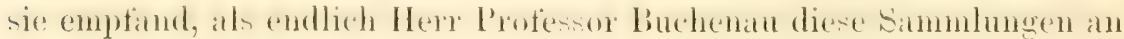


mich gelangen liess. Im allgemeinen war der Eindruck so, als ob diese Pflanzen nicht aus einem nordischen, an Feuchtigkeit nicht armen Lande, sondern aus der ödesten Wiiste kïmen, wo sie, kaum ron fenchten Niederschlägen genetzt, kimmerlich ihr Leben gefristet hitten. Fast alles hatte sich in dichte, vollkommen compacte liasen gefliichtet; in Rasen, die, meist von einem unbestimmten braunen Colorit gefarbbt, durch den dichtesten Wurzelfilz gleichsam zusammengekittet waren. Aehnliche Erscheinungen sind zwar auf unsern höchsten Alpenhöhen nicht unbekannte Erscheinungen, besonder's an sterilen Felsen und auf jenem dichten, unfuchtbaren und steppenartigen Grasboden, den die Aelpler mit dem Ausdrucke ,Bretboden" zu bezeichnen ptlegen; allein es sind doch immer nur einzelne Moosurten, welche die dichtgedrängte Geselligkeit zeigen und sich durch dieselbe offenbar gegen die Ausdiinstung in der dimnern, trockenern Luft schiitzen. Dass aber eine ganze Moosflor im allgemeinen diesen Charakter ammimmt, diufte wol eine nene Erscheinung sein. Sic erklart himeichend den Ausspruch des Herr'n Di: Pansch, ohne dass ich diesen unterschreiben möchte. Nach den mitgebrachten Moosen ist die Verbreitung derselben in Ostgrönland sicher keine ärmere, als in allen polaren liegionen; sie treten aber weniger hervor, weil sie, in unbestimmte diistere Farben gehüllt, durch die compacten Rasen sich wenig ron dem Exdueiche unterscheiden, das sie bewohnen. Dazu kommt, dass riele dieser Rasen tief in dem erwärmenden Erdreich stecken; oft glaubt man nichts als einen Erdballen in der Hand zu haben, und doch ist es ein Moosrasen, dessen oberste Imnovationen sich über das Eroreich ein wenig erheben. In heissem Wasser saugen diese Rasen begierig die Flüssigkeit ein, als wenn sie Schwämme wären, die eine weit wössere Wassernenge aufuehmen, als ihr scheinbares Volumen beträgt.

Im allgemeinen nehmen folgende Gattungen oder Gruppen an dieser Eigenthïmlichkeit Theil: Bryum, Dicranum, Conostomm, AuTacomminm, Angströmia, Distichium, Bartramia, Splachmum, viele Hypna und selbst Mecsea; iiberhaupt solche Moose, die schon ron Haus geneigt sind, ihre Blätter dichter übereinanderzustellen, und mehr oder weniger einen spindelförmigen Stengel bilden. Das erklärt auch, warum Hypnaceen der Gruppe Orthothecium daran theilnehmen könmen, also selbst Hypmu (Orthothecium) chryseum vollkommen compacte Rasen bilden, an denen nur die jüngsten Innovationen, d. h. die iber den Wurzeltilz hinatusagenden stengeltheile atusgenommen bleiben.

Bei diesem dichten Wachsthum ereignet sich nun dasselbe, was in dichtgenchlossenen Wäleru geschieht. Wie hier die staimme inmer 
schlanker werden, je dichter sie zusammen zum Lichte aufstreben, so auch hier: in der Regel werden die Moosstämmchen fadenförmig und länger als unter wärmem und feuchtern kosmischen Verhältnissen. Mitunter sehen sie gerade so aus, als ob sie im Dunkehn gewachsen wären, wobei sich die Achse verdiinnte, verlängerte, die Blätter auseinandergerückt wurden. So z. B. die Meesea longiseta, wo diese Forma luxurians häufig wiederkehrt. Daher kommt es auch, dass manche Arten, wie die genannte, auf den ersten Anblick gar nicht wiedererkannt werden und völlig fremde Trachten annehmen. Das geschieht aber auch, wemn die Arten keine Forma luxurians bilden, sondern ihnen Stengel nur fadenförmig verdiumen, um compacte schwanmige Rasen zu bilden; z. B. bei Bartramia cespitosa. Damn glaubt man in diesen arktischen Formen völlig neue Arten zu erblicken, während doch nur die äussere Tracht verändert ist. Bei den BryumArten, die schon an sich dahin neigen, keht häufiger als in gemässigteren Zonen das Streben wieder, ihre Achsentheile rankenförmig auszudehnen, also eine Forma cirrhata zu bilden. Eine Erscheinung, die vielleicht nur daher kommt, dass diese Moose schon früher, schon unter der wärmenden Schneedecke erwachen, aber, vom Lichte abgeschlonsen gleich den Kartoffelkeimen im finstern Keller natch allen Richtungen hin wachsen.

Sie sind es auch vorzugsweise, die gern in verschiedenen Arten untereinander wachsen, so dass man bei einzelnen Rasen seine liebe Noth hat, die Arten voneinander zu tremnen. Wollte man die 'Trennung bis auf den letzten Noosstengel vornehmen, so bliebe häufig nichts anderes übrig, als Stengel für Stengel zu mitersuchen, d. h. den ganzen Rasen in einzelne Stengel zu zerlegen. Ueberhaupt neigen die arktischen Moose wie die der Alpenhöhen dazu, gesellig zu wachsen, wobei natürlich immer ganz bestimmte Formen (Arten) zusammentreten. Doch nehmen andere Arten wieder den entgegengesetzten Charakter an; z. B. Dicramum strictum. Dieses ist vielleicht eins der am exclusivsten lebenden Moose, das wahrscheinlich zugleich die compactesten Rasen erzeugt, indem die einzelnen Stengel bis zur äussersten Spitze eine innig zusammenhängende Masse bilden. die sich eher schneiden als zerreissen lässt.

An und für sich hat dieses gesellige Untereinanderwachsen fïr

die vorliegende Sammlung seinen besondern Werth gehabt. Dem ohne dasselbe würde ich schwerlich so viele Arten herausgefunden haben, als es der Fall ist; manche konnten eben nur durch Brocken als Bewohner der ostgrönländischen Küste bestätigt werden. In anderer Beziehung freilich reigen die mitgebrachten Moosrasen wieder einen 
grossen Nachtheil, den nämlich, dass die allermeisten Arten ohme Früchte sind. Ob diese Unfruchtbarkeit mit dem Klima, mit dem compacten Wachsthum zusammenhängt, wobei alles gleichsam in die Wurzeln geht, steht dahin, ist aber wahrscheinlich. Die meisten Arten scheinen sich eben mehr durch Sprossung, als durch Keimung fortzupflanzen. Nur solche Arten, welche sozusagen den Aufung des polaren Moosteppichs bilden, wenn von einem solchen gesprochen werden darf; Arten, welche zu den gemeinsten und robustesten der arktischen Flora gehören, tragen auch unter Verhältnissen, die für die meisten übrigen Moosarten ungïnstig sind, reichlich Friichte, z. B. Aulacomnion turgidum, Polytrichum polure 1t. a. Es sind zugleich dieselben, welche die grössten und ausgedehntesten Rasen bilden und wahrscheinlich auch nur die feuchtesten Orte bewohnen; dieselben, welche freudig ihre Rasen in die Luft erheben, obschon auch Autrcommion höchst compacte Rasen zu bilden vermag. Höchst wahrscheinlich eleignet sich das auf trockenern, niedrigern Stellen. Denn es liegt auf der Hand, dass ein solches filzbildendes Wachsthum in ganz besonderm Zusammenhange mit der Erdwäme stehen muss; sicher wird diese durch den zarten Wurzelfilz am leichtesten aus dem Boden, der Hauptquelle aller Wärme fiur arktische Pflanzen, bis zu den äussersten ober-ten stengeltheilen geführt, ja imnerhall, des porösen schwammartigen Rasens am leichtesten erhalten. Sonderbar genug, bewahren gewisse Moostypen denselben Habitus auch unter dem polaren Klima, wie sie ihn bei uns an sich tragen; z. B. Grimmiaceen. Ihren Rasen sieht man es nicht an, dass sie in dem kältesten Klima der Erde gewachsen sind. Nur eine Eigenthïmlichkeit zeichnet sie, wenigstens innerhalb der Gruppe der Rhacomitrien aus, die nämlich, dass manche Arten, die sich bei uns sehr zu rerzweigen pflegen, fast keine Spur einer Terastelung zeigen und larum eine ganz cigenthümliche Tracht annehmen, die sie der Gruppe Grimmia rollkommen ähnlich macht; z. B. Rhacomitrium lamainosum. Die Exemplare, welche Herr Dr. Copeland auf einer Höhe ron etwa 7000 Fuss sammelte, gleichen mehr einer Grimmia elatior als einem Rhacomitrium.

Doch ist das rorliegende Material, obgleich es eine ganze Kiste anfüllte, noch weit davon entfernt, diese und ähnliche Gesichtspunkte durch alle Moosgruppen durchführen zu lassen. Ich vermisse eine grosse Menge ron Arten, die nicht gesammelt wurden, deren Torhandensein aber um so sicherer vorausgesetzt werden muss, als manche Brocken das Dasein einer bestimmten Gruppe rerrathen, die nicht gesammelt wurde, z. B. Splachnaceen, andere Noose durch ihre sonstige seltenheit anf andere deuten, fle mit ihnen rorzukommen pHegen,

Zweite Deutsche Nordpolfahrt. II. 
z. B. Bryum demissum und Desmatodon Laurevi. Auch bestätigt sich unsere Vermuthung einer reicheren Moosflor', sobald wir nur einen Blick auf Spitzbergen werfen, das doch nur um ein paar Grade nördlicher liegt, als die Koldewey'sche Expedition gelangte. So fehlen unter anderm: Catharinea lacriguta, Paludella, Orthotrichum, Andreater. Voitia, Sphagmum u. a.; und doch müssen diese Typen in Ostgrönland rorausgesetzt werden, da die mitgebrachten Moose in ihrem allgemeinen ('harakter entschieden auf' spitzhergen hindeuten. Yon dieser eisigen Insel sind bisher gegen 136 Arten bekamnt geworden, während Ostgrönland nur wenig uiber die Hälfte dieser Arten lieferte. Schwerlich aber ist mit jener Summe die ganze Moosflor Spitzbergens erschöpft; um so weniger, als wir durch von Heuglin wissen, dass diese Insel in ihren Formen höchst moosreich genannt werden muss. Es wäre folglich sonderbar, wenn Ostgrönland, selbst die ungünstigsten Verhältnisse für Moose angenommen, nicht noch eine namhafte Anzahl von Arten beherbergen sollte. die bisjetzt nicht gesammelt wurden. Auch deuten Proben ron steril mitgebrachten Arten darauf hin, die, weil vieldeutig, keine Bestimmung zuliessen.

Indem ich num die Aufzählung der Moose selbst gebe, bemerke ich, dass ich hierbei keine andere Reihenfolge anwende, als diejenige ist, welche S. O. Lindberg gab, als er in seiner Förteckning öfver mossor, insamlade under de srenska expeditionerna till Spitsbergen 1858 och $1861 \mathrm{in}$ der Oefvers. af K. Vet.-Akad. Förh. 1866, die bis dahin ihm ron Spitzbergen bekannten Moose aufzählte. Wer im Besitze dieser wichtigen Arbeit ist, wird es gern sehen, die ostgrönländischen Noose ganz in derselben Reihenfolge rergleichen zu kömnen.

\section{1) Нyр11111 L.}

1) H. surmentosum Wahlenbg. Sabine-Insel.

2) H. Schreberi Willd. Julianshaab im sïdlichen Grönland, von den Sichiffbrichigen der Hansa mitgehracht; jedoch im ästlichen firönland sicher vorhanden.

3) H. nitens Schreb. Sabine-Insel, unter Aulacomnion turgidum, IIymum pratense, Brynu crmum, Inizm affine und andern Moosen. Auch am Fjord unter Aulacomn. turgidum.

4) H. stramineum Dicks., var. Taxifolium. Nit Hymm fhitans am Fjord.

var. fluitans, fotiis remotissimis caulibusque flaccidis intricatis; Walross-Insel und Sabine-Insel unter andern Wassermoosen. meist mit Hypn. fluitans. 
5) H. julaceum Vill. Unter Dicramm Homami am Nordosthange des Heidelbeerberges am Fjord, sehr spärlich.

6) H. apiculatum Thed. Clavering-Insel, unter Brymm rutilans und Distichium capillaceum.

7) H. cirrhosum Schw. Sabine-Insel, unter andern sterilen Moosen, besonders einer Brachythecium-Art.

8) H. plumosum Sw. Sabine-Insel.

9) H. salebrosum Hoffm.? Sabine-Insel, in einem Gletscherbache.

10) H. Mitdeamum Schpr. Am Fjord und der Mackenzie-Bucht; einigermassen zweifelhaft als steriles Moos, doch am besten noch hierher gehörig.

11) H. polygamum Schpr. Tordosthang des Heidelbeerberges am Fjord; Clavering-Insel.

12) II. uncinatum S'w. Mackenzie, Fjord, Sabine-Insel, südliches Grönland bei Julianshaab (Hansa).

13) $H$. fluitans, var. pseudostramineum C. Müll., vermischt mit $H$. stramineum, am Nordosthange des Heidelbeerberges am Fjord.

14) H. Witsoni Schpr. Ebendaselhst. Auch auf spitzhergen ganz ähnlich als forma simplex minor.

15) H. revolvens Sw. Walross-Insel, Sabine-Insel, hier auch unter Aulacomnion turgidum.

16) H. pratense K. Sabine-Insel, nur brockenhaft unter Aulac. turgidum, Mnium affine und andern Moosen.

17) H. hamulosum, var. julaceum, Sabine-Insel und Klein-PendulumInsel, immer versteckt unter andern Moosen und steril; als völlig fadenförmige Form merkwïrdig, doch am besten hierher gehörig.

18) $H$. revolutum Lindb. (H. Heufleri Jur.). Sabine-Insel.

19) $H$. molle Dicks. var. Unter andern Moosen am Fjord, auch mit $H$. stramineum vereint.

20) H. chryseum Hsch. Kilein-P'endulum- und Sabine-Insel, gern mit andern Moosen verbündet und von kurzer, gedrungener Form.

\section{2) IInium L.}

21) MIn. affime Bland. Sabine-Insel, unter Aulacomnion turgidum und andern Moosen versteckt. Diöcisch.

2.2) MIn. subglolosum Br. Eur. vur. pusilla foliis minoribus cmarginatis tenerius reticulatis. Hermaphroditisch. Sabine-Insel, mit Aulacomn. turgitum, Hypmum sarmentosum, Conostomum boreale und andern Moosen in dichten Rasen wachsend.

Diese nur steril beobachtete Art weicht durch einige Merkmale so sehr von der echten ab, dass man sie, wenn auch die Früchte 
Verschiedenheiten zeigen sollten, als eigene Art betrachten kamn. Die kleinern, stets röthlich anlaufenden Blätter entfernen sich besonders durch das Kellgewebe und den Blattrand. Jenes besteht am Girmde aus sehr grossen und lockern Zellen, während die Zellen der Blattspitze auffallend kleiner, in der Regel zusammengepresst sind und von der verschwindenden Rippe ans fast in einem Kreisbogen nach dem Blattrande hin rerlaufen. Der Blattrand besteht aus einem Timbus incrassatus purpureus. Auch die Blattform weicht etwas ab, so nïmlich, dass die Basis auffallend rerschmälert ist mol der obere Blattheil num in Verbindung mit diesen Grumde eine weit gefälligere spatelfömige, oben etwas ausgerandete Form amnimmt. Dagegen weichen die Blätter der echten Art ab: durch gleichmässig grosse Zellen, einen nicht verdickten hellen aus zwei Zellenreihen bestehenden lockern Tiand, grössere Dimensionen und einen breitern Grund. Nur die Wahrnehmung, dass die Exemplaxe, welche Drummond auf feuchten Marschen und in feuchten Wäldern der Felsengebirge sammelte (Nr. 253 seiner Sammlung), durch röthliche Blätter, röthlichen Blattrand und obere Blattzellen eine Art Mittelform darstellen, hat mich bestimmt, die Art bei $\boldsymbol{W}$. subglobosum zu belassen, obgleich sie mehr mach Cinclidium stygium hinneigt.

23) Mn. (Aulacomion) turgidum Wahlenbg. Als echtes nordisches Moos, wie es scheint, gemein an den rerschiedensten Orten: KleinPendulum, Walross-, Sabine-, Shannon-Insel und am Fjord, am Hange des Heidelbeerberges.

24) Mn. (Aulacomion) palustre Hdw. Shannon-Insel und am Fjord, Nordosthang des Heidelbeerberges, mol gewiss auch anderwärts gemein.

var. compactum: Sabine-Insel. Aehnliche dichte Rasen bildend, wie man es in den Alpen z. B. an Anöctangium compactum gewohnt ist.

\section{3) Timmia Hdw.}

25) T. Austriaca Hdw. Nur Spuren rom Nordosthange des Heidelbeerberges nuter andern Moosen.

26) T. Megapolitana Hdw. Unter Barbula ruratis auf der SabineInsel.

var. foliis trevioribus obtusioribus magis convolutis summo dorso rugulosis. Am C'ap Borlase Warren.

\section{4) Bry $1111 \mathrm{~L}$.}

27) $\mathrm{Br}$. pscudotriquetrum Schw. var. foliis ad alas longe decurrentes 
maxime ventricosis caulibusque clongatis gracitibus. Cap Borlase Warren. Eine ähnliche Form, wie sie auch auf Spitzbergen vorkommt, die man als forma arctica bezeichnen kamn.

28) $\mathrm{Br}$. calopleyllum R. Br. Eine, wie es scheint, in vielen Formen im hohen Norden vorkommende Art, aber immer leicht erkennbar an den röthlichen stumpfen Blättern und dem weichen, röthlichen, aber doch chlorophyllösen Zellgewebe, das bei den grossen schlaffen Formen bei wiederholtem Aufweichen leicht cyanescirt, wie ich das wenigstens an Spitzbergen'schen Exemplaren beobachtete. Wahrscheinlich ist diese grössere Form, welche an $B r$. cyclophyllum erinnert, das $B r$. obtusifotium Ldbg. in dessen oben genannter $\mathrm{Ab}$ handlung (S. 544). Es gibt aber auch eine

var. compacta caule gracili musillo subjulaceo folis minoribus, die ich typisch nicht von der grossen IIuptform zu trennen rermag. Letztere wurde auf der Sabine-Insel, erstere auf Klein-Pendulum am Germaniahafen gesammelt.

29) Br.teres Lindb. (S. 545). Hierher ziehe ich ein Moos, das auch aus Suidgrönland bekannt ist und von Ilampe $B$ r. crispulum Mss. genannt wurde. Es kommt sowol in hohen als auch in niedrigen aber stets compacten Rasen vor und charakterisirt sich durch einen caulis subjulacens foliis cochleariformi-concavis limbatis evamidinerviis subcrispatis virentibus laxe cellulosis, ohne dass es mit dem verwandten $\mathrm{Br}$. Ferchelii zusammenfiele. Leider nur beobachtete ich das Moos ohne früchte, sodass ich den Lindberg'schen Namen nur mit Einschränkung annehme, obwol ich nach der Beschreibung nicht an der Richtigkeit meiner Bestimmung zweifeln kann. Das schöne Moos kommt, wie es scheint, an vielen Stellen als ein echtes Charaktermoos des hohen Nordens vor und wurde gesammelt auf Klein-Pendulum, auf der Sabine-Insel, wo es auch mit Br. rutilans Brid. erscheint, und am Nordostabhange des Heidelbeerberges am Fjord.

30) $\mathrm{Br}$. metilans Brid. Auf Clarering-Insel in einem grossen compacten Rasen gesammelt, sonst vermischt mit dem vorigen auf der Sabine-Insel. Obwol das Moos leider auch steril gesammelt ist, so fällt es doch ganz mit einem Originalexemplare von der Melville-Insel aus Bridel's Herbar zusammen und verräth sich durch die röthlichen sehr locker gewebten kleinen Blätter.

31) $\mathrm{Br}$. nitidulum Lindb. (S. 545). Dem vorigen nahe verwandt, aber durch den hermaphroditischen Bliitenstand schon abweichend. Auf der Sabine-Insel, mit andern Bryumarten vermischt, in dichten compacten Rasen. Nach dem Bliitenstande und sonstigen Charakteren 
zu schljessen, glaube ich die echte Lindberg'sche Art ror mir zu haben.

32) $\mathrm{Br}$. cermum Br. u. Sch. Vereinzelt und in V'erbindung mit Aulacommion turgidum, Hypmem pratense, Inium affine und andern Moosen auf' der Sabine-Insel.

33) Br. Archangchicum Schpr. Sabine-Insel, rermischt mil Weheren. Wahrscheinlich nur eine Form der vorigen Art, wie auch schon Lindberg vermuthete.

34) Br. Alyoricmm Sendtn. Sabine-Insel. Einigermassen an Br. subrotundum Brid. erinnernd, doch nach den bekannten Charakteren der. Sendtner'schen Art hierher gehörig und wegen derselben von $\mathrm{Br}$. cermum getrennt zu halten.

35) $\mathrm{Br}$. arcticum Br. u. Sch. Clavering-Insel und auch sonst an andern nicht näher bezeichneten Orten.

36) Br. Brownei Schpr. Berg am Fjord, am Nordosthange des Heidelbeerberges, unter Aulucommion palustre höchst sparsam.

37) Br. bimum Schreb. Ebendaselbst mit Spluchmem Wormstioldii, steril, auch auf Weidenstämmen daselbst. Zwitterblütig.

38) $\mathrm{Br}$. cirrutum H. u. H. Ebendaselbst und Nackenzie-Bucht.

39) Br. demissum Hook. Sabine-Insel, mit Frucht; ganz ohne Veränderung die Form, welche wir auch in der Nähe unserer Gletscher sammeln, sogar gut entwickelt.

40) Br. Ludwigii Spr., var. gracile elongatum luxurians, auf der Sabine-Insel.

41) Br. mutans Schreb. Ebendaselbst.

42) $\mathrm{Br}$. annotimum Hdw. Ehendaselbst, mit Lulucommion turgidum und Dicrumem arcticum.

4:3) $\mathrm{Br}$. crudum Schreb. Iuf Klein-Pendulum in äusserst lockern und iippigen Rasen.

5) Meesea Hdw.

44) 11. tristicha Br. u. Sch. In sehr grossen Rasen, aber steril auf der Sabine-Insel.

45) M. longiseta Hdw. var. luxurians. Ebendaselbst steril.

\section{b) Bartramia Hdw.}

46) B. ithyphylla Brid. Ebendaselbst.

47) B. fontuna Sw. Gemischt mit andern Moosen und steril am Germaniahafen auf Klein-Pendulum, gewiss auch anderwärts; nur brockenhaft gesammelt.

48) B. cespitosa Wils., var compacta. Auf Clavering-Insel mit Br. metilans Brid., in grossen Rasen auf Sabine-Insel. Weicht auf den 
ersten Blick so sehr von der vorigen $a b$ und nähert sich im Habitus so sehr der B. Marchica, dass ich das Moos vorläufig als gute Art betrachten möchte, obschon auch gewisse Uebergänge zu der vorigen bei uns nicht selten sind.

\section{7) Conostomum Sw.}

49) C. boreale Sw. Nur in Spuren unter andern Moosen auf der Sabine-Insel gesammelt.

\section{8) Splachunm L.}

50) Spl. mnioides L., var. compactum. Steril am Cap Borl. Warren mit Bryum bimum gesellschaftlich wachsend.

51) Spl. Wormskioldii Sw. In einem fruchtbaren Rasen am Fjord gesammelt.

\section{9) Polytrichum L.}

52) P. commune L. Clavering-Insel.

53) P. polare C. Müll. in Bot. Zeit. 1859, S. 205. In sehr schönen Rasen besonder's auf der Sabine-Insel aufgenommen. Nach denselben muss ich die Selbständigkeit der Art ganz besonders betonen, da die Kapsel stets eine geneigte Stellung, ganz nach Art der Psilopila hat und niemals die aufrechte cylindrische Form des $P$. alpinum, seines nächsten Verwandten, annimmt. Nur ist sie eigentlich nicht eckig, wie ich sie zuerst beschrieb; vielmehr wiederholt sie das unbestimmte Kantige des $P$. gracile, sodass sie fast an Conostomm boreale erimnert. Die Niitze, an sich sehr klein und höchst zottig, bedeckt doch die ganze Frucht, aber so, dass das schiefe Deckelchen einen schiefen Schnabel durch sie hindurch bildet. Die Exemplare der Sabine-Insel besitzen sehr schlanke Stengel mit dicht angepressten Blättern; doch werden diese Stengel auf Klein-Pendulum auch dicker, behalten aber die dichte Imbrication der Blätter bei. Am meisten nähert sich dem P. alpinum eine Form aus Siidgrönland, welche auch die HansaSchiffbrichigen ron Julianshat) mitbrachten, durch sparrigere Blätter. Jedenfalls ist die Art von den meisten Bryologen, welche gerade diese Form zur Hand hatten, mit $P$. alpinum vereinigt worden. An und für sich dürfte das Moos zu den schönsten der Polarwelt gehören; nur dürfte es zugleich im höhern Alter allein geschehen, dass es jenen merkwürdig firnisartigen Glanz und jene dunkle Färbung ammimmt, die ich zuerst a. a. O. beschriel). Die vorliegenden Exemplare erfreuen sich eines lebhaften Grüns an den obern, einer bramen Färbung an den untern Theilen, wie sie Polytricha zu zeigen pflegen. 


\section{0) Eilcalypta Schreb.}

54) E. procerc Br. Eur. In sehr schmutzigen liasen auf ClaveringInsel steril gesammelt. Doch unterscheidet sich die schöne Art auch im unfruchtbaren Zustande leicht und sicher von der nahe verwandten $E$. streptocarpa durch grössere höchst papillöse und allmählich ohne Absatz in die Basilarzellen iibergehende Zellen.

55) E. Habdocurpa Schw. Auf Clavering-Insel brockenweise gesammelt, auch unter Distichium cupillaceum $\mathrm{Br}_{1}$. Lur. daselbst, sonst ebenfalls aufgenommen.

\section{1) Grimmia Ehrh.}

56) Gr. apocerpa Hdw. Am Kaiser-Franz-Josephs-Fjord und auf der Sabine-Insel mit Hypmum cirrhosum.

57) Gr. unicolor Grev. Von unbekanntem Standorte, aher nach bestimmten Zeichen sicher von der Shannon-Insel, steril.

58) Gr. (Dryptodon) Panschii C. Mïll. 11. sp.; cespites robusti laxe cohaerentes sordide virides pollicares; caulis robustiusculus strictus, ramis dense appressis superne furcatus vel simplex densifolius; fotia cantina sicce et madefacte erecto-putentia aequatia numquam torta vel crispula, inferiora sordida nigricantia superiora saturate viridia vel lutescentia, latiuscula, ex axillis radiculas paucas erectas hyalinas exmittentia, e basi subdecurrente late ocalia in acumen breve ligulato-obtusum plus minus latiusculum productu, apiculo hyatino brevissimo lato denticulato actute obsoleto torminata, margine e basi usque ad apiculum valde revoluta subpapillosa integerrima, Thic illic compresse igitur plicatula mofunde et latinscule canaliculata, nove depresso ex striis pancis composito supra medium dissoluto ct scepius furcuto; cellulae series distinctas erectas sistentes, alares parenchymaticae quadratae laxiores paucae, basilares (nerrum cingentes) rectangulares angustae longiores, ad parietes pachydermos crenulatae, superiores indistincte hexagonae pachydermae jurentute chlorophyllosae molles rotundatae. Caetera ignota.

Locus. Insula Sabine, ubi cespes singulus collectus est sterilis.

Ex habitu Grimmium aciculurem perfecte referens, sed notis typographice illustratis species insignis. A formis robustioribus Grimmiae apocurpae aliquantulum similibus primo visu distinguitur: foliis numquam reflexis, late canaliculatis ovato-ligulatis, margine ubique fere valde revoluto atque cellularum structura.

59) Gr. (Rhucomitrium) canescens C. Miill. Am Nordosthange des Heidelbeerberges am Fjord, häufiger von der Walross-Insel.

60) Gr. (Rhacomitrium) lanuginosa C. Miill. In grossen festen P'olstern 
zwischen den Felsen der Shamon-Insel, wahe am Strande auf fast gänzlich ausgedörrtem Boden in zwei Formen, von denen die eine die bekannte Tracht der fast wolligen Art besitzt, während die zweite die 'Tracht ron Gr. microcupa und ihren Verwandten annimmt. Eine dritte höchst merkwiudige Form ist

var. arctica, caule rigidissimo thexuoso gracili subsimplice, foliis dense appressis incanibus. Diese ähnelt ganz und gar einer Grimmia elutior, funclis und ihren Verwandten. Sie wurde auf der Payer-Spitze am Kaiser-Franz-Josephs-Fjord bei etwa 7000 Fuss gesammelt und bietet beim ersten Ansehen den Anblick eines völlig eigenartigen Mooses.

\section{2) Gïmbelia Hpe.}

61) G. aretice C. Miill. n. sp.; Gümbeliae cespiticiae simillima, sed pulvinuti extensi humiles densi e viridi fuscescentes, foliu breviora e bresi ovata longa latiusculâ breviter acuminate plus minus obtusiuscula, superiora acutiona et mucrome indistincto hyalino saepius terminata, nervo depresso apiceni versus parum dilatato dorso vix lamelloso infra apicem dissoluto, plicis binis utrinque nervis indistinctis, cellulis ubique pottioidcis mujusculis mollibus chlorophyllosis prominentibus ituque veluti tuberulatis, basi pellucidis. Caetera ignota.

Grimmia Jacquini, var. subimbcrbis Lindlb. in Muscis Spitzberg. Oefvers. at K. Vet.-Akad. Förh. 1866, p. 552?

Locus. Kaiser-Franz-Josephs-1 jord inter 73-7t lat. bor., unde cespes singularis relatus est.

Obgleich diese Art nur steril gefunden wurde, so stehe ich doch nicht an, sie als eigene gute lit und als Gïmbelia aufzustellen. Demn so nahe sie auch mit $G$. cespiticia verwandt ist, so kenne ich doch keine zweite Art, die, $G$. mollis ausgenommen, ein so weiches grosszelliges Gewebe in allen 'Theilen des Blattes besässe. Die obigen, durch Cursivschrift ansgezeichneten Charaktere reichen hin, sowol Verwandtschaft als Unterschied von $G$. cespiticia klar darzulegen.

13) Barbula Holw.

62) B. ruralis Hdw. In grossen Rasen auf der Shamnon-Insel. Eime etwas schlankere Form, als unsere landläufige Art, auch tiefer braun getälot als gewöhnlich.

63) B. Tencostoma R. Br.? Unter andern Moosen von der Sabine-Insel brockenhaft und steril, sodass die Bestimmung um so zweifelhafter 
bleiben musste, als die Diagnose ron Robert Brown zu kurz gehalten ist, um endguiltig zu entscheiden.

\section{4) Trichostom 1 m.}

(it) $T r$. rubellum liabenh. var. dentutum. ('lavering-Insel unter andern Moosen brockenhaft versteckt. Dieselbe Form mit gezähnten Blättern, wie sie auch in unsern Alpen vielfach vorkommt.

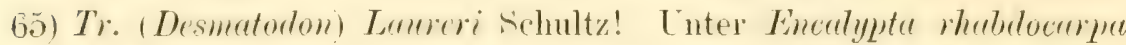
rom Fjord und von einem unbekannten Standorte, wahrscheinlich von der Shamnon-Insel.

15) Distichinm Br. Eur.

66) D. capillaceum Br. Eur. Clavering-Insel, mit Hypmum julaceum am Cap Borl. Warren, am Fjord und ebendaselbst am Nordosthange des Heidelbeerberges; sonst auch in Brocken versteckt unter andern Moosen an andern Orten.

16) Leptotrichum Hpe.

67) L. flexicaule Hpe. Shamnon-Insel, unfruchtbar und tiefgriun.

17) Angströmia Br. Eur.

68) A. Wahlenbergii C. Müll. Sabine-Insel als forma genuina compacta; in der Form des Dicromum Homumi Boek als forma gracillima compacta am Nordosthange des Heidelbeerberges.

18) Dicranum Hdw.

69) Dicr. strictum Schl., var. compactum. Steril von der Sabine-Insel, aber so dichte Rasen bildend, dass dieselben fast mit dem Messer durchschnitten werden miissen.

70) Dicr. arcticum Schpr. Wahross-Insel, unter Rhacomitrium canescons, ebenso von Klein-Pendulum, unter sterilen Bryumarten am Nordosthange des Heidelbeerberges, mit Bryum amotimum und Aulucomion turyidum auf der Sabine-Insel, ïberall steril.

19) Weisia Hdw.

71) W. curvirostris Syn. Musc. In dichten, dem Anöctungium compactum ähmlichen Rasen auf Klein-Pendulum, steril. 


\section{4. \\ Flechten. \\ Bearbeitet von \\ G. W. K $\ddot{o} \mathrm{r} b$ e r \\ in Breslau.}

Die auf der zweiten Expedition (1870-71) namentlich von den Herren Dr. Pansch und Dr. Copeland gesammelten Lichenen, deren Untersuchung und Bestimmung ich auf Anfrage des Herm Professor Dr. Buchenau gern ïbernahm, gelangten leider sämmtlich unpräparirt (d. h. olne von ilrrem Substrat, namentlich Erde und Moosen, möglichst getrennt und einer leichten l'ressung unterworfen zu sein) in meine Hände und waren infolge dessen und durch den weiten Transport viele Exemplare zerbröckelt, sodass ich einen nicht unbedentenden Bruchtheil des gesammten Vaterials als völig unbauchbar und unbestimmbar beseitigen musste. Das nur irgend Erkennbare und wenn auch oft nur in kleinen Pröhchen Vorliegende habe ich indess gewissenhaft geprüft und dabei die Freude gehabt, mehrere ganz neue Arten, ja sogar eine neue Gattung unter den Funden zu ermitteln. Leider ist es mir nicht gelungen, die unlängst erschienene Arbeit über westgrönlïndische Flechten in den Limn. Transact. XXVIII, III (1871) benutzen und dadurch etwa constatiren zu können, dass diese Arten, wie ich vermuthen muss, auch wirklich neu sind. Das Eine kann ich indess auf das Bestimmteste versichern, dass sie weder in der grössten bisjetzt iiber arktische Flechten erschienenen Schrift, nämlich in Theod. Fries' Lichenes arctici Europae Grönlandiaeque hucusque cogniti (Lpsala 1860) noch in Nylander's Synopsis methodica lichenum (Paris 1855-1860) beschrieben sich vorfinden.

Bei der nachfolgenden Aufzählung der sesimmelten Lichenen hin ich der in meinen Parerga lichenologica (Breslau 1865) niedergeleg- 
ten systematischen Ordnung gefolgt. - Ich schicke nur noch die Bemerkung voraus, dass das nachfolgende Verzeichniss 52 Flechtenarten aufzählt, von denen 10 noch unbeschrieben waren.

1) Usnea melaxantha Ach. Shamon-Insel, Fjordgletscher und besonders schön auf der Sabine-Insel an lose auf der Erde liegenden Steinen.

2) Stereocauton paschale v. gracitentum Th. Fr. Kaiser-Franz-JosephsFiord. (Fraglich, weil ohne Friichte.)

3) Stereocaulon alpinum Laur. An Erde ïber Moosen. Klein-Pendulum und Sabine-Insel.

4) Cladonia rangiferina L. Julianshaab im südlichen Grönland.

6) Cetraria nivalis L. Walross-Insel und Sabine-Insel.

7) Peltigera mefescons Fr. Eine kleine gekrïuselte sterile Form auf der Sabine-Insel.

8) Imbricaria stygia et $\beta$ lanata Ach. Shannon-Insel; Fjordgletscher.

9) Imbricaria alpicula Th. Fr. Fjordgletscher. Steril, darum fraglich.

10) Imbricaria olivacea L. Sabine-Insel auf Steinen.

11) Parmeliu muscigence Ach. Anfliige davon am Cap Borl. Warren.

12) Physcia parietina $\gamma$ ectence Ach. (= Ph. fallax Hepp.). Sabine-Insel.

13) Gyrophora unthacinu Wulf. Walross-Insel; Shannon-Insel; Kaiser-Franz-Josephs-Fjord und Gipfel des Berges am Fjord (namentlich in der Form tesselata Ach. vorkommend).

14) Gyrophora cylindrice L. Shamnon-Insel und Kaiser-Franz-JosephsFiord.

15) Gyrophore arctice Ach. (G. probosciden $\beta$ arctica Kbr. Pg. L.). Fjordgletscher sehr häufig.

16) Gyrophore Tramitziana Kbr. nov. sp. Thallus coriaceus polyphyllus subalutaceo-incusus aetate subrimulosus e glauco cinereorufescens subtus pallide miniatus dense velleo-fibrillosus. Apothecia confertissima adnata atra constanter plana simpliciterque patellata margine tenui demum sinuato-flexuoso. Sporae in ascis clavatis octonae, minutae, ovoideae, monoblastae l. obsolete pseudodyblastae, diam. 1\%-2plo longiores, hyalinae.

Hab. Kaiser-Franz-Josephs-Fjord an Steinen.

Die jedenfalls entschieden ausgeprägte Species, welche leider nur in einem einzigen lixemplar gesammelt wurde, verbindet gleich- 
sam G. anthracina, der sie in den patellarischen (niemals sprossenden, auch selbst nicht genabelten) Frïchten gleichkommt, mit $G$. vellea und hirsuta, mit denen sie die zottige Unterfläche des Lagers gemein hat. - Ich benannte die Flechte zu Ehren des an der zweiten Deutschen Nordpol-Expedition betheiligt gewesenen Herrn Tramnitz und seines um die Forstwissenschaft hochrerdienten Vaters, des wirklichen Forstmeisters und Präsidenten des schlesischen Forstrereins. Herrn Tramnitz zu Breslau.

17) Gyrophora Koldeweyi Kbr. nov. sp. 'Thallus coriaceo-cartilagineus fragilissimus (humectatus flaccidus mollissimus) laevis caesio-cinerascens 1. albicans subtus fusco-nigricans obsolete fibrilosus, rosulas sisteus minutas centro subareolatas ambitu ad modum Imbricariae cujusdam gracillime pinnato-simuatoque-dilaceratas varie irregulariterque adscendentes. Apothecia satis sparsa minuta pedicellato-elevata suborbicularia dein elliptica aterrima parallele prolifica. Sporae nondum visae.

Hab. Shannon-Insel an granitischen, wie es scheint rom Wasser rundlich abgespülten Steinen.

Jedenfalls der interessanteste Fund! Wenn nicht die centrale Anheftung des Lages (mittels eines gomphus)\} und die charakteristischen gerillten Frichte diese bisher unentreckt gebliebene höchst auffallende Flechte für eine Gyrophora documentirten, wiirde man die meist sterilen und höchst unregelmässig gestellten kleinen Thallusrosetten für eine Imbricaria halten miissen. Doch ist die fiedrige Zertheilung des Laubes weit zierlicher als bei letztgenamnter Gattung. Anfangs ist der Thallus dem Substrat riemlich eng anliegend und lässt kaum die Anheftung mittels eines Flechtennagels (gomphus) ahnen und selbst auch später, wemn sich die Thalluslacinien erhoben haben, macht die Flechte noch keineswegs den Eindruck einer echten Gyrophora. Ja im Alter der Flechte verfärben sich auf krankhafte Weise die anfangs schön bläulichweissgrauen Thallusläppchen ins Dunkelbraune, zeigen dann eine warzig-unebene Oberfläche, legen sich dem Substrat wieder mehr an und erinnern einigermassen dam an eine Imbricaria Sprengetii. Auf den mir vorliegenden Steinstiicken wuchert diese kleine und zierliche Gyrophora in zahlreichen, durcheinanderwachsenden und oft nur rudimentären Exemplaren, zeigt aber nur einige wenige (etwa 15) änsserlich gut entwickelte Früchte, in denen ich aber leider bisher noch keine Sporen entdecken konnte.

Ich benannte die Flechte zu Ehren des verdienstrollen Führers des Expeditionsschiffes Germania, Herrn Kapitän Koldewey. 
1×) Smphitoma elegans Lk. Sehr häutig: Walrosis-Insel, Sahine-Insel, Kaiser-Franz-Josephs-Ford, Fjordgletscher auf Steinen und über Moosen.

19) Amphilona muram $\beta$ miniatum Hoffm. Sabine-Insel.

20) Acarospora petiscypha Wahlnbg. (= A. rugulosa Kbr. Pg. L.; der Wahlenberg'sche Name hat die Priorität). Fjordgletscher.

21) Candelaria vitellina Ehrh. nelsst rar. anrella Hoffm. Saline-Insel auf nackter Erde, erstere meist steril.

22) Calopisma Jungermanniae (Vahl). 'Th. Fries, Lich. Alct. 121 (sub) Caloplaca). Klein-Pendulum-Insel.

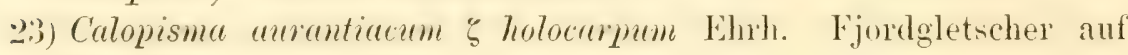
Knochen.

24) Calopisma mydaleum Kbr. nov. sp. 'Thallus tartareo-farinosus continuus ex ochroleuco albidus pruinatus, protothallo indistincto. Apothecia innato-adnata creberrima plana mutua pressione mox angulata disco e cerino tandem fuscidulo margine integro subpulverulento albido dein coeruleo-nigricante. Sporae in ascis obovatoclaratis octonae, submediocres, orculaeformes, polari-dyblastae, diam. 2 plo longiores, hyalinae.

Hab. An Erde wie iber Moosen, Grasresten u. s. w. auf der Insel Sabine.

Auf zwei düftige Exemplärchen hin habe ich es rersucht, eine Diagnose dieser immerhin interessanten Flechte zu geben, deren (uibrigens durch die zahlreichen Frichte fast verdrängter) Thallus den Eindruck macht, als ob ex durch langes Liegen im Feuchten verschimmelt wäre (daher der Speciesname!). Bei bessern Exemplaren diufte wahrscheinlich ein bläulicher Hypothallus zu erkennen sein, wie denn auch der zeorinische Rand der Apothecien dies zu verrathen scheint.

25) Rimodina turfacea Wahlubg. at $\beta$ microcarpa Help). Kilein-Pendulum-Insel.

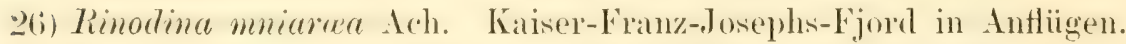

27) Rinodina Panschiana Kbr. nor. sp. 'Thallus effusus farinoso-tartareus matrici arete adnatus rimuloso-areolatus ambitu sublobulatus rubicundo-cinereus protothallum nigrum obtegens. Apothecia confertissima minuta ex innato adnata tandem confluentia disco semper plano fuscoatro tenuiter marginato. Sporae in ascis clavatis octonae, mediocres, obtuse biscoctiformes medio vix constrictae, dyblastae, diam. 2-21/2plo longiores, fuscae.

Hab. Anf nackter Frde der Sabine-Insel.

Unterscheidet sich ron R. miarca und den verwandten Arten 
durch den niemals körnigen, zusammenhängenden und gefelderten (in den ersten Anfängen wol auch graugrünlichen) röthlich-grauen Thallus, durch stets flache Apothecien und durch kleinere Sporen. Den Namen gab ich zu Ehren des Herrn Dr. Pansch in Kiel, welcher die meisten der hier aufgeführten Flechten gesammelt.

28) Lecanora Hageni Ach. Cap Borl. Warren iiber Moosen; Fjordgletscher.

29) Lecanora subfusca a 5 bryontha (Ach.) Kbr. Pg. L. Sehr häufig auf nackter Erde und über Moosen: Klein-Pendulum-Insel, Cap Borl. Warren, Kaiser-Franz-Josephs-Fjord und Fjordgletscher.

Die Varietät allophana dieser Flechtenart fand sich in einem kleinen, noch wenig entwickelten Exemplare mit unreifen Apothecien auf einem abgestorbenen und von der Witterung bereits stark mitgenommenen Weidenstanme unmittelbar über dem Wurzelhalse. 30) Lecanora atrosulphurea Wahlnbg. Auf Steinen: Walross-Insel, Fjordgletscher und Sabine-Insel.

31) Aspicitia calcarea $\alpha^{*}$ ochracea Kbr. Pg. L. Fjordgletscher auf Opal. 32) Aspicitia rosulata Kbr. nor. sp. Thallus crustaceus cartilagineus (humectatus subgelatinosus) rosulas sistens plus minusve orbiculares centro areolatas ambitu eleganter dendritico-effiguratas lacinulatas fuligineo-atras pulvere cinereo vulgo suffusas, protothallo nullo. Apothecia minuta crebra centripeta ex innato urceolatoque tandem sessilia plana atra elevato-marginata. Sporae in ascis elongatoclavatis octonae, mediocres, ovoideae, monoblastae, diam. 2-21/2plo longiores, hyalinae.

Hab. An rom Wasser bespülten Steinen im Kaiser-Franz-JosephsFjord.

In der Wachsthumsweise erimmert die Flechte stark an Biatorina diaphana Kbr. Pg. L., in der Bekleidung und Felderung des Lagers wie im imern Fruchtbau dagegen an manche Psorotichia-Arten.

33) Psora rubiformis (Wahlnbg.). Th. Fries, Aret. 169. ('larering-Insel.

34) Blastenia fuscolutea Dcks. Klein-Pendulum-Insel.

35) Biatora polytropa Ehrh. Häufig: Kaiser-Franz-Josephs-Fjord und Fjordgletscher.

36) Bitimlia Regetiana (Hepp.) Kbr. Pg. L. Cap Borlase Warren.

37) Buellia stigmatea Ach. Shamnon-Insel; Sabine-Insel anf rothem Sandstein.

38) Buellia Copelandi Kíbr. nov. sp. Thallus subtartareus firustulosus e squamulis discretis rotundiusculis planis $1 . \operatorname{mox}$ convexulis in crustam subareolatam congestis caesio-cinerascentibus protothallo atro maculari insidentibus compositus. 
Apothecia sat sparsa protothallo oriunda aterima opaca plana tandem convexa marginem tenuem obtusum excludentia. Sporae in ascis creberrimis clavatis octonae, mediocres 1. submajusculae, obtuse biscoctiformes medio rix constrictae, dyblastae, diam. 2-3plo longiores, fusco-nigricantes.

IIat. Auf feldspathaltigen Geröllsteinen der Shannon-Insel.

Die Flechte sieht aus wie ein in Grau ausgeblichenes kleinscholliges Rhizocarpon geographicum v. alpicolum, weicht aber in der Form der friichte und in den dyblastischen kleinern Sporen wesentlich ab. Die Keimplatte ist unterm Mikroskop oberwärts braun, die Paraphysen sind verleimt und entspringen einem dicken schwarzbramen Hypothecium. Herr Dr. Copeland, welchem ich diese Species widme, hat wesentlichen Antheil genommen an dem Sammeln der vorliegenden nordischen Flechten.

39) Buellia Payeri Kbr. nov. sp. 'Thallus eftusus crassiusculus tartareus (humecto subspongiosus) areolatus cinereus, areolis laxe cohaerentibus subahutaceo-rugulosis planis, protothallo indistincto. Apothecia immixta 1. levissime adnata thallum rix superantia atra plana rugulosa tenuissime marginata. Lamina sporigera angustissima paraphysibus conglutinatis apice fuscidulis farcta hypothecio fulro enata. Sporae in ascis claratis mox evanidis 6-8nae, subminutae, obtusissime biscoctiformes, obsolete dyblastae, diam. duplo longiores, obscure fuscae.

Hab. Auf losen Steinen in Gesellschaft mit Lecidella hansatica auf dem Fjordgletscher.

Die Apothecien sitzen äusserst seicht auf den Thallusareolen, wie dies in ähnlicher Weise z. B. bei Lecidella insularis der Fall ist. Sporen meist uiberreif, ihr Dyblastisches nicht deutlich mehr erkemnen lassend und gleichsam rerticale brame Striche in der Schlauchschicht bildend. - Die Species benannte ich zu Ehren des rühmlichst bekamuten Lientenant Pajer, welcher mit Dr. Copeland die Bergspitze am Kaiser-Franz-Josephs-Fjord bestieg.

40) Lecidella sabuletorum. Schreb. Meist in der (lagerlosen) Form depauperata; am Kaiser-Franz-Josephs-Fjord und auf den Fjordgletschern.

41) Lecidella sabuletorum $\beta$ anquata Flk. Fjordgletscher auf Knocheri.

42) Lecidella goniophila Flk. Fjordgletscher.

43) Lecidella hansatica Kbr. nor. sp. Thallus effusus areolato-rerrucosus ochraceo-luridus, protothallo albido subindistincto. Apothecia ex areolis oriunda conferta adnata atra plana nitidula margi- 
nata dein convexa immarginata opaca. Lamina sporigera hyalina substuppea paraphysibus laxiusculis apice viridulo-fuscis farcta hypothecio incolorato enata. Sporae in ascis clavatis octonae, parvulae 1. submediocres, ovoideae 1. ovoideo-ellipsoideae, monoblastae, diam. 2-21/. plo longiones, hyalinae.

Hab. An losen Steinen anf dem Fjordgletscher wie auf der Sabine-Insel.

Aus der Reihe der gelbkrustigen Lecidelleen ist etwa nur Lecidella sulphurella 'Th. Fries, Lich. Arct. 220 der vorliegenden einigermaassen nahestehend.

44) Rhizocarpon geographicum v. alpicolum Wahlb. - Shannon-Insel.

45) Rhizocarpon inops Kbr. nov. sp. Thallus tartareus e frustulis 1. squamulis discretis solitaris lentiformibus lacteis dein varie (flavide 1. rubicunde) decoloratis constans, protothallo tenui sordide nigricanti insidens. Apothecia e protothallo oriunda sessilia aterrima plerumque plana subscabrida tenuiter marginata. Sporae in ascis clavatis solitariae 1. binae, majusculae, ellipsoideae, muriformi-polyblastae, tiam. 21/2-3plo longiores, fuscae.

Hab. An umherliegenden Steinen auf der Shannon-Insel, in Gesellschaft von Gyrophora Koldeweyi.

Die 'Lagerschollen treten noch vereinzelter' auf als jene der' Buellia Copelandi und rereinigen sich niemals zu einem zusammenhängenden 'Thallus. Die Flechte scheint nur an dem Lichte entzogenen Stellen des Gesteins zu wachsen und hat schon um deswillen den Charakter des Diuftigen an sich. Junge Friichte haben eine concave, fast krugförmige Scheibe, während die ailtern (wie solche in der Mehrahl rorliegen) etwas Terkommenes an sich haben, daher auch meist iiberreife Sporen zeigen. Die Paraphysen der unterm Mikroskop bräunlichen Schlauchschicht sind völlig rerleimt.

46) Sporastatia Morio Ram. Walross-Insel.

Orphniospora Kbr. nor. gen. Apothecia lecideina, jam primitus aperta, excipulo proprio(?) cupulari atro marginata, constanter patellaria. Lamina sporigera hypothecio simplici fusco enata sporas monoblastas coloratas in ascis oligosporis forens. Thallus crustaceus uniformis.

47) O. groenlandica Kbr. Thallus interuptim effusus tenuiter furfuraceo-gxanulosus aterimus opacus cum protothallo concolore dendritice effigurato confusus. Apothecia rara sessilia aterima plana tenuiter marginata. Lamina sporigera superne violacea paraphysibus conglutinatis hypothecio grumoso fusco enatis farcta. Zweite Deutsche Nordpolfakrt. II. 
Sporae in ascis late claratis 6 -snae, minutae, ex oroideo subglobosae, monohlastae, diametrum transversalem in longitudine rix superantes, e coeruleo tandem pulchre fuscae.

Hab. Shammon-Insel an quarzigen Steinen.

Die nene Gattung mit ihren monoblastischen, fast kugeligen, gefärbten Sporen nimmt unter den lecidinischen Flechten eine gleiche isolirte Stellung ein wie Pyrhospora unter den biatorinischen. Wären die Sporen dyblastisch und dabei weniger zum Kungehunden geneigt, so wïrde man bei oberflächlicher Beurtheilung die diese Gattung repräsentirende Flechte leicht für eine Buellia stigmater ansprechen können, ron der sie indess auch im äussern Habitus genugsam verschieden ist.

48) Rhiaphiospor flavovirescens Dcks. Steril aui nackter Erde der Sabine-Insel.

49) Endopyremium rufescens Ach. Anf nackter Erde und iiber Moosen am Kíaser-Franz-Josephs-Gletscher.

ö0) Endopyreminm daedaleum Kmph. Anf gleichem Substrat ebendaselbst.

51) Pertusaria glomerata Schl. Clavering-Insel.

52) Tirhothecinm pygmacum Kibr. Fijord-(iletscher ant den Apothecien der Biatora polytropa Ehrh. 


\section{j. \\ A l g e e 11 .}

Bearbeitet ron

(i. $\%$ e l l e r

in Stuttgart.

Die in der Nähe der grönländischen Küiste gesammelten Algen beschränken sich auf die kleine Zahl von 17 Arten, deren Vorkommen in jenen Gegenden grösstentheils schon früher bekannt war. Mit Ausnahme eines bei der Walross-Insel und zweier bei Julianshaab im südlichen Grönland gefundenen Exemplare stammen alle, deren Ursprung bekamnt ist, vom Cap Wymn und der Sabine-Insel. Bei einer kleinen Zahl, welche sich in einer früher in Alkohol anfbewahrten Masse nachträglich vorfand, ist kein Standort angegeben; ohne Zweifel ist dies jedoch ebenfalls die Sabine-Insel. Nach Kützing's System geordnet sind es folgende.

\section{1) Lyingloyeac.}

1) Lyngbya, wahrscheinlich glutinosa $\mathrm{Ag}$. Der Inhalt der Fäden fast ganz zerstört, daher mit Sicherheit nicht zu bestimmen. Standort mbekannt (wahrscheinlich Sabine-Insel).

\section{2) Confervaceae.}

2) Chactomorpha melayonium, Küitzing: spec. Alg., S.379. = Conferva melagonium Web. und Mohr. Oestlich und siidlich von der SabineInsel in 10-2+ Faden Tiefe häufig. Kommt auch bei Spitzbergen und sonst im Norden häutig ror.

3) Rhizoclonium litoreum, Kóg., spec. Alg., S. 386. = Zygnema littoreum Lymgb. Auf Ptilota serrata bei Cap Wymm in fünf Faden T'iefe. Scheint bisher noch nicht so hoch im Norden gefunden worden zu sein. 


\section{3) Ectocarpeac.}

4) Ectocarpus ochraceus, Kg., spec. Alg., S. 45\%. An der Sabine-Insel. Auch bei Lichtenau in Grönland ron Wenck gefunden.

Diese in grosser Masse mitgebrachte Mlge variut bei der Fructification, indem sich bei einzelnen Exemplaren Reihen von zu Friichten entwickelten Zellen, wie bei $E$. litoralis vorfinden, mit welchem sie daher um so eher verwechselt werden können, da dieser ebenfalls im Nordmeer vorkommt.

5) Stypocaulon scoparium, Kg., 1. c., S. 466. Unter vorstehendem in einigen diurftigen Exemplaren. Sonst noch nicht aus dieser Gegend bekannt.

\section{4) Enteromorpheae.}

6) Enteromorpha vamilosa Hook., Kg., 1. c., S. 479. Mit vorstehendem unter Ectocarpus ochraceus.

\section{5) Mesogloeaceac.}

7) Chordaria flagelliformis Ag., Kg., 1. c., S. 546. Exemplare von sehr zarter Form mit hardünnen Zweigen. Standort wahrscheinlich die Sabine-Insel.

\section{6) Sporochneat.}

8) Desmarestia aculcata Lamx., Kg., 1. c., S. 571. Im Germaniahafen an der Sabine-Insel häufig in zwei Faden Tiefe. Einige der vorliegenden Exemplare sind zart, die Zweige häufig gegenüber stehend, die äussersten /weigchen hardiinn, so dass diese Alge wohl fiir die Desmarestia merlia Grér. erklärt werden könnte, wenn die letztere als selbstindige Art haltbar wäre. Dies ist jedoch zweifelhaft, und ich schliesse mich gern J. G. Agardh an, der in dem Bidrag till kaennedomen af Spetsbergens alger (kongl. VetenskapsAkademiens Handl., VII, Nr.8, S. 31) die verschiedenen Formen dieser bei Spitzbergen und auch sonst im Norden sehr gemeinen Alge ungetrennt unter dem alten Namen Desmarestia aculcala zusammenfasst, ohme auf die neuen Benennungen einiger hauptsächlich im Stillen Ocean rorkommenden Formen Rïcksicht zu nehmen. Andere, mit den vorgenamnten vermischt vorgekommene Lxemplare zeigen ganz die normale Form.

\section{7) Laminariea.}

9) Laminavia phyllitis Lx., Kg., spec. Alg., S. 575. An der SabineInsel in 10-24 Faden Tiefe. Eine bisher mehr süllich gefundene 
Art, welche nach Agardh (spec. Algarum, I, 132) vielleicht blos eine junge Laminaria saccharina ist.

10) Laminaria digitata Lamx. = Hafgygie digitate, $\mathrm{Kg}$., spec. Alg.. S. 577. Die Sammlung enthïlt blos ein sehr junges, noch ungetheiltes Exemplar ron der Sabine-Insel. Ihr Vorkommen im höchsten Norden ist bekannt.

\section{8) Fineae.}

11) Fucus vesiculosus L. Zwei Lxemplare rom felsigen Strand der Sabine-Insel, 1-2 Fatden Tiefe. Sic haben keine Blasen und scheinen zu der von J. Agardh in der angegebenen Schrift als besondere Art aufgestellten (als solehe jedoch schwerlich haltbaren) Varietï, Fucus evenescens, zu gehören.

\section{9) Callithamnieae.}

12) Ptilota serrata, Kg., spec. Alg., S. 670 (Ptilota plumosa $\delta$, serrata). Vom Cap Wymm und Julianshaab. Fine im Norden sehr verbreitete llge.

\section{0) Uystoclonieat.}

13) Cystoclonium purpurascens, Kg., 1. c., S. 756. Zwei sterile Exemplare von Julianshaab, das eine anf Ptitote serrate und mit Crisia scruposa, Lx. besetzt.

\section{1) Tylocarpeac.}

14) Coscotylus Brodiaci, Ko., 1. C., S. $791=$ Phyllophore Brodiaci Harv, rom Cap Wynn und der Sabine-Insel, in der durch breite runde Lappen ausgezeichneten, an Sphacrococus palmettu erinnernden Form, welche Kützing in Tabulae phycologicae, tom. XIX, tab. 7t, fig. a, als forma latifolia abbildet. Ëinige längere Zeit in Alkohol aufbewahrt gewesene, ziemlich verdorbene Exemplare, wovon eines mit Cystocarpien, zeigen kaum eine Spur von rother Farbe und sehen olivengrün, fast wie junge Lammarien, aus. Ob sie urspringlich, vielleicht wegen Mangels an Licht, so anfgewachsen sind, oder ob durch die Einwirkung des Alkohols die rothe Farbe in grin verwandelt worden ist, vermag ich nicht zu entscheiden.

\section{2) Polysiphonieae.}

15) Polysiphonic stricta Grév., Kg., 1. c., S. 819. Von der Sabine-Insel in $10-24$ Faden Tiefe. 


\section{3) Delessericae.}

16) Phycodrys simuosa, Kg., 1. c., S. 874 (Delesseria Lx.). Ton der Walross-Insel, Cap Wynn und der Sabine-Insel in 5-27 Faden Tiefe; von letzterer die Varietït lingulate Ag.

\section{4) Dictyosiphoneac.}

17) Dictyosiphon foeniculaceus Grér., Kg., 1. c., S. 485. Ton der Sabine-Insel.

Verzeichniss der Algen-Ausbeute der zweiten Deutschen Nordpol-Expedition.

Walross-Inse1. 29. October 1869.

Ni. 1. Phycodrys simuosa Krg.

Cap Wynn, 1. November 1869.

.. 2. Phycodrys simuosa $\mathrm{Kg}$.

"3. Coccotylus Brodiuei Kg.

. 7. Ptitota serrata lí.

., D. Dasselbe, besetzt mit

Phisortonium Titoreum Kg.

Sabine-Insol und in deren Nähe.

.4. Laminaria phyllitis Lx.

.. 5. Ectocarpus ochracens Kg.

.. 6. Polysiphonia stricta Grér.

9. Laminaria phyllitis Lx.

"10. Cocentylus Brodiaci lig.

.11. Laminaria digitata jucenilis.

.12. Laminure phyllitis juvenitis.

"13. Chectomorphe meleyonium $\mathrm{Kg}$.

,14. Pluycodrys sinuosu Kg., var. lingulete.

"15. Coccotylus Broeticei líg.

"16. Fucus vesiculosus L. val.

.17. Desmurestin aculeutu $\Lambda$ g.

Julianshath im südlichen Grönland.

"18. Cystoctonium purpurascens Kig.

"19. Dasselbe auf Plilote serrete mit Crisin sempose lax. 
Ohne Bezeichnung des Fundorts, jedoch wahrscheinlich von der sabine-Insel.

Nr. 20. Lyngbya glutinose Ag.

"21. Chatomorphe melegonium $\mathrm{Kg}$.

.92. Ectocurpus ochraceus $\mathrm{Kg}$.

"23. Stypocaulon scoparium Kg.

"24. Enteromorpha ramelosa Hook.

. 25. Chordaria flagelliformis Ag.

. 26. Desmurestic aculeate $\mathrm{Lx}$.

"27. Coccotylus Brodicuei Kg.

"28. Polysiphonia stricte Grér.

"29. Dictyosiphon foeniculaceus Grér. 
6.

\title{
$\mathrm{P}$ i $1 \mathrm{z} e$. \\ a) Fle is ch p i l ze.
}

\author{
Bearbeitet von
}

H. F. Bonorden

in Herford.

\begin{abstract}
Vorbemerkung der Redaction. Inter dem ron dey Experlition mitgebrachten Materiale befanden sich zwei zugelöthete Blechbüchsen mit Hutpilzen in Spiritus, die an der Ostkiiste, wahrscheinlich an der Sabine-Insel, gesammelt wurden, und ein rom Kapitän Hegemamn ans der Gegend ron Julianshab mitgebrachter Blätterschwamm (Amanita). Die Vereinigung zahlreicher Hutpilze in einer weingeistigen Fliissigkeit, welche unter den obwaltenden dringenden Umständen gewiss geboten war, komnte natiirlich der Erhaltung der Pilze nicht sehr günstig sein; indessen unterzog sich Herr liegimentsarzt Dr. H. F. Bonorden in Herford doch freundlichst der nicht unbedentenden Mühe, das Material zu durchmustern. Da es sich hierbei selbstverständlich noch nicht um eine, auch nur annähernd vollständige Aufzählung der Hutpilze Ostgrönlands handelt, sondern nur um die Constatirung der Anwesenheit einer Reihe ron Formen, so theilen wir die Bemerkungen des Herrn Dr. Bonorden ganz in der Form mit, in welcher sie uns zugegangen sind.
\end{abstract}

\section{1) Pilze von der arktischen 0stküste.}

In dem ersten Blechgefässe (bezeichnet $\mathrm{N}_{1}$. V) befanden sich untermischt folgende Pilze:

1) Lycoperdon fuscum Bon. Bot. Zeit., Bd. 15, Nr. 37; bei Fries unter Lycoperdon gemmatum, Var. papillatum, Syst. III, S. 38 
enthalten, welcher noch durch Gestalt und durch seine kleinen gelbbramen Sporen sich zu erkennen gibt.

2) Paxillus griseo-tomentosus Fr., E.p. S. 318. Die grossen dunkelrostfarbenen kugelrunden Sporen, wie sie der Gattung Paxillus eigen sind und die grau-purpurrothen, am Stiele je zwei vereinigten (Lamellis postice bifidis) Lamellen, sowie andere noch erhaltene Eigenschaften des Pilzes lassen keinen Zweifel uibrig, dass der Pilz der P. griseo-tomentosus ist; auch der subexcentrische Stiel ist vorhanden.

3) Ausser diesen beiden genamnten Pilzen enthielt die Büchse:

a) noch zwei Agarici rhodospori. Der eine grössere hat grosse ovalrunde glatte Sporen und scheint den vorhandenen Triimmern nach der Agaricus simutus Fr., Epic. S. 143̈, Gruppe Entoloma, zu sein; der andere ist ein kleinerer, der Gruppe Leptonia Fr., ibicl. S. 151, angehöriger, mit eckigen rothen Sporen, welche dieser Gruppe eigen sind.

b) einen kleinen Lactarius, der Gruppe Russulares Fr., Epic. S. 341, angehörig, mit ovalen kleiigen Sporen, welche in der Gattung Lactarius häufig vorkommen, dagegen in den übrigen Gruppen des Agaricus nur bei $A$. laccatus $\mathrm{Fr}$. vorhanden sind.

c) Mehrere Exemplare eines Leucosporus mit ovalen weissen Sporen, der Gruppe Clitocybe - Orbiformes Fr., Epic. S. 76, angehörig.

Die zweite Büchse (Nr. VI) enthielt:

1) mehrere kleine Exemplare des Lycoperdon Bovista Fr. Sie sind bereits vollständig in der Reife am oberen Theile zerfallen, somit weitlappig geöffnet; ein noch geschlossenes Exemplar ist nicht vorhanden. Das nur schwache unfruchtbare Markstratum am Wurzelende und die ungestielt abgefallenen sporae olivaceo-fuligineae geben bestimmt die Art zu erkennen.

2) Drei fast ganz zertriimmerte und erweichte Exemplare eines der Gruppe I'ratellus Fr., Epic. S. 212, XXIII Psalliota, angehörigen Agaricus mit ovalrunden, schwarz-purpurfarbigen Sporen. Ein rom Stiel abgetrennter Hut war noch in zusammenhängender Form vorhanden und liess erkennen, dass der Pilz zu der Untergruppe der Lepiotideae gehört, eine Armilla war jedoch am Strunk nicht mehr vorhanden, der Stiel aber knopfförmig in den Hut eingefügt und die Lamellen ganz frei. Dem Habitus nach ist es Agaricus campestris var. silvicola, stipite elongato-subbulboso. 


\section{2) Pilz von Siidgröinland.}

Dieser Pilz gehört zur Gattung Amanita, wie sich aus den grossen kugeligen, glatten weissen Sporen desselben sogleich ergibt. Der eigenthiimliche Bau der Gattung ist zwar in dem mir vorliegenden trockenen Exemplare nicht mehr wahrnehmbar; die Zellen sind durch Compression und Eintrocknung ganz unkenntlich geworden, nehmen auch durch längeres Einweichen in Wasser ihre eigenthimliche Form nicht wieder an, wie es bei dieser Aufbewahrungsmethode der Pilze die Regel ist, die sonstigen noch wahrnehmbaren Kenmzeichen lassen jedoch keinen Zweifel übrig. dass es Ag. vaginatus $\mathrm{F}_{\mathrm{i}}$. ist. Der Hut ist duim, an Rande häutig und hier gerippt-gefurcht, die Volva noch sichtbar, der Strunk nach oben verdünnt und noch erkembar Hockig-schuppig. Fries, Epic. S. 11. Die Sporen sind weiss-glinzend, glatt, was ich nur bei dieser Species gefunden habe.

Die unkemutliche Beschaffenheit der meisten Specimina machte es leider ummöglich, alle Species genau zu bestimmen; das Resultat meiner Untersuchung ist aber insofern doch ein erfieuliches, als sicher daraus hervorgeht, dass fünf Gattungen der höhern Piłe und zwar Amanita, Lycoperdon, Paxillus, Lacterius und Agaricus, von letzterer Arten mit rothen, weissen und schwarz-purpurfarbenen Sporen, in Grönland vorkommen.

\section{b) Endophytische Pilze.}

Bearbeitet voll

L. Fuckel

in Oestrich (Rheingau).

Das Nachfolgende wind, wenn auch als ein kleiner, vielleicht erster Versuch zu constatiren, ob und von welchen Repräisentanten die Pilzwelt in den arktischen Regionen vertreten ist, um so mehr fiir die Wissensehatt wichtig sein, weil damit dargethan ist, dass nicht allein Pilze dort vorhanden sind, sondern anch. dass die ark- 
tischen Regionen wahrscheinlich zahlreiche und unter diesen viele, nur ihnen eigenthümliche Pilze beherbergen. Ich sagte , wahrscheinlich zahlreiche", denn das von der zweiten Deutschen Nordfahrt mitgebrachte mir zur Untersuchung gestellte Material ${ }^{1}$ wurde angenscheinlich nicht zu mycologischen Zwecken aufgenommen, es war deshalb mehr dem Zufall iiberlassen, ob Pilze daran wucherten oder nicht. Trotzdem hatte ich die Freude, von 13 Arten bestimmbare Formen aufzufinden. Ausser diesen konnten noch viele unentwickelte Vorformen und Mycelien in den verwesenden vegetabilischen Ueberresten nachgewiesen werden, so, dass mbestritten dort wie hier die Pilzmycelien die Zerstörung der organischen Leichen besorgen. Dieses häufige Auftreten der Pilze zeugt anch dafür, dass mindestens ein par Monate lang eine feuchte Atmosphäre in den arktischen Regionen herrschen muss. Bisher fand ich nur Repräsentanten von drei grössern Pilzamilien, nämlich einen der Uredineen, elf der Pyrenomyceten und einen der Discomyceten. Aufgefallen sind mir die im Verhältniss zu den Perithecien meist schr grossen Schläuche und Sporen, ähnlich wie dem ersten Besucher der Alpen die im Verhältniss zur Stengelbildung grossen Bliiten der meisten Alpenptlanzen auffallen.

Es wire sehr zu wïnschen, wenn zukiunftige Nordfahrer ihr Augenmerk mehr auf diese Pflanzenfamilie richteten und alles dort Verwesende, anch besonders thierische Excremente, in dieser Hinsicht untersuchten. Es nehmen derartige Untersuchungen nicht so viel Zeit in Anspruch, als man wol glauben mag, und wemn anch, so wird, ich bin es überzeugt, die Miihe reichlich belohnt werden.

\section{1) Tredinei.}

1) Melampsora salicina 'T'ul. Forma Saticis arcticae F'ckl. Auf' beiden Flächen lebender Blïtter von Salix arctica Pall.

${ }^{1}$ Ich halte mich zu der Bemerkung verpttichtet, dass Iferrn Fuckel bei weitem nicht das ganze von der Expedition mitgebrachte botanische Material vorgelegen hat. Als er seine fremulliche Bereitwilligkeit zur Untersuchung der mikroskopischen Pilze erklärte, war ein grosser Theil der gesammelten Phanerogamen bereits an verschiedene Museen vertheilt und die mitgebrachten Weiden - und Birkenstïmme befanden sich zum Theil gerade nicht in Bremen. Ich musterte das vorhandene Naterial durch, um möglichst viele abgestorbene und mit Pilzen behaftete Pflanzentheile herauszulesen. Ohme Zweifel würde aber das nachfolgende Verzeichniss noch reichhaltiger ausgefallen sein, wem IIerr Fuckel das ganze Material bald nach der Rückkehr der Expedition hätte untersuchen kömnen.

Buchenau. 
Sabine-Insel und andere Standorte nicht eben selten (Pansch).

Der Pilz steht jener Form von MI. salicina sehr mahe, welche sich nicht selten auf Sulix reticulata L. der Schweizer Alpen findet.

Auf den vorliegenden Lxemplaren ist nur die Uredo-Form vorhanden, mit verschieden grossen, oft zusammenfliesenden, gewölbten, anfangs mit einer Lpiderm überzogenen, dium freien, hell-ochergelben Häufchen. Die Stylosporen sind rundlich, eiförmig oder umregehnässig, mit gitterigem, hyalinem Episporium und gelbem Kern, meist 22-2t Mik. lang und 16 Mik. breit. Bei der Form auf Salix Caprea sind die Stylosporen kleiner.

\section{2) Pyrenomycetes.}

2) Pleosporch hyperborec nor. spec. (Taf. I, Fig. 1.)

Peritheciis in foliorum aridorum pagina superiori nidulantibus, sparsis, punctiformibus, semimmersis et basi globosa a foliorum substantia grisea elevata cinctis, parte libera obtuse conical, siceis applanata, aterrima, perforata; ascis oblongo-ovatis, utrimque attenuatis, 8sporis, 60 Mik. long., 24 Mik. crass.; sporidiis in asci media parte conglobatis, oblongis, utrimpue obtusis, rectis, 3septatis, ad septum intermedium constrictis, flaro-fuscis, 24 Mik. long., 8 Mik. crass.

Auf der Oberfläche dïrrer, noch hängender Blättchen von Andromeda tetragona L. Auf der Shannon-Insel, 751/2 nördl. Br.

Ein sehr ausgezeichneter Pyrenomycet, welcher im Aeussern viele Aehnlichkeit mit Sphaeria Mryricariue Fckl., Fung. rhen. 2437 hat.

3) Pleospora arctica nov. spec. (Taf. I, Fig. 2.)

Fungus conidiophorus in capsularum valvis aridis luxurians, Cladosporium exhibens. Acervulis minutis, maculaeformibus, olivaceis, velutinis; hyphis subsimplicibus, cylindraceis, septatis, sub lente fuscis, apice conidiophoris; conidiis oblongo-ovatis vel subclavatis, 1-2septatis, quandoque oblique pedicellatis, flavo-fuscis, 24 Nik. long., 8 Mik. crass.

Peritheciis ascigeris in caulibus aridis, sub epidermide cinerascente nidulantibus et epidermidem pustulatim inflantibus, sparsis, media magnitudine, globosis, atris, ostiolis papillaeformibus, perforatis, prominulis; ascis oblongis, plerumque curvatis, tunica crassa, breviter crasso stipitatis, 8sporis, 132 Mik. long., 36 Mik. crass.; sporidiis imbricato-distichis, oblongo-ovatis, medio constrictis, 6-7septatis muriformibusque, primo hyalinis, demum aureis, postremo atro-olivaceis subopacis, 28 Mik. long., 14 Mik. 
crass.; paraphysibus (seu psendoparaphysibus) linearibus, septatis, multiguttulatis, hyalinis.

Die Conidienform an den diurren Fruchtkapseln, die Schlauchform an düren Stengeln von Epilobium latifolium; Kaiser-FranzJosephs-Fjord.

4) Pleospora pancitricha nov. spec. (T'af. I, Fig. ö.)

Peritheciis minutissimis, sparsis, subsuperficialibus, conicis, aterrimis, vertice pilis paucis, brevibus, rigidis, concoloribus obsitis; ascis ovato-oblongis, utrimque obtusis, subcurvatis, tunica crassa. Ssporis, 112 Mik. long., 34 Mik. crass.; sporidiis imbricato-subdistichis, oblongo-oratis, utrimque obtusis, rectis, 5septatis muriformibusque, medio constrictis, fuscis, 34 Mik. long., 13 Mik. crass.

An dïrren, abgefallenen Blätter'n ron Satix arctica Pall. KaiserFranz-Josephs-Fjord, $73^{1 / 2}{ }^{\circ}$ nördl. Br.

Der Pilz hat im Aeussern viel Aehnlichkeit mit Sphaeria chlorospora Ces. (Cfi. Fekl. Symbol. myc. 1) 111.)

5) Pleospora Dryadis nov. spec. (Taf. I, Fig. 4.)

Peritheciis in foliorum aridorum arhuc gerentium, pagina superiori sparsis, punctiformibus, globoso-conicis, atris, demum subliberis, ostiolis perforatis; ascis oblongo-ovatis, oblique stipitatis, tunica crassa, Ssporis, 88 Mik. long., 32 Mik. crass. sporidiis subdistichis, oblongis, utrimque obtusis, uniseptatis, ad septum constrictis, loculis miguttulatis, primo hyalinis, demum flavofuscis, 30-32 Mik. long., 12 Mik. crass.

Auf der obern Seite noch stehender, dürrer Blätter ron Diyas octopetala L. Clarering-Insel und Sabine-Insel, 74-75. nördl. Br.

6) Pleospora herbarum Tul. (Fungus ascophorus.)

Auf diirren Blättem und Stengeln ron Polemonimm Tumile IVilld. Sabine-Insel.

Stimmt, bis auf die kleinern Perithecien, in allem mit dem bei uns so häufig rorkommenden Pilze vollkommen überein. Uebrigens variut auch hier die Grösse der Perithecien sehr, so dass an der Identität beider kein Zweifel obwalten kann.

7) Sphaeria mivalis nov. spec. ('laf. I, Fig. 5.)

Peritheciis sub foliorum cauliumque aridorum epidermide albescente nidulantibus, gregariis, minutis, globosis, aterrimis, ostiolo atro, acuto, prominulo; ascis oblongo-ovatis, utrimque attenuatis, tunica crassa, 8sporis, 94 Mik. long., 20 Mik. crass.; sporidiis conglobatis subdistichisve, oblongis, inaequaliter didymis, utrim- 
que obtusis, ad septum parum constrictis, hyalinis, 20 Mik. long., 8 Mik. crass.

An dürren, noch stehenden Stengeln und Blättern ron Epilobium latifolium L. Kaiser-Franz-Josephs-Fjord.

8) Sphacria arctica nov. spec. (Tat. I, Fig. 6.)

Peritheciis in macula cinerascenti, gregariis seu lineari dispositis, erumpentibus, globoso-conicis, minutis, aterrimis, demum perforatis; ascis fasciculatis, oblongis, contortis, sessilibus, tunica crassa, 8sporis, 72 Mik. long., 17 Mik. crass.; sporidiis imbricatodistichis, oblongis, utrimque parum attenuatis, rectis, uniseptatis, ad septum constrictis, loculis inaequalibus biguttulatisque, hyalinis, 24 Mik. long., \& Mik. crass.

Dieser Pilz scheint in den arktischen Regionen häufig und weit verbreitet zu sein, er fand sich häufig anf dürren Blättern und Blattscheiden von Poa caesia und andern Gräsern des KaiserFranz-Josephs-Fijord und der Sabine-Insel.

9) Ceratostoma folicolum nor. spec. (Taf. I, Fig. 7.)

Peritheciis Gnomoniarum habitu, sparsis, primo tectis, ostiolo longissimo, aterimo exserto, demum subliberis, globosis, minutis, atris; ascos nondum ridi; sporidiis perfecte globosis, nucleatis, episporio laevi, luteolo, 8 Mik. diam.

An der mern Fläche diurrer Blätter ron Salix arctica Pallas; wahrscheinlich von der Sabine-Insel. Wie es scheint sehr selten.

10) Cytispora capitata (Vitsae nov. spec. Forma spermogon. Fig. 8).

Spermogoniis sub corticis epidermide nidulantibus, multilocularibus, locellis radiatim dispositis, gelatinosis, olivaceis; disco perfecte globoso, I Mill. diam., puberulo, olivaceo, poro centrali, punctiformi; spermatiis cylindraceis, curvatis, continuis, hyalinis, \& Mik long., 1 Mik. crass.

Lis gelang mir nicht, auf' den mir zu Gebote stehenden Aestchen die dazn gehörige Schlauchform, welche aweifelsohne einer nenen Valsa angehört, anfzufinden.

Auf diurren Aestehen von Salix arctice Pallas.

11) Phomu Drubue (Sphieriacearum nov. spec. Forma pycnophore. T'ilf. I. Fing. !).

P'eritheciis sparsis, sub caulis epidermide nidulantibus, demum liberis, minutis, depresso-glohosis, vertice umbonatis, pallidioribus. nigris; stylosporis angustissime fusiformibus, curvatis, continuis. hyalinis, 22.2 Mik. long., 2 Mik. crass.

An diirren, noch stehenden Stengehn ron Draba spec. Anf' der Clavering-Insel, $7 t^{1 / 2}$ nördl. Br. 
12) Rhizomorpha arctica nov. spec. (Taf. I, Eig. 10.)

Stromate adnato, crustoso vel tenuissime effuso, fusco; peritheciis gregariis, saepe confluentibus, raro sparsis, semi-rel totis liberis, carbonaceis, aterrimis, 1/2 Mill. diam., subrugulosis, globosis sed antice lato-conicis, ostiolo brevi, cylindraceo, truncato, perforato; sporidiis (asci?) fusiformibus seu subovatis, plerumque inaequilateralibus, guttulatis, fuscis, 12-14 Mik. long., $6-8$ Mik. crass.

Auf faulenden Wurzelstrïnken von Srrtix arcticr Pall. KaiserFranz-Josephs-Fjord.

Der Pilz hat im Habitus viel Aehnlichkeit mit Hypoxylon effusım Nke, nach seiner Fruchtbildung aber gehört er zur Gattung Rhizomorpha, wie ich dieselbe in Symbol. myc., S. 236, definirt. Von der ihm nahe stehenden Rhizomorpha adnata F'ckl. 1. c. unterscheidet er sich durch die grössern, kürzer geschnäbelten Perithecien und durch die im Verhältniss zur Länge meist breitern Sporen (Schläuche?).

\section{3) Discomycetes.}

13) Xylographa arctica nov. spec. (Taf. I, Fig. 11.)

Cupulis in macula griseo-nigra, quandoque ligni durissimi totam superficiem occupanti, parum elevata, dense gregariis, parallele dispositis, ermpentibus, minutis, atris, primo clausis, sphaeriaeformibus, demum apertis, rotundatis seu ellipticis, rima longitudinali dehiscentibus, margine integro, disco fuscescente; ascos nondum inveni; sporidiis oratis orato-oblongisre, nucleatis, fuscis, $10-12$ Mik. long., 8 Mik. crass.

An sehr hartem, von der linde entblösstem Holze von Salix arctica Pallas; nicht weit verbreitete, grauschwarze Flecken bildend. Kaiser-Franz-Josephs-Fjord.

Steht Xylographa flexella Fries sehr mahe, unterscheidet sich aber durch die angegebenen Merkmale sicher von derselben.

\section{Erklärung der Abbildungen.}

\section{Tafel 1.}

Fig. 1. Pleosport hyperborea. a. Schlauch mit 8 Sporen; $b$. einzelne Spore, wie alle folgenden Schläuche und Sporen bei 380 facher Vergrösserung gezeichnet.

2. Pleospora arctica. a. der ssporige Schlauch; b. umreife Spore; c. reife Spore; $d$. Pseudoparaphyse; $e$. Endstuick einer Hyphe des Conidienpilzes mit aufsitzender Conidie; $f$. zwei Conidien. 
Fig. 3. Pleospora pancitricha. a. Perithecium ca. 32 mal vergrössert; $b$. der 8 sporige Schlauch; $c$. eine Spore.

4. Plcospora Dryadis. a. der 8sporige Schlauch; $b$. unreife Spore; c. reife Spore.

;. Sphaeria nicalis. «. der 8 sporige Schlauch; $b$. eine Spore.

i. Sphaevia arctica. a. zwei Schläuche; b. eine Spore.

7. Ceratostoma foliicolum. $a$. Perithecium, 30 mal vergrössert; $b$. Spore.

8. Cytispora capitata. Spermatie.

9. Phoma Drabae. Stylospore.

10. Rhizomorpha arctica. a. b. c. Sporen. (Schläuche?)

11. Xylographa aretica. a. b. c. Sporen. 


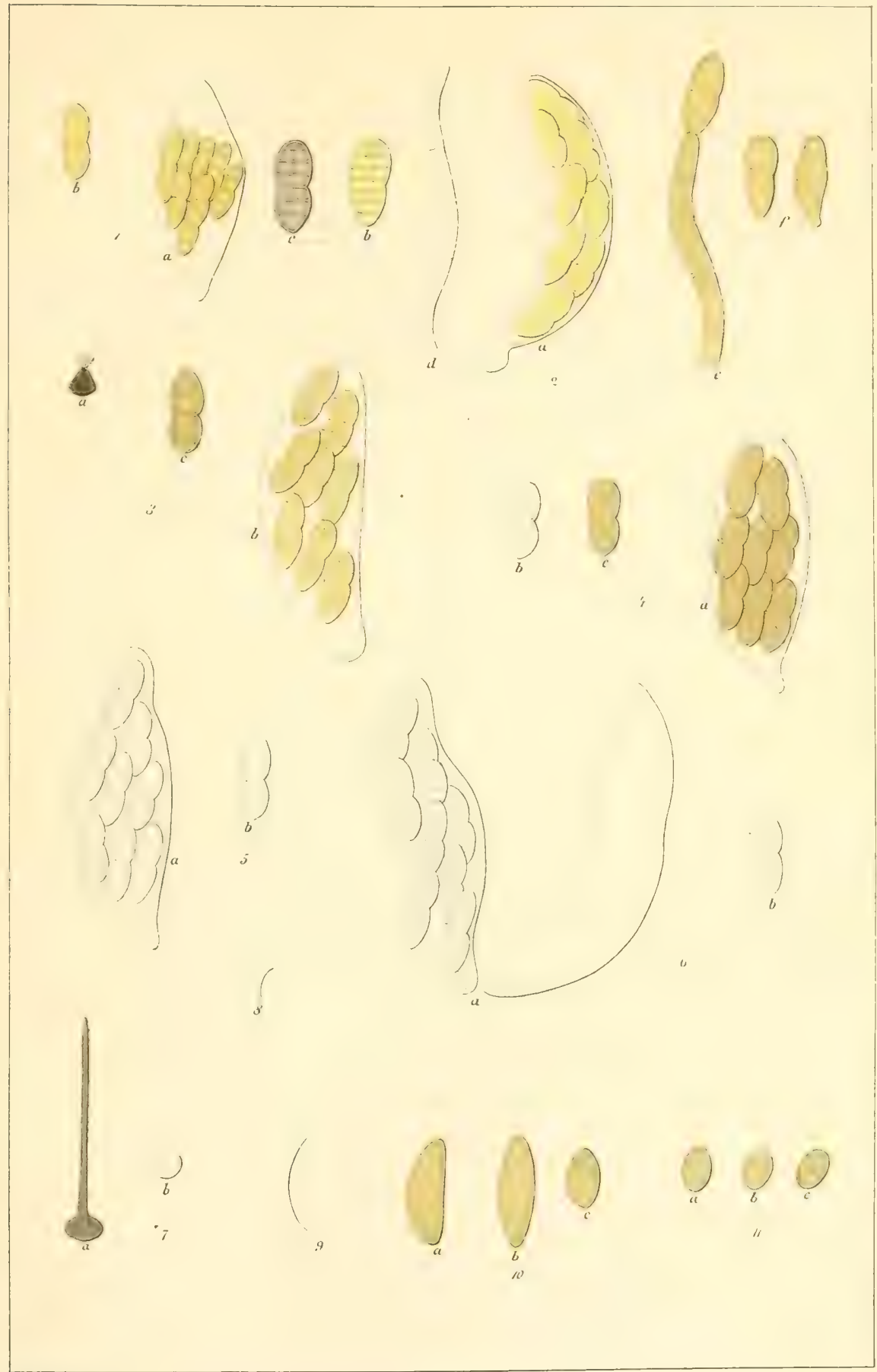
ratostoma folücolum.8. Cylsipora capitata.9. Phoma Drabae. 10. Rhizomorpha ardica.1L.tylographa arctica. 



\title{
ү. \\ Tre ib hölzer.
}

\author{
Bearbeitet von \\ Gregor Kraus \\ in Erlangen.
}

\section{E in le itung.}

Es war als eine der Aufgaben der Deutschen Nordpolexpedition bezeichnet worden, dem Treibholze im arktischen Meere Aufmerksamkeit zu schenken und gezeichnete Proben desselben an Bord zu nehmen, damit durch spätere Untersuchungen über den Ursprung des Holzes Schliisse ïber die Meeresströmungen in jenen Gegenden gezogen werden könnten. (Instruct. f. d. Befehlshaber, §. 25. Petermann, Geogr. Nitth., 1868, S. 217.)

In der That sind die Treibhölzer eins jener eigenthümlichen und grossartigen Phänomene des arktischen Neeres und seiner baumlosen Ufer, welche die Aufmerksamkeit der Wissenschaft im hohen Grade beanspruchen dürfen.

Denn diese von den Meereswogen in Menge getriebenen und ans Ufer geworfenen Holzmassen sind nicht etwa eine zufällige Erscheinung, die ausnahmsweisen Ereignissen, etwa dem Scheitern von Schiffen oder ausserordentlichen Ueberschwemmungen ferner Flussufer ihr Dasein verdanken; der nur einigermassen Kundige ${ }^{1}$ weiss, dass dort im Meere in gewissen Breiten zahllose schwimmende Stämme

1 Ein höchst lehrreicher und werthvoller Aufsatz: „Ueber die Treibproducte des Nordatlantischen Oceans", von Gumbrecht, findet sich in der Zeitschrift für allgemeine Erdkunde, 1854, III, 409-432. Weitere Angaben bei Petermann, "Das T'reibholz im Eismeer", in dessen Geographisehen Mittheilungen, 1870, S. $230-232$. 
und Stammfiramente angetroffen werden 1, dass an den Faröern ". an den Nord - und Nordwestküsten Islands ${ }^{3}$, an der Ostküste von Grönland ${ }^{4}$, auf Spitzbergen ${ }^{5}$ und an den Nordkiisten Sibiriens ${ }^{6}$ ellenhohe Wälle von Treibproducten angeschwemmt werden, deren Hauptmasse aus Baumstïmmen, Wurzeh, desten und Holzfragmenten aller Art besteht, Massen so bedeutender Mächtigkeit, dass sie seit Jahrhunderten die einzige und ausreichende Quelle für Nutz- und Brennholz in jenen baumlosen Gegenden bilden.

Die Thatsache, dass diese Hölzer seit Menschengedenken in gleicher Nenge und in einer bestimmten Richtung nur auf der Nordund Nordostkïste der arktischen Länder angetrieben werden ${ }^{7}$, beweist, dass sie aus unerschöpflichen Reserroiren fliessen und durch regelmässige Strömungen des Neeres an ihren Fundort gelangen miissen.

Unter diesen Úmstånden erlangen diese Hölzer eine Bedeutung, die iiber das blosse botanische Interesse hinausgeht:

Es ist in den arktischen Regionen, wo die zwei grossartigsten Meeresströme, der Golf- und Polarstrom, ihre Wasser mischen. Der Verlauf dieser Strömungen im Einzelnen, ihre Endigungen an bestimmten P'unkten, uiberhaupt ihre Verbreitung und Begrenzung ist nichts. weniger als sichergestellt.

Die Treibhölzer, die in jene absolut holzlosen Regionen nothwendig durch eine dieser Strömungen aus fernen Ländern gebracht sein müssen, bieten einen vorzüglichen Anhaltspunkt für die Beurtheilung der Strömmagen, einen Anhaltspunkt, der nicht allein wie die gewöhnlichen Nittel zur Constatirung der Strömungen (Temperaturmessungen. Farbe des Wassers u.s.w.) bIos ïber die Strömung an Ort und Stelle

1 Nach den Angaben von Koldewey z. B. zwischen der Südspitze von Spitzbergen und Jan Mayen. Vgl. Petermann's Mitheilungen, 1870, S. 227.

${ }^{2}$ Irminger, Zeitschrift für allgemeine Exdkunde, IlF, 188-190.

3 a. a. O. und Gumprecht, a. a. O., S. 425.

- Gumprecht, a. a. O., S. 427.

${ }^{5}$ Petermann's Mittheilungen, Erg.-Bd. IV, 31, nebst Karte. Petermann's Mittheilungen, 1870 , S. 231 .

${ }^{6}$ Middendorff's Reise in den äussersten Norden und Osten Sibiriens, IV, 1.; $252-256$.

; Dies Factum kann gar nicht genug betont werden. Man darf sich nur, wie es auf der oben citirten spitzbergischen Karte im speciellen geschehen, und wie ich es auf der Berghaus'schen Chart of the World auch für die übrigen Länler gethan, die Fundorte der IJölzer durch Farben auszeichnen, um sofort zu sehen, dass dahin die IJölzer nur durch eine siidwestliche (Polar-) Strömung gelangt sein konnten. 
Rechenschaft gibe, sondern uns auch äber die Richtungen der ströme: in fernen bisher unerreichten, vielleicht unerreichbaren Regionen danu: aufklärt, wenn die Natur des Holzes den bestimmten Wohnort der Mutterpflanze erkennen lässt.

Es ist klar, dass ein Strom, der seinen Ursprung aus den Tropen nimmt und dort an wald- oder vegetationsreichen Küsten, an den Nündungen grosser, aus dem continentalen Innern kommender Ströme rorbeitliesst, wie der Golfstrom, nothwendig tropische Producte führen muss; während der kalte Polarstrom nur solche Hölzer führen kaun, welche grosse Flüsse des nordeuropäischen, nordasiatischen, nordamerikanischen Continents aus den Waldgebieten iiber das arlische Land hinaus ins Eismeer geschremmt haben.

So wird sich je nachdem das Treibholz nördliche oder südliche Mutterpflanzen rerräth, (ine nördliche oder sülliche Strömung nicht allein an Ort und Stelle, sondern auch eine Richtung der Strömung ron dem Fundorte bis zur Geburtsstïtte des Holzes erschliessen lassen.

Aber nicht allein der Geographie des Oceans kommt eine solche Cntersuchung zugute. Sie hat noch ein speciell phinzen-geographisches Interesse.

Die ron Hooker ${ }^{1}$ gefundene sehr merkwürdige Thatsache, dass die grönländische Flora nïher mit der des entfernt liegenden alten Continents als mit der des nah gelegenen neuen verwandt ist, wird ron diesem mit Hülfe der Glacialhypothese, in neuester Zeit, wie ich glitube viel sicherer, ron Griesehach ${ }^{2}$ mit Hiilfe der Meeresströmungen erklïrt, indem er annimint, dass die Pflanzenkeime, durch Treibeis transportirt, ron den sibirischen Küisten successire nach Nowaja-Semlja. Spitzbergen, Ostgrönland und Island gewandert seien. Nit Recht weist er darauf, dass die Zahlen- wie die verwandtschaftlichen Verhïltnisse nach diesen rïumlichen Beziehungen sich ordnen. Die Wahrscheinlichkeit dieser Annahme wirde zu einer fast evidenten Gewissheit werden, wenn aus den botanischen Treibproducten cin Zusammenhang der ostgrönländischen Küiste und sibiriens durch die Meeresströmungen könnte dargethan werden.

Die einzigen Anhaltspunkte, die man bis in die jüngste Zeit über die Natur und Abstammung der Treibhölzer hatte, waren die Namensbezeichnungen der Isländer für dieselben, oder die spärlichen Angaben der Besucher jener Gegenden (vgl. Gumprecht, a. a. 0., S. 428 fg.), die als von Laien stammend nicht von Gewicht sein konnten, zumal

1 'Transact. Linn. Soc., Vol. XXIII.

2 Vegetation der Frile, 1871, I, 61-69. 
da dis enzige einem Botaniker (Brongniart) zu Gesicht gekommene IIolz aus jener Gegend sich als total falsch bestimmt erwies (vgl. Gumjrecht, a. a. O., \$. 426).

Lurst in jüngster Zeit wurde eine wissenschaftliche Untersuchung iiber eine Anzahl spitzbergischer Treibhölzer, welche ron der schwedischen Expedition dahin mitgebracht worden waren, gemacht. ${ }^{1}$ So dankenswerth auch diese Untersuchung ist, welche ergab, dass die IIölzer lauter Nadelhölzer und 7 ron den vorliegenden 18 Stücken Lïrchenhölzer aus Sibirien waren, so kann sie natürlich nur für einen dem Ursprungsort nähern Fundort Rechenschaft geben und löst die Frage uiber die Holzquelle entfernter arktischer Länder nicht. Strenggcnommen lässt sie sogar für die spitzbergisehen Hölzer noch Zweifel ïbrigs; denn da von 18 Hölzern nu $7^{2}$ wirklich bestimmt wurden, so könnte man immerhin einwerfen, es bestehe noch die Möglichkeit, (lass trotz der 7 Lärchenhölzer der grössere Theil (die iibrigen 11) andern Ursprumg habe.

Um so lebhafter musste die von der Deutschen Expedition von der astgrönländischen Kïiste mitgebrachte aus 25 Hölzern bestehende collection begrïst werden, deren Lntersuchung, die ich im Folgenden niederlege, ein iiberaus klares und sprechendes Resultat ergeben hat.

\section{Aeusseres der Hölzer.}

Die mir vorliegenden 'Treibhölzer, 25 an der Zahl, waren nebst. zwoi kleinen Rindenstiickchen sümmtlich an der ostgrönländischen Küiste aus dem Meere aufgenommen worden; eins derselben, durch dunklere Farbe und einen hohen Grad von Verwitterung vor den bleigrauen oder silberweissen andern ausgezeichnet, war im Kaiser-FranzJosephs-Fjord gefunden, die übrigen in der Nähe der PendulumInseln.

Sollten aus den botanischen Untersuchungen über den Ursprung der Hölzer sichere Schlüsse auf Strömungen u. s. w. gezogen werden, so kam es vor Allem darauf an, diejenigen Stücke, die sich durch Spuren menschlicher Finwirkung als Werkhölzer erkennen liessen, rorläufig zu sondern und von der Betrachtung auszuschliessen, da es auf der Hand liegt, dass bei solchen Hölzern, die beispieIsweise von

${ }^{1}$ Om den Spetsbergstia Drif-vedens ursprung. Af J. G. Agardh. - Öfversigt af kongl. Vetenskaps-Academiens Förhandlingar, 1869, No. 2, S. 97-119.

2 So wenigstens verstehe ich Agardh nach S. 99 seiner Abhandlung. Nach meinen Erfahrungen möchte ich nicht zweifeln, dass wol Alles Lärchenhölzer waren. 
gescheiterten Schiffen, von verlorenen Werkzeugen u. s. w. stammen, sich nachträglich nicht mehr eruiren lässt, wie wcit beim 'Transport derselben an ihre Fundstellen die natürlichen Kräfte (Strömungen), wie weit menschliche Willkür mitgewirkt haben; woraus erhellt, dass sie fiir weiter tragende Schlïsse nicht wohl zu gebrauchen sind.

Es genügte num allerdings ein oberflächlicher Blick auf die mitgebrachten Stiicke, um sofort die Ueberzengung zu gewinnen, dass die weitaus grösste Mehrzahl derselben nie eine bearbeitende Hand gesehen hatte. Nicht allein, dass Spuren menschlicher Thätigkeit überhaupt nicht zu sehen waren, sie gaben schon durch ihre äussere Gestalt hinreichend zu erkennen, dass sie zu jeder Nutzung als Werkholz von vornherein völlig unbrauchbar gewesen wären.

Schon der Umstand, dass die meisten derselben nicht vollcylindrische Hölzer waren, sondern höchst unregelmässige Fragmente schlecht gewachsener, sei es nun Stämme oder Wurzeln, darstellten, war geeignet, jeden Gedanken an Nutzholz auszuschliessen.

Es waren meistentheils unregelmässige radiale Ausbrüche des Holzcylinders, seltener Hälften desselben, meist keilförmig, nicht einmal bis auf das Mark gehend herausgerissen.

Alle Begrenzungsflächen waren uneben und splitterig, sie gingen stets nach der Richtung leichtester Spaltbarkeit, d. h. den Markstrahlen entlang und genau nach dem Faserverlauf des Holzes da, wo eingerwachsene Aeste einen geschwungenen Verlauf erforderten. Die Enden waren nicht quer abgeschnitten, wie durch Werkzeuge, sondern mit abgerundeten Spitzen versehen, stumpfsplitterig, auch wol trichterförmig, so, wie Holz unter Wirkung roher Gewalt zu brechen pflegt. Einzehe Hölzer waren tangential al)gesonderte Schalenstiicke; andere erwiesen sich als Wurzelstöcke; wieder andere zeigten kleineré und grössere Aststïmpfe.

Die wirklichen Vollhölzer waren auffallend unregelmässig gewachsen; eins fast brettartig flach, ein anderes Sförmig gebogen, cin drittes seltsam gedrehter Faser.

Nur wenige Stücke waren verdächtig.

Hierher gehörten vor allem die grössten der mitgebrachten Stiicke, ohne Frage Stämme, die anderthalb Decimeter Durchmesser und in einem Falle eine ansehnliche Länge (9 Fuss) hatten, an deren Enden alte Sägeflächen vorhanden waren. Ihre regelmässige Cylindergestalt liess in ihnen auch leicht Flosshölzer vermuthen. Gleichwol werden wir sehen, dass sie in Wuchs und Bau mit den übrigen Hölzern übereinkommen, und mit den reinen Naturhölzern gewiss Eine Mutterpflanze und einen Stammort haben. 
Ein Stück ron etwa zwei Decimeter Länge und mehrerin Centimeter Dicke ist ron zwei parallelen und ebenen Flächen begrenzt, die nicht in der Richtung der Markstrahlen, sondern schief dagegen rerlaufen; es scheint ein Stück Brett zu sein. Es ist auf der Aussenfliche nit eincr rissigen dunkeln Kruste iiberzogen, in welcher thierische Haare unschwer zu erkennen sind." Wahrscheinlich haben wir es hier mit einem Bootfragmente zu thun. Uebrigens stimmt anch dicess Holz mit den iibrigen iiberein, tud kann ron ihnen nicht getrennt werden.

Nur ein drittes Stiick, das einem Stamm von wenigstens $2,5^{\mathrm{dm}}$ angehörte, zeigt sich auf der schiefen Querfläche nicht allein abgenutzt und theilweise verkohit, sondern auch Jahrringe ron einer Weite, die ein riel weniger nördliches Klima rerrathen als die andern Hölzer, und mehr an das Wachsthum in unsern Breiten erinnern. Doch war es im Bau von den andern Stiicken, die wir als. Picen bezeichen werden, nicht zu unterscheiden.

Was allen Stiicken, auch die eben besprochenen Nutzhölzer nicht. ausgenommen, einen gemeinschaftlichen Charakter verleilit, das ist der eigenthïmliche Erhaltungszustand.

Lis sind lauter nackte Holzkörper, an denen gewöhnlich nirgends eine Spur ansitzender Rinde zu finden ist; nur an zweien wurden bei genanerer Bisichtigung kleine Rindenfleckchen entdeckt, die sich, wie cinige aus der Umgebung eingerachsener Aeste heransgespaltene Rindenspuren, für die nïhere systematische Bestinmung der Hölzer ausserordentlich werthroll erwiesen.

Die Spuren der Einwirkung roher mechanischer Gewalt, rollender, schleifender und splitternder Kräfte traten an der Oberfläche aller Stücke zu Tage. Die ursprïunglich offenbar scharfen Begrenzungen waren abgestumpft, die Kanten abgerieben, Leste abgestossen und die Oberflïchen in rerschiedenem Grade abgenutzt, je nachdem die weichern oder härtern Partien der Jahrringe nach aussen lagen. Das schon erwähnte brettartig gewachsene Holz war z. B. auf seiner breitern Seite, wo die engen Jahrringe lagen, glatt, auf seiner schmälern, aus weichen Schichten zusammengesetzten, mannichfach zerfasert, da hier das Holz mechanischem Drucke u. s. w. weniger Trotz bot.

Wie hätte man bei diesen Hölzern auch nicht die Spuren roher Tubilden finden sollen? Mussten sie doch, wie wir später sehen wer-

${ }^{1}$ Mein College Professor Ehlers, der die Substanz ansah, versichert, dass es nicht thierische Hant sei. 
den, nothwendig schon bevor sie ins Meer kamen eine lange Flussreise unternehmen (aus dem Waldgebiete des östlichen Continents durch das arktische Gebiet desselben), auf welcher sie Strandungen, Rollungen am Ufer ausgesetzt waren; wurden sie vielleicht an den arktischen Ufern wiederholt von den brandenden Wogen ans Ufer geworfen und wieder aufgenommen (vgl. die unten citirten Schilderungen Middendorff's), beror sie noch den schleifenden und brechenden Zerstörungen des Eises im stürmischen Polarmeere ausgesetzt waren!

Verrathen sich so mechanische Einwirkungen, so ist andererseits die merkwürdige Fïrbung der Oberflïche der Zeuge langen Einflusses chemischer Agentien, der Wirkung von Wasser ${ }^{1}$, Luft und Licht.

Alle Hölzer ohne Ausuahme erscheinen oberflächlich auffallend verbleicht, bald bleigran und matt, bald glänzend und silberweiss. Die Verbleichung dringt, wie man auf dem Querschnitt sieht, nicht tief ein; gewöhnlich ist sie von unmessbarer Dünnheit, seltener bis 1 oder $2^{\mathrm{mm}}$ ins Innere gedrungen; nur wo Risse im Holze sind, ist sie selbstrerständlich auch im Innern zu gewahren. Wenn man ander's will, dass diese Stücke bei ihrem langen Aufenthalt im Wasser sich tiefer damit erfüllen, so verrïth diese blos oberflächliche Bleichung. dass der Process nicht von der. Einwirkung des Wassers allein abhangen kann, sondern dass auch der Zutritt von Luft (und Licht?) dazu beitragen muss.

Der Einfluss dieser Atmosphärilien macht sich noch in andern Erscheinungen geltend. Die Oberfläche des Holzes ist zwar in vielen Fällen ganz glatt, ja glänzend, in andern dagegen erscheint sie wie mit feinen Haaren besetzt oder kurzwollig, oder es sind feine Lamellen von $1 / 2-2^{\mathrm{mm}}$ Breite vorhanden, die sich als losgelöste Holzfasern zu erkennen geben.

Wenn man die Radialflächen von Hölzern mit etwas weitern Jahrringen näher betrachtet, so erscheinen die weitern Partien des Jahrrings vertieft, die dichtern und härtern erhöht, die ganze Fläche wie cannelirt; Cannelirungen, die je nach der Breite der Jahreslagen gröber oder feiner, nach dem raschern oder langsamern Uebergang der

1 Es sei nur im Vorbeigehen erwähnt, dass man den ehemaligen Aufenthaltsort in der See sehr leicht nachweisen kann, wenn man die Oberfläche eines Holzes durch einen Strahl reinen Wassers mit der Spritzflasche abspült und das angesäuerte Wasser mit salpetersaurem Silber versetzt. Man erhält einen sehr starken in Salpetersäure löslichen Niederschlag von Chlorsilber. Ein zufällig unter die Treibhölzer gerathenes Farbholz zeigte auf diese Weise sogleich, dass es niemals nähere Bekanntschaft mit Scewasser gemacht liatte. 
Schichten ineinander scharf abgesetzt oder thach sind. Die Angriffe äusserer Agentien machten in den weichern Partien raschere Fortschritte als in den harten.

Dịe nähere anatomische Untersuchung zeigt als Ursache dieser Èscheinungen eine eigenthïmliche Auslaugung der äussern Holzelemente. Die Wände der Zellen silberweisser und glänzender Holzpartien sind sehr verdiunt, oft zusimmengefallen; die spiraligen Dichtigkeitsstreifen treten in einer Dentlichkeit herror, als ob es schraubenförmige Verdickungen der Membran seien; dabei erscheinen sie hyalinweiss und nicht von der gelblichen Farbe verholzter Häute, wie denn auch die Anwendung ron Jod und Schwefelsäure reine Zellstoffreaction zoigt (während das intacte innere Holz Ligninmembranen hat). Es ist offenbar, dass die dïmnen, lufterfïllten Röhrehen (Zellen) die weisse Farbe, ihre parallele Lage den Seidenglanz hervorrufen. ${ }^{1}$

Wo auf dem Holze haarförmige Ueberzïge vorhanden sind, findet man die eben geschilderten Zellen für sich oder zu mehrern durch Zerstörung der Intercellularsubstanz aus dem Verband gelöst.

Kurz wir haben hier den Zustand des Holzes vor uns, den man als "Vergrauung" desselben bezeichnet ${ }^{2}$ und der sich an allen Hölzern findet, die dem wiederholten und wechselnden Einflusse ron Wasser, Luft und Licht ausgesetzt sind; z. B. ganz allgemein bei hölzernen Dachschindeln. Es ist vielleicht nicht ohne Bezug auf unsere Hölzer, wenn ich bemerke, dass ich solche Zerstörungen nirgends schöner als an dem Holzwerk der Gradirhäuser (Saline Orb, Kissingen) gesehen habe.

Es steht auch nichts entgegen, sich unsere Treibhölzer lange Zeit in einen solchen Zustand rersetzt zu denken. Mag man num annehmen, dass dieselben an der Stätte ihres Wuchses in den Wäldern der Sonne und atmosphärischem Wasser ausgesetzt waren, oder dass sie auf ihrer Flussreise gelegentlich anfs Trockene geriethen, oder an den arktischen Ufern unter dem Einfluss der mehrmonatlichen Sonne bleichten.

Die Vorstellungen, die man aus den grossartigen Schilderungen Niddendorff's ${ }^{3}$ iiber das Treibholz an der arktischen Küste Sibiriens gewinnt, werfen ein klärendes Licht auf alle die Zustände, die wir

1 Vgl. die Beschreibung gleicher Erscheinungen bei Krraus, Würzburger naturwissenschaftliche '/eitschrift, 1864, V, 182.

${ }^{2}$ Krats, a. a. O.; Wiesener, Sitzungsberichte der Wiener Akademie, 1864, XLIX, $65 \mathrm{fg}$.

${ }^{3}$ Reise in den üussersten Xorden und Osten Sibiriens, IV, 1., 252-256. 
bei unsern Hölzern finden. Er hebt besonder's hervor, wie sich die dortigen Treibhölzer durch, ,Zeichen gewaltsamer Zerstückelung und Abreibung", welche einerseits das ,Polareis", andererseits ,die Ufer= brandung" bewirkt, charakterisiren. Seine Angaben zeigen auch, wie lange möglicherreise in jenem arktischen Klima unsere Hölzer dem EinHusse der Atmosphärilien ausgesetzt sein komnten, bis sie die bleiche Farbe erlangten, die für sie so charakteristisch ist. Er berichtet, dass Holz, welches nachweislich iiber 100 Jahre in der 'Taimyrtundrat gelegen, nur auf der Wetterseite einen graulichen Verwitterungsanflug hatte ron nicht einmal einer Viertellinie Dicke (a. a. 0., S. 255 und 263).

Eine Aeusserlichkeit, die auf den ersten Blick wahrzunehmen, darf hier als bedeutungsvoll für das Kümpftige nicht übergangen werden; ich meine die nicht unbeträchtlichen Drehungen der Holzfaser. Ein schaliges Stück zeigt z. B. eine Drehung der Faser von $10-12^{\circ}$ Neigung gegen die Achse (nach rechts im Simne Limés); cine (Lürchen-) Wurzel ist um etwa $5^{\circ}$ rechts gedreht; ein Stück, das sich später als Erle erwies, zeigte eine Drehung von $6-7^{\circ}$ gegen links. Yon den drei grossen Stammstiicken, die späiter als Läirchenholz bewiesen werden, waren zwei rechts, eins links gedreht. Besonders auffallend zeigte sich ein spitzkegelfömmiges Stïck Holz, an welchem, der Richtung der Holzfaser entlang (stark links) Auslaugungen stattgefunden hatten, so dass der Faserverlauf klarstens hervortrat.

Diese Drehungen sind insofern von Bedeutung, als ihr excessives Auftreten auf eine nordische Abstammung unserer Hölzer hinweist. Wenn auch, wie wir besonders aus den schönen Untersuchungen A. Braun's (Monatsberichte der Berliner Akademie, 185̆t. S. 4:32 fo.) wissen, bei allen Bäumen, auch unsers Klimas, solche Faserdrehungen rorkommen, so sind doch die bedeutendern Drehungen ein besonderes Charakteristicum bammartiger Gewïlse des hohen Nordens. Schon Linné hat bekanntlich darauf hingewiesen, dass in Lappland die Kiefern (Pinus sylvestris) einen schiefen Faserverlauf, der Sonne entgegen" zeigen (Flora lapponica, Amstelod. 1737, S. 237). Von andern Angahen mag nur darauf hingewiesen werden, dass Middendorff (a. a. O., S. 603) bei der Lärche und Kiefer die ,Drehkrankheit“6 des Holzes als eine häufige Erscheinung in den Gegenden der sibirischen Baumgrenze hervorhebt.

Eine letzte Eigenschaft, die ohne weiteres an den Hölzern wahrgenommen werden kann, ist die auffallende Schwere der meisten. Besonders fiel hierdurch ein starkes, radial herausgobochenes stiick auf, von stark splitterigem Bruch. Es ist so schwer, dass ich erst 
durch den Versuch mich ron dem Zweifel befreite, ob es in gewöhnlichem Wasser schwimme, und dass ich lange Zeit daran dachte, ein so schweres Holz müsse wol unter sehr giunstigem Himmelsstriche, vielleicht unter den Tropen gewachsen sein. Wir werden aber sehen, dass sich die Sache in gerade entgegengesetzter Weise, durch Wachsthum im hohen Norden, erklïrt. Ëine Anzahl anderer Hölzer fiel nicht für sich, wol aber dann durch ihre Schwere auf, wenn man sie mit den leichtholzigen Nadelhölzern - denn solche waren es - unserer Breite verglich.

Im Verein mit dieser Eigenschaft war bei den meisten Hölzern eine beträichtliche Härte und eigene Sprödigkeit zu gewahren, die das leichte Springen der stärkern Rundstïcke verständlich macht.

\section{Querschnitt der Hölzer.}

Im der Bestimmung unserer Hölzer einen Schritt näher zu rücken, wurden zunächst an allen geeigneten Stellen glatte Querschnitte angefertigt.

Was sich schon bei der äussern Ansicht der Hölzer hatte rermuthen lassen, bestaitigte der Querschnitt augenblicklich, dass nämlich die meisten derselben Nadelhölzer seien, kenntlich an den deutlichen weichern und hïrtern Schichten des aus gleichartigen Elementen bestehenden, nur hier und da von Harzgängen durchsetzten Jahrringes, während nur drei Exemplare mit der Lupe unverkennbare Gefässöffnungen zeigten und sich damit als Laubhölzer manifestirten.

Diese Beobachtung stelle ich absichtlich mit der Bemerknng voraus, dass sich alles im Folgenden Gesagte zunïchst auf diese Nadelhölzer bezieht; da es sich von selbst versteht, den Hauptstock der IIölzer zuerst einer nähern Prüfung zu unterwerfen. Zwei Dinge sind es, die auf dem Querschnitt vor allem interessiren mussten, die Farbe des Holzes und der allgemeine Bau der Jahrringe.

Die erstere war in mehr als Einer Hinsicht von Wichtigkeit. Bekanntlich sind in allen Berichten über Treibhölzer Farbhölzer als integrirende Bestandtheile derselben erwähnt, ja in Island werden dieselben nach ihren Farben geradezu benannt und in verschiedenem Grade geschätzt. Nach den rerschiedenen Angaben, die wir über diese Producte haben (vgl. Gumprecht, a. a. 0., S. 426, 428, 429; Irminger, a. a. 0., S. 189), lïsst sich allerdings die Möglichkeit nicht leugnen, dass diese als Werkhölzer so sehr geschätzten 'Treibproducte wirkliche Farbhölzer sind. d. h. in die Kategorie der aus den 'Tropen 
stammenden, in der Technik zur Bereitung rother und blaner Farben verwendeten Hölzer, etwa Campeche-, Fernambuk-, Santelhölzer gehören. Andererseits ist allerdings auch leicht möglich, dass in jenen holzarmen Gegenden auch nur einigermassen durch ihre Farbe auffallende Hölzer diesen Namen erhalten. Die Vermuthung, dass die Nordländer und vielleicht auch zahlreiche Berichterstatter aus jenen Gegenden mit dem Namen Farbholz ganz andere Dinge als wir, etwa uiberhaupt nur lebhaft (nicht weiss) gefärbte Hölzer, belegen, erhält dadurch Raum, dass ein von E. Robert als Acajou mitgebrachtes Holz (Gumprecht, l. c., S. 426) von Brongniart als Nadelholz erkamnt worden ist. Es kommt noch hinzu, dass in der That einige Nadelhölzer (z. B. die Lärche, Juniperus, Taxus) ziemlich lebhaft gefürbte Hölzer haben.

Die Existenz wirklicher Farbhölzer unter den Treibproducten wäre insofern von ausserordentlicher Wichtigkeit, als sich aus ihr da die Farbhölzer nur in der warmen Zone Amerikas vorkommen mit apodiktischer Gewissheit auf eine Herbeiführung durch den Golfstrom schliessen liesse; während die Nadelhölzer, möglicherweise nordischer Herkunft, ebenso gut durch den Polarstrom kömnten herbeigeführt sein.

Aber abgesehen davon gibt die Farbe der Hölzer einen guten Anhaltspunkt für die Bestimmung derselben; es ist eine bekannte Thatsache, dass das Kernholz zahlreicher Bäume eine ganz charakteristische Färbung hat. Man darf sich nur an die verschiedenen Nuancen von Braun, Roth und Gelb erinnern, welche unsere eigenen Nadelhölzer darbieten, die, so sehr sie auch innerhalb ganz feiner und nicht leicht definirbarer Nuancen schwanken, doch fuir den Kundigen untrïgliche Erkennungszeichen gewisser Hölzer sind. Schon in dieser diagnostischen Hinsicht musste der Farbe des Holzes einige Aufmerksamkeit geschenkt werden.

Es zeigte sich num freilich sogleich, dass von eigentlichen Farbhölzern bei den unserigen nicht die Rede sein komnte. Kein einziges Holz zeigte auch nur eine Annäherung an die Intensitït der Fïrbung, die man bei wirklichen pigmenthaltigen Hölzern findet, oder anch nur die Nuance eines Farbenholzes.

Nach dem Gesammtanblick liessen sich aber drei Kategorien von Färbungen unterscheiden, röthliche, braune und weisse, ähnlich wie es $A$ gardh bei den spitzbergischen Hölzern (a. a. 0., S. 97) gefunden hatte.

Zwei Stücke, die ihrer Form nach offenbar Wurzelstöcke waren, und :iusserlich glänzend silbergrau waren, zeigten sich im Innern 
schön röthlich, Die Farbe war ein Gemisch von Mattrosa und Braun, und erinnerte lebhaft an die Färbung gewisser Bleistifthölzer. Dies waren die lebhaftest gefürbten Stiicke. Mochten sie auch den Kundigen nicht im entferntesten an tropische Farbchölzer gemahnen, man findet bei ihrem Anblick doch begreiflich, wie der Laie, besonders wenn er wie die Nordländer nur farblose Tannenhölzer gewohnt ist, solche Stücke vielleicht als Farbhölzer ansprechen könnte. Zwei weitere Hölzer, ein åusserlich wohl erhaltenes und jenes vermulmte Stäck aus dem Kaiser-Franz-Josephs-Fjord hatten zwar ebenfalls eine röthliche Fïrbung; diese spielte aber auffallend mehr ins Weissliche. Auch wiesen die undeutlichern und engern Jahrringe, der fast körnige Querbruch und die wenig faserige Längsansicht auf eine ganz andere Natur des Holzes; es waren die zwei später zu beschreibenden Erlenlı̈lzer.

Veitaus die grössere Mehrzahl der Hölzer war braun gefärbt, cin Braun, das bald mehr lederbraun, bald ins Ockerfarbene spielte. Meist fiel die Farbe von selbst, ohne Vergleich mit andern Hölzer'n auf; bei einer geringern Zahl war sie minder ausgesprochen, und erschien erst deutlich, wenn man die Hölzer von der Seite betrachtete oder mit gewöhnlichen weissen Nadelhölzern, z. B. dem Holze unserer Veisstanne oder Fichte verglich.

Neben diesen befand sich ein kleiner Rest (fünf), die rein weiss erschienen, soweit man überhaupt bei Hölzern von reiner Farbe sprechen kann.

Es braucht kaum eigens bemerkt zu werden, dass diese Farben von dem Gesammtaspect gelten, und dass im einzelnen nicht allein die verschiedenen Jahrringe verschiedene Nuancen haben konnten, sondern dass auch, wie gewöhnlich, der härtere Theil des Jahrrings tiefer, der weichere schwächer gefürbt erschien, und dass z. B. auch bei den weissen Hölzern die härtern Partien mehr oder weniger bräunlich waren. -

Lan wird mit Recht die Frage anfwerfen, wie weit diese Färbung der Hölzer als eine ursprüngliche anzusehen, und wie weit angenommen werden kann, dass dieselbe vielleicht durch Einwirkung des Seewassers hervorgerufen sei, zumal da das Seewasser dem Lärchenholze "einen röthlichen Schimmer"6 verleihen soll (Irminger, a. «. O., S. 189).

Es lässt sich in unserm Talle nachweisen, dass die Färbung eine rein natürliche ist; denn wir werden später sehen, dass sich die meisten Hölzer auf anatomischem Wege mit voller Sicherheit bestimmen lassen, und dass in diesen Falle die Fabbe des geschwemmten 
Holzes mit der des natiirlichen genan iibereinkommt. Wir werden ferner sehen, dass in den aufgefischten Borkestiickchen, in denen Schichten sehr lebhafter Fürbung miteinander abwechseln, die Fürbung aufs schönste und reinste erhalten ist und diese Erfahrungen dit, wo der anatomische Befund zur systematischen Bestimmung nicht himreicht, benutzen dürfen; um zu einer Artendiagnose zu gelangen.

Viel bedentungsvoller als die Färbung wird der Bau der Jahrringe für uns.

Als die merkwürdigste Eigenschaft derselben fiel sofort die ausserordentliche Schmalheit derselben auf. Unter den 25 Holzstïcken waren es blos die röthlichen Wurzelstöcke, die hinsichtlich der Jahrringweite etwa mit Hölzern unserer Gegenden verglichen werden könnten; noch etwa zwei oder drei hätten engringigen Nadelhölzern unsers Ḱlimas verglichen werden können; bei allen übrigen waren die Jahrringe so schmal, dass sie oft mit der Lupe nur mühsam unterschieden werden konnten; sellsst an ganz glatten Schnitten gab stellenweise erst das Mikroskop Aufschluss. So hatte z. B. ein radial.aus dem Stamm gespaltenes brettartig diinnes Stiick auf einem Radius von nicht ganz $10^{\mathrm{cm}}$ mehr als 200 Jahrringe aufzuweisen; von diesen kamen die äussern 100 Ringe auf nur $3^{\mathrm{cm}}$; Jahrringe von $4-8$ Zellen im Durchmesser waren hier sehr gewöhnlich.

Eine genauere Naassbestimmung der Jahrringe war nicht allein ihrer grossen Enge wegen, sondern auch wegen des excentrischen Wachsthums nicht leicht. Gleichwol mussten eine Anzahl Messungen vorgenommen werden, da sich aus ihnen für unsere Zwecke sehr dienliche Schliisse ziehen liessen.

Ich habe die Messungen nur an solchen Stücken gemacht, welche eine Zählung bis ins Mark erlaubten, da auf diese Weise zugleich das Alter des Jahrrings in Betracht gezogen werden konnte. Da die Stïcke fast ohne Ausnahme excentrisch gewachsen waren, komnte nur ein bestimmter, der grösste oder kleinste oder mittlere Stammradius bei der Berechnung zu Grunde gelegt werden. Die Jahrringe komnten oft nur approximativ geschïtzt werden, da im Lmfang des Stammes häufig Zerstörungen des Holzgewebes eine genauere Zïhlung unmöglich machten. Es wurden nur Stamm-(nicht Wurzel-) stïcke zur Messung verwendet.

1) No. IV. Stammstiick von $95^{\mathrm{mm}}$ grösstem, 65 kleinstem Radius.

Die innersten 28 Jahre maassen $35^{\mathrm{mm}}$, mittlere Jahrringweite 1,3 .

Die äussern (folgenden) 70 Jahre maassen $30^{\mathrm{mm}}$, mittlere Jahrringweite 0,4 .

Mittlere .Tahrringweite ïberhaupt nach dem grössten Radius $0,9^{\mathrm{mm}}$, nach dem kleinsten Radius 0,6 . 
2) Stammstick von $95^{\mathrm{mm}}$ Durchmesser.

Innere 44 Jahre $60^{\mathrm{mm}}$, mittlere Jahrringweite $1,4^{\mathrm{mm}}$.

Aeussere (etwa) 100 Jahre $15^{\mathrm{mm}}$, mittlere Jahringweite 0,14 .

Mittlere Jahrringweite $0,7^{\mathrm{mm}}$. Grösster Jahrring $2,5^{\mathrm{mm}}$.

3) Stammstück A. 2. Grösster Radius $100^{\mathrm{mm}}$.

Die 46 innern Jahre messen $61^{\mathrm{mm}}$; ein Jahrring $1,3^{\mathrm{mm}}$.

40 weitere ,, $25^{\mathrm{mm}} ;,, \quad, \quad 0,6^{\mathrm{mm}}$.

$100 \quad, \quad, \quad 14^{\mathrm{mm}} ;, \quad, \quad, \quad 0,14^{\mathrm{mm}}$.

Mittlere Jahrringweite für 186 Jahre $0,53^{\mathrm{mm}}$.

Weitester Jahring $2^{\mathrm{mm}}$ (nicht ganz).

4) No. 4. $80^{\mathrm{mm}}$ im (Mittel-) Radius haltendes Stück.

Die innersten 13 Jahre messen $23^{\mathrm{mm}}$; ein Jahrring $1,7^{\mathrm{mm}}$.

Weitere $29 \quad, \quad, \quad 32^{\mathrm{mm}} ; \quad, \quad, \quad, \quad 1,1^{\mathrm{mm}}$.

Die äussersten $48 \quad, \quad \quad, \quad 24^{\mathrm{mm}} ; \quad, \quad, \quad, \quad 0,5^{\mathrm{mm}}$.

Mittlere Jahrringweite in 90 Jahren $0,9^{\mathrm{mm}}$.

5) No. 6. Ein sechsundzwanzigjühriges Stammstück von $36^{\mathrm{mm}}$ Ratrdins. sehr regelmässig gewachsen, mittlere Jahrringweite $1,4^{\mathrm{mm}}$.

6) Stammstiick von $45^{\mathrm{mm}}$ Radius (mittlerer).

Innerste 40 Jahre $25^{\mathrm{mm}}$; ein Jahrring $0,6^{\mathrm{mm}}$.

Aeussere $50 \quad, \quad 20^{\mathrm{mm}} ;$, , , $0,4^{\mathrm{mm}}$.

Mittlerer Durchmesser des Jahrrings in 90 Jahren $0,5^{\mathrm{mm}}$.

Stärkster Jahring $1^{\mathrm{mm}}$.

In ähnlicher Weise verhalten sich, soweit sich das bei marklosen Stiicken beurtheilen lässt, noch 10 Stücke.

Das Stïk A. 3, welches oben als mit Brandspuren und weitern Jahringen versehen schon erwihnt wurde, hatte einen mittlern Halbmesser von $40^{\mathrm{mm}}$ und zählte 105 Jahre, ein Jahrring also $1,3^{\mathrm{mm}}$ im Mittel.

Im Einzelnen verhielten sich die Maasse also:

Die innersten 16 Jahre maassen $48^{\mathrm{mm}}$; ein Jahrring. $3^{\mathrm{mm}}$.

$\begin{array}{lllllll}\text { weitere } 16 & , & , & 32^{\mathrm{mm}} ; & , & , & 2^{\mathrm{mm}} . \\ \text { weitere } 22 & , & , & 17^{\mathrm{mm}} ; & , & , & 0,8^{\mathrm{mm}} \\ \text { endlich } 31 & , & , & 16^{\mathrm{mm}} ; & , & , & 0,5^{\mathrm{mm}} .\end{array}$

Aus dieser Uebersicht wird klar, dass bei der Mehrzahl der Hölzex die Jahrringe eine ganz ausnehmende Engheit besitzen; sie beträgt im Mittel gewöhnlich unter $1^{\mathrm{mm}}$, selbst der weiteste Jahrring kommt gewöhnlich nicht auf $2^{\mathrm{mm}}$. Nur das zuletzt genannte oben schon verdichtigte Exemplar weicht ab und hat ansehnlichere Jahrringe.

Diese Enge würde, wenn sie bei einem oder dem andern Exemplar vorkïme. nicht auffallend sein, da sie anch hei unsern Bäumen bei schlechtem Wuchse vorkommt; sie wiirole auch nicht auffallen, 
wenn sie an Aesten oder Wurzeln vorhanden wäre, bei denen sehr engringige Stiicke zur Regel gehören; sie würde endlich auch nicht auffallen, wenn sie blos in der Peripherie sehr alter Stämme stattfände: wir sehen sie aber hier an Stämmen von den ersten Lebensjahren an ohne Ausnahme.

Um eine Vorstellung von der Engheit dieser Jahrringe im Verhältniss zu den unserigen zu geben, füge ich hier einige Zahlen an, die ich von bei uns gewachsenen Kiefern-, Fichten-, Weisstannenund Lärchenstämmen entnommen habe.

1) Kiefer (Pinus sylvestris). Siebenundzwanzigjähriger Stamm hat $95^{\mathrm{mm}}$ Raclius; mittlere Jahrringweite $3,5^{\mathrm{mm}}$. Erste 10 Jahre kein Jahrring unter $5^{\mathrm{mm}}$; engster Jahrring des Stammes $2^{\mathrm{mm}}$.

2) Weisstanne (Abies pectinata), 52 Jahre alt, mit $105^{\mathrm{mm}}$ mittlerm Halbmesser. Mittlere Jahrringweite $2^{\mathrm{mm}}$; anfängliche gewöhnlich gegen $4^{\mathrm{mm}}$; engster $1^{\mathrm{mm}}$.

3) Fichte (Picea excelsa). Stamm von 25 Jahren mit $110^{\mathrm{mm}}$ Radius; mittlere Jahrringweite über $4^{\mathrm{mm}}$; der weiteste Jahrring über $6^{\mathrm{mm}}$; der engste üiber $2^{\mathrm{mm}}$.

4) Ein kleines, in spätern Jahren sehr schlecht gewachsenes Lärchenstämmchen, etwa dreissigjährig, hat $45^{\text {1mm }}$ Halbmesser, also $1,5^{\mathrm{mm}}$ mittlere Jahrringweite. Der weiteste Jahrring ist über $5^{\mathrm{mm}}$ stark; Jahrringe im Alter von $7-15$ Jahren alle $2-3-4^{\mathrm{mm}}$ stark. Diese Angaben, beliebigen Stiicken von Stämmen, die in der Umgebung Erlangens auf sehr mittelmässigem Boden gewachsen waren. entnommen, enthalten durchaus keine ungewöhnlichen Zahlen; man kann sich durch Tergleich z. B. der Maasse, die Göppert (Mon. foss. Conif., S. 32) oder Decandolle (Phys., üb. v. Röper II. Tabelle, z. p. 809, F. G. K.) gibt, überzeugen, dass es die gewöhnliche Jahrringweite unserer Abietineen ist.

Man sieht aber nun hieraus, dass bei uns ein Baum in 25, 30 oder 40 Jahren fast ebenso viel wächst, als jene Exemplare, von denen unsere Treibhölzer stammen, kaum in 100 oder 200 Jahren erreichten.

Man kann sich anch durch Vergleich der Zahlen überzeugen, dass die Differenz im Wachsthum sich kaum ändert, wenn man hier und dort etwa gleichalterige Exemplare nimmt.

Eine so constant auftretende Erscheinung, wie die Schmalheit der Jahrringe in unserm Falle, kann unmöglich als Spiel des Zufalls oder rein localer Verhältnisse betrachtet werden, es muss ihm eine an der Geburtsstätte des Holzes alløemein und constant wirkende Ursache zu Grunde liegen. 
Wir kemnen einen Factor, der die Jahrringe gesetzlich rerengert, es ist dies die zunehmende geographische Breite. Wir wissen, dass die Bämme (wenigstens Nadelhölzer) derselhen Art um so engere Jahrringe bilden, je höhere Breiten sie erreichen; dass beispielsweise eine bei uns gewachsene Conifere viel weitere Jahrringe als unter dem 60. Grade und dort noch stärkere als unter dem 69. Grade nördl. Br. hat.

Zum Belege führe ich einige Zahlen aus der Arbeit an, welche diese gesetzmässige Aenderung in der Jahrringweite zuerst festgestellt hat, aus der Arbeit von Martins und Bravais: Ueber das Wachsthum von Pinus sylvestris im Norden Europas. ${ }^{3}$ Die Zahlen geben das Wachsthum eines Jahrrings ron 50 zu 50 Jahren im Mittel (aus sehr zahlreichen Messungen) und zwar von fünf Orten:

a) von Kaafjord unter $69^{\circ} 57^{\prime}$ nördl. Br.

b) von Pello " "6 $66^{\circ} 48^{\prime}, "$,

c) von Geffle $\quad, 60^{\circ} 40^{\prime}, \quad, \quad$,

d) von Halle a./S. , $, 51^{\circ} 30^{\prime},,,$,

e) ron Hagenau, $48^{\circ} 43^{\prime}, "$,

1-50 Jahre. 50-100 Jahre. 100-150. Jahre. 150-200 Jahre.

$\begin{array}{llll}\text { a) } 1,0 & 0,8 & 0,68 & 0,5^{\mathrm{mm}} \\ \text { b) } 1,4 & 0,8 & 0,6 & 0,5^{\mathrm{mm}} \\ \text { c) } 2,0 & 1,5 & 1,0 & 0,8^{\mathrm{mm}} \\ \text { d) } 2,4 & 1,2^{\mathrm{mm}} & - & - \\ \text { e) } 3,2 & 3,2^{\mathrm{mm}} & - & -\end{array}$

Nehmen wir einstweilen an, das für Pinus sylvestris aus dem Vorstehenden ersichtliche Gesetz über die Verschmälerung der Jahrringe mit der zunehmenden geographischen Breite sei für alle Nadelhölzer guiltig, so genügt ein. Blick auf die rorstehende Tabelle und die oben gefundenen Zahlen, um sofort zu erkennen, dass unsere Hölzer der Mehrzahl nach nur mit denen der Jahrringbildung iibereinstimmen, die zwischen dem 66. und 69. Grade gewachsen sind, und dass nur einige etwa unter dem 60. Grade gewachsen sein könnten.

Die Thatsache würde noch schlagender hervortreten, wenn wir die Jahrringe mehr im einzehen vergleichen wollten; ich will in der Beziehung nur Eins hervorheben.

Es ist von Martins besonders betont worden, dass sich der Unterschied in der Jahrringweite am deutlichsten in den ersten Jahrzehnten des Wachsthums ausspricht, später aber mehr und mehr verwischt.

1 Mém. couronn. publ. p. l'Acad. de Bruxelles, T. XV, p. II, 1841, P. 1 sq. 
Man findet das aufs deutlichste durch Vergleich unserer 'Treibholz-Exemplare mit den oben angeführten Stämmen unseres Klimas bestätigt.

Unter allen Exemplaren (20) des 69. Grades, die Martins gemessen, ist kein einziges, dessen mittlere Jahrringweite in den ersten 50 Jahren $2^{\mathrm{mm}}$ gewesen wäre; unter denen des 66. Grades kommt in den ersten 25. Jahren nur eins mit $2^{\mathrm{mm}}$ ror. mehrere sehr mahe daran; ein Gleiches gilt von den Jahren 25-50.

Auch unter unsern Exemplaren findet sich, wie man sieht, kein einziges, das $2^{\mathrm{mm}}$ Jahrringweite im Mittel erreicht.

Noch viel wichtiger für uns, als die Beobachtungen von Martins, sind Viddendorff's ibber das Wachsthum der Bïume in hohen Norden, weil sie in einem Lande gemacht sind, aus dem, wie wir sehen werden, unsere Hölzer stammen, in Sibirien, und an Bäumen, von denen die Mehrzahl unserer Hölzer abzuleiten ist, an Lärchenstämmen. Unter den geistrollen schilderungen desselben über die sibirische batmonvegetation (Reise, IV, 1., $525-684$ ) ist uns das Kapitel ,Holzansatz und Lebensdauer der sibirischen Bäume" (a. a. O., S. 630-640) ganz besonders werthvoll. Die Messungen, welche in seiner Tabelle zu S. 633 von im Norden gewachsenen Kiefern und Lärchen mitgetheilt werden, bestätigen nicht allein das von Martins für die Kiefer gefundene Gesetz (S. 633, Amm.), sie dehnen es auch auf die Lärche aus. „Unter $60^{\circ}$ nördl. Br.", sagt er, , ist selten ein Bam zu finden, dessen breitester Jahring unter $3^{\mathrm{mm}}$ misst; günstige Umstände lassen ihn $5^{\mathrm{mm}}$ und mehr erreichen, während unter dem Polarkreis und nördlich von demselben kein Jahrring $2^{\mathrm{mm}}$ breit wird" (a. a. O., S. 633). Man braucht nur dessen 'Tabelle zu vergleichen, um sofort zu erkennen, dass unsere Hölzer nur unter dem Polarkreis und nördlich von demselben $\left(66-72^{\circ}\right.$ nördl. Br.), an der Grenze der Baumvegetation überhaupt gewachsen sein können.

Gegen diese Schlussfolgerung aus der Jahrringweite könnte man vielleicht den Einwand erheben wollen, dass die Schmalheit der Jahreslagen nicht durch klimatische (äussere), sondern durch innere Lebensgesetze der Bäume selbst gegeben sei, mit andern Worten, dass unsere Hölzer Bäumen angehören, die von Natur aus enge Jahrringe machen. Dieser Einwand wäre insofern möglich, als es in der 'That Nadelhölzer gibt, die auch bei üppigerm Wachsthum nur enge Jahringe produciren (Cupressineen, Taxineen). Wir werden nun später mit voller Klarheit erweisen, dass msere Hölzer zu den weitringigen Nadelhölzern (Lavix, Piran) gehören. Aber dieser Buweis wire 
nicht eimmal nothwendig, im den Einwand zu entkräften. Man kann, Dank den schönen Untersuchungen H. von Mohl's (Botanische Zeitung, 1862) aus dem Bau der Jahrringe selbst erkemen, ob derselbe ron Natur aus engringig oder durch klimatische Einflüsse geworden ist.

Bekanntlich besteht der Jahrring bei den Nadelhölzern im wohlgebildeten Falle aus drei Theilen: der innere, zuerst gebildete Theil desselben wird aus dünnwandigen, im Querschnitt viereckigen, nur auf der Radialwand getiipfelten Prosenchymzellen gebildet; er geht allmählich in den mittlern Theil über, dessen Zellen meist polygonal gegen aussen an Wanddicke zu-, an radialem. Durchmesser abnehmen, um so allmählich in den äussersten 'Theil überzugehen, der aus dickwandigen, radial zusammengedrückten Zellen besteht, die auch tangential getiipfelt sind.

H. von Mohl hat uns zuerst gezeigt (a. a. O., S. 228) und ich habe das bestätigt (Würzburger naturwissensehaftl. Zeitschrift, V, 148-150), dass bei Verschmälerung der Jahrringe durch äussere Bedingungen nicht alle Schichten in gleichem Maasse abnehmen, sondern (im Stamm) die innern dïnnwandigen Schichten fast gänzlich verschwinden, während die mittlern und äussern Schichten sich erhalten, so dass enge Jahringe nux aus diesen beiden Schichten bestehen.

Unsere Hölzer, soweit sie Stammhölzer sind, zeigen die Jahrringe fast nur aus der mittlern und äussern Lage gebildet, der weichere Theil fehlt fast in allen Ringen.

Zeigt uns dies Verhalten einerseits, dass die Engringigkeit der Jahrringe ein P'roduct äusserer (klimatischer) Bedingungen ist, so erkärt es andererseits auch die anffillende Härte und Schwere des Holzes, eine Eigenschaft, die Middendorft ohnehin als ein Charakteristicum nordsibirischer Lärchenstänme bezeichnet hat (a. a. O., S. 603$)$.

Lis bleibt noch iibrig, Einiges über die unter den Hölzern befindlichen Wurzehn zn bemerken. Von den vier Stiicken, die sich durch ihr Aensseres sofort als Wurzeln zu erkennen geben, stammen zwei wol rom Wurzelhalse eines Baumes, die andern beiden (ein schwach Störmig geschwungenes und ein brettartig flach gewachsenes) sind Wurzeläste. Lis ist anffallend, dass bei diesen Wurehn die Jahrringe so stark, ja stäirker als bei den Stammhölzern sind.

An dem flachen Stiick sind dieselben auf der geförderten Seite im Durchmesser von $1 \frac{1}{2^{m m}}$ ganz gewöhnlich, der weiteste hat $2^{\mathrm{mm}}$. Das S förmig gebogene Stuick von $45^{m m}$ grösstem, $133^{m m}$ kleinstem Radius zeigt folgende Dimensionen: 
Innerste 23 Jahre messen $31^{\mathrm{mm}}$; ein Jahrring $1,3^{\mathrm{mm}}$ Die äussern $16 \quad, \quad$ " $14^{\mathrm{mm}} ;, \quad, \quad 0,9^{\mathrm{mm}}$ Nach dem grössten Radius $1,1^{\mathrm{mm}}$ mittlerer Durchmesser. " " kleinsten " $0,3^{\mathrm{mm}} \quad$ " ,

Diese weichen noch nicht vom Stamme ab; dagegen besitzen die zwei röthlichen Wurzelstöcke Ringe von $5-6^{\mathrm{mm}}$; der weiteste ist sogar $8^{\mathrm{mm}}$ gross; nur die äussersten sinken auf $1 / 2 \mathrm{~mm}$.

Leider lässt sich über das Alter der Stöcke, da sie, fern rom Mark, keilförmig aus der Peripherie des Holzcylinders ausgesprengt, und noch dazu excentrisch gewachsen sind, nichts Sicheres eruiren. Nach der etwaigen Grösse des Bogens der Jahrringe zu schliessen mochten 15-20 Jahre fehlen, und die Hölzer etwa einem 60-70jälrigen Baume angehört haben.

Soll man annehmen, dass diese Stöcke in einem suidlichern Klima gewachsen, oder dass sie nur unter günstigern Bedingungen gewachsen seien? dass für die Wurzeln unten die Vegetationsbedingungen (in dem Boden) günstiger sein mögen, als fuir die in der Luft vegetirenden Stämme; doch zeigen gerade die oben angeführten Wurzeln, dass wir dies allgemein anzunehmen kein Recht haben. Es scheint mir vielmehr, dass in jenem nördlichen Klima so gut als bei uns die Stammbasen, da wo sie sich piedestalartig verbreitern, überhaupt ungemein weite Jahreslagen bilden. - Wie es immer sei, praktisch ist die Sache für uns insofern ohne Bedeutung, als die Mehrzahl der Hölzer ihre hochnordische Geburtsstätte unzweifelhaft documentirt hat.

\section{Systematische Bestimmung der Holzer.}

Es ist schon oben bemerkt worden, dass das ganze Aeussere die Nadelholznatur unserer Hölzer nicht verkennen liess: die sehr deutlichen Jahrringe, deren innerer und hellerer weicher 'Theil gegen den dunkeln und harten äussern sehr scharf abstach, der langfaserige Bruch, die fast mit blossem Auge sichtbaren Holzzellen, an einigen Hölzern ansitzende Harzmassen wiesen von vornherein der Mehrzahl ihre Stellung unter den Coniferen an. Es waren 22 von 25 Hölzern.

Der geglättete Quer- und Längsschnitt bestätigte nur diese Beobachtung. Er zeigte unter der Lupe die Zusammensetzung des Jahrrings aus einerlei gleichatigen Elementen (Holzzellen) von einer (irösse. wie sie nur bei Nadelhölzern rorkommen, Gefässöffnungen waren nirgends zu sehen, die da und dort bei allen zu findenden IIarzgänge nicht zu rerwechseln. Auch ein Merkmal, auf das Agardh schon auf- 
merksam gemacht hat, die harten und rerharzenden eingewachsenen Aeste, konnten als Charakteristicum der Nadelhölzer genommen werden.

Ich brauche kaum zu erwähnen, dass der erste beste Radialschnitt unter dem Mikroskop das untrüglichste Zeichen der Zapfenbäume, die grossen runden Hoftiipfel zeigte.

Nur drei Hölzer, die äusserlich Zweifel liessen, wurden erst mit der Lupe erkannt; diese zeigte sofort zahllose Gefässporen im Holz; es waren Laubhölzer.

Das eine, ein sehr leichtes, im Querschnitt weisses, mit ansehnlichem runden und rostbraunen Mark versehenes, ganz gerades Stähchen, etwa $2^{\text {im }}$ lang und $3^{\mathrm{cm}}$ dick ( 6 bezeichnet), auf dem Längsbruch weiss und zartfaserig, mit etwas ïber $1^{\text {mm }}$ starken Jahrringen, in denen zahllose Gefässporen zu sehen waren, konnte später als Salicineenholz erkannt werden.

Zwei Stiicke, die sich später als Erlenholz erwiesen, waren äusserlich sehr verschieden erhalten. Das eine äusserlich matt silhergrau, gedreht, fest und rollrund erhalten, hatte einige dunkelbraune Rindenschiippehen ansitzen, welche die an sich schon sichere Holzdiagnose bestens bestätigen sollten. Das andere war das mehrerwähnte Holz ans dem Kaiser-Franz-Josephs-Fjord. Auf dem Querschnitte zeigten beide eigenthümlich röthliches Holz und ein dreickiges, chocoladebrannes Mark. Die Jahrringe waren von zahllosen feinen Gefïssporen durchsetzt.

Wir wollen die Nadelhölzer, da ihre Bestimmung nach ron der der Laubhölzer verschiedenen Gesichtspunkten rorgenommen wird, gesondert betrachten.

\section{1) Die Nadelhölzer.}

Die Wahrnehmmg, dass 22 von den mitgebrachten Hölzern zu Coniferen gehören, war zwar nicht uiberraschend. Man komnte darauf, sowol nach den Angaben der Seefahrer als nach dem, was Agardh iiber die spitzbergischen Hölzer mitgetheilt hatte, vorbereitet sein. Aher der Bestimmung setzten die Nadelhölzer viel mehr Schwierigkeiten in den $\mathbf{W e g}$, als bei Laubhölzern wäre zu erwarten gewesen. Denn es ist durch alle Untersuchungen ïher den Ban der Nadelhölzer (Göplert, De structura Coniferarum anatomica und Monogr. foss. Coniferar.; Hartig, Naturg. forstl. Culturpfl.; ron Mohl, Bau der Baumwureln, Bot. '/tg., 1862; Schacht, Baum) dargethan, dass in dieser Gruppe der Holzbau ein ungemein übereinstimmender ist.

Meine in dieser Hinsicht vorgenommenen Untersuchungen (Kraus; 
Bau lebender und vorweltlicher Nadelhölzer, Würzburger naturwissenschaftliche Zeitschrift, $1864, \mathrm{~V}, 144 \mathrm{fg}$.) haben ergeben, dass nicht allein - etwa einzehe L'inusarten ausgenommen - die einzelnen Arten und Gattungen der Coniferen nicht unterschieden werden können; sie ergab das wenig tröstliche liesultat, dass ganze Familien (Podocarpeen, Cupressineen, Theil der Taxineen) nach dem Holzban allein nicht unterschieden werden können. So ist es nach meinen Untersuchungen z. B. ummöglich, die einzelnen Gattungen der Cupressineen zu unterscheiden, geschweige denn die einzelnen Arten einer Gattung. Lis latsen sich überhampt unter den Coniferen - die Gnetaceen ausgenommen - nur finf Gruppen unterscheiden, innerhalb deren es unmöglich ist, die einzelnen Gittungen oder Arten voneinander zu sondern. Ich unterscheide folgende Typen (vgl. a. a. O. und Schimper, Traité de palaeont. végét., II, 1., 36:3).

1) Typus der Abiesarten. Das Holz besteht nur aus Holzzellen; Harzgänge und Harzzellen (Holzparenchym) fehlen. Holzzellen nur getiipfelt, ohne Spiralen. Tüpfel einreihig, wemn zweireihig auf gleiche Höhe gestellt. Markstrahlen (tangential) einreihig, Zellen poris.

Hierher die Gattungen Abies und Cedrus.

2) Typus der Araucarien. Holz nur aus Holzzellen bestehend ohne Harzgänge und Holzparenchym. Holzzellen getiipfelt, ohne Spiralfasern. Der wesentliche Unterschied gegen die vorige Gruppe liegt in der Stellung der 'Tüpfel. Diese sind, wenn einreihig, so gedrängt, dass sie sich mit planem Hofrande berïhren, wenn mehrreihig, in Spiralen angeordnet. Markstrahlen wie vorher.

Die Gattungen Dammere und Aranceria.

3) Typus von Taxus. Holz nu' aus Holzzellen bestehe nd oh,n Harzgänge und Harzzellen. Der wesentliche Unterschied dieser Gruppe von andern liegt darin, dass die Zellenwände nicht allein mit Tüpfeln. sondern auch mit Spiralfasern besetzt sind. Markstrahlen einreihige Taxus, Cophalotaxus und Torreya gehören hierher.

4) Typus der Cupressineen. Das Holz besteht aus Holzzellen, die ein-oder auf gleicher Höhe stehende mehrreihige Tüpfel haben, ohne Spiralfasern." Charakteristisch sind die zahlreichen Harzzellen; Harzgänge fehlen. Markstrahlen einreihig.

Hierher gehören alle Cupressineen, Podocarpeen nud von den T'axineen Phyllocladus und Stexegothere.

5) Typus der Pinusgattung im engerm Sinne. Holz aus Holzzellen bestehend; diese getiipfelt, ohne Spiralen. Hier finden sich 


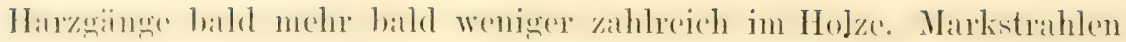
öfter Harzgïnge enthaltend und dann mehrreihig.

In dieser $\Lambda$ btheilung lassen sich nach der Sculptur der Zellwände der Markstrahlen drei Unterabtheilungen unterseheiden.

In der ersten Unterabtheilung besitzen die Markstrahlenzellen alle nur kleine P'oren, gewöhnlich vier auf der den Holzzellen zugekehrten Wand. Hierher gehört z. B. die Lürche (Larix), die Fichte (Picen), P. Latricio.

In der zweiten Lniterabtheilung zeigen die Markstrahlenzellen gegen die Holzzellen je ein orler zwei grosse ovale Poren („Eiporen"-Schacht). So Pinus Strobus und Cembre.

Die dritte Unteralotheilung endlich zeichnet sich dadurch aus, dass hier neben den "Eiporen" noch eigenthümliche zackige Verdickungen der Winde vorhanden sind. So bei der Kiefer (P. sylvestris), 1. Pinaster, Pumilio, palustris u. s. w.

Vgl. die Abbildungen dieser Typen bei Kraus, in Schimper's 'T'aité, II, 2, pl. LXXIX. -

Die nähere mikroskopische Untersuchung unserer 'Treibhölzer auf' dem Querschnitt und den beiden Längsschnitten ergab für alle gleichen Bau.

Das Holz aller besteht aus Holzzellen, die blos. 'Tüpfel, gewöhnlich eimreihig, seltener zweireihig auf gleicher Höhe besitzen; eigentliche Spiralfasern sind nirgends, wohl aber spiralige Streifungen häufig vorhanden. In allen Jahrringen beinahe finden sich Ilarzgänge zerstreut, deren Umgebung aus dickwandigen und porösen Parenchymzellen gebildet ist. Keine Markstrahlzelle zeigte zackige Verdickungen, sie besassen nur kleine Poren, gewöhnlich zu vier auf einer den Holzzellen zugekehrten Wand.

Das Vorhandensein der Harzgïnge stellt unsere Hölzer in den P'inustypus. Durch den Mangel der zackigen Verdickungen wird die dritte, durch den der Eiporen die zweite Unterabtheilung ausgeschlossen. Unsere Hölzer gehören in die erste Unterabtheilung, wo die Lärche und Fichte sich finden.

Um Weitlïufigkeiten in der Auseinandersetzung zu vermeiden, mag hier nun gleich darauf hingewiesen werden, dass wir aus dem Ban der Jahrringe mit aller Sicherheit für unsere Hölzer ein hochnordisches Klima, ein Leben unter dem 66.-70. Grade, an der Baumgrenze, geschlossen haben.

Diese Thatsache erleichtert uns die Bestimmung der Mutterpflanze, indem auf diese Weise eine Menge von Nadelhölzern des gleichen 
Banes ausgeschlossen werden, insofern sie nämlich in ein nordisches Klima selbst nicht vordringen.

Werfen wir einen Blick auf die Nadelbäume, die durch ihre Organisation befähigt sind, in dem breiten Waldgürtel, der die beiden Continente in mittlern Breiten auf der nördlichen IIalbkugel durchzieht (Grisebach, Vegetation der Erde, 1871, 2. Bd., Karte), als äusserste Vorposten bis in jene unwirthlichen Gegenden vorzudringen, so erhalten wir nur eine sehr beschränkte Zahl, nur einige wenige Baumarten, die sich noch dazu in den verschiedenen Weltheilen (Luropa, Asien, Amerikit) correspondiren.

In Europa (Schiibeler, Culturpflanzen Norwegens, S. 56 for.) dringen im Norden am weitesten vor die Kiefer (P. sylvestris) und Fichte (Picer excelsa). Die Lürehe ist mit Ansnahme liusslands diesseits des Ural ron ganz untergeordueter Bedentung.

In nördlichen Asien, durch ganz Sibirien rom Ural bis nach Kamtschatka (Middendorft, Reise, IV, 1., $525 \mathrm{fg}$. und $746 \mathrm{fg}$.) bildet den Hauptbaum die Lärche in ihren asiatischen Formen, der Larix sibirica und dahurica. Daneben erscheint als am weitesten verbreitet die Kiefer, Pinus sylvestris (a. a. O., S. 750), und neben dieser die Arve, $P$. cembra, die sibirische Tamme, Picen obovata, und Edeltame, Abies Pichtu (a. a. O., S. 753).

In Norden Amerikas, in der von uns berihiten Breite bestehen die Wälder vorwiegend aus Picen albu, der amerikanischen Form unserer Fichte; nur als unwesentliche Beimengung darf Larix microcarpa gelten (Grisebach, a. a. O., Il, 239).

Fine Anzahl dieser Bäume schliessen sich für unsere Betrachtungen von selbst aus, da ihr Holzbau ein anderer als der gefundene ist. So vor allem die Kiefer ( $P$. sylvestris) mit ihren zackigen Verdickungen der Markstrahlzellen; ferner die Arve ( $P$. Cembra), deren Zellen "Eiporen" besitzen; entlich Lbies Pichtu durch den Mangel der Harzgänge. Es bleiben nur die zwei Gattungen mit ihren Formen:

1) Larix mit den sibirischen Formen sibirica und deherica und der amerikanischen microcurpu.

2) Pica, in ihrer europäischen ( $P$. excels( $)$, sibirischen (obovata) und amerikanischen Gestalt $(P$. alba).

Nach meinen Erfahrungen (a. a. O., S. 178) ist es nun nicht möglich ${ }^{1}$, dem Ilolzban nach diese Arten oder anch nur die Gattun-

${ }^{1}$ Es ist vielleicht nicht überflüssig hier ausdrücklich noch einmal darauf aufmerksam zu machen, dass ich bei der. Bestimmung der Hölzer, sowie jetzt unsere 
gen Picea und Larix 'roneinander zu unterscheiden; und es stünde sehr misslich um die weitere Bestimmung, wem nicht noch andere Handhahen dafür da wïren. Diese bieten sich aber eimmal in dem Vorhandensein von Rinden, die sehr fragmentarisch an einzehen Stiicken :msitzen, andererseits in der eigenthümlichen Farbe des Holmes.

Es ist ein sehr gliicklicher '/ufall, diss an einem Stiick - es ist eine Wurel, Nr. 8 bezeichnet - einige diunne und wohlerhaltene Rindenschuppen aufsitzen. Nachdem an diesen charakteristische und beweisende Structur gefunden worden, suchte ich eindringlicher nach Rindenspuren an den Hölzer'n und kam auf den Gedanken, mehrere Exemplare, die eingewachsene Aeste hatten, zu spalten, um etwa mit eingewachsene Rindenfragmente zu erreichen. In der That fanden sich so drei Stiicke ( $\mathrm{X}, \Lambda_{2}$ und 7 ), an deren eingewachsenen Aesten morsche oder verharzte Rindenfragmente zu finden waren, die noch hinreichende Structur zeigten.

Um kurz zu sein gebe ich hier eine T'abelle, welche charakteristische Eigenschaften der Rinden hier in Betracht kommender Bäume enthält, nach den Untersuchungen von Schacht (Baum, 2. Auf., S. 358), ron Mohl (Botanische Zeitung, 18555, S. 891) und meinen eigenen Ergänzungen, wobei ich bemerke, dass es sich um mehrjährige Rinden handelt.

I. Bastschicht mit dickwandigen Prosenchymzellen, die einzeln nebeneinander in concentrischen Reihen liegen:

Cupressineen, Tuxus.

II. Bastschicht ohne dickwandige Elemente:

Pinusarten: sylvestris, Combra, Strobus, nigricans, auch Picea alba?

III. Bastsehicht mit dickwandigen Prosenchym- oder Parenchymzellen.

a) Die dickwandigen Zellen prosenchymatisch einzeln: Larix.

Kenntnisse liegen, jede Charakteristik durch Merkmale relativen Werths für unthunlich halte, mul nur absolute Merkmale (An-oder Abwesenheit eines Elementes, Bau desselben) benutze. Aus diesen Grunde lasse ich atuch die Zellenmessungen, die Agardh in seiner Abhandlung über spitzbergische I'reibhölzer bei der Bestimmung der IIölzer in den Vordergrund gestellt hat, ganz ausser Spiel, nicht als ob ich den grüudlichen Untersuchungen 11. von Mohl's misstraute, sondern weil ich der Ansicht bin, dass derlei Messungen erst dann brauchbar wiren, wenn wir von zahlreichen Coniferen und ihren einzelnen Organen so genaue Zellmessungen hätten, als sic von Mohl von wenigen geliefert hat. 
b) Dickwandige Zellen in Gruppen, veriistelt und mregelmässig gestaltet:

Abies pectinata, Pichta.

c) dickwandige Kellen in Gruppen, aber parenchymatisch, mehr oder weniger cubisch, Steinzellen ähnlich:

Piece excelsa.

Man sieht aus dieser Tabelle, dass sich glicklicherweise die beiden für uns übrigen Gattungen, die im Holzbatu iibereinkommen, gerarle in der Rinde auffallend charakterisiren.

Die vorhandenen Rinden zeigten alle iibereinstimmend in dem sonst bramen und dünnwandigen Gewebe rerstrente, lange, an beiden Enden spitze, dickwandige Prosenchymzellen, ganz von dem Anssehen der Bastfasern, wie sie für die Lärchenrinde charakteristisch sind.

Daraus folgt mit voller Sicherheit, dass die vier rindentragenden Stïcke Lärchenhölzer sind.

Nun bietet sich ein weiterer Anhaltspunkt, mit diesen vier durch ihre Rinde ganz sicher als Lärchen bestimmten Hölzern noch weitere elf Stück zu identificiren, die ausser im Holzbau besonders noch in der Farbe und dem ganzen äussern Ansehen völlig ïbereinstimmen.

Es ist schon oben daranf hingewiesen worden, dass die Mehrzahl der Hölzer eine eigenthimliche leder-, oft fast ockergelbe Farbe besitzt, und bewiesen worden, dass diese Farbe Naturfarbe sei. Die drei Stöcke, aus deren Imnern Rindenfragmente herausgespalten wurden, gehören dazu und sind ron elf weitern werler der Farbe, noch der 'Textur, der Jahringbildung, iiberhaupt dem ganzen Aeussern nach zu unterscheiden. Diese Uebereinstimmung erlaubt nicht nur, sie verlangt sogar, dass wir diese iibrigen Stïcke ebenfalls für Lärchenhölzer erklärèn.

Eine Stütze erhält diese Identificirung durch Erfahrungen ïher die Farbe der ausserdem in Betracht kommenden Hölzer. Es ist mir nicht bekannt, dass die ausser Larix in Betracht kommenden oben genamnten Picearten je brames oder braungelbes Holz hätten; dagegen zeigte ein Lärchenstämmchen (es ist das oben bei den Jahrringmessungen angeführte), das frisch zu untersuchen ich Gelegenheit hatte, im Stamme das Keruholz genau von dexselben braungelben Farbe, wie sie die 'l'reibhölzer zeigten; sie war selbstverständlich intensiver, aber derselben Nuance. Es war mir leicke nicht möglich. ïber die Färbung der Lärchenhölzer reichere Erfahrungen zu sammeln, da der baum bei uns nicht einheimisch ist; gewiss ist, dass das mentersuchte Exemplar völlig gesundes Holz hatte. 
Zweifle ich demnach nicht einen Augenblick, dass die branngefärbten Hölzer als Lü̈rchenhölzer anzusprechen sind, so wïre es andererseits unrichtig, die oben erwähnten fünf weissen Hölzer als Lärchenhölzer abzuweisen. Ls ist gewiss, dass unter bestimmten Verhïltuissen das Holz der Lärche weiss erscheint, ebenso gut als es eine rothe Farbe annehmen kann (in den bairischen Alpen, vgl. Sendtner, Vegetationsverhältnisse Südbaierns, 1854, S. 555). Ein mir vorliegendes Stämmehen, das in der Nähe von Würzburg gewachsen ist, zeigte sich ebenfalls weisslich, wie auch das Stiick Wurzel (Nr. 8), an dem Rinde äusserlich haftend gefunden wurde. Dies zeigt, dass wenigstens auf die Farbe hin diese Hölzer nicht als Lärchenhölzer zuriickzuweisen sind. Freilich machen dieselben auch im übrigen (besonders das rerbrannte Stiick Nr. A. 3) ihrem ganzen Aenssern nach einen etwas andern Eindruck als die Lärehenhölzer, sodass es mir zweifelhaft bleibt, ob man dieselben dazu rechnen darf. In diesem Falle könnte man num an Piceu (excelsu, obovata, alba) denken. Von diesen dreien könnten mit einigem Rechte nur die beiden ersten in Anspruch genommen werden, da, wie wir später sehen werden, eins der mitgebrachten Rindenstiicke einen Bau hat, der mit dem von P'icer excelsa (und obovata?) nicht aber nit dem von Picea alba iibereinstimnt.

Es bleibt noch ïbrig der röthlichen Wurzelstöcke zu gedenken. Sie weichen von den ïbrigen Iölzern nur insoweit im Bau des Holzes al), als Wurzel- und Stammholz differiren. Stammen sie aus jenen nördlichen Gegenden, so kömnen sie nur von Picen oder Lavix sein.' Da es mir nicht gegliickt ist, lindenfragmente an ihnen zu entrlecken, so bleibt nur übrig sich an die eigenthümliche Farbe des Ilolzes zu halten. In dieser Beziehung ist wiederum obige frisch gefällte Lïrche sehr lehrreich gewesen. Wie nämlich das Stammkernholz mit den hraunen Hölzern in Farbe ibbereinstimmte, so zeigte das Kernholz der Wurzel eine schöne rothe Farbe, die mit der unserer in Rede stehenden Wurzelstöcke auffallend harmonirt. - Fichtenwurzehn, die ich zahlreich untersuchen konnte, zeigten mir niemals anderes als weissliches Holz. Ich glaube demnach anch diese beiden Stuicke als Lïrchenhölzer ansprechen zu dürfen. Dass die schon erwïhnte nach der Rinde sicher als Lärche bestimmte Wurzel weisses Holz besitzt,

1 Ich will ausdriticklich darauf hinweisen, dass P'inus Cembra dem Bau der Markstrahlen nach sicher ausgeschlossen ist (vgl. Gumprecht, Zeitschrift für allgemeine Lidkunde, III, 199). 
beweist nur, dass die Farbe der Lärchenwurzel wie die des Stammes Wandlungen unterworfen ist. ${ }^{1}$

Es ergibt sich demnach aus dem Vorstehenden, dass von den 22 Natelhölzern 4 mit voller Sicherheit nach Holz- und Rindenbau nur von der Lärche (Larix) stammen können, und dass diesen sich 11 andere nach Bau, Farbe und sonstigem Aussehen des Holzes zweifellos anreihen; mit grösster Wahrscheinlichkeit dürfen ferner die zwei rothen Wurzelhölzer als Lärchen betrachtet werden. Die 5 weisslichen Hölzer könmen von Larix oder Picea stammen; ich möchte sie eher zu letzterer rechnen.

So haben wir durch eine Reihe, wie ich glaube, vollberechtigter Schlüsse die Abstammung der Nadelhölzer mit voller Sicherheit festgestellt, die nach den gegebenen Anhaltspunkten möglich ist; wemn ich sage durch eine Reihe von Schlüssen, so möchte ich dabei nicht die Vorstellung hervorrufen, als ob die einzelnen Glieder, die wir zu den Schlïssen benutzten, so zusammenhängen, dass mit dem Talle rines derselhen sofort die ganze Schlussfolge alterirt wiirde. Das seheint mir gerade von hohem Werthe, dass die erbrachten 'Thatsachen der' Art sind, dass sie parallel nebeneinander her laufen und gleichmässig eine die andere bestätigt. Wenn wir beispielsweise oben aus dem Bau der Jahringe ein nordisches Klima erschliessen, eine Anzahl Nadelhölzer - als südlichere Formen - ausser $\Lambda$ cht liessen, so wiur das eine rein willkürlich gewählte Form des Beweises, wir häitten ebenso gut blos aus dem Holz- und Rindenbau die Lürche erschliessen und aus diesem Resultat das nordische Vaterland des Baumes folgern können.

Da im Laufe der Untersuchung wiederholt von Stamm- und Wurzelstöcken die Rede war, so mag hier nachträglich bemerkt werden, dass im ganzen fünf Stöeke als Wurzeh erkannt wurden; abgesehen von den mehr erwïhnten äussern Kemzeichen zeigten dieselben die weiten Zellen, doppelte 'Tüpfelreihen und den Bau der engen Jahrringe, den uns von Mohl (a. a. O.) als charakteristich kennen lehrte.

\section{Die Rinden.}

Da die mitgebrachten lindenstïcke ebenfalls von Coniferen stammen, so mögen dieselben hier anhangsweise besprochen werden, um so mehr als sie das Vorhergehende bestätigen.

1 Sendtner (a. a. O.) sagt, dass das rothe Lärchenholz besonders dauerhaft sei und der Fïulniss widerstehe. Es darf hier vielleicht daran erimert werden, dass die Isländer ein rothes Treibholz (ilır Rauda Grene) seiner Danerhaftigkeit wegen besonders schätzen. 
Ein Stïckchen ron etwa $1^{\mathrm{dm}}$ Länge und mehrern Centimeter Breite, iiber $1^{\mathrm{km}}$ dick, bot den Anblick der Coniferenborke, anch waren daran einige Hazbrocken, welche sofort entschieden. Auf dem Quer-, wie auf dem Längsschnitt zeigte sich diese atus abwechsehnd schwärzlichen und kirschrothen Gewebelagen gebildet. Die kirschrothen Lagen bestehen aus sehr regelmässig radial gereihten Korkzellen: es sind die Korkschichten; die schwarzen Lagen aus tiefbranwandigem Gewebe, in welchem dickwandige P'rosenchymzellen eingestrent sind (einzehn). Diese letztern crscheinen auf dem Querschnitt rund, mit schön geschichteten hyalinen Wïnden und sehr kleinem Lumen, anf dem Längsschnitt prosenchymatisch beiderseits spitz, seltener eimmal umegelmässig angeschwollen oder mit stumpfen Fortsätzen versehen.

Lis ist der bau der Lärchenborke.

Ein zweites einige Quadratcentimeter grosses Stïckchen, von einigen Millimeter Dicke, ist verkrümmt und macht äusserlich den Eindruck einer Wurelrinde; auf der Aussenseite erscheint es mit feinen Borkeschüppchen bedeckt, imnen fein lamellös und tiefbraun. Beim Schneiden bemerkte man härtere Partien und beim Anfenchten erschienen im bramen Gewebe tangential gestreckte weissliche harte Kellgruppen. Der Vergleich mit den Wurzelrinden bei uns vorkommender Nadelhölzer ergalb sofort äusserlich wie imerlich völlige Identitït mit der Rinde von P'icen excelsa. So gross war die Gleichheit, dass das Stiickchen, unter andere Stiicke der Fichtenwurzelrinde gemengt, kaum an andern als ansserwesentlichen Formmerkmalen hätte herausgefunden werden können. Die mikroskopische Untersuchung stellt die Identität völlig fest. Hier wie dort sind die tangential gestreckten harten Zellgruppen ans dickwandigen, unregelmässig vier- bis vieleckigen Zellen gebildet, deren Wünde sehr schön geschichtet und porös sind. Es sind die ,cubischen" Zellen, welche die Fichtenrinde charakterisiren (Schacht, Bamm, S. 355); die Zellen der Stammrinde erschienen viel weniger porös, Zellen wie Zellgruppen mehr abgerundet. Ich lasse dahingestellt, ob dies wesentlich oder zufällig ist.

\section{2) Die Laubhölzer.}

Die dahrringe der drei Hölzer, die, wie schon oben bemerkt, Laubhöber nach den Gefïsporen sein mussten, waren sehr eng und liessen ebenfalls ein nordisches Kima erwarten.

Dats stark vermulmte Holz war in seinem Umfang nicht gut erhalten; nach lichtung der besterhaltenen stelle misst es $3 t^{m m}$ liadius und sind 27 dithre zu rählen. sodass der mittlere Durchmesser des Jahrrings $1,2^{\mathrm{mm}}$ betraigt. Der weiteste Jahrring war etwas iiber $2^{\mathrm{mm}}$. 
Das zweite wohlerhaltene Rundholz hatte $30^{\mathrm{mm}}$ mittlern Radius und zeigte 40 Jahrringe; der mittlere Jahrringdurchmesser betrug also $0,75^{\mathrm{mm}}$. Der stärkste maass $1^{\mathrm{mm}}$.

Vergleichen wir diese beiden Hölzer mit bei uns gewachsenen Erlenhölzern - um solche handelt es sich. Ich benutze zum Vergleich die in den Nördlinger'schen "Holzquerschnitten" befindlichen Durchschnitte der Stämme von Almus ghutinosa, incana und viridis.

Bei Almus glutinosa ist der geringste Durchmesser $1,55^{\mathrm{mm}}$, der stïrkste über $2^{\mathrm{mm}}$.

Bei Almus incana hat der'engste Jahrring iiber $2^{\mathrm{mm}}$, der weiteste iiber $5^{\text {mm }}$ Durchmesser.

Aehnlich verhalten sich Exemplare von Almus glutinosa aus hiesiger Gegend, und von incana aus dem Würzburger botanischen Garten. An den Exemplaren von Alme viridis in Nördlinger's Holzquerschitten ist die mittlere Jahrringweite $1^{\mathrm{mm}}$, der stärkste Jahrring hat $2^{\mathrm{mm}}$.

Geht man einfach nach den gefundenen Zahlen, so wüirden unsere Erlenhölzer am ersten mit Almus viridis zu vergleichen sein, mit der die Zahlen völlig stimmen; die Dicke der Hölzer ist auch nicht der Art, dass sie eine Strauchform der Mutterpflanze ausschlössen. Vermöge ihres Heimatlandes wiese diese Pflanze nothwendig auf ein nordisches Klima, auf jenes Land hin, wo anch unsere Nadelhölzer gewachsen sind (Middendorff, IV, 1., 570 und 590). Wollte man ammehmen, dass unsere Hölzer nicht von dieser Erlenart, sondern einer andern stammen, so nöthigen uns die engen Jahrringe, auf sehr ungünstige äussere Wachsthumbedingungen zu schliessen, als die wir wieder am ehesten nordisches Kilima annehmen können. Freilich bliebe dam von den beiden andern obengenannten Erlen nur A. incana möglich, da diese, nicht aber glutinosa, ein Bewohner des hohen Nordens ist.

Auf die Jahrringe des dritten Holzes, der Pappel, kommen wir unten zurïck; auch sie sind von solcher Engheit (der weiteste 1,5mm), dass sie im hochnordischen Klima gewachsen sein kömen.

Bin ich nun anch nicht geneigt auf die Jahrringe dieser Hölzer (da ihrer zu wenige sind, um ein allgemeineres Resultat ableiten zu kömen) ein allzu grosses Gewicht zu legen, gewiss ist, dass die Lrfahrungen an den Laubhölzern dem an den Nadelhölzern nicht widersprechen, und dass nichts im Wege steht, die Laubhölzer in demselben hochnordischen Ḱlima gewachsen zu denken, in welchem die Coniferen sicher gewachsen sind. 


\section{a) Die beiclen Erlenhölzer.}

Was die beiden Hölzer sofort als zusammengehörig erwies, war einmal die Farbe des Holzes, eigenthümlich zart röthlich, freilich beim vermulmten Holze nur imnerlich deutlich sichtbar, besonders aber das dreieckige bramschwarze Mark, das für Erlen, wie allgemein bekannt (vgl.z. B. Hartig, Naturg. forstl. Culturpfl., 1851, S. 366 , oder Rossmässler, Anatomische Charakteristik der deutschen Bäume, 1847 , S. 24 und 34) charakteristisch ist. Dass die Drehung des guterhaltenen Holzes linkswendig (südwestlich — rechts im Sinne von Braun) gefunden wurde, kamn selbst der 'Thatsache gegenïber, dass liraun (l. c.) die Drehung gewöhnlich umgekehrt fand, nicht ins Gewicht fallen, da die Drehungen der Bäume überhaupt in ihrer Richtung inconstant sind, und die Diagnose des Holzes durch Ban von Holz und Rinde ïber allen $/$ wweifel feststeht.

Mikroskopischer Bau. Der Jahrring zeigt sich im Querschnitt aus einem engmaschigen, nur mässig dickwandigen Holzgewebe zusammengesetzt, das in einem Zwischenraum von 3-8 tangentialen Zellreihen von einreihigen Markstrahlen regehmässig durchzogen und von ziemlich engen und zahlreichen Gefässen durchsetzt ist. Die letztern sind im Beginn des Jahrrings etwas reichlicher vorhanden, und liegen dort in radialen Rieihen von 2-10, gewöhnlich $3-5$; gegen die Nitte nehmen dieselben an Zahl und Reihenlänge ab, liegen mehr zerstreut zu 2-5 eine lieihe bildend; an der Jahresgrenze enge, machen sie schliesslich einigen Reihen radial zusammengedrückter Prosenchymzellen P'latz. Die Gefässe sind häufig von einer gelbbraunen homogenen, gummiartig aussehenden Masse erfiillt, wie man es auch bei lebenden Erlenhölzern in Kernholz ganz gewöhnlich findet.

In engen Jahringen überwiegen die Gefässe in hohem Grade. An einzelnen Stellen, aber selten, sieht man das Holz radial markstrahlenartig ron gefässlosem Holze durchzogen (,falsche Markstrahlen. $\cdots)$.

Im Radialschnitt erscheinen die Gefässe alle einerlei Art, auf ihren Wïnden dicht mit mässig grossen 'Tüpfehn versehen (ohne Spiralfasern) und leiterförmig durchbrochen, die feimporösen Narkstrahlzellen enthalten gewöhnlich die genannten bramen Massen. Ilolzparenchym in ganzen Jahrring.

In T'angentialschnitt endlich ergibt sich zunächst, dass die Markstrahlen einreihig, d. ho in der líchtung der 'J'angente nur aus einer Reihe (sehr schmaler) \%ellen gebilelet sind; in der Richtung der Stammachse sind sie ans 25 bis zu 30 \%ellen zusammengesetzt. 
Dimch Isolin'ung der Holzelemente wurde festgestellt, dass in den äussern Jahringpartien, und nur in diesen, sogenamnte Ersatzfasern (Sanio) vorhanden sind.

Diese Merkmale erreisen das Holz auf das bestimmteste als Erlenholz. Obwol ein einfacher Vergleich unseres und wirklichen Erlenholzes sofort die Identität feststellte, will ich hiex doch die distinguirenden Merkmale hervorheben. Sie sind:

1) Das Areieckige Mark.

2) Farbe und Weichheit des Holzes.

3) Gereihte, blos getïpfelte, leiterfömig durchbrochene Gefässe. Solche kommen zwar auch bei der Birke vor; allein diese hat mehrreihige Markstrahlen u. s. w.

4) Eimreihige Markstrahlen. Pappel und Weide, ein gleiches reigend, haben rund durchbrochene Gefässe.

5) Sogenannte falsche Markstrahlen. Mit Corylus und Carpinus gemeinschaftlich, beide aber mit mehrieihigen Markstrahlen r. s. w.

6) Eine sonst bei Almus gewöhnliche Erscheinung, die sogenamnten Markfleckchen werken hier nicht gefunden.

Das anatomische liesultat des Holzes - bei beiden Hölzen gleich - wird duxch die Rinde des einen Stückes nur noch bestätigt. Sie stimmt in ihrer tiefbramen Farbe und dem Bau völlig mit Lirlenrinde, sowol was die Lagen enger zusammengepresster, mit dünnen hyalinen Wänden versehener Korkzellen, was das ïbrige diunn- und bramwandige Gewebe, als insbesondere was die ,Steinzellen"-Gruppen anlangt. Letztere finden sich gewöhnlich als Fortsetzungen der , falschen Markstrahlen" des Holzes in markstrahlartigen radialen Zügen (vgl. Schacht, Baum, 2. Aufl., S. 358).

Von welcher Alnusart stammt unser Holz?

Wenn man die Angaben in dem Schlüssel zur Untersuchung der Holzarten in Nördlinger"s Holzquerschnitten vergheicht, sollte man meinen, die in Betracht kommenden Erlenarten seien anatomisch nicht schwer zu unterscheiden. Ich muss aber gestehen, dass meine Erfahrungen mir nicht erlauben, die von dem verdienstvollen Herausgeber der Holzquerschnitte angefuhrten Unterschiede der A. incana, glutimosa, viridis u. s. w. für constante und wirkliche zu halten.

Derselbe charakterisirt zunächst nach den ,falschen Markstrahlen", die bei A. incana und viridis sparsam, bei glutinosa zahlreich seien. Mag dies im allgemeinen immerhin richtig sein; dass davon Ausuahmen statthaben, beweist mir das schon erwähnte Stammstiick von $A$. incana aus dem Wiirzburger botanischen Garten, wo ich auf je einige Millimeter einen ,falschen Markstrahl" finde. Fürs zweite unter- 
scheidet er nach der Zahl der "Poren "1 in einer Gefässreihe; aber die Zahl derselben ist je nach der Weite der Jahrringe ganz inconstant, wie man sich leicht an lebendem Material überzeugen kann.

Unter diesen Umständen halte ich mich an folgende Punkte.

Die Schmalheit der Jahrringe weist uns nach dem oben angeführten auf eine nordische Heimat. Im höhern Norden kommen nur zwei Erlenarten vor: Almus vividis und incana, die erstere strauch-, die letztere baumartig (Ledebour, Flor. ross., III, 656-658; Middendorft, a. a. O., S. 570). Wenn auch die beiden Treibholzstiicke nicht ron so beträchtlicher Dicke sind, dass daraus auf eine Strauch-oder Bammatur der Mutterpflanze ein sicherer Schluss gezogen werden könnte, so scheint doch die Weisserle (Alnus incana) als die häufifigere und holzreichere Pflanze in der Wahl den Vorzug zu verdienen.

Uebrigens ist die specifische Bestimmung des Holzes viel weniger wichtig als das Resultat, das aus den Jahrringen (vgl. oben) auf jeden Fall hervorgeht: die mögliche Abstammung aus dem hohen Norden.

b) Das Salicineenholz.

Unter diesem Titel soll zuletzt ïber das schon oben beriihrte kleine Stïck weissen und leichten Holzes berichtet werden, das, 1:) Jahrringe ron $1^{\mathrm{mm}}$ mittlern Durchmessers, einen (grössten) ron nicht ganz $1,5^{\mathrm{mm}}$ hat. Ls besitzt ein Mark von $3^{\mathrm{mm}}$ Durchmesser, und rostbrauner Farbe, wie denn auch das IIolz in der Markumgebung ähnlich gefirirbt ist.

Die mikroskopische Untersuchung zeigt die Jahrringe aus engmaschigem gleichartigen IIolzgewebe zusammengesetzt, das sehr häufig von femen Markstrahlen durchsetzt ist. Die Holzzellen sind von mässiger Wanddicke und zwischen denselben auffallend gleichmässig, enge Gefüsse, cinzeln, selten zu 2-3, eingestrent; am Anfing des Jahrpinges lassen sich kaum zahlreichere Gefässe unterscheiden; der Jahresschluss wird durch wenige Reihen radial zusammengedriickter Zellen sembilatet.

In Radialschnitt erscheinen die Gefässwïnde mit schönen grossen polygonalen 'Tïpfeh bedeckt, und ron runden Gefässöfthnungen durch-

1 Lis muss hier daranf hingewiesen werden, dass die Begrifte "Pore" (Nördlinger) mud "Gefässöffnumg" sich durchaus nicht decken, dass die Zahl der mit dem blossen Ange ouler der Lupe an den Nördlinger'schen Ilolzquerschnitten sichtbaren Poren nicht identisch ist mit der Zahl der Gefïsse selbst, weil häufig die kleinen an den Enden der Reihe liegenden Gefässe, wie manche in der Reihe liegende (radial) selr schmale Gefässe nur mikroskopisch sichtbar sind. 
bohrt. Die Markstrahlen bieten nichts Auffallendes; sie sind im Tangentialschnitt eimeihig und aus sehr schmalen, zahlreich übereinander gesetzten Zellen gebildet.

Die weitere Untersuchung (vgl. Sanio, Botanische Zeitung, 1863, S. 405) ergab, dass das Holz mit Salix und Populus iibereinkommt.

Ich kenne keine Merkmale, durch die ich das $\mathrm{Holz}$ der beiden genannten Gattumgen voneinander scheiden könnte; auch das Mik bot keine Anhaltspunkte dazu. Die Anordnung der Gefässe, die ron Nördlinger betont wird, konnte ich nicht distinguirend finden.

Die Jahringe der untersuchten Pappeln und Weiden (der zahlreichen in Nördlinger's Holzquerschnitten vorhandenen) waren alle sehr weit (im Mittel 5-7mm; einzelne erreichten 15 $\mathrm{mm}$ ); nur Populus tremula und angulata hatten engere. Ich wage aber auf die Engringigkeit hier kein höheres Gewicht zu legen, da bei der Diumhheit des Holzes schwer zu sagen ist, ob man es mit klimatischer Verengerung der Jahrringe zu thun hat, oder mit einer, die von der Natur des Organs (Aeste) abhängt.

Dürfte man amnehmen, dass unsere engen Jahrringe Folge klimatischer Bedingungen, also hoher geographischer Breite seien, so diirfte darin wohl ein WVink liegen, unser Holz für das Holz der Espe (Populus tremula) zu halten, die mit Coniferen vergesellschaftet in den Wäldern Nordsibiriens sehr gewöhnlich ist (Middendorft, a. a. O., S. 572 fg.; 590 ).

\section{Das Mntterland unserer Iölzer.}

Ein Rückblick auf die erhaltenen systematischen Resultate zeigt uns, dass von den 25 Hölzern weitaus die grösste Mehrzahl, 17, von der Lärche $(\operatorname{Larix}), 5$ weitere wenn nicht von dieser nur vou Picea stammen. Ton 3 Laubhölzern gehören 2 der Erle (Aturs) an, und cin jedenfalls der Salicineenfamilie angehöriges bleibt als Weidenoder Pappelholz zweifelhaft.

Es hätte nicht leicht ein Resultat geben können, das mumeidentiger auf den Wohnort der Mutterpflanzen unserer Hölzer hinweisen komnte. Denn mag man die Gesammtheit der gefundenen Pflanzen oder das Vorwiegen eines Nadelbaumes zunächst näher ins Auge fassen: die 'Treibhölzer geben in ganz überraschender Weise das Bild nordischer Wälder wieder, wie sie die Grenze des Waldgebietes auf der nördlichen Halbkugel, sei es im alten oder neuen Continent, den Waldsaum des Polarlandes von Lappland durch liussland, Sibirien und Kamtschatka, durch ganz Nordamerika bis Neufundland darstellen. 
Ceberall bildet den Hauptbestandtheil dieser äussersten Bamposten gegen Norden das Nadelholz, und ihm mischen sich mehr oder weniger von Laubhölzern die Pappel, Erle und Birke zu. So stützt das systematische Resultat in sprechendster Weise den Schluss, den wir bereits früher aus den Jahrringen gezogen haben.

Freilich entsteht nun, da dieser nordische Waldgürtel ein weit ausgedehnter, circumpolarer ist, die Frage, welches das engere Vaterland unserer Hölzer sei, der Norden Europas, Asiens oder Amerikas.

Diese besonders wichtige Frage zu entscheiden befähigt uns der specifische Charakter der nördlichen Baumfloren der rerschiedenen Erdtheile.

Denn so sehr auch die Waldvegetation dieses Gebietes in ihrer allgemeinen Zusammensetzung übereinkomnt, ebenso sehr sind doch die eimzelnen Abschnitte desselben durch die Art des vorwaltenden Nadelholzes charakterisirt und scharf von einander zu unterscheiden.

Während im europäischen Lappland die Kiefer und daneben die Fichte der naassgebende Baum ist (Schübeler, a. a. 0.; Wahlenberg, Flora lapponica, p. 255), bildet rom Weissen Neere bis nach Kamtschatka, besonders aber durch ganz Nordsibirien die Lärche den charakteristischen Baumrepräsentanten (Ledebour, Flor. ross., III, 672; Middendorff, Reise IV, 1., 582-592), während jenseits der Beringsstrasse durch das ganze nordische Amerika bis Neufundland die Oregontanne (P'icea alba) dominirt, die Lürche aber ganz zurücktritt.

Man sieht, wie zweifellos die Zusammensetzung der Treibhölzer auf das Waldgebiet des asiatischen Nordens hinweist. Wenn ein Kundiger die Holzflora Sibiriens hätte repräsentiren wollen, so hätte er die Bäume nicht richtiger zusammenstellen können, als hier ein scheinbarer Zufall ihre Hölzer als Treibproducte zusammengeschwemmt hat.

In der That, wer die lebensvollen Schilderungen Middendorff's (Reise, IV, 425-684) der sibirischen Wïlder, ihres Lebens und Wachsthums liest, wird auf jeder Seite unverkennbar unsere Hölzer geschildert sehen, und sich der Ueberzeugung nicht entziehen, dass es sich hier nur um sibirische Hölzer handeln könne.

Findet sich nun auch freilich diesseit des Ural von diesem bis zum Weissen Meere die gleiche Flora wie in Nordasien, so fällt doch dies kleine europäische Gebiet kaum in Betracht gegen das weite Gebiet jenseit des Ural, ron diesem Gebirge bis nach Kamtschatka, in welchem wie in keinem andern Lande die Chancen für Treibholzbildung gïnstig realisirt sind:

Zahlreiche gewaltige Ströme, die das ursprüngliche Waldgebiet 
des Landes viele hundert Neilen weit durchziehen; welche regehmässig im Jahre das Land in kolossalen Leberschwemmungen unter Wasser setzen (Middendorff, a. a. O., S. 241); deren Bette, pflanzenbebautes Land zerstörend, in merkwürdigen Wanderungen begriffen ist und die schliesslich alle in jenes arktische Becken münden, für welches das Treibholzphänomen ein so charakteristisches ist.

Kein Wunder, wenn in diesem Lande an den Flüssen und baumlosen Nordküsten nicht nur jetzt ungeheuere Massen Stïmme, Wurzeln, Aeste und Holz aller Art, das die Flïsse ans dem tiefen Innern des Landes und seinem Waldgebiete fortgeschleppt haben, gefunden wird, sondern auch im sogenamnten Noahholz (bramkohlenartig gewordenes, weit vom südlichern Stammort, im Taimyrland begrabenes Lärchenholz) ein Zeugniss aufbewahrt ist, dass in jenen Lïndern seit Jahrtausenden der Process der Treibholzbildung besteht. ${ }^{1}$

Ist Nordasien und Sibirien das Mutterland unserer Hölzer, so dïrften sich auch die Baumarten, von denen sie stammen, von selbst ergeben, unsere Lärche wird ohne Zweifel Larix sibirica Ledeb. sein, das von Picea abgeleitete Holz kann nur auf Picea obovatu Ledeb. sich beziehen, die Erlen stammen von Alnus incana L., das Salicineenholz von der in Sibirien so gemeinen ${ }^{2}$ Espe, Populus tremula L.

Man wird wol nicht einwenden wollen, dass die ganze Zusammensetzung der Hölzer nur ein Spiel des Zufalls sei; man könnte das zugeben und den Zufall um so mehr preisen, dass er uns so schöne Daten an die Hand gegeben. Allein ich kann nicht glauben, dass die Sache so zufällig sei, da ja anch Agardh aus Spitzbergen lanter Coniferen erhielt, und darunter eben die Lärche bestimmte; von den übereinstimmenden Angaben der Polarfahrer in dieser Hinsicht ganz zu schweigen.

So stammen denn die grönländischen Treibhölzer zweifellos aus den Waldgebieten Sibiriens, die auch Agardh als das Mutterland der spitzbergischen erkannt hat.

Diese Thatsache bietet eine feste Handhabe für die von Grisehach jüngst so klar ausgeführte Hypothese, dass Grönland sich ron Sibirien aus mit Pflanzen bevölkert habe, dass von letzterm Lande aus eine Wanderung ging, die der Reihe nach Nowaja-Semlja, Spitzbergen, Grönland und Island mit Pflanzen versehen habe. ${ }^{3}$

1 Vgl. Middendorfi, a. a. O., S. 251-256, 262 Anm., 265-267.

${ }^{2}$ Vgl. Middendorff, a. a. O., S. 256. - Vgl. auch bei Irminger, a. a. 0., S. 189 eine Angabe Wrangell's.

${ }^{3}$ Vegetation der Erde von A. Grisebach (1871), I, 61-69. 
Unsere Untersuchung wirft ein bestätigendes Licht auf die ron deutschen Geographen rertretene Ansicht, dass das arktische Treibholz überhaupt ein nordisches und ein Product des Polarstroms sei.'

Die Thatsache der nordischen Abstammung kann nicht erschüttert werden durch Beobachtungen über das vereinzelte Vorkommen tropischer Samen oder Früchte, wie sie z. B. jüngst von den Schreden² gemacht rurden, Vorkommnisse, die nicht in Betracht kommen gegen die gerraltigen Massen des Holzes, die aber selbstverständlich sind für Jeden, der weiss, dass der Golfstrom in jene Regionen seine letzten schwachen Ausläufer sendet.

1 Petermann, Das Treibliolz im Eismeer, in dessen Geographischen Mittheilungen (1870), XVI, 230-232.

2 Petermann, Geographische Hittheilungen, a. a. O., und Ergänzungsband IV. 
8.

\title{
Einige Bemerkungen über Alter und Wachsthums- verhältnisse ostgrönländischer Iolzgewächse.
}

\author{
Von \\ Gregor Kraus. \\ in Erlaugen.
}

Während äber die Lebensdauer und die Wachsthumsverhältnisse des Holzkörpers nordischer Bäume an ihrer P'olargrenze werthvolle Untersuchungen ${ }^{1}$ vorliegen, Untersuchungen, die uns im Vorhergehenden bei der Bestimmung des Vaterlandes der Treibhölzer sehr förderlich waren, scheint iiber die Lebensdauer und die Jahrringbildung der wenigen strauchigen Holzgewächse, die in dor arktischen Zone selbst ihr kïmmerliches Dasein fristen, so gut wie nichts bekannt zu sein. Wenigstens wird bei der Beschreibung der Pflanzen des sibirischen Hochnordens (Middendorff, a. a. O., I, 2) in dem gleichlautenden Kapitel (S. 108) die Frage weder erörtert, noch einer Bearbeitung derselben Erwähnung gethan; alles, was mir sonst in dieser Beziehung bekannt geworden², besteht in einer kleinen Notiz in Petermann's Geographischen Mittheilungen, XV, 110-111, aus Rob. Brown's Florula discoana. Dort ist bei Besprechung des Brennmaterials der Westgrönländer, offenbar als eines liesenexemplars, einer

1 Von Middendorff, in dessen Reise u. s. w., IV, 630-610.

2 Dieser Mangel an Augaben über das Alter nordischer Strauchpthanzen kamn nicht wundernehmen, wenn man sieht, dass über das Alter der Sträucher überhaupt in der Literatur nichts zu finden ist. Nan sieht sich in den ältern und netern allgemein-morphologischen und physiologischen Werken von Meyen, Treviranus, Decandolle, Sénébier, Schleiden, Schacht u. s. w. beim Kapitel "Lebensdance" umsonst nach Daten über Strüucher u. s. w. um; nur in Humboldt's , Ansichten ${ }^{\text {c6 }}$ (II, 101-108) ist z. 13. der bekannte Hildesheimer Rosenstranch erwälnt. 
Zwergbirke gedacht, die (unter $72^{\circ} 48^{\prime}$ gewachsen) 2 Zoll Stammdurchmesser hatte.

Und doch wäre die Frage nach dem Alter hochnordischer Holzgewächse von besonderm Interesse, indem man sich darüber von vornherein zwei ganz entgegengesetzte Ansichten bilden könnte. Man könnte fürs erste geneigt sein zu glauben, dass die Pflanzen in jenen Gegenden, wo sie so zahlreichen Unbilden ausgesetzt sind, nur eine sehr geringe Lebensdauer haben, und einen Beweis in der Kleinheit und sehr geringen Missonentwickelung derselben finden wollen. Andererseits möchte man. den Kampf ums Dasein in Rechnung ziehend, der Ansicht sein, dass die Natur in jenen Gegenden, wo der Bliten- und Fruchtbildung und damit der Vermehrung der Individuen oft grosse Schwierigkeiten im Wege stehen, auf die Erhaltung des Einzelwesens besondere Sorgfalt verwende und demselben eine möglichst lange Lebensdauer sichere. Die letztere Ansicht, der erstern mehr populären entgegenstehend, schien mir wissenschaftlich wahrscheinlicher. Nach ihr deuten die Eingangs erwähnten Beobachtungen Middendorff's hin, der an der sibirischen Bamgrenze durch die, scheimbar jungendliche Physiognomie des Waldes" iiberrascht wurde, bei näherer Untersuchung aber fand, dass er es mit ,verkümmerten Greisen" zu thun hatte.

Die Kleinheit der Exemplare, die Dünnheit der Stämme der Polarsträucher wäre dann nur Folge eines ausserordentlich geringen jährlichen Längen- und Dickenzuwachses, und die scheinbar jugendlichen-Individuen könnten uralte krüppelhafte Greise sein.

Die Untersuchung ïber diese interessante Frage war durch ein reiches Strauchmaterial ermöglicht, das auf der Expedition an verschiedenen Orten gesammelt worden war. Es standen mir zur Verfïgung:

10 Weiden (Salix aretica Pall.) von der Sabine-Insel,

5 Birken (Betula nana L.) rom Kaiser-Franz-Josephs-Fjord,

2 Heidelbeeren (Taccinium uliginosum L.),

cin Rasen alter Exemplare von Dryas octopetala L.

und ein starkes Exemplar von Empetrum nigrum L., an dem leider Jahrringbildung nicht sicher zu unterscheiden war.

Ich setzte mir zur Aufgabe, an diesen Exemplaren die mittlere Jahrringweite und das Alter der Pflanzen zu studiren. Zu diesem Behufe wurden die Exemplare am Wurzelhalse durchschnitten und auf dem geglätteten Querschnitt der IIalbmesser des Stammes und die Zahl seiner Jalnringe ermittelt; letatere mussten, da sie makroskopisch niemals deutlich waren, mikroskopisch abgezählt werden. Dil das Wachsthum fast immer excentrisch ist, so wurde öfter der grösste 
8. Bemerk. über Alter u. Wachsthumsverhältnisse ostgrönland. Holzgewächse. 135

und kleinste, sonst der mittlere Stammhalbmesser ermittelt. Nach Richtung des grössten und kleinsten Halbmessers ist die Anzahl der Jahrringe nicht gleich.

Die gefundenen Masse und Zahlen sind in folgender Tabelle zusammengestellt. Die Maasse bedeuten Millimeter; die eingeklammerten Zahlen geben neben dem grössten Halbmesser den kleinsten an; in der Columne, ,Alter" die Anzahl der gefundenen Jahrringe nach der einen oder andern Richtung. In den ,Bemerkungen“" wurde das Nöthige ïber die allgemeinen Wachsthumsverhältuisse hinzugefügt.

1) Salix aretica Pall.

Auf der Sabine-Insel gesammelt.

\begin{tabular}{|c|c|c|c|c|}
\hline Nr. & Alter. & $\begin{array}{l}\text { Stamm- } \\
\text { halb- } \\
\text { messer. }\end{array}$ & $\begin{array}{l}\text { Jahrring- } \\
\text { weite. }\end{array}$ & Bemerkungen. \\
\hline 1 & 3.1251 & ば(6) & $(1,5 \quad(0,2)$ & $\begin{array}{l}\text { Kräftiges, ubor } 1 \text { Meter langes, mit mel- } \\
\text { rern daumendicken Aesten versehenes } \\
\text { Exemplar; stärkster Jahrring } 1,5^{\text {min }} \\
\text { stark. }\end{array}$ \\
\hline 2 & $36(29)$ & $8,5(6)$ & $0,24(0,21)$ & $\begin{array}{l}0,5 \text { Meter lang mit mehrern daumdicken } \\
\text { Aesten. }\end{array}$ \\
\hline 3 & 42 & 8,5 & 0,2 & $\begin{array}{l}\text { Oberirdischer mehrfach verästelter Stamm } \\
2^{\text {dum lang, daumendick; Wurzel gut ent- }} \\
\text { wickelt. }\end{array}$ \\
\hline 4 & 35 & $27(5)$ & 0,7 & $\begin{array}{l}\text { Ueber Meter lang mit nehrern federkiel- } \\
\text { dicken Aesten. }\end{array}$ \\
\hline 5 & 26 & 2,5 & 0,09 & $\begin{array}{l}\text { Stamm kaum } 1^{\text {dm }} \text { lang, mit mehrern } \\
\text { Aesten; schwache Wurzel. }\end{array}$ \\
\hline 6 & 24 & 4 & 0,13 & Ein Gleiches. \\
\hline 7 & ca. 100 & 16 & 0,16 & $3^{\text {tm }}$ langer Krüppel mit wenig Aesten. \\
\hline 8 & 91 & 17 & 0,18 & $\begin{array}{l}\text { Alter Krüppel mit melrem daumdicken } \\
\text { Aesten von } 2^{\text {du Iange. }}\end{array}$ \\
\hline 9 & ca. 130 & 31 & 0,24 & 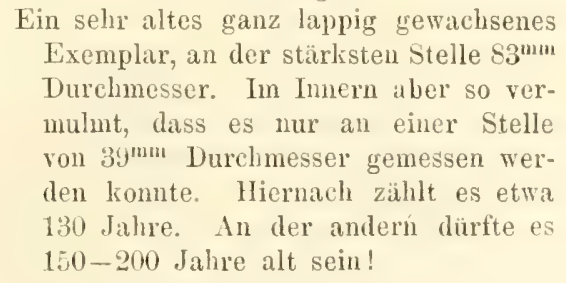 \\
\hline 10 & 62 & 20 & 0,32 & $\begin{array}{l}\text { Starke excentrisch gewachsene Wurzel, } \\
\text { in Richtung des grössten IIalbmessers } \\
\text { gremessen. }\end{array}$ \\
\hline
\end{tabular}




\section{2) Betula nana L.}

Unter $73 \%$ + $^{\circ}$ nödl. Br. gewachsen.

\begin{tabular}{|c|c|c|c|c|}
\hline Nr. & Alter. & $\begin{array}{l}\text { Stamm- } \\
\text { halb- } \\
\text { messer. }\end{array}$ & $\begin{array}{l}\text { Jahrring- } \\
\text { weite. }\end{array}$ & Bemerkungen. \\
\hline 1 & 40 & 4 & 0,1 & $\begin{array}{l}\text { Excentrisch gewachsenes, federkieldickes } \\
\text { Exemplar, etwa } 1^{\text {dm }} \text { langes, reich ver- } \\
\text { zweigtes Stämmchen mit entsprechen- } \\
\text { dem Wurzelwerk. Grösster Halbmesser } \\
\text { 4, kleinster } 3^{\text {mm. }}\end{array}$ \\
\hline 2 & 80 & 6,0 & 0,07 & Sehr regelmüssig gewachsenes Exemplar. \\
\hline 3 & 53 & 12 & 0,23 & Schöner vollrunder Stamm. \\
\hline 4 & 67 & 8,5 & 0,13 & Stammdurchmesser $12^{\mathrm{mm}}$. \\
\hline 5 & 62 & 9,0 & 0,14 & Wurzel. \\
\hline 6 & 10 & 16,0 & 1,6 & $\begin{array}{l}\text { Aus dem Würzburger botanischen Garten } \\
\text { stammendes Exemplar. }\end{array}$ \\
\hline
\end{tabular}

3) Vaccinium uliginosum L.

Vom Kaiser-Franz-Josephs-Fjord, 73 $\frac{1}{2}{ }^{\circ}$ nördl. Br.

\begin{tabular}{|c|c|c|c|c|}
\hline $\mathrm{Nr}$. & Alter. & $\begin{array}{l}\text { Stamm- } \\
\text { halb- } \\
\text { messer. }\end{array}$ & $\begin{array}{l}\text { Jahrring- } \\
\text { weite. }\end{array}$ & Bemerkungen. \\
\hline 1 & 93 & 3,0 & 0,032 & $\begin{array}{l}\text { Federkieldick. Durchmesser } 6,0^{\mathrm{mm}} \text {, klein- } \\
\text { ster Halbmesser } 2,5 \text {, grösster } 3,5^{\mathrm{mm}} \text {. }\end{array}$ \\
\hline 2 & 85 & 3,0 & 9,035 & Durchmesser $5^{\mathrm{mum}}$ \\
\hline 3 & 11 & 8,0 & 0,7 & Aus den Erlanger botanischen Garten. \\
\hline
\end{tabular}

4) Dryas octopetala L.

Von der Sabine-Insel, $74 \% 2^{\circ}$ nördl. Br.

\begin{tabular}{|c|c|c|c|c|}
\hline Nir. & Alter. & $\begin{array}{l}\text { Stamm- } \\
\text { halb- } \\
\text { messer. }\end{array}$ & $\begin{array}{l}\text { Jahrring- } \\
\text { weite. }\end{array}$ & Bemerkungen. \\
\hline 1 & $2 ;$ & 2,0 & 0,08 & $\begin{array}{l}\text { Starkes Stämmclicn; IIolz } 3^{m m} \text { Durel }- \\
\text { messer. Stärster Ilalbmesser } 2,0^{m m} \text {. }\end{array}$ \\
\hline
\end{tabular}

Aus der vorstehenden Liste ergeben sich folgende Schlïsse:

1) Die grönländischen Holzgewïchse erreichen ein sehr beträchtliches Alter. Die ïlteste /wwergbirke ist 80 , die älteste arktische 
8. Bemerk. über Alter u. Wachsthumsverhältuisse ostgrönländ. Holzgewächsc. 137 Weide wohl ïber 150 Jahre alt. Es ist kein Girund rouhanden anzunehmen, dass es nicht noch ältere Exemplare gebe. - Nan sicht daraus, dass sich diese Stranchgewächse im Alter ganz wohl messen können mit ihren baumartigen Verwandten unserer Klimate. - Auffallend hochbejahrt ist die Sumpfheidelbeere, sie kam wol über 100 Jahre erreichen.

2) Das jährliche Dickenwachsthum (die Jahrringweite) ist ein ausserordentlich geringes. Der stärkste ïberhaupt gefundene Jahrring betrug $1,5^{\mathrm{mm}}$. Der mittlere Zuwachs der Weide ist einige Zehntel Millimeter; der der Zwergbirke noch weniger; bei der Heidelbeere wird sehr gewöhnlich in den spätern Jahrzehnten der ganze Jahrring (radial) nur aus einem Gefäss und einer Holzzelle zusammengesetzt. Die Folge des sehr geringen Dickenwachsthums ist, dass ganz schmächtige, jugendlich aussehende Stämmchen in der That hochbejahrt sind. Aus den angeführten in unserm Klima gewachsenen Exemplaren sieht man, dass dies geringe Dickenwachsthum nicht innern Ursachen, sondern dem Klima zuzuschreiben ist. Deshalb ist auch das Holz, ähnlich wie bei Laubhölzem, die in unserm Klima aus äussern Ursachen engringig gewachsen sind, ansserordentlich weich. 

II.

Z0OLOGIE. 



\section{Vorbemerkung.}

Während fast alle Gebiete der arktischen Zone in Bezug auf Zoologie als mehr oder minder vollständig bekannt gelten durften, liess sich dies hinsichtlich der Ostlküste Grönlands keineswegs behaupten. Der zweiten Deutschen Polarexpedition blieb die ehrenvolle und dankbare Aufgabe rorbehalten, uns in diese hochinteressanten Strecken einzuführen und dadurch eine wesentliche Lücke unserer Kemntniss der arktischen Fauma auszufüllen. Wenn auch weniger orwartet werden durfte, dass die Forschungen durch zahlreiche Novitäten belolnt werden wïrden, so konnte man doch mit Gewissheit eine Bereicherung bezüglich der weit wichtigern und interessantern Verbreitungsverhältnisse der polaren Thierwelt voraussetzen. Und diese Voranssetzungen wurden nicht getäuscht, nachdem, Dank der umsichtigen und verständigen Führung Kapitän Kolderwey's, das Expeditionsschiff Germania glücklich das Ziel, die Ostkuiste Grönlands, erreicht hatte und dadurch in grösstentheils neue, undurchforschte Gebiete eindrang. Was in denselben für Zoologie geleistet wurde, ist zunächst dem Eifer und Fleisse des unermiddlichen Dr. Pansch zu verdanken, dessen Streben von seinen Gefährten, ganz besonders durch Dr. Copeland und Obersteuermamn Sengstake, soweit als thunlich Förderung fand.

Der höchst beklagenswerthe Zufall, dass Dr. Pansch gleich bei der Ankunft (am 5. August 1869) durch einen Schuss in seinen rechten Arm für Wochen der Thätigkeit entrissen wurde, musste auf den Fortgang der Sammlungen selbstrerständlich nachtheilig wirken, aber bereits Mitte October sehen wir den wackern Forscher, den Arm noch in der Binde tragend, auf neuen Excursionen. Die beste Zeit des Jahres 1869 war indess leider verloren und auch das folgende gestaltete sich für Sammelzwecke weniger günstig, namentlich weil die 
Vorarbeiten zu den grossen Schlittenreisen viel Zeit erforderten, und weil die Germania selbst grossentheils anf weitern Entdeckungsreisen unterwegs war.

Welch trauriges Loos die Hansa und mit ihr den wissenschaftlichen Begleiter Dr. Buchholz traf, ist genugsam bekannt. Der eifrige und kemntnissreiche Zoologe konnte beim Lntergange des Schiffes eben nur seine zoologischen Tagebücher retten.

Trotz diesen unvorhergesehenen höchst bedauerlichen Ereignissen, durch welche ganz besonders die Zoologie den empfindlichsten $\mathrm{Ab}$ hruch erlitt, hat das glïcklich Heimgebrachte die Erwartungen uibertroffen: 218 Thierarten, worunter sich 15 als neu erwiesen, konnten bestimmt und somit Ostgrönland als ein zoologisch bekanntes Gebiet eingetragen werden, mit dem der Name seines kirforwchers, Dr. Pansch's, fïr immer ehrenvoll verbunden bleibt.

Nicht minder wichtig gestalteten sich in Bezug auf das mikroskopische Leben der nördlichen I'olarzone die dankenswerthen Tiefseelothungen, welche Kapitän Koldewey auf der ersten und zweiten Expedition ausführte: 240 terrestrische und oceanische Formen, darunter nicht weniger als 56 neue, wurden der Wissenschaft gësichert.

Diese Ergebnisse liessen sich selbstrerständlich erst übersehen, nachdem das gesammelte Material von Seiten der Fachgelehrten genau untersucht und bearbeitet worden war. Der Verein für die Deutsche Nordpolfahrt ertheilte mir den ehrenvollen Auftrag, diese wissenschaftlichen Bearbeitungen zu reranlassen, nachdem mir schon früher, bei Rückkehr der Expedition, vom Bremer Comité die Sorge für die zoologischen Sammlungen übertragen worden war.

Der allseitig liebenswürdigen Bereitwilligkeit der Fachgenossen, Zeit und Kräfte im Interesse des nationalen Werkes zu opfern, ist es zu danken, wenn mir die Freude zutheil wird, im Nachfolgenden eine Reihe hervorragender Gelehrter auffiihren zu können, deren Nitmen für den Werth der einzelnen Abschnitte volle Bürgschaft leisten und die dem zoologischen Theile einen ebenso ehrenvollen als wichtigen Platz sichern werden.

1) Anthropologie. Bearbeitet von Dr. A. Pansch in Kiel.

2) Säugethiere und Fische. Bearbeitet von Professor Dr. W. C. II. Peters in Berlin.

3) Bemerkungen über die Schädel der Eskimohunde. Von Dr. II. von Nathusius auf Hundisburg.

4) Vögel. Bearbeitet von Dr. Otto Finsch in Bremen; mit Noten von Dr. A. Pansch.

5) Eier. Bearbeitet von Professor Dr. Alfred Newton in Cambridge.

6) Tunicata. Bearbeitet von Professor Dr. C. Kupffer in Kiel.

7) Mollusken, Würmer, Echinodermen und Coelenteraten. Bearbeitet von Professor Dr. Karl Möbius in Kiel. 
8) Crustaceen. Bearbeitet von Professor Dr. R. Buchholz in Greifswald.

9) Arachniden. Bearbeitet von Dr. Louis Koch in Nürnberg.

10) Hymenoptern und Diptern. Bearbeitet von Dr. A. Gerstäcker iu Berlin.

11) Lepidoptern. Bearbeitet von Hauptmann Alexander von Homeyer in Schweidnitz.

12) Hydroiden und Bryozoën. Bearbeitet von Bürgermeister Dr. Kirchenpauer in Hamburg.

13) Kieselspongien. Bearbeitet ron Professor Dr. Oscar Schmidt in Gratz.

14) Kalk- und Gallertspongien. Bearbeitet von Professor Dr. E. Häckel in Jena.

15) Das unsichtbar wirkende Leben der Nordpolarzone, am Lande und in den Meeres-Tiefgründen bei 500 mal verstärkter Sehkraft, nach Materialien der Germania. Erläutert von Geheimrath Professor Dr. C. G. Ehrenberg in Berlin. Bremen, im Juni 1872.

\section{Otto Finsch.}


1.

\title{
Anthropologie.
}

\author{
Bearbcitet von
}

Adolph Pansch

in Kiel.

Unsere Hoffnungen, an der Ostkïste Grönlands noch Menschen anzutreffen, wurde, wie bekannt ist, leider nicht erfüllt. Selbst ein Besuch der Niederlassung, wo Clavering noch 1823 mit 12 Eingeborenen in Verkehr trat, zeigte uns nur verfallene und längst verlassene Wohmsitze. Da mun auch Scoresby bei seinen Landungen keinem Eingeborenen begegnete, so sind die Berichte Clarering's iiber die 12 Bewohner der Clavering-Insel das einzige Sichere, was wir über die äussere Erscheinung der Bevölkerung vom nördlichen Ostgrönlad wissen. - Es heisst hierin unter anderm:

„Die Haare waren schwarz, die Gesichter rund, die Hände und Füsse sehr fleischig und geschwollen." Ein rein gewaschenes Kind. zeigte, ein lohbraunes kupferiges Aussehen". "Ihr Gesichtsausdruck war äusserst stupid und nichtssagend, doch wurde dies wahrscheinlich durch ihr Erstaunen iiber Alles, was sie sahen, erhöht." _ _ — - ,Sie gehören offenbar zu derselben Rasse wie die Eskimos in andern Gegenden Grönlands und in den nördlichsten Theilen Amerikas." "Unser Verkehr war zu kurz, um von der Sprache etwas zu erlemen, aber die von den Kapitänen Parry und Lyons gegebenen Beschreibungen der Eingeborenen zu Iglulik passten in allen Stiicken anf unsere Freunde.6

Fïgen wir hier gleich hinzi, was Graal iiber das Aeussere der Bewohner des südlichen Grönlands sagt, so ist es Folgendes:

,'The greenlanders inhabiting the souther'n part of the West coast, have little in their exterior in common with the genume Esquimaux 
and the inhabitants of the country about the Bay of Disco in NorthGreenland; and the natives of the East coast seem to me to have still less. They have neither the full, fleshy person, nor the prominent paunch of the Esquimaux, but are, on the contrary, slender and even meagre. 'They are, moreover, distinguished from the Esquimanx by their form of head, and cast of countenance, which is handsomer and more expressive. The women and children have, many of them, brown hair, and a complexion scarcely less fair than that of our peasantry, that is to say, when they scrape and wash off the filth that in general hides it from view. - Their lank hair, their black and somewhat Chinese eyes, their disproportionately, large hands and feet, their temper and disposition, their manners, customs and language, all indicate that they are of the same stock, originally, with the Esquimaux. They have, all of them, thick, arched, black eyebrows, and the men, in summer, paint a ring of black, with lampsoot under their eyes. Some few of them wear beards and moustachios, but by far the greater number eraticate the beard as it appears."

Zeichnungen und Messungen an Lebenden sind damals, soviel ich weiss, von Graah nicht gemacht worden und ebenso wenig von Clavering.

Wie man aus Clavering's 'Tagebuch ersehen kann, und wie wir selbst noch erkennen konnten, hat dieser Reisende mehrere der Gräber auf Sabine-Insel und Kap Borlatse Warren geöffnet und Schädel daraus entnommen. Diese ostgrönländischen Schädel, ebenso wie einige von Scoresby gefundene, werden sich wol in englischen Museen finden.

Auch Graah scheint einzelne Schädel aus dem suidlichen Grönland mitgebracht zu haben; wenigstens erwähnt lietzius ${ }^{1}$ eines crönländerschädels in Musem zu Stockholm, der verunthlich dort seine Iteimat haben soll.

Doch dürfte Genaueres und Eingehendes über diese Schädel noch nicht bekannt sein.

Es wurden von uns an Ort und Stelle gesammelt: 11 Schädel, ainige Schürlelsticke und eine ziemliche Rieihe ron Skeletknochen, jedoch kein einziges einigermaassen vollständiges Skelet. Simmtliche Knochen wurden eigenhändig den Gräbern entnommen, nur 1 Schädel und einige andere Kinochen lagen frei in unmittelbarer Nähe der Gräber.

1 Müller's Archiv, 1845, S. 122.

Zweite Dentsche Nordpolfahrt. II. 
Sie stammen also sicher ron Leichen, die dort begraben wurden, und glaube ich sicher annehmen zu diirfen, dass es alles Lingehorene waren. Darauf weist schon die Form und Lage der Gräber hin, wie sie im erzählenden Theil geschildert sind. Es liesse sich freilich anch denken, dass Walfischfahrer einstmals ihre Todten an einem der hervorragenden P'unkte (Sabine-Insel, Klein-Pendulum und Kilp Borlase Warren) begraben hätten, denn es ist bekannt, dass sie ruweilen in die Nähe der Kïiste gekommen, ja cinzehn auch wol dort gelandet sind. Doch bietet diese Annahme nur sehr geringe Wahrseheinlichkeit.

Wie die rorgefundenen Gräber und die Lagerung des Skelets war, wurde ebenfalls im erzählenden Theil beschrieben. Ich bemerke hier nur, dass die meisten Gräber ganz frei auf flachen Stellen lagen, und dass die meisten Knochen von der (hineingewehten) Erde bedeckt waren, sodass öfters nur die Schädel mit einem gewissen, weissgebleichten Theile hervorschimmerten. Die Conservirung der Knochen war theilweise eine sehr gute, da die Errle meist schr sandig (fein steinig) war, und die Gräiber fast stets an trockenen Orten lagen. Doch hatten bei vielen Skeleten anch die feineren Theile gelitten, und waren namentlich die schwammigen Knochen vielfach ganz rerschwumden.

Es begreift sich leicht, wie unter diesen Umständen eine auch nur anmähernde Bestimmung der Lünge der Zeit, die seit dem Begräbnisse rerflossen ist, ron rornherein numöglich ist. Fis wïrden dazu wenigstens ganz andere Kenntnisse des Klimas und seiner Linwirkungen gehören, als wir sie in dem einen Jahre erlangen kounten. Und wenn sich anch an Schäideh, die auf der Clavering-Insel gefunden wurden, noch Spuren von Periost und Kopithant fanden, ja in einem sogar noch das eingetrocknete Gehirn, so giht dies immerhin keinen sichern Anhalt; denn dass dort ror 46 Jahren noch Lingeborene lebten, wissen wir ja bereits, und für viel geringere 'Zeitläume können wir ans jenem Befunde doch anch keine Schlïsse ziehen.

Von den erwähnten 11 Schäilehn gehören nur 6 Lirwachsenen an; bei 2 ist das Wachsthum noch nicht ganz vollendet und : gehören sechshis siebenjährigen Kindern an; aus den ersten Jugendjahren sind keine rorhanden. Ueber das Geschlecht liess sich von vornherein nichts bestimmen, da in den Gräbern Instrumente und Waffen nie gefunden wurden.

Von den \& Schädeln sind nur 5 mit Unterkiefer rersehen; kein einziger derselben aber hat so gelitten, dass eine vergleichende Untersuchung oder Messung dadurch mmöglich gemacht wäre. 
In Folgendem sind nur die Schïdel der krwachsenen (Nr. 1-6) berïcksichtigt.

Was num zunichst die Hirnschädel angeht, so gehören dieselben durchgehends zir den stark dolichocephalen. In der Scheitelansicht stellen sie eine längliche Ellipse dar mit einem etwas breitern vordern und einem meist abgesetzt zugespitzten hintern Ende. Die breiteste Stelle liegt in orler etwas hinter der Mitte, ein wenig iiber der Schuppenmaht.

Die absolute Länge der Schädel ist eine recht bedentende. Die grösste Länge beträgt im Mittel 189,7', im Maximum 196. Die grösste Breite ist im Mittel 138,2 (Min. 131, Max. 145). Demmach ist des Breitenindex $=73,3$ und schwankt nach beiden Seiten mu 2- $3^{\mathrm{mm}}$.

Nach Welcker's Methorle stellt sich $\mathrm{L}=185,8, \mathrm{Q}=1: 3,3, \mathrm{~L}: \mathbf{Q}$ $=70,8(69,4-74,6)$.

Die Tubera parictatia sind wenig herrorragend, theilweise sogar ganz verstrichen; ihre Distanz betrïgt 116,8 .

In der Profilansicht ist der Schädel lang eiförmig mit etwas nach hinten und unten vorragendem Hinterharpt. Die grösste Höhe beträgt 139,5 (Mittel ans $\left.\mathrm{Nr}_{1} \cdot 1-4=143.5\right)$. Nach Welcker wäre II $=136$ $(\mathrm{Nr} \cdot 1-4=140$ ) und somit L: $\mathrm{H}=73,3$ (resp. 74,5). Die Profillinie des Scheitels ist rerschieden gestaltet, bei $\mathrm{Nr}$. und 9 (Mïnner?) schön kugrelig gewölbt, bei den übrigen mehr flach und abgesetzt. Der höchste Punkt liegt in der Mitte der rordern IIiilfte der Pfeilnaht. Die Stirn erhebt sich anfangs, orler auch in grösserer Länge ziemlich steil. Die Glabella erscheint dabei wenig rertieft und die Stirnhöcker sind stark rerstrichen. - Die Ohröffinung liegt weit vor der Mitte des horizontal gestellten Schädels und ist iiberhaupt die ungemein starke Entwickelung des Hinterhauptes auf den ersten Blick zil erkennen.

Die Ebene des Foramen magmm fällt etwas nach hinten ab; sein vorderer Rand liegt unter oder etwas vor der Ohröffnung. Die Neigung des Clivus ist ziemlich wechselnd. Das Minterhaupt sinkt zuweilen noch unter die Ebene des Foramen magmum hinab. Die Spina accipitalis tritt eigentlich nur bei dem alten Mannsschädel Nr. 3 merklich hervor. Zugleich ist an demselben, wie auch in zwei andern Fïllen, die Schuppe oberhalb der Spina und unterhalb an den beiden Seiten stark bauchig nach aussen vorgetrieben.

Die Sagittallängen der einzelnen Kinochen ergeben: Fr.. 127, Par.: 125, Occip). (squama): 126.

1 Alle Maasse sind in Millimetern angegeben. 
Die Länge der Schädelbasis (line nasoluasitaris Welcker) ist im Mittel 104. Bei dem iiberhaupt kleinen Schädel Nr. 6 nur 98 zählend, erreicht sie bei $\mathrm{Nr} .2113$, und zeigt bei den andern vier Schädeln grosse Uebereinstimmung (103-104). Der sagittale Umfang der Calvaria (nclb) ist 431, sodass sich das Verhältniss $\frac{\mathrm{nb}}{\mathrm{nclb}}=411$ ergibt.

Von hinten gesehen lässt der Schädel am deutlichsten seine eigenthïmliche Form hervortreten und erscheint als meistens starker Scaphocephalus oder Leptoscaphocephalus (Virchow).

Er zeigt hier ein Fünfeck mit rorwiegend entwickeltem Höhendurchmesser. Die Basis ist zwischen dem Processus mastoideus sanft nach unten ausgerundet. Die Seiten erheben sich fast senkrecht, doch oben oder unten etwas ausgebuchtet bis zur Höhe der Tubera parietalia, von wo sie umbiegen in die dachförmig ansteigenden Scheitellinien, die sich in einem schärfern oder flachern Kamme oben verbinden.

Das Extrem dieser Form bietet Nr. 3. Die Basis ist hier stark nach unten gerundet und ron der stark vortretenden Mastoidalgegend an zeigen die Seitenwände sogleich eine starke Convergenz nach oben, sodass hier fast ein abgerundetes Dreieck erscheint. Dieses Scheiteldach findet sich bei allen 6 Schädeln, ja sogar schon bei den nicht ausgewachsenen Nr. 7 und 8.

Der Mastoidal-Durchmesser ist 126. - Auch hier wieder tritt die starke Lntwickelung des Orcipitale in der moewöhnlich hohen Lage der Lambdanaht hervor. Bei $\mathrm{Nr} .7$ und 8 ist es noch nicht so ausgebildet.

Die Norma facialis bietet am Gehirnschädel wenig Besonderes. - Von der Basis gesehen erscheint die Hirnkapsel schön länglich oval. Die Pars basilaris ossis occipitalis ist ziemlich breit und sehr flach; in gleicher Weise lagern sich jederseits die benachbarten Theile an.

An besondern Bemerkungen iiber den Hirnschädel wäre etwa Folgendes noch hinzuzufïigen:

Die Nähte sind vielfach obliterirt und nur bei $\mathrm{Nr}$. 1 vollständig frei. An der Obliteration nimmt anch vielfach der grosse Keilbeinflïgel Theil und nur die Schläfenschuppe bleibt stets mverwachsen. Sehr eigenthïmlich ist bei $\mathrm{Nr}$. 5, einem ältern Schärlel, ein Ueber-

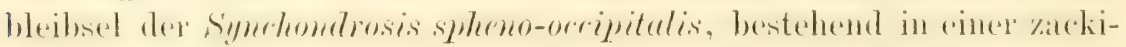
gen Fissur.

Die Arcus superciliures sind meist nur schwach entwickelt und selbst bei Nr. 3 durchaus nicht ungewöhnlich stark.

Die Muskelleisten des Nackens sind ebenfalls durchschnittlich 
nicht besonders stark. Eine Linca muchue suprema ist öfters deutlich erkennbar.

Der Processus mastoideus bietet nur bei Nr. 3 Interesse, wo er einen scharf von der Umgebung getrennten abwärts gerichteten Zapfen darstellt, dessen äussere Basis, zwischen dem Ende der Linea mehae und dem Ende der Jochbogenkante stark nach aussen aus dem Schläfenbein hervortritt.

Das Planum semicirculare ist meist sehr gross; in drei Fällen nur läuft die Linca temporalis über das Tuber parietale hin, bei den iibrigen Schädehn, selbst schon bei Nr. 7 und 8, iiberschreitet sie dasselbe und riickt bei $\mathrm{Nr}$. 3 bis anf $39^{\mathrm{mm}}$ an die P'feilnaht heran.

Zu beachten dürfte noch die Form des Os tympanicum sein. Von vorn gesehen erscheint dasselbe am menschlichen Schädel gewöhnlich als eine viereckige Platte, die sich hinter der Gelenkflïche herabsenkt. Der untere freie Rand derselben legt sich nun gewöhnlich zugeschärft als Scheide an den Griffelfortsatz, und mit einer ebenfalls mehr oder minder schmalen Kante an den Zitzenfortsatz an. Hier geht meistens, abgesehen von der Fissura tympanico-mastoiden die Fläche der Platte ummittelbar in den vordern Rand (Fläche) des Proccssus mastoideus über.

Auffallend anders verhält es sich aber bei diesen grönländischen Schädeln. Hier findet sich statt des untern Randes eine breite rauhe Fläche, die sich vom Processus styloideus bis zur äussern Ohröffnung erstreckt und $5-8^{\mathrm{mm}}$ breit ist. Die von dem Os tympanicum gebildete untere Wandung des Gehörganges ist auf diese Weise bedeutend verdickt und erscheint im Durchschnitt oder von der Seite gesehen breit (dick) halbmondformig.

Was nun den Gesichtstheil des Schädels betrifft, so ist hier eine in verschiedenen Richtungen starke Ausbildung der Knochen unverkembar, obgleich sich bestimmte deutlich ausgesprochene Kemzeirhen nach dieser geringen Anzahl von Exemplaren schwer angeben lassen. Ober- und Unterkiefer, sowie Jochbein sind meist ziemlich entwickelt. Die Jochbogen stehen nicht so weit ab, als es auf den ersten Blick scheint, und sind öfters sehr schwach.

Die meisten Schädel bieten das Bild ausgesprochener Prognathie, zuweilen in hohem Grade. Doch lässt sich nicht verkennen, dass diese Erscheinung sehr viel durch die oft stark vorragenden Zahnfortsätze und die schräg vorstehenden Zähne erzeugt wird. Bestimmt man die Kieferlage nach der Welcker'schen Methode, so ergibt sich ein Nasenwinkel von 66,4 Grad, d. h. von einer mittlern Grösse, und es würden danach bei angenommenen drei Gruppen die Schädel mitten unter die orthognathen zu stellen sein. 
Die Fossa camina und Fossa incisiva sind zuweilen sehr stark vertieft, die Foramina infraorbitalia sind sehr weit.

Die Augenhöhlen sind bald mehr rundlich, bald mehr vierKantig, aber stets sehr gross; die Gestalt der Nasenöffinung wechselt. Constant aber ist die eigenthiumliche Bildung der Nasenwurzel. Sie ist immer schmal, zuweilen sehr schmal und dabei anffallend platt. Nur die Nasenbeine bilden eine schmale rorstehende Längsleiste und sind in ihrer obern Hälfte so schmal, dass sie zuweilen fast zu fehlen scheinen. Ebenso schmal sind zuweilen die Thränenheille.

Der Unterkicfer ist nicht besonder's stirk und hoch, der liamus aber ist "niedrig und der Amgutus stmmpf, das Kimm ist vorragend.

Ueber den Gammen, die Proccssus pteryyoidei und die iibrigen Theile lässt sich kaum Allgemeines sagen.

Die Zähne waren an mehreren Schädeln vollständigg; erst mit der Zeit oder beim Herausnehmen aus der Erde gingen deren viele verIoren. Der letzte Backenzahn scheint häufiger auszubleiben. So fund sich bei $\mathrm{Nr}^{2}$. 6 und 8 nur ein cinziger rerkimmerter ror; bei Nr. 1 fehlt er unten rechts.

Fast iiberall sind die Kauflichen der Zïhne abgeschlifien, aber in rerschiedenem Grade. Am stirksten ist es bei Nr. 3 an den zwei noch vorhandenen Zïhnen der Fall. Ilüufig waren die Züline auch schon bei Lebzeiten verloren gegangen, und die Alreolarfortsaitze sind damn auch wol ganz lesorbirt.

Ueber die Schädel Nr. 7 und 8 lässt sich wenig Besonderes sagen. Bei Nr. 8 ist der letzte Motaris eben durchgebrochen, bei $\mathrm{N}_{1}$. 7 noch nicht. Die Synchondrosis spheno-oceipitalis ist bei beiden noch vollständig offen, ebenso alle Niahte nuverwachsen, sodass das Alter vielleicht auf etwa 16-25 Jahre zu setzen wïre. Die Tubere springen noch mehr vor, die Proccssus mastoidei sind noch wenig vorragend, die Linea temporatis noch sehwach entwickelt (doch erreicht sie bei Nr. S bereits das Tuber); aber die ganze Schäidelform in ihren llauptzügen ist doch schon deutlich zu crkennen. Die Nasenbeine sind bei Ns. 7 äusserst schmal, die Nasenöffnumg anffallend schmal mud länglich. Die Kanflächen der Zähne sind noch sehr wenig abgenutzt.

Einige weitere Verhälnisse finden in der' 'Tabelle ihe Er'ledigmung.

Was die Kinderschädel Nr. 9-11 angeht, so sind ihrer zu wenige und liegt noch iiberhaupt iiber junge liassenschädel zu wenig Material vor, als dass ich, namentlich bei dem grossen Mangel an vergleichbaren Objecten, Eingehendes dariiber ¿̈ussern kömnte. Den- 
noch habe ich die Maasse in die Tabelle anfgenommen, weil sie Manchem vielleicht willkommen sein diiften.

Betrachtet man diese in manchen' Theilen defecten Schictel, so lïsst es sich ïhrigens nicht verkennen, wie sich schon der 'Typus der alten Schädel geltend macht. Man erkennt bereits die stanke Ausbildung des Oberkieferapparates, sowie das hervorragende Iinterhaupt und die mehr lang elliptische Schädelform. Auch die glatte Nase und die massige Entwickelung des Os tympanicum treten dentlich hervol.

Vergleichen wir nun zunächst das, was ich über die von uns mitgebrachten Schïdel gesagt habe, mit dem, was über die Schädel der Eskimos anderer Gegenden bekannt ist, so werden wir eine sehr auffallende Uebereinstimmung finden.

Verschiedene Muscen Deutschlands, nimentlich aher Dänemarks, Englands und Amerikas besitzen eine ziemliche Anzahl Eskimoschiidel, die vorzugsweise aus Westgrönland und Labrador stammen. Trenn num auch nur ein Theil derselben genauer untersucht wurde, so ist doch der Schädel des Eskimo in seinen Itautzügen schon seit langer Zeit bckannt. Ich erimnere hier nur an die Beschreibungen, welche Blumenbach ", lietzius ${ }^{2}$ und van der IIoeven ${ }^{3}$ geben. Aus der nenesten Veit finden wir die besten Aufschlüsse über Grönlindersehädel bei Nelekert und Virchow5.

Wie sehx die von den letztgenamnten Autoren angeführten Maasse mit den unsern zusammenfallen, zeigt ein Blick auf die 'Tabelle.

Nirgends eigentlich sind die Abweichungen bedeutender, als es bei der relativ geringen Kahl der Schädel begreillich ist, und als sie schon imerhall, der lieihe der wenigen ostgrönländischen Schärlel selbst vorkommen. Dals Linzige, was man anfïhren könnte, wäre vielleicht, dass unscre Schädel in den verschiedenen Richtungen verhïltnissmässig gross erscheinen.

Die lange nnd hohe Form des Schäidels, das hohe Gesicht, die srossen Augenhöhlen und die thachen schmalen Nasenbeine werden bereits ron van der Hoeven hervorgehohen, derselbe bezeichnet auch schon den dachförmigen Scheitel als einen wesenthchen Charakter des Grönländerschärlels. Blumenbach führt ausserdem noch die grosse

1 Blumenbach, Decades collect. Suae craniorum, Tab. XXIV-XXV und Tab. XXXVI-XXXVII.

2 Ueber die Schüdelformen der Nordbewohner in Müller's Arehiv, 18t5, S. 122.

3 Catalogus craniorum div. gentium (Lugd.-Bat. 1860), S. 58-59, Nx. 166-168.

1 Wachsthum und Bau des menschlichen Schädels, an verschiedenen Orten. Kraniologische Nittheilungen. Archiv für Anthropologie, Heft 1.

`Die altnordischen Schüdel in Kopenhagen, Arehiv für Anthropologie, IV, 1. 
mit nach hinten vorgetriebenem Occiput rersehene Calvariu auf, sowie die flache, wenig tiefe Fossa basilaris (d. h. den zwischen Foramen magnum und den Choanen gelegenen Theil der Basis).

Wenn wir die Flachheit anch bereits erwähnten, so wird man die geringe Tiefe, beziehentlich den sehr stumpfen Winkel, den die Processus pterygoidei mit der Pars busiluris ossis occinitis bilden, doch bei unsern Schädeln znweilen vermissen.

Dem allgemeinen Typus nach glaubt Blumenbach seine Eskimoschädel in die Mitte zwischen die der mongolischen und amerikanischen Rasse stellen zu müssen.

Retzius gibt ausführliche Beschreibungen zweier Grönländerschädel. Die meisten seiner Angaben finden sich an unsern Schädehn bestätigt. Angeführt werden die niedrigen Unterkieferäste. Ferner sagt Retzins, dass ausser den vorstehenden runden Oberkiefern die schräg nach aussen abfallende Fläche der Jochbeine am meisten in die Augen falle, wodurch der Schädel gerrissermatassen ein etwas pyramidales Aussehen erhalte. Auch bei unsern ostgrönländischen Schädeln findet sich etwas Aehnliches, doch könnte man es hier nicht wol als etwas Charakteristisches hinstellen. - Nach Retzius gehören die Grönländer selbstrerständlich zu den gentes dolichocephulae prognathae.

Virchow betrachtet und beschreibt die Grönländerschädel hauptsächlich im Vergleich und Gegensatz zu Lappen und Fimnen, sowie zu Schädeln früherer Zeiten. Er erwähnt die bedeutende Länge und Höhe und die geringe Breite, sowie namentlich auch die starke Betheiligung des Hinterhauptes und weist hin auf die starke Entwickelung des Kieferapparates in Breite und Höhe, auf' die grossen Augenhöhlen und die schmale Nasenwurzel. Wemn sich alle diese l'unkte auch auf das genaueste an unsern ostgrönländischen Schäideln wiederfinden, so entbehren die letztern doch der ansserdem erwïhnten stark vortretenden Ausbildung der Supraorbitalgegend.

Auch die Höhe und Ausdehnung des Planum semicirculure ist durchaus nicht durchgängig so bedeutend, wie Virchow angibt, und nöthigt zu einer kurzen Bemerkung.

Die Grösse und Gestalt des Planum semicirculare, beziehentlich des Musculus temporalis, oder was dasselbe heisst, Lage und Verlauf der Linca semicircularis ist sehr starken individuellen Schwankungen unterworfen.

Die Lage, die diese Linie ursprünglich bei jugendlichen Schädehn einnimmt, behält sie in allen Völkern wol nur bei ganz muskelschwachen und weiblichen Schädehn. Sie liegt hier zwischen Tubera 
parictalia und Sutora squamosa etwa in der Nitte und geht in geradem Bogen rom Jochfortsatze des Stirnbeins zur Wurzelkante des Jochbogens hinuiber. In späterem Mlter aber steigt sie bei männlichen und muskelstarken Sehädeh stets weiter hinauf und riickt namentlich auf dem. Scheitelbein am weitesten vor, nach oben, aber zugleich auch nach hinten gegen die Lambdanaht anf die Trurzel des Processus mastoidens. Die Tubera parietalia erreicht sie num öfters, und zwar findet man das nicht nur an den mit kräftigen Kauorganen versehenen holsteinischen Schädehn gewöhnlich, sondern auch bei den Schädeln anderer Völker, so z. B. selbst bei den Hindus. Einzelne holstemische Schädel zeigen das Planum bis weit über die Tubera parictalia hinausreichend und hinten bis fist an die Lambdinaht herantretend, sodass selbst manche unserer Eskimoschädel dahinter zuriickstehen müissen.

Wenn hierdurch darauf hingewiesen werden soll, dass eine starke Entwickelung des Planum scmicinculure kein den Eskimos eigenthümlicher Charakter ist, so muss man democh sagen, dass bei ihnen diese Erscheinung häufig und in sehr hohem Grade zu finden ist.

Aus der Untersuchung der ostgrönländischen Schädel und dem, was ïber die lebenden Eingeborenen daselbst rorher erwähnt wurde, ergibt sich somit mabweislich und lïsst sich trotz der geringen Zahl der Schädel ziemlich sicher hinstellen, dass die ausgestorbenen Bewohner der nördlichen Ostküste, ebenso wie die wol noch hente lobenden des südlichen Theiles wirklich, Eskimos" sind, das heisst zu dem Volke gehören, welches an den Eisküsten der Nenen Welt, von Grönland an bis nahe an die Beringstrasse hin seit undenklichen Zeiten seine Heimat hat.

Von irgendwelchen von Osten her kommenden fremden Einfliissen, vou, ,normannischer" Beimischung, an die so Mancher noch glauben möchte, ist auch hier keine Spur nachzuweisen.

Es braucht kaum erwähnt zu werden, dass diese Schädel ein besonderes Interesse bieten, weil sie den äussersten östlichen Eskimos angehören, die zugleich auch die am meisten isolirten waren, da sie wol nur mit den benachbarten südlicheren Niederlassungen im Verkehr standen.

Auf die höchst interessante Frage nach den anthropologischen Beziehnugen der Eskimos zu den Polarvölkern der Alten Welt sowie zu den ihnen benachbarten südlicheren Völkern einzugehen konmt mir nicht zu. Ich darf hier nur daran erimnerm, dass die Schädel der

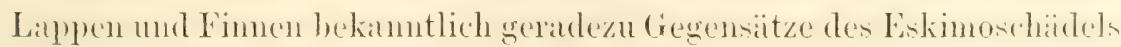
bilden, und dass die Schädel der asiatischen Polarvölker noch wenig 
bekannt sind. Einen für monsere Frage höchst interessanten Beitrag hat ror kurzem I)r. Wyman in Boston gegeben ', indem er seine Untersuchungen über fünf Lixemplare der so seltenen T'schnktschenschädel mittheilt. Wr komnte dieselben mit Schüdeln ron Fiskimos und Indianern verschiedener St:̈mme, namentlich auch denen der Indianer, die am Yukon - den Eskimos und den T'sehuktschen ummittelbar benachbart - wohnen, vergleichen; Wynan findet num, dass die Eskimos den T'schuktschen näher stehen als den Indianem, und so folgt daraus, Tas: der Polarmensch Imerikas, die paraborïische Rasse Geoffroy Saint-Hilaire's, in ,enem Weltheile anthropologisch scharf isolint erscheint mud höchstens noch einige Verwandtschaft mit den Iyperborïiern Asiens zeigt. Da nun die Eskimos seit sehr langer 'Zeit jedenfalls in ihner gegenwïrtigen Ilemat wohnen, da sie mit den benachbarten siidlichen Stimmen in steter Feindschaft und dem geringsten Verkehr stehen, oder gar nicht mit ihnen in lierïhung kommen, dit ihre Existenz, iiberhaupt nur bei einem vollstïndigen "llineinleben" und "Anpassen" an die Natur des Landes möglich ist, und irgendwelcher Fortschritt zur Cultur einfach umöglich ist, so kimn man in der That wol sagen, dass wir in dem Lskimo den wirklichen IFomo poluris erblicken müssen, den "durch die specifisehen Finflüsse dex aritischen Provinz bedingten licpräsentanten der Limana:". Der Fskimo ist ein reiner Carnivore.

Aus allen diesen Betrachtungen ergibt sich also die Bedeutung ciner genauen Untersuchung und Kemntniss des Eskimoschädels, zu der auch unsere Expedition hiermit hoftentich einen kinen beitrag geliefert laben dürfte.

$1 \mathrm{Vgl}$. Zeitschrift für Ethmolorie, 1869 , IIeft III, \$. 251-255.

"Vgl. \%eitschrift für Ethnologie, 1869, Heft 1, S. 9 fog., wo Bastian, indem or iiber ,das naturliche System in der Ethnologie" handelt, dieses beispiel weiter prliutert. 
1. Anthropologin.

$1: 1,1$

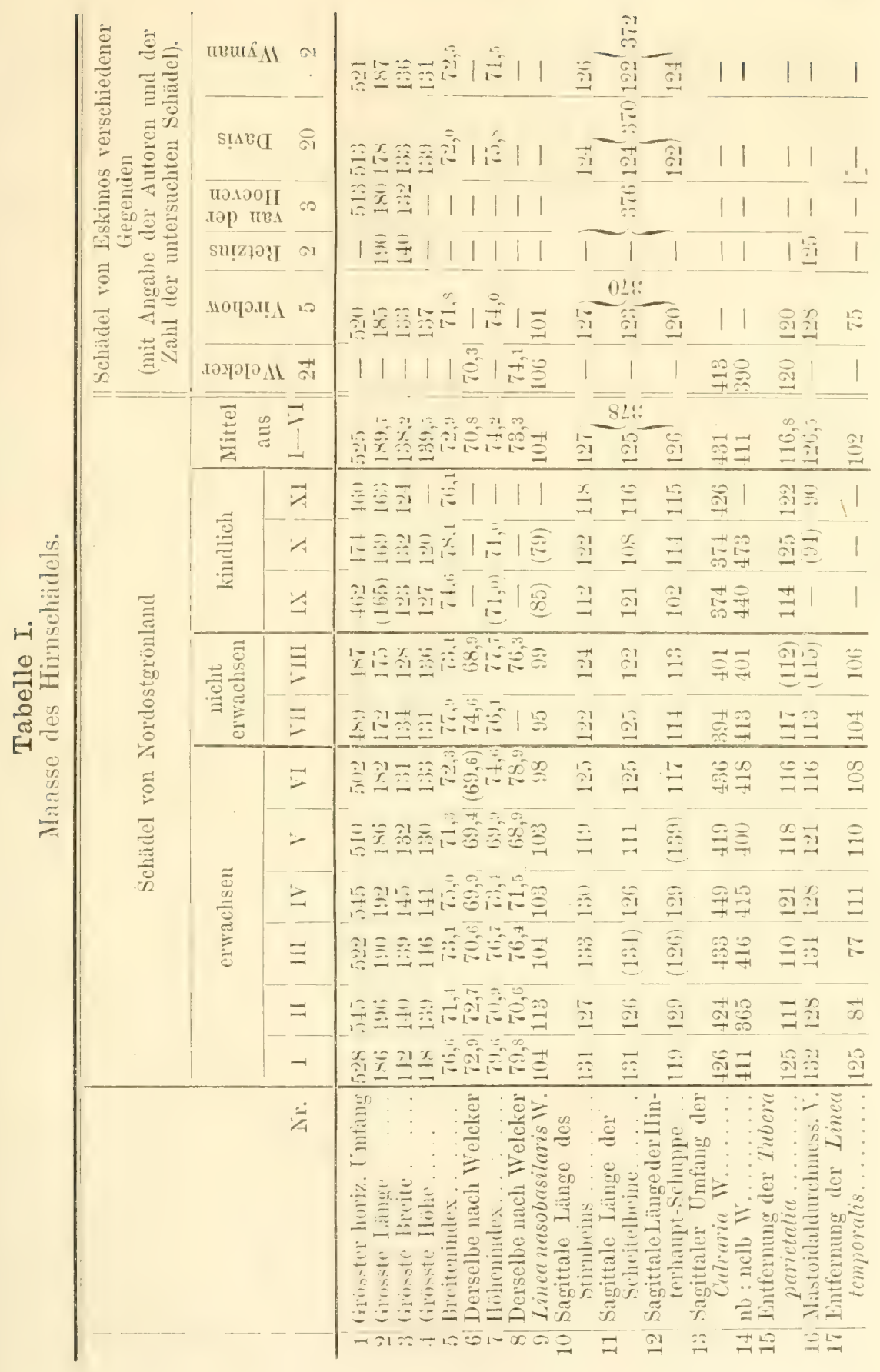




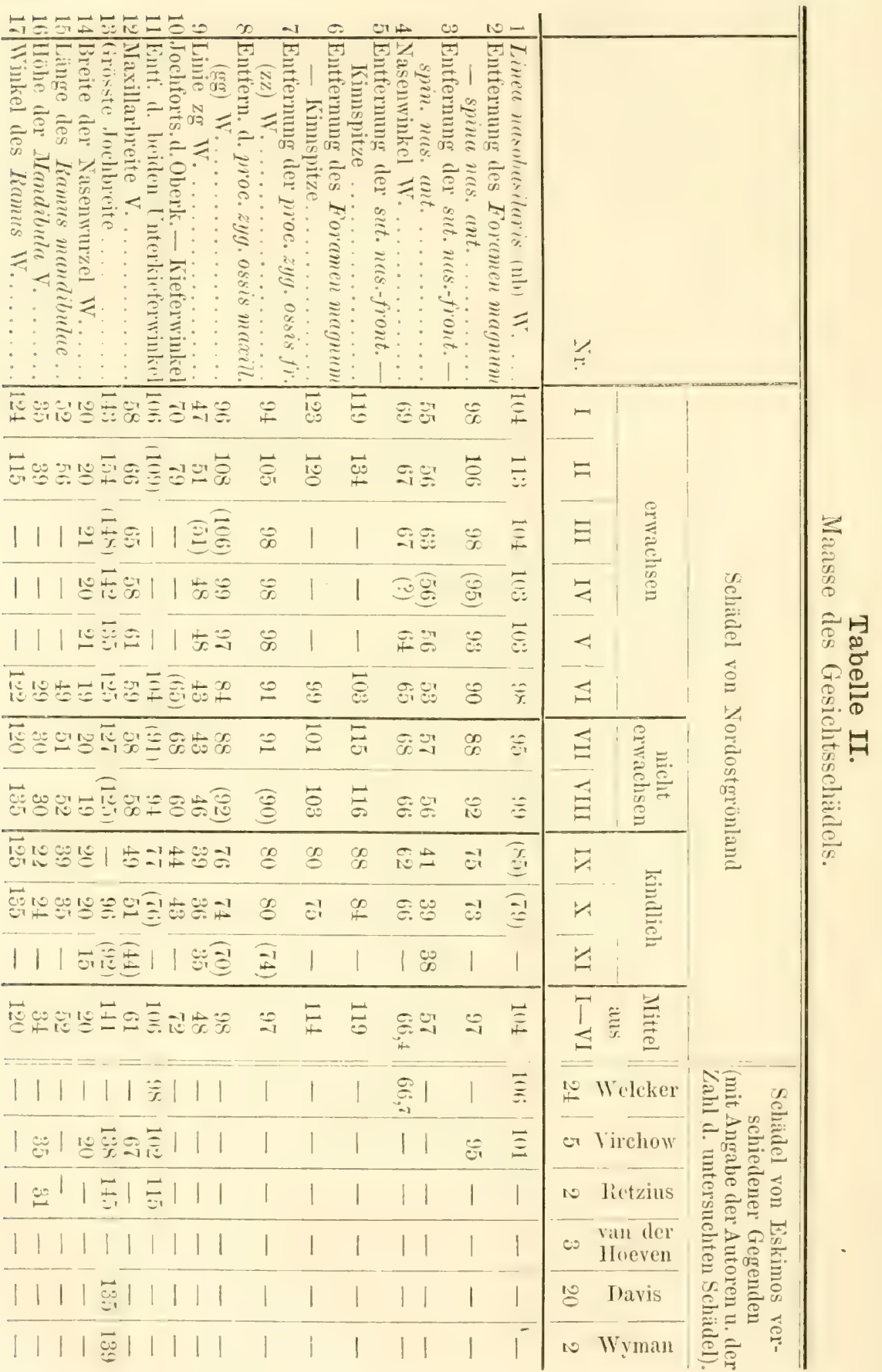




\section{2.}

\section{Sängethiere und Fische.}

Bearbeitet von

W. Peters

in Berlin.

Mit zwei lithographirten Tafeln.

a) Säugethiere.

Ferae, Ra ub thiere.

1) Ursus (Thalassarctos) maritimus Linné. Eisbär. ${ }^{1}$

Sowol im Packeise als längs der Küste von Ostgrönland nicht selten, nur im Winter sparsamer. - Dr. Pansch sah nur einmal, gegen Ende April, eine Bärin mit zwei ganz kleinen Jungen, während Dr. Buchhol\% mehrmals Gelegenheit hatte, das drollige Treiben derselben zu beobachten. Im allgemeinen waren die Bären ziemlich dreist und reigten in der Regel wenig Neigung aus dem Wege zu gehen. Wurde aber auf sie geschossen, ohne dass sie verwundet wurden, dann trabten sie so schnell davon, dass sie nicht mehr einzuholen waren.

Ein im Juli erlegtes Männchen hatte ganze Stïcke von Robbenfellen im Magen.

2) Mustela (Putorius) erminea Linné. Hermelin.

var. Putorius novaeboracensis Dekay, Baird, Mammals of North-America, 1859 , S. 166.

Es liegen zwei Exemplare vor, eins mit ganz zerschmettertem Schädel; beide stimmen ganz mit denen überein, welche das Berliner Museum aus Labrador erhalten hat. Die Oberlippe ist weiss wie bei

I In Betreff des Thierlebens in Ostgrönland und namentlich der Begegnungen der Expedition mit den grössern Säugethieren ist noch besonders das 13. Kapitel des erzählenden Theiles: "Thierleben und Jagden in Ostgrönland", zu vergleichen. 
dem emropäischen IIermelin, sodass sie nicht zu der von Bonaparte M. Richardsomii genannten Art oder Abart gehören kömnen, da bei dieser sich die braune Färbung auch über die Oberlippe ausdehen soll. Mir scheint das Gebiss und auch der Schädel ein wenig kleiner zu sein als bei dem europäischen Iermelin, indessen gehören grössere Reihen ron Exemplaren zur Vergleichung dazu, um über die nenerdings anch wieder ron Allen (Bulletin of the Huseum of Comparative Zoology, of Harvard College, Mass. Nr. 8, S. 167 sq\%.) bestrittene Terschiedenheit des europäischen und nordamerikanischen Hermelins entscheiden zu können.

Ton den ron Dr. Panseh erbenteten Exemplaren wurde eins im Anfang Juni 1870 auf der Kuhn-Insel, das andere bei dem Gletscher im lijord im August erlegt.

D1. Copeland sah im Herbst 1869 auf dem Schnee des Sattelberges Spuren, die dem Hermelin anzugehören schienen.

3) Canis (Vulpes) lagoms Linné. Polarfuchs, Eisfuchs, Steinfuchs.

Canis lagopus Linné, Syst. Nat. el. X. 1758, 1. 40; Faun. suce., 2. ed., $1761,1) .4$.

Canis lagopus Schreber, Süngethiere, 1778, 111, 362, 'T'af. 93, 93*.

Canis lagopus Fabricius, Fauna grwenland., 1780, p. 19.

Cunis lugopus Pallas, Zoogr. Rosso-Asiat., 1811, 1, 51, Taf. 5.

Canis Tagopus Blainville, Ostéographie. Canis, Taf. 5.

Lencocyon lagopus Gray, Proc. Zool. Soc. Iond., 1868, 1). 521; Catal. Carnir. Pachyd. Edent., 1869, 1. 208.

Der Polarfuchs ist durch seine kurzen abgerundeten Ohren, den dicken buschigen Schwanz und die dichtheharten. Sohlen, sowie durch seine Fïrbung leicht von allen verwandten Arten zu unterscheiden. Der Schädel ist durch seine gedrungene Gestalt und durch die flache Auftreibung der Schnauzenbasis ror den Augenhöhlen kenntlich. IIerr Gray hat hieraus Veranlassung genommen, für diese Art cine besondere Gattung, Lencocyon, aufanstellen.

Unter den vorliegenden Fellen, die leider nicht gut erhalten sind, befinten sich zwei Männchen, welche bis auf einen schmalen bramen Augenring ganz weiss sind und am 19. September und 13. December 1869 erlegt wurden. Zwei andere, am 19. September und 29. November 1869 erlegte haben auf dem Rücken eine bräunlich-graue Färbung, welehe auf die Obersehenkel herabsteigt und sind im ïbrigen weiss. Ein fünftes Exemplar, im Juni 1870 erlegt, hat den Kopf brann und weiss gemengt, indem die bramen Haare weisse Spitzen haben, den Riücken bis auf die Schwanzbasis, sowie eine rordere 
auf die vordere, und eine hintere auf die hintere Extremität herabsteigende Querbinde ganz braun, indem die Iaare meistens an der Basis blüulich-grau, an der Spitze braun oder gelblich oder mit cinem subapicalen gelblichen Ringe versehen sind, und die iibrigen Theile gelblich-weiss. Endlich liegen noch zwei Felle ror, welche ganz brïunlich-grau gefürbt erscheinen, indem die an der Basis blïulich-granen Inare brame Spitzen haben. Diese beiden Exèmplare sind am 23. November und 2. December 1869 geschossen worden.

Aus den Notizen der Reisenden über dieses Thier ist noch Folgendes zu entnehmen:

Der Polarfuchs wurde fast überall zu jeder Jahreszeit angetroffen, niemals aber in grösserer Anzahl als bis zu fünf zusammen. Die weissen wurden riel häufiger gesehen als die schwarzen, beide öfters nebeneinander bei demselben Löder. Von Mitte Juni an wurden anch bunte gesehen.

In der Nähe des Scoresby-Sund sah Dr. Buchholz sie meilenweit auf treibenden Eisschollen, die durch weite Wasscrstreifen voneinander getrennt waren, und auf denen sie wahrscheinlich an den Ueberresten der Mahlzeiten der Eisbären ihre Nahrung finden. Mit grosser Geschicklichkeit gehen sie von einer Eisinsel auf die andere, indem sie kleine im Wasser schwimmende Eisstiicke als Anhaltspunkte benutzen.

In dem Fuchsbraten fanden die Reisenden von der IIansa, nächst der Walrosszunge, das wohlschmeckendste Wilkret, besser als die anch nicht $7 u$ verachtenden Eisbärenschinken, welche immer einen etwas thranigen Beigeschmack hatten.

\section{P'inipedia, Flossenfüsex'.}

4) Odobaemes Tiosmanes Linné. Walross. - Taf. I, Tig. 1 и. 2.

Odobcemus I.imné, Syst. nat., ed. I. 1735; übers. Halle 1740, 1. 15.

Phoca Rosmarus Limé, Syst. nat., ed. X. p. 38.

T'vichechus Rosmarms Limé, Syst. nat., ed. XII. I. 49.

Rosmarus arcticus Pallas, '/oogr. Rosso-Asiat, 1811. I. 269, Taf.

Odobaemus Fosmanes Steenstru\} et Sundevall, Öfvers. K. Vetensk. Ak. Förh. Stockh. 1859, p. 441.

Odobaenus Rosmavis Malmgren, Öfvers. K. Vetensk. Förhandl. Stockh. 1863, 1). 130 .

In Betreff des Gattungsnamens erlaube ich mir auf die Auseinandersetzung von Sundevall zu verweisen und daran zu crinnern, dass von Artedi und nach ihm ron Limné der Name Trichechus („Häare habend") auf den Trichechus manatus, den sie zu den Fischen zähl- 
ten, angewandt wurde, und dass letzterer diesen Namen bis zur 10. Ausgabe seines Systema auf den Manatus beschränkte und erst in der letzten 12. Ausgabe das Walross dem Manatus in der Gattung Trichechus hinzufügte, indem er annahm, dass das Walross gar keine Schneidezähne habe. Dieses ist aber bekanntlich ebenso falsch, wie eine anderweitige spätere Annahme, nach welcher der Ursus labiatus keine Schneidezähne haben sollte und demzufolge als Bradypus ursinus mit den Faulthieren vereinigt wurde. Daher würde auch der Name bradypus ebenso passend oder ebenso unpassend und mit ebenso vielem Rechte auf den Lippenbären anzuwenden sein, wie der Name Trichechus auf das Walross.

Es liegt mir ein Schädel von einem ganz jungen weiblichen Exemplare vor, welches nach der Mittheilung des Hern Dr. Pansch am 5. August 1869 bei der Sabine-Insel nebst zwei erwachsenen erlegt wurde und ungefähr $4-4_{/ 2}^{1 / 2}$ Fuss lang war. Dieser Schädel hat eine Lïinge von $191 / 2^{\mathrm{cm}}$ und noch sïmmtliche Zähne unter der Mundschleimhaut versteckt. Er ist daher nur wenig grösser, als der des Embryo, den Malmgren (Öfvers. K. Vetensk. Ak. Förhandl., 1863, p. 505, Taf. 7) abgebildet hat. Von dem Nilchzahngebiss ist noch vorhanden: oben links der erste nur $1 / 2^{\mathrm{mm}}$ im Durchmesser habende, rechts der zweite und an beiden Seiten der dritte Schneidezahn, der an der Aussenseite des bleibenden liegende Eckzahn, der zweite, der vierte und fünfte (ron Malmgren nicht beobachtete) Backzahn an jecler Seite. Die letzten beiden Zähne sind ebenso regelmässig entwickelt, wie in den friiher von mir abgebildeten Schïdel (Monatsher. Berlin. Akit. Wissensch., 1864, p. 685, Taf.). In dem Unterkiefer sind noch vorhanden rechts der zweite und links der dritte Schneidezahn, der nach aussen neben und nicht hinter dem Ersatzeckzahn liegende Milcheckzahn, rechts der erste und an beiden Seiten der vierte Backzahn. Es geht hieraus hervor, dass die Schneidezähne nicht schon oder wenigstens nicht immer vor der Geburt resorbirt werden.

Von Walrossen wurden von der Hansa überhaupt nur zwei Exemplare gesehen, von denen das eine Anfang November auf dem Eise liegend geschossen wurde. Nachdem es bereits zwölf Stunden bei sehr niedriger 'Temperatur im Wasser gelegen hatte, fand sich das Innere noch so warm, als wenn es eben getöltet wäre, ein Beweis, wie sehr die dicke Speckschicht unter der Haut den Körper vor $\Lambda$ bkiuhlung schützt.

Von der Germania berichtet dagegen Dr. Pansch: "Walrosse zeigten sich fast längs der ganzen Küste. Doch waren sie stets am zahlreichsten bei der Sabine-Insel und hat die "Wahoss-Insel" ihren 
Namen mit Recht bekommen. Sie waren meist zu 2-10 zusammen. Anfang Juli schienen sie aus der ganzen Umgegend zusammengekommen zu sein. Sie lagen auf drei Eisschollen dicht gedrängt beisammen, im ganzen gegen 60 Stück.

"Ihr liebster Aufenthalt ist die Kante des Landeises oder die davorliegenden Schollen. Doch sahen wir sie auch, wie die Seenunde, durch weit im Innern der gefrorenen Buchten befindliche Löcher hervorkommen.

„Spät in Herbst, ja bis in den December hinein, hörte ich ihre Stimme bei Cap Winn. Ich möchte glauben, dass sie den ganzen Winter in der Nähe bleiben. Ende Juni hatten sie ziemlich grosse Junge."

Im Magen fand Dr. Pansch, ganz uibereinstimmend mit Mitmgren, der im Jahre 1861 die schwedische Expedition nach Spitzbergen begleitete, nur die weichen Körper der Mya truncata und unter $5-600$ dieser Schalthiere nur ein einziges kleines Schalenstiick. Herr Malmgren hat in seinen interessanten Nittheilungen darauf aufmerksam gemacht, dass die jungen Walrosse zwei Jahre bei der Mutter bleiben, bis ihre Hauer hinreichend gewachsen sind, um sich die im Meeresgrunde steckenden Klaffinuscheln herauszuholen.

5) Phoca gronlandica Müller. Grönländischer Seehund, Sattler.

Pagophitus gronlendicus Gray, Catalogue of Seals and Whales, 1865, S. 25. „In dem die Ostkuiste Grönlands umgebenden, 20-30 Meilen breiten Eisgürtel ungemein häufig, überall, wo nur irgend freies Wasser zwischen dem Eis rorhanden war, in grosser Nenge zum Torschein kommend. Diese kleinste und munterste aller im grönländischen Meere vorkommenden Robben ergötzt sehr durch die Behendigkeit ihrer Bewegungen und durch die Geschicklichkeit, mit der sie sich auf schwimmenden Eisstücken zu bewegen weiss, worin sie es ihren grössern schwerfälligen Verwandten, der Bartrobbe und Klappmütze, die man oft stundenlang fast regungslos auf dem Eise liegen sieht, bei weitem zuvorthut. Die grönländische Robbe sieht man fast immer in Bewegung und wenn sie sich auch mitunter längere Zeit behaglich auf dem Eise sonnt, so. wendet sie doch vorsichtig umherspähend den Kopf nach allen Seiten, um bei dem geringsten verdächtigen Umstande sich kopfüber ins Wasser zu stürzen. Wir beobachteten z. B. einnal ein 'Thier. welches in tollem Uebermuthe wol fünf bis sechs mal in einer Ninute ïber einen kleinen, steil aus dem Wasser hervorragenden Eisblock herauf und hinunter mit unglaublicher Behendigkeit 
turnte, und sieht man sie diese Künste ausführen und mit grosser Schnelligkeit und Zierlichkeit auf der Oberfläche des Eises hin- und herlaufen, so muss man wol das Torurtheil, die Robben seien unfähig, sich ausserhalb des Wassers zu bewegen, ablegen.

„Bekanntlich liefert die grönländische Robbe den Hauptertrag für den Robbenschlag, der alljährlich Tausende von jungen 'Thieren, die auf dem Eise gesäugt werden und während dieser 'Zeit nicht ins Wasser gehen, zum Opfer fallen. Die Paarungszcit fällt, wie ich bestimmt glaube, in die Mitte des August, denn zu dieser Zeit bemerkten wir, als wir uns wieder an der äussern Eisgrenze befanden, dass die Thiere sich rudelweise im Wasser zusammenrotteten und die eigenthiumlichsten Sprünge und Tänze aufführten, wobei sie häufig mit dem halben Körper aus dem Wasser auftauchten. Auch fand ich bereits Anfang September bei einem Weibchen einen mehrere Linien langen Embryo im Uterus vor. Anfang Mïrz oder Ende Februar werden die Jungen auf dem Kise ahgesetzt.

„Das Fell eines jungen $84^{\mathrm{cm}}$ langen Nännchens war sehwarz mit schmutzig weissgelblichen Ringflecken auf Rücken und Seiten, unten heller. Dieses sowie andere im Julimonat geschossene hatten im Magen nur kleine Krebse (Themisto).

„Ein am 7. August erlegtes Weibchen von $93,5^{\mathrm{cm}}$ Länge war dunkelschwärzlich glänzend mit spärlichen schr unregelmässigen hellen lingen, ein anderes von $105,5 \mathrm{~cm}$ Länge auf dem Rücken dunkelschwärzlich glïnzend, an den Seiten melr ins Graue, am Bauche weisslichgran mil dunkeln grauen Flecken, am Ruicken und an den Seiten mit weisslichen Ringflecken.

„Am 7. September wurde ein $118^{\mathrm{cm}}$ langes Weibchen erlegt, welches einen einzigen ganz kleinen Lmbryo enthielt. Ausserdem fanden sich in der Leber viele Knoten, die massenhaft ein langgestrecktes Distoma enthielten und im Dickdarm ein eigenthümliches Trematode mit sehr grossem Saugnapf am Hinterende." (Dr. Buchholz.)

Von der Germania wurde diese Art, einzeln oder zu 2-5 Stück zwischen dem Eise angetroffen, während sie an der Küste während des ganzen Jahres selten war. In den Magen der Erlegten fanden sich Crustaceen und Fischreste, während Herr Dr. Buchholz letztere niemals, sonder'n ausschliesslich Crustaceen (Gammams arcticus und Themisto) rorfind.

6) Phoca barbata Mïller. Bartrobbe.

Diese durch ihre beträchtlichere Grösse, die am Rande geraden nicht wellenförmigen Bartborsten und die wegen der Verlängerung des 
dritten Fingers verschiedene Gestalt der Vorderextremitïten sehr ausgezeichnete Art wurde ron der Germania nur einmal am Ausgange des Fjordes gesehen.

Von der Hansa wurde am 29. Juli 1869 ein ganz altes Männchen mit völlig abgeschliffenen Zïhnen erlegt, welches Dr. Buchholz ausmaass :

Totallänge bis zur Schwanzspitze . . . . . . . $218^{\mathrm{cm}}$

Körperumfang hinter der Vorderextremität . . . $149^{\mathrm{cm}}$

Kopfumfang am Scheitel . . . . . . . . $59^{\mathrm{cm}}$

Länge der Vorderextremität, Vorderrand . . . . $26^{\mathrm{cm}}$ Hinterrand . . . . $17^{\mathrm{cm}}$

" " Hinterextrenität. . . . . . . . . $37^{\mathrm{cm}}$

Entfernung der Geschlechtsöffnung rom After . . $28,5^{\mathrm{cm}}$

Schwanzlänge . . . . . . . . . $21^{\mathrm{cm}}$

Von der Nasenspitze bis zum Nacken . . . . . $30^{\mathrm{cm}}$

" " " " bis zur Höhe des vordern Augenwinkels $\quad 9,5^{\mathrm{cm}}$

Breite zwischen den rordern Augenwinkeln . . . . $9^{\mathrm{cm}}$

Längste Bartborsten . . . . . . . . . 10,5

Vom hintern Augenwinkel zur Ohröffnung . . . $6^{\mathrm{cm}}$

Augenlidspalte . . . . . . . . . . $3^{\mathrm{cm}}$

Länge des Nasenlochs . . . . . . . . . $3^{\mathrm{cm}}$

Ueber die Farbe ist ausser der bramen Iris leider nichts aufgezeichnet worden.

7) Cystophora cristata Erxleben. Klappmütze.

Auch die Klappmuitze wurde nur selten beobachtet.

Von der Germania aus wurde Mitte Juli eine junge Klappmützc im Packeise erlegt und im April sah man bei der Sabine-Insel einen "Seehund mit einem grossen Aufsatz auf dem Gesichte".

Dr. Buchholz führt in seinem Journal an, dass am 1. August eine junge weibliche Klappmiitze von 150 Lünge, mit braungeller Iris und weissen Krallen und am 13. desselben Monats ein junges Männchen von $124^{\mathrm{cm}}$ Länge erlegt wurde. Dieses letztere hatte noch keine Spur von einer Miïtze und war auf dem Rücken schwarz-dunkel, an den Seiten und am Bauche grauweiss, ohne Spur ron Flecken.

\section{Glines, Nager.}

8) Miyodes torquetus Pallas. Lemming.

Mhus torquatus Pallas, Nov. spec. quadrup. e Glir. ord. (Erlangen 1778), 1. F. 206, Taf. XI B.

Mryodes torquatus Pallas, Zoogr. Rosso-Asiat. (Petrop. 1811), I, 173. 
Mus groenlandicus Traill, Scoresby Journ. Voy. North. Whale-Fish., 1833, p. 417. Myodes torquatus Middendorfi, Reise in Nord-und Ostsibirien, Zoologie, II, 1853 , p. 87 , Taf. IV - VII, und X, Fig. I.

Myodes torquatus Baird, Hammals of North-America, 1859, p. 558.

Misothermus torquatus Hensel, Zeitschrift der zoologischen Gesellschaft, 1855, VII, 492, 'laf. 25, Fig. 12 (Backzühne).

Lemminge wurden nur von der Germania angetroffen. Dr. Pansch sigt :

,Die Lemminge scheinen auf den Pendulum - Inseln ziemlich häufig zu scin, obgleich es uns trotz aller angewandten Miihe nur gelang, ein einziges Exemplar zu erlangen, das im September zwischen den Steinen umherlaufend erschlagen wurde. Geseheu wurden Lemminge vou mix übrigens gleich am ersten Tage auf der Sabine-Insel, wo sie die Wände der Eskimohiitten vielfach mit ihren Gängen durehsetzt hatten. Ich komnte hier unterscheiden, wie eins dieser Thiere ein svauliches, das andere aber ein deutlich schwarzes Fell hatte. Den Eingang der Eskimohïtte schienen sie zur Winterwohnung gemacht zu haben, da hier zollhoch ihre Excremente lagen.

,Auf Shannon wurde 1869 ein todtes 'Thier gefunden, von dem ich jedoch, da es sehr stark in Terwesung war, nur den Schädel überliefert erhielt.

„Im November sal ich sowol in der Nähe der Hütte als auch namentlich auf der Walross-Insel ziemlich viele Spuren im Schnee.

„Im Jahre 1870 wurden auch an andern Orten wieder Mäuselöcher entdeckt, aber es wurde kein einziges Thier gesehen, trotzdem ein Preis darauf gesetzt war. Auch komnte ich trotz aller $\Lambda$ ufmerksamkeit keine frischen Spuren entdecken.

,Als Ersatz sammelte ich Fuchsexcremente ein, die neben den Haaren die meist noch unversehrten Knochen der Lemminge enthalten und sich besonders auf der Walross-Insel äusserst reichlich vorfanden."

Nach dem von Herrn Dr. Pansch mitgebrachten Material kamn gar kein Zreifel iiber die Uebereinstimmung der ron ihm beobachteten Art mit $\boldsymbol{M}$. torquatus Pallas bestehen, welche neuerdings ron Middendorff so genau und ausführlich untersucht worden ist. Das mitgebrachte Exemplar stimmt ganz überein mit anderu, welche das Berliner Museum aus Sibirien besitzt.

9) Lepus glacialis Leach, Waterhouse. Polarhase. 'I'af. II.

Lepus timidus Fabricius, Jam. grœnl., 1780, p. 25.

Lepus glacialis et arcticus Leach, Ross Voyage, $8^{\text {ro }}$ ed. Lond. 1819, II, app. IV, p. 151, 170 (fide Waterhouse). 
Lepus gluciatis Leach, Parry's First Voy., Suppl. to the Appendix, 1821, p. CLXXXVII.

Lepus glacialis Waterhouse, Nat. hist. Mamm., 1848, II, 102 (syn. part.).

Von allen nenern Schriftstellern ist Waterhouse der einzige, welcher die charakteristischen Merkmale dieser von Sabine wol unterschiedenen Art, wie sie sich an den von der Expedition mitgebrachten Exemplaren zeigen, hervorgehoben hat. Die meisten Autoren haben diese Art offenbar gar nicht gekannt und sie daher mit $L$. variabilis, L. timidus L. (borcalis Nilsson) und L. campestris oder andern Arten confundirt, die zum Theil in denselben Ländern, wenn auch wahrscheinlich nicht in denselben Gegenden mit ihr vorkommen. So kann weder Bachmann's L. glacialis mit sehr gebogenen und tief gefurchten, gelblichweissen obern Schneidezähnen und ebenfalls gefurchten sccundären Schneidezähnen (Journ. Acad. Nat. Sc. Philadelphia, 1834, VII, I., p. 287), noch Baird's Lepus glacialis mit Gebiss und Schädel, die nicht von denen des L. variabilis zu unterscheiden (Mamm. NorthAmerica, 1859, p. 577, Taf. 86, Fig. 1) sind, hicrher gehören.

Drei Felle ansgewachsener Thiere von Klein-Pendulum sind, wis Fabricius schon angegeben, ganz schneeweiss bis auf die äusserste Ohrspitze, welche schwarz ist. Diese schwarze Farbe erstreckt sich aber, wie Waterhouse bemerkt, nicht auf die Ohrmuschel selbst, sondern nur auf einen verhältnissmässig kleinen Büschel längerer Haare, welcher von eben solchen weissen Haaren zum Theil verdeckt wird. An dem einen Exemplar sind die Haare zwischen den Ohren mit einem breiten braungelben Ringe versehen, und die Gegend um die Schnurrhaare und die Submentalgegend ist wie die Fusssohle ocherfarbig. Ein anderes Exemplar hat dagegen auch die Schnurrhaare bis zur Basis ganz weiss und nur einen 'Theil der Fusssohlen bräunlich-gelb.

Die Ohren sind ron der Länge des Kopfes und die Fusssohlen, wie Waterhouse bereits anführt, relativ kürzer als bei $L$. variabilis Pallas. Der kurze Schwanz ist dicker buschiger behaart als bei dieser letztern Art und die Krallen sind auffallend stumpf, merklich länger und stärker als bei $L$. variabitis. - Länge des Ohrs 12ºm, der Fusssohle $15^{\mathrm{cm}}$, längste Vorderkralle $16^{\mathrm{mm}}$ und längste Hinterkralle $17^{\mathrm{mm}}$.

Zwei Felle von jungen Exemplaren, welche am Kap Ph. Broke erlegt wurden, sind ebenfalls weiss, haben aber die Grundhälfte der Haare gelblich-grau, indem die Ilaare hicr dreifarbig, am Grunde schwarzbram, in der Mitte schmutziggelb und an der Spitze weiss sind. Die Ohren haben am vordern Drittel der Aussenseite und am hintern Drittel der innern Seite graugelbliche Iaare mit schwärzlicher 
Basis, den ïbrigen Theil der Aussenseite, die vordere Hälfte des hintern Randes und den ganzen hintern Rand mit weissen Haaren bekleidet. Aelnliche sparsame weisse Haare finden sich anf der Mitte der Innenseite des Ohres und an der Spitze befinden sich längere schwarze Haare, welche zum Theil ron den weissen rersteckt sind. Die Fusssohlen sind rorn ocherfarbig. - Länge des Ohrs $65^{\mathrm{mm}}$, der Fusssolle $95^{\mathrm{mm}}$, lïngste Vorderkrallen $7 \frac{1}{2} \mathrm{~mm}$, längste Hinterkrallen $8^{1 / 2} \mathrm{~mm}$.

Es liegen acht Schädel vor, fünf ron ansgewachsenen und drei ron ganz jungen Exemplaren, und diese zeigen so constante auffallende Unterschiede ron allen andern Arten, dass die Art darnach mit keiner andern zu verwechseln ist. Wem dieses democh, auch nach den trefflichen Bemerkungen Waterhouse's geschehen ist, so kann dieses meiner Ansicht nur daran liegen, dass die zur Vergleichung benutzten Exemplare eben keine Polarhasen waren. So ist es mir auch noch nicht gelungen, aus Labrador Polarhasen zu erhalten, obgleich sie dort vorkommen sollen, und die Schädel, die ich von dort unter diesem Namen erhielt, gehörten theils dem L. campestris? theils dem kleinen $L$. amoricames an.

Was zunächst das Gebiss anbelangt, so sind die ganz weissen Schneidezähne viel weniger gekrümmt als bei irgend einer andern Art und die Wurzel der obern Schneidezähne ragt ziemlich weit in den Oberkiefer hinein, während ich bei den mir vorliegenden Exemplaren von $L$. timidus L. ( $=L$. boreatis Nilsson) und andern europäischen und aussereuropäischen Arten dieselbe allein vom Zwischenkiefer eingeschlossen finde. Auch die Form der Schneidezähne ist eine ganz andere. Denn während sie bei den andern Arten im Querdurchschnitt breiter als lang sind, findet hier das umgekehrte Verhältniss statt 1 , oder höchtens ist an den obern Schneidezähnen der ganze Durchmesser dem Lïngsdurchmesser gleich, und im Vergleich mit andern Arten sind sie an gleich grossen Schädeln durchaus schmäler als bei irgend einer andern Art. Auch erscheinen die obern Schneidezähne an ihrer vordcrn Fläche dadurch viel convexer, dass die Zahnfläche nach aussen ron der nahe dem innern Rande gelegenen Furche sogleich so abfällt, dass die vordere und seitliche Fläche zusammenfallen. Die secundären Schneidezähne haben ebenfalls eine mehr horizontale Richtung, sind an ihrer obern Seite convex und haben keine Spur einer Iängsfurche. Die untern Schneidezähne sind auf ihrer

1 Nur bei den ganz jungen Thicren ist der Längshlurehmesser des vordern Endes der obern Sehneidezähne nicht grösser, sondern kleiner als der quere. 
untern Seite mit einer flachen Längsfurche versehen und reichen mit ihrèn Wurzeln bis unter den vordersten Backzahn. Die Backzähne stimmen im Allgemeinen mit denen von $L$. dimidus Limé überein und weichen darin von $L$. europaus Pallas ab, dass die erste Einhuchtung der Schmelzfalte des vordersten obern Backzahns nach innen und nicht nach vorn liegt. An den untern Backzähnen erscheinen die seitlichen Einbuchtungen tiefer als bei jenen Arten.

Die Supraorbitalfortsätze sind in ihrem vordern Theile mehr in die Höhe gebogen und daher erscheint die Mitte der Interorbitalgegend vertiefter, und da diese Fortsätze zugleich breiter sind, so ist der Abstand der Orbitae in dieser Gegend breiter als bei irgend einer andern Art. Der Jochbogen hat in seiner Gestalt am meisten Aehnlichkeit mit dem von L.campestris (nach Baird's Abbildung), ist aber viel höher. Die Foramina incisiva sind hinter ihrem rordern zweiten Fünftel eigenthiumlich rerengert und hinter der Intermaxillarnaht macht sich an der Gaumenfläche des Oberkiefers ein flacher Höcker bemerklich, welcher dem Ende der Schneidezahnwurzel entspricht. Das vordere Ende des Unterkiefers ist ganz horizontal und nicht wie bei den andern Hasen in die Höhe gebogen. Der anfsteigende Ast des Unterkiefers hat in seiner allgemeinen Gestalt, auch in der Bildung des untern wulstigen Randes des Unterkieferwinkels am meisten Aehnlichkeit mit dem von L. canescens, während die geringere Breite der flachen zu dem Foramen alveolare herabsteigenden Grube mehr an $L$. cuniculas erinnert.

Der grösste der vorliegenden Schädel hat von der Spitze der Schneidezähne bis zum vorragendsten Theile des Hinterhauptes rine Länge von 108 und zwischen den Jochbögen eine Breite von $53^{\mathrm{mm}}$.

Nach Herm Dr. Pansch fanden sich diese Hasen allenthalben in der Ebene und auf den Gebirgen, obgleich nie zahlreich. Sie scheinen den ganzen Winter auf den Pendulum-Inseln zu bleiben. Am 24. April geschossene Männchen befanden sich in starker Brunst und Herr Tramnitz fand Mitte Mai trächtige Hasen, deren Fötus eine Totallänge von $6 \tau^{\mathrm{mm}}$ und beträchtlich kürzere $\left(4,5^{\mathrm{mm}}\right.$ lange) Ohren haben, als (nach der Abbildung von Pallas, Nor. spec. Quadrup. Glir. Taf. 4 A, Fig.g. 1) Lepus variabilis.

Pecola, Wiederkäuer.

10) Cervus tarandus Linné. Renthier.

Von der Truhn-Insel im Norden bis 'in die Tiefe des Fjordes himab, sowie auf der Sabine-Insel wurden Renthiere in Hecrden bis 
zn 20 Stïck oder in geringerer Anzahl beobachtet. In den südlichern Gegenden sind sie am zahlreichsten.

Ein Mitte Juni auf der Sabine-Insel erlegtes Thier hatte fast vollständig schon das Sommerkleid. Das Geweih war noch mit Haren bedeckt und an den Spitzen noch nicht ausgewachsen. Ganz junge Thiere wurden nicht gesehen.

11) Oribos moschatus Zimmermann. Moschusochse.

Ovibos moschatus Gray, Cat. Ungul. Furcipedn. 1854, p. 43.

Ovibos moschatus Richardson, Zoology Voy. Herald. 1854, p. 66, 119 (Osteologie).

An der ganzen Küste in Heerden ron meist 10-20 Stiick umherziehend. Auf den Insehn Shannon (Osthälfte), Pendulum und Sabine scheinen sie nur im Sommer vereinzelt vorzukommen. Ende März wurden sie schon auf Südwest-Shannon und dem Festlande gesehen, sodass sie auch im Winter dort sich aufzuhalten scheinen.

Am 26. März wurde ein erst wenige Tage altes Kalb gefangen und Anfang Juni wurden verschiedene Kälber bei den Heerden gesehen, von denen noch ein Balg mitgebracht werden konnte. Spuren dieser Thiere fanden sich sowol in den Ebenen als oben auf den Bergen.

Die Nahrung besteht aus Gras, Kräutern und Moosen.

\section{Cete, Walthiere.}

12) Batona mysticetus Linné. Grönlandswal.

In der Nähe wurde kein Walfisch geschen. Ueberhaupt wurde ron der Germania sowol auf der Hin-als Rückreise im Eise und längs der Küste nur zweimal das Blasen dieser Thiere deutlich gesehen.

Zwei kleine Stuicke von Barten, von denen eins bearbeitet war, wurden am Strande gefunden.

Von der Hansa wurde nur einmal durch das Fernglas der grönlimdische Wal, der Bowhead, an seiner eigenthiimlichen Kopfform mit Sicherheit erkannt.

13)? Balcenoptera boops Eschricht.

Finnfische von riesiger Grösse wurden in grösserer oder geringerer Entfernung von der Hansa im nordatlantischen Neere gesehen, welche mit ihrer spitzigen Rückenflosse hervortauchten. Aber ausser dem der Rückenflosse angrenzenden Theile des Rückens konnte man nichts von ihnen erblicken. Nur die aufsteigende Athemsäule konnte 
man beobachten und meilenweit schon ihr lautes Blasen höron, ein Geräusch, welches mit dem Ausströmen des Dampfes auf einem grossen Dampfer die meiste Aehnlichkeit hat. Jene oft beschriebene Fontaine schien nicht allein als der Niederschlag der mit Feuchtigkeit gesättigten Lungenluft anzusehen zu sein, sondern da sich das Spritzloch bei dem Blasen gewölnlich etwas unter der Wasseroberfläche befindet, wird eine Menge hier vertheilter Wasserbläschen mit emporgerissen, welche das Bild einer Fontaine darbieten. Denn nach Kapitän Hegemann's Mittheilungen spritzen auch die Potwale in dem warmen tropischen Neere häufig und andererseits hörte man auch die arktischen Wale öfters blasen, ohne eine Fontaine zu sehen, dann nämlich, wenn das Spritzloch sich ausser dem Wasser befindet.

\section{4) Monodon monoccros Linné. Narwal.}

Wurde sehr häufig zwischen dem Eise, zuweilen in ganzen Heerden gesehen. Der Lärm, den eine solche Heerde in dem sonst so stillen Eismeer verursacht, ist ausserordentlich gross; ausser dem schnaubenden und keuchenden Geräusch, welches sie beim Athmen hervorbringen, lassen sie mitunter auch einen sehr lauten stöhnenden Laut hören. Häufig hoben sie ihren braunmarmorirten Rücken weit aus dem Wasser hervor, aber nie liessen sie den Kopf und den Stosszahn iiber dem Wasser sichtbar werden. Es gelang nicht, weder mit dem Zündnadelgewehx noch mit der Harpune eins dieser Thiere zu erlegen.

15) (?) Delphimus globiceps Cuvier. Grinddelphin.

Von der Hansa wurde mehrmals ein stumpfköpfiger Delphin gesehen, in welehem Hex Dr. Buchholz 7). globicens zu crkennen glaubte.

\section{b. Fische.}

Gapleracti, Panzerfische.

\section{1) Cottus hexacomis Richardson.}

(?) Cottus scorpius Fabricius, Fam. grœnl. p. 156. (C. grœnlandicus Cuv. Val.) Cottus hexacornis Richardson, Faun. Boreali-Americana, III. Fische. p. 44.

Drei Exemplare eines Cottus, welche am 15. Juli bei Broer-Ruys gefangen worden sind, scheinen mir zu dieser Art zu gehören, welche 
offenbar äusserst nahe verwandt ist mit C. quadricornis Linné aus unsern Meeren. Vielleicht gehört sie auch zu C. scorpius Fabricius (C. grcenlandicus C. V.), da er von derselben (Fauna groenl., 1780, p. 156) sagt: "In capite et anteriore parte corporis 16 aculeos numeravi - - et praeter hoc tubercula obtusa scabra in vertice capitis situ quadrato locata." Verglichen mit einem Exemplar von C. quadricomis L. haben die rorliegenden Exemplare etwas kürzere Oberkiefer und die Interorbitalgegend mehr vertieft. Auch ist die Flossenstrahlenzahl eine verschiedene, indem das grösste Exemplar ron $27^{\mathrm{cm}}$ Länge, ganz wie Richardson es von einer Art angibt, in der ersten Ruickenflosse 7 Stacheln und in der zweiten 13 Strahlen hat. Indessen variirt diese Zahl, indem die beiden andern Exemplare D. 8-14 zeigen, ebenso wie alle drei in der Strahlenzahl der Analflosse voneinander abweichen, da dieselbe bei dem grössten Exemplare 14, und bei den andern beiden 13 und 15 beträgt. Das eine der Exemplare ist auch noch dadurch ausgezeichnet, dass der längste Dorn des Vordeckels der linken Seite an der Spitze gabelförmig ist, wie bei Cottus tricuspis. Es findet sich aber auch hei unsern Cottusarten oft eine nicht geringe Variation der Flossenstrahlen und anderer zur Unterscheidung der Arten benutzter Merkmale. So besitzt das Berliner Museum drei Exemplare von Cottus scorpius, welche der vorstorbene Dr. Strahl yor einigen Jahren aus der Ostsce mitbrachte (Nr. 7296 M. B.), welche ebenfalls alle eine verschiedene Strahlenzahl zeigen: 1) D. $9-15$; A. 11 . 2) D. $10-15$; A. 12 . 3) D. $10-16$; A. 13. Ausserdem hat das eine Exemplar an dem linken Vordeckel 4 anstatt 3 Dornen, ganz in derselben Weise gebildet, wie bei $C$. quadricomis. Fis bleibt daher noch immer zweifelhaft, ob die geringen Unterschiede zwischen C. hexacomis und quadricomis bei Verglcichung einer grössem Reihe stehen bleiben.

\section{2) Cottus porosus Cuv. Val.}

Cottus prorsus Cuv. Val., Hist. nat. Poiss. VIII. p. 498.

Cottus grontandicus Günther, Cat. Fish. II. p. 161 (e. p.).

Ein einziges noch junges, $12^{\mathrm{cm}}$ langes Exemplar hat Herr Dr. -Pansch im Juli 1870 in der Claveringstrasse erhalten. Es weicht nur dadurch von der von Cuvier und Valenciennes gegebenen Beschreibung ab, dass die Strahlenzahl D. 10--16; A. 13, anstatt D. 11-17; A. 13 ist, was aber nach dem bei der vorigen Art mitgetheilten von gar keinem Belange ist. Auch sind die Bauchflossen nicht in die Futfermung von der Analöfhumg gerüclit, wie res sich bei einem grossen const ganz damit ibbercinstimmenden Exemplar aus Grönland findet, 
welches unsere Sammlung aus Kopenhagen erhalten hat, und welches als C. groentandicus aufgestellt war. (Nr $70 \pm$ M. B.)

\section{3) Icelus hamatus Kíöyer.}

Icelus hamatus Kröyer, Naturh. Tijdsskr. 1844. I. 1. 253, 262; Gaimard, Voy:. commiss. scientif. Nord. etc. Zool. Poiss. Taf. I, Fig. 1.

Zwei kleine, $45^{\mathrm{mm}}$ lange Exemplare dieser Art wurden am 29. October 1869 auf ungefähr zwei Faden 'Tiefe bei 15 Zoll dickem Eise im Germaniahafen gefangen, die zu der genauen Beschreibung, welche Herr Kröyex von derselben gegeben, vollkommen passen.

Discoboli, Scheibenbäuche.

4) Liparis getatinosus Pallas. - Taf. I. Fig. 2.

Cyclopterus gelatinosus Pallas, Spicil. zoolog. 1769. VII. 1. 19. 'T'af. 3, Fig. $1-6$.

C'yclopterus liparis Fabricius, Faun. groul. 1780. p. 135.

Liparis communis Richardson, Faun. Boreali-Americ. 1836. III. p. 263,

Liparis tunicata Reinhardt, Vidensk. Selsk, oaturv, og math. Alf VI. 1837. p. CXI.

Liparis Fabricii Kröyer, Naturh. Tidsskr. II. 1847. p. 274; Gaimard, 1. c., I'af. 13. Fig. 2.

Liparis Fabricii Günther, Catal. Fish. III. 1861. p. 161.

Von dieser auffallenden Art, deren Fleisch selbst von den Hunden verschmäht wird, liegen mehrere Exemplare von $3 \frac{1}{2}-12^{\mathrm{cm}}$ Länge vor. Sie ist zuerst ron Kröyer nach frischen Exemplaren genauer beschrieben und auch abgebildet worden. Nach einer sorgfältigen Vergleichung der Pallas'schen Beschreibung, welche nach einem schlecht erhaltenen trockenen Exemplare gemacht ist, glaube ich nicht, dass die zuerst bei der Behrings-Insel beobachtete Art von der bei Spitzbergen und Grönland vorkommenden verschieden ist.

Nach Pallas ist die Strahlenzahl B. 7 (?); P. circa 30; D. 50 +; A. circa 45. Kröyer zählt B. 6; D. 13,27; P. 34; A. 2,30: C. 9 und Herr Dr. Günther B. 5ँ D. 42 ; A. 33-35; C. 12 . An einem $120 \mathrm{~mm}$ langen Exemplare finde ich B. 6; D. 46; A. 39; C. 11; P. $3 \check{.}$

Ich glaube daher, dass die Flossenstrahlenzahl bei dieser Art variirt, und ausserdem ist das Zählen wegen der Feinheit der Strahlen und auch weil sie leicht in ihre beiden Hälften zerfallen, mit einiger Schwierigkeit verbunden. Dagegen finde ich constant sechs Kiemenhautstrahlen, vou denen, wie Kröyer angibt, die beiden vordersten in einiger Entfernung von den andern liegen. Wemn Pallas sieben Kiemenhautstrahlen fand, so mag dieses wol daher rühren, 
dass er das fadenförmige Interopereulum mitgezïhlt hat und Günther's geringere Zahl mag daher entstanden sein, dass der hinterste Kiemenstrahl zuweilen sehr versteckt unter dem Interoperculum liegt.

Nach einer rom Herm Dr. Pansch gemachten Zeichnung vom 20. Mai 1870 sind der Kopf und die Flossen ochergelb mit dunkehn Pünktchen, der Bauch und der äusserste Rand der Brustflossen weiss.

Die Exemplare wurden theils im Germaniahafen bei der SabineInsel im October 1869, theils bei der Jackson-Insel, theils bei Shannon am 26. August 1869 gefangen. Exemplare, welche die Berliner Sammlung durch Herrn Hofrath ron Heuglin aus dem Storfjord in Spitzbergen erhalten hat, stimmen ganz mit den grönländischen überein.

\section{Gadini, Dorsche.}

5) Gadus glaciatis Ptrs. n. sp.

B. 7. P. 18 ; D. $12-18-22$; V. $6 ;$ A. $21-21$.

Der Unterkiefer überragt den Zwischenkiefer und ist am finn an der Stelle des Tiatfadens mit einem kleinen hä̈utigen Kü̈tchen rersehen. Schnauze von der Länge des Augendurchmessers, welcher nicht ganz drei und ein halb mal in der Kopflänge enthalten ist. Das vordere Nasenloch liegt doppelt so weit von der Schnauze, wie vom Auge entfernt, etwas höher als das doppelt so grosse hintere, welches sich näher vor dem Auge befindet. Dic Breite des Interorbitalraumes kommt nur zwei Drittel des Augendurchmessers gleich. Ueber jedem Supraorbitalbogen zieht eine Reihe von Schleimporen hin, ein anderer querer Bogen derselben befindet sich auf dem hintern und noch andere kürzere Linien auf der Schnauze. Die Zähne sind mässig lang und stehen auf den Kiefern, dem Vomerund den Gaumenbeinen in einfacher Reihe; nur am vordersten Ende des Zwischenund Unterkiefers finden sich ein parr Zähne, welche den Anfang einer doppelten Reihe bilden und die der Vomers stehen in Form eines nach linten offenen $\mathrm{V}$.

Die grösste Körperhöhe hinter den Brustflossen erreicht nicht ganz zwei Drittel der Kopflänge, welche $3^{1 / 2} \mathrm{mal}$ in der Totallänge ohne die Schwanzflosse enthalten ist. Der Schwanz ist nach seinem Ende hin sehr verdiinnt.

Die Körperschuppen sind sehr klein. Die Seitenlinie, welche wenig Zusammenhang zeigt, verläuft anfangs ungeführ unter dem obersten l'ünftel der Körperhöhe, steigt damn zwisehen der ersten und zweiten Rüickenflosse bogenförmig nach der Nitte der ersten Anal- 
flosse hin, fast bis zum untern Drittel des Körper's herab, um dam bis zum Schwanzende in gerader Richtung zu verlaufen.

Die senkrechten Flossen sind deutlich voneinander durch Zwischenräume getrennt. Die zweite Rückenflosse ist ein wenig länger als die dritte, aber etwas kürzer als die erste Analflosse, deren Anfang dem dieser zweiten Rückenflosse gegenübersteht, so dass di e Analöffuung etwas vor dem Anfange der zweiten Rückenflosse liegt und das Ende dieser letztern von dem Ende der Analflosse überragt wird. Die Brustflossen enthalten 18 Strahlen und erscheinen zugespitzt, indem die mittlern Strahlen verlängert sind. Auch die Bauchflossen sind spitz, indem ihr zweiter Strahl fadenförmig verlängert ist. Die Schwanzflosse ist gabelig ausgeschnitten.

Der ganze Körper und die Flossen sind dicht mit feinen schwarzen Punkten bestreut, welche nirgends zu Flecken zusammenfliessen. Am Kopf und Bauche schimmert durch die braune Grundfarbe silberiges Pigment durch.

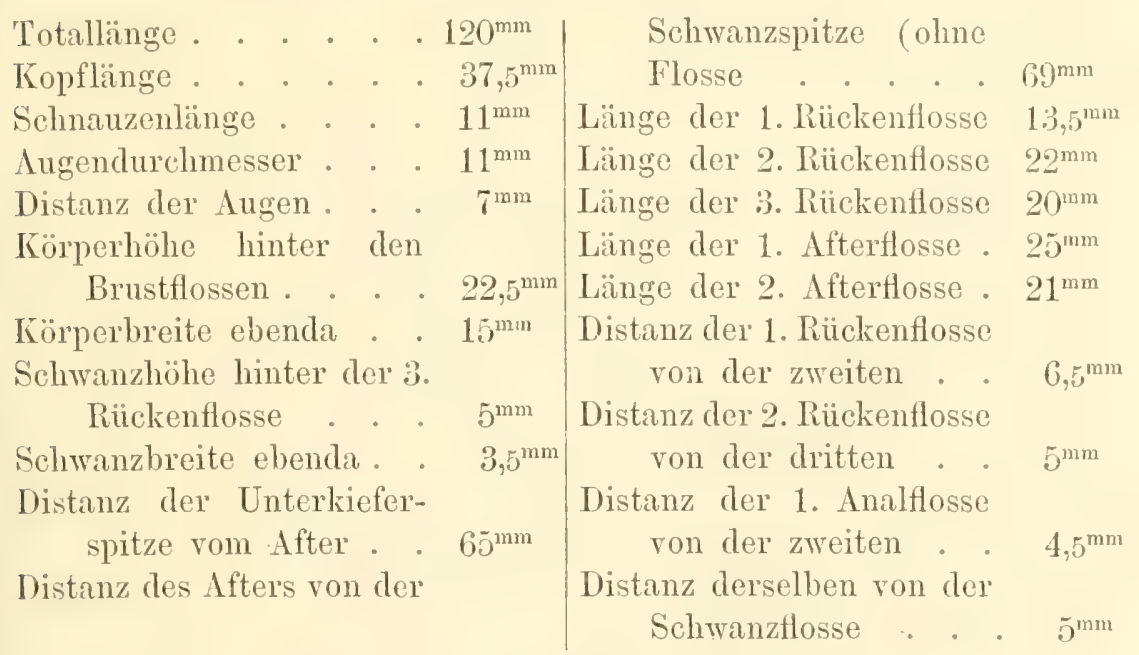

Diese Dorschart, von welcher leider nur ein einziges Exemplar rorliegt, schliesst sich in Bezug auf die Entwickelung der Flossen, die Form der Seitenlinic n. A. zunächst an $G$. navaga an, während der rorspringende Unterkiefer und die Zahnbildung sie dem G. polavis ammïhert.

Fundort: Sabine-Insel. 
Salmonini, Lachse.

(i) ? Salmo Hoodii Richardson.

Salmo Hoodii Richardson, Fauna Boreali-Americana. III. Fish. 1836. p. 173. Taf. 82, Fig. 2; 'laf. 83, Fig. 2; Taf. 87, Fig. 1.

(?) Salmo nitidus Günther, Cat. Fish. 1866. VI. p. 150.

Zwei noch sehr junge Lachse, einer von 12, und der andere von nur $5^{\mathrm{cm}}$ Iänge sind von Dr. Copeland im Juli aus dem obern Sïsswassersee auf der Sabine-Insel gefischt worden, welche mir zu der ron Richardson als Salmo Hoodii beschricbenen Art zu gehören scheinen, obgleich dieses nach so jungen Exemplaren mit rollkommener Sicherheit nicht nachzuweisen ist. Aber die ganze Körpergestalt, die Form der Schnauze, die Flossenstrahlenzahl, D. 12; A. 11, die sehx kleinen Schuppen, 28-29 Längsreihen zwischen der Seitenlinie und Rückenflosse, stimmen mit der Beschreibung und den Abbildungen ron Richardson überein. Die von Giinther unter S. nitidus gegebene Abbildung stimmt vielmehr mit derjenigen ïberein, welche Richardson S. Hoodii und gar nicht $7 u$ der, welche er S. nitidus nennt.

\section{Erklärung der Abbildungen.}

Tafel I.

Fig. 1. Oberes Gebiss eines jungen weiblichen Walrosses.

$i^{1}, i^{2}, i^{3}$, Milchschneidezïhne.

$e$, Milcheckzähne.

$p^{2}, p^{3}, p^{4}, p^{5}$, Milchbackzähne.

$I^{3}$, Ersatzschncidezalm.

$C$, Ersatzeckzahn.

$P^{1}, P^{2}, P^{3}$, Ersatzbackzahn.

$x^{1}, x^{2}, x^{3}$, Lücken der ausgefallenen Schneidezähne.

Fig. 2. Unteres Gebiss desselben. Bezeichnung wie oben.

Fig. 3. Liparis gelatinosus Pallas. Nach einer Zeichnung ron I)r. Pansch.

Tafel 11.

Schählel und Gebiss von Lepus glacialis Leach. 
Z00L0GIE, 2. Säuggethiere und Fische Taf.1.
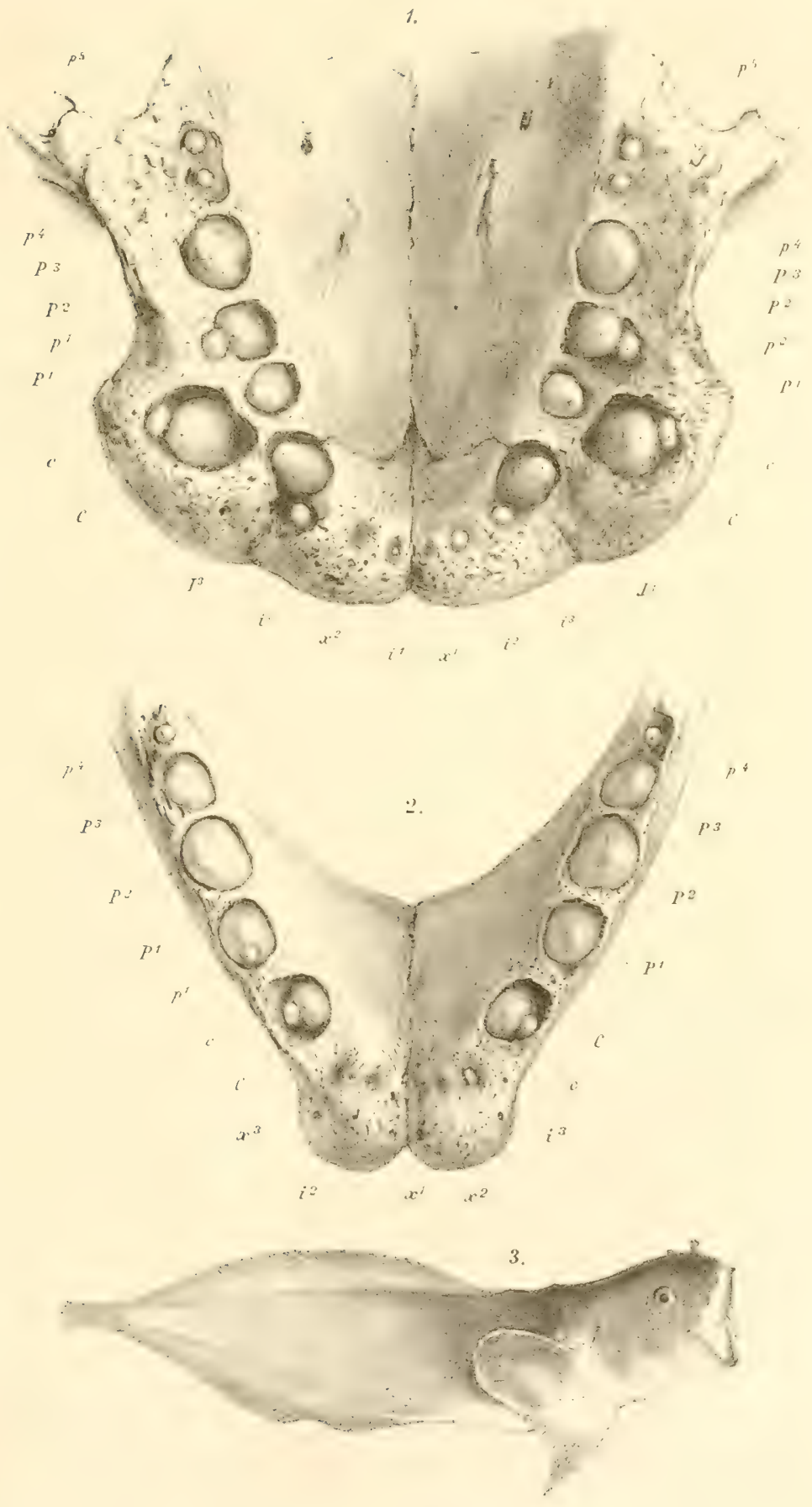

1.2. Odobaenus Rosmarus L. 3.Liparis gelatinosus Pallas. 

ZOOLOGIK, 2. Säuggethiere und Fisch" Taf. "2.

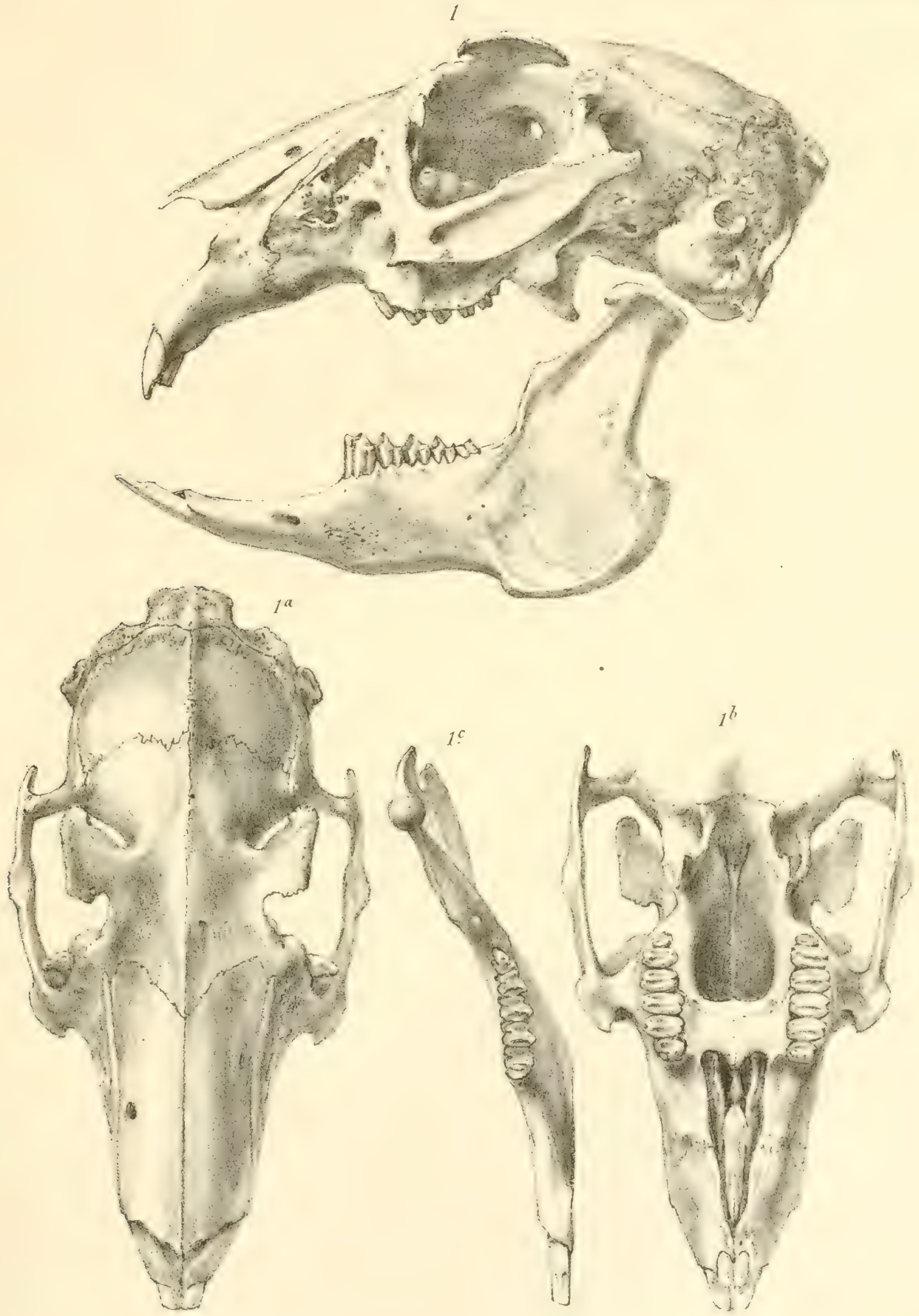

Lepus glaciatis Leach. 

3.

\title{
Bemerkungen über die Schädel der Eskimohunde.
}

\author{
Bearbeitet von \\ Hermann von Nathusius \\ in Hundisbarg.
}

Eis liegen vor an mehr oder weniger vollständigen Schädeln:

5 von der Sabine-Insel; Nr. 107, 288, 373, 438, 439. ${ }^{1}$ Warren.

1 jüngerer Schädel ohne alle Zähne; Nr. 108, von Kap Borlase

1, Nr. 437, von der Jackson-Insel und

1, Nr. 444, von der Shannon-Insel.

Ferner 3 Schädelfragmente: "

Nr. 294 und Nr. 380 von der Sabine-Insel;

Nr. 445 von der Jackson-Insel.

6 Unterkieferhälften, von denen die zwei zusammengehörenden Nr. 441, dann zwei einzelne, Nr. 444 und 443, yon der Jackson-Insel kommen, Nr. 110 von Kap Borlase Warren und die letzte, Nr. 515, nicht näher bezeichnet ist.

Ausserdem finden sich bei der Sendung das Fragment eines Eckzahns und ein erster Schneidezahn des rechten Oberkiefers, welcher vielleicht zu dem Schädel Nr. 439 gehört.

Die Schädel sind sämmtlich in der Nähe verlassener Eskimohütten gefunden.

Alle Knochen sind stark verwittert, daher von leichtem Gewicht und ohne alles Fett, sie sind sämmtlich mehr oder weniger defect.

Es ist nicht möglich aus dem Zustand der Knochen ïber die Zeit zu urtheilen, welche seit dem Tode der Thiere rergangen ist.

1 Nr. 438 und 439 sind im Terzeichniss als ron der: Sabine-Insel stammend angeführt, auf beiden Schädeln ist mit Bleistift "Jackson" notirt. 
Der Schädel Nr. 288, nach der Abnutzung der noch vorhandenen beiden Kauzühne von einem 'Thier von hohem Alter herrührend. ist durch einen Schlag auf das linke Hinterhauptbein zertrümmert.

Alle diese Knochen stammen unzweifelhaft von Haushunden her, und zwar, soweit sich dariuber nach den Schädeltheilen ein Urtheil fällen lïsst, alle von einer und derselben Rasse.

Was die Rasse betrifft, so ergibt sich in keiner Weise ein Unterschied ron dem jetzt lebenden Eskimohunde, von welchem eine Suite ron Schädehn zum Vergleich vorliegt, von denen die meisten durch die Herrnhuter Nissionare aus Labrador iiberschickt sind.

Der grösste der messbaren Schädel, Nr. 439, hat vom untern Rande des Hinterhauptlochs bis zum vordern Alveolarrande des ersten Schneidezahns eine Längenachse von $189^{\mathrm{mm}}$; der kleinste misst in derselben Dimension $175^{\mathrm{mm}}$. Es ergibt dies dieselbe Grösse, welche die Schädel der jetzt lebenden Eskimohunde haben. Es ist dies auch ungefähr dieselbe Grösse, welche die stärkern Formen der deutschen Hirtenhunde und einige unserer Vorstehhunde haben, wogegen bei dem grössern der bei uns gehaltenen Neufundländer $210^{\mathrm{mm}}$ vorkommt; dieselbe Dimension hat der Tibet-Mastiffe. (Der grösste von mir bis jetzt gemessene Hundekopf, ein doggenartiger Mischling, hat we 2um; der kleinste, ein Terrino mit Blut vom Wachtelhund, dagegen nur $67^{\mathrm{mm}}$. Der grösste mir bekannte europäische Wolf $235^{\mathrm{mm}}$.)

Es ist von besonderm Interesse, bei einer Suite von Schädeh. welche aller Wahrscheinlichkeit nach von Thieren stammen, welche einer und derselben Rasse angehören, die Variabilität der Gestalt zu beobachten. Es ist wol nicht zu gewagt, anzunehmen, dass die vorliegenden Hunde einigermaassen gleichartig gewesen sind; die dort ausgestorbenen Eskimos werten nicht in lebhaftem Verkehr mit andern Volksstämmen gewesen sein, sie werden schwerlich ihre Hunde mit andern Rassen gekreuzt haben, man wird demnach diese Thicre für einigermaassen rasserein halten dürfen. Es zeigen aber die sämmtlichen acht Schädel in denjenigen Theilen, welche bei dem Hundeschädel besonders variabel sind, mehr oder weniger auffallende Differenzen, agbesehen, wie sich von selbst versteht, von denjenigen, welche durch verschiedene Altersstufen bedingt sind, wie z. B. die Occipitalkïmme.

Dic Nasenbeine treten tiefer in die Stirn hinein als die Frontalränder der Oberkiefer, oder sie erreichen nicht eine Linie, welche diese Ränder beider Oberkiefer tangirte; die Orbitalleisten sind mehr oder weniger aufgetrieben, damit die Stirnhöhlen mehr oder weniger gross; die Stirn zwischen den Orbitalfortsïtzen ist mehr oder weniger 
tief concav, oder fast ehen; die Augenhöhlen sind kleiner oder grösser; die Jochbogen mehr oder weniger weit und hoch, soweit dies aus den vorhandenen Resten zu schliessen, denn nur ein Schädel, Nr. 107, hat unverletzte Jochbogen.

Es sind alles dieses Kennzeichen, durch welche man versucht hat, Hunde von Wölfen zu unterscheiden. Die Nasenbeine sind in ihren vordern Theilen bei keinem Exemplare unverletat und müssen deshalb hier ausser Petracht bleiben.

So gibt dem auch wieder diese kleine Sammlung einen Beitrag zu der Beobachtung, dass die Hausthierrassen, und ganz besonders die Hunde, auch imnerhalb der Grenze, welche einen Rassetypus umschreiben, äusserst variabel in der Schädelform sind.

Die Zähne sind zu unvollständig, um umfassendere Vergleiche anstellen zu können. Die sonst in der relativen Grösse so variabeln Reisszühne des Oberkiefers (es sind nur in vier Schädeln einige davon vorhanden) ergeben nur insofern wichtigere Differenzen, als sich anch hier zeigt, dass der Imnenhöcker dieses Zahns, unabhängig ron der Abnutzung, rerschieden stark entwickelt ist.

Alle Schädel sind hinlänglich erhalten, um zu zeigen, dass an keinem derselben ein dritter Kauzahn im Oberkiefer vorhanden war, ein sonst nicht so seltenes Vorkommen, wie man nach der Untersuchung einzelner Hundeköpfe, wol anzunehmen pflegt. 


\section{4. \\ Vög e l.}

Bearbeitet von

Ot to Fin s ch

in Bremen.

Mit Noten von Adolf Pansch in Kiel.

Der nachfolgende Bericht iiber die durch die zweite Dentsche Polarexpedition gesammelten und beobachteten Vögel darf als die erste sichere Kunde über die Avifauna Ostgrönlands gelten. Alles was wir bisher über dieselbe wussten, beschränkte sich auf das Namensverzeichniss im Anhange zu Kapitän Graah's Reisewerke, dem aber nur Beobachtungen $7 u$ Grunde liegen, da der muthige Reisende anf seiner chenso gefahrollen als miihseligen und enthehrungseichen Bortfihrt ganz auswer Stand war Sammlungen anzulegen. Ausserdem führt uns die deutsche Expedition in ein ornithologisch röllig unbekanntes Gebiet ein, welches sich ungefähr vom 73. bis zum 76 . Grade erstreckt, während Graah's Beobachtungen nur bis etwa zum 66. Grade reichen.

Graah's Liste verzeichnet nur 23 Vogelarten, denen die deutsche Expedition 11 weitere hinzufügen kann, sodass die Gesammtzahl der bis jetrt aus Ostgrönland bekannten Arten 34 beträgt. Wenn diese Zahl im Vergleich zu den 118 ron der Westküste nachgewiesenen Arten auffallend gering erscheint, so dürfen wir nur daran erimnern, dass in jenen, im geregelten Verkehr mit Europa stehenden Gebieten, schon seit einer Reihe von Decennien eifrig gesammelt wurde, dass

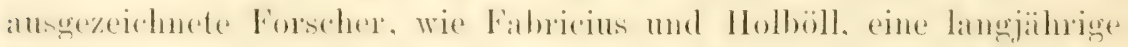
Thätigkeit in denselben entfalteten und dass sie überhaupt mit zu den bestdurchforschten gehören. Ohme Zweifel werden fortgesetzte 
Untersuchungen an der Ostkiiste die Zahl der Arten nicht mbeträchtlich vermehren, wir sind aber nach den bisherigen Erfahrungen zu dem Schlusse berechtigt, dass Ostgrönland ein bei weitem ärmeres Vogelleben besitzt als die westlichen und südlichen Küisten. Es muss dies hauptsäichlich mit auf liechnung des Einflusses gebracht werden. den die bedentend reichere und formenbelebtere Thierwelt des arktischen Amerikas, durch die Lage begïnstigt, auf jene Gebiete ausiiht; aher nicht minder wichtig erscheinen die Einwirkmngen der klimatischen Verhältnisse, welche das Vogelleben an der Ostküste uffenbar beeinträichtigen. Während die Westkuiste neben 19 emropäischen Arten nicht weniger als 35 amerikanische unter ihren mehr oder minder häufigen oder zufälligen Besuchern zählt, hat Ostgrönland nur allgemeiner verbreitete Polarvögel aufzuweisen, die ohne Ausnahme anch an der Westkiiste rorkommen und sümmtlich Furopa beriihren. Fast alle Arten sind auch auf Island heimisch, 21 finden sich zugleich auf Spitzhergen, 29) in arktischen Amerika und $26 \mathrm{im}$ nördlichsten Asien. Es ist aber nicht nur die beträchtlich geringere Artenzahl; welche hei der Vogelwelt Ostgrönlands auffällt und fiir dieselbe charakteristisch wird, auch das Auftreten der einzelnen Arten ist ein an Individuen ungleich beschrinkteres. Unsere Polarfahrer fanden nirgends Localitäten, welche nur im entferntesten mit den Schilderungen zu vergleichen wären, wie sie Holböll ${ }^{1}$ von den Vogelbergen an der Westküste entwirft, dem es an Worten mangelt, um ihre unzählbaren Bewohner zu schätzen. Ich habe mich nach diesen Verhältnissen, die mich speciell interessiren, bei allen mir befreundeten Mitgliedern der Expedition erkundigt, sie vermochten mir aher nicht bessere Auskunft zu ertheilen, als sie durch Dr. Pansch in den nachfolgenden Blïtern, auf (irund sorgfïltiger Renbachtungen. gegeben wird.

Dieser eifrige und unermuidliche Forscher hat sich, unterstüt durch andere Mitglieder der Expedition, namentlich den trefflichen Dr. Copeland, die Förderung der Ornithologie in hohem Grade angelegen sein lassen, was hiermit öffentlich anerkennend 7.11 erwähnen mir zur angenehmen Pflicht wird.

1 Holböll vergleicht den Felsen Kassarsoak, südlich von Upernevik, auf dem hauptsächlich Uri̊ Brïmichi brütet, mit einem Bienenstock zur Zeit des Schwärmens: ,Fält ein Schuss, so wird im eigentlichen Sinne des Wortes die Sonne verdunkelt." Und Faber schätzt die Zahl der auf Westmannöe bei Island jährlich ausgenommenen Jungen ron Procellaria glacialis auf wenigstens 20000. 


\section{Ve1\%eichniss}

der

bis jetzt in 0stgrönland beobachteten Vögel.

G. = Graah, P. = Pansch, C. = Copeland, B. = Buchholz.

\begin{tabular}{|c|c|c|c|c|c|c|c|c|}
\hline & & $\begin{array}{l}\text { Gröir } \\
\text { Ost- } \\
\text { küste }\end{array}$ & $\begin{array}{l}\text { land } \\
\text { West- } \\
\text { kuiste }\end{array}$ & $\begin{array}{l}\text { Is- } \\
\text { lant }\end{array}$ & $\begin{array}{c}\text { Spitz- } \\
\text { bergen }\end{array}$ & $\begin{array}{l}\text { Eu- } \\
\text { ropa }\end{array}$ & $\begin{array}{l}\text { Nori- } \\
\text { Ame- } \\
\text { rika }\end{array}$ & $\begin{array}{l}\text { Yord- } \\
\text { Asien }\end{array}$ \\
\hline 1. Falco? candicans & G. P. & $"$ & $"$ & $n$ & ? & 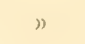 & $"$ & $n$ \\
\hline 2. Haliaëtus albicilla & G. -1 & $"$ & ” & $"$ & - & $n$ & - & ? \\
\hline 3. Nyctea nivea & G. P. & $n$ & $"$ & $"$ & $"$ & 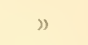 & ” & 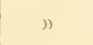 \\
\hline 4. Saxicola oenanthe & $-P$ & ") & $"$ & 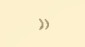 & - & $n$ & $"$ & $n$ \\
\hline 5. Corvus corax & G. P. & $"$ & $n$ & $n$ & - & ” & 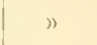 & " \\
\hline 6. Aegiothus canescens & $-P$ & $"$ & ” & - & - & $"$ & - & ” \\
\hline 7. Plectrophanes nivalis & G. P. & $n$ & ") & $"$ & $"$ & $n$ & $"$ & $n$ \\
\hline 8. $\quad$ "lapponicus & $-P$ & » & " & » & - & ” & $n$ & $n$ \\
\hline 9. Lagopus atpinus & G. P. & $"$ & $n$ & $n$ & - & 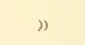 & $?$ & » \\
\hline 10. Charadrius hiaticula & $-\mathrm{P}$ & ” & $"$ & 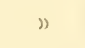 & $»$ & $"$ & - & $n$ \\
\hline 11. Strepsitas interpres. & $-\mathrm{P}$ & " & $m^{*}$ & $"$ & " & $"$ & ” & " \\
\hline 12. Catidris arenaria & $-\mathrm{P}$ & $n$ & ” & $"$ & - & $”$ & $n$ & $"$ \\
\hline 13. Tringa maritima & $-\mathrm{P}$ & ” & ” & 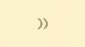 & $"$ & $n$ & " & ” \\
\hline 14. Anser albifrons & $-\mathrm{C}$ & $”$ & $n$ & 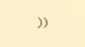 & - & $"$ & - & $n$ \\
\hline 15. ", leucopsis & G. C. & ” & $"$ & 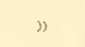 & $”$ & $"$ & ? & $n$ \\
\hline 16. Cygnus musicus & G. - & $n$ & $"$ & ” & ? & ” & - & $n$ \\
\hline 17. Harelda glacialis & G. P. & $n$ & 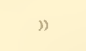 & $"$ & $n$ & $"$ & $n$ & $"$ \\
\hline 18. $\quad "$ histrionica & G. - & $"$ & $n$ & $n$ & - & » & ” & ” \\
\hline 19. Somateria molissima & G. P. & $n$ & 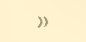 & ") & $n$ & $n$ & $n$ & - \\
\hline 20. $" \quad$ spectabilis & G. P. & $"$ & $”$ & 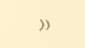 & $"$ & $n$ & $”$ & $"$ \\
\hline 21. Colymbus torquatus & G. - & $n$ & $"$ & ” & 一 & $»$ & $n$ & $"$ \\
\hline 22. $\quad "$ septentrionalis & G. P.| & 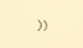 & $"$ & ” & ” & ” & ” & $"$ \\
\hline 23. Uria Brïnnichi & G. P. & $n$ & $n$ & ” & ” & 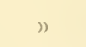 & $"$ & - \\
\hline 24. $\quad, \quad$ grylle & P. B. & 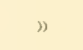 & $"$ & ” & $"$ & $n$ & $"$ & - \\
\hline 25. Mergulus alle & P. B. & $\eta$ & ” & ” & $»$ & $"$ & $"$ & - \\
\hline 26. Procellaria glaciatis & G.P. & 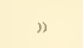 & ” & ” & $"$ & 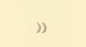 & $n$ & - \\
\hline 27. Larus glaucus G. & P. B. & » & $"$ & ” & ” & - $)$ & 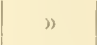 & $"$ \\
\hline 28. , Ieucopterns & P. & ” & $n$ & ” & - & $"$ & $n$ & ? \\
\hline 29. " "eburneus & P. B. & $n$ & " & - & $"$ & )$. & ” & - \\
\hline 30. $\quad$ " tridactylus & G. P. & $n$ & ” & $"$ & $»$ & ” & ” & - \\
\hline 31. Stercorarius parasiticus & G.P.B. & ” & » & $n$ & $"$ & $"$ & $»$ & $"$ \\
\hline "longicaudatu & us $\mathrm{P} . \mid$ & ") & 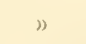 & $n$ & ? & ") & $"$ & $n$ \\
\hline 33. Sterna macroura G. & P. B. & $"$ & " & $\Rightarrow$ & $"$ & $n$ & $n$ & $"$ \\
\hline 31. Graculus carbo & G. & $"$ & $"$ & $n$ & " & " & $"$ & - \\
\hline
\end{tabular}


R a paces. Raubvögel.

\section{1) Falco areticus Holb. Polarfalke.}

Blasius, Nachtrïge zu Naumamn's Vögel Deutschlands, XIII, 19.

Falco candicans, Naumann, 'Taf. XXI, Fig. 1.

Kapitän Hegemam erhielt durch Güte der Missionare in Lichtenau in Südgrönland ein prachtvolles altes Exemplar eines weissen Falken, der nach Blasius' Darstellung zu $F$. arcticus gehört. Er trägt auf den obern Schwanzdecken die charakteristischen dunkeln Querbinden und stimmt fast ganz mit der oben citirten Abbildung Naumann's überein; aber die ganze Unterseite ist bis auf einige wenige dunkle Strichelchen an den Banchseiten, die sich auf den Hosen zu etwas grössern pfeilförmigen Fleckchen gestalten, rein und einfarbig weiss; auf dem Weiss des Oberkopfes sind äusserst schmale schwärzliche Schaftstrichelchen;. der Schwanz trägt 11 dunkle Querbinden, die anf der Innenfahne der äussern Federn theilweise sehr undeutlich erscheinen, schmäler sind und sich auf einzelnen Federn bis auf 14 steigern.

Ob $F$. arcticus wirklich als gute Art betrachtet werden darf, wie Blasius (l. c.) annimmt, wird nach den spätern Mittheilungen dieses Gelehrten (Journ. f. Orn., 1862, S. 43-59) zweifelhaft. Vier aus Suidgrönland erhaltene weisse Falken, die ich der Güte von Missionar Starick in Lichtenfels verdanke, zeigen allerdings die dunkle Längsfleckung auf dem Bürzel, obschon in sehr verschiedener Ausdehnung, aber ein Männchen (5. December) besitzt ausserdem eine Bürzelfeder, die deutlich drei dunkle Querbinden zeigt. Es liefert dies Exemplar also einen neuen Beleg zu den bereits durch Blasius angeführten Beispielen und macht dessen Annahme, dass die Polarfalken der arktischen Zone nur Eine Art bilden, sehr wahrscheinlich.

\begin{tabular}{|c|c|c|c|c|c|c|c|c|}
\hline Fl. & $\begin{array}{l}\text { Flügel- } \\
\text { spitze. }\end{array}$ & Schw. & F. & $\begin{array}{l}\text { Mund- } \\
\text { spalte. }\end{array}$ & L. & M. Z. & $\begin{array}{l}\text { Nag. } \\
\text { ders. }\end{array}$ & 1 \\
\hline $16^{\prime \prime}$ & $5^{1 / 2} 2^{\prime \prime}$ & $8^{\prime \prime} 7^{\prime \prime \prime}$ & $12^{\prime \prime \prime}$ & $18^{\prime \prime \prime}$ & $36^{\prime \prime \prime}$ & $27^{\prime \prime \prime}$ & $10^{1} / 2^{\prime \prime \prime}$ & 2 arcticus. \\
\hline 14 & 310 & 79 & $10^{1 / 2}$ & 15 & 33 & 22 & & ô candic. Südgrönl \\
\hline $159^{\prime \prime \prime}$ & $4 \quad 4$ & 9 & $11^{1 / 2}$ & 16 & 30 & 25 & 10 & 2 \\
\hline 162 & 48 & 93 & 12 & 19 & 31 & 25 & $9^{1 / 2}$ & 2 \\
\hline
\end{tabular}

1 Die Maasse sind nach dem altfranzösischen Fussmaasse. Fl. = Flügel, Schw. = Schwanz, F. = Firste, L. = Lauf, M. Z. = Mittelzehe. 
Sowol Kapitän Graah, als Dr. Pansch und Dr. Buchholz ${ }^{1}$ (1. c., p. 12) rerzeichnen ,weisse Falken" als von ihnen an der Ostküste beobachtet. (F. cundicans Gratah, 1. 178. - F. islundicus Holb., p. 18.)

Graah notirt auch Haliuëtus albicille (Veltur [Aquilu]) albicilla ${ }^{2}$ (p. 178) von der Ostküste.

\section{2) Nyctea niver (Daud.). Schneeeule.}

Strix nyetea L., Naumann, Vögel Deutschl., I, 417, Taf. 41.

Strix myctea L., Holböl, Fauna Grönlands ${ }^{3}$, S. 21.

Strix myctea L., Graah, Reise, S. 178.

Strix nyctea L., Middendorfi', Sibirische Reise, S. 130.

Nycter nivea Baird, B. N.-Am., 1. 63.

Nyctee niven Dall and Bamnister, B. of Alaska, 1. 273.

Strix nyeter Nahmgren, Journal für Ornithologie, 1563, S. 385 (Spitzbergen).

Nycten nivea Newton, Ibis, 1865, 1. 501 (Spitzbergen).

Nycter niver Gillet, Ibis, 1870, 1. 305 (Nowaja-Semlja).

Surnia nycte Heuglin, Ibis, 1872, p. 61.

Ein im August 1869 auf Shamon gefundenes, wohlerhaltenes mit Federn bekleidetes Bein, dem noch ein Stück des Beckens anhängt, liefert einen nenen Beleg für das Vorkommen der Schneeeule in Ostgrönland, welches bereits durch Kapitain Grah notirt wurde.

Nach Mahngren gehört die Schneeeule auf Spitzbergen zu den grössten Seltenheiten. Gillet verzeichnet sie sehr häufig auf NowajaSemlja und vermuthet ihre hauptsächlichste Nahrung. werde in Seevögeln und Polarfïichsen bestehen.

Heuglin fand drei Nester mit Dunenjungen an der Mündung der Natthews-Strasse.

Das auf Shannon gefundene, am Beckentheile oftenbar von Zähnen bearbeitete Bein, lässt an der Annahme kaum zweifeln, dass die Schneeeule unter Umständen auch ein Opfer des Eisfuchses werden

${ }^{1}$ Der Reisende gibt sehr interessante Notizen und Beobachtungen über Säugethiere und Vögel in: Erlebnisse der Mammschaft des Schiffes Hansa bei der zweiten Dentschen Nordpolfahrt, nebst Bemerkungen über das Leben der Thiere in hohen Norden, nach brieflichen Nittheilungen des Herrn Dr. Buchholz herausgegeben von der königl. physikal.ökonom. Gesellschaft zu Königsberg, 1871.

${ }^{2}$ Ich citire mach der englischen Ausgabe: Narrative of an Expedition to the East-coast of Greenland, sent by order of the king of Denmark, in search of the lost colonies, under command of Captı. W. A. Graah, of the Danish Royal Navy. Iranslated from the Danish by the late G. Gordon Macdougall, F. R. S. N. A., for the Royal geographical Society of London with the Original Danish Chart completed by the expedition (London, John W. Parker, 1837).

${ }^{3}$ Uebersetzt von J. H. Paulsen, Leipzig 1816. 
kann, denn offenbar ist es das Ueberbleibsel einer Mahlzeit dieses gefrässigen Räubers.

Ein prachtrolles altes Exemplar der Schneeeule ist von Kapitän Hegemam atus sidgrönland mitgehraht worden. Er erhielt es dureh Giite der Missionare in Friedrichsthal.

[Lebend wurden von uns keine Schneeeulen beobachtet. 'Trotz vielen Unherstreifens auf dor Walross-Iusel habe ich auch nie Spuren derselben wahrgenommen, obschon die der Lemminge häutig waren. Ich schliesse daraus, dass die Schneeule eine seltene Erscheinung an der Ostkuiste ist. - P.]

\section{l'asseres. Sperlingsvögel.}

3) Saxicola wnanthe L. Gl'auer Steinschmätzer.

Naumann, Vögel Deutschlands, III, 863, Taf. 89.

Faber, Prodr. island. Ornith., p. 18.

Sabine, Limn. Traus., XII (1818), p. 531.

Holböll, Faun. Grönl. (1846), p. 23.

Reinlı., Ibis, 1861, p. 5 .

Middendortt, Sibirische Reise, S. 174.

Saxicola cenanthoides Vig., Cass. Ill. B. of Calif., p. 208, Taf. 34.

Saxicola wenthe Baird, B. N.-An., p. 220.

Saxicole wnanthe Dall and Bamister, B. of Alaska, p. 276.

Die von der Shamnon-Insel heimgebrachten drei Exemplare stimmen durchaus mit solchen aus Deutschland iiberein. Ein Weibchen zeigt die grauen Federn der Oberseite fein rostbrämlich gespitzt, sodass der Mantel und der Hinterricken fast von letzterer Farbe ersheinen; Kimn, Kehle. Kropt und IIalsseiten sind lebhaft roströthlichgelb, die iibrige Unterseite ebenso, aber weit blasser. Dieses Exemplar, ein Weibchen, wurde am 13. Mai 1870 erlegt und stimmt mit der Beschreibung überein, wie sie Naumaun (S. 867) vom frisch vermauserten Herbstkleide entwirft.

Die beiden andern Exemplare (am 26. Juli 1870 auf der ShannonInsel geschossen) sind junge Vögel, (lie sich theilweise in voller Mauser befinden. Sie haben die Oberseite braun, den Augenstreif, die Backen und die Unterseite dunkel rostroth gefärbt, gegen den Bauch und die untern Schwanzdecken zu heller; die obern Flügeldecken sind roströthlich gespitzt und die völlig vermauserten und ausgevachsenen Schwingen und Schwanzfedern haben roströthliche Spitzenkanten.

Diese beiden Exemplare sind sichere Belege dafür, dass S. cenunthe auch in Ostgrönland Brutrogel ist, wie dies bereits durch Holböll fiir Westgrönland nachgewiesen wurde. 
Der Mageninhalt der in Spiritus präservirten Exemplare bestand bei dem einen ans liesten von Beeren, bei dem andern in Ueberbleibseln von Kïfer'n.

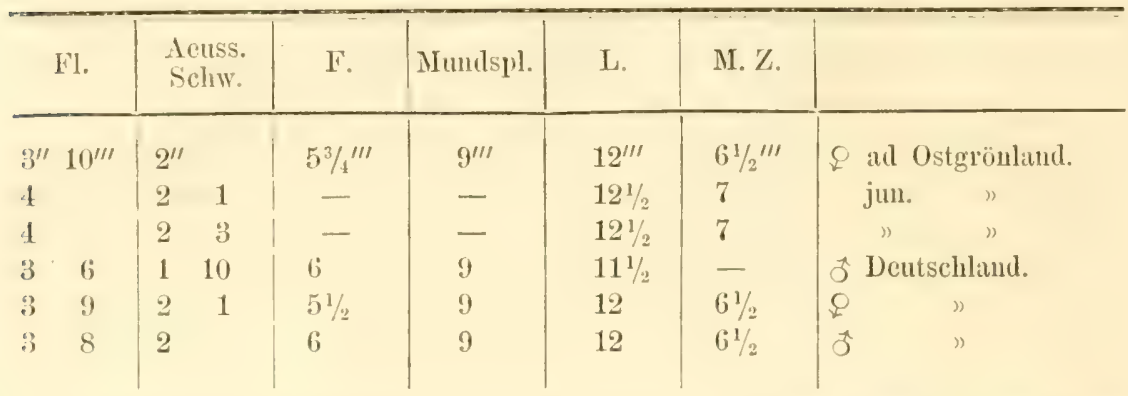

Wie die hier mitgetheilten Messungen zeigen, hat es den Anschein als ob die grönländischen Exemplare etwas grösser wären, worauf Cassin auch bei amerikanischen Exemplaren aufmerksam macht, doch sind diese Unterschiede so geringfügig und es zeigen sich so entschiedene Uebergangsformen, dass ron einer artlichen Abtrennung der arktischen Exemplare gar nicht die Rede sein kann.

Das Vorkommen des grauen Steinschmätzers in Grönland wurde bereits durch Holböll nachgewiesen, der ihn an der Westküste bis uiber den 73. Grad hinaus antraf. Es ist daher interessant ihn num anch als Bewohner der Ostküiste notiren zu kömnen, wo er noch über dem 75. Grade vorkommt, etwa in denselben Breiten, in welchen ihm von Middendorff in Nordsibirien als häufig begegnete. Dass die nordamerikanische $S$. conanthoides Vig. unbedenklich mit dieser Art zusammenfällt, hat Professor Baird bereits nachgewiesen. Bisher waren nur vereinzelte Fälle des Vorkommens in Nordamerika bekannt, sodass man dieselben auf Tersprengte aus Grönland beziehen zu mïssen glaubte. Die Naturforscher der Russisch-Amerikanischen TelegraphenExpedition haben indess $S$. cenanthe in Nordwest-Amerika angetroffen und zwar in grössern Fliigen, sodass das gleichzeitige, keineswegs zufällige Vorkommen der Art in der nenen Welt ausser aller Frage steht. Bemerkenswerth ist es, dass die Art in Ostsibirien und Kamtschatka zu fehlen scheint.

Nit Ausnahme der Uferschwalbe (Cotyle riparia) gilot es unter sïmmtlichen kleinen Landvögehn wol keinen weiter, dessen Verbreitungsgebiet nur ammähernd so ausgedehnt wäre, als das des grauen Steinschmätzers. Wenn wir bedenken, dass ihn seine Winterwanderungen bis in das Innere Afrikas (Quellenländer des Nil, Rothes Neer, Senegal), auf die Canarischen Insehn, in Asien bis Bengalen südlich 
hinab führen, während er von Kleinasien und dem Libanon an bis zum hohen Norden hinauf als Brutrogel angetroften wird, so müssen wir billig darüber stamen und dürfen uns nicht verhehlen, dass wir so exceptionelle Verbreitungsverhältnisse vorläufig nicht genügend zu erklïren wissen.

[Am 13. Mai 1870 verfolgte ich auf der Höhe der Walross-Insel einen Vogel, den ich anfänglich für einen Plectrophanes lapponicus hielt. Er hiupfte zwischen den Steinen umher und war wenig scheu. Als ich ihn erlegt hatte, erkamnte ich sogleich unsern Steinschmätzer in ihm, was mich nicht wenig überraschte. 'Zwei andere Exemplare wurden später auf Shamnon (26. Juli 1870) von mir geschossen. Wir sahen sonst nur noch wenige dieser Vögel. - P.]

4) Corvus corax L. Kollkrabe.

Naumam, Vögel Deutschlands, II, 43, Taf. 53, Fig. 1.

Corvus corax, var. littoralis Holböll, Faun. Grönl., p. 28.

Corvus corax Graah, Reise, S. 178.

Corvus corax Reinh., Ibis, 1861, p. 7.

Corvus corax Sabine, Linn., Trans., vol. XII (1818), p. 530.

Corvus simuatus Wagl., Isis, 1829, p. 748 (Mexico).

Corvus cacolotl Wagl, l. c., 1831, p. 527 (Mexico).

Corvus nobilis Gould, Proc. Z. S., 1837, p. 79 (Nexico).

Corvus corax Middendorfi, Sibirische Reise, S. 161.

Corvus carnivorus Batram, Baird, B. N.-Am., p. 560.

Corvus cacolotl Batram, Baird, l. c., p. 563.

Corvus carnivorus Dall and Bamister, B. of Alaska, p. 285.

Die genaue Vergleichung der aus Ostgrönland heimgebrachten drei Exemplare lïsst nicht den geringsten Zweifel an der Gleichartigkeit mit Corvus corax, wie dies bereits durch Schlegel (Mus. P. B. Coraces, p. 11) und Rieinhardt ïberzengend nachgewiesen wurde.

Holböll wïhnte in dem etwas längern Schnabel einen genïgenden Grund gefunden zu haben, den Kolkraben Grönlands als constante Varietät absondern zu dürfen, allein wie trügerisch dieses Kennzeichen ist, wird der Vergleich nur weniger Exemplare iiberzeugend beweisen.

Ein am 30. Januar 1870 auf Sabine-Insel geschossenes Männchen stimmt bis auf den etwas längern, mehr gestreckten Schnabel durchaus mit einem solchen aus der Umgegend Bremens überein.

Das Weibchen (15̃. Mai 1870, Sabine-Insel) ist von einem deutschen aus der Harzgegend gar nicht zu unterscheiden. Das stark abseschlissene Gefieder zeigt, namentlich an den Schwingen und trehwanzfedern, nur sehr wenig Purpurschimmer; die Unterseite der Schwingen, ganz besonders deren Schäfte, sind weit heller als beinr Männchen, 
aber alle diese leichten, durch die Jahreszeit entstandenen Unterschiede finden sich in derselben Weise beim deutschen Exemplare.

Exemplare atus Mexico und Nordwest-Amerika (Alaska), welche mehrmals als eigene Arten beschrieben wurden, bin ich, in Uebereinstimmung mit Schlegel und Prinz Max, nicht im Stande von europäischen zu unterscheiden.

Dass der Rabe des Himalayal, C. tibetemus Hodgs. (Jerdon, B. of Ind., II, 29-) unzweifelhaft ebenfalls mit $C$. corax zusammenfällt, ist nenerdings durch Ifume evident nachgewiesen (Ibis, 1870, p. 141).

Ich selbst komte Exemplare aus dem Amurlande (De Castris-Bai) vergleichen, die ich unbedenklich für identisch erklären muss.

\begin{tabular}{|c|c|c|c|c|c|c|c|c|c|}
\hline Flüg. & $\begin{array}{l}\text { Mittl. } \\
\text { Schw. }\end{array}$ & $\begin{array}{l}\text { Aeuss. } \\
\text { Schw. }\end{array}$ & I: & $\begin{array}{c}\text { Nund- } \\
\text { sp. }\end{array}$ & $\begin{array}{l}\text { Schna- } \\
\text { belh. an } \\
\text { Bas. }\end{array}$ & L. & MI. Z. & Nag. & \\
\hline $171 / 21$ & $\begin{array}{ll}9^{\prime \prime} & 2^{\prime \prime \prime}\end{array} \mid$ & $7^{\prime \prime} 9^{\prime \prime \prime}$ & $36^{\prime \prime \prime}$ & $41^{\prime \prime \prime}$ & $13^{\prime \prime \prime}$ & $32^{\prime \prime \prime}$ & $23^{\prime \prime \prime}$ & $91 / 2 " \prime \prime$ & ô Ostgrönl. \\
\hline 16 & $9 \quad 1$ & 78 & 32 & 38 & $121 / 2$ & 30 & 20 & & 2 \\
\hline $16^{1 / 2}$ & 9 & 75 & 31 & 36 & 13 & 29 & 20 & $81 / 2$ & " \\
\hline $16 y^{\prime \prime \prime}$ & 810 & - & 32 & 35 & 13 & 30 & 21 & - & Westgröul. \\
\hline $17^{1 / 2}$ & 9 & 7 & 31 & 34 & $13 \frac{1}{2}$ & 32 & 21 & - & of Bremen. \\
\hline $15 \frac{1}{2}$ & 86 & - & 30 & 35 & 13 & 34 & 21 & - & o Harz. \\
\hline 15 & 89 & & 30 & 34 & 12 & 31 & 19 & 8 & Mexico. \\
\hline 159 & $8 \quad 6$ & 66 & 31 & 37 & $131 / 2$ & 31 & 20 & $91 / 2$ & Alaska. \\
\hline 17 & 10 & - & 31 & - & - & - & - & - & Amurland. \\
\hline
\end{tabular}

Ebenso hinf:illig wie die Differenzen in der Grösse als Speciescharakter sind, ehenso mumeichend und variabel erweisen sich diejenigen der Schwingenverhältnisse, auf welche die amerikanischen Ornithologen so vieles Gewicht zu legen scheinen. In den meisten Fällen sind zwar die dritte und vierte Schwinge die längsten, zuweilen ist es aber atuch die vierte oder die dritte allein, welche die ibrigen merklich iiberragt; die erste verkiirzte Schwinge ist so lang als die siebente oder achte und $4-5 \frac{1}{2}{ }^{\prime \prime}$ kürzer als die längste. Ganz gleiche Verhältnisse zeigt der Alaskit-Rabe.

Neben den geringen Abweichungen in der Schnabellänge war es hauptsächlich die verschiedene Lebensweise, auf welche hin Holböll den grönländischen Raben alogesondert wissen wollte. Nach ihm ist der Kolkrabe in Grönland ein kiihner Räuber, der sich hauptsächlich längs den Küsten aufhält, dabei gesellig lebt und ohne Scheu unnittelbar neben den Niederlassungen erscheint. In ganz ähnlicher Weise berichten von Kittlitz und neuerdings Dall und Bannister über den Raben Sitkas und des nordwestlichen Amerikas. Der Grund, 
warum er in jenen unwirthbaren Gegenden die Nähe des Menschen aufsucht, erklärt sich sehr leicht dadurch, weil man ihn ungestört lässt, indem er sich durch das Wegrätumen von Unrath sogar nützlich macht, weshalb ihm die liussen auf Sitka den Namen "Polizei" beilegten.

Auffallend und sonderbar klingend ist, was Kittlitz uiber den . formlichen Gesange des Sitka-Rabens austuihrlich herichtet (D)enkwïrdigkeiten einer Reise nach dem russischen Amerikit etc., I, 20ã und 206). Dall und Bannister wissen davon nichts zu erzählen.

Den Kolkraben kamnten wir schon durch Kapitän Graah von der Ostkiiste Grönlands. Auf Spitzbergen und Nowaja-Semlja scheint er zu fehlen, wenigstens liegen keine Beobachtungen hieriiber vor.

Nach den Beobachtungen Dr. Buchholz' (1. c., p. 12) ist der Rabe zumal in grösserer Nähe der Kuiste recht häufig: „er scheint längs der Küste zu brïten und auch den Winter über zu verweilen".

[Wir trafen den Kolkraben an allen von uns besuchten Punkten der Küste und fast zu allen Jahreszeiten, aber stets nur parrweis, nie gesellig. Dem ersten begegneten wir im Angust 1869 auf Shannon. Ende September zeigten sie sich einzehn oder in Paren öfters iiber der Bucht, ebenso auf' der Walross-Insel und bei Kap Wynn. Ende Januar 1870 liessen sie sich zuerst wieder auf der Insel sehen; am 15. April sah ich mehrere nordwärts ziehen. Ferner beobachtete ich am 9., 11. und 15. Mai, sowie am 11. und 12. Juni Raben; ebenso traf ich sie im Fjord an und zwischen Klein-Pendulum und Shamon wurden ebenfalls welche beobachtet.

Obwol es als sicher angenommen werden darf, dass der Kolkrabe an der Küste brïtet, so waren wir doch nicht so glïcklich ein Nest zu finden. Ein am 16. Nai erlegtes Weibchen zeigte röllig unentwickelte Eierstöcke.

In Flug, Stimme und Betragen fand ich den ostgrönländischen Kolkraben iibrigens ganz mit unserńn deutschen iibereinstimmend. Was den erstern anbelangt, so ist derselbe langsam, aber kräftig, zuweilen ein elegantes ruhiges Kreisen. Die Stimmlaute bestanden in einem heisern, zuweilen hellern Krächzen, oder in dem bekannten eigenthümlichen, fast melancholisch klingenden, g, ${ }^{\circ 6}$ oder "gorr" Ich bemerke noch, dass wir nach den Jahreszeiten keinerlei Verschiedenheiten der Stimmlaute wahrnahmen.

Die fast sprichwörtliche Vorsicht des Raben konnten wir auch in Grönland wahrnehmen, denn selten liessen sie sich näher als auf Schussweite herankommen und entflohen meist schon in grosser Entfernung. 
Die Nahrung des Raben besteht aus allerlei thierischen, durch das Meer ausgeworfenen und angespülten Körpern, unter denen er besonders von dem Aase von Wathieren und Robben angezogen wird; ausserdem ist er, wie bei uns, ein kühner Rüuber. So beobachtete ich am 11. Juni auf der Walross-Insel zwei Raben, die sich auf die brütenden Bürgermeister-Mö̈ven stürzten, offenbar in der $\mathrm{Absicht}$ ihnen die Eier zu rauben. Sie brachten dadurch die ganze Brutcolonie in Aufregung, fanden indess tapfern Widerstand. Die Möven griffen nämlich vereint die Raben an und schlugen sie mit kräftigen Schnabelstössen in die Flucht. Ich bemerkte nicht, dass es den Raben gelang ihre beabsichtigte Beute, die Eier, zu erobern. Auch später sah ich ïber dem Germaniahafen zwei Möven und einen Raben sich hoch in der Luft bekämpfend umhertummeh. Ein mit drei Eiern belegtes Növennest fand ich ein parr Tage später seines Inhalts beraubt und bin ïberzeugt, dass es durch Raben beraubt und zerstört wurde. Dass der liabe umgekehrt zuweilen ein Opfer des Eisfuchses wird, bestätigt eine Beobachtung Dr. Copeland's, der sah, wie ein Fuchs einen Raben im Matule davontrug. Auch mit den Raubmöven haben sie manchen Strauss zu bestehen. So sahen wir während einer Renthierjagd an der Eleonoren-Bai einen auf der Erde hockenden Raben, welcher nur mühsam die Angriffe zweier laut schreienden Raubmöven abzuvehren vermochte. - P.]

\section{5) Aegiothus canescens Gould. Birkenzeisig.}

Bonap. ct Schleg., Monogr. des Loxiens, 1850, p. 47, Taf. 51.

Ueber das einzige durch die Expedition mitgebrachte Lxemplar, welches Anfang August 1870 in dem romantischen Kaiser-Franz-Josephs-Fjord, wahe dem Waltershausen-Gletscher erlegt wurde, kam ich nur bemerken, dass dasselbe ganz mit der oben citirten Abbildung (links, hintere Figur) übereinstimmt. Der Buirzel ist fast einfarbig weiss, mit einzelnen kaum bemerkbaren dunklern Strichen, wie die Unterseite, welche ebenfalls nur an den Seiten des Kopfes und der Brust schmale dunkle Schaftstrichelchen zeigt; die rothe Scheitelplatte ist deutlich entwickelt; der Schmabel dunkelbräunlich und nur an der äussersten Basis gelblich scheinend.

Das Kleingefieder ist theilweis in Mauser begriften, welche bei den Schwingen und Schwanzfedern noch nicht eingetreten ist; dieselben sind daher etwas abgerieben, wodurch namentlich die beiden hellen Flügelquerbinden schmïler erscheinen. Die Federchen, welche die Nasenlöcher bedecken, reichen etwas über die Schnabelmitte hinatus. 
Das Exemplar stimmt iibrigens durchaus mit einem solchen der Bremer Sammlung aus Norwegen überein; letzteres zeigt aber den Unterschmabel bis auf die äusserste Spitze blassgelb, was bekimntlich Folge der Jahreszeit ist.

Fs ist in der That sehr zu bedauern, dass es nicht gelang weitere Exemplare dieses Birkenzeisigs, den wir zum ersten Male von der Ostküste Grönlands kennen lernen, einzusammeln. Grössere Reihen würden es wahrscheinlich ermöglicht haben, diese so interessante Gruppe borealer Finken eingehender zu behandeh, was der ausführlichen Arbeit von Coues ${ }^{1}$ unerachtet, keineswegs iberflüssig gewesen sein wuirde. Coues versucht es in seiner sorgfältigen Abhandlung sechs Arten als sichere nachzuweisen, indem er zu den bekannten: Ae. linarius, canescens und rufescens noch drei neue hinzufügt: A.rostratus (von Grönland), Ae. fuscescens (aus Nordamerika) und Ae. cxitipes (ebenfalls aus Nordamerika). Weit entfernt, mich auf eine Kritik derselben einlassen. zu wollen, wozu es mir auch an ausreichendem Material gebricht, kam ich es demnoch nicht unterlassen leise Zweifel hinsichtlich des Werthes dieser Arten auszusprechen. Als eine sehr empfindliche Lücke jenex Arbeit muss mit Recht der L'mstand gelten, dass in derselben die Birkenzeisige Asiens so gut als unerwähnt bleiben und dass die so ausserordentlich wichtigen Mittheilungen Viddendorft's, Schrenk's und liadde's gänzlich unbeachtet bleiben. Jene Forscher, welche aus eigener Anschauung sprechen und das Kapitel der Birkenzeisige anscheinend mit hesonderer Torliebe behandehn, sind einstimmig der Ansicht, dass die erheblichen Abweichungen, welche atuch die Norditsien bewohnenden darbieten, keinen Artenwerth verdienen.

Nach dem mir vorliegenden Material muss ich Ae. cuncscens für eine wohlbegründete Art halten, die sich, wie schon Bonaparte und Schlegel sehr richtig bemerken, von Ae. Tinarius ausser der im Ganzen hellern Färbung, besonders dem fast weissen Bürzel, durch bedentendere Körpergrösse, namentlich den stets länger'n Schwanz unter'scheidet. Wegen der lïngern Borstenfederchen der Nitsenlöcher, welche den Schnabel über die Hälfte decken, erscheint der letztere relativ kiirzer. Wichtige Verschiedenheiten der Lehensweise kounte Holböll beobachten (L. Hornemanni Holb., p. 30). Die Art scheint weniger

1 A Monograph of the Genus Aegiothus, with descriptions of new species. By Elliot Cones in: Proceed. of the Acad. of Natural Sciences of Philadelphia, 1861, p. $373-390$. 
zu wandern; Aoch wird sie ron Swinhoe als regelmässiger Wintergast in Nordchina erwähnt (Proc. Z. S., 1863, p. 299).

Ae. linarius L. (Bp. und Schleg., Taf. 52), von welcher ich die etwas kleinere Ae. mufescens Vieill. (Bonap. und Schleg., Taf. 54) nicht zu trennen vermag, ist stets kleiner als concscens, namentlich der Schmabel (dessen Grösse iibrigens auch sehr erheblichen Schwankungen unterworfen ist) und hat den Bürzel in allen Kleidern stark bram gefleckt. Es liegen mir Fxemplare ans l bentschland, Schweden, Nordamerika, Sibirien (Baikal-fee) und ()stasien (Ochotsk) ror, die ich unbedenklich als zu ein und derselben Art gehörig betrachten muss.

Dall und Bannister verzeichnen den von ihnen in NordwestAmerika gefundenen Birkenzeisig, ïber welchen sie hiilssche Beobachtungen geben, als Ae. linarius (B. of Alaska, p. 281), obwol Coues gerade auf Exemplare aus diesem Gebiete seinen $A c$. fuscescens begründete.

Fïr die dritte Form, welche vielleicht als Art Beachtung verdient, Ac. Holbölli ${ }^{1}$ Brehm (Bonap. und Schl., Taf. 53), wäre nur der längere und spitzere, im Ganzen also grössere Schnabel als artliches Unterscheidungskennzeichen zu notiren. Inwieweit dasselbe constant ist, vermag ich nach den wenigen, mir vorliegenden Exemplaren aus Grönland und Schweden nicht zu bestimmen.

Ob Ae. vostratus Coues (Elliot, Introd. B. N.-Am., Abbild., Kopf') als Art Beachtung verdient, scheint mir noch sehr zweifelhaft. Es liegen mir drei Exemplare aus Südgrönland (Lichtenfels) vor, die sich allerdings durch bedententere Grösse auszeichnen, namentlich den ansehnlich längern Flügel. Sie tragen ein vorherrschend rostbraunes, dunkel geflecktes Kleid, ohne Spuren ron Roth auf Kopf oder Bürzel; nur die Scheitelplatte ist roth, aber theilweise sehr verschossen, weil sich die Exemplare (23. September) in der Matuser befinden.

${ }^{1}$ Ich hatte seither das Vergniugen unter einer Sendung von Alaska vier Birkenzeisige untersuchen zu können. Dieselben bieten so entschiedene Mittelformen bezüglich der Schnabelgrösse, dass an. eine constante Unterscheidung von Holbü7li nicht gedacht werden kann. Ich muss hierbei zugleich die vollständige Unhaltbarkeit von Ae. fuscescens Coues, der auf Exemplaren aus jenem Gebiete begründet wurde, constatiren. 


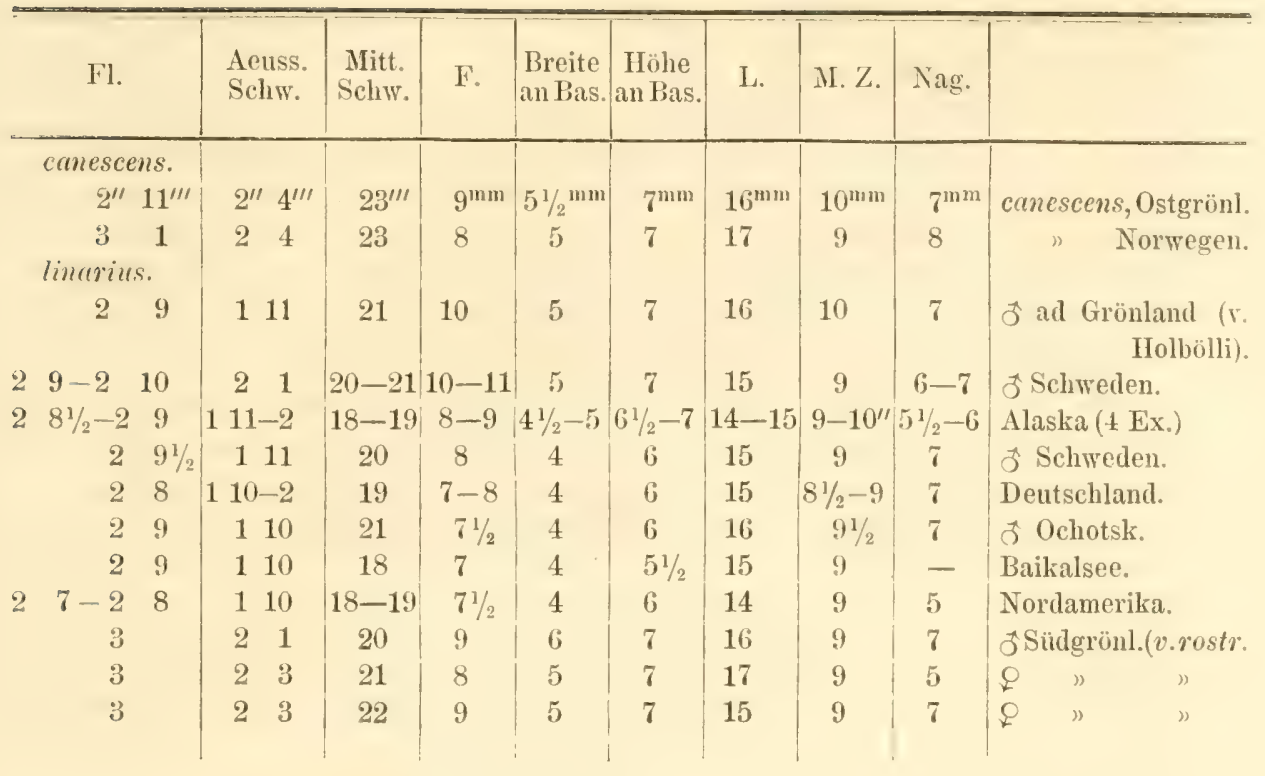

[Zwei Exemplare wurden angetroffen. Sie trieben sich fröhlich zwitschernd zwischen und auf den grossen Steinen und Felsblöcken umher, mit denen der sonst üppig bewachsene Berghang hier bedeckt ist. Nach dem ersten vergeblichen Schusse wurden die Vögelchen sehr scheu, sodass es mir trotz aller Mühe nur gelang, den einen zu erlegen. - P.]

6) Plectrophanes nivalis L. Schnee-Spornammer.

Emberiza nivalis Naumam, Vögel Deutschlands, IV, 297, Taf. 106, 107.

Emberiza nivatis Holb., Faun. Grönl., S. 25.

Emberiza nivalis Sabine, Linn., Trans., XII. (1818), p. 531.

Emberiza nivatis Graah, Reise, S. 178.

Plectrophanes nivalis Reinhardt, Ibis, 1861, p. 7.

Plectrophanes nivalis Middendorft, Sibirische Reise, S. 134.

Plectrophanes nivalis Baird, B. N.-Am., p. 432.

Plectrophanes nivalis Dall and Bamnister, B. of Alaska, p. 282.

Emberiza nivalis Malmgren, Journal für Ornithol., 1863, S. 370 (Spitzhergen).

Plectrophanes nivalis Newt., Ibis, 1865, 1. 502 (Spitzbergen).

Plectrophanes nivalis Heugl., Peterm., Geogr. Mitth., 1871, S. 64 (Spitzbergen).

Plectrophanes nivalis Gillet, Ibis, 1870 , p. 306 (Nowaja-Semlja).

Plectrophanes nivaliz Heuglin, Ibis, 1872, p. 61 (Nowaja-Semlja).

Von dieser wohlbekamnten Art liegen einige zwanzig Exemplare vor, im Mai 1870 auf den Pendulum-Inseln und im Juli und August anf Shannon- und Jackson-Insel eingesammelt; ausserdem fünf, wenige 
Tage alte Junge, die am 12. Juli 1869 auf Sabine-Insel dem Nest entnommen wurden.

Alte Vögel, im Frühling (26. April bis 24. Mai) erlegt, dem Taf. 107, Fig. 2 bei Naumann dargestellten Mïmnchen gleichend, sind im theilweisen Wechsel der Schwingen und Schwanzfedern begriffen; bei einigen haben die weissen Federn des Oberkopfes hier und da zarte rostfarbene Spitzen; bei allen tragen die drei äussern weissen Schwanzfedern auf der Aussenfahne einen schwarzen Längsstrich; die weissen Deckfedern der ersten Schwingen sind schwarz geendet, oder bei andern ganz schwarz; die schwarzen Mantel- und Schulterfedern haben äusserst schmale weisse Spitzensäume; der dunkel-hornschwärzliche Schnabel ist an den Tomienrändern und gegen die Basis der Unterkinnlade zu mehr oder minder breit horngelbbräunlich verwaschen.

Die Ende April auf den Pendutum-Inseln eingesammelten Vögel haben ebenfalls einen dunkeln Schnabel; die Federn des Oberkopfes und der Backen sind braun und wie die schwarzen Mantel- und Schulterfedern schmal bräunlich-weiss gesäumt.

Am 1. August auf Jackson-Insel erlegte Exemplare sind in voller Manser des Kleingefieder's hegriffen; Schnabel hornorange nit dunkehm Firstenrüicken.

Frisch vermauserte Vögel im August und September erlegt, tragen das bekannte Kleid, wie es Naumann (S. 303) beschreibt: Schnabel lebhaft orange mit dunkler Spitze.

Sehr interessant ist das anscheinend noch unbeschriebene Nestkleid, welches ich durch Güte von von Heuglin erhielt. - Kopf, die gamze Oherseite, Kopfseiten, IInlsweiten, Kichle, Kropf und Brust sind düster bräunlichgrau, auf Schultern, Mantel, Brust und den Seiten mehr fahlbräunlich mit sehr verwaschenen dunklern Flecken; Kinn weisslich; Unterbrust und übrige Unterseite nebst den untern Flïgeldecken weiss; die (kitum $3^{\prime \prime}$ langen) Schwingen 1. Ordnung und deren I)eckfulern schwarz mit filhlen Endsämmen; Schwingen 2. Ordnung weiss, an Endle der Aussenfahne mit langen schwarzem Endflecke; letyte Sohwinge 2. ()rohumg schwar\% mit sehr hreiten braunen Rä̈ndern an Aussenfahne und Ende; I)eckfedern der zweiten Sichwingen schwarz mit fahlisabellbrïunlichen Aussen- und Endsäumen, daher von letzterer Farbe; obere Deckfedern dunkel braungrau, die grössten breit weiss geendet, daher eine weisse Flïgelquerbinde; Schwanzfedern schwarz, am Ende und Rande der Aussenfahne braun; die äussern drei Schwanzfedern weiss mit schwarzer Aussenfahne; die dritte mit breitem schwarzen Endflecke an Innenfahne. 

dunkel.

Schnabel dunkel hornfarben, der untere horngelbbräunlich. Beine

Das beschriebene Exemplar wurde durch ron Heuglin am 19. Juli auf Spitzbergen eingesammelt.

Ein am 12. Juli gefundenes Nest war unter Steinen angelegt. Es ist sehr gross, circa $61 / 2$ " lang und fast $4^{\prime \prime}$ breit, aber die Wandungen sind so ausserordentlich dick, dass der eigentliche Nestnapf nur $3^{\prime \prime}$ in der Länge und 2" Durchmesser hat. Der kunstrolle Bau besteht anssen aus dicht ineinander verflochtenen Grashalmen, Würzelchen, Haidlekrautstengehn etc.; der imnere, aus sehr feinen Hälmchen geflochtene, Theil ist mit Haaren und einzelnen Mövenfedern warm und dicht ansgepolstert.

\begin{tabular}{|c|c|c|c|c|c|c|}
\hline $\mathrm{FI}$. & Schw. & F. & L. & M. Z. & $\begin{array}{c}\text { Xag. d. } \\
\text { II. } \% .\end{array}$ & \\
\hline $3^{\prime \prime} \quad 9^{\prime \prime \prime}-4^{\prime \prime} 3^{\prime \prime \prime}$ & $2^{\prime \prime} 1^{\prime \prime \prime}-2^{\prime \prime} 7^{\prime \prime \prime}$ & $\mid 10-11^{\mathrm{mm}}$ & $\left|20-22^{m m}\right|$ & $15 \mathrm{~mm}$ & $9-11^{\mathrm{mm}}$ & Ostgrönl. (20 Ex.) \\
\hline $\begin{array}{llll}3 & 10 & -4 & 1\end{array}$ & $\begin{array}{llll}2 & 3 & -2 & 4\end{array}$ & 10 & 20 & 14 & 8 & Spitzbergen. \\
\hline 311 & 2.4 & 9 & 1 & 14 & 9 & Ostsibirien. \\
\hline 42 & 26 & 10 & 20 & 15 & 10 & Kamtschatka. \\
\hline 311 & 26 & 10 & 20 & 14 & 10 & Nordamerika. \\
\hline
\end{tabular}

In der Färbung ebensowol als in den Dimensionen bieten Exemplare ans den drei Erdtheilen keinerlei Anhalt zu einer specifischen Absonderung, die nur ron Chr. L. Brehm, seiner bekannten Manie folgend, versucht wurde.

Von der Ostküste bereits durch Graah nachgewiesen.

[Der Schneespornammer ist der häufigste Landvogel. Wir begegneten ihm iiberall an der Küste und im Imern. Zugleich ist es derjenige Vogel, der am frühesten (Anfang April) ankommt und am spätesten (Ende September) wegzieht.

Ein vereinzeltes Exemplar erschien bereits am 9. April beim Schiffe; am folgenden 'Tage liess sich ihre Stimme rom Lande her vernehmen und vom 15. April an bemerkten wir sie ïberall, sowol in der Ebene als bis hoch in die Berge hinauf. In der Zeit rom 15. bis etwa 26. April hielten sie sich meist parrweis zusammen, anscheinend Männchen und Weibchen, und nie bemerkten wir mehr als tünf Exemplare; aber in den letaten Apriltagen und während der ersten drei Wochen des Mai sahen wir sie in Schaaren von 10-40, zuweilen bis zu 60 Stiick. Ende Mai hörte dieses gesellige Leben auf, weil sich die Vögel gepaart und weit über das Land 
zerstreut hatten. Anfang Juni liessen die Männchen zuerst ihren zwitschernden fröhlichen Gesang hören, der in mancher Hinsicht an den unserer Feldlerche erimnert.

Gegen Mitte Juni (10.-12.) bemerkten wir auf der WalrossInsel ein Schneesporner-Paar, welches in auffallender Weise in ein Felsloch ein- und ausschlïpfte und dadurch deutlich zu erkennen gab, dass es mit dem Nestbau beschäftigt war, doch gelang es uns nicht die Stelle zu entdecken. Erst am 12. Juli fand Dr. Copeland ein Nest, welches unter einem ziemlich grossen Steine, an den sich mehrere kleinere anlagerten, angebracht war. Der Eingang zum Neste wurde durch eine circa 1 1 /2 Fuss lange Röhre gebildet, die so eng war, dass man nicht mit der Hand bis zum Neste gelangen konnte. Durch Abwälzen des Steins konnte das letztere erst freigelegt werden.

Im Herbst 1869 bemerkten wir Pl. nivalis ebenfalls häufig, die letzten wurden am 29. September gehört.

Ich bemerke noch, dass wir im Frühjahr 1870 mehrmals erfrorene Schneesporner fanden. A. P.]

7) Plectrophanes lapponicus $\mathrm{I}_{\text {. }}$. Lerchenspornammer.

Emberiza lapponica Naum., Vögel Deutschlands, IV, 319, Taf. 108.

Emberiza calcarata Holb., Faun. Grönl., S. 27.

Plectrophanes lapponicus Reinh., Ibis, 1861, S. 7.

Plectrophanes lapponica Midlend., Sibirische Reise, S. 136.

Plectrophanes lapponicus Baird, B. N.-Amer, p. 433.

Plectrophanes lapponicus Dall and Bann., B. of Alaska, p. 283.

Zwei Männchen, am 25. Juli auf Shannon geschossen, tragen beide das rollkommene Sommerkleid Naumann, a. a. O., Taf. 108, Fig. 3), doch sind die Federspitzen, namentlich die Enden der Schwumgund Schwanzfedern stark abgerieben.

\begin{tabular}{|c|c|c|c|c|c|c|}
\hline Fl. & $\begin{array}{l}\text { Aeuss. } \\
\text { Schw. }\end{array}$ & $\mathrm{F}$. & L. & M. Z. & $\begin{array}{c}\text { Nag. d. } \\
\text { H.-Z. }\end{array}$ & \\
\hline $3^{\prime \prime} 5^{\prime \prime \prime}$ & $2^{\prime \prime} 1^{\prime \prime \prime}$ & $10^{\mathrm{mm}}$ & $20^{\mathrm{mm}}$ & $14^{\mathrm{mm}}$ & $13^{\mathrm{mm}}$ & ơ Ostgrönland \\
\hline 36 & 24 & 11 & 22 & 14 & 11 & $\overrightarrow{3}$ \\
\hline 35 & 21 & 10 & 22 & 15 & - & $\&$ Alaska. \\
\hline
\end{tabular}

Diese circumpolar verbreitete Art wird von Kapitän Graah nicht verzeichnet, obschon sie Holböll als von ihm an der Ostküste beobachtet notirt.

Auf Spitzbergen und Nowaja-Semlja fehlt sie. 
[Der Lerchenspornammer war keineswegs häufig. Der erste liess sich am 9. Mai beim Schiffe sehen und kam furchtlos an Bord geflogen. Am 16. Mai stellte sich abermals ein solcher Togel ein, der wie der erste das zutraulichste Wesen bekundete. Selbst wiederholte Fehlschüsse vermochten ihn nicht scheu zu machen und er kehrte stets wieder in ummittelbare Nähe des Schiffes zuruick, wo er in einem Kehrichthaufen eifrig nach Nahrung suchte. A. P.]

Loxia leucoptera wird ron Holböll (p. 4) als von Graah an der Ostküste beobachtet angeführt, jedoch fehlt die Art in Graah's Verzeichniss.

Gallinae. Hühnervögel.

8) Lagopus alpinus Nilss. Sehneehuhn.

Lagopus Briss. Orn., I, 1760, p. 216 (descr. bon.). Alpen.

Tetrao lagopus Temm. (nec L.), Hist. Gall. III, 1815, p. 185 et 707.

Tetrao alpinus Nilss., Orn. suec., 1817, p. 311 (Skandinarien).

Tetrao lagopus Sabine, Trans. Lin. Soc. XII (1818), p. 530.

Tetrao lagopus Temm., Man. d'Orn., II (1820), p. 468.

Tetrao islandorum Faber, Prodr. isl. Orn., 1822, p. 6 (Island).

Tetrao lagopus Otho Fabricius (nec L.), Fauna grœnlandiae, 1780, p. 114, Nr. 80 (Grönland).

Tetrao lagopus Vieill., Ene. Méth., I, 201, 202 (ex Fabric.). Grönland.

Lagopus Reinhardti Brehm, Lehrb. Nat. europ. Vögel, 1823, S. 986 (Grönl.).

Lagopus montanus Brehm, Handb. Nat. Vög. Deutschl., 1831, S. 516.

Lagopus alpinus Keys. und Blasius, Wirbelthiere Europas, S. 199.

Tetrao lagopus Naum., Vögel Deutschlands, VI, 401, Taf. 160, 161.

Tetrao Tagopus Holb., Faun. Grönl., S. 33.

Tetrao lagopus Graah, Reise, S. 178.

Lagopus montanus, alpinus, islandicus Reinhardti und granlandicus Brebm, Vogelf., S. 263, 264.

Lagopus Reinhardti Reinh., Ibis, 1861, S. 9.

Lagopus alpinus Middend., Sibirische Reise, S. 190.

? Lagopus mupestris Baird, B. N.-Amer., p. 635.

? Lagopus rupestris Dall. and. Bann., B. Alaska, p. 289.

Lagopus mutus Degl. et Gerbe, II, 40.

Die schöne, durch die Expedition heimgebrachte Reihe von 10 Exemplaren, welche auf Sabine- und Clavering-Insel eingesammelt wurden, gibt mir die erfreuliche Gelegenheit das Schneehuhn Grönlands eingehender zu behandeln und dadurch, wie ich hoffe, zur bescern Kenntniss der Schneehühner beizutragen. Da bisjetzt keine ausfïhrliche Beschreibung des grönländischen schnechuhns vorliegt. so lasse ich dieselbe zunächst folgen, muss dabei aber auf einzelne Lixemplare eingehen, un zu zeigen, wie erheblich manche ('haralitere, 
anf welche man bisher grosises Gewicht legte, so z. B. das Weiss an der Basis der Schwanzfedern, variiren.

\section{Winterkleider.}

Altes Männchen. (Januar 1870, Sabine-Insel.)

Rein und blendend schneeweiss; ein breiter sammtschwarzer Ziigelstreif entspringt am Nasenloche und zieht sich oberseits in gerader Linie bis zum untern Augenrande, unterseits ist derselbe mehr ausgedehnt, begimnt am obern Rande des Unterkiefers, der schmal gesäumt wird, und steigt in schiefer Linie nach oben bis zum untern Augenrande, dieses unterseits sehr schmal säumend und sich hinter dem Auge als schmaler schwarzer Längsstrich bis auf die Schläfe fortsetzend; die zwei mittelsten Schwanzfedern einfarbig weiss, die uibrigen (sieben jederseits) schwarz, gegen die Basis zu heller, ins Schieferschwarze, an der äussersten Basis weiss, am Ende weiss gesäumt, sehr schmal an der äussersten Feder, breiter (circa 3"') an der innersten. Schäfte der Schwingen 1. Ordnung an der Basishälfte weiss, an der Endhälfte allmählich ins Bräunliche, gegen die Spitze zu ins Schwärzliche übergehend; die äusserste Spitze weiss.

Schnabel hornschwarz, Oberschnabel mit durchscheinend hellerm Spitzenrande; Nägel durchscheinend horngraufahl, an der verdeckten Basis ins Schwärzliche.

Männchen. (2. Januar 1870, Sabine-Insel.)

Wie das vorhergehende, aber der schwarze Ziugelstrich breiter, namentlich auch hinter dem Auge; das Weiss an der Basis der Aussenfahne der sieben äussern Schwanzfedern breit, auf der äussersten, wo es die ganze Aussenfahne sehmal säumt, circa 1" breit, nach den innern Federn zunehmend, sodass es auf der siebenten, wo es zugleich die Inmenfahne bedeckt, über 2 " breit wird.

Männchen. (Januar 1870, Sabine-Insel.)

Der schwarze '/iigelstreif weit schmäler mit einzehnen weissen Federchen gemischt; das Weiss an der Basis der Schwanzfedern ganz versteckt wie bei $\mathrm{Nr}_{\mathrm{r}}$ 1, aber die siebente Feder an der ganzen Innenfahne weiss; an der schwarzen Aussenfahne, die zwei bramgesprenkelte Querbinden zeigt, mit sechs Linien breitem weissen Endrande, der auf den iibrigen f'edern äusserst schmal ist, zum Theil ganz fehlt.

Schnabel schwar\% mit gellolicher Basis des Unterschnabels.

Männchen. (9. December 1869, Sabine-Insel.)

Weisse Basis der äussern Schwanzfedern sehr versteckt, kaum 
$5^{\prime \prime \prime}$ breit; Schwingen 1. Ordnung fast bis zur Basis dunkelschäftig; Züigelstreif sehr breit.

Spitzenrand des schwarzen Schmabels kaum bemerkbar heller; Nägel durchscheinend hornweisslich mit dunkelbramer Basis.

Männchen. (õ. Februar 1870, Sabine-Insel.)

Weisse Basis der äussern Schwanzfedern so gut als fehlend, der weisse Spitzensaum äusserst schmal. Schäfte der Schwingen weiss, nux an Ende blassbräunlich; schwarze Zügel sehr breit.

Schmabel durchaus hornschwarz; Nägel dunkelhornbraun, 1 ur anf dem Rïcken heller durchschimmernd; über dem Auge eine nackte röthliche Stelle.

Weibchen. (Januar 1870, Sabine-Insel.)

Ganz wie das Männchen, aber der schwarze Zügelstreif fehlend, mur durch einige wenige schware Federchen vor und hinter dem Auge angedentet; die sieben äussern Schwanzfedern fast an der ganzen Basishälfte über beide Fahnen weiss, auf der äussersten, die zugleich an der ganzen Aussenfahne weiss ist, 14" breit, auf der siebenten $2^{\prime \prime} 2^{\prime \prime \prime}$ breit, dabei mit breitem ( $t^{\prime \prime \prime}$ ) weissem Spitzenrande. Schwingenschäfte an der Endhälfte deutlich schwarz.

Nïgel hornweiss mit dunklerer Basis.

Weibchen. (5. Februar 1870, Sabine-Insel.)

Schwarze Zügel so gut als ganz fehlend, d. h. nur Spuren einzelner schwarzer Federchen vorhanden; das Weiss an der Basis der Schwanzfedern mehr beschränkt, auf der äussersten, die an der Aussenfahne nicht ganz bis zur Spitze weiss ist, $14^{\prime \prime \prime}$ breit, auf' der siebenten, die an der Innenfahne braun gesprenkelt ist, $18^{\prime \prime \prime}$ breit.

Schnabel durchaus hornschwarz; Nägel dunkel, mit heller durchschimmenden Seitenrändern.

Männchen aus Island (Bremer Museum). Ganz wie grönländische; der schwarze Zügelstreif hinter dem Auge etwas breiter und linger ausgedehnt, weiss an der Basis der Schwanzfedern sehr schmal (katum $6^{\prime \prime \prime}$ ), eben wie der Spitzensaum; Schäfte der Schwingen 1. Ordnumg bis zmr Basis schwarz; die der zweiten Schwingen an der Basishälfte ebenfills schwarz.

Schnabel hornschwarz; Nägel durchscheinend hornfahl mit dunklerel Basis.

Männchen aus Norwegen (Bremer Museum). Ganz wie grönländische. Schwanzfeder'n mit ganz ver'steckter, kaum sichtbarer weisser Basis; Schäfte der ersten Schwingen mit weisser Basishälfte; dann ins Bräunliche nit i̊usserster weisser Spitze; Nägel hornbräunlich. 
İ̈̈nuchen ron den Schweizer Alpen (Bremer Museum), wie grönländische; Weiss an Basis der Schwanzferdern ganz fehlend; weisser Endrand dentlich; Schäfte der ersten Schwingen hornweisslich mit fast schwarzer Endhälfte; Nägel dunkel mit durchscheinenden Seitenrändern.

Weibchen ron den Schweizer Alpen (Bremer Museum) stimmen durchaus mit grönländischen überein; bei einem sind auf dem Zügel ebenfalls einzelne schwarze Federchen vorhanden und der Basistheil der Schwanzfedern ist braungrau gesprenkelt mit äusserster weisser Basis. Nägel dunkel.

\section{Sommerkleider.}

Männchen (Anfing August 1869 auf dem Hühnerberg von Dr. Copeland erlegt), stimmt fast ganz mit der Beschreibung des einjährigen Männchen bei Naumann überein und einem Männchen aus Ost-Finnmarken im Bremer Museum; wie das Letztere zeigt es die fein grau gesprenkelte Rückenzeichmung. Zügel schwarz; Schwanzfedern im Wachsthum begriffen, mit sehr wenig bemerkbarer weisser Basis. Die fast ganz entblössten Nägel horubräunlich.

Altes Männchen (8. Juli 187(), Silhine-Insel) mit stark entwickeltem franzigem, rothem Hautkamme über dem Auge, ist im vollen Wechsel des Kleingefieders begriffen; einzelne der Schwingen spriessen ebenfalls aus den Blutkielen hervor. Es trägt ganz das rostbraune Kleid, mit schmalen dunkeln Querlinien auf der Oberseite und breiten schwarzen und rostgelben auf Kopf und Hals, wie es Faber („Altes Männchen“, S. 6) für L. istandorum beschreibt; der grösste Theil der Flügel und Unterseite sind weiss; die kurzen breiten Nägel hornbraungelb.

Weibchen (16. Juli 1869, Clavering-Insel), trägt ein breit rostgelbund schwarz quergebändertes Kleid, ganz wie ein Exemplar von den Schweizer Alpen im Bremer Museum und stimmt ganz mit der Beschreibung des alten Weibchen in summer bei Faber (s. 8) überein. Die Schwanzfedern zeigen sehr wenig Weiss an der Basis, und kaum Spuren eines weissen Spitzenrandes. Dieses Lxemplar zeigt nur noch an einzelnen Schwungfeder'n Federwechsel; der grösste Theil des Kleingefieders ist bereits völlig vermausert. Nägel horngraubraun; Zehen haarig zerschlissen befiedert.

Ein ganz junger Vogel, am Anfang August 1869 auf dem Hühnerberg von Dr. Copeland erlegt, im ersten theilweis noch mit Dunen vermengten Ferlerkleide, ist, ̈̈hnlich dem vorhergehenden, rostgell, und schwarz quergebändert und zeigt auf den Flïgeln ebenfalls bereits einzelne weisse Federn. 


\begin{tabular}{|c|c|}
\hline & 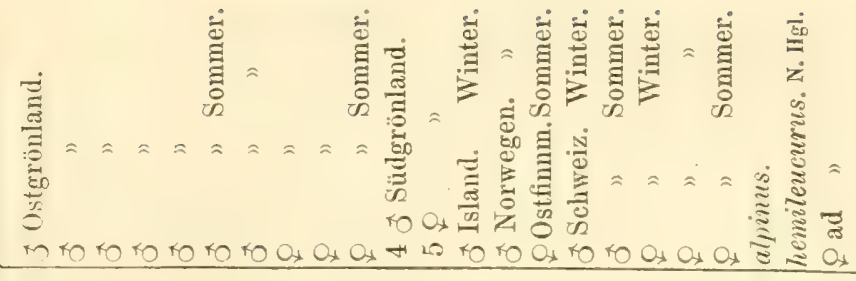 \\
\hline 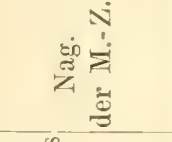 & 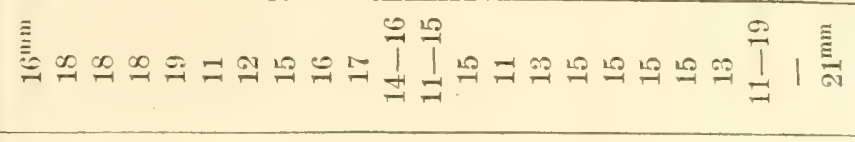 \\
\hline 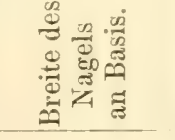 & 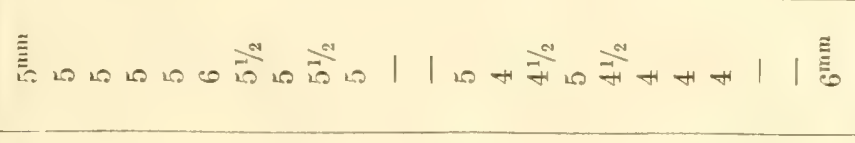 \\
\hline$\stackrel{i}{* i}$ & 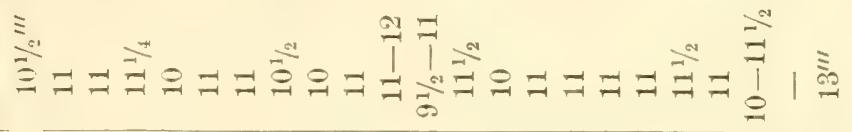 \\
\hline$\stackrel{\dot{I}}{ }$ & 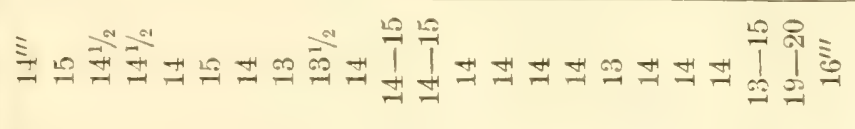 \\
\hline 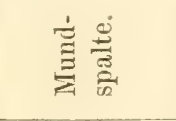 & 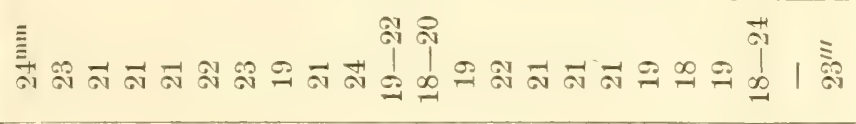 \\
\hline 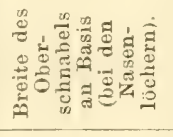 & 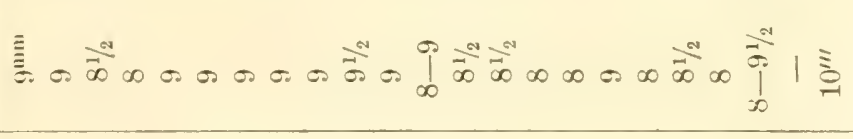 \\
\hline 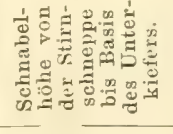 & 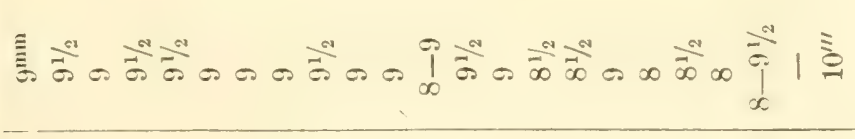 \\
\hline 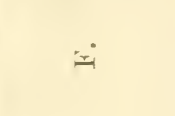 & 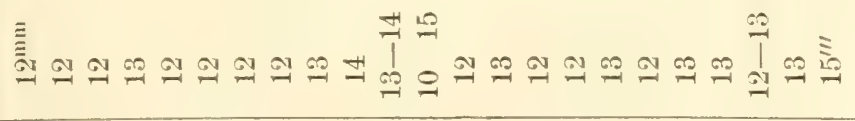 \\
\hline 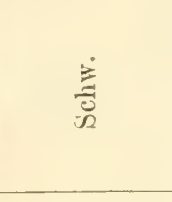 & 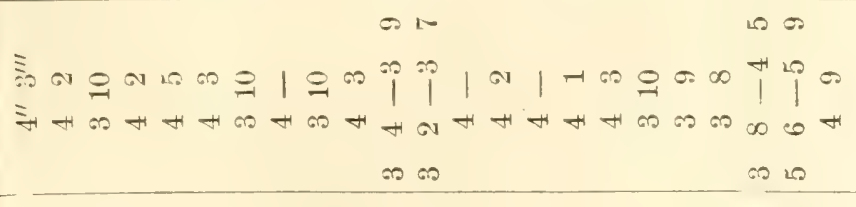 \\
\hline 宝 & 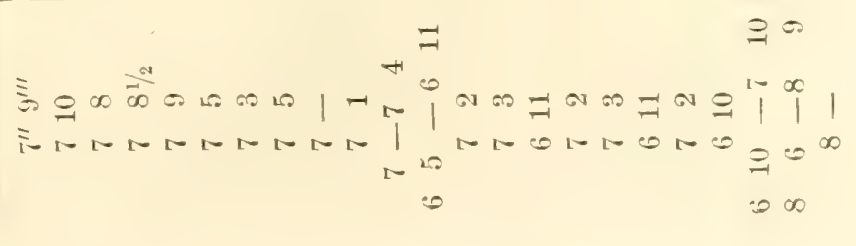 \\
\hline
\end{tabular}


Nach der gegebenen ausfiihnlichen Darstellung stehe ich nicht an, die Schneehiuhner, welche Grönland, Island, Skandinavien und die hohen Gebirge Nitteleuropas bewohnen, als zu einer Art gehörig zu betrachten. Wenigstens sehe ich mich ausser Stand, den mehr oder minder erheblichen, im ganzen aber ziemlich bedeutungslosen $\Lambda \mathrm{b}$ weichungen, auf welche hin verschiedene Arten oder Rassen begriinret wurden. Artrecht zu vindiciren. Die erheblichen Verschiedenheiten der grönländischen Exemplare, welche sämmtlich von ein und derselben Localität herstammen, beweisen am besten, dass die individuelle Abweichung sehr berücksichtigt zu werden verdient.

Eine durch Missionar Starick in Lichtenfels erhaltene schöne Reihe von Schneehiihnern im Sommer- und Winterkleide aus Südgrönland, die ich nochmals sorgfialtig mit msern ostgränlandischen verglieh, ïherzeugte mich von der vollstïndigen Uebereinstimmung. Lin junges Männchen (12. August) ist von einem aus den Schweizer Alpen gar nicht zu unterscheiden; im August erlegte Weibchen stimmen mit solchen aus Finmmarken iiberein, variiren aber unter sich sehr erheblich.

Nach den Angaben von Middendorff's ist das Schneehuhn Nordsibiriens identisch mit dem $L$. alpimus Norwegens. Leider gelang es mir bisher nicht Exemplare aus dem arktischen Amerika untersuchen zu können; nach den Darstellungen der amerikanischen Ornithologen unterliegt es für mich aber kaum einem Zweifel, dass auch das amerikanische (L. mupstris) sich als gleichartig mit dem europäischen erweisen wird. In diesem Falle würde die Verbreitung der Art eine circumpolare sein, wie bei $L$. albus, von dem ich Exemplare aus beiden Continenten vergleichen konnte, die ich, in Uebereinstimmung mit Professor Newton, vollkommen gleich fund.

Letzterer Forscher, der iiber Schneehühner umfassende Studien anstellen konnte, namentlich in Bezug auf die Phasen des Sommerkleides, hält $L$. alpinus (= mutus) für eine von $L$. rupestris (=islandonm, = Rcinhardtii) verschiedene Art. Letztere wiirde Island, Grönland und das arktische Amerika bewohnen, während das erstere sich uiber Schottland, Norwegen, Schweden, Fimland, das nördliche Russland, die Alpen der Schweiz und Pyrenïen verbreitet. Ich verdanke dem genannten Gelehrten interessante Mittheilungen, die ich nicht unterlassen will hier anzufügen, um so mehr als sie verschiedentlich den von mir gebrachten Angaben entgegenstehen.

„Bei $L$. alprimus wird sehr häufig oder fast immer das Friihlingsoder erste Sommerkleid mit dem Herbst-oder zweiten Sommerkleide verwechselt. Das erstere ist bei den Weibchen beider Arten (alpims und rupestris) sehr ähnlich und hat die schön rostgelbe oder rost- 
orange Firbung mit dunkeln Querlinien und dunkler Vermiculirung. Dieses Kleid wird während der Brütezeit getragen, aber nachdem die Jungen völlig befiedert sind, von dem Weibchen von alpinus mit einem granen gewechselt, bis zum Anlegen des rein weissen Winterkleides. Uebrigens sind Spuren der letztern fast immer, auch während des Sommers bemerkbar, und unter Umständen kann man an im August geschossenen Weibchen vier verschiedene Färbungsstufen ausgesprochen finden, nämlich 1) das alte Winterkleid (weiss), 2) das Frühlings- oder erste Sommerkleid (orange), 3) das Herlost- oder zweite Sommerkleid (grau) und 4) das neue Winterkleid (weiss). - Ob das Weibchen von mpestris jemals das rein graue Kleid erhielt, vermag ich nicht anzugeben.

„Die Männchen beider Arten legen das Frühlingskleid viel später an als die Weibchen und man sieht sehr selten ein Männchen im vollständigen Frühlings- oder ersten Sommerkleide, da sie schon sehr früh in das graue oder braune Herbstkleid vermausern. Das alte Männchen von $L$. alpinus in der vollen Friihlingstracht hat die Brust glïnzend schwarz. Ungefälı zu derselben Zeit, wemn das Weibchen in Grau verändert, ist dasselbe beim Männchen auch der Fall; beide Geschlechter ähnehn sich damn einander sehr. - Das Männchen von L. rupestris zeigt im Friihlingskleide auf der Brust braungesprenkelte Federn, aber niemals eine die ganz schwar"z wäre, auch scheint es nie das schöne graue Herbstkleid (post nuptial-dress) zu erhalten wie alpinus, sondern nur ein über und über graubrames Kleid, doch bin ich in dieser Hinsicht nicht völlig sicher.

„Es hat mich viele Mühe, Zeit und die Untersuchurg einer grossen Anzahl von Exemplaren gekostet, ehe ich klar darüber wurde, dass die Vögel dreimal im Jahre mausern. Exemplare beider Arten im vollen Winterkleide maasse ich mir ïbrigens nicht an mit Sicherheit zu unterscheiden." (N.)

Weiteres ïber diesen Gegenstand theilt Professor Newton in: Proc. Acad. Phil., 1871, p. 96 mit.

Dr. von Heuglin sandte mir fünf von ihm auf Spitzbergen erlegte Exemplare von $L$. hemilencurus Gould $=$ hyperboreus Sunder zu, eine Art, die ich nach den Nittheilungen Malmgren's und von Heuglin's wegen der viel bedeutendern Körperverhältnisse als eine unbedenklich gute betrachten zu müssen glaubte. Nach eigener Vergleichung finde ich aber, dass diese Unterschiede keineswegs so erheblich sind, als es den Anschein hatte. Dennoch dürfte das Schriechuhn Spitzbergens als besondere Art anzusprechen sein. Im Sommerkleide ist der rostgelbe Grundton mit schmalen schwarzen Querlinien dicht be- 
setzt, während das wrönländische sichnechuhn hreit schwarz und rostgelb quergebändert erscheint.

[Schneehühner waren den ganzen Winter ïber sehr zahlreich auf der Shannon-Insel, namentlich in den Niederungen nahe dem Hafen. Sie hielten sich während dieser Periode in Ketten von 620 Stiick und waren so wenig scheu, dass wir sie mit leichter Miihe erlegen komnten, ja sogar mit dem Ladestocke wurden einzelne erschlagen. I) Ke Kröpte der erlegten fand ich meist mit jungen Weidenschösslingen rollgepfropft, aber auch mit Blättern und Sprossen ron Saxifraga, Cerastium und Ramunculus, dagegen in denen, welche wir Anfang August erhielten, hauptsächlich Samenkapseln von Cruciferen, nebst Blättern und Sprossen verschiedener Pflanzen.

Mit dem Erscheinen der Sonne wurden die Schneehühner auffallenderweise selten und auf unsern zahlreichen Excursionen durch die Insel bemerkten wir keine. Nur am 1. Mai sah Dr. Copeland ein Paar fliegen, die noch das Winterkleid zu tragen schienen. Auch Ende Mai wurden von dem genannten Forscher hin und wieder Männchen beobachtet und eins von ihm erlegt. Dasselbe trug noch das vollkommene Winterkleid, nur auf den kleinen Flügeldecken mit einzehnen braunen Federn gemischt; der nackte Hautkamm über dem Auge war stark ausgebildet, ebenso die Testikeln. Die Stimme des Schneehuhns bekamen wir nur einmal, Ende Mai, zu hören; sie bestand in einem knarrenden Tone.

Ich vermuthe, dass die Schneehühner grösstentheils während des Sommers mehr ins Innere ziehen, wo eine reichere Vegetation herrscht, während die Niederungen der Küste ihnen im Winter insofern gïnstiger sind, als die heftigen Stiirme die Ansammlung von Schnee mehr verhinderu, sodass die Vögel leichter zu den zahlreich vorhandenen Weiden gelangen können. - P.]

Grallatores. Stelzvögel.

9) Charadrins hiaticula L. Halsband-Regenpfeiffer.

Naumaun, Vögel Deutschlands, VII, 190, 'Taf. 175.

Sabine, Linn. 'Trans., XII, 534.

Holb., Faun. Grönl., S. 37.

Middendorff, Sibirische Reise, S. 213.

Malmgren, Journal für Ornithologie, 1863, S. 372 (Spitzbergen).

Newton, Ibis, 1865, S. 504 (Spitzbergen).

Gillett, Ibis, 1870 , S. 306 (Nowaja-Semlja).

Heuglin, Ibis, 1872, S. 62 (Nowaja-Semlja).

Tom Halsband-Regenpfeifer liegen fünf Exemplare vor, und 
zwar alte und junge Vögel, die meist auf der Sabine-Insel eingesammelt wurden. Davon wurde ein Exemplar Ende September 1869 erfroren gefunden und ein Weibchen am 16. Juli 1870 auf ClaveringInsel beim Nest geschossen; letzteres enthielt vier Eier. Die übrigen Exemplare sind junge völlig vermauserte Vögel, die im September 1869 erlegt wurden. Sie stimmen mit der Beschreibung, wie sie Naumann S. 196 entwirft, gut überein, scheinen aber kaum Spuren einer dunklen Kropfquerbinde zu besitzen und haben einfarbig hornschwarze Schnäbel.

Eine genatere Beschreibung ist wegen des schlechten Zustandes der in Spiritus aufbewahrten Exemplare leider nicht zu geben.

\begin{tabular}{|c|c|c|c|c|c|}
\hline Fl. & Schw. & F. & L. & II. Z. & \\
\hline $\begin{array}{c}4^{\prime \prime} 10^{\prime \prime \prime} \\
4 \quad 11 \\
48^{4}-411\end{array}$ & 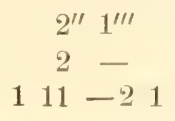 & $\begin{array}{c}6^{1 / 2^{\prime \prime \prime}} \\
\text { circa } 6 \\
6-6^{1 / 2}\end{array}$ & $\begin{array}{l}101 / s^{\prime \prime \prime} \\
11 \\
11^{1 / 2}\end{array}$ & $\begin{array}{l}8^{\prime \prime \prime} \\
7^{1 / 2} \\
7\end{array}$ & $\begin{array}{l}0 \\
0 \\
\text { juv. }\end{array}$ \\
\hline
\end{tabular}

In den von mir untersuchten Mägen fanden sich nur einige kleine Quarzkörner und undeutliche Reste von Insekten.

Der buntschnäblige Regenpfeifer, bisher noch nicht aus Ostgrönland nachgewiesen, gehört mit zu den verbreitetsten Vögeln, wie ich andern Orts (Finsch und Hartl., Vögel Ostafrikas, S. 659) ausführlich erörterte.

10) Strepsitas interpres L. Steinwälzer.

Naumann, Vögel Deutschlands, VII, 303, Taf. 180.

Holböll, Fauna Grönlands, S. 37.

Middendorff, Sibirische Reise, S. 213.

Baird, B. N.-Amer., p. 701 und 702.

Dall and Bannister, B. of Alaska, p. 290, Nr. 104 und 105.

Newton, Ibis, 1865, S. 505 (? Spitzbergen).

Malmgren, Journal für Ornithologie, 1865 , S. 386.

Heuglin, Ibis, 1872, S. 62 (Nowaja-Semlja).

Es liegen nur zwei durch die Expedition mitgebrachte Steinwälzer vor; ein im October 1869 auf Sabine-Insel geschossenes Männchen trägt bereits das ausgefärbte Winterkleid; das andere Anfang August auf Kap Broer Ruys erlegte Exemplar scheint ein jüngerer Vogel zu sein, ist aber arg zerschossen und durch Aufbewahrung in Spiritus noch mehr unkenntlich geworden. 


\begin{tabular}{|c|c|c|c|c|c|}
\hline $\mathrm{Fl}$. & Schw. & F. & $\mathrm{I}_{\text {s. }}$ & M. Z. & \\
\hline $\begin{array}{ll}5^{\prime \prime} & 7^{\prime \prime \prime} \\
5 & 5\end{array}$ & $\begin{array}{ll}2^{\prime \prime} & 2^{\prime \prime \prime} \\
2 & 1\end{array}$ & $\begin{array}{l}9^{\prime \prime \prime} \\
-\end{array}$ & $\begin{array}{l}11^{\prime \prime \prime} \\
11^{1 / 2}\end{array}$ & $\begin{array}{l}9^{\prime \prime \prime} \\
9^{1 / 2}\end{array}$ & $\begin{array}{c}\text { jum. } \\
\sigma\end{array}$ \\
\hline
\end{tabular}

Im Magen des letztern fand ich nur einige kleine Quarzkörner.

Graal notirt den Steinwiilzer nicht unter den von ihm in Ostgrönland beobachteten Vögehn; doch liess sich das Vorkommen dieses Kosmopoliten auch hier füglich erwarten, da wir durch Holböll wissen, dass er sowol in Süd-als in Nordgrönland brïtet.

Das von Newton zuerst beobachtete Vorkommen der Art auf Spitzbergen, welches Malmgren lang und breit (l. c.) zu widerlegen versuchte, hat nenerdings volle Bestätigung gefunden (vgl. Heuglin in P'etermam's Geographischen Mittheilungen, 1871, S. 66).

Dall und Bamister verzeichnen Strepsitas als häutig am Jukon, Sanct-Michael und von Sitka und geben dankenswerthe Notizen über das Brutgeschäft.

Die geographische Verbreitung des Steinwälzers haben wir (Orn. Centr. Polynesiens, S. 196, und Vögel Ostafrikas, S. 664) in ansführ'licher Weise geschildert.

11) Calidris arenariu L. Sanderling.

Naumann, Vögel Deutschlands, VII, 360, Tat. 182.

Holböll, Fauna Grönlands, S. 36.

Middendorff, Sibirische Reise, S. 219

Baird, B. N.-Amer., p. 723.

Dall and Bamister, B. of Alaska, p. 292.

* Ileuglin, Ibis, 1872, S.63 (Nowaja-Semlja).

Unter den von der Ostkïste mitgebrachten Exemplaren ist ein jumger, hallfliigger Vogel ron Interesse, im August 1869 auf SabineInsel eingesammelt. Derselbe zeigt, bei bereits stark entwickelten Schwingen, noch Spuren vom Dunenkleide. Auf dem Oberkopfe, Mantel und den Schultern sind die Federn bereits vorhanden, schwarz mit roströthlichen Endsäumen, daher die letatere Farbe vorherrschend; die Unterseite erscheint weiss mit rostfarbencm Anfluge auf dem Kropfe.

Von alten Vögehn liegt ein Anfang August bei Kap Philip Broke nud ein anderes auf Sabine-Insel (in demselben Monat) erlegtes Exemplar vor, sowie ein drittes, olne Angabe des Fundorts und Datums. Das letztere trägt ein Jugendkleid, ähnlich dem, wic es Nau- 
mann (S. 868) beschreibt; die andern zeigen auffallenderweise ebenfalls nichts von dem rostrothen Sommerkleide, in welchem man sie in diesem Monate zu finden voraussetzen durfte. Auf eine nähere Beschreibung kann leider nicht eingegangen werten.

\begin{tabular}{c|c|c|c|c}
\hline Fl. & Schw. & F. & I. & M. Z. \\
\hline $4^{\prime \prime} 3^{\prime \prime \prime}$ & $22^{\prime \prime \prime}$ & $y^{\prime \prime \prime}$ & $10^{\prime \prime \prime}$ & $7^{\prime \prime \prime}$ \\
$46^{\prime \prime}$ & 21 & $10^{1 / 2}$ & $10^{\prime / 2}$ & $7 \frac{1}{2}$ \\
4 & 21 & 10 & 10 & 7
\end{tabular}

Nach Holböll bereits durch Kapitän Graah von der Ostlïste nachgewiesen, aber nicht in dem Verzeichniss von Graah aufgefiihrt.

Beziiglich der geographischen Verbreitung muss ich anch bei dieser Art auf unsere, ,lögel Ostarikas" (S. 769) verweisen. Dall und Bammister fanden sie häufig am Jukon; sie erscheint dort mit am ersten (schon Anfang Mai) und zieht am spätesten weg. Einzelne wurden noch im October angetroffen.

12) Trimgr maritima Brimnich. Meer-Strandläufer.

Naumann, Vögel Deutschlands, VII, 467, Taf. 188.

Sabine, Linn. Trans., XII (1818), p. 532.

Holböll, Fauna Grönlands, S. 39.

Reinhardt, Ibis, 1861, S. 11.

Middendorff, Sibirische Reise, S. 220.

Baird, B. N.-Amer, p. 717.

Dall and Bannister, B. of Alaska, p. 291.

Malmgren, Journal für Ornithologie, 1863, S. 372 (Spitzbergen).

Newton, Ibis, 1865, S. 505 (Spitzbergen).

Heuglin, Petermann's Geographische Mittheilungen, 1871, S. 61 (Spitzbergen).

Gillett, Ibis, 1870, S. 306 (Nowaja-Semlja).

Heuglin, Ibis, 1872, S. 72 (Nowaja-Semlja).

Tringa mimeta Walker, Ibis, 1860 , S. 166 (Nowaja-Semlja).

Tringa mimuta Reinhardt, Ibis, 1861, S. 3 (= maritima).

Vier von den mitgebrachten Exemplaren wurden im August und September 1869 anf der Niederung der Sabine-Insel eingesammelt und tragen das bekannte Winterkleid, in welchem die Art während ihres Herbstzuges bei uns erscheint. Bei zweien besitzen die Federn auf Mantel, Schultern und Oberkopf noch roströthliche Endsäume, was bei einem am 13. September auf Spitzbergen erlegten Weibchen (Coll. von Heuglin) ebenso der Fall ist. Bei dem am 21. Juni 1870 auf Sabine-Insel erlangten Exemplare sind die Mantel- und Schulterfedern 
mit breitern rostgelben und rostfarbenen Spitzenflecken rersehen, ohne indess diesen Theilen vorherrschend diese Färbung zu verleihen. Naumamis treftliche Beschreilumg des .. Hochzeitkleides." (S. 472) passt übrigens genau auf dieses Exemplar; ebenso die ron Heuglin im Juli auf Spitzbergen eingesammelten, die mir zum Vergleiche vorliegen.

Die Grössenverhältnisse, namentlich die des Schnabels variiren nicht unerheblich.

\begin{tabular}{|c|c|c|c|c|c|}
\hline Fl. & Schw. & F. & I. & M. Z. & \\
\hline $4^{\prime \prime} 7^{\prime \prime \prime}$ & $25^{\prime \prime \prime}$ & $12^{3 / 2}{ }^{\prime \prime \prime}$ & $91 /{ }^{\prime \prime \prime}$ & $10^{\prime \prime \prime}$ & Ostgrönland. \\
\hline 44 & 24 & 14 & 10 & 11 & » \\
\hline 48 & - & $11^{1 / 2}$ & 10 & 10 & " \\
\hline 45 & 26 & 10 & $91 / 2$ & $91 / 2$ & " \\
\hline 49 & 27 & 11 & 10 & 10 & $"$ \\
\hline 411 & 26 & $15^{1 / 2}$ & 10 & 10 & Südgrönland. \\
\hline $44-411$ & $24-26$ & $11 \frac{1}{2}-14$ & 10 & $9-10$ & Spitzbergen. (4 Expl.) \\
\hline 46 & 24 & $121 / 2$ & 10 & - & Kap. \\
\hline $4 \quad 6^{1 / 2}$ & 24 & 12 & 10 & 10 & Alaska. \\
\hline
\end{tabular}

Tr. maritime war bisher nicht aus Ostgrönland bekannt, obwol sich sein Vorkommen hier wol annehmen liess. Holböll spricht schon seine Verwunderung darüber aus, dass Kapitïn Graah die Art ganz unerwähnt lässt.

So genau wir auch mit der nördlichen Verbreitung dieses circumpolaren Vogels bekannt sind, so wenig genaue Kunde besitzen wir hinsichtlich der Ausdehnung seiner Winterwanderungen. Sein im Ganzen seltenes Vorkommen an den Gestaden des gemässigtern Europa und Deutschlands, in dessen Innern er nach Naumann noch niemals beobachtet wurde, liessen darauf schliessen, dass er, als Ausnahme von der Regel, schon in nördlichen Breiten überwintert. Die gründlichen Beobachtungen nordischer Forscher, unter denen ich nur Faber und Hallgrimsoni nemnen will, geben rolle Bestitigung; wir erfuhren durch sie, dass Tr. maritima z. B. schon auf Island in grosser Anzahl ïberwintert. Andererseits war bereits Naumamn sein alljährliches Erscheinen an den Gestaden des Mittelmeeres bekannt und Erhardt (Naumannia, 1858, S. 13) notirt ihn unter den regelmässigen Durchzïglem auf den Cycladen, eine Angabe, welche von Droste (Vogelwelt Borkums, S. 215) bezweifeln zu müssen glaubt. Ohne Zweifel hat diesellow aber ihre volle Richtigkeit und die Wamdermgen von $T r$. maritima exstrecken sich viel weiter als wir glauben. 
Es ist mir erfreulich einen eclatanten Beweis dafür beibringen zu können, indem ich eine unzweifelhafte $T r$. maritima unter einer Vogelsendung rom Kap der guten Hoffnung erhielt.

[Ende Mai in Flügen von 20-30 Exemplaren auf der feuchten Niederung der Sabine-Insel von uns beobachtet; Anfang Juni sahen wir sie nur noch in Paaren. Auf Shannon, Pendulum, Kap Broer Ruys und im Fjord ebenfalls von uns angetroffen. - P.]

Phalaropus hyperboreus findet sich in Graah's Liste nicht, obschon Holböll (S. 2) diese Art von der Ostküste notirt, wo sie aller Vermuthung nach auch nicht fehlen wird.

\section{Nat a tores. Schwimmrögel.}

13) Anser albifrons Gml., Blässen-Gans.

Holböll, Fauna Grönlands, S. 62.

Reinhardt, Ibis, 1861, S. 12.

Middendorff, Sibirische Reise, S. 227.

Durch die Mitglieder unserer Expedition wurden Gänse verschiedene male beobachtet, ohne dass es indess gelang Exemplare zu erlegen. Dem umsichtigen Eifer des Dr. Copeland ist es zu danken, dass wenigstens einige der umherliegenden, infolge von Mauser ausgefallenen Sichwungfedern mitgehrateht wurden, welche das Vorkommen zweier Gänsearten constatiren. Zwei Schwingen 1. Ordnung, mit weissen Schäften, darf ich ohne Bedenken auf obige Art beziehen, die wie wir durch Holböll wissen, in Grönland sehr häufig ist. Nicht bei Graah.

\section{4) Anser leucopsis Bechst. Weisswangen-Gans.}

Holböll, Fauna Grönlands, S. 62.

Reinhardt, Ibis, 1861, S. 12.

Malmgren, Journal für Ornithologie, 1863, S. 378 (Spitzbergen).

Heuglin, Petermann's Geographische Mittheilungen, 1871, S. 65 (Spitzbergen). Middendorff, Sibirische Reise, S. 228.

?Anas (Anser) bernicla Graah, Reise, S. 179.

Eine durch Dr. Copeland mitgebrachte erste Schwungfeder (dunkelschaftig) liisst in Bezug auf obige Art nicht den geringsten \%weifel. Anas (Anser) bernicla in Graah's Verzeichniss bezieht sich wahrscheinlich auf diese Art; Holböll erwähnt nicht, dass sie von Graah beobachtet wurde.

[Wir beobachteten diese Gänse öfters an der Küste, namentlich Ende Mai und Anfang Juni, wo sich einige 20 Stück in der 
Nähe des Hafens in einer fenchten Nierlerung aufhielten und öfters am Schiffe vorbeiflogen, doch gelang es uns nicht einen dieser änsserst vorsichtigen und schenen Vögel zu erlegen. - P.]

Cygmus musicus wird in Graah's Terzeichniss (S. 179) als ron ihm bei liap Farewell eingesammelt notirt (Cygmus melanorhymcher Holböll, S. 61).

15) Harelda glacialis L. Eisente.

Anas glaciatis L., Naumann, Vögel Deutschlands, XII, 210, Taf. 319.

Anas glaciatis Sabine, Limn. 'Trans., XII, 555.

Clangula glaciatis Holböhl, a. a. 0., S. 64.

Anas hiemalis (glaciatis) Graah, Reise, S. 179.

Anas glacialis Middendorff, Sibirische Reise, S. 286.

Harelda glacialis Baird, B. N.-Amer., p. 800 .

Harelda glacialis Dall and Bannister, B. of Alaska, P. 298.

Harelda glaciatis Malmgren, Journal für Ornith., 1863, S. 379 (Spitzbergen).

Harelda glacialis Newton, Ibis, 1865, S. 515 (Spitzbergen).

Hurelda glaciatis Ileuglin, Petermann's Geogr. Mitth., 1871, S. 65) (Spitzbergen).

Harelda glacialis Gillett, Ibis, 1870, S. 309 (Nowaja-Semlja).

Harelda glaciatis Heuglin, Ibis, 1872, S. 63 (Nowaja-Semlja).

Das einzige durch die Expedition mitgebrachte männliche Exemplar, am 16. Juli bei Kap Borlase Warren erlegt, trägt das dunkle Sommerkleid, wie es Nammann, 'Taf. 319, Fig. 2, darstellt, nur ist die hintere Angengegend deutlicher weiss, auch am Kinn zeigen sich helle Fedem; die Federn, welche die obere Mantelmitte decken, haben breite rostbraune Seitensämme, wie die Schulterdecken, welche noch mit einzelnen schmuzigweissen Federn gemischt sind.

\begin{tabular}{c|c|c|c|c|c|c|c}
\hline Fl. & M. Sehw. & $\begin{array}{c}\text { Zweit mittl. } \\
\text { Schwanz. }\end{array}$ & F. & $\begin{array}{c}\text { Iöhe des } \\
\text { Oberschn. }\end{array}$ & $\begin{array}{c}\text { Breite des } \\
\text { Oberschn. }\end{array}$ & I. & M. Z. \\
\hline $8^{\prime \prime}$ & $5^{\prime \prime} 4^{\prime \prime \prime}$ & $3^{\prime \prime} 3^{\prime \prime \prime}$ & $11^{1 / 2} 2^{\prime \prime \prime}$ & $7^{\prime \prime \prime}$ & circa 8' & $15^{\prime \prime \prime}$ & $21^{\prime \prime \prime}$
\end{tabular}

Auch diese eirempolar verbreitete $\Lambda$ rt wurde bereits durch Kapitän Graah an der Ostkiiste Grönlands nachgewiesen, ebenso wie Haretda histriomica (Graah, Reise, S. 179).

[Die Eisente war keineswegs häufig und wurde von uns nur bei Kap Borlase Warren und auf der Fahrt von hier nach der Clavering-Insel beobachtet. Sie flog hier in kleinen Gesellschaften ron wenigen Lxemplaren öfters am Schiffe vorber. Das erlangte Männchen hielt sich mit andern auf einem kleinen Wassertümpel auf 
dem flachen Strande an der Südseite von Kap Borlase Warren auf. - P.]

? Anas clangula wird von Dr. Buchholz (1. c., S. 12) als muthmasslich von ihm gesehen verzeichnet. "Nahe der Kïste waren werler Eiderenten, noch andere Finten zu sehen." 13.

\section{6) Somateria mollissima L. Eiderente.}

Anas mollissima Naumann, Vögel Deutschlands, XII, 252, Taf. 321 und 322. Anas mollissima Sabine, Linn. Trans., XII, 554.

Somateria mollissima Holböll, Fauna Grönlands, S. 73.

Anas mollissima Graah, Reise, S. 179.

Somateria mollissima Reinhardt, Ibis, 1861, S. 14.

Somateria mollissima Baird, B. N.-Am., p. 809.

Somateria mollissima Evans und Sturge, Ibis, 1859, S. 167 (Spitzbergen).

Somateria mollissima Malmgren, Journ. f. Ornith., 1863, S. 380 (Spitzbergen). Somateria mollissima var. Malmgren, ebend., 1865, S. 214 (Spitzbergen).

Somateria thutensis Nalmgren, ebend., 1865, S. 396 (Spitzbergen),

Somateria mollissima Newton, Ibis, 1865, p. 515 (Spitzbergen).

Somateria thulensis Newton, Journal für Ornith., 1867, S. 210 (Spitzbergen). Somateria thulensis Heugl., Petermann's Geogr. Mitth., 1871, S. 59 u. 65 (Spitzb.). Somateria mollissima Gillett, Ibis, 1870, S. 309 (Nowaja-Semlja).

Somateria mollissima Heuglin, Ibis, 1772, S. 63 (Nowaja-Semlja).

Die Sammlung enthält zahlreiche alte Vögel (6 Männchen und 13 Weibchen), sämmtlich im Juni und Juli anf Sabine-Insel und deren Umgegend eingesammelt; ausserdem Dunenjunge in den verschiedensten Entwickelungsstufen. Solche am 18. Juni erlangte sind offenbar nur wenige Tage alt, während ein Anfang August erlegtes Junges auf dem Riicken bereits zahlreich hervorspriessende schwarzbraune, rostbraun geendete Federn besitzt. Bei diesem Exemplar sind die Dunen dunkler als bei jüngern Vögeln, der helle Zuigel- und Augenstreif schmäler und minder deutlich. Ein knde August eingesanmeltes. Junges ist bereits fast rollstandig mit ferlern bekleidet und die Schwingen entwickeln sich bereits bei ihm.

Ich wïrde mich jeder weitern Bemerkung iiber diese so äusserst genau bekannte Entenart haben enthalten können, hätte nicht Dr. Malmgren die Eiderente Spitzbergens zu einer hesondern Localform erhoben, der er Artrecht vindicirt und die neuerdings auch durch von Heuglin angenommen worden ist. Letzterer Forscher vermuthet ausserdem (briefliche Mittheilung), dass die ostgrönländische Eiderente mit der Spitzbergens zusammenfallen werde.

Diese ,neue Art" hat in dem kurzen Zeitraume, seitdem man von ihr spricht, bereits sonderbare Phasen der Anerkennung und 
Vichtanerkennung durchgemacht, die schon von vornherein ernste Bedenken gegen dieselhe hervorrufen musten. Sachdem Mahmgren auf seiner ersten Reise in der Eiderente Spitzhergens nichts anderes als when S. mollisimu erhlickte und auch der treftliche Beohachter Professor Newton nach eigener Anschaumg keine Verschiedenheiten wahrzunehmen vermochte, erklïrte sie Malmgren zwei Jahre später für eine Varietiit, von der er hemerkt: ,Die spitzlergensche Eidergans ist merklich kleiner als diejenige, welche in der Ostsee oder Bohuslïn rorhanden ist, und sie hat einen etwas schmïlern, kiirzern, besonders :m der Wuzel niedrigern und nach oben mehr alogeplatteten Schmabel als unsere skamdinavische; da jedoch diese Art gerade riicksichtlich der Körpergrösse und der Form des Schnabels bedeutenden Variationen unterworfen ist, die gleichwol durch Zwischenformen zusammenfliessen, so kann gar nicht die Rede davon sein, die spitzbergensche Form zu einer besondern $\Lambda$ rt z.n erheben. In der Vertheilung der Farben kommt kein anmerkenswerther Unterschied von der skandinavischen vor; aber der Körper ist etwas kleiner und der Schnabel hat eine etwas abweichende Form. Der Tarsus und die mittlere Zehe mit dem Nagel ebenso lang oder mbedeutend linger als bei der skandinavischen; der Fligel von dem Gelenk bei der letzterwähnten ungefähr einen halben Zoll lïnger." Kurze Zeit darauf genïgt es Dr. Malmgren nicht mehr die Eiderente Spitzhergens als Localform hetrachtet zu wissen, er erheht sie frischweg zur Art und sagt iiber dieselbe: „Die spitzhergensche Eidergans ist, wie ich in meinem letzten Aufsatze gezeigt habe, bei weitem kleiner, als die in Bohuslïn und in der Ostsee vorkommende und hat eine so abweichende Schnabelform, dass sie ohne Zweifel die hïchst gemässigten Anspriiche unserer Zeit a uf eine eigene Art, die einen eigenen Namen verdient, befriedigt. Sie ist rollkommen so verschieden von der im sïdlichen Skandinavien vorkommenden Eidergans, wie Anser brachyrrhynchus sich von Anser segetum und Alca Brimnichi von Alca troile(??) unterscheidet und muss als eine ausgezeichnete Art angesehen werden, im Vergleiche mit z. B. Uria Mandtii, Uria columba(??), Mormon glacialis u. a. m. Da es nothwendig ist, die Formen zu unterscheiden und den wichtigsten derselben Namen zu ertheilen, - jeder mag sie damn von seinem Standpunkte aus Arten, Varietïten oder Rassen nennen - sehe ich mich genöthigt, die spitzbergische Eidergans mit einem eigenen Namen anszuzeichnen und schlage dazu vor: Somateriat thulensis. Dass ich dieselbe nichtsdestoweniger fiir eine nordische Localform unserer gewöhnlichen Eidergans halte, die also 
in zoologischem Sinne dem Artenhegrifte Somoteria motissima angehört, bedarf wol kaum einer Erwähnung."

von Heuglin, der Somateria thulensis, die ,wohl zu unterscheidende Art von Somateria molissima" noch nicht mit continentalen Vögeln vergleichen konnte, findet dennoch heraus, , dass sie sich schon durch die Form des Schnabels und Farbe der Weichtheile hinlänglich zu unterscheiden scheine", und schreibt mir hieriber": "Sie scheint jedenfalls kleiner und ist der Schnabel (auch beim Weibchen sogar) immer gelb; anch scheint mir die Form des Schnabels verschieden und nicht so bauchig in der Stirn verlaufend(?). Ich habe Tausende von Eiderenten oft in nächster Nähe zu beobachten Gelegenheit gehabt und glaube die spitzbergische Form, zu der ohne Zweifel auch die grönländische gehört, auf den ersten Blick von der norwegischen unterscheiden zu können. sowol nach Form der Firste als Farhe des Schnabels und der Haltung."

Obwol, im Hinblick auf diese ungewissen und sich theilweis widersprechenden Angaben mein Vertrauen zu der neuen Somateria thulensis ein eben nicht sehr starkes war, so glaubte ich mir doch nicht eher ein Urtheil ammaassen zu diufen, ehe ich nicht selbst Exemplare zu untersuchen im Stande war, namentlich desshalb, weil die Schnabelform als eine so durchaus verschiedene beschrieben wurde. Durch gütige Vermittelung von von Heuglin's erhielt ich nun spitzbergensche Exemplare und war nicht wenig erstaunt, in der Schnabelform gar nichts Alosonderliches und Ahweichendes entrlecken zu kömnen. Ich habe das reiche mir vorliegende Material, einige zwanzig Exemplare aus Ostgrönland, Spitzhergen. Toxwegen und Sohweden mul ein prachtrolles Männchen im vollen Iochzeitskleide, am 13. April 1868 auf der Weser unweit Bremen erlegt, mit einer Genauigkeit rerglichen, die vielleicht eines Bessern würdig gewesen wäre, und muss meine vollste Ueberzeugung dahin aussprechen, dass Somateria thulensis weder als nordische Localform oder Rasse oder Varietät die geringste Beachtung verdient und von der bekannten Somateria molissima in keiner Weise getrennt werden darf.

Da Dr. Malmgren an Messungen von vier spitzbergischen und drei ()stsee-Lixemplanen die constanten Abweichungen in der Schnabelform zu constatiren versuchte, so habe ich mich der zeitraubenden und müherollen Arbeit unterzogen, sïmmtliche mir vorliegende Exemplare auf das Genaueste zu messen. Die nachfolgende 'Tabelle, welche ich zu anderer Zeit für überflüssig erachtet haben würde, wird auf das 
iiberzengendste beweisen, das ron einer, ,hei weitem" geringern Körpergrösse, schmälern, kürzern, niedrigern oder mehr abgeplatteten schmabel hei spitzbergischen Exemplaren gar nicht die Rede sein kạn, und dass vielmehr alle diese leichten $\mathrm{Abweichungen} \mathrm{lediglich} \mathrm{in-}$ dividueller Natur sind. Naumann hat diese Verhältnisse bereits eingehend erörtert, es scheint aber nothwendig hier nochmals auf die betreftende stelle (s. 254-250) hinzuweisen. Was die Breite des Schnabels anbelangt, so schwankt dieselbe (in der Höhe der Nasenlöcher gemessen) von $17-22^{\mathrm{mm}}$, bei den beiden spitzbergischen von $17-19^{\mathrm{mm}}$. In dem Verlauf des Firstenrickens stimmen Exemplare aus Spitzbergen, Grönland u. s. w. ebenfalls auf das Genaneste überein, die Einbiegung vor dem Nagel ist zuweilen stärker, zuweilen sehr schwach ausgesprochen. Wichtiger schien mir anfänglich die geringe Breite und Lünge des nach Imnen zu nicht immer scharf abgesetzten Sihnabehnagels bei den spitzbergen-Lxemplaren. die beim Mämnchen 20, beim Weibchen nur $16^{\mathrm{mm}}$ beträgt. Doch muss ich auch dies Kennzeichen als werthlos aufgeben, nachdem ich gefunden, dass es ebenfalls individuell variirt, und zwar bei Mämehen von $18-27^{\mathrm{mm}}$, bei Weibchen von $17-25^{\mathrm{mm}}$. Die Fürbung der Nacktheile, wie sie sich mir an trockenen Bälgen darbietet, ergibt keinerlei Verschiedenheit. Sie schwankt am Schnabel von einem hellern bis zu einem sehr dunkehn Grïnschwärzhichgratu, welches zuweilen den ganzen schnabel cimninment, in den meisten Fällen aber den Nagel oder nur den Spit\%enrand dessellyen horngelbfahl oder grïnlichgrau lisst; die Fäbung der Beine weehselt ron cinem selmutzigen dunkeln (iraugriun bis ins röthliche Dunkelbraun.

Ueber die Firrbung der Nacktheile im Leben vermag ich natiirlich nicht zu urtheilen. von Heuglin bezeichnet den Schnabel des Mämohens als ,lebhaft orange, nach der Spitze zu mehr hell griunlich, die Füsse als trüb orangefarly mit schwä̈zlichen sehwimmhäuten”. wogegen Naumamn den Schnabel nur als , frisch olivengelh, die Füisse als hell olivengrïn, an den Schwimmhänten katmm dunkler" beschreiht. Jedenfalls darf ich behaupten, dass sich an trockenen Bälgen keinerlei stichhaltige Cnterschiede crgeben, und dass die Jahreszeit und das Alter die Färbung des Schnabels u. s. w. sehr wesentlich beeinflusst, wird Niemand in Abrede stellen können.

Nach dieser, wider meinen Willen so ausfühlichen Darstellung wird man wol nicht anstehen, Somateria thulensis ein für allemal zu den 'Torten zu legen. 


\begin{tabular}{|c|c|}
\hline & 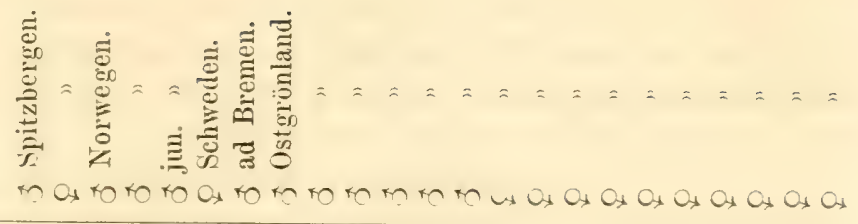 \\
\hline 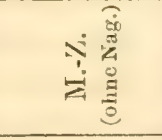 & 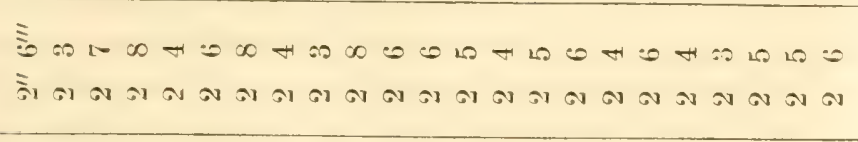 \\
\hline$\stackrel{-}{ }$ & 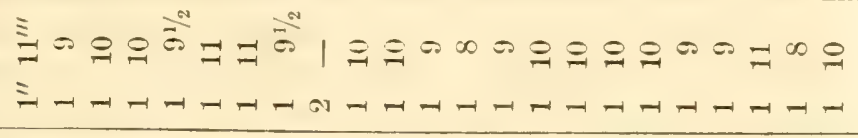 \\
\hline 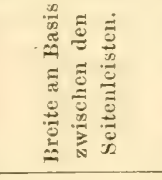 & 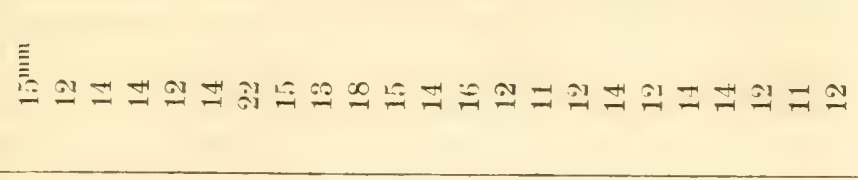 \\
\hline 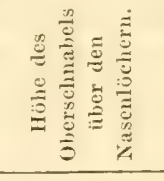 & 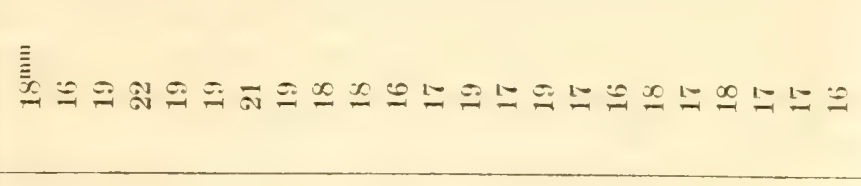 \\
\hline 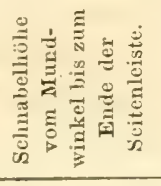 & 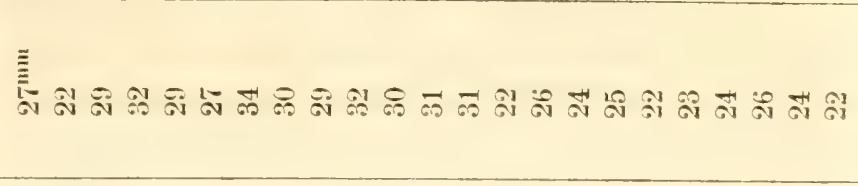 \\
\hline 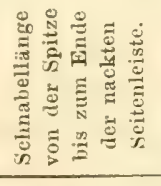 & 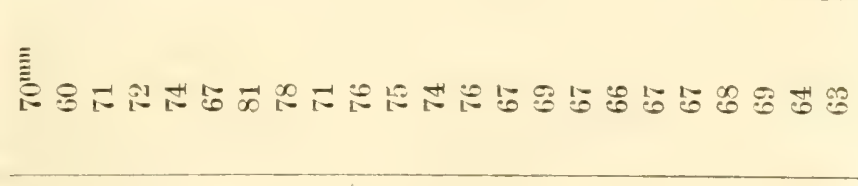 \\
\hline 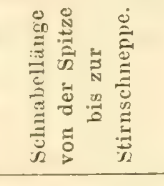 & 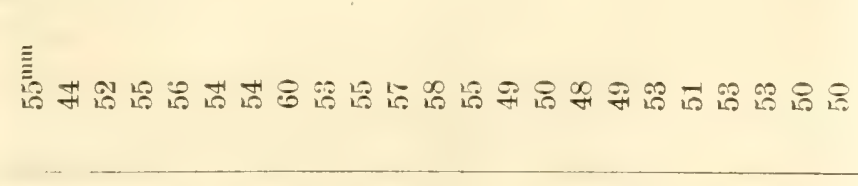 \\
\hline 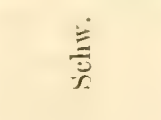 & 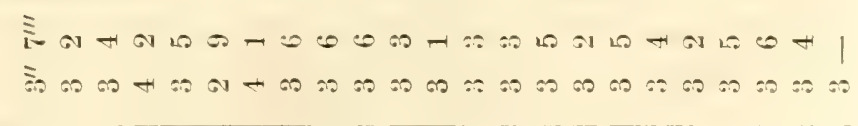 \\
\hline$=$ & 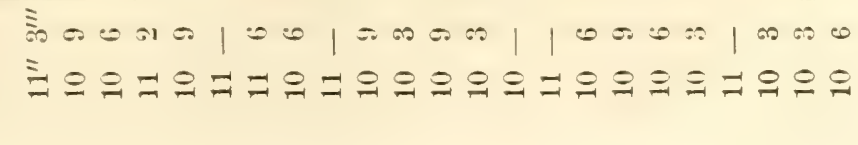 \\
\hline
\end{tabular}


Die Eiderente ist bereits durch Kapitän Graah von der Ostkiiste Grönlands bekannt.

Sie scheint in ihrer Verbreitung mehr beschränkt als die folgende Art (Somateria spectabilis), indem sie im Norden Sibiriens und in Nordwestimerikit nicht rorkommt, wenigstens weder ron Middendorff. noch von Dall und Bamnister erwähnt wird.

[Wir haben die Eiderente fast an allen ron uns besuchten Punkten dex liöste angetroffen und zwar in ziemlicher, of bedentender Anzalle. Die ersten will Herr Tramnitz schon am 18. April an der Walross-Insel beobachtet haben, aber erst Ende Mai und Anfing Juni liessen sie sich auf dem Eise in ummittelbarer Nähe des Schiffes sehen, meist Flïge von 5-15 Männchen. Eine grössere Schaar, ebenfalls nur aus Männchen bestehend, komnte ich am 9. Juni ganz in der Nähe beobachten und am 15. Juli trafen wir östlich von Kap Borlase Warren an 100 Eiderenten-Mämchen, die sich in einer langen Linie über das ruhige Wasser vertheilten. Einzehnen Paren und kleinem Flïgen begegneten wir in der Gael Hamkes-Bai, an der Clavering-Insel, auf Klein-Pendulum, bei Shannon, JacksonInsel, Kap Broer Ruys und in der Falschen Bai. Im Herbst 1869 trieben sie sich bei Sabine-Insel so lange umher, als es noch ein Fleckchen offenes Wasser gab; wir beobachteten sie am 29. September zuletzt.

Die Eiderente zählt mit zu den wenigen Vögeln, die wir das Vergnügen hatten brütend anzutreffen und während ihres Brutgeschäfts zu beobachten. Schon Anfang Juni trieben die Männchen die Weibchen, wobei sie eigenthümliche Töne, wie Wo oder Wu klingend hören liessen.

Den einzigen Brutplatz auf der Pendulum-Gruppe besuchte ich am 14. Juni. Er befand sich auf dem schräg abfallenden Strande der Walross-Insel, am Fusse der 3-500 Fuss hohen steilen Klippen der Nordustseite, die daturch, dass sie im Norden und Osten schroff ins Meer fallen, den unwillkommenen Besuch von Eisfüchsen gänzlich ummöglich machen. Ich zählte an 40 Nester, die aus einer einfachen runden, sehr flachen Vertiefung des steinigen oder mit Graswuchs hedeckten Bodens bestanden, welche mit den bekamnten Eiderdunen atusgepolstert war, jedoch in sehr verschiedener Menge, denu in manchen Nestern lagen die Eier fast auf dem blossen Erdboden. Die Zahl derselben wechselte von eins bis vier, doch fanden wir Ende Juni auch bis fünf und eimmal sogar sieben in einem Nest.

Die Nester waren meist 20-50 Schritt vom Ufer entfernt, 
theilweis aber noch viel höher hinauf, ummittelbar am Fusse der Klippen angebracht, sodass es für die Jungen schwierig sein muss, ïber das mächtige Gerölle hin die See zu erreichen.

Die Männchen standen meist neben den brütenden Weibchen. doch beobachtete ich zweimal, dass das Männchen auf den Eiern sass. Die Vögel waren sehr wenig scheu und exhoben sich erst bei unmittelbarer Amnäherung. Am 21. Juni besuchte ich diesen Brutplatz abermals und fand die Weibchen eifrig briitend. Da es stark geschneit lratte, so lagen die Nester meist in einem tiefen Trichter von Schnee. Die Eier waren grossentheils noch wenig bebrütet, sodass wir einen schönen Vorrath zum Verbrauche einsammeln konnten. Nur sehr vereinzelt fanden sich die Männchen bei den Nestern; sie trieben sich meist am Strande und auf der Eiskante umher.

Ueberraschend war es für uns zweimal Eiderenten-Weibchen auf den drei Eiern der Burgemeistermöve (Larus glaucus) brütend zu beobachten.

Die ersten zum Anskriechen reifen Eier funden wir am 1. Juli: in den folgenden Tagen waren Dunenjunge, die ron der Mutter geführt wurden, in den Buchten und an der Küste häufig; doch erlegten wir noch am 20. September einen jungen Hlugunfähigen Vogel.

An der Falschen Bai wurden, um dies noch zu bemerken, zwei Nester gefunden, an dem hohen Strande, welcher von dem offenen Meere $1 / 2-1$ Meile entfernt ist. - P.]

17) Somateria spectabilis L. Pracht-Eiderente.

Anas spectabilis Naumann, Vögel Deutschlands, XII, 285, Taf. 292 und 323. Anas spectabilis Sabine, Limn. Trans., XII, 553.

Somateria spectabitis Holböll, Fauna Grönlands, S. 75.

Anas spectabilis Graah, Reise, S. 179.

Somateria spectabilis Reinh., Ibis, 1861, S. 14.

Somateria spectabilis Middendorff, sibirische Reise, s. 233.

Somateria spectabilis Baird, B. N.-Amer., 1. 810.

Somateria spectabilis Dall and Bannister, B. of Alaska, p. 301.

Somateria spectabilis Malmgren, Journ. f. Ornith., 1863, S. 380 (Spitzbergen). Somateria spectabilis Newton, Ibis, 1865, S. 516 (Spitzbergen).

Somateria spectabilis Heugl., Peterm. Geogr. Mitth., 1871, S. 59, 65 (Spitzbgn.).

Somateria spectabilis Gillett, Ibis, 1870, S. 309 (Nowaja-Semlja).

Somateria spectabilis Heuglin, Ibis, 1872, S. 63 (Nowaja-Semlja).

Ein altes Nännchen der Prachteiderente, am 25. Juni bei der Sabine-Insel geschussen, liegt ror. Es trägt das rollste Hochzeitskleid. in welchem der Schnabelhöcker ausserordentlich atufgeschwollen ist, 
ganz wie auf Naumann's Fig. 1, Taf. 323. Der Schnabel nebst dem Häcker sind lebhaft orangeroth gefärbt, mit dunkelhornbramem Nagel; Beine brïunlichroth mit dunkeln Schwimmhïuten. Middendorfo macht darauf aufmerksam, dass er bei alten Männchen im Leben den Schniabel röthlich-violett gefïrbt fand, ummerklich übergehend in das P'omeranzigroth des Höckers.

Ein altes Männchen der Bremer Sammlung aus Kamtschatka stimmt übrigens durchaus mit dem grönländischen überein.

\begin{tabular}{|c|c|c|c|c|c|c|c|c|c|}
\hline Fl. & Schw. & 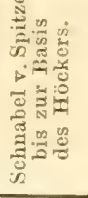 & 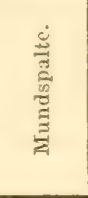 & 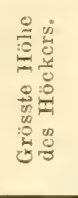 & 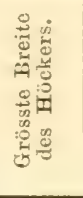 & 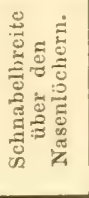 & L. & M. $-Z$. & \\
\hline $10^{\prime \prime} 9^{\prime \prime \prime}$ & $3^{\prime \prime}$ & $28^{\mathrm{mm}}$ & $62^{\mathrm{mm}}$ & $43^{\mathrm{mm}}$ & $29^{\mathrm{mm} m}$ & $19^{\mathrm{mm}}$ & $1^{\prime \prime} 10^{\prime \prime \prime}$ & $2^{\prime \prime} 6^{\prime \prime \prime}$ & of Ostgrönland. \\
\hline 109 & $36^{\prime \prime \prime}$ & 33 & 63 & 36 & 20 & 17 & 18 & 24 & ô Kamtschatka. \\
\hline 94 & 29 & 33 & 69 & 26 & 18 & 20 & 1 & 24 & ô Südgrönland. \\
\hline 98 & 29 & 32 & 60 & 20 & 18 & - & 1 & 24 & " \\
\hline
\end{tabular}

Die Prachteiderente verbreitet sich über den ganzen arktischen Kreis, ist aber an allen Orten minder zahlreich und somit seltener als die gewöhnliche Eiderente, dringt auch weiter nach Norden vor.

Aus Ostgrönland wurde sie schon durch Graah nachgewiesen. IIolböll verzeichnet (S. 3) ausserdem "Somateria perspicillate" als ron diesem Forscher beobachtet; obwol sie in Graah's eigenem Verzeichiss fehlt.

[Wir trafen nur dies eine Exemplar, welches an der Eiskante erlegt wurde, doch glaube ich ein Pärchen schon Ende Mai am Gänseteich gesehen zu haben, wenigstens war beim Männchen das lebhafte Gelb am Schnabel sehr auffallend. - P.l

18) Colymbus torquetus Brünnich. Eis-Seetaucher.

Eudytes glacialis Naumann, Vögel Deutschlands, XII, 397, Taf. 327.

Colymbus glaciatis Holböll, Fauna Grönlauds, S. 79.

Colymbus glaciatis Graah, Reise, S. 179.

Colymbus glaciatis Reinhardt, Ibis, 1861, S. 14.

Colymbus glacialis Middendorfi, Sibirische Reise, S. 238.

Colymbus torquatus Baird, B. N.-Amer., p. 888.

Colymbus torquatus Dall and Bamister, B. of Alaska, p. 307.

? Colymbus glaciatis Gillett, Ibis, 1870 , S. 308 (Nowaja-Semlja).

Lin junger Vogel dieser Art wurde von Kapitän Hegemamn aus Sirdgrönland mitgebracht, wo er ihn durch die Missionare in Fried- 
richsthal erhielt. Derselbe stimmt ganz mit der Abbildung bei Naumamn (Fig. 2) iibcrein, aber der Unterschmabel und ein breiter Schneidenrand des Oberschnabels sind hornweisslich und nur der übrige Theil des Oberschnabels hormbraun. Hiddendorff macht ebenfalls auf ein Exemplar mit ganz gelbweissem schnabel aufmerksam, welches er am Taymirflusse erhielt.

\begin{tabular}{|c|c|c|c|c|c|c|c|}
\hline $\mathrm{Fl}$. & F. & $\begin{array}{l}\text { Mund- } \\
\text { spalte. }\end{array}$ & $\begin{array}{l}\text { Schmabelh. } \\
\text { an Basis. }\end{array}$ & L. & $\begin{array}{l}\text { Aeuss. } \\
\text { V. Z. }\end{array}$ & $\begin{array}{l}\text { Nagel } \\
\text { ders. }\end{array}$ & \\
\hline $12^{\prime \prime} 10^{\prime \prime \prime}$ & $2^{\prime \prime} 7^{\prime \prime \prime}$ & $3^{\prime \prime} 8^{\prime \prime \prime}$ & $9^{\prime \prime \prime}$ & $3^{\prime \prime} 2^{\prime \prime \prime}$ & $4^{\prime \prime} 1^{\prime \prime \prime}$ & $4^{\prime \prime \prime}$ & jun. Südgrönl. \\
\hline 146 & 32 & 45 & 11 & 34 & $4 \quad 4$ & 5 & 0 ad \\
\hline
\end{tabular}

Aus Ostgrönland wurde die Art durch Graah nachgewiesen. Gillett fiihrt sie als zweifelhaft von Nowaja-Semlja an. Auf Spitzbergen bisher nicht beobachtet. Nach Dall und Bannister häufig am Yukon.

COb unter den Seetauchern, die wir bei Sabine-Insel im Juni und Juli fist täglich sahen und hörten, diese Art sich befand, kann ich nicht constatiren. - P.]

19) Colymbus septentrionalis L. Rothkehliger Seetaucher.

Eudytes septentrionalis Naumaun, Vögel Deutschlands, XII, 434, Taf. 329.

Colymbus septentrionalis Sabine, Trans. Lim. Soc., XII (1818), 1) 542.

Colymbus septentrionalis Holböll, Fauna Grönlands, S. 79.

Colymbus septentrionalis Graah, Reise, s. 179.

Colymbus septentrionalis Reinhardt, Ibis, 1861, S. 14.

Colymbus septentrionalis Hiddendorff, Sibirische Reise, s. 239.

Colymbus septentrionatis Baird, B. N.-Amer., p. 890.

Colymbus septentrionatis Dall and Bannister, B. of Alaska, p. 307.

Colymbus septentrionatis Malmgren, Journ. f. Ornith., 1863, S. 382 (Spitzbergen).

Colymbus septentrionalis Newton, Ibis, 1865, S. 517 (Spitzbergen).

Colymbus septentrionalis Heugl., Peterm. Geogr. Mitth., 1871, S. 65 (Spitzbergen).

Colymbus septentrionatis Heuglin, Ibis, 1872, S. 64 (Nowaja-Semlja).

Ein altes Nïnnchen im vollen Prachtkleide (wie bei Naumamn Taf. 329, Fig. 1), am 17 Juli $1870 \mathrm{im}$ Germaniahafen erlegt.

\begin{tabular}{|c|c|c|c|c|c|c|c|}
\hline Fl. & Schiv. & F. & $\begin{array}{l}\text { Mund- } \\
\text { spalte. }\end{array}$ & $\begin{array}{l}\text { Schnabelh. } \\
\text { an Basis. }\end{array}$ & L. & $\begin{array}{l}\text { Aeuss. } \\
\text { V. Z. }\end{array}$ & \\
\hline $10^{\prime \prime} 3^{\prime \prime \prime}$ & $2^{\prime \prime}$ & $23^{\prime \prime \prime}$ & $36^{\prime \prime \prime}$ & $6^{\prime \prime \prime}$ & $2^{\prime \prime} 8^{\prime \prime \prime}$ & $3^{\prime \prime} 1^{\prime \prime \prime}$ & ô ad Ostgrönland. \\
\hline $10 \quad 9$ & 一 & 23 & 36 & $5^{3} / 2$ & 25 & $3-$ & $\hat{\delta}$ ad Südgrönland. \\
\hline
\end{tabular}


Der rothkehlige Seetaucher, schon von Kapitän Graah in Ostsrönland gefunden, zählt zu den an weitesten nath Norden vordrinsrenden Vögehn; er geht noch ïber den achtzigsten Grad hinatuf. Die Verbreitung erstreckt sich über dats ganze arktische Gebiet beider Welten.

[In den ersten 'Tagen des Juni bemerkten wir diesen Seetaucher zuerst. Er hielt sich meist in kleinen Scharen, aber auch einzeln und flog in bedeutender Höhe über der Germaniabucht hin und her, wobei er seine Stimme, ein schnell wiederholtes ,ga-ga-ga" Hleissig hören liess. Während der Nacht hörten wir oft eigenthümliche Klagelaute, fant wie menschliche klingend, die, wie ich später in Erfahrung brachte, von Colymbus septentrionalis herriihrten. Gegen die Vitte des Julimonats zeigten sie sich einzeln oder zu zweien oder dreien im Hafen, es gelang aber trotz aller Nihhe und stundenlangen dagens nur ein Exemplar zu erlangen, welches durch Herrn Sengśtacke erlegt wurde.

Die Nistplätze dieser Vögel waren wir nicht so glïcklich zu finden. $-\mathrm{P} .1$

20) Pocticeps cormutus Gml. Gehörnter Steissfiuss.

Colymbus cornutus Naumann, Vögel Deutschlands, IX, 739, Taf. 244.

Colymbus areticus Boie, p. 755̃, Taf. 245.

Podiceps cornutus Holböll, Fauna Grönlands, S. 2, Nr. 36.

P'odiceps comutus Reinhardt, Ibis, 1861, S. 15.

Podiceps cormutus Middendorfi, Sibirische Reise, S. 238.

Podiceps cormutus Baird, B. N.-Amer., p. 895.

Podiceps cormutus Dall and Bannister, B. of Alaska, 1. 308.

Kapitïn Hegemann brachte ein Exemplar aus Siidgrönland mit, ein Geschenk der Missionare in Friedrichsthal. Es ist ein junger Vogel, ganz wie ihn Naumann Taf. 245, Fig. 4 darstellt.

\begin{tabular}{c|c|c|c|c|c}
\hline Fl. & F. & Mundspalte. & L. & Aeuss. Z. & Nag. ders. \\
\hline $4^{\prime \prime} 10^{\prime \prime \prime}$ & $9^{\prime \prime \prime}$ & $14^{\prime \prime \prime}$ & $20^{\prime \prime \prime}$ & $22^{\prime \prime \prime}$ & $3^{\prime \prime \prime}$ \\
\hline
\end{tabular}

Ich sehe mit Schlegel und andern Forschern keinen Grund Podiceps arcticus boie als Art zu betrachten.

Durch Herm Sengstacke erhielt ich die Ueberreste eines Steissfusses, der während der ersten deutschen Polarfithrt auf Spitzbergen 
erlegt wurde und sich als Podiceps griseigence Bodd. (rubricollis Gml.) erwies, eine Art, die meines Wissens noch nicht aus diesem Gebiete nachgewiesen wurde.

\section{1) Uria Brimnichii Sabine. Briunnich's Lumme.}

Trans. Liun. Soc., XII (1818), p. 538 et 540.

Uria troite Brümich (nec L.).

Cepphus Arra Pall.

Uria Arra Naumamn, Vögel Deutschlands, XII, 535, Taf. 333.

Uria Brünnichii Holböll, Fanna Grönlands, S. 81.

Alca pica (Uria Brünnichii) Graah, Reise, S. 179.

Uria Arra Baird, B. N.-Amer., p. 914.

Uria Arra Dall and Bannister, B. of Alaska, p. 309.

Alca Brünnichii Malmgren, Journal für Ornithol., 1863, S. 382 (Spitzbergen).

Uria Brïnnichii Newton, Ibis, 1865, S. 520 (Spitzbergen).

Alca troile var. Brïnnichii Malmgren, Journal für Ornithol., 1865, S. 263.

Uria troile var. Heuglin, Petermann's Geograph. Mittheilungen, 1871, S. 65.

Uria Brïnnichii Gillett, Ibis, 1870, S. 308 (Nowaja-Semlja).

Uria Brïnichii Heuglin, Ibis, 1872, S. 64 (Nowaja-Semlja).

Zwei Exemplare (o und શ), am 16. und 22. Juli 1870 an der Eisgrenze unter dem 75. resp. 74. Grad erlegt. Beide tragen das vollkommene Sommerkleid und stimmen gatnz mit Exemplaren aus Westgrönland und einem zwischen Bireninsel und spitzbergen erlegten (durch von Heuglin) iiberein. Das letztere zeigt indess längs Kimnund Kehlmitte zahlreiche weisse Federn, obschon es Mitte Juli (11.) geschossen wurde. Das $\&$ (22. Juli erlegt) hat die Schwingen und Deckfedern stark abgerieben, sodass die Spitzen der erstern bräunlichweiss, die Schulterdecken in diesem Tone grefleckt erscheinen. Der Basistheil des Oberschmabels, vom Mundwinkel bis unterhall, del Nasenlöcher ist schön bleiblau, welches auch im getrockneten Zustande in triiber bleigrauer Färbung deutlich bemerkbar ist. Das spitzbergensche Exemplar zeigt diese Eigenthümlichkeit gleichfalls.

\begin{tabular}{c|c|c|c|c|c|c|c|c}
\hline \hline Fl. & Schw. & F. & $\begin{array}{c}\text { Nund- } \\
\text { spalte. }\end{array}$ & $\begin{array}{c}\text { Höhe } \\
\text { an } \\
\text { Basis. }\end{array}$ & $\begin{array}{c}\text { Breite } \\
\text { an } \\
\text { Basis. }\end{array}$ & L. & M. Z. & \\
\hline $8^{\prime \prime}$ & $21^{\prime \prime \prime}$ & $14^{\prime \prime \prime}$ & $25^{\prime \prime \prime}$ & $15^{\prime \prime m}$ & $10^{\mathrm{mm}}$ & $15 \frac{1}{1 / 2}$ & $21^{\prime \prime \prime}$ & 2 \\
8 & 21 & 16 & 27 & 14 & 9 & 16 & 20 & 0 \\
8 & 21 & 16 & 25 & 12 & 7 & $151 / 2$ & 19 & var. alba. \\
8 & 21 & 15 & 28 & 15 & 9 & 16 & 20 & Bäreninsel. \\
$71^{\prime \prime \prime}-76^{\prime \prime \prime}$ & $21-22$ & $20-21$ & $29-31$ & $13-14$ & $8-9$ & 15 & 1920 & troile (3 Expl.).
\end{tabular}


Eine höchst interessante prachtrolle Varjetät brachte Kapitän Hegemann aus Westgrönland mit, wo er dieselbe durch Güte der Brïder in Lichtenau erhielt. Dieses Exemplar zeigt ein durchaus schneeweisses Gefieder, welches weder durch einen dunklern 'Ton, noch irgendwelche Fleckung getribt ist; der schmabel zieht ins Iforngellslichweisse, gegen die Basis zu röthlich; Beine, Füsse und Nägel sind hell röthlichbraun, die Schwimmhäute heller. Man darf vermuthen, dass sowol Schnabel als Beine im Leben fleischroth oder iiberhaupt röthlich gefüribt waren.

Dieses Exemplar ist um so mehr ron Interesse, als meines Wissens bisher nirgends einer rein weissen Varietät dieser Art erwähnt wird. Holböll gedenkt nur einfarbig schwarzer, hell aschgraner und blass rothgrauer Lxemplare, die ihm wïhrend semes lingjiihrigen Aufenthalts in Grönland vorkamen.

Die Artselbständigkeit von Uria Brïnnichii, von den ältesten bis zu den neuesten Forschern anerkannt, ist neuerdings durch Dr. Malmgren angezweifelt worden, der sie ,nur als eine für den höchsten Norden eigenthïmliche Localform" betrachtet wissen möchte, wogegen schon Professor Newton mit Recht protestirte. Dieses Verfahren Malmgren's muss nm so mehr Verwunderung erregen, als er selbst sehr treffend die Unterscheidungskennzeichen von Uria Brünnichii und Uria troile angibt und bemerkt, sie seien constante, ,so dass man auf den ersten Blick die eine Art von der andern nnterscheiden kann". Meine Vergleichungen mit Exemplaren von Uria troile bewiesen mir, dass die von Malmgren angegebenen Unterschiede feststehende sind, mit Ausnahme ron der unter 4) bemerkten, die auf die Färbung der untern Flïgeldecken Bezug haben. Uria Brimnichii unterscheidet sich sehr leicht von Uria troile

1) durch das glänzende Braunschwarz der Oberseite, welches auf den Ziigehn, an Kopf- und Halsseiten, Kimn und Kehle in T'iefbraun iibergeht (bei troile die Oberseite tiefbram);

2) durch den kiirzern Schnabel, der zugleich auch meist höher und breiter ist, daher kräftiger erscheint, dessen Basistheil des Oberschnabels blaugrau (Brimnich sagt gelblich) gefärbt ist;

3) durch längere Fliigel und, möchte ich hinzufïgen:

1) durch die einfarbig weissen Federn der Brust- und Bauchseiten, welche bei Uria troile mehr oder minder breite dunkle Seitensäume zeigen, dather längsgestreift erscheinen, ein Kennzeichen, auf welches schon der treftliche Faber hinweist (Prodx. isliund. Ornith., 1822, S. 41).

Diese als constant erwiesenen Charaktere dürten wol himreichen 
Artenrecht gelten zu lassen; doch muss ich erwähnen, dass nach den Messungen, welche Professor Schlegel (Mus. P. B. Urinatores, p. 15 et 16) notirt, kaum eine Unterscheidung nach der Schnabel- und Flïgellänge durchfühbar erscheint.

Uria Brïmichii wurde schon durch Kapitïn Graah an der Ostkiiste Grönlands nachgewiesen, während Uvia troile I. bisjetat aus diesem Gebiete nicht bekannt ist.

Ueber das unzählbare Auftreten dieser Art an ihren Briiteplätzen in Westgrönland berichtet Iollöll in anziehender Weise. Auch Malngren weiss keine Worte zu finden, um die Anzahl der von ihm in Spitzbergen angetroftenen Brümichs-Lummen nur amnähernd zu reranschanlichen.

[Ausser den beiden erlegten Exemplaren bemerkten wir in und am Eise nur noch sehr wenige und an der Kiiste gar keine.

22) Uria grylle L. Teiste.

- I.

Cepphus grylle Naumanu, Vögel Deutschlands, XII, S. 461, Taf. 380.

Uria grylle Sabine, Linn. Trans., XII (1818), p. 540.

Uria grylle Holböll, Fauna Grönlands, S. 80.

Uria grylle Graah, Reise, S. 179.

Uria grylle Reinhardt, Ibis, 1861, S. 16.

Uria grylle Baird, B. N.-Amer., p. 911.

Exemplare aus Spitzbergen und Nowaja-Semlja.

Uria Mundtii (Licht.) Mandt, Dissertatio de itinere Groenland., 1822, p. 30.

Uria Mandtii Licht., Doubl.-Verz., 1823, S. 88 (Spitzbergen).

Uria Mandtii Reinhardt, Ibis, 1869, S. 240 (Mandt's Dissert. reproducirt).

Uria Mandtii Naumann, Vögel Deutschlands, XII, 462 (Spitzbergen).

Cepphus glacialis Brehm, Handbuch Vög. Deutschl., 1831, S. 989. - Brehm, Vogelf., S. 407.

Uria IIandtii Evans und Sturge, Ibis, 1859, S. 172 (Spitzbergen = grylle).

Uria grylle Malmgren, Journal für Ornithologie, 1863, S. 382 (Spitzbergen).

Uria grylle, var. glacialis Brehm, Malmgren, ebendas., 1865, S. 261 (Spitzh.).

C'epphus Mandtii et grylle Newton, Ibis, 1865, S. 518, 519.

Cepphus Mandtii Newton, Ibis, 1869, S. 241.

Uria grylle var. et Ceppluus Columba Pall, Henglin, Petermamn's Geographische Mittheilungen, 1871, S. 64, 65 (Spitzbergen).

Cepphus Mandtii? Gillett, Ibis, 1870, S. 307 (Nowaja-Semlja).

Cepphus MIndtii Heuglin, Ibis, 1872, S. 64 (Nowaja-Semlja).

Die von der Expedition heimgebrachte schöne lieihe von 10 Exemplaren wurde im Juni und Juli auf Sabine-Insel und deren Umgebung eingesammelt. Sie setzt mich, im Verein mit weitern Exemplaren aus Siid- und Westgrönland, Spitzbergen und den Küisten Schleswigs, die ich zum Theil der fremndlichen Unterstiitzung von Professor Möbius und Dr. von Heuglin verdanke, in Stand nachzuweisen, dass 
Tria Mandtii als Art unhalthar ist oder höchstens Ansprüiche als Localform machen kamn. Bei Durchsicht der Literatur wird es auffallen, dass jeder Schriftsteller, der aus eigener Anschanung iiber diese Art spricht, sich bemiiht neue, von seinem Vorgänger nicht erwähnte Kennzeichen aufaustellen. Mandt, der die ersten Exemplare vom einer lieise mit einem hamburger Walfischtinger zwischen Spitzhergen und ()stgrönland heimbrachte, will die drt wegen des schlankern Schnabels, der längern Extremitäten und der lïngern weissgespitzten Armschwingen von Tria grylle unterschieden wissen, welche Kennzeichen Lichtenstein als specifische acceptirt, während Naumann ansserdem noch auf die grössere Ausdehnung des Weiss an der Innenfahne der Schwingen aufmerksam macht. Letzteres Kemnzeichen wird nun von Keyserling und Blasius (Wirbelthiere Europas, S. 237) benutzt; Urin grylle soll , ,die Innenfahne der Handschwingen kaum iiber die untern Fliigeldeckfedern hinaus weiss" haben, wihrend bei Uria Mandtii „,die Innenfahne der grossen Schwingen zur Hälfte, über die untern Deckfedern hinausragend weiss" ist. Nachdem Holböll, Naumann u. A. die erheblichen Abweichungen in der Grösse und Schnabelform längst als zufällige erkannt hatten, glaubte man in den weissen Spitzen der zweiten Schwingen ein constantes Kennzeichen für Uria Mandtii gefunden zu haben, bis Professor Newton auch dieses und mit Recht fiir unhaltbar erklürte, dagegen aber ein nenes, allerdings etwas tiefliegendes aufstellte, welches er als ,unfehlbares" erklärt. Er sagt: "In der mehr nördlichen Form (Mandtii) von Grönland und Spitzbergen sind die Federn, welche das weisse Flügelfeld bilden, rein weiss bis zur Basis, während bei der wahren Uria grylle ron unsern Inseln, Island und Norwegen, die einen kräftigern Schmabel besitzt, diese Federn an der Basis stets schwarz sind, und so ein fast oder ganz bedecktes dunkles Querband bilden."

Bei der ansehnlichen mir vorliegenden Reihe von etlichen zwanzig Exemplaren war es daher ziemlich umständlich und zeitraubend jedes einzelne Individum auf alle diese Abweichungen hin genau zu untersuchen, um festzustellen, welche sich als constante erweisen würden. Das Resultat resumirt sich nun einfach darin, dass keins der erwähnten Kennzeichen Stand hält und dass es mir demnach nicht möglich ist, Uria Mandtii nur als Localform im Simne Malmgren's anzuerkennen.

Die nachfolgende Maasstabelle wird zunächst beweisen, dass hinsichtlich der Grösse, des kräftigern oder schlankern Sichnabels nicht einmal amühernd sichere Grenzen zu ziehen sind. Genau ebenso verhält es sich in Bezug auf die Vertheilung ron Weiss auf dem Fliigel 
und den Schwingen. Dass zunächst die mehr oder minder deutlich markirten dunkeln Endspitzen der weissen Deckfedern, welche sich zuweilen zu regelmässigen Querbinden gestalten, Reste des Jugendkleides sind, wurde bereits durch Faber nachgewiesen und allgemein als richtig angenommen. Die weissen Endspitzen der Schwingen zweiter Ordnung und Deckfedern der ersten Schwingen haben einen ganz gleichen Ursprung; wie schon aus dem Umstande erhellt, dass sie stets bei Exemplaren mit dunkeln Endflecken vorkommen, während der alte Vogel mit rein weissem Flügelschild (Nammann, 'Taf. 330, Fig. 1) nie Spuren daron zeigt. Bei einem Spitzbergen-Exemplare (junges Männchen) sind auf den Deckferlern nur einzelne fahlbraune sehr kleine Endflecke vorhanden; ron den sehr abgeriebenen und abgebleichten fahlbraumen Schwingen tragen die der zweiten Ordnumg eine abgeriebene weisse Endkante; auf den weissen untern Flïgeldecken findet sich in der Daumengegend ein grösseres schwarzes Feld. Ein anderes junges Männchen aus Spitzbergen (Juli, von Heuglin) zeigt (wie alle ibrigen Exemplare) daron keine Spur; die dunkeln Endspitzen der obern Deckfedern sind äusserst schwach angerlentet und die weissen Endsäume der zweiten Schwingen fast ganz abgerieben und nur an einzelnen Federn sichtbar. Ebenso verhält es sich mit einem Spitzbergen-Vogel der Bremer Sammlung; die dunkehn EndHecke der Deckfedern deutlich, aber nur die letzten zweiten Schwingen weiss geendet; die Deckfedern der ersten Schwinge breit weiss gespitzt. Dieselben Verschiedenheiten bieten Exemplare aus Ostgrönland dar. Bei einem bilden die dunkeln Endspitzen der Deckfedern zwei breite Querbinden und nur an den letzten zweiten Schwingen zeigen sich schmale weisse Endsäume, während letztere bei einem andern Exemplare an allen Schwingen zweiter Ordnung dentlich vorhanden sind, von den dunkeln Endspitzen dagegen nur so schwache Spuren, dass das ganze Flügelfeld fast rein weiss erscheint. Ein bei Schleswig erlegtes Männchen zeigt die weisse Endkante der zweiten Schwinge und die dunkeln Endflecke der Deckfedern so deutlich als Exemplare aus Spitzbergen und Grönland.

Nammann hat jedenfalls Recht, wenn er annimmt, dass so gezeichnete Vögel noch nicht ein Jahr alte sind, und ihr Kleingefieder, aber nicht die Schwingen wechselten, denn die letztern sind durchgehends mehr oder minder stark abgenutzt. Dass die Vögel in diesem Kleide nicht fortpllanzmosfahig sind ist newerdings durch Malmgren bestätigt worden.

Junge Tögel im ersten Federkleide (ähnlich wie das bei Naumann, Taf. 330, Fig. 3 dargestellte) zeigen zuweilen ebenfalls eine weisse 
Endkante an den zweiten Sohwingen. So ist sie bei einem SpitzbergenExemplare (1. September: von Heuglin) deutlich entwickelt, während ein anderes von dorther (24. August: von Heuglin) nur an den letzten Schwingen spuren weissel Gndkinten zeigt; wol der deutlichste Beweis, wie zufällig und variabel diese Zeichnung ist.

Nicht minder zufällig und unabhängig von Localität und Alter variirt das Weiss an der Innenfahne der ersten Schwingen. Zuweilen ist es auf die Basis beschränkt, wird also von den zweiten Schwingen bedeckt, meist erstreckt es sich aber ïber die letztern hinaus und reicht zuweilen fast bis zur Spitze; in den meisten Fällen ist es rom Schwarz des Spitzentheiles scharf abgesetzt, manchmal aber auch allmählich verfliessend.

Ich komme nun zu dem Kennzeichen, welches ron Professor Newton als letzter Rettungsanker für Uria Mandtii als , unfehlbar" autgestellt wurde, nämlich der dunkeln oder einfarbigen Basis der Federn des weissen Flügelfleckes, womit, präciser ausgedriekt, zunächst die Deckfedern der Schwingen zweiter Ordnung, also die der Armschwingen, gemeint sind.

Wenn ich dies Kennzeichen weiter oben als ein "tiefliegendes" bezeichnete, so hat dies seine Richtigkeit, indem man äusserlich rom demselben keine Spur bemerkt, sondern erst nachdem man die dariiher liegende grösste Reihe der obern Flügeldecken aufgehoben hat.

Ich habe eine wahre Musterkarte ${ }^{1}$ der betreffenden Federn höchst sorgfältig ausgezogen vor mir liegen, und will gern zugeben, dass bei Spitzbergen-Exemplaren der Basistheil im Ganzen heller erscheint, wenigstens nie eine so scharf abgesetzte dunkle Zeichmung zeigt; aber wo lassen sich die Grenzen beider Extreme feststellen?

Ich halte dies nach der mir vorliegenden Reihe geradezu fiir unmöglich, denn sie überzengt mich, dass sich zwischen der Form mit scharf alggesetzter schwärzlicher Basishälfte bis zu der fast oder ganz einfarbig weissen, alle möglichen Uebergänge, sowol in Ausdehnumg als Intensität der dunkeln Basisfärbung finden. Ostgrönländische Exemplare, an ein und derselben Stelle erlegt, reigen diese Deckfeder

"Professor Newton und Dr. von Henglin, denen ich diese ,Musterkarte" zur Ansicht übersandte, haben sich nicht von ihrer Meinumg trennen können und halten Uria Alandtii für verschieden, ohme sich indess völlig klar darüber zu sein, ol, sie als Art oder liasse hetrachtet werden muss. Ersterer Forscher schreibt mir: ,Es scheint gewiss, dass in Grönland alte Vögel rorkommen, die mit spitzbergischen ganz ïbereinstimmen, aber man kann annehmen, dass Uria grylle hier die gewönlichste Art ist, während Uria Mandtii (wenn die Art überhaupt als solche betrachtet werden (arf) selten rorkommt." 
so weiss als spitzbergische, oder so dunkel als solche ans der Kielev Bucht, während andererseits Exemplare von letzterel Localität sie ebenfalls ganz weiss besitzen, und dagegen wieder Spitzbergen-Tögel einen so trübschwarzen verwaschenen Basistheil zeigen als Individuen aus Ost- und Nordgrönland und ron den Kiisten Schleswigs. Wie bereits erwähnt gehen alle diese Verschiedenheiten ineinander iiber, es muss aber ausserdem bemerkt werten, dass der schwarze Basistheil der Deckfedern bei ein mol demselben Togel in Intensität und Ausdehnung variirt, ebenso wie die Länge dieser Deckfedern selbst. Es können daher alle diese geringen Abweichungen somit nur als individuelle, beeinflusst durch Alter und Jahreszeit, betrachtet werden. denen in keiner Beziehung Species- oder Rassenwerth beigelegt werden darf. Wer sich indess demmoch zu der letztern Ansicht bekennt. würde consequenter Weise die auf ebenso variable, also gleichwer-

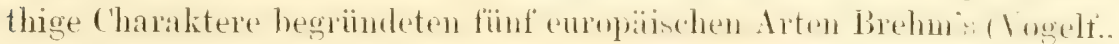
S. 407) anzunehmen genöthigt sein.

Schlegel hat newerdings nach der schönen Reihe ron 28 Exemplaren im Leydener Museum wiederholt anf die Unhaltbarkeit der Lria Mandtii aumerksan gemacht (Mus. P. B. Urinatores, 1867, p. 18) mol betrachtet sogar die Uria columbr als gleichartig, indem er ein angeblich aus Kamtschatka ( $\mathrm{Nr}_{1}$, 5) stammendes Lxemplar nicht ron monserer gewöhnlichen Jria grylle zu unterscheiden remag. Jedenfalls hat hier in Bezug auf die Localitïtsangabe eine Verwechselung stattgefunden, đenn alle aus Kamtschatka, der Beringsee und dem nordwestlichen Amerika herstammenden Lxemplare gehören zu Uria columba, einer ausgezeichneten Art, die Pallas unter Cepphus columba (Zoogr. Rosso. as., II, 349) als Localform erwähnt und die erst ron Cassin ausfïhrlich dargestellt wurde (Unit. St. Expl.-Exp., 1858 , p. 346, pl. 38, fig. 1.-Baird, B. N.-Amer., p. 912.-Baird, Atlas, t. 96. - Newton, Ibis, 1865, S. 519.-- Dall and Bannister, B. of Alaska, 1. 309).

Die geographische Verbreitung ron Uria grylle erstreckt sich daher nicht über den ganzen Polarkreis, wie Schlegel annimmt, sondern beschränkt sich auf die arktischen Gebiete Europas, des östlichen Amerikas und roraussichtlich des Norden Asiens; wie weit sie im Osten dieses Weltheils vordringt ist zur Zeit noch unbekannt.

In Ostgrönland wurde die Art bereits durch Graah nachgewiesen. In Journal von Ir. Buchholz wird Lriug grylle mehrfach aufgezeichnet. Der eifrige Sammler beobachtete sie zuerst am 18. Juli unterm 75. Grad an der iussern Eisgrenze, später im September längs der Reise an der Ostküste. „Iris braungelb; Schnabel schwarz; Füsse corall- 
roth; Nägel schwarz; Zunge und Rachen blutroth" (Buchholz). - „In

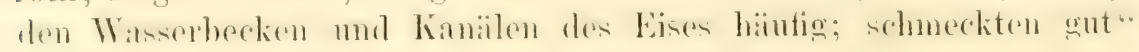
(Buchholz, a. a. O., S. 11).

von Heuglin erlangte auf Spitzbergen ein Weibchen mit 14 anstatt 12 Schwanzfodern; es zeigt im iibrigen nicht die geringste Abweichung.

\begin{tabular}{|c|c|c|c|c|c|c|c|c|}
\hline Fl. & Schw. & F. & $\begin{array}{l}\text { Muni- } \\
\text { spalte. }\end{array}$ & 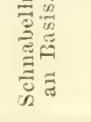 & 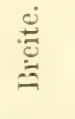 & $\mathrm{I}_{\text {s. }}$ & $\stackrel{-1}{\ddot{*}}$ & \\
\hline$i^{\prime \prime} \bar{\imath}^{\prime \prime \prime}$ & $19^{\prime \prime \prime}$ & $121 / 4 " \prime$ & $19^{\prime \prime \prime}$ & $9^{\mathrm{mm}}$ & $7^{m ! m}$ & $18^{\prime \prime \prime}$ & $14^{\prime \prime \prime}$ & Ostgrönland. \\
\hline 59 & 19 & 13 & $181 / 2$ & 9 & 7 & $13 \%$ & 15 & $n$ \\
\hline i 1 & 21 & 12 & 18 & 8 & 7 & 13 & $14^{1 / 2}$ & $n$ \\
\hline 511 & 20 & 13 & 19 & 8 & 6 & 13 & 15 & $n$ \\
\hline 59 & 22 & $13^{1 / 2}$ & $201 / 2$ & $10^{\prime \prime \prime}$ & $8^{\prime \prime \prime}$ & $1: 3 / 2$ & $151 / 2$ & $"$ \\
\hline (i) 1 & 23 & $1: ;$ & 20 & 9 & 7 & 14 & 15 & $n$ \\
\hline ii - & 21 & 13 & 21 & 10 & 7 & 13 & 16 & 1 \\
\hline ¿) 9 & 23 & $12^{1} / 2$ & 20 & 8 & $i$ & $18^{1 / 2}$ & 15 & of Schleswig. \\
\hline 57 & 19 & 15 & 22 & 10 & S & 14 & 15 & $\hat{j}$ \\
\hline ¿ 4 & 21 & $11 \frac{1}{2}$ & 18 & 8 & 6i & 15 & 15 & o jum. Kieler Bucht. \\
\hline 5) 6 & 21 & 13 & 20 & 11 & 8 & 15 & 15) & Q jum. Schleswig. \\
\hline 57 & 20 & 13 & 20 & 10 & 7 & 12 & 14 & Nordgrönland. \\
\hline (j) 1 & 23 & 13 & 18 & !) & 6 & $12 \frac{1}{2}$ & 14 & $n$ \\
\hline $59-6 ;$ & $19-22$ & $11 \frac{1}{2}-13$ & $18-21$ & $9-10$ & 8 & 14 & 16 & ad Südgrönland. \\
\hline $6-$ & 19 & $11^{1 / 2}$ & 18 & 8 & 5 & 13 & 14 & Spitzhergen. \\
\hline 57 & 23 & 13 & 18 & 10 & 7 & 13 & 15 & t3 \\
\hline 59 & 18 & $1: 3$ & 20) & 9 & 7 & $131 / 2$ & $15 \frac{1}{2}$ & "W.Thymen. \\
\hline 54 & 22 & 10) & 16 & $71 / 2$ & 5 & 14 & 14 & " jin. \\
\hline 67 & 21 & $14 \frac{1}{2}$ & 20 & 10 & 8 & 17 & 17 & $\begin{array}{l}\text { U. columba. } \\
\text { Kamtsehatka. }\end{array}$ \\
\hline
\end{tabular}

[Die Teiste gehört mit zu den Vögehn, welche wir am häufigsten und zugleich zahlreichsten antrafen. Wir begegneten ihr 1869 zuerst Ende Juli als wir ins Lis eindrangen, und 1870 liessen sich die ersten Anfang Juni hei der Cairnspitze an der Eiskante sehen. Am 12. Juni sah ich ron der Spitze der Walross-Insel eine ganze Ciesellschaft ron cirea 50-60 Stiick, die sich munter auf dem Wasser tummelten, und bis z.1 nuserer Abfahrt komnten wir sie täglich in Scharen von 20-30 Stiick his weit in See hinaus beobachten. - In den Klippen der Walross-Insel, etwa in halber Höhe, befanden sich Brutcolonien der Teiste, die indess leider gånzlich unzugïnglich waren. - P.] 
23) Mergutus alle L. Krabbentaucher.

Naumann, Yögel Deutschlands, XII, 552, Taf. 334.

Alcre alle Sahine, Linn. Trans., XII, 537.

Uria alle Holböll, Fauna Grönlands, S. 83.

Alca alle Graah, Reise, S. 179.

Arctica alle Reinhardt, Ibis, 1861, S. 16.

Mergulus alle Baird, B. N.-Amer., p. 918.

Mergula alle Malmgren, Journal für Ornithologie, 1863, S. 383 (Spitzbergen).

Mergulus alle Newton, Ibis, 1865, S. 521 (Spitzhergen).

Mergulus alle Heuglin, Petermann's Geogr. Mitth., 1871, S. 66 (Spitzhergen).

Mergulus alle Gillett, Ibis, 1870, S. 308 (Nowaja-Semlja).

Merguhus alle Heuglin, Ihis, 1872, S. 64 (Nowaja-Semlja).

Dr. Buchholz rerzeichnet diese unverkembare Art in seinem Journal. Die ersten wurden am 7. August 1869 an der Eisgrenze unter circa 74 Grad beobachtet und erlegt, ausserdem am 5. September an der Eisgrenze der Ostkiiste, darunter Exemplare mit schwarzer und weisser Kehle, also letztere bereits im Winterkleide.

"Iris gelbbraun (jung) bis braun; rïsse schwarz; die Schilder an der Vorderseite des Laufes weisslich" (Dr. Buchholz). „Häufig in den Kanälen und Wasserbecken des Eises" (Dr. Buchholz, a. a. O., S. 11).

[Wurde während der Fahrt im Fise mehrfach ron uns beobachtet, aber niemals an der Küiste. - P.l

Durch Kapitän Graah bereits von der Ostküste bekannt.

24) Procellaria glaciatis L. Eissturmogel.

Naumann, Vögel Dentschlands, X, 589, Taf. 276.

Sabine, Linn. Trans., XII, 553.

Holböll, Fauna Grönlands, S. 58.

Graah, Reise, S. 179.

Reinhardt, Ibis, 1861, S. 16.

Procellaria minor Kjaerb., Reinhardt, Ihis, 1861, S. $16(=$ glaciali).

Procellavin glaciatis Baird, B. N.-Amer., p. 826.

Procellaria glacialis, Auduboni et minor, Bp. Consp., II, 187.

Procellaria glacialis Evans und Sturge, Ibis, 1859, S. 168 (Spitzbergen).

Procellaria glacialis Malmgren, Journ. f. Ornith., 1863, S. 377 (Spitzbergen).

Procellavia glaciatis Malmgren, ebendas, 1865, S. 207 (Spitzbergen).

Procellaria glacialis Newton, Ibis, 1865, S. 511 (Spitzbergen).

Procellaria glacialis Hengtin, Peterm. Geogr. Mitth., 1871, S. 65 (Spitzbergen).

Procellaria glacialis Gillett, Ibis, 1870 , S. 307 (Nowaja-Semlja).

Procellavia glacialis Henglin, Ibis, 1872, S. 65 (Nowaja-Semlja).

Es liegen alte und juingere Vögel ror; die erstern mit fast weissem Kopfe, Halse und Unterseite und weissen untern Flügeldecken; die letztern an den genannten Theilen bräunlich-aschgrau, welcher Ton auf Kehle und Brust ansehnlich blasser erscheint; die untern Flïgel- 
decken und Achseln dunkel graubram. Zirischen der hellen und dunkehn Färbung existiren alle möglichen Uebergangsstufen. Solche dunkle Exemplare aus Spitzbergen, welche ich durch Giite von von Heuglin zum Vergleich erhielt, darunter auch ein einfarbig weisses, stimmen in jeder Hinsicht mit ostgrönländischen iiberein. Dass sich diese Färbungsstufe auf das Jugendlkleid bezieht, war bereits Naumam bekannt und ist neuerdings von Dr. Malmgren und durch 'von Henglin bestïtigt worden.

\begin{tabular}{|c|c|c|c|c|c|c|c|c|c|}
\hline Fl. & Schw. & F. & $\begin{array}{l}\text { Mund- } \\
\text { spalte. }\end{array}$ & $\begin{array}{c}\text { Lünge } \\
\text { der } \\
\text { Tuben. }\end{array}$ & 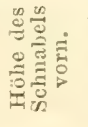 & $\begin{array}{l}\text { Breite } \\
\text { an ler } \\
\text { Basis. }\end{array}$ & Lanf. & M. Z. & \\
\hline $12^{1 / 2} / 1$ & $4^{\prime \prime} 6^{\prime \prime \prime}$ & $41^{\mathrm{mm}}$ & $51^{11+\cdots}$ & $12^{m m}$ & $16^{1 \mathrm{~mm}}$ & $20^{\mathrm{mm} \mathrm{m}}$ & $24^{\prime \prime \prime}$ & $26^{\prime \prime \prime}$ & Ostgrönland. \\
\hline $121 / 2$ & 310 & 36 & 45 & 11 & 16 & 19 & 23 & 23 & $n$ \\
\hline 13 & 49 & 41 & 50 & 14 & 18 & 21 & 25 & 29 & $"$ \\
\hline $121 / 2$ & 45 & 39 & 50 & 13 & 15 & 19 & 23 & 27 & јun. " " \\
\hline 13 & 46 & 40 & 46 & 15 & 17 & 20 & 24 & 28 & $"$ \\
\hline 12 & 44 & 39 & 49 & 13 & 16 & 19 & 23 & 26 & Süđgrönland. \\
\hline $119^{\prime \prime \prime}$ & 45 & 33 & 46 & 10 & 15 & 18 & 20 & 22 & Nordgrönland. \\
\hline 116 & 46 & 36 & 45 & 11 & - & 19 & 21 & 26 & o Spitzhergen. \\
\hline 12 & 46 & 36 & 48 & 10 & 16 & 18 & 22 & 26 & " \\
\hline 123 & 46 & 38 & 47 & 11 & 15 & 18 & 22 & 24 & "(var. alba). \\
\hline
\end{tabular}

Bei den erheblichen Abweichungen in den Dimensionen, namentlich der Lünge des Schnabels, welche durch vorstehende Nessungen erörtert werden, war es nicht zu verwundern, wenn man mehr als eine Art vor sich zu sehen glaubte und eine artliche Abtrennung versuchte. Reinhardt hat inzwischen nachgewiesen, dass Procellaria minor, die' auf Nordgrönland beschränkt sein sollte, sich lediglich auf kleine Exemplare von Procellaria glacialis bezieht, die er sowol aus Südgrönland als von den Fär-Inseln erhielt, was ich nach Ver-

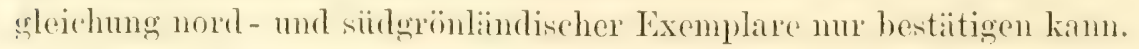

Unsere Kemntniss iiber das Veibreitungsgebiet von Procellaria glacialis ist eine beschränkte. So fehlt uns bisjetat Kunde ihres Vorkommens im Norden Sibiriens, im nördlichen Stillen Ocean und in Nordwestamerika. Es wird zwar angenommen, dass die $\Lambda \mathrm{rt}$ in diesen Gebieten durch Procellaria pacifica Audubon (Baird, B. North-Amer., p. 826 ) vertreten sei, allein es entstehen gewisse Bedenken gegen letztere, welche stark vermuthen lassen, dass sie sich vielleicht nur auf

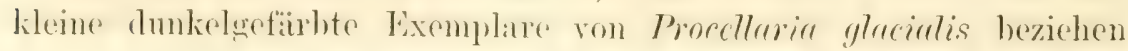


werde. So untersuchte Naumann (Tote auf S. 592) alte Tögel von den Curilen, die er der kleinen Schuäbel halber anfäinglich geneigt war für eine besondere Art zu halten, die er aber später von solchen aus den grönländischen Meeren nicht zu unterscheiden vermochte. Und was Schlegel (Mus. P. B. Procellaria, p. 22) nach dem einen Exemplar des Leydene1 Museums aus Kamtschatka hinsichtlich der specifischen Lnterschiede bemerkt, erseheint ziemlich werthlos, da die Messungen keineswegs die geringere Gräse als durchgreifenden Charakter bewahrheiten.

Die Exemplare aus dem nördlichen Stillen Ocean und der Beringsstrasse sind von Cassin, s. n. Fulmalus Rodgersi getrennt worden (s. Proced. Acad. Phil., 1862, 1. 290. - Comes, ibid., 1866. p. 29. - Baird in Dall and Bannister, j. 323, 'Taf. 24, Fig. 1).

Procellaria glaciatis gehört zu den schon von Kapitän Graah in Ostgrönland beobachteten Vogelarten.

[Schon bei unserm Eintritt in das P'olarmeer beobachteten wir diese Art einzeln; immerhalb der Eisgrenze war sie aber eine gewöhnliche Esscheinung, verschwatnd aber wieder mehr, sobald wir uns der Küste näherten. Sowol im Herbst 1869, als im Friihjahr und Sommer 1870 sahen wir sie in diesen Gegenden nur höchst selten und nie mehr als zu zweien oder dreien. - P.]

25) Larus glaucus Brïnich. Polirmöve.

Orn. bor. (1764), 1. 44.

Naumann, Vögel Deutschlands, X, 350, Taf. 264.

Sabine, Limn. Trans., XII, 543.

Holböll, Fauna Grönlands, S. 45.

Graah, Reise, S. 179.

Reinhardt, Ibis, 1861, S. 16 .

Baird, B. North-Amer., 1. 812.

Dall and Bannister, B. of Alaslia, p. 304.

Middendorff, Sibirische Reise, S. 241.

Nalmgren, Journal für Ornithologie, 1863, S. 376 (Spitzbergen).

Newton, Ibis, 1865, S. 509 (Spitzbergen).

Heuglin, Petermann's Geographische Mittheilungen, 1871, S. 65 (Spitzbergen). Gillett, Ibis, 1870 , S. 306 (Nowaja-Semlja).

Heuglin, Ibis, 1872, S. 65 (Nowaja-Semija).

Blasius, Journ. f. Orn., 1865, S. 831 (= glancescens Licht. = glancopterus Kittl.).

Bei dieser und der tolgenden Mövenart kommt bekanntlich eine in der Jugend fust einfarbig weisse Varietät vor, welche Holböll ausfiihrlich bespricht (Larus glaucus, Nr. 2, S. 46) und die unter dem Namen Larus arcticus Macgill. (glacialis Benicken - Bp., Consp., II. p. 216) noch heute von manchen Forschern als eigene Art betrachtet 
wird. Die Bremer Sammlung besitzt ein solehes Exemplar aus SüdErönland. Ditselbe ist rein weiss. mit einem blassen isabellgelblichen Anfluge, und zeigt auf dem Bürzel, sowie auf den zweiten Schwingen noch sehr blass angedeutete Spuren der bramen Querzeichnung des Jugendkleides; auch am Ober- und Hinterkopfe finden sich leise Andeutungen dunklerer schattstrichelung; der schnabel ist horngelb mit bräunlichem Spitzentheile.

Die ron der Ostküste mitgebrachten Exemplare, ein Männchen im vollkommenen Sommerkleide (Ende April 1870) und ein im September 1869 auf Sabine-Insel eingesammelter junger Yogel, stimmen vollkommen mit mir vorliegenden Exemplaren aus Westgrönland, Norwegen und Spitzbergen (von Heuglin) überein. Der junge Vogel ist anm liopfe, Halse und der Lnterseite merklich dunkler graubräinlich, namentlich auch um das Auge herum und auf den Backen.

Bei den in Salz präparirten alten Männchen ist die Färbung der Nacktheile noch sehr wohlerhalten, obschon allem Anscheine nach etwas dunkler geworden. Der Schnabel ist livid grinbräunlich (merklich heller als bei leucopterus), an den Tomienrändern heller, grünlichgrau; der Lnterschnibel besitzt iiber dem Eck einen lebhaft rothen Fleck und hat eine horngelbliche Spitze; der Oberschnabel hinter den Nasenlöchern ist horngelb (ohne rothen Schein) und zieht gegen die Spitze zu ins blass Horngrauliche. Beine und Füsse wie bei Larus leucopterus gefärbt.

Dr. Buchholz notirt diese Art ebenfalls in seinem Journal. „Häufig tiefer im Eise" (Buchholz, a. a. 0., S. 12).

\begin{tabular}{|c|c|c|c|c|c|c|c|}
\hline Fl. & Schw. & F. & $\begin{array}{l}\text { Mund- } \\
\text { spalte. }\end{array}$ & $\begin{array}{c}\text { Schmabelhöhe } \\
\text { an Basis. }\end{array}$ & L. & MI. Z. & \\
\hline $17^{\prime \prime}$ & $7^{\prime \prime} 3^{\prime \prime \prime}$ & $27^{\prime \prime \prime}$ & $41^{\prime \prime \prime}$ & $11^{1 / 2} / 2^{\prime \prime \prime}\left(27^{m+m}\right)$ & $2^{\prime \prime} 9^{\prime \prime \prime}$ & $2^{\prime \prime} 5^{\prime \prime \prime}$ & $\hat{s}$ \\
\hline $176^{\prime \prime \prime}$ & 71 & 23 & 36 & (19) & 28 & $2 \quad 3$ & jun. \\
\hline 173 & 74 & $271 / 2$ & 37 & 11 & 210 & 25 & O ad Spitzbergen. \\
\hline
\end{tabular}

In Uebereinstimmung mit Schlegel, Reinhardt, Blasius u. A. unterliegt es für mich nicht dem geringsten Zweifel, dass die weisse Form als Art keine beachtung verdient, besonders da wir durch Holböll wissen, dass dieselbe (im dritten Jahre) das vollkommene, aul Rïcken und Flïgel mövengrane Kleid des alten Lams glaucus erhält. Auf' diese weisse Jugendvarietät bezieht sich jedenfalls die Möve, welche Iichardson (lich. et Sws., Faun. Bor. Amer., II, 1831, p. 419) in 
einer Ammerkmeg zu Larus cburners erwähnt und die er als muthmasslich neue "Larus Hutchinsii" nemnt. Unter diesem Namen fïhren Dall und Bamnister (13. of Alaskid, 1) 305) eine ,White Gull" vou Fort Yukon an, die also, wenn nicht anf Larus glancus, ohne Kweifel auf Lams leucopterus Bezug hat.

[Die ersten dieser Möven bemerkten wir Ende A]pril 1870 und fanden eine Brutcolonie Anfang Juni auf der Walross-Insel. Die Nester, etwa 50-60, standen sowol auf den Klippen selbst oder am I'usse derselben, hier theilweis unter Nestern der Eiderenten: ein Nest war wenige Schritte rom Meere auf einem einzelstehenden Felsblock angelegt. Am 10. Juni enthiclten die meisten Nester 1Eier, am 1. Juli fanden sich bereits ausgeschliipfte Junge. - Brutplïtze dieser Arten fanden wir an verschiedenen Stellen der Küste. indess stets in sehr beschrinkter Anzahl, und zwar bei Kap Borlase Warren cirea 5-8 Paare, bei Kaj Mary 2 Pare, anf Jackson-Insel etwa 8-12 Nester, auf der Sürlseite dieser Insel circa 4 Nester, ebenso bei liap Broer linys und auf Shamnon. - P.J

26) Larus lencopterus Waber. Weisstliugelige Möve.

Larus argentutus Sabine (nec auct.), Trans. Lim. Soc., vol. XII, 1818, p. 546.

Larus leucopterus Faber, Prodr. isländ. Ornithol., 1822, S. 91.

Laves leucopterus Naumann, Vögel Deutschlands, X, 367, Tat. 265.

Larus leucopterus Holböll, Fauma Grönlands, S. 48.

Larus leucopterus Reinh., Ibis, 1861, S. 17 (cum L. chalcopterus Licht.).

Larus leucopterus Baird, B. N.-Amer, p. ot..

Larus leucopterus Dall and Bannister, B. of Alaska, p. :304.

Lurus leucopterus Middendorff, Sibirische Reise, S. 242.

Larus leucopterus Blasius, Journal für Ornithologie, 1865, s. 382.

Von der Polarmöve liegen zwei Hamplare vor, ein altes Weibchen, Ende April 1870, und ein junges Weibchen, im September 1869 auf Sabine-Insel erlegt, die beide ganz mit den Abbildungen bei Xaumann, Taf. 265, Fig. 1 und 3 ibereinstimmen.

Das alte Weibchen triagt ein vollkommen ausgefirbtes Sommerkleid; an den blendend weissen Federu des Kopfes und Halses finden sich auch nicht mehr die leisesten spuren dumklerer Schaftstrichelung. Die Färbung der Nacktheile hat sich durch die Aufbewalurung in Salz ziemlich gut erhalten, ist aber oftenbar etwas nachgedunkelt.

Der schnabel ist dunkel livid grimbriunlich mit hellern horngranen Tomienrinder'n; der spitzentheil des Lnterschnabels zeigt über dem Eck einen verwaschenen dunkelrothen Fleck, die Dillenkante ist heller, horngell,; der Oberschmabel ist am spitzentheile hinter dem Nasenloche ebenfalls roth gefarbt, aber blasser als der Unterschuabel, 
am Schneidenrand und der äussersten Spitze blass horngrau. Beine nnd Füsse sind bräunlich-fleischfurben mit dunkeln Nägeln.

Die Schnabelfärbung beim jungen Vogel ist so, wie sie Naumann darstellt, d. h. hell fleischbräunlich mit bramschwarzem spitzentheil.

\begin{tabular}{|c|c|c|c|c|c|c|c|}
\hline $\mathrm{Fl}$. & Schw. & F. & $\begin{array}{l}\text { Mund- } \\
\text { spalte. }\end{array}$ & $\begin{array}{c}\text { Schuabelhöhe } \\
\text { an Basis. }\end{array}$ & L. & MI. Z. & \\
\hline $16^{\prime \prime}$ & $6^{\prime \prime} 9^{\prime \prime \prime}$ & $24^{\prime \prime \prime}$ & $29^{\prime \prime \prime}$ & $81 / t^{\prime \prime \prime}\left(19^{m+m}\right)$ & $2^{\prime \prime} 4^{\prime \prime \prime}$ & $2^{\prime \prime} 2^{\prime \prime \prime}$ & ad. \\
\hline 15 & 63 & 20 & 29 & $6^{1} / 4 \quad(15)$ & 25 & 22 & \& jun. \\
\hline
\end{tabular}

Diese sehr nahe mit Luves gluucus verwandte Mövenart unterscheidet sich von letzterer hauptsächlich und constant durch die geringere Grösse, namentlich den stets kürzern und schwächern Schnabel. In der Färbung des Gefieders ergeben sich keinerlei Unterschiede, doch muss ich bemerken, dass an dem vorliegenden Exemplare der zarte mövengraue 'Ton auf Mantel und Flïgel merklich dunkler als bei Lanes glancus ist.

Nach Holböll ist Lame leucopterus neben Lavus tridactylus die häufigste Möve in Süd- und Nordgrönland; von der Ostküste war sie bisher nicht nachgewiesen.

Auf Spitzbergen und Nowaja-Semlja fehlt sie entschieden; wie anch die neuern Forsehungen Malmgrents, IIenglin's und Gillett's gelehrt haben. Dagegen kennen wir die Art durch Dall und Bamnister aus Nordwestamerika, wo sie am untern Yukon und um Sanct-Michael ungemein häufig ist.

von Middendorft' glaubt sie am T'aymirflusse in Nordsibirien unterm 75. Grad gesehen (?) zu haben.

Dass auch bei dieser Art eine in der Jugend fast einfarbig weisse Varietait angetroffen wirl, hat Itolböll ïberzengend nardhgewiesen. Ine weisse Möve aus Davisstrasse, welehe Kapitän Sabine (Trans. Limn. Soc., XII, 1818, p. 545) ausführlich beschreibt, ist, wie aus den angegebenen Itesingen erhellt, jedenfalls eine junge Larus teusouterus, welche Art Sabine bekanntlich, auf 'T'emminek's Rath, mit Larus argentatus verwechselt.

27) Larus eburneus Phipps. Elfenbeinmöve.

Naumann, Vögel Deutschlands, X, 341, Taf. 263.

Sabine, Limn. 'Trans., XII, 548.

Ilolböll, Fauna Grönlands, S. 51.

id.? Larus brachytarsus Holböll, ebendas., S. 52. 
Pagophita ebumea Reinhardt, Ibis, 1861, S. 18.

id.? Pagophila brachytarse Reinhardt, ebendas., S. 18.

Pagophila eburnea et brachytarsa Baird, B. N.-Amer., p. 856.

Pagophila eburnea Evans und Sturge, Ibis, 1859, S. 171 (Spitzbergen).

Larus cburneus Malmgren, Journal fur Ornith., 1863, S. 373 (Spitzbergen).

id.? Pagophila cburnea Malmgren, ebendas., 1865, S. 200 (Spitzbergen).

Pagophila cburnea Newton, Ibis, 1865, S. 507 (Spitzbergen).

Larus cburneus Heuglin, Peterm. Geogr. Mitth., 1871, S. 65 (Spitzbergen).

Pagophila eburnea Gillett, Ibis, 1870, S. 306 (Nowaja-Semlja).

Pagophila eburnea Ileuglin, Ibis, 1872, S. 65 (Nowaja-Semlja).

Dr. Buchholz und Dr. Pansch haben die Elfenbeimmöve, welche bisher noch nicht aus Ostgrönland nachgewiesen war, verschiedene male angetroffen. In Buchholz' sorgfïltig geführtem Journale wird sie als am 22. Juli, 28. August und 2. September 1869 in mehrem Exemplaren (alte und junge) erlegt, notirt. Die IIansa befand sich bekanntlich an den genannten Tagen im Eise, etwas nördlich vom 74. Grade.

"Ganze Länge am frischen Vogel $161 / 2 "-16^{\prime \prime} 9^{\prime \prime \prime}$.

Iris braungelb; Schuabel griunlichgelb, an der Wurzel blaugriun; Füsse schwarz (alt); Iris braungelb; Schnabel an der Wurzel bläulich, mitten grïnlich, an der Spitze roth (alt); Iris braungelb; Schnabel schwarz; Gefieder getleckt" (Buchholz). - "Hïufig in den Wasserbecken und Kanälen des Eises; umringten oft das Schiff in Menge" (Buchholz, a. a. O., S. 11).

Dr. Pansch traf sie ebenfalls im Eise an, aber nicht an der Küste.

Holböll's Larus brachytarsus, welche sich durch einen kürzern Lauf $\left(12-13^{\prime \prime \prime}\right.$, statt $\left.15-17^{\prime \prime \prime}\right)$ von Larus cburneus unterscheiden soll, verdient als Art kaum weitere Beachtung. Malmgren hat nachgewiesen, dass die Tarsenlänge selbst bei Exemplaren von derselben Localität ansehnlich variut. IJolboill erlangte bekamntlich nux drei Exemplare dieser sogenannten neuen Art, die leider sämmtlich verloren gingen, sodass selbst das königliche Museum in Kopenhagen kein Exemplar erhalten konnte, da Holböll's Bemühungen weitere zu erlangen vergeblich blieben. Diesen, von Holböll selbst herrührenden Angaben gegenüber, auf die sich auch Professor Reinhardt beruft, muss es einigermaassen befremden und gewisse Zweifel erregen, wenn Professor Schlegel von einem Exemplar dex Leydener Sammlung bemerkt: , un des types du Larus brachytarsus de Holböll, acquis de Mr. Holböll'"(!!).

28) Larus tridactylus L. Dreizehige Möve.

Naumann, Vögel Deutschlands, X, 322, Taf. 262.

Sabine, Linn. Trans., XII, 549. 
Holbüll, Fauna Grönlands, S. 50.

Graah, Reise, S. 179.

Rissa tridactyla Reinhardt, Ibis, 1861, S. 18.

Rissa tridactyla Baird, B. N.-Amer., p. 854.

Kisse tridectyle Dall and Bannister, B. of Alaska, 1. 305.

Rissu triductyle Evans und Sturge, Ibis, 1859, S. 169 (Spitzbergen).

Larus tridactyhus Malmgren, Journal für Ornith., 1863, S. 375 (Spitzbergen).

Rissa tridactyla Malmgren, ebendas., 1865, S. 202 (Spitzbergen).

Tiesa triductyla Newton, Ibis, 1865, S. 508 (Spitzbergen).

Lanus triductylus Heuglin, Peterm. Geogr. Nitth., 1871, S. 65 (Spitzbergen).

Rissa tridactyle Gillett, Ibis, 1870, S. 306 (Nowaja-Semlja).

Rissa tridretyla IIeuglin, Ibis, 1872, S. 65 (Nowaja-Semlja).

Das einzige durch die Expedition heimgebrachte Exemplar, ein junger Vogel (wie Fig. :3 bei Naumamn), wurde auf der Heimreise am 20. August 1870 in der Nïhe der Fï-Inseln erlegt. Dr. Buchholz gedenkt der Art in seinem Journal als in der Xïhe der norwegischen Küste beobachtet, notirt sie aber auch als ,häufig tiefer im Lise" (Buchholz, it. a. O., S. 11).

Graah führt sie in seinem Verzeichniss auf, obschon dies Holböll zu notiren vergisst.

Nach letzterm Forscher ist sie im Westen äusserst häufig, ilne Zahlil an den Vogelbergen unermesslich und ambähernd natch Millionen zu schätzen. Nalmgren und von Heuglin nemnen sie die häufigste Möve Spitzbergens. An dem nördlichsten von Parry erreichten Punkte. unter $82^{\circ} 45^{\prime}$, wurde sie noch beobachtet. Obwol circumpolar verbreitet, fehlt uns noch die Kunde ihres Vorkommens im Norden Sibiriens. Dagegen erfahren wir durch Dall und Bamnister, dass sie im Nordwesten Amerikats, auf Sitka und in Káantschatka ungemein liäutig er'scheint.

TWir beobachteten die Dreizehenmöve von der Nordsee bis nach der Eiskante hin, am häutigsten in der Nähe der norwegischen Küste, doch fehlte sie im Eise selbst und an der Küste Grönlands ginzlich. - P.]

29) Stercorarius parasiticus Brün. (nec L.). Schmarotzer-Raubmöve.

Lestris paresitica Briunich.

Lestris paresitica Naum., Vügel Deutschlands, X, 506, 'Taf. 272 und 273.

Lestris parasilica (Schlepii, Brehm) Ilolböll, Fauna Grönlands, S. 55.

Cateracta parasitice Grath, lieise, S. 179.

Stercorarines peresiticus leinhardt, 1bis, 1861, S. 16 .

Zestris parasitica Midendorff, Sibirische Reise, S. 241.

Stercorarizes parasiticus baird, B. N.-Amer., 1) 8339.

Stercorarius parasiticus Dall and Bammister, B. of Alaskat, p. 304.

Stercorarius parasiticus Erans und Sturge, Ibis, 1859, S. 172 (Spitzlergen). 
Lestris parasitica Malmgren, Journal für Ornith., 1863, S. 376 (Spitzbergen).

Stercorarius parasiticus var. Malmgren, a. a. 0., S. 205 (Spitzbergen).

Stercorarius tephras Malmgren, a. a. 0., S. 392 (Spitzluergen).

Stercorarius parasiticus Newton, Ibis, 1865, S. 510 (Spitzbergen).

Lestris parasitica var. tephrus Heuglin, Petermann's Geographische Mittheilungen, 1871, S. 65 (Spitzbergen).

Stercoravius parasiticus Gillett, Ibis, 1870, S. 307 (Nowaja-Semlja).

Stercorarius parasiticus Heuglin, Ibis, 1872, S. 65 (Nowaja-Semlja).

Stercorarius spinicauda Layard (nec Hardy), B. South-Africa, p. 366.

Diese bereits durch Kapitän Graah aus Ostgrönland bekannte Art wird im Journal von Dr. Buchholz mehrmals als von ihm gesehen und eingesammelt verzeichnet. So wurde sie schon am 4. Juli 1869 in der Nähe der norwegischen Küste von ihm erlegt und am 31. Juli im Eis beobachtet.

"Iris braungelb; Schnabel schwarz mit grünlicher Basishälfte“ (Buchholz). - „Häufig tiefer im Eise“ (Buchholz, a. a. O., S. 12).

[An der Küste nicht von uns gesehen, dagegen öfters bei Jan Mayen und in der Nordsee. Zwei von mir im Fjord beobachtete Raubmöven dürften zu dieser Art gehören. - P.]

Durch Güte von Heuglin's konnte ich Spitzbergen-Exemplare (darunter auch die einfarbig brame Form) untersuchen, welche Dr. Malmgren als eigene Art unter dem Namen "Stercorarius tephras" abzusondern versuchte, weil dieselben angeblich durch weisse Unterseite, schwärzern Rücken und ein breites dunkelasehgraues Brustquerband abweichen sollen. Professor Newton hat bereits darauf aufmerksam gemacht, dass es ihm nicht möglich war Unterschiede zwischen Exemplaren aus Spitzbergen und von den Shetlands aufufinden, welcher Ansicht ich mich vollkommen anschliessen muss.

Nach meinen genauen Vergleichungen vermag ich die Exemplare von Spitzbergen nicht eimmal als Rasse anzuerkemnen. Die dunkle Kopfquerbinde ist keineswegs als constantes Kennzeichen zu betrachten; ein Weibchen (Walther-Thymen-Fjord) zeigt dieselbe nur äusserst schwach angedeutet, während andererseits bei einem Exemplare von Helgoland dieselbe so dentlich als an spitzhergen-Exemplaren vorhanden ist, ebenso bei solchen aus Siidgrönland, die ich verglich. Auch die iibrige Färbung und die Dimensionen ergeben keinerlei durchgreifende Charaktere, auf welche sich eine specifische Absonderung begründen liesse. Es ist in der That schwer die Consequenzen zu begreifen, welche Dr. Malmgren veranlassten, für thatsüchlich nicht constante Verschiedenheiten gewisser Exemplare Artrecht zu heanspruchen, während or anderereits die nicht unbedentenden und 
dabei als constant erwiesenen Abweichungen, wie sie Cria Brïnnichii von Uriu troile bietet, nur als eine "Localform" abgefertigt wissen will.

Sehr beachtenswerth und von höchster bedeutung für den Artenwerth der Raubmöven ist die in der ganzen Vogelwelt fast einzig dastehende 'Thatsache ihres. gleichzeitigen Auftretens auf' dem südlichen Halbrunde. So liegt mir ein Exemplar des Stercorarius parasiticus Brïnnich (Sterconurius ITurdyi, Bp. Comp., II, 210) vom Kap der guten Hoffinung vor, welches ron unsern nordischen nicht zu unterscheiden ist, unter andern die dunkle Brustquerbinde so deutlich als spitzbergische Exemplare besitzt. Durch Layard, der die Art trotz des ihm durch Gray und Tristram gewordenen richtigen Nachweises irrig als Stercorarius spinicunda (B. S. Afr., p. 366) bezeichnet, wissen wir, dass dieselbe in den Sommermonaten häufig an den Küsten des Kaplandes erscheint. Stercorarius spinicundus Hardy ist, wie Schlegel nachweist (Mus. P. B., p. 50), nichts anderes als Stercorarius longicoudatus, die aus suidlichen Breiten ebenfalls bis zun Kap und zuweilen bis Sanct-Helena vordringt. Die südliche Form des Stercorurius cutaractes, der sogenannte Stercorarius antarcticus Less., lïsst sich wirklich in keiner Beziehung von unserer nördlichen unterscheiden, wie mir vorliegende Exemplare von Kerguelenland auf das Deutlichste beweisen.

30) Stercorarius longicaudatus Briss. Pfeilschwanz-Raubmöve.

Ornith. VI $(1760), 155$.

Lans parasiticus L., Faun. suec, 2. ed. (1761), 1) 55.

Lestriò crepidata Brehm, Naum., Vögel Deutschl., X (1810), 534, Taf. 274.

Lestris Bufjoni boie, Holböll, Fauma Grönlands, S. 56.

Stercorarius Buffoni leinhardt, Ibis, 1861, S. 16.

Lestris Buffoni Middendorft, Sibirische Reise, S. 241.

Stercorarius ceppleus Baird, B. N.-Amer., p. 840.

Stercorarius Buffoni Dall and Bannister, B. of Alaska, p. 304.

Stercorarius Buffoni Malmgren, Journal für Ornithologie, 1865, S. 206 (Spitzbergen).

Stercorarius Buffoni Newton, Ibis, 1865, S. 511 (Sjitzbergen).

Lestris Buffoni Ileuglin, Peterm. Geogr. Mittheil., 1871, S. 65 (Spitzbergen) Stercorarius lonficaudatus Gillett, Ibis, 1870, S. 307 (Nowaja-Semlja).

Stercorarius longicaudetus Heuglin, Ibis, 1872, S. 65 (Nowaja-Semlja).

Ein altansgefäibtes Männchen, am 18. Juli 1870 an der Eiskante erlegt, stimmt ganz mit der Abbildung bei Naumann überein und einem lixemplare der bremer Sammlung aus Nordsibirien. 


\begin{tabular}{|c|c|c|c|c|c|c|c|c|c|}
\hline L. & F1. & M.-Schw. & \begin{tabular}{c|} 
zweit \\
mittlere \\
Schwz.
\end{tabular} & $\mathrm{F}$ & $\begin{array}{l}\text { Mund- } \\
\text { spalte. }\end{array}$ & $\begin{array}{c}\text { Breite } \\
\text { an } \\
\text { Basis. }\end{array}$ & I. & M. $/$. & \\
\hline c. $23^{\prime \prime}$ & $\begin{array}{l}11^{\prime \prime} 3^{\prime \prime \prime} \\
12\end{array}$ & $\begin{array}{l}11^{\prime \prime} \\
12 \quad 2^{\prime \prime \prime}\end{array}$ & $\begin{array}{ll}4^{\prime \prime} & 9^{\prime \prime \prime} \\
4 & 8\end{array}$ & $\begin{array}{l}12^{\prime \prime \prime} \\
12^{1 / 2}\end{array}$ & $\begin{array}{l}18^{\prime \prime \prime} \\
18^{1 / 2}\end{array}$ & $\begin{array}{l}11^{14+1} \\
11\end{array}$ & $\begin{array}{l}18 \%^{\prime \prime \prime} \\
20\end{array}$ & $\begin{array}{l}13 \frac{1}{2}{ }^{\prime \prime \prime} \\
13 \frac{1}{2}\end{array}$ & Nordsibir. \\
\hline
\end{tabular}

Die pfeilschwänzige Raubmöve war bisher nicht ron der Ostküste Grönlands bekannt. obschon man ihr Vorkommen hier voraussetzen durfte, da sie bekanntlich eine circumpolare Verbreitung besitzt. Dr. Malmgren hat sie neuerdings auf Spitzbergen, Gillet auf NowajaSemlja angetroffen und iiber ihr häufiges Vorkommen im nordwestlichen Amerika (Sanct-Michael, Yukon) und in Ostsibirien (Anadyrgolf) erhielten wir durch Dall und Bannister in interessanter Weise Aufschluss.

In Bezug auf die äusserst verworrene Synonymik der Raubmöven wird es sich empfehlen für diese Art ein für allemal die älteste Benennung Brisson's beizubehalten, da die in der ersten Ausgabe in Linné's Fauna suecica (1746) angefuihrte Lams parasiticus nicht mit Sicherheit zu deuten ist. Dagegen lässt die Diagnose in der zweiten Ausgabe dieses Werkes (1761) ,rectrices duae intermediae ensiformes duplo longiores" nicht den geringsten Zweifel, dass wirklich diese Art gemeint ist, wie auch aus den beigegebenen Citaten (Brisson, 1. c.; Edw., pl. 148) deutlich hervorgeht.

[Wir haben diese Raubmöre nur wenige male an der líuste beobachtet. Am 18. Juli 1870 zeigten sich ein Paar an der Eiskante, von dem das Männchen erlegt wurde. Den folgenden T'ag stellte sich wiederum ein Pärchen ein, woron ein Lxemplar sich auf dem Maste ausinhte. Auch am 25. Juli beobachtete ich diesen Vogel im Eise. - P.]

31) Stema macroura Naumann. Küsten-Seeschwalbe.

Nammann, Vögel Deutschlands, X, 114, Taf. 253.

Sterna hirundo Sabine, Limn. Trans., XII (1818), p. 542.

Sterna aretica Temm., Holböll, Fauna Grönlands, S. 42.

Sterna hivendo (aretica) Graah, Reise, S. 179.

Sterna macroura Reinhardt, Ibis, 1861, S. 19.

Stema macroura Middendorff, Sibirische Reise, S. 245.

Stema macroura Baird, B. N.-Amer, p. 862.

Sterna macroura Dall and Bamnister, B. of Alaska, p. 306.

Sterna macroura Evans und Sturge, Ibis, 1859, S. 167 (Spitzbergen).

Sterna arctica Malmgren, Journal fur Ornithol., 1863, S. 373 (Spitzbergen). 
id. Stema macrura Malmgren, ebendas., 1865, S. 200 (Spitzbergen).

Sterna macrura Newton, Ibis, 1865, S. 506 (Spitzbergen).

Sterna macrura Heuglin, Peterm. Geogr. Mittheil., 1871, S. 65 (Spitzhergen).

Stema macmera Gillett, Ibis, 1870, S. 306 (Nowaja-Semlja).

Sterna macrura IIenglin, Ibis, 1872, S. 64 (Nowaja-Semlja).

Alte im Juni und Juli bei Sabine-Insel erlegte Vögel tragen das vollkommene Sommerkleid (Naumann, 'Taf. 253, Fig. 1) mit ganz. schwarzem Ober- und Hinterkopf. Bei einem im September eingesammelten, in der Mauser begriffenen Männchen zeigen sich an Stirn und Vorderkopf deutliche Spuren ron dem Weiss des Winterkleides. In der Fïrbung herscht eine fast rollkommene Uebereinstimmung; nur ist das Gran an der Aussenfahne der zwei bis drei ïussersten Schwanzfedern bald heller bald dunkler und zuweilen schon auf der zweiten Feder nur schwach angedeutet.

Lin junger auf der Heimreise Ende August bei den Fïr-Inseln erlangter Vogel ähnelt ganz dem bei Naumann (Fig. 3) dargestellten, nur sind auf Mantel und Schultern die halbmondförmigen dunkeln Bändchen yor den Lnden der Federn fast ganz verwaschen und die Ferlern dieser 'Theile haben nur schmale weissliche Endsäume; Stirn, Vorderkopf, Zïgel, sowie dic ganze Unterseite sind rein weiss; der hornschwärzliche Schnabel zieht an der Basis und dem Mundwinkel ins blass Hornröthliche; leine und Schwimmhänte sind fleischbrännlich; Nägel dunkel.

Die Maassverhältnisse, namentlich die Länge der weit hervorragenden änssersten Schwanzfeder und des Schnabels variiren sehr exheblich.

Dr. Buchholz notirt diese Art ebenfalls in seinem Journal: „Iris bramm; Schnabel und liusse roth; waren hent und in den rorhergehenden 'Tagen sehr zahlreich an der Eisgrenze; 7. Angust $1869^{\text {"* }}$ (Buchholz).

\begin{tabular}{|c|c|c|c|c|c|c|c|c|c|}
\hline \multicolumn{2}{|c|}{ Fl. } & MI. Schw. & $\begin{array}{l}\text { Aenss. } \\
\text { Schw. }\end{array}$ & $\mathrm{F}$. & $\begin{array}{l}\text { Mund- } \\
\text { spalte. }\end{array}$ & $\begin{array}{l}\text { Schnabel- } \\
\text { höhe an } \\
\text { Basis. }\end{array}$ & L. & M. Z. & \\
\hline $3^{\prime \prime}$ & $5^{\prime \prime \prime}$ & $2^{\prime \prime} 10^{\prime \prime \prime}$ & $55^{\prime \prime} 10^{\prime \prime \prime}$ & $13 \%$ & $18^{\prime \prime \prime}$ & $8^{m+11}$ & $61 / 211$ & $7^{\prime \prime \prime}$ & ad. \\
\hline 10 & & 2) 11 & 64 & 15 & 21 & 9 & 6 & $61 /$ & " \\
\hline 10 & 3 & 28 & $6-$ & $14^{1} / 2$ & 21 & 9 & $61 / 4$ & 7 & ") \\
\hline 9 & 9 & 9 & 7 & $15 \%$ & 21 & 9 & 7 & 7 & n) \\
\hline 10 & 9 & $2 \quad 10$ & $6 \quad 10$ & 14 & 20 & 9 & $63 / 4$ & 7 & $"$ \\
\hline 9 & 1 & 2 & 44 & 12 & 18 & 7 & $61 / 3$ & 7 & jun. \\
\hline
\end{tabular}


Sterna macroura ist eine der wenigen Seeschwalben, welche im arktischen Kreise vorkommen, und hier circumpolar verloreitet. Malmgren fand sie auf Spitzhergen noch unterm 80. Grad briitend. Nach Dall und Bannister sehr häufig am Jukon und hier Brutrogel.

Von Kapitän Graah bereits in Ostğrönland nachgewiesen.

[Die Küsten-Seeschwalbe gehörte zu den häufigern Erscheinungen. Wir trafen sie ror und im Eise, in geringerer Zahl bei Shamon-, zahlreicher bei Jackson-Insel, nahe bei Kap Broer Ruys und einzeln im Fijorde. Am Südwestende der Walross-Insel fand ich am 10. Juni eine Colonie, die am 200 Stiick zählen mochte. Die Vögel sassen auf dem diirren Lrdboden oder flogen schreiend umher. Wir fanden hier ein Li, welches ohne jede Unterlage auf der blossen Erde lag. - P.J 
5 .

\section{E i e r.}

Bearbeitet von

Altied $\mathrm{Nemtan}$

in Cambridge. 1

Die kleine Sammlung von Eiern, welche ron der zweiten Deut-

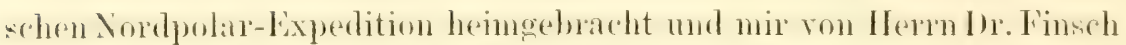
zur liestimmung iibersandt wurle, enthält einige lixemplare ron grossem Interesse. Leider aber ist die Mehrzahl der gesammelten Eier in ziemlich schlechtem Zustande, und noch mehr ist zu bedauern, dass gerade manche der seltensten nicht mit genïgender Sicherheit identificirt werden können.

1) Plectrophanes mivatis von der Sabine-Insel. Normal.

2) Lagopms rupestris. Lin nicht ausgeblasenes, halb zerbrochenes Lxemplar, durch atmosphärische Einflüsse fast ganz entfärbt; nur auf der Seite, auf welcher dats Ei lag, sind noch Farben zu erkennen.

3) Acgialites hiaticula. Das erste dieser Eier, von der Falschen Bai, ist in gutem Zustande, die andern drei sind dagegen nur Fragmente und dazu mausgeblasen. Sämmtlich von normalem Gepräge.

4) Augenseheinlich die Eier einer Art von Strandläufer (Limnicolac), einer Gruppe, aus welcher die Expedition nur die vier Arten Aegialites hiaticulu, Strepsilas interpres, Tringu maritima und Calidris arenaria einsammeln komnte. Man erkennt sofort, dass sie nicht der ersten derselben angehören. Schon mehr ähmeln sie den Liern der zweiten, sind aber kleiner und weichen doch auch zu beträchtlich in der Färbung ab, um sie derselben zusprechen zu kömnen. Sie sind

1 Aus dem Englischen äbersetzt von 1)r. G. Ilartlaub. 
auch kleiner als mittelgrosse Eier der dritten Art und in einer Reihe von 120 Stück finde ich keins, das ihnen in Farbe und Zeichnung ähnlich wäre. Die vierte der genannten Arten, also Calidris arenaria, wäre dagegen ernsthaft in Betracht zu ziehen. ${ }^{1}$ Von diesem Vogel habe ich bisjetzt nur ein mzweifelhaft echtes Ei gesehen, dasselbe, welches mir in vorigen Jahre die Smithsonian Institution in Washington zuschickte und ron welchem ich in den Proceed. Zool. Soc. 1871 eine Abbildung veröffentlicht habe (pl. IV, fig. 2). Es wurde dieses Ei durch Herm N[cFarlane an der arktischen Küiste Amerikas, östlich vom Andersonfluss erlangt und durch gleichzeitige Erlegung des weiblichen Vogels mit voller Sicherheit identificirt. Vergleicht man nun dieses Ei mit den von Dr. Pansch mitgebrachten Exemplaren (oder Fragmenten), so legt sich die Vermuthung nahe, dass sie einer und derselben Art angehören, und die sorgfältigste Untersuchung hat mich keine irgend erhehlichen Lnterschiede zwischen ihnen erkemen lassen. Diese 'Thatsache, in Verbindung mit der Auskunft, die mir Herr Dr. Finsch über die von der deutschen Expedition auf der Ostküste Grönlands angetroftenen Arten ertheilte, macht es im höchsten Grade wahrscheinlich, dass es sich in der That um die solange vergebens gesuchten Eier von Calidris avenaria handelt. Die Grundfarbe derselben ist ein blasses Lehmgelblich; bei zweien ist ein griunlicher 'Ton bemerkbar und eins ist entschieden bräunlich. Auf diesen (irundfarben stehen bei der Mehrahl einige schwach purpurhräunlicho Flecken und damn etwats unregehmässige gelblichbramne \%eichnung in zwei Schattirungen, bisweilen ziemlich gleichnüssig iiber die ganze Oberfläche vertheilt, bei andern aber zu grössern Flecken-vereinigt. Bei diesen letztern erscheint dann die Farbe am dunkelsten. Die Exemplare mit grünlicher Grundfarbe ähnelm in etwas einem stark verwaschen gefärbten Eie von Strepsilas; aber eine Verwechselung beider erscheint dennoch für ein Kennerauge unmöglich. Die Exemplare mit den grossen Flecken (blotches) ähneln einer seltenen Varietät des Eies einer kleinen Rasse der Tringa alpina (der Tr. Schinzii einiger Autoren) und man könnte sich, lätte man nur solche grossgefleckte Exemplare vor sich, rersucht fühlen, sie dafür zu nehmen. Aber die Reihe, klein wie sie ist, zeigt, dass dies nur eine extreme Abreichung von der normalen Färbung ist.

Diese Reihe setzt mich zugleich einigermaassen in den Stand in

1 Wahrscheinlich kommen beide Phalaropis-Arten, fulicarius und hyperborens, brütend an der Ostküste Grönlands vor, obgleich sie nicht eingesammelt wurden Aber auch deren Eier sind total verschieden von den for mir liegenden. 
einer Sache klarer zu sehen, die für mich ron grossem persönlichen Interesse ist.

Als ich 1858 in Island war, kauften Herr Wolley und ich eine kleine Sammlung ron Eiern, die ein Junge in Reykjarik zusammengebracht hatte. Seiner Aussage zufolge - und diese war ohne Zweifel wahrheitsgemäss - stammten sie sämmtlich aus der nächsten Umgebung. Unter ihnen befand sich num ein Ei, desgleichen weder mein Freund noch ich selbst je zuror gesehen hatten, und welches ich immer wieder auf die Möglichkeit hin musterte, es könnte das eines Sanderling sein. Als ich num im rerflossenen Jahre das schon erwähnte authentificirte Exemplar durch l'rofisere Baird erhielt, tiihlte ich mich

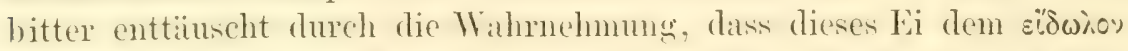
meiner Hofthumgen und meiner anticipirten Vorstellung so wenig entsprach. Jetzt wird mir aus der Reihe, die ich vergleichen kann, klar; dass jene beiden Exemplare die entgegengesetzten Endpunkte derselben bilden und ich nehme kaum noch Anstand mein isländisches Ei ron 1858 für eins von Calidris arenaria zu halten. Dasselbe zeigt den normalen lehmfarbigen Grundton mit den schwachen purpurbrïmlichen Flecken, aber die brame Keichnumg darauf steht dichter als auf irgend einem der grönländischen Eier. Folgendes sind die Dimensionen (nach engl. Maass) derjenigen unter diesen, welche ich zu bestimmen im Stande bin.
A. $1.44 \times .99 ; \quad$ B. $1.35 \times .97$;
1. $1 .: 34>1$;
E. $1 \cdot 4 \times 1 \cdot 1$;
C. $1.34 \times 1.02$;
F. $1.42>\cdot 97$.

Das isländische Ei stimmt in der Grösse ïberein, da es aber an den Enden ausgeblasen ist, so lässt sich seine grössere Axis nicht mit Sicherheit messen; die kleinere ist .98. Das echte Sanderlingei ron der Smithsonian Institution misst $1 \cdot 43 \times \cdot 98$. Vier unter den grönländischen Ëiern sind geradezu nur Scherhen und kömen höchstens dazu dienen die Art der Färbung zu versinnlichen. Ein fünftes ist unausgeblasen und ich befürchte sehr dasselbe nicht conserviren zu kïmnen; die ïbrigen fünf, wahrscheinlich stark bebriitet, sind durch grosse Löcher entstellt, ja zum 'Theil ganz zerbrochen.

Ich kann nicht umhin hinzuzufügen, dass weder die von 'Thienemamn gegebenen $\Lambda$ bbildungen (Fortpflanzungsgeschichte der gesammten Vögel, 'Taf. LXII, Fïg. $2 a-c$ ), noch die in Bädeker's Eierwerk ('Taf. LXXI, Fig. 5) mir zuverlässig erscheinen. Sie zeigen keine Aehnlichkeit mit dem Lï von der Smithsonian Institution und nur höchst geringe mit irgend einem der übrigen ron mir erwähnten. Dazu kommt, dass wir hinsichtlich des Geschichtlichen der Originale keine Art ron Aufklärung erhalten. 
5) Sterna arctica. Ein ausgeblasenes Exemplar und dabei so zerbrochen, dass es für eine Sammlung unbrauchbar. In Färbung und Gestalt normal.

6) Lams glaucus. Zwei angeblich demselben Neste entnommene Eier weichen in Färbung und Zeichnung so bedeutend voneinander ab, dass sie sehr wahrscheinlich ron rerschiedenen Individuen herstammen. Wo Möven häufig sind, kommt es gar nicht so selten vor, dass sie sich anstatt des eigenen eines fremden Nestes beim Legen bedienen. Die Eier ron Larus glaucus sind meiner Ansicht nach von denen von Larus marimus nicht unterschieden worden und darum sind diese Eier von um so grösserm Werthe, indem sie aus einer Gegend kommen, wo Larus marinus gar nicht vorkommt.

7) Somateria mollissima. In gutem Zustande und von gewöhnlichem Ansehen.

Indem ich diese Noten schliesse, sei es mir gestattet meine ernste IIoftinung dahin auszusprechen, dass eine dritte deutsche NordpolarExpedition das Ziel erreichen werde, das ihre Freunde und Förderer so heiss ersehmen und das Diejenigen in so hohem Grade verdienen, welche bereits ihr Leben bei dem Versuche aufs Spiel gesetzt haben. Sollte es wirklich dazu kommen, so vertraue ich, dass man auch der Oologie die ihr gebührende berücksichtigung nicht versagen werde. Noch immer liegt ein Land der Verheissung vor uns, welches, wenngleich nicht überfliessend ron Milch und Honigg, wahrscheinlich das Fortpflanzungsgebiet von Tringa camutus und Tringe subrempuate ist, und die noch mentdeckten Eier dieser beiden semeinen enropäischen Vögel werden jedenfalls der schönste Lohn für den oologischen Forscher sein. 


\title{
6. \\ T in in i a ta.
}

\author{
Bearbeitet von
}

C. K u p f fer

in Kiel.

\section{Gattung Cyuthia Sarigny。}

\section{1) Cynthia villosa Fabricius.}

Ascidia villosa O. Fabricius, Fauna Grönlands, S. 333.

Gesammtkörper konisch oder birnförmig, bis $2^{\mathrm{cm}}$ lang, das breitere Ende int das freje und trägt die Oeffinungen, das verjüngte Ende spitzt sich zu und ist nicht direct angeheftet, sondern mit einer grössern Zahl von langen theils unverzweigten, theils sich wurzelartig verästelnden weisslichen IIaftfiiden besetzt, durch die die Befestigung erfolgt. Tunicata derb lederartig, quer gerunzelt, fast durchweg, ausgenommen die vordere Endfläche, mit groben Sandkörnern inkrustirt.

Mundöffinung (Kiemenöffinung) riereckig, auf dem Scheitel der Vorderflïche sitzend, die ebenfalls riereckige Koloakeniffinung etwas zur Seite gerückt. - Ueber die Farbe lässt sich nach den Spiritusexemplaren nichts aussagen.

Kiemensack durch die ganze Länge des Innenkörpers reichend, gefaltet, Falten ungleich breit und hoch, acht an der Zah. In der dorsalen Mittellinie des Kiemensacks eine bandartige, mit der einen Kante angeheftete Leiste, deren freie Kante eingerollt ist. 'Tentakeh am Kiemeneingange einfach. Afteröftnung ron einem liranze hakenförmig zurïckgebogener Papillen umgeben.

Ovarien aus vier bis fünf quer verlaufenden, isolirten, der Hautmuskelschicht eng angehefteten, cylindrischen Schläuchen bestehend, 
die je an einem Ende eine Oeffnung haben. Sie liegen an der ventralen Seite.

Die Identität mit der von Fabricius kurz beschriebenen Art ist nicht zweifellos, da er die Oberfläche wollig nennt, wovon an den vorliegenden Exemplaren wegen der Inkrustation mit Sand nichts zu bemerken ist. Die äussere Gestalt, das zugespitzte Hinterende, die Stellung der beiden Oeffinmgen und namentich die charakteristischen Wurzelfärden an dem Hinterende stellen aber diese Art der von ihm beschriebenen näher als irgendeiner andern bekannten. Daher ist die Artbezeichnung beibehalten, obgleich "radicata" passender wäre.

Fundort: Germaniahafen.

2) Cinthic Adolplii' nor. spec.

Gesammtkörper walzen- oder tonnenförnig, 1-1,5 $5^{\mathrm{cm}}$ lang, beide Geffinmgen an Vorderende, aber gleichmässig rom scheitel abgeriickt. Das Hinterende mit kleiner Fläche angeheftet, über die hinaus platte, verïstelte Haftzotten sich auf der Unterlage, die bei allen Exemplaren Gestein war, verbreiten.

Tunica weisslich, an Schnittflächen durchscheinend, zäh lederartig, an der Oberfläche grob warzig und runzelig, kein Beleg von fremden Gegenständen. Beide Oeffnungen abgerundet viereckig.

Der Kiemensack erstreckt sich durch die ganze Länge des Innenkörpers, hat sieben Falten, die siebente nimmt die dorsale Nittellinie ein. Die Bauchfurche ist ungewöhnlich sturk entwickelt, ihre Ränder erheben sich in die Kiemenhöhle so hoch wie die Falten. Tentakeln am Kiemeneingange einfach.

Nagen und Darm liegen an der linken Seite des Kiemensackes, der Darm ist abgeplattet. Das einfache Ovarium liegt rechts; es bildet einen Sförmig gekriimmten Schlauch, der bei einem Exemplar am blinden Ende gespalten war.

Fundort: Insel Shamnon.

Anmerkung. Die Bezeichnung der Regionen ist auf die Stellung des Thieres bezogen, bei der die die tlimmernde Bauchfurche enthaltende Seite die untere (ventrale) ist, die Flimmergrube und das Centrahnervensystem oben (dorsal) liegen und das Vorderende durch die Mundöffinung (Kiemen- oder Eintrittsöftinung) bestimmt wird.

1 Zu Ehren des Sammlers, Dr. Adolf Pausch. 


\title{
$\%$.
}

\section{Mollusken. Wiirmer. Echinodermen und Coelenteraten.}

Bearbeitet von

\author{
Kaxl Möbius
}

in Kiel.

IIt einer Tafel in Kupferstich.

Der Bezirk, in welchem die in dem folgenden Verzeichniss angefühten wirbellowen seethiere rom Strande an bis zu 30 Faden Tiefe durch Herrn Dr. Pansch gesammelt wurden, erstreckt sich vom $73^{\circ}$ $50^{\prime}$ bis $75^{\circ} 15^{\prime}$ nördl. Br.

Hier leben diese 'Thiere in einer 'T'emperatur, welche sich im Laufe des Jahres nur wenig verändert.

Nach dem Tagebuche der Germania, Kapitän Koldewey, schwankte das Tagesmittel der Oberflächentemperatur vom 9. Juli bis zum 13. September 1869 zwischen $70^{\circ} 44^{\prime}$ bis $75^{\circ} 30^{\prime}$ nördl. Breite nur von $1,62-1,29^{\circ}$ R. Dann entstand Eis, unter welchem vom 3. October 1869 bis 21. Mai $18701,5-2^{\circ} \mathrm{R}$. herrschten.

Messungen der 'Temperatur bis zu 220 Faden Tiefe innerhalb derselben Breitengrade zwischen dem 13. Juli und 3ٌ. August 1869 ergaben $0,4-1,3^{\circ} \mathrm{R}$.

Im Jahre 1870 fand man zwischen $71^{\circ} 20^{\prime}$ und $75^{\circ} 26^{\prime}$ nördl. Br. vom 11. Juli bis 28. September an der Oberfläche $0,02-4,62^{\circ}$. Zwischen $73^{\circ} 11^{\prime}$ und $71^{\circ} 30^{\prime}$ wurde vom 12. August bis 27. September 1870 von $20-300$ Faden Tiefe $0,7-2,6^{\circ} \mathrm{R}$. beobachtet.

Nach dem Tagebuch der Hansa, Kapitïn Hegemann, fand man am 14. und 15. Juli 1869 unter $74^{\circ} 37^{\prime}$ und $74^{\circ} 57^{\prime}$ nördl. Br. $20-75$ Faden tief $1-0,6^{\circ}$ R.; am 19 . September unter $73^{\circ} 5^{\prime}$ nördl. Br. 100 Faden tief $1^{\circ} \mathrm{R}$. 
In seinem Vortrag ,Ueber die wissenschaftlichen Ergebnisse der ersten Deutschen Nordpolfahrt von 1868" sagt Herr von Freeden S. 4: „Ueber dem Parallel von Jan Mayen $\left(71^{\circ}\right.$ nördl. Br.) bis $77^{\circ}$ finden wir eine grosse Meeresfläche, welche vom 1. Juni bis 1. September eine zwischen $0^{\circ}$ und $2^{\circ}$ schwankende Temperatur besitzt und welche von schmelzenden Eisschollen mehr und mehr erfüllt ist, je westlicher man kommt."

Räcksichtlich der Wärmeschwankungen ihres Mediums sind also die grönländischen Seethiere ebenso günstig gestellt, wie die Thiere der tropischen Meere.

Nach Dana's Classification and geograph. distribution of Crustacea, 1853, p. 1483, betragen die Nittel der Oberflächentemperatur der kältesten 30 und der wärmsten 30 aufeinanderfolgenden Tage bei

Venezuela und Surinam 18,66 und $21,32^{\circ} \mathrm{R}$.

Bahia und Pernambuco 18,66 und $22,64^{\circ} \mathrm{R}$.

Singapore . . . . 18,66 und $23,08^{\circ} \mathrm{R}$.

Viti-Inseln . . . . 18,66 und $23,52^{\circ}$ R.

Tahiti . . . . 18.66 und $2.0 .61^{\circ} \mathrm{R}$.

Manilla . . . 20,88 und $23,52^{\circ} \mathrm{R}$.

Aus den Temperaturbeobachtungen, welche Herr Professor C. Semper im Neer der Philippinen machte und welche er mir für diese Vergleichungen guitig zur Verfügung stellte, entnehme ich Folgendes:

Im Jahre 1861, am 26. Juni, bewegte sich ron 10 Uhr morgens bis 10 Uhr abends bei Anhuplate

die Temperatur der Luft . . zwischen 20,6 und $22,9^{\circ} \mathrm{R}$.

die Temperatur der Oberfläche zwischen 21,3 und $21,8^{\circ} \mathrm{R}$.

An demselben 'Tage und Orte betrug die T'emperatur:

5 Faden tief $21,5^{\circ}$ R., 10 Uhr vormittags.

17 Faden tief $21,4^{\circ}$ R., 21/2 Uhr nachmittags.

22 Farden tief $21,4^{\circ}$ R., 3 Uhr nachmittags.

5 Faden tief $21,5^{\circ}$ R., 5 Uhr nachmittags.

In den hier angeführten Tiefen weicht also, ebenso wie in dem nördlichen Eismeere, die Wärme sehr wenig von der Wärme der Oberfläche al).

Ich vermuthe, dass die wenig reränderliche Wärme, in welcher die hochnordischen Seethiere leben, eine der Hauptursachen der ansehnlichen Grösse sein wird, durch die sie sich nach vielen Beobachtungen vor Individuen derselben Art in gemässigten Gegenden auszeichnen. Demn am Boden des Eismeeres sind Arten, die ihrer Natur nach in einer niedrigern Temperatur gedeihen kömnen, den Störungen, welche die grössern Temperaturschwankungen in den 
Jebensverrichtungen der Thiere genässigter Meere hervorrufer, selur wenig oder gar nicht ausgesetzt; die Organe können daher ihre Functionen, soweit dieselben von der Temperatur abhängig sind, in einer gleichmässigern Weise fortsetzen, als in Individuen derselben Art. welche z. B. mittlere und höhere Regionen der Nord- und Ostsee bewohnen, woselbst die Unterschiede zwischen der niedrigsten und höchsten Wassertemperatur 10-15 und zuweilen noch mehr Grade betragen, was H. A. Neyer für verschiedene Punkte des vestlichen Ostseebeckens ${ }^{1}$ und ich für zwei Stellen der Nordsee an der deutschen Küste nachgewiesen habe."

\section{0 L L U S C A.}

1) Chiton albus Linné.

\section{Gasteropoda.}

Fabricius, Fauma grœenlandica, S. 422. - Forbes and Hanley, Brit. Moll., p1. 62, fig. 2. - Jeffreys, Brit. Couch., V, pl. 56, fig. 3.

Grösse: $15^{\mathrm{mm}}$ lang, $8^{\mathrm{mm}}$ breit.

Verbreitung: Spitzhergen bis Kattegat und Britannien, Massachusetts (Gould-Bimey). Bis 550 Faden.

2) Lepete creca Miiller.

Zool. dan., I, 12, tab. XII, fig. 1-3. - Jeffreys, Brit. Conch., III, 252; V, pl. 58, fig. 6,7 .

Grösse: $11^{\mathrm{mm}}$ lang, $8^{\mathrm{mm}}$ breit, $5^{\mathrm{mm}}$ hoch.

Walross-Insel. 25 Faden.

Terbreitung: circumpolar; Sitka, nordjapanisches Meer (Schrenck), Spitzbergen bis Kattegat und Britannien.

3) Trochus gromlandicus Chemnitz.

Chemnitz, Conchyl. Cab., V, 108, Fig. 1671 (schlechte Abbildung). - Forbes and Hanley, Brit. Moll., H1. 68, fig. 1, 2.

Grösse: $13^{\mathrm{mm}}$ lang, $15^{\mathrm{mm}}$ breit.

Sabine-Insel, Jackson-Insel, Nordshamnon-Insel, Germaniahafen. 2-30 Faden.

Verbreitung: Labrador bis Massachusetts, Weisses Meer bis Kattegat und Britamnien.

${ }^{1}$ II. A. Meyer, Untersuchungen uber physikalische Verhältuisse des westlichen Theils der Ostsee (Kiel 1871), §. 27.

${ }^{2}$ Zeitschrift für wissenschaftliche Zoologie, Bd. XXI, 1871, S. $301-302$. 


\section{4) Trochus helicinus Fabricius.}

Fabricius, Fama gronlandica, S. 393. - Forbes and Ifanley, Brit. Moll., pl. 68, fig. 4, 5 und pl. CC, fig. 4. - Jeffreys, Brit. Conch., III, 295; V, pl. 61, fig. 4.

Grösse: 15ّm lang, 20mm breit.

Sabine-Insel, Jackson-Insel, Nordshannon-Insel, Walloss-Insel. $4-27$ Faden.

Verbreitung: circumpolar; Massachusetts, Japanisches Meer, Norwegen bis Kattegat und Britannien.

5) Pleurotoma pyramidalis Ström. 'Taf. I, Fig. 1-3.

Ström, Nye Samling af det Kongelige Danske Videnskab. Selskabs Skrifter, III, 1788, 296, Fig. 22 (Buccinum pyramidale). - Mörch., Moll. Grönl., nemnt sie Pleurotoma pyramidale und führt als Synonym an Defrancia Vahlii. Beck in Möller's Index Moll. Grœnl., p. 86. (Kröyer's Naturhist. Tidskrift, IV, 184243.) Die Möller'sche Diagnose passt auf die vorliegende Schnecke.

Die Schnecke hat einen Deckel, el ist halbmondfömig; Nucleus excentrisch, in einer Ecke der geraden Seite. Taf. I, Fig. ว̇.

Schale $12^{\mathrm{mm}}$ lang und $6^{\mathrm{mm}}$ breit.

Giftsack eifölmig, $1^{\mathrm{mm}}$ lang. Del Ausführungsgang ist $7-\mathrm{g}^{\mathrm{mm}}$ lang und enthält kugelfömige \%ellen. Pfeilsack schlauchförmig. Die Pfeile sind mit kleinen kenhaltigen Kellen erfüllt; an ihrem Basalstiick ist jederseits ein Haken. Taf. I, Fig. 1 und 2.

Sabine-Insel, Jackson-Insel, Shannon-Insel. 4-30 Faden.

Verbreitung: Grönland bis Massachusetts, Spitzbergen bis Norwegen (Bergen).

6) Fusus propinquus Alder.

Forbes and Hauley, Brit. Moll., pl. 103, fig. 2. - Jeffreys, Brit. Conch., pl. 86, fig. 3. - Middendorff, Malacozool. Rossica, II, 471, tab. IV, fig. 13 (Tritonium islendicum, var. sulcatc).

Grösse: $72^{\mathrm{mm}}$ lang, $33^{\mathrm{mm}}$ breit.

Subine-Iusel, Clavering-Insel, Germaniahafen. 2-20 Faden.

Viele Schalen am Strand von Shannon. Hier auch Eierkapseln mit Embryonen.

Verbreitung: russische Eismeerküste bis Kattegat und Irland.

7) Buccimum undatum Linné.

Limé, Syst. nat., ed. XII, 1. 1201. - Forbes and Hauley, Brit. Moll., III, 401, 11. Lus, fig. ", 5 und I'l. L. L. 5.

Grösse: $42^{\mathrm{mm}}$ lang, $30^{\mathrm{mm}}$ breit.

Die Schnecke ist diunn, wie bei der Varietät, welche auf Schlammgrund im westlichen Ostseebecken und in der Helgolander Bucht lebt. Vou dieser unterscheidet sie sich aber dudurch, dass ihre Aussenlippe in der Nähe der Spindel melu verdickt ist. 
Jackson-Insel, Clavering-Insel. 4 Faden.

Verbreitung: circumpolar; nordatlantischer Ocean an der europäinchen und nordanerikanischen Kï̈ste, Mittelmeer, Ochotskisches Meer.

8) Scaleriu grantandice Chemnitz.

Chemuitz, Conch. Cab., XI, Fig. 1878, 1879. - Kiener, Geure Scalaria, p. 18 (Scalaria platicostata), 1). VII, fig. 21 (gute Abb.). - Forbes and Hanley, Brit. Moll., pl. 70, fig. 5, 6 .

Grösse: $30^{\mathrm{mm}}$ lang (nach einer einzigen verletzten Schale).

Nordshannon-Insel. 30 Faden.

Verbreitung: nördliches Eismeer, Norwegen bis Bergen.

9) Neticu clunsu Brod. et Sow.

Kapitain Beechey's Voyage, pl. 34, fig. 3 und pl. 37, fig. 6. - Gould (Binney), Invertebrata of Massachusetts, 1870, p. 343, fig. 612 (gut).

Grösse: $29^{\mathrm{mm}}$ lang, $20^{\mathrm{mm}}$ breit.

Die Spitze schon bei Jungen verwittert.

Nordshannon-Insel, Sabine-Insel, Jackson-Insel, Clavering-Strand. 30 Faden.

Verbreitung: circumpolar; Japanisches Meer; Finmarken.

10) Cylictuna cylindraceu P'enn. 'Taf. I, Fig. 4-9.

Forbes and Hanley, Brit. Moll., pl. 114 B, fig. 6. - Jeffreys, Brit. Conch., pl. 93, fig. 4.

Grösse: $19^{\mathrm{mm}}$ lang, 4,5 $5^{\mathrm{mm}}$ breit.

Radula 16 Glieder. Formel: 5.1.1.1.5. Basis des Mittelzahns fast vierseitig; die Krone mit $16-18$ Zähnchen. Zwischenzahn und Seitenzïhne seusenförmig. Die Schneide ihrer Krone gezähnelt. Basis des Zwischenzahus fast rautenförmig, zweilappig. 'Taf. I, Fig. 8 und 9.

Drei lang orale, glatte Magenplatten in tiefen T'aschen des Magens. In dem Vormagen eines Exemplars waren 72 junge Schnecken (Trochus helicinus). Schalenstiickchen von ebensolchen Schnecken enthielten auch die Kothballen der Cylichna, in denen sich ausserdem noch Diatomeen und Chlorophyllkörner vorfanden. 'T'at. I, Fig. 4-7. Jackson-Insel. 4 Faden.

Verbreitung: Finmarken, Canaren, Nittelmeer. 3-160 Faden.

\section{1) Clione limacina P'hips.}

Phipps, Reise nach dem Nordpol, 1773. Aus dem Englischen 1777. Tagebuch, S. 101. - Martens, Spitzbergische und grönländische Reisebeschreibung im Jahre 1671, S. 128, "Sec-Gots-Pferd", Taf. P, Fig. f. - Eydoux et Souleyet, Voy. Bonite, Mollusques, Atlas, T. 15bis, Fig. 1-19 (Clio borealis Brug.). - Rang, Descript. d'un genre nouv. de la cl. Pterop. et de deux espèces nour. du genre Clio. Am. scienc. nat., 1825, Y, 285, 'laf. 7, Fig. 2 (Clio Miquelonensis von Neufundland). 
7. Mollusken, Würmer, Echinodermen und Cœelenteraten.

Grösse: $36^{\mathrm{mm}}$ lang.

Verbreitung: Westgrönland, Massachusetts.

\section{Lamellibranchia.}

1) Modioluria discors Linné.

Linné, Syst. nat., ed. XII, p. 1159. - Forbes and Hanley, Brit. Moll., II, 195, pl. XIV, fig. 5, 6.

Grösse: bis $26^{\mathrm{mm}}$ ling $16^{\mathrm{mm}}$ loch, $11^{\mathrm{mm}}$ hreit.

Shannon-, Sabine-, Clavering- und Jackson-Insel. 4-30 Faden.

Verbreitung: circumpolar; Nordostamerika, nordjapanisches Meer, Mittelmeer, Nordsee, westliche Ostsee.

2) Cardium gronlandicum Chemnitz.

Chemnitz, Conch. Cab., VI, Taf. 19, Fig. 198. - Sowerby, Conch. Mannual, p. 70, fig. 123. - Gould (Binney), Inverteb. of Massachusetts, p. 144 (Aphrodite gronlandica), Fig. 454 (gute Abb.)

Grösse: $70^{\mathrm{mm}}$ lang.

Verbreitung: Westgrönland, Massachusetts, Beringsstrasse.

3) Astarte borealis Chemnitz (Astarte arctica Goutht).

Chemnitz, Conch. Cab., VII, Taf. 39, Fig. 412. - Philippi, Abb. und Beschreib. Conch., II, Taf. I, Fig. 12. - Gould (Binney), Invert. Massach., Fig. 433 (Astarte semisulcata). - Meyer und Möbius, Fauna der Kieler Bucht, II, S. 1.

Grösse: $33-35^{\mathrm{mm}}$ lang, $27^{\mathrm{mm}}$ hoch, $7-10^{\mathrm{mm}}$ breit.

Viele von Gasteropoden durchbohrt.

Shannon-, Sabine-, Clavering- und Jackson-Insel. 4-10 Faden.

Am Strande von Shannon viel angespuilte Schalen.

Verbreitung: nördliches Eismeer, von der Beringsstrasse bis Lappland, Norwegen, Ostsee bis Bornholm.

4) Astarte suleate da Costa.

Da Costa, Brit. Conch., p. 192. - Forbes and Hanley, Brit. Moll., I, 452, pl. 30, fig. 5, 6 (Astarte Dammoniensis).

Grösse: 25̃ $5^{\mathrm{mm}}$ lang, $18^{\mathrm{mm}}$ hoch, $10^{\mathrm{mm}}$ breit.

Verbreitung: circumpolar; Ochotskisches Meer, Canaren, Nordostamerika, Kieler und Flensburger Bucht.

5) Astarte compressu-Montagu.

Montagu, Testac. Brit. Suppl., 1. 43, pl. 26, fig. 1. - Forbes and Hanley, Brit. Moll., I, 464, pl. 30, fig. 1-3.

Grösse: 14 $4^{\mathrm{mm}}$ lang, $12^{\mathrm{mm}}$ hoch, $7,5^{\mathrm{mm}}$ breit.

Jackson.

Verbreitung: nördliches Eismeer, Nordostamerika, Spitzbergen, Norwegen, Britannien, Kieler Bucht. 
(i) Asturte crebricastatu-Forbes.

Annals nat. hist., vol. XIX, 1847, 1. 98, pl. IX, fig. 4. - Gould (Bimney), Invert. Massach., p. 126 , Fig. 440.

Der Bauchrand der ostgrönländischen Exemplare ist ziemlich flach. die Cuticula strohgelb, feinfaserig. Vorder-, Bauch- und Hinterrand älterer Lixemplare sind rerdickt und crenulirt. Die meisten haben ebenso flache und dichte Anwachsiippen, wie Astarte borcalis; einige jedoch so wenige und fast ebenso starke wie Asturte sulcatu.

Grösse: $28^{\mathrm{mm}}$ lang, $22^{\mathrm{mm}}$ hoch, $13^{\mathrm{mm}}$ breit.

Shannon. 30 Faden.

Verbreitung: Westgrönland, Norwegen, Nordostamerika.

7) Venus asturtoides Beck.

Middendorfi, Mal. Ross., III, 572. - Philippi, Abb. und Beschreib. Conch., III, 61, Taf. IX, Fig. 4. - Gould (Bimey), Invert. Massach., 1. 136, fig. 447 (Tapes fluctuosa).

Grösse: $16^{\mathrm{mm}}$ lang, $12^{\mathrm{mm}}$ hoch, $7^{\mathrm{mm}}$ breit.

Shannon-Insel, Jackson-Insel. 4-30 Faden.

Verbreitung: Westgrönland, Massachusetts, Ochotskisches und Japanisches Meer.

8) Mya truncata Linné.

Limné, Syst. 11at., ed. XII, p. 1112. - Forbes and Hanley, Brit. Moll., I, 163, pl. $\mathrm{X}$, fig. $1-3$.

Dr. Pansch fand in dem Magen eines Walrosses 500 Körper dieser Nuschel und nur ein einziges Stiickchen einer Schale. Neben den Eislöchern, aus denen die Wahrosse auftauchen, lagen Haufen ron Schalen.

Sabine-Insel, 10-20 Faden. Am Strande von Shamnon viel angespiilte Schalen.

Verbreitung: circumpolar; Ochotskisches Meer, Nordostamerika, Britanien, Busen von Biscaya, Norwegen, westliche Ostsee.

9) Saxicuva rugosa Linné.

Limé, Syst. nat., ed. XII, p. 1113 (rugosa) und 1. 1116 (arctica). - Forbes and Ilanley, Brit. Noll., I, 141, pl. VI, fig. 7, 8.

Grösse: 4:mu lang, 22mm hoch. Schale sehr dick.

Shamnon-Insel. 30 Faden. Am Strande viele angespüilte Schalen.

Verbreitung: circumpolar; Japanisches und Chinesisches Meer; Nordostamerika, Sitka, Nittelmeer, Canaren, Nordsee, westliche Ostsee. 


\section{Brachiopoda.}

1) Terebratula psittacea Gmel.

Middendorff, Mal. Ross., III, Taf. XI, Fig. 11-17. - Gould (Bimney), Invert. Mass., p. 210, fig. 501.

Grösse: $21^{\mathrm{mm}}$ lang, $22^{\mathrm{mm}}$ breit, $15^{\mathrm{mm}}$ hoch.

Jackson-Insel.

Verbreitung: Westgrönland, Massachusetts, Spitzhergen, Finmarken.

2) Terebratula cranium Müller.

Zool. dan. Prodr., p. 249. - Jeffreys, Brit. Conch., II, 11; V, pl. 19, fig. 1. Grösse: $16^{\mathrm{mm}}$ lang, $11^{\mathrm{mm}}$ breit, $11^{\mathrm{mm}}$ hoch.

Shannon-Insel. 30 Faden.

Verbreitung: Norwegen, Shetland-Inseln, Fimmarken bis Kattegat.

\section{E R M E S.}

\section{Annelides.}

1) Polynoë cirrosa Pallas.

Pallas, Miscell. Zool., 1766, p. 95, tab. 8, fig. 3-6. - Malmgren, Nord. Hafs-Amn., 1. 58, tab. VIII, fig. 1A-E (Nychia cirrosa).

Grösse: $47^{\mathrm{mm}} \mathrm{lang}, 10^{\mathrm{mm}}$ breit.

Saline-Insel.

Verbreitung: Fimmarken bis líattegat, Britannien, Westgrönland, Spitzbergen. 3-120 Faden.

2) Polynö̈ cirrata Pallas.

Pallas, Miscell. Zool., 1. 94, tah. VII, fig. 15 a, b) und tab. VIII, fig. 1, 2. Malmgren, Nord. Hafs-Anmul., p. 67, Taf. IX, Fig. 8 (Hermothoë imbricata L.), p. 71, Taf. IX, Fig. 7 (Evarne impar), p. 74, Taf. IX, Fig. 6 (Antinoë Sarsii), p. 73, Taf. 1X, Fig. 5 (Lrenilla glabra). In dem Bericht über die Expedition zur Untersuchung der Ostsee im Sommer 1871 (Berlin 1872), S. 111, habe ich gezeigt, dass diese vier Species und Gattungen nur als Formen einer Art anzusehen sind.

Grösse: $33^{\mathrm{mm}}$ lang; $10^{\mathrm{mm}}$ breit.

Sabine-Insel, Clavering-Strasse. 4-12 Faden.

Verbreitung: circumpolar; Ostsee bis Sitka.

3) Nereis diversicolor Miiller.

O. F. Müller, Prodr. Zool. dan., p. 277. - Derselbe, Von Würmern des süssen und salzigen Wassers, S. 104, Taf. 6. - H. Rathke, Nova Acta Ac. C. L., xx, 161, tab. 8, fig. $6-8$. 
Shannon-Insel.

Verbreitung: Norwegen, Nordsee, Ostsee.

4) Nercis pelagica Linné.

Örsted, Ann. Dan. consp., p. 21, fig. 72, 75, 76. - Malmgren, Amm. polych., p. 164, tab. VI, fig. 25 . - Rathke, Beiträge zur Fauna Norwegens, S. 155, Taf. VII, Fig. 13, 14 .

Grösse: $75^{\mathrm{mm}}$ lang, vorn, $65^{\mathrm{mm}}$ breit.

Die Heteroneveis-Form hat im Vorderkörper 22 Segmente (Rathke und Malmgren beobachteten 16, Örster 20), im Hinterkörper 65.

Verbreitung: westliche Ostsee bis Finmarken, Spitzbergen, Island, Westgrönland.

5) Leipoceras g. $\mathrm{n}$.

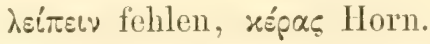

Kopf ohne Fühler und Fühlercirren. Das fünfte Körpersegment ist länger als die vorhergehenden und nachfolgenden und enthält jederseits eine kammförmige Reihe dicker Borsten. 'Taf. I, Fig. 17. Kiemen zungenförmig, beiderseits auf dem Rücken der Segmente.

Leipoceras wiferum spec. nov. Taf. I, Fig. 10-20.

Ein $38^{\mathrm{mm}}$ langer, spiralig zusammengerollter Wurm, vorn $1,5^{\mathrm{mm}}$ breit, hinten 1,2. 70 Segmente, das Hinterende ist rerletzt. Vorderkörper oben concav, unten gewölbt. Vom 11. Segment an verliert sich die Concavität und der Riïcken wird auch gewölbt, sodass der Körper von da an fast drehrund ist. Kopf nach rorn etwas verschmälert (Taf. I, Fig. 10). Vorn am Kopflappen zwei kleine runde Vorsprünge. Zwei Augen auf zwei flachen Wülsten, die hinterwärts verschmelzen und in eine flache und schmale Wulst auslaufen, welche sich bis zum vierten Körpersegment erstreckt.

II undöffnung rechts und links von einer wulstigen Lippe begrenzt, die beide unten spitzwinkelig zusammenstossen (Fig. 11).

Das erste Körpersegment trägt zwei kleinere Büschel ron Borsten, als die drei folgenten. I) ie Borsten der obern Buischel des Vorderkïrpers (ror dem fünften segment) sind pfriemenförmig, die Borsten der untern Büschel schmal lanzettlich (Fig. 15 und 16). Im fünften Segment ist sowol über als unter den dicken Borsten ein kleiner Biischel feiner Borsten (Fig. 17 und 18).

Yom sechsten Segment an befinden sich an der Bauchseite Häkchen, 5-6 in jeder Reihe, schwach sigmaförmig gebogen und zweispitzig (Fig. 14). Die Borsten der Riickenseite stehen auf der Vorderfläche kleiner Höcker und hinter diesen die Kiemen, die erst vom 
zehnten Segment an so lang werden, dass man sie zungenförmig nennen kann. Ihre grösste Länge haben sie am siebzehnten Segment. Vor den längern Kiemen sind die Borstenhöcker kleiner, als vor den kürzern. Jede Kieme enthält eine einfache Gefäisschlinge ohne Anastomosen.

Vom achtzehnten Segment an stehen an den Seiten des Leibes auf der Grenze zweier Segmente, tiefer als die Kiemen, Wärzchen, welche weiter nach hinten traubig werden. Es sind Eiertrauben oder äussere Ovarien, Fig. 12 und 13, mit noch nicht völlig ausgebildeten Eiern Fig. 20. Auf der immern Fläche der Leibeswand stehen längliche Eier (Fig. 19) anch in solchen Segmenten des Körpers, die aussen Ovarien tragen.

Leider wurde nur ein Exemplar dieses Wurmes gefunden. Es ist bräunlichgelb (in Spiritus) und hat mitten auf dem Hinterrücken zwei braune Längslinien, welche verdickte Stellen der Cuticula sind.

Ich stelle diese neue Gattung zu den Spioiden. Sie hat keine liopfuhhïnge, wie Prionosin Malmgren, besitzt zungenförmige Kiemen mit einer einfachen Gefässschlinge, wie Spio Fab. und eine kammförmige Revihe dicker Borsten im fünften Kïrpersegment wie Polydora Buse (Leucodore Johnston).

Die Bildung ron Eiern in äussern Orarien ist eine bei Anneliden noch nicht beobachtete Erscheinung.

6) Scoloplos armiger Miiller.

O. F. Müller, Zool. dan., I, 22, tab. 22.

Sabine-Insel.

Verbreitung: Spitzbergen bis in die Ostsee, Nordfrankreich.

7) Travisia Forbesii Johnston.

Johnston, Amn. nat. hist., IV, 373, tab. XI, fig. 11-18. - Ratlike, Acta nova Ac. C. L., 1843, XX, 192, tab. X, 9-12 (Ammotrypane cestroides).

Grösse: $40^{\mathrm{mm}}$ lang, $6^{\mathrm{mm}}$ dick (in der Mitte).

Sabine-Insel.

Verbreitung: Westgrönland, Spitzbergen bis in die westliche Ostsee, Schottland.

8) Scalibregma inflatum liathke.

Rathke, Beiträge zur Famna Norwegens, S. 184, Taf. IX, Fig. 15-21. Sars, Fauna litt. Norveg., I, 91, tab. X, fig. 20-27 (Oligobranchus roseus).

Grösse: $50^{\mathrm{mm}}$ lang. Sechs Exemplare (mit Eiern).

Verbreitung: Kattegat bis Spitzbergen, Schottland, Westgrönland. 5 -280 Faden. 
9) Thelepus circinatus Fabricius.

Fabricins, Fauna grœenlandica, S. 286. - Nalmgren, Nord. Hafs-Ann., p. 287, 'T'af. 27, Fig. 58.

Sabine-Insel. 20 Faden. ('Kwei unvollständige Exemplare.)

Verbreitung: Mittelmeer, Britamnien, Kattegat bis Finmarken, Island, Spitzbergen, Westgrönland.

10) Protula matia Stimpson. T'af. I, Fig. 21-24.

Stimpson, Invertebrata of Grand Manan, p. 30.

Sabine-Insel. 20 Faden.

Die kurze unvollständige Beschreibung, welche Stimpson gibt, veranlasst mich, einiges über diesen Wurm mitzutheilen.

Körperlänge ohne die Kíemen (welche bei den mitgebrachten Exemplaren schlecht conservirt sind) $28^{\mathrm{mm}}$. Breite des Körpers vorn $2,2^{\mathrm{mm}}$, hinten, wo die Haarborsten anfangen, $2^{\mathrm{mm}}$.

Vorn 7 Segmente mit grossen Büscheln gelber Borsten (über 60) auf der Oberseite und Häkchen auf der untern; dann folgen 52 Segmente mit Häkchen an den Seiten, aber ohne Borsten, 22 die unten ennige Borsten (gewöhnlich vier) und oben Häkchen haben, darauf 5 Segmente, oben mit Häkchen ohne Borsten und endlich ein Analsegment.

Die IIakchen stehen in einer Reihe so dicht nebencinander, dass der folgende den rorhergehenden grösstentheils deckt. In den mittlern Segmenten liegen in einem flachen ovalen Höcker 104-110 Häkchen in der Reihe. Ls sind beilformige Platten mit kammartigen Riefen (Fig. 23). Die Borsten sind pfriemenförmig (Fig. 24).

Die Röhre ist kalkig, weiss; meist angewachsen an Steine und Muscheln, fast drehrund, wo sie frei liegt, an der anliegenden Seite aber flach und rauh, der Unterlage entsprechend. Auf der freien Seite erscheinen schwache Anwachsstreifen und in der Mitte des Rückens oft eine schwachvertiefte Längslinie. Durchmesser der Röhre 1-3mm. Ihr Durchmesser wäichst sehr allmählich. Dicke der Röhrenwand $0,4^{\mathrm{mm}}$. Die Windungen sind nicht regelmässig (Fig. 21 und 22). Verbreitung: Grand Maman (Fundy Bai, 45ำ nördl. Br.).

11) Serpula sprirorbis Miiller.

Miüller, Zool. dlan., tah. 86, fig. 1-3.

Grösse: $3^{\mathrm{mm}}$ (Durchmesser des Gewindes).

Shamnon - Insel.

Verbreitung: Westgrönland, Nordsee, Ostsee. 
12) Chone infundibuliformis Kröyer.

Kröyer, Om Sabellexme. Danske Vidensk. Selsk. Forh., 1856, p. 33. - Malmgren, Nord. Hafs-Annul., p. 404, tab. 28, fig. 87.

Sabine-Insel, 21/2 Faden.

Verbreitung: Finmarken, Spitzbergen, Westgrönland. 15-40 Fdn.

\section{Gephyrea.}

Priapulus caudatus Lam. (Ehler's).

Darm so lang wie der Körper.

Acht grosse Riisselretractoren.

Ehlers, Ueber die Gattung Priapulus, Zeitschr. für wissenschaftliche Zoologie, XI, 1862, S. 205, Taf. XX, Fig. 1-13, und Taf. XXI, Fig. 14-23.

\section{Turbellaria.}

Polystemma roseum Miiller.

Zool. dan., tab. 64. - Örsted, Plattwürmer, S. 92.

Grösse: $50-53^{m m}$ lang, $8^{m m}$ breit, $4^{m m}$ hoch (in Spiritus). Der ausgestiilpte Ruissel eines Exemplars $22^{\mathrm{mm}}$ lang, $2^{\mathrm{mm}}$ dick.

Clavering-Strasse. 15 Faden.

Verbreitung: Norwegen, Sund, westliche Ostsee.

\section{Nematodes.}

Ascaris mystax Zed. (marginata Rud.).

Zedest., Nachtrag zur Naturgeschichte d. Eingeweidewürmer von Göze, S. 45. Bremser, Icones Helminth., tab. IV, fig. 22 (Ascaris triquetra Schrank). - A. Schneider, Monographie der Nematoden, 1866, S. 38, Taf. I, F'ig. 4.

Die Seitenmembranen des Kopfes sind etwas länger als bei Ascaris mystax aus der Katze, welche ich vergleichen komnte.

Grösse: Männchen $30^{\mathrm{mm}}$ lang, $1^{\mathrm{mm}}$ dick.

Weibchen $80^{\mathrm{mm}}$ lang, $1,6^{\mathrm{mm}}$ dick.

Aus dem Darm von Canis lagopus, November 1869.

\section{festolles.}

1) Tetrabothrium anthocephalum Rudolphi.

Fabricius, Danske Selsk. Skrift., I, 2., p. 152, tah. X, tig. 3.

Aus dem Darm von Cystophora cristuta, Juli 1869.

Fabricius fand ihn in Phoca barbeta.

2) Tenia expansa Rudolph.

Rudolphi, Entozoogr. Synopsis, p. 144. - Göze, Eingeweidewürmer, Taf. 28. Gurlt, Pathologische Anatomie der Hanssäugethiere, I, 381, Taf. 10, Fig. 1, 2.

Zweite Deutsche Nordpolfahrt. II. 
Bis $50^{\mathrm{cm}}$ lang. Die letzten Glieder sind $12^{\mathrm{mm}}$ breit und $1^{\mathrm{mm}}$ lang.

Aus dem Darm von Ovibos moschatus. - Die Würmer riechen moschusartig, auch nachdem sie in neuen Spiritus gesetzt worden sind.

Diese Taenie ist in vielen Wiederkïuern aller-Zonen gefunden worden.

3) Tania Conurus Küchenmeister.

Küchenmeister und Haubner in Gurlt nnd. Hertwig's Nagazin für die gesammte Thierheilkunde, 1854, II, 243. - Leuckart, Nenschliche Parasiten, I, 315. Krabbe, Helminth. Undersögelser in Danmark og Island. K. Danske Vid. Selsk. Skrift., VII, 1568, 352, tab. II, fig. 7-9 und tab. IV.

Läinge $5 \check{5}-6 \tilde{5}^{\mathrm{mm}}$ mit $9 \bar{\partial}-113$ Gliedern, wenn ich die feinsten Glieder des Halses mitrechne. - Kopf $0,8^{\mathrm{mm}}$ breit. Zweidrittel der ganzen Länge vom Kopf entfernt sind die Glieder quadratisch, $2^{\text {mm }}$ lang und breit. Die letzten Glieder sind $3^{\mathrm{mm}}$ lang und 2,6 ${ }^{\mathrm{mm}}$ breit.

26 Haken in zwei Kreisen. Länge der grössern $0,16^{\mathrm{mm}}$, Länge der kleinern $0,12^{\mathrm{mm}}$. In den letzten Gliedern hat der Uterus jederseits $12-16$ Hauptzweige.

Die Eier sind bräunlichgelb und ellipsoidisch; ihr äusserer Umfang hat $31,5 \mu$. Länge und $27,4 \mu$ Breite.

Obgleich die Exemplare kleiner sind und weniger Uteruszweige hahen als die von Leuckart beschriebenen, so rechne ich sie demnoch - nnter den Speciesbegriff der Trenia Comurus Küchenmeister, da sie riicksichtlich der Zahl, Form und Grösse der Haken und der form der Glieder mit dieser ïbereinstimmen.

Im Darm von Canis lagopus im September, November und December an mehrern Punkten Ostgrönlands.

Anhang. In der Nordsee sammelte Herr Dr. Pansch Epibdella Hippoglossi Nïller von der Haut von Hippoglossus vulgaris und Rhombus maximus und Ascaris clavata Rudolphi aus dem Magen und Darmanfing des Gadus morrhua.

\section{E C H I N O D E R M A T A.}

\section{IIolothurioidea.}

1) Myriotrochus Rinkii Steenstrup. Steenstrup, Myr. Rinkii, en ny Form af de lungelöse og fudlöse Söpölsers 
Gruppe. Vid. Medd. fran de naturh. Forening i Kjöbenhavn, 1851, p. 55, tab. III, fig. 7-10. - Chr. Lütken, Grönlands Echinodermata, S. 22.

Nach einer Zeichnung von Dr. Pansch im ausgestreckten Zustande $45^{\mathrm{mm}}$ lang und bis $8^{\mathrm{mm}}$ dick.

Germaniahafen, 2 Faden. October 1869.

Verbreitung: Westgrönland bis 10 Faden.

\section{Echinoidea.}

1) Echinus dröbachiensis Miiller.

Zool. dan. Prodr., p. 235. - Lütken, Grönlands Echinodermata, S. 24. Forbes, Brit. Starfishes, p. 172 (Echinus neglectus Lmck.).

Schale ohne Stacheln $35^{\mathrm{mm}}$ Durchmesser, Höhe halb so gross.

Die Kahl der Porempare in einem Bogen der Ambulacra ist nicht immer fünf, wie Lïtken und Forbes beobachteten; in der Aequatorialzone der Schale gehören nicht selten sechs Paar Poren zu einem Bogen. Dujardin et Hupé sagen auch, dass füinf, sechs oder zuweilen sieben Porenpare in einem Bogen vorkommen. Echinodermes, p. 532.

Clavering-Insel, 15 Faden.

Verbreitung: circumpolar, Neufundland, Golf von Georgia, Weisses Meer, Kamtschatka, Ochotskisches Meer, Nordkap) bis Sund, Britamnien.

\section{Asteriodea.}

1) Asteracanthion albulus Stimpson.

Stimpson, Invertebr. of Grand Manan, 1853, p. 14, fig. 5. - Lütken, Grönlands Echinodermata, S. 30 (Asteracanthion problema Steenstrup).

Sieben Exemplare mit ungleichen Ammen; zwei mit sechs gleich langen Armen. Das grösste spannt $27^{\mathrm{mm}}$.

Auf dem Ende der Stacheh stehen feine Dörnchen.

Sabine-Insel.

Verbreitung: Westgrönland, Grand Manan (Fundy Bai, Nordamelika).

2) Ophioglypha robuste Ayres.

Lyman, Illustr. Catal. Mus. compar. Zool. at Harvard College, I. Ophiur. and Astroph., 1865, p. 45. - Iütken, Additam. al hist. Ophiur., I. Danske Vidensk. Selsk. Skriftl., p. 5. Række, Nat. og mat. Afdel., Bd. 5, 1858, S. 46, Taf. I, Fig. 7 (Ophiura squamosa).

Grösse: Durchmesser der Scheibe 11-12mm, Länge der Arme $36-37^{\mathrm{mm}}$.

26 Faden (olme speciellen Fundort).

Verbreitung: Westgrönland, Massachusetts, Island, Spitzbergen, Norwegen bis Sund, Grossbritamnien. 
3) Ophiocten sericeum Forbes.

l'orbes, Southerlands Journ. of a Toy. in Baffinsbay, II, App., p. 215. Lütken, Add. ad hist. Ophiur., I, 52, tab. I, fig. 5 (Ophiocten Kröyeri).

Lin unvollstindiges Lxemplar, dessen Scheibendurchmesser $10^{\mathrm{mm}}$. 26 Faden.

Verbreitung: Ostgrönland, Westgrönland, Spitzbergen.

4) Asterophyton encnemis Mïiller und Troschel.

Müller und Troschel, System der Asteroiden, S. 123. — Lütken, Addit. Ophiur. I, 70, tab. II, fig. 17-19.

Lin junges Exemplar; Scheibendurchmesser $9 \mathrm{~mm}$.

Verbreitung: Westgrönland, bis 1000 Faden.

\section{OELENTERATA.}

1) Actinia nodosa Fabricius,

l'abrieius, Fanna Grenlandica, p. 350.

Ein kleines Exemplar, welches sich kugelförmig zusammengezogen hat und so $12^{\mathrm{mm}}$ lang und breit ist.

2) Briarcum grandiftorum Sars.

Sars, Fama litt. Norvegix, II, 1856, p. 63, tab. X, fig. 10-12.

Anf Hornera Tichenoides I imné.

Die grössten Stiicke sind $18^{m m}$ lang.

Terbreitung: Öxford in Finmarken, Arendal (Dentsche OstseeExpedition 1871). 
'ZOOLOGIE, 7. Mollusken Tat'. I

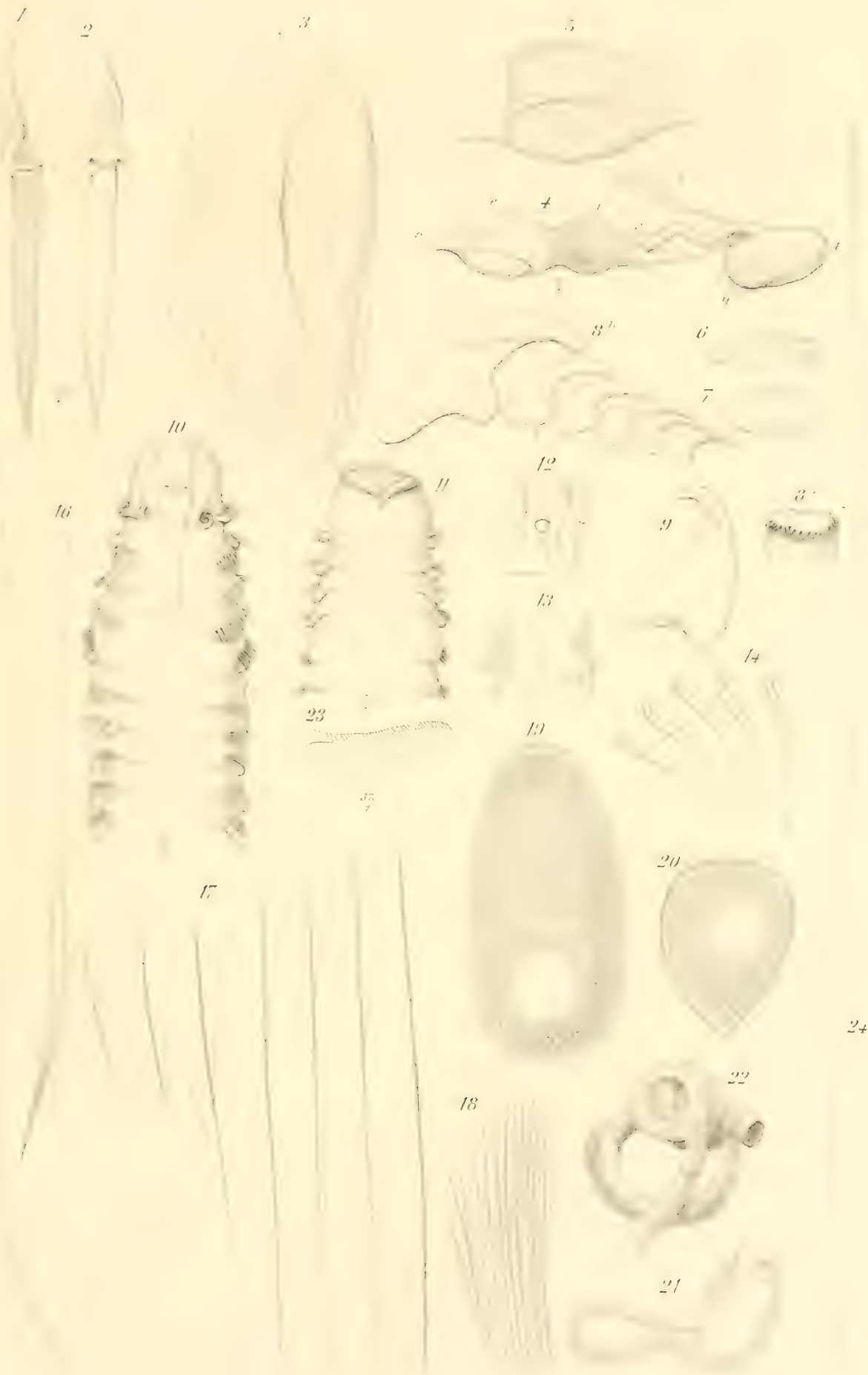





\section{Erklärung der Abbildungen.}

\section{Tafel I.}

Pleurotoma pyramidalis (Fig. 1-3). S. 249.

Fig. 1 und 2. $(25 \%)$ Pfeile aus dem sogenannten Giftsacke.

Fig. 3. Deckel.

$$
\text { Cylichna cylindracee (Fig. 4-9). S. } 250 .
$$

Fig. 4. $(1 \% / 1) a$. Nund; $b$. Speicheldrusen, hinteu oben in die Mundmasse eimmündend; $c$. Speiseröhre; $d$. Vormagen mit jungen Schnecken (Trochus helicinus) angefüllt; e. Kaumagen; f. Darm; g. Radulapapille.

Fig. 5. Zwei der drei Taschen des Kaumagens, mit Ring - und Lüngsmuskeln.

Fig. 6. Kauplatte im Profil.

Fig. 7. Kauplatte von der Innenfläche.

Fig. S. $(25 \%$ ) Radula, a. Mittelzahn; b. der Zwischenzahn und die Seitenzahne.

Fig. 9. $(25 \%)$ Der Zwischenzahn in anderer Lage; die Selueide im Profil.

$$
\text { Leipoceras uiferum (Fig. 10-20). S. } 254 .
$$

Fig. 10. (12/1) Kopf und Vorderkörper von oben.

Fig. 11. (12/1) Kopf von unten.

Fig. 12. Das 19. und 20. Segment; rechte Seite mit den Anfüngen der äussern Ovarien.

Fig. 13. Das 42. und 43. Segment, mit weiter entwiekelten äussem Ovarien.

Fig. 14. $\left({ }^{40 / 1}\right)$ Haken des 15 . Segments von unten.

Fig. 15. Borste cines obern Büschels im Vorderkörper.

Fig. 16. Borste eines untern Büschels im Vorderkörper.

Fiig. 17. Dicke Borste des 5. Segments.

Fig. Is. Untere feine Borste des 5. Segments.

Fï. 1\%. (375/1) Ei aus der Leibeshöhle des Hinterkörpers.

Fig. $2 \%$. $(575 / 1)$ Ei aus einem äussern Ovarium.

$$
\text { Protula medice (Fig. 21-24). S. } 256 .
$$

F'ig. 21. Eine Röhre.

F'ig. ㄹ.2. Eine längere und dickere Röhre.

Fig. 23. $(37 / 1)$ Ein Häkchen von der Unterseite des füuften Körpersegments.

Fi. 't. Eine Borste aus demselben Segment. 


\section{8. \\ Cr lus tace ell.}

Bearbeitet von

R. B 11 : h h

in Greifswall.

Wit 15 lithogrophirten Tafeh.

\section{Vorbemerkung der -Redaction.}

Durch freundliche Vermittelung des Herrn Professor Dr. W. Peters in Berlin hat die Königliche Akademie der Wissenschaften zu Berlin, zur Herstellung der so sorgfältig gezeichneten Tafeln zu der Abhandlung iiber die Crustaceen des Herrn Dr. Buchholz, die ansehnliche Summe von 500 Thalern zu bewilligen die Güte gehabt, für welches schöne Geschenk der Verein für die Deutsche Nordpolarfihrt hiermit seinen wärmsten Dank anszusprechen sich gedrungen fühlt, mit dem Bemerken, dass és nur durch diese liberale Unterstïtzung möglich war das nationale Werk mit diesen für die Wissenschaft so werthvollen 'Tateln zu bereichern.

Bremen, Januar 1873.

Dr. O. Finsch

für die Redaction des wissenschaftlichen Theils.

Das Material für die nachstehende Bearbeitung besteht aus denjenigen Crustaceen, welche Herr Dr. Pansch während der zweiten Ientishen Nordpolar-Experdition in dem von der ciermatnia beribrten (iebiete der ostgrönländischen Kï̈ste oder in Eismeer gesimmelt 
hatte, und welches mir von dem Verein fïr die Deutsche Nordpolarfahrt zu Bremen zuging.

Was die Ergebnisse der anf der Expedition gemachten Sammlungen anlangt, so ist es natürlich nicht anders möglich, als dass hei den eigenthiimlichen schwierigkeiten. welche der Expedition sirh darboten, und bei der verhältnissmässig kurzen Zeit, während welcher iiberhaupt gesammelt werden konnte, die Anzahl der aufgefundenen Arten eine nicht sehr bedeutende sein komnte. Neine eigene auf der Hansa gemachte Ausbeute musste an und fïr sich nur gering bleiben, da wir stets zu weit vom Lande entfernt waren, und ging uiberdies mit dem Verluste des Schiffes gänzlich verloren. Unter diesen Umständen wird man es gewiss nicht als ein zu geringes Ereigniss ansehen, dass die Anzahl der an der grönländischen Küste und im Eismeer von Dr. P'ansch gesammelten Crustaceen-Arten, mit Ausschluss der Pycnogoniden, sich auf 55 belïuft. Unter diesen sind:

an Decapoden 13, worunter drei neue Arten; an Isopoden nur 3 Bopyriden, worunter eine neu oder wenigstens früher nicht ausreichend bekannte; an $\Lambda$ mphipoden 27 , worunter nur zwei neue drten; an Phyllopoden 1, Copepoden 8 und Cirrhipedien 1.

Drei der erwähnten Arten wurden von Herrn Dr. Pansch wïhrend der lieise durch die Nordsee gesammelt.

Was die geographische Verbreitung der betreffenden Arten betrifft, so ergibt sich der gegenwärtige Stand unserer Kenntnisse dirüber leicht aus der nachstehend mitgetheilten Uebersichtstabelle. Ieh labe mich darauf beschränkt nur die auf den Deutschen Expeditionen gesammelten und nachstehend abgehandelten Arten in dieselbe aufzunchmen, dat für eine vollständige Uebersicht aller in arktischen Gebiet rorkommenden Crustaceen, welche allerdings sehr von Interesse sein wiirde, die Materialien voraussichtlich in späterer Zeit sehr viel vollständiger vorliegen dürften, da immer noch ein grosser Theil des durch die Schwedischen Expeditionen nach Spitzbergen gewonnenen Materials nicht vollständig bearbeitet ist und anch eine Reihe neuer Expeditionen theils bereits gemacht worden, theils demuächst zu erwarten sind.

Was nun die nachstehend beschriebenen 55 Arten von Crustaceen von Grönland anbetrifft, so sind davon

1) als dem arktischen Gebiet auschliesslich eigenthiimlich anzusehen (mit Einschluss von Finmarken und Nordland): 


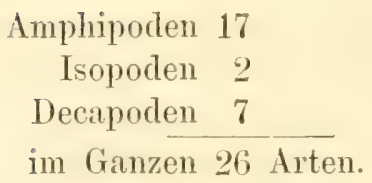

2) Gleichzeitig an der norwegischen Küste beobachtet wurden dagegen:

Amphipoden 12
Decapoden 5
Isopoden 2
Copepoden 6
Cirrhipedia 1
im Ganzen 26 Arten.

wobei allerdings nur die rollkommen unzeifelhaft festgestellten Arten in Rechnung gebracht wurden, sodass die Anzahl der beiden Faunengebieten gemeinsamen Arten wol in Wirklichkeit noch etwas heträchtlicher sein diurfte.

3) Gleichzeitig an den englischen Küsten sind davon (nach den Zusammenstellungen ron Spence Bate und Westwood, Bell und Baird) beobachtet:

$$
\begin{aligned}
\text { Amphipoden } & 5 \\
\text { Isopoden } & 2 \\
\text { Phyllopoden } & 1 \\
\text { Copepoden } & 7 \\
\text { Cirrhipedia } & 1 \\
\text { im Ganzen } & 16 \text { Arten. }
\end{aligned}
$$

von welchen aber ein grosser 'Theil (ansgenommen die Copepoden und Nebaliu bipes) nur entweder an den nördlichsten Küsten Schottlands oder sehr vereinzelt daselbst beobachtet wurde und kaum in diesem Faunengebiete als besonders heimisch anzusehen sein dürfte.

4) Die Ostsee exdlich hat nur noch fünf Arten gemeinsam, näm-

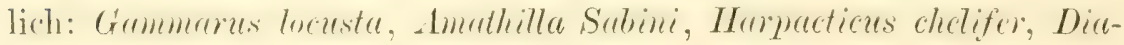
ptomus Castor, Balanus porcatus, von welchen iiberdies Amathilla Sabini und Balanus porcatus nux bei Kiel beobachtet wurden.

Als besonders erwilmenswerthe I'mute glaube ich folgende hervolheben zu müssen. Zunächst ist die verhältnismässig bedeutende Verbreitung arktischer Arten an der norwegischen Küiste, welche meistentheils längs ihrer ganzen Ausdehnung daselbst beobachtet wurden, sehr auffällig, zumal wenn man damit das sehr spärliche Vorkommen derselben an den englischen Nordseeküsten, welche doch in neverer Zeit so sorgfältig erforscht wurden, damit vergleicht. Es ist wol sehr wahrseheinljeh, dass die zusimmenhängende Instehnung dieser Küste in hohe Breitengrade, sowie die beträ̈htliche Ieerestiefe daselbst der 
Verbreitung der arktischen Fama nach süden sehr viel güustigere Bedingungen darbietet; als der Neeresborten in der Richtung nach der englischen Küste hin, welche durch dic ïberaus ticfen Alogründe des Eismeeres von dem arktischen Kiistengehiete getremnt ist, die wol der Verbreitung der Arten eine Schranke darbieten.

Was die übrigen Küistengebiete der Nordsee anbetrifft, so sind sie leider noch bei weitem nicht in der genügenden Ausdehnung erforscht worden, um mit in die Vergleichung gezogen werden zu könren; doch dürften sie, wie die englischen Küsten, ein Ueberwiegen der atlantischen und mittelmeerischen Fauna aufweisen.

Wenden wir uns nummehr zu der arktischen Fauna selbst, so erscheint das grosse Trebergewicht der (iruple der Amphipoden, welche der Artenzahl nach allein die Hälfte sämmtlicher gesammelten Crustaceen ausmachen, zienlich auffällig und ist es besonders auch diese Ordnung, welche eine besonders grosse Anzahl dem hohen Norden ausschliesslich eigenthimlicher Irten (labletet. Dagegen ist es muter den Decapoden voryighlich die Gattung IIippolyte, welche sowol durch die beträchtliche Artenzahl, als auch durch die ungemeine Massenhaftigkeit der Individuen vorzugsweise bezeichnend erscheint. Die Auffindung einer neuen P'asiphä̉ bestätigt von Neuem, dass auch diese Gattung als dem arktischen Famnengehiet eigenthiumlich anzusehen ist, während für Thysanopoda bisher eine Verbreitung bis in den höchsten Norden noch nicht bekannt war. Indessen gehören diese interessanten Formen so sehr zu den vereinzelten Erscheinungen, dass sie für die Gesammtheit der Famma sehr zuricktreten.

Hinsichtlich der Isopoden ist die auffallige Spärlichkeit des Vorkommens in dem littoralen Faunengebiet von Ostgrönland sehr sonderbar, und wenngleich diese Ordnung gegenüber den Amphipoden im hohen Norden sehr zurücktritt, ist doch der gänzliche Mangel an Arten in den Sammlungen von dorther sehr auffällig. Es scheint, dass sie grössere Wassertiefen als diejenigen, in welchen die meisten Sammlungen gemacht wurden, bewohnen.

Was endlich die Copepodenfauna des höchsten Norden anbetrifft, so ergibt sich aus den darïber mitgetheilten Ermittelungen, obwol sie sehr unvollständig bleiben mussten, zum wenigsten so viel, dass sie in einen viel höhern Grade mit derjenigen der Nordseekiisten und des atlantischen Gebiets übereinstimmend sich verhält, als diejenigen der übrigen Crustaceenordnungen.

Bisher waren es fast ausschliesslich die in so ungeheurer Individuenmasse die Obertläche des Eismeers allenthalben erfüllenden pelatgischen Formen der Calaniden, welche ane Berieksichtigung durch 
frihere Beobachter gefunden hatten. Gerade ïber diese Formen musste ich leider unentschieden lassen, ob sie einer einzigen oder einigen sehr nahestehenden Arten angehören, trotzdem das gesammelte Material ausserordentlich beträchtlich war. Dagegen dürfte es ron Interesse sein, dass die littorale Copepodenfauma Grönlands, welche bis dahin noch gänzlich als unbekannt anzusehen war, nunmehr doch bereits sieben Arten aufweist, nnter denen freilich keine einzige eigenthümliche ist, sondern die sämmtlich bereits an den Küsten der Nordsce aufgefunden wurden. Freilich dürfte die Möglichkeit. dass die dortige Fama ihr besonders eigenthümliche Irten darbieten kamn, damit durchaus nicht ausgeschlossen sein, da diese kleinen mikroskopischen ('rustaceen nur sozusagen zuf:illig zwischen anderm Material herausgesucht werden komnten, und bei genauerer Beachtung derselben an Ort und Stelle noch eine grössere Anzahl an Arten sich wol ergeben kömnte.

Ein besonderes Interesse in der Verbreitung der Crustaceen im hohen Norden gewähren die an der Neeresoberfläche allenthalben im Eismeer so überaus massenhaft verbreiteten pelagisch auftretenden Arten. Ich habe diesen Gegenstand bereits in einer fruihern kleinen Schrift' kurz berührt, doch konnte ich damals, da mir weder meine Notizen noch Sammlungen zur Hand waren, nur wenige der betreffenden Arten namhaft machen.

Es ist zunächst hervorzuheben, dass die Anzahl der Arten, welche in regelmässiger Weise ziemlich universell im Eismeer anftreten, wenn man eben von vereinzelten mehr als zufällig anzusehenden Vorkommnissen absieht, eine verhältnissmässig sehr geringe ist. Zu diesen Arten sind zu rechnen: Anonyx littoralis, Anomyx plautus, Gammanus locusta, Paramplithoë fulvocincte und incrmis, und Themisto libellule, sowie von Copepoden: Cetochilus septentrionalis, welche sïmmtlich in so grosser Individuemmasse allenthalben im Eismeer auftreten, dass man sie als die vorzugsweise vorherrschenden und für die Fauna des von uns berührten Polarmeeres am meisten charakteristischen bezeichnen kanm. Unter diesen diirfte indessen allein Themisto als wirklich ausschliesslich pelagische Form anzusehen sein, dat sie nur sehr vereinzelt an der Küste selbst vorzukommen scheint, während alle ïbrigen gleichzeitig aut dem Meeresgrunde und zwar in sehr ausgebreiteter Weise, wie es scheint, lebend angetroffen werden. Es ist bemerkenswerth, dass es sämmtlich Arten sind, welche zu den am

1 Erlebnisse der Mannschaft des Schiftes Hansa nebst Bemerkungen über das Thierleben im hohen Norden (Künigsberg 1871). 
läutigsten und im höchsten Norden allgemein verbreiteten drten gehören. Dennoch besitzt unter denselben nur Gammarus locustu und vielleicht C'etochilus septentrionulis eine weit ausgedehnte Verbreitung in südlichen Breiten, während die übrigen als arktische Formen anzusehen sind. Auch bleibt es immerhin sonderbar, dass diese Arten gerade es sind, welche sich so reränderten Lebensbedingungen anpassen, da es doch eine grosse Menge anderer Mrten gibt, welche fast ebenso verbreitet und massenhaft an der Küste auftreten, welchen man aber kaum je anders als zufällig in grösserer Entfernung vom Lande begegnen dürfte.

Was num ferner diejenigen Arten anlangt, welche neben den erwähnten gelegentlich an der Meeresoberfläche getroffen werden, so sind nur tolgende von Dr. Panseh gesammelt worden: Lusirus cuspidatus, Thysanopoda Raschii und Pasiphä glacialis. Das überans seltene Vorkommen dieser Arten macht es schwierig dariber zu urtheilen, ob man in diesem beobachteten Vorkommen etwas anderes als eine reine Zufälligkeit erblicken darf.

Was endlich die Ordnung der Oetracoden betriftt, so gelang es mir allerdings ein geringes Material zwischen versehierlenen Ruickständen herauszusuchen, indessen bei der grossen Schwierigkeit der Bearbeitung und der Geringfügigkeit des Materials hielt ich es für gerathener, dasselbe für eine spätere Untersuchung zu bewahren.

Schliesslich habe ich noch einen Umstand zu erörtern, welcher als eine besondere Eigenthümlichkeit der Fauna des Polarmeeres bereits mannichfach die Aufmerksamkeit auf sich gelenkt hat. Es ist dies die im Allgemeinen beträchtliche Grösse, welche die Arten daselbst grossentheils erreichen. Es gilt dieses nicht allein für die Amphipoden, bei denen nicht nur, wie es den Anschein hat, eine Anzahl ron verhältnissmässig sehr bedentende Grösse erreichenden eigenthïmlichen Arten daselbst vorkommt, sondern auch bekanntlich die grosse Mehrzahl derjenigen Arten, welche gleichzeitig in südlichern Gebieten auftreten, daselbst bei weitem geringere Grösse erreichen, als innerhalb des arktischen Gebietes. Auch bei vielen Arten aus andern Ordnungen fundet-sich dieselbe Erscheinung, wie z. B. die Calaniden und Nebalia dieses in auffällig hohem Grade darbieten.

Welchem Umstande dieses eigenthïmliche Gedeihen der Arten im Eismeere zuzuschreiben ist, dürfte schwierig zu erklären sein, sicherlich darf wol der Salzgehalt des Wassers nicht als die Ursache anzusehen sein. Ich wollte hier nur auf einen Umstand die Aufmerksamkeit lenken, nämlich anf die hedeutende Schwankung in der Grösse der erwachsenen Thiere, welche bei einigen Arten und zwar bei In- 
dividuen von einer und derselben Oertlichkeit auftritt. So war mir dieses besonders bei Peramphithö̈ inormis und fulvocinctu anffällig, woselbst sich zwischen den mit Brut versehenen, also zweifellos röllig

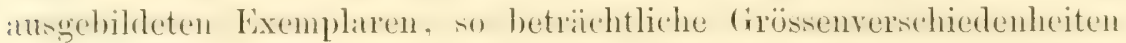
darbieten, dass die Grössesten über das Doppelte der Grösse der Kleiner'n erreichen. Leider ist bei einer grossen Anzahl von Arten das Material so spärlich, dass über diese Verhältnisse keine sichern Lirmittelungen zu machen sind, doch ist sicher, dass manche Arten durchaus nicht zu derartigen Grössenverschiedenheiten himneigen, wie man aus den Angaben bei den einzehen Arten genauer entnehmen kamn. Es ist zu bedauern, dass die Grössenangaben von den meisten Beobachtern so fragmentarisch gemacht werden, dass sie über derartige Verhältnisse keinerlei Auskunft geben.

\section{Systematisches Verzeichniss \\ der in Ostgrönland gesammelten Crustaceen, \\ nebst}

Uebersicht der geographischen Verbreitung.

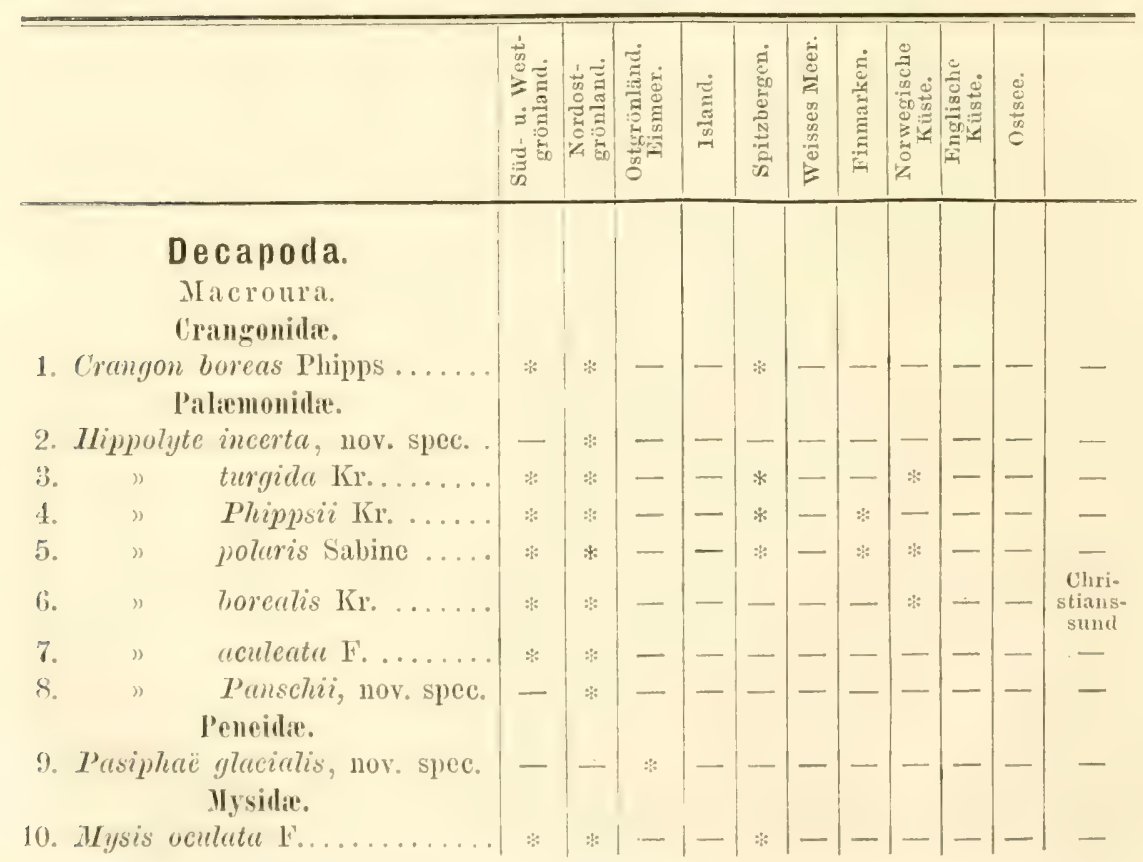




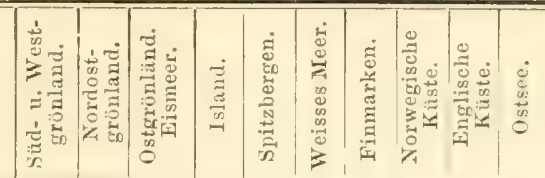

11. Thysanopoda norvegica Sars. 12.

Raschii Sars. . . Brachyura.

13. Corystes Cassivelamus Penn.

Isopoda.

Bopyrilar.

14. Gyge lippolytes $\mathrm{Kr}$.

15. Phryxus abdominatis Kír.

16. Leptophryxus Mysidis, 11. sp).

\section{Amphipoda.}

Iysianassidar.

17. Anomyx lagena Kr.

1.. " Tittoralis $\mathrm{Kr}$.

19. " plautus Kr.

Syrrhoinar.

3). Syprhoü cremulata Goës.......

Pardaliscinx.

21. Pardalisca cuspidata Kr.

Lencothoinar.

2.). Eusinus cuspidatus $\mathrm{Kr}$.

23. Amphithonotus aculeatus Lepech.

24. Iritropis fragitis Goës

\section{0edicerinte.}

25. Oerliceros boreatis Bock

26. "Iynceus Sars.

\section{Plenstinx.}

27. Pleustes panoplus $\mathrm{Kr}$.

28. Parapleustes gracilis, nov. spec. Iphimedina.

29. Vertummus serratus $\mathrm{F}$

(iammarinx.

30. Gammane 7ocusta L

31. Amathilla Sabini Leach.....

32. " pinguis $\mathrm{Kr}$.

$$
\text { Atylinir. }
$$

33. Atylus carinatus F. .

i4. "Smithii Goës.

35. Acanthozone hystrix Ow.

36. Paramplithoë inermis Kr.

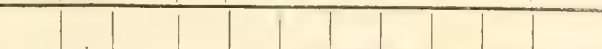

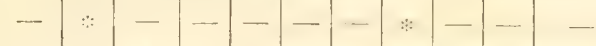

$-1-*$

$-$

-

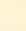

(n)

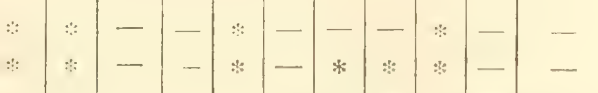

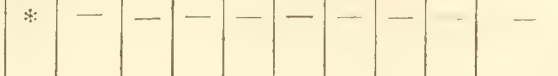

.

\begin{tabular}{c|c|c|c|c|c|c|c|c|c|c}
$*$ & $*$ & - & $*$ & $*$ & $*$ & $*$ & $*$ & $*$ & - & - \\
$*$ & $*$ & $\because$ & - & $\ddots$ & - & $*$ & - & - & & - \\
& $*$ & $*$ & - & $*$ & - & - & $*$ & $*$ & - & - \\
- & $*$ & - & - & $*$ & - & - & $*$ & - & -
\end{tabular}

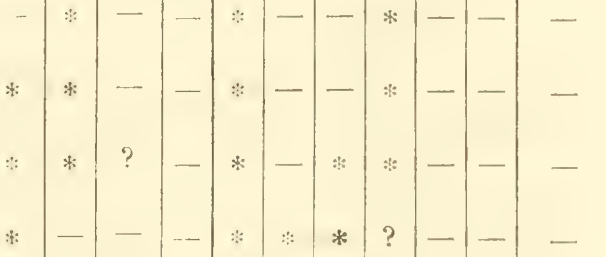

*

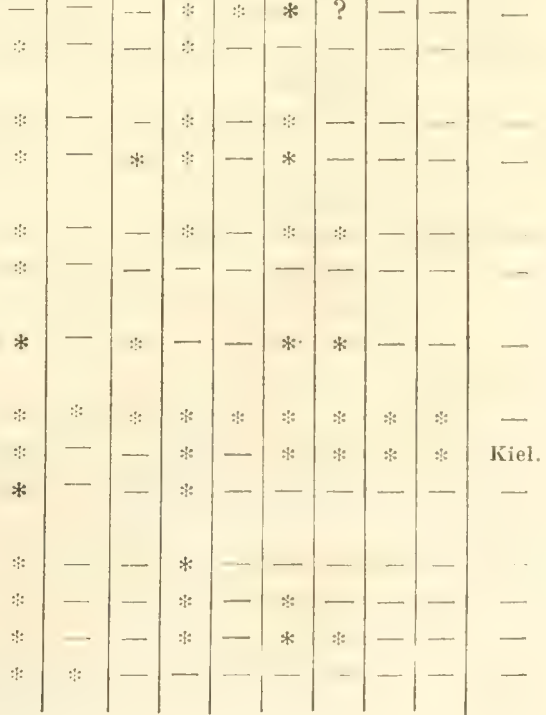




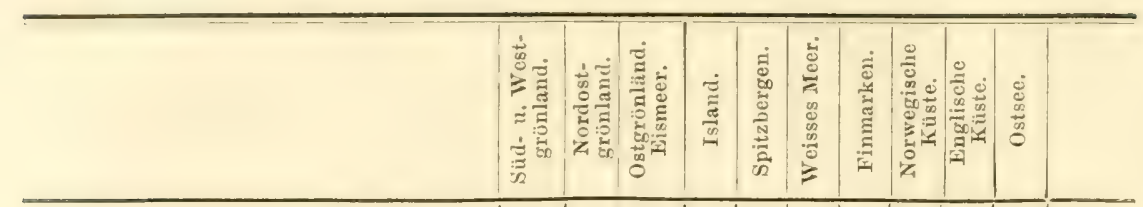

37. Paramphithoë fulvocincta Sars.

:ir. "megalops, n. sp. Ampeliscina.

39. Ampelisca Eschrichti Kr...... Pollocerinie.

411. Poclocerus anguipes $\mathrm{KL}$ ('orophinte.

11. Glauconome leucopis $\mathrm{Kr}$. Hyperidie.

42. Themisto Tibellula Mandt Caprellina.

43. Aegina spinifera Bell

\section{Phyllopoda.}

Yebaliada.

44. Nebalia bipes F'.

\section{Copepoda.}

Calanidie.

45. Cetochitus septentrionalis Good.

41. Diaptomus Castor Jucine

IIarpactida.

47. Harpacticus chelifer O. F. MI.

$4 \therefore$. Tisbe furcate Baird

4\%. Cleta minuticomis Müller ..

Peltididse.

5). Zaus spinosus Claus

i1. " ovalis Good.

Cyclopida.

5.). Thorellia Enmea Boeck Caligidae.

53. Iepeophtheirus hippoglossi Kr. Lernapopolide.

is. Brochiella rostrata $\mathrm{Kr}$.

\section{Cirrhipedia.}

55. Batames porcatus da Costa

\section{Pyenogonidat.}

1. Nympleon grossipes O. I

$\because$ " mixtum Kr.

3. " hirtum Kr... 


\section{E C A P O D A.}

Macroura.

\section{Crangonidae Edw.}

\section{1) Crangon boreas Phipps.}

Cancer boreas Phipps, Voyage towards the North Pole, p. 190, tab. XII, fig. 1. Cancer homaroïdes O. Fabr., Fauna gronlandica, Nr. 218.

Cancer homaroïdes Mohr, Islandske Naturhistorie, Nr. 245, tab. V.

Crangon boreas Sabine, Supplement to the Append. of Capt. Parry's Second Voyage, p. 235.

Crangon boreas Beechey, Voyage Zoologie, p. 87.

Crangon boreas H. Kröyer, De hidtil bekjendte nordiske Crangon-Arter, Natırhist. Tidskr., IV, 218.

Diese im hohen Norden überall häufige Art ist die einzige, welche in den Sammlungen von Ostgrönland vorhanden ist. Sie gehört daselbst ebenfalls zu den sehr häufig vorkommenden Formen, da sie in sehr reichlicher Anzahl von verschiedenen Fundorten gesammelt worden war.

Sie ist von Kröyer, a. a. O., so genau beschrieben worden, und anch namentlich die in den verschiedenen Alterszuständen auftretenden Abänderungen so ausführlich erörtert, dass den Angaben jenes vorzïglichen Beobachters nichts hinzuzufügen ist.

Das grösste Exemplar von Ostgrönland besass eine Gesammtlänge von $82^{\mathrm{mm}}$, es war ein weibliches, das grösste männliche $72^{\mathrm{mm}}$, bei der Mehrzahl der Erwachsenen die Grösse zwischen 60 und $80^{\mathrm{mm}}$ betragend; das jüngste Exemplar $20^{\mathrm{mm}}$.

Vorkommen: Sabine-Insel, 10-20 Faden reichlich. Sabine-Insel, ohne Angabe reichlich. Sabine-Insel, 27 Faden, ein ganz junges Exemplar. Jackson-Insel, 4 Faden, mehrere.

\section{Palaemonidae.}

Hippolyte Leach.

Es ist diese in den arktischen Meeren vorzüglich artenreiche und namentlich in grosser Massenhaftigkeit der Individuen auftretende Gattung in Kröyer's Monographie ${ }^{1}$ in vorzïglicher Weise bearbeitet worden, sodass ich mich wol begniigen darf, die von Dr. Pansch an der

1 H. Kröyer, Monographisk Fremstilling af Slægten Hippolytes Nordiske Arter. K. Danske Vidensk. Selsk. Skrifter, 1842. 
nstgrönländischen lïste gosammelten Arten einfach anfzumählen. Tur die Hälfte der arktischen, bisher bekamnten Arten sind vertreten, namentlich kam es auffïllig erscheinen, dass die bei Spitzhergen nach

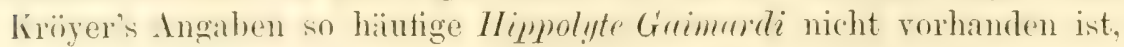
sie scheint indessen auch im südlichen Grönland selten. Zwei neue, freilich nur in je einem Exemplar vorliegende Arten wurden gesammelt. Was die Begrenzung der Arten anbetrifft, so kamn ich nur Kröyer's Angaben vollkommen beipflichten. Die Form des Rostrum ist ziemlich variabel und nur mit grossen Linschränkungen zur $\mathrm{Ab}$ grenzung der Formen zu verwerthen. Sehr sichere und durchaus zuverlïsige (haraktere bietet dagegen die Bildung der Maxillarfüise und der vordern Fusspaare, wie sie von Kröyer zuerst erkannt und zur Charakteristik der Arten verwendet worden sind. Bei allen Arten, mit Ausnahme einer einzigen, befindet sich an dem Wurzelgliede der Maxillarfüsse, sowie einer grössern oder geringern Anzahl der rordern Fusspare ein äuserst kleiner gekrümmter Geisselfaden, der nur beim Aufheben des Riickenpanzers bei sehr genauer Besichtigung sichthar ist. Ausserdem sind die Maxillarfüisse bei einer Reihe von Arten mit einem an der Wurzel des zweiten verlängerten Gliedes inserirten Taster von verschiedener Grösse versehen, welcher bei andern Arten völlig fehlt.

Ich habe diese Charaktere an einem ïusserst reichhaltigen Material durchweg constant gefunden, da ich Hunderte von Exemplaren daranf besichtigte. Das Erkennen des kleinen Geisselfadens ist allerdings anfangs etwas schwierig, doch kann man bei erlangter Uebung denselben mit Sicherheit olne Verletzung der Exemplare wahrnehmen.

Die Zahl und Stellung der Stacheln am vordern Rande des liiickensehildes liefort gleichfills constante mol leichter zu erkemende Artmerkmale.

A. Mit Taster und Geisselfaden an den Maxillarfiissen.

a) Ein Geisselfaden an den zwei vordersten Fusspaaren. Gruppe der Hippolyte Gaimardi.

\section{1) Hippolyte incerta Buchholz, nov. spec.}

Scutum dorsale antice ad mediam partem usque carinatum et dentatum. Rostrum frontale horizontale, cultellatum longitudinem scuti dorsalis aequans, appendice antennarum externarum paullo brevius; margine superiore dentibus acutis septem, margine inferiore apicem versus quatuor dentibus instructum. Margo anterior Scuti dorsalis in utroque latere aculeis tribus, quorum longissinus supra 
oculum, alius minor infra oculum, tertius minutissimus ad angulum inferiorem marginis anterioris situs.

Pedum maxillarium externorum palpus longus, attamen articulo secundo eorum paullo brevior.

Ich muss allerdings gestehen, dass die Begründung einer Art auf ein einzelnes Stuick hin etwas misslich ist, doch kann ich das betreffende Exemplar, welches zwischen einer Menge Individuen anderer Arten allein angetroffen wurde, nicht mit einer der bisher beschriebenen Formen in Einklang bringen.

Von Hippolyte Gaimardi unterscheidet sich diese neve Art durch den starken Supraorbitalstachel, welcher der längste der drei am Vorderrand des Rïckenschildes befindlichen Stachehn ist, und der bei jener Art fehlt. Aus Kröyer's sehr umfassenden und auf sehr reichem Naterial begründeten Angaben geht hervor, dass hierin bei den Arten wol keine Variationen auftreten.

Der 'Taster der äussern Maxillarfüsse ist verhältnissmässig gross, drei Viertel so lang als das zweite Glied derselben und gegliedert. Letztere selbst reichen nach vorn ansgestreckt nicht ganz bis zur Spitze des blattförmig verbreiterten Basalgliedes der äussern Antennen; das Rostrum wie bei Hippolyte Gaimardi.

Der Caudalanhang stimmt im Wesentlichen mit der Bildung bei Hippolyte Gaimardi überein, or ist an den Seiten mit fünf Paar Stachelborsten versehen, der Endrand im Ganzen wie bei jener bestachelt, in der Mitte desselben eine kleine dornartige Spitze und jederseits drei starke Stacheln, von denen der mittlere bei weitem am längsten ist. Das innere Paar der Stacheln etwa halb so lang als die mittlem; Kröyer gibt sie bei Hippolyte Gaimardi und verwandten Arten als gefiedert an, was indessen wol nicht ganz richtig sein dïrfte. Ich finde wenigstens bei der vorliegenden Art die.Stacheln selbst wie die übrigen gebildet, dagegen befinden sich zwischen ihnen und den äussern Stacheln einige sehr dünn gefiederte Borsten, welche leicht eine Täuschung bei nicht starker Vergrösserung herbeiführen können.

b) Ein Geisselfaden an den drei vordersten Fusspaaren. Gruppe der Hippolyte turgida.

\section{2) Hippolyte turgida Kröyer.}

Monographisk Fremstilling af Slægten Hippolytes Nordiske Arter, Kjöbenhavn 1842 , p. 100 , tab. II, fig. $57-58$; tab. III, fig. $59-63$.

Vorderer Seitenrand des Rückenschildes mit vier Stacheln jederZweite Deutsche Nordpolfahrt. II. 
seits, davon zwei oberhalb des Auges. Rostrum kurz, ziemlich gerade und sehr breit im senkrechten Durchmesser.

Sie ist an der ostgrönländischen Küste häufig und sehr verbreitet.

Die Grösse erwachsener eitragender Weibchen betrug zwischen 30 und $36 \mathrm{~mm}$. Zwischen einigen 20 Fixemplaren, welche vorlagen, auch zwei ziemlich erwachsene Männchen, von $30-: 35 \mathrm{~mm}$.

Nach den Angaben von Goës ${ }^{1}$ hätte derselbe unter 100 Exemplaren dieser Art kein einziges mämnliches, sowie von Hippolyte Phippsii unter Hunderten von Spitzbergen herrihhenden kein weibliches gefunden, und will daher beide Arten als die geschlechtlich verschiedenen Formen einer Art auffassen. Ich muss bemerken, dass allerdings bei Hippolyte turgidu auch bei dem mir voliegenden Material die Männchen verhältnissmässig sehr selten sind, wogegen ich hei HippoTyte Phippsii unter circa 30 Exemplaren nur ein einziges weibliches antraf. Ich kann daher Goës' Ammahme nicht für richtig ansehen, glaube aber in der 'That, dass beide Arten nu Abarten derselben Form darstellen, da die Form des Lostrum bei Ilippolyte turgida einigen Abänderungen unterworfen ist und wol, namentlich bei juingern Exemplaren Uebergangsformen vorkommen. Daneben besityt

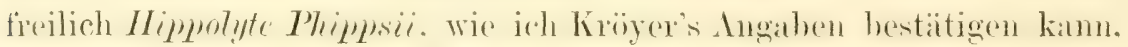
bei beiden Geschlechtern längere obere Antennen als Hippolyte turgida, welche bei letaterer kaum, bei ersterer recht betrïchtlich iiber das blattartige Basalglied der äussern Fühler hervorragen und hier ein Viertel, dort nur ein Fünftel der Körperlänge des Thieres betragen.

Vorkommen: Kap Wynn 5 Faden, Sabine-Insel 27 Faden reichlich, Sabine-Insel 20-110 Faden, Shannon-Insel, August 1869, Nordshannon-Insel 30 Faden.

\section{3) Hippolyte Phippsii Kröyer.}

Kröyer, Naturhist. 'Tidskrift, I, Række, III, 575.

Ders., Monographisk Fremstilling af Slægten Hippolytes Nordiske Arter, Kjöobenlavin $1842,4^{\text {to }}, \mathrm{p} .106$.

Goës, Crustacea Decapoda Podophthalma Marina Sueciæe ete., Översigt af kongl. Vetensk. Ac. Förh., 1863, p. 169.

Von der vorigen nur durch das sehr viel schmälere fast lineare liostrum und durch die etwas längern obern Fühler verschieden.

Die Grösse ziemlich wie bei der vorigen Art, das grösste mir rorliegende Exemplar war das erwähnte Weibchen, welches alle Art-

' Crustacea Decapoda Marina Snecie ete. Öfvers. af kongl. Vet. Ac. Förh., 1863 , p. 169. 
charaktere darbietet; dasselbe ist $33^{\mathrm{mm}}$ lang. Die Männchen etwas kleiner, bis zu $30^{\mathrm{mm}}$.

Verbreitung: Nit der vorigen; Kap Wynn 5 Farden reichlich, Sabine-Insel 27 Faden.

B. Die Maxillarfüsse ohne Taster. Ein Geisselfarlen an den Maxillarfüssen und den zwei vordersten Fussparen. Gruppe der Hippolyte polaris.

\section{4) Hippolyte polaris (Sabine).}

Alphens polaris Sabine, Supplem. to the Append. of Parry's Voy., p. 238, tal. 2 , fig. $5-8$.

Hippolyte polaris Kröyer, Naturh. Tidskr. förste Række, III, 577.

Kröyer, Monographisk Fremstilling of Slægten Hippolytes Nordiske Arter, Kjö. henhavn 1842 , p. 116 , tab. III, fig. $78-81$; tab. IV, fig. 82.

Goës, Crustacea Decapoda Podophthalm. Sueciæ etc., Översigt, 1863, p. 169.

An der ostgrönländischen Küste bei Weitem die an Massenhaftigkeit der Individnenzahl vorherrschende Art. Es lagen einige hundert Exemplare von dort her, beide Geschlechter ziemlich gleich zahlreich, in Dr. Pansch's Sammlung vor.

Die grössten Exemplare bis $60^{\mathrm{mm}}$, einschliesslich des Rostrum; letzteres $10^{\mathrm{mm}}$.

Die grössten Exemplare vorzugsweise Weibchen, die Männchen durchschnittlich kleiner bis zu 50 , orler höchstens $55^{\mathrm{mm}}$. Sie besitzen ansehnlich längere und stärkere obere Fühler als die Weibchen. Bei den Männehen sind die obern Fïhler ziemlich so lang als der Cephalothorax und ragen bedeutend iiber das Basalglied der äussern Antennen hervor, bei den Weibchen dagegen sind sie fast um die Hälfte kiirzer als der Rückenpanzer und sehr 'wenig über' das Basalglied der äussern hervorragend. Auch hier die Männchen etwas weniger zahlreich als die Weibchen, jedoch gerade nicht spärlich vorhanden.

Die Geissel der äusserm Fühler ist roth gefärbt. Uebrigens die Fürbung an Weingeistexemplaren gleichmässig hellgelblich.

Das Rostrum ist in der Form beträchtlich variabel, bald breiter, bald sehr schmal und die Anzahl der Zähne wechselnd. Mitunter findet man Individuen, deren liostrum wie es scheint abgebrochen gewesen, und alsdam wieder ersetzt eine ganz neue abnorme Form darbietet, indem es äusserst kurz zugespitzt und oben nur mit 1-2 Zähmen rersehen ist.

Verbreitung: Sabine-Insel 20-100 Faden, sehr massenhaft von verschiedenen Stellen, Kap Wynn 5 Faden, Shannon-Insel 2 Faden. 


\section{5) Hippolyte borealis Owen.}

Owen, Appendix to the Voyage of Ross., p. 84.

Irröyer, Naturhist. Tidskr. förste Rrkke, III, 577.

Ders., Monographisk Fremstilling af Slæuten Hippolytes Nordiske Arter, p. 122, tah. III, fig. $74-77$.

Der rorigen sehr nahe stehend und nur durch die sehr eigenthiimliche Form des Rostrum verschieden, welches gerade, an der Wurzel sehr dick und am obern Rande ganz ungezähnt ist, sowie auch auf dem Rïckenpanzer Kiel und Zühne fehlen. Zusammen mit der vorigen, von welcher sie vielleicht nur eine Abänderung ist, indessen viel weniger zahlreich.

Die grössten Lixemplare bis $57^{\mathrm{mm}}$ lang.

Sämmtliche ostgrönländische Stiicke sind Mämmchen und bieten wie bei Hippolyte polaris die männliche Form in demselben Verhältniss etwas verlängerte immere Fïhler dar; im Ganzen sind nur sechs Exemplare in der Sammlung enthalten.

Sabine-Insel 20-110 Faden, Kap Wym 5 Faden.

C. Maxillarfïsse ohne Taster. Fin Geisselfaden an den drei vordern Fussparen. Gruppe der Hippolyte aculcata.

7. 6) Hippolyte aculeata (Fabricius).

Cancer aculeatus labricius, Fauna groulandica, no. 219, p. 239.

Alpheus aculeatus Sabine, Suplem. to the Append. of Parry's Voyage, p. 237, tab. II, fig. 9.

Hippolyte aculeata Kröyer, Monographisk Fremstilling af Slægten Hippolỵtes Nordiske Arter, p. 126, tab. IV, fig. 83-98; tab. V, fig. 99-104.

R. Owen, The Zoology of Beechey's Voyage, p. 86-89.

Die grösste Art, durch die verhältnissmïssig breiten und gedrungenen Formen und den feinbehaarten Körper leicht von den ïbrigen Arten zu unterscheiden. Der Rüickenpanzer ist im Verhältniss zur Höhe kurz, stark gewölbt und fast bis zum Hinterrande gekielt, der Kiel mit vier sehr starken Kähnen.

Die grössten Exemplare bis $70^{m m}$ lang. Mïmnchen etwas spärlicher als die Weibchen und nicht ganz die Grösse der letztern erreichend, auch hier mit etwas lïngern imnern Antemen versehen.

Die Färbung wie bei den verwandten Arten hellgelblich, die Geissel der iussem Antemen roth und weiss gebändert.

Verbreitung: An den ostgrönlindischen Küsten häufig und wie es scheint ziemlich allgemein verbreitet; Sabine-Insel 10-120 Faden, reichlich an mehrern Stellen; Kap Wynn á Faden; Shamnon-Insel, 20. August 1869. 
D. Maxillarfüsse mit einem Taster versehen; kein Geisselfaden an irgend einem der Fusspaare. Gruppe der Hippolyte varians.

Nur ein einziges erwachsenes weibliches Exemplar, welches dieser Gruppe angehörig ist, wurde unter den ostgrönländischen Iippolyte ron mir gefunden, welches indessen ron Hipholyte smaragdina Kröyer (Hippolyte varians Leach) sonst wesentlich verschieden sich erwies, und mit keiner der bisher genügend beschriebenen Arten übereinstimmt. Ich erlaube mir diese Art daher ihrem Entdecker, Herrn Dr. Pansch zuzueignen.

8. 7) Hippolyte Panschii Buchholz, nov. spec. 'Taf'. I, Fig. 1.

Corpus parvum, valde tenerum epidermide pellucida, glabra. Rostrum brevissimum, subulatum, apice acuminata leviter deorsum curvato; nullis, nec marginis superioris, nec inferioris, dentibus. Rostri longitudo scuti dorsalis tertiam partem aequans, oculis parris paullo major, antennarum exteriorum appendice folii formi tertiam fere partem formans. Scutum dorsale breve, sat convexum, in anteriore parte dimidia carinatum, carina elevata, dentibus duobus acutis. Margo anterior scuti dorsalis anterior dentibus tribus in utroque latere quorum maximus supra oculum situs curvatus, secundus infra oculum, tertius paullo infra medium marginis anterioris situs.

Antennae superiores scapo ad mediam appendicis foliiformis antennarum exteriorum partem porrecto, flagello externo elongato, filiformi, in basi haud incrassato, multo longiore quam interno vix ad apicem appendicis porrecto.

Antennae externae appendice foliiformi magno, scutum dorsale longitudine aequante, cum Hagello corporis longitudinem totalem paullo superantes.

Pedes maxillares fere ad finem appendicis foliiformis antennarum porrecti palpo brevi, tertiam fere articuli secundi partem aequante. Pedes secundi paris articulo penultimo decem articulato, ultimo chelam perparvam formante.

Appendix caudalis quatuor paribus aculeorum lateralium, in medio margine posteriore aliquantum emarginatus.

Segmentum abdominis tertium in femina valde gibbosum processum magnum valde prominentem formans.

Die Art hat, wie man hieraus ersieht, in manchen Punkten Aehnlichkeit mit Itipmolyte microceres hröyer, mit welcher sowol die eigenthümlich pfriemförmige Gestalt des Rostrum, als die von den iibrigen Hippolyte-Arten abweichend gestalteten innern Fühler growe Achnlichkeit zeigen. Indessen ist das Rostrum gänzlich ohne Zähne, die 
Maxillarfiisse mit einem kurzen, aber beiderseits rorhandenen Taster rersehen, und es fehlt der kleine Geisselfaden sowol an ihnen als an den vordersten Eusspatren gänzlich. Das vorliegende Lxemplar stammt von Nordshamon aus 30 Faden Tiefe, woselbst es nebst zahlreichen andern Crustaceenarten ron Dr. Pansch entdeckt wurde. Es ist mit zahlreichen Eiern versehen, sodass es als völlig erwachsen betrachtet werden muss. Die Bildung der innern Antemmen ist ganz charakteristisch, der äussere Geisselfaden ist ganz olme einen verdickten Basaltheil, gleichmässig fadenförmig; er ist wie es scheint beträchtlich länger als der innere viel dünnere Geisselfaden, doch nur eine kurze Strecke weit ïber den blattförmigen Anhang der äussern Fühler erhalten. Das zweite F'usspaar sehr verlingert mit ganz ungewöhnlich zahlreich gegliedertem fünften Gliede; ich finde es aus zehn sehr deutlich abgegrenzten Gliedern gebildet, ron denen das erste und letzte am längsten sind. Der liückenschild im Verhältniss zur Höhe kurz, ziemlich stark gewölbt, der Kiel in seiner vordern Ilälfte ziemlich stark vortretend mit zwei ziemlich starken spitzen Zähnen.

Das dritte Abdominalsegment des Weibchen tritt in Form eines seh1 grossen stumpfeonischen Höckers mach hinten hervor, welcher bis zu drei Viertel des folgenden Segmentes nach hinten reicht.

Die Gesammtlänge einschliesslich des Rostrum. beträgt $35^{\mathrm{mm}}$. Riickenschild ohne Riostrum $8^{\mathrm{mm}}$, Höhe desselben $7^{\mathrm{mm}}$.

Verbreitung: Nordshammon-Insel 30 Faden.

Peneidae, Milne Edwards.

Pasiphaë Savigny.

Von dieser sehr interessanten Gattung kamnte man bis vor kurzem nur zwei Arten, die zuerst bekannte Pasiphaë sivado aus dem Nittelmeer und eine späterhin von Kröyer beschriebene Art, Pasiphaë tardu von Südgrönland. Von Sars wurde alsdamn ${ }^{1}$ in neuerer 'Zeit nicht nur Pasiphaë sivada als, wenn auch äusserst selten an der norwegischen Küste heimisch nachgewiesen, sondern ebendaselbst auch eine neue Art, welche Kröyer's Pasipluë tarda sehr nahe steht, Pasiphä norvegica, aufgefunden.

Unter diesen Umstïnden muss es als ein besonder's gliicklicher Zufall angesehen werden, dass die Sammlung von Ostgrönland abermals eine neue und zwar sehr charakteristische Art enthält, sodass p. $42 \mathrm{sq}$.

1 M. Sars, Bidrag til liundkkil, on Christianiafjordens Fauna (Christiania 1868), 
die Vermuthung von Sars, wonach die Gattung als eine eigenthich dem arktischen Gebiete angehörige zu betrachten sei, von Neuen eine gewichtige Stiitze erhält.

Das betreffende Exemplar, welches auffäligerweise an der OberHäche des Meeres in der Nähe der Eisgrenze gefischt wurde, weicht von den bisher bekannten Arten viel beträichtlicher ab als diese untereinander, sodass es vielleicht gerechtfertigt erscheinen könnte, dasselbe als Typus einer besondern Gattung anzusehen, da indessen die wesentlichsten Merkmale mit den ïhrgen P’asphä̈-Irten ïhereinstimmen und iiberdies leider der etwas beschäidigte /ustand des einzigen Exemplars kein genaueres Lrkennen aller 'Theile zulassen konnte, scheint es, gerathen es zunächst den übrigen Arten einfach anzureihen.

9. 1) Pusiphä̈ glacialis Buchholz, nov. spee. 'l'af. I, Fig. 2.

Diagnosis. Pasiphaë forma robustione quam in speciebus affinibus. Cephalothorax tertiam fere longitudinis corporis partem formans, altior quam in illis, antice parum angustatus, sat compressus, carinam praebet acutam, per duas anteriores partes carapacis porrectam, antice dentes tres parvos acutos formantem. Rostrum parvum triangulare valde acutum. Abdomen sat robustum, dorso rotundatem carnat nullit. Segnentum abdominis sextum malrgine postico simplici aculeis mullis. Appendix caudalis media segmento abdominis sexto longior, postice truncatus, aculeis .... quatuor aculiorum marginis lateralis paribus. Oculi parvi, pigmento nigro carentes.

Pedes maxillares externi ejusdem formae ac in ceteris, ad antennarum externarum appendicis foliformis apicem porrectae.

Pedes primi secundique paris breves, sequentibus multo brevioribus, chelis parvis haud elongatis; pedes tertii et quarti paris graciles elongati, longitudine inter se aequales, ungue magno gracili instructi.

Pedum thoracicorum par quintum aequan praecedentium longitudinem praebet, sed paullum robustius, articulo ultimo brevi conico, unguem minutissiman curvatam margine interiore pectinatam ferente.

Pedum abdominalium par primum uniramosum, quintum antecedentibus paullo brevius.

Color pallide carneo miniaceus; corpus valde pellucidum epidermide tenera.

Longitudo corporis totalis $36^{\mathrm{mm}}$.

Die vorliegende Art unterscheidet sich von Pasiphä̈ sivado durch den vorhandenen Kiel des Rückenschildes, die beträchtliche Läinge des mittlex'n Caudalanhanges, von Pasiphä: tarda und nomegica durch 
die Abwesenheit des Kieles auf dem hintern 'Theile des Rückenschildes sowie anf dem Abdomen und die auf dem Kiel des Riickenpanzers rorhandenen Zähne. während sie von allen drei Arten durch die be-

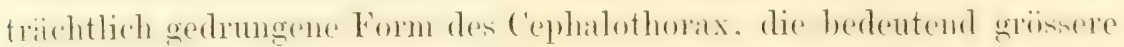
Kürze der Scheeren der beiden vordern Fusspare, sowie vor allem mamentlich durch die sehr abweichende Bildung des vierten 'Thoraxfussparares abweicht, welches bei den genamiten Arten im Verhältniss zum dritten sehr verkinzt erscheint und abweichend geformt ist durch das nicht krallenförmige sechste Glied, welches wie am fünften liusspaar ein rerkiirztes stumpfes Endglied bildet. Dagegen sind bei $P(t-$ siphaë glaciatis die beiden letzten Pusspare von gleicher Länge und mit einer schlanken zugespitzten Kralle versehen.

Der Cephalothorax ist ber dieser Art allerdings im Ganzen wie bei der Gattung iiberhaupt ron verlängerter Form, indem seine Länge last doppelt so gross erscheint als die grösste Höhe, indessen ist dieser Charakter bei den ibrigen Arten doch bedentend stärker ausgeprägt, indem bei dieser der Rückenschild nach Sars' Darstellungen dreimal länger als hoch erscheint. Dasselbe ist wie bei den übrigen Arten ziemlich stark seitlich zusammengedriickt, doch mit etwas gewölbten Seiten, der Dickendurchmesser etwas geringer als die grösste Höhe. Nach rorn erscheint derselbe weit weniger verschmälert als bei den genannten Arten, indem die Höhe am Vorderrand sich zu der grössten Höhe hinten nur wie $2: 3$ verhält, doch könnte das Exemplar möglicherweise ein jugendliches 'Thier sein.

Der Nittelkiel des Rückens beginnt auf der Grenze des hintern und mittlern Drittels und nimmt nach vorn gleichmässig an Höhe zu, namentlich bedeutend an der Wurzel des Rostrum, in welches er sich ummittelbar fortsetzt. Die drei Zähne desselben befinden sich dicht hinter dem Ursprunge des Rostrum und stehen in gleichen Zwischenräumen, sie sind klein, spitzig und mach vorn gerichtet.

Der vordere Seitenrand des Cephalothorax (Taf. I, Fig. 2b) besitzt keinen eigentlichen Stachel, sondern nur zwei etwas vorspringende spitze Ecken, unterhalb der Orbita und an der untern Ecke an der Verbindung des Vorderrandes mit dem Unterrande.

Die Augen sind auffällig klein, sie ragen nach vorn ebenso weit vor als die Spitze des Rostrum, das kugelige Auge selbst erscheint katum dicker als der Augenstiel, während bei den ïbrigen Arten dasselbe beträchtlich erweitert ist. An der innern Seite der Cornea ein kleiner spitziger Vorperung. Die Fïrbung des Luges ist an dem stiicke gelblichweiss, jedenfalls sind also die Augen beim lebenden Thiere nicht wie bei den übrigen Arten schwar\% gefïrbt. 
Die Antennen waren leider nur in ihren basalen Theilen erhalten. welche sich im Ganzen wie bei den iibrigen Theilen verhalten. Der viergliederige Stiel der innern Fühler reicht bis zu zwei Drittel der Länge des blattfömigen Anhanges der äussern, das erste Glied ist gebogen und an der obern Seite für die Aufnahme des Auges ausgehöhlt, an seiner Wurzel ist ein langer lanzettförmiger, zugespitzt endender blattförmiger Anhang an Stelle des sonst hier gewöhnlich befindlichen Stachels vorhanden, welcher das Ende des Gliedes etwas überragt. Das folgende Glied am Endrande aussen mit einer kleinern zahnartig rorspringenden Spitze; das vierte Glied sehr kurz.

Von den beiden Geisselfäden ist der äussere, wie bei den übrigen Arten, an der Wurzel stark verbreitert; bedeutend dicker als der fadenförmige innere; sie sind deutlich gegliedert, aber nur theilweis erhalten.

Der blattförmige Anhang der äussern Antemnen ist wie bei Pasiphäe norwegica schmal, beinahe dreimal so lang als an der Basis breit, gegen das Ende zu verschmälert und schräg abgeschnitten mit etwas gerundeten Ecken, auf der äussern Ecke ein kleiner Dornstachel, der sehr hinfällig ist; der äussere Rand in der ganzen Länge mit einfachen Borsten gewimpert, ebenso der Innenrand, an welchem die Borsten indessen bedeutend länger sind. Der Schaft der äussern reicht nur zur Mitte des blattförmigen Anhanges.

Die äussern Maxillarfüsse sind schlank; nach vorn ausgestreckt reichen sie bis zum Ende des blattförmigen Anhangs der äussern Fühler. Das Endglied derselben (Taf. I, Fig. $2 \mathrm{~g}$ ) ist wie bei den andern Arten schlank cylindrisch, nach dem Ende spitz zulaufend ohne Kralle. Es ist von derselben Länge als das verlängerte zweite Glied, und an der äussem Seite mit zahlreichen starken in Querreihen gestellten feingezïhnclten Borsten hesetzt. I) gegliederte, an dem Basalglied befindliche Geisselfaden is so lang als das zweite Glied.

Die beiden vordern F'usspaare (I'at. 1, lïg. 2d), welche kleine Scheeren tragen, sind verhältnissmässig kurz; sie sind ebenso lang als die äussern Maxillarfuisse. Das zweite und dritte Glied derselben von gleicher Länge, am innern Rande mit langgefiederten dichtstehenden Borsten der ganzen Länge nach gewimpert, die etwa so lang sind als die Breite des Gliedes; Stacheln konnte ich daran nicht elkemnen. Das vierte Glied kurz, halb so lang als das zweite. Die Scheere ist schmal und langgestreckt, nicht breiter als die iibrigen Glieder, sie ist beträchtlich kuirzer als das dritte Glied, die Finger kurz, an der Spitze wie gewöhnlich hakig gebogen und gekreuzt. 
Das dritte (Taf. I, Fig. 2e) und vierte Fusspatr sind, was der Art wie bereits benerkt einen besonders eigenthïmlichen Charakter verleiht, ebenfalls muter sich von gleicher Lïnge und gleichgestaltet, sie sind bedentend länger als die vordersten Paare, welche sie um die Länge ihres sehr verlïngerten Endgliedes überragen. Dats zweite Glied ist am immern Rande mit 10 etwas weitlüufig stehenden gekrümmten Stacheln besetzt, am dritten Gliede finden sich nur 5-6 solcher grösserer Stachehn und dazwischen einige kürzere, während der untere Theil des Gliedes ohne dieselben ist. Das dritte Glied kurz, kaum halb so lang als das zweite und mit vereinzelten Borsten, das vierte dagegen bedentend verlïngert und sehr viel diuner als die vorangehenden, es ist merklich lïnger als das dritte Glied und nur mit sehr kurzen vereinzelten Börstchen besetzt. Die Kralle sehr schlank, stark gekrïmmt und spitz zulaufend, kaum ein Viertel so lang als das Endglied. Der Geisselfaden bis zu zwei Drittel der Länge des dritten Gliedes reichend.

Das fünfte lusspar (Taf. I, Fig. 2f) zeigt eine eigenthümliche Bildung, welche gleichfalls von dem Verhalten bei den ïbrigen Arten albweichend sich verhält. An diesem Fusspare findet sich, wie ich aus Sars' Darstellung entnehme, bei allen drei bekannten Arten keine Kralle, sondern ein eigenthümlich kurzes, erweitertes, dicht beborstetes kleines Lindghed, wekches maweifelhatt als Analogon der Líralle zu betrachten ist. Bei Pasiphaë glacialis verhält sich die Sache etwas anders, indem das hier ebenso vorhandene kleine Glied in der That

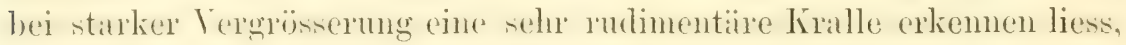
welche allerdings bei den iibrigen Arten der Beobachtung sich hätte entziehen können.

Es ist dieses l'usspaar fast ebenso lang oder doch nur sehr unnerklich kürzer als die beiden rorangehenden und etwas kräftiger, namentlich in den Endgliedern. Ausser dem die Kralle ersetzenden Endgliede tritt hier noch ein accessorisches, von dem Basalgliede abgetrenntes, zwischen dem ersten und zweiten Gliede eingeschobenes kleines Glied hinzu. Das zweite und dritte Glied am Aussenrande mit ziemlich weitlïnfigon kiirzern und lïngern (infitchen Borsten, am Innenrande 4-5 riemlich kurze Stacheln.

Das dritte Glied ein wenig kürzer als das zweite, das vierte ctwas über halb so lang als jenes, das fünfte Glied stark verlängert, schlank cylindrisch, am Ende mit einem sehr kleinen kurzen, conisch ahberundeten, an Stelle dor kiralle vorhandenen Endglierle verbunden. Lis ist das fünfte Glied von einem liande, ausgenommen im obern Drittel, mit zahlreichen Gruppen in Querreihen angeordneter eigen- 
thümlicher Sägehorsten verschen, welche ganz die eigenthiumliche Beschaffenheit besitzen, wie sie unter den Amphiporlen bei Pleustes punoplus von mir beschieben wurden. ${ }^{1}$ Zwischen ihnen stehen vereinzelte längere einfache Haarborsten, welche namentlich am Ende des Gliedes dichte Querreihen bilden.

Das conische sehr kleine Endglied ist iiberall buischelförmig dicht und lang mit Haarborsten besetzt; die Kralle schwierig zu erkennen, sehr klein, stark gekriimmt und am innern Rande mit feinen Kammzïhnen dicht besetzt.

Der am Basalgliede befindliche Geisselfaden reicht nur bis zum Ende des zweiten Gliedes.

Die Abdominalfüisse verhalten sich im Ganzen wie bei den iibrigen Arten. An dem ersten Paare ist der innere Endast durch einen kurzen schuppenförmigen Fortsatz ersetzt, der etwa ein Drittel so lang als der geisselförmige äussere Ast ist. Das fünfte Paar ist etwas kiurzer als die vorangehenden, im übrigen nicht verschieden.

Die Abdominalsegmente sind, wie es den Anschein hat, bei den verwandten Arten lïnger und schlanker als bei Pasiphaë glacialis, was mit zu dem gedrungenen Habitus der letztern wesentlich beiträgt.

Das sechste Abdominalsegment so lang als die beiden vorangehenden, der Hinterrand desselben einfach.

Der Candalanhang (Taf. I, Fig. 2c) ist von betrïchtlicher Lünge, so lang als die beiden Lndsegmente des Abdomen zusammengenommen und sehr schmal. Er erscheint unmittelbar hinter dem breiten Basalabschnitt ziemlich plötzlich stark verjiingt, sodass sein Hinterende kaum ein Drittel so breit als die Basis. Die Seitenränder etwas concav ausgeschweift, hinter der Nitte mit vier Paaren ziemlich kleiner Seitenstacheln versehen, welche von dem Seitemrande selbst etwas entfernt auf einer erhabenen Linie befindlich sind. Der mittlere 'Theil der Dorsalfläche des Caudalanhangs bildet ein etwas erhabenes, in der Mitte leicht rimnenförmig vertieftes Feld, welches in den erwähnten beiden Linien winkelig zu den Seitenrändern abgedacht erscheint. Der Endrand ist an dem Stiicke leider schlecht erhalten, sodass selbst die Wurzeln der Endborsten nicht erhalten waren und über ihre Anzahl nichts ermittelt werden komnte.

Die beiden Seitenlamellen sind etwas kuirzer als der Caudalanhang, die äussere etwas länger als die innere, oblong, nach dem Ende zu etwas verschmälert und daselbst schräg abgeschnitten, auf

${ }^{1}$ Sars beschreibt ähuliche Borsten am vierten Fusspaar und den Maxillarfüssen von Pasiphä̈ norwegica. 
dem Ende des äussern Randes mit einem kleinen Stachel; der ganze iussere Rand mit kurzen Fiederborsten dicht gewimpert. Die innere Lamelle etwas schmäler, lankettörmig, zugespitzt endend, an beiden Rändern mit längern Fiederborsten gewimpert.

Die Gesammtlänge des Lxemplares beträgt $36^{\mathrm{mm}}$.

Länge des mittlern Caudalanhanges . . . $7^{\text {mmn }}$ "der äussern Seitenlamelle . . . $6,5^{\mathrm{mm}}$. ., des Rïckenschildes . . . . . . $13^{\mathrm{mm}}$.

Höle des Rïckenschildes vorn . . . . $4,5^{\mathrm{mm}}$. , des liückenschildes an der höchsten Höhe $6,6^{\mathrm{mm}}$.

Verbreitung. Von Dr. Pansch am 12. Juli 1869 an der Oberfläche des Neeres gefangen, also in der Nähe des $74 .^{\circ}$ nördl. Br. in beträchtlicher Entfernung von der Grenze des Packeises.

\section{Mysidae.}

10. 1) Mysis oculata (Fabricius).

Cancer oculatus Fabricius, Fauna grœenlandica, Nr. 222.

Mysis Fabricii Leach, Limn. Transact., XI, 350.

IIysis oculata Köröyer, Naturh. Tidskr., II, 255.

Kröyer, Bidrag til Kundskab om Krebsdyrfamilien Mysidæ.

Schiödte, Naturhist. Tidskr., 1861, p. 13.

Diese im hohen Norden wie es scheint allgemein häufig verbreitete Art ist die einzige der Gattung, welche in den Sammlungen von Ostgrönland ziemlich reichlich vertreten war. Sie ist von Kröyer nenerdings so umstiindlich beschrieben, dass dessen Angaben nichts himzuzufiigen ist.

Die grössten grönländischen Exemplare bis zu $22^{\mathrm{mm}}$ Länge.

Kap Philipp Brooke 3 Faden, August 1869; Sabine-Insel 4 und 10 Faden, zahlreiche Exemplare.

Sie scheint auf den höhern Norden beschränkt zu sein, da sie nach Kröyer's Angahen wenigstens an den norwegischen Küsten noch nicht angetroffen wurde.

Gen. Thysan opoda, Milne Edwards.

Nur zwei dieser Gattung zugehörige Stiicke waren in Dr. Pansch's Sammlung von Ostgrönland enthalten. Soweit die Theile der sehr zarten Benchatfenheit der Thierehen halher verolichen werden konnten, stimmen sie mit den von Sars angegebenen Merkmalen der folgenden beiden Arten von der norwegischen Küste überein. 
11. 1) Thysanopoda norwegica Sars.

Sars, Forhandl. Skand. Naturf. i Christiania, 1856, p. 169-174.

Ders., Om Slægten Thysanopoda. Christiania Vidensk. Selsk. Forhandlingar for 1863, p. 2 .

Ein Exemplar von $22^{\mathrm{mm}}$ Lünge, bei Kap Wynn aus 5 Faden Tiefe.

Stimmt in der Abwesenheit des Rostrum, der Bildung der Antennen und des Caudalanhanges ganz mit Sars' Angaben über diese Art iiberein, sodass die Identitït nicht zweifelhaft erscheint.

12. 2) Thysanopode Reaschii Sars.

Sars, Om Slægten Thysanopoda, 1. c., p. 14.

Ein Exemplar von $19^{\mathrm{mm}}$ Länge mitten im Packeise, der Angabe nach aus 175 Faden Tiefe am 1. August 1869 von Dr. Pansch gesammelt.

Rostrum, die Stellung des Vorderrandstachels des Cephalothorax etwas über der Mitte, sowie die Form des Caudalanhanges mit Sars' Angaben iibereinstimmend.

\section{Brachyura.}

Die an und für sich im Norden spärlich erscheinenden Kurzschwänzer sind in den Sammlungen von Ostgrönland gar nicht vertreten, was auffällig erscheinen kann, da doch Carcimus menas wenigstens in Südgrönland noch ziemlich häufig vorzukommen scheint. Nur die nachstehende Art war während der Reise in der Nordsee gesammelt.

13. 1) Corystes Cassivelaumus Penn.

Von dieser hinreichend bekannten Art wurden fünf ziemlich grosse Exemplare, sämmtlich Weibchen, in dem Magen von Gadus Morrma auf der Fahrt durch die Nordsee, auf der Nordseebank zwischen England und Norwegen, von Dr. Pansch gefunden. Das grösste mit ausgestrecktem Abdomen $40^{\mathrm{mm}}$ lang.

\section{S 0 P 0 D A. ${ }^{1}$}

Diese Abtheilung ist auffallenderweise in den Sammlungen von Ostgrönland nur durch einige Bopyriden vertreten.

${ }^{1}$ Ansser Munnopsis typica Sars erhielt ich durch Herrn von Heuglin ron Spitzbergen, durch ihn gesammelt, aus der Familie Idotheidre folgende neue Art: Idothea rugulosa Buchholz.

Diagnosis. Corpus modice elongatum marginibus lateralibus subparallelis, pos- 


\section{Bopyridae.}

14. 1) Gyge hippolytes (Kröyer).

Bopyrus Hippolytes Kröyer, Grönlands Amphipoder, 1. 78, tab. IV, fig. 22.

Ders., Monographisk Fremstilling af Slegten Hippolytes Nordiske Arter, p. 54.

Gyge hippolytes Spence Bate and Westwood, Hist. of British Sessile Eyed Crustacea, II, 230.

Diese von Kröyer zuerst an einem grönländischen Exemplar von Hippolyte polaris entdeckte Art lag auch in Dr. Pansch's Sammlung reichlich vor.

Simmtliche Exemplare waren ebenfalls an Hippolyte polaris befindlich, und zwar zeigten sich 14 Stiicke dieser Art, welche am Rïckenpanzer die durch die Anwesenheit der Parasiten bedingte eigenthïmliche Auftreibung darboten. Es entspricht somit die Häufigkeit annähernd einem Vorkommen desselben bei 10 Proc. des rorliegenden ostgrönländischen Materials der Itippolyte polvers, während dieselbe niemals bei einer der iibrigen Arten bemerkt wurde.

Der Sitz des Thieres ist ausnahmslos unterhalb des Ruickenpanzers immer an derselben Stelle, und zwar an dem hintern Rande desselben, an der Stelle wo der Hinterrand mit dem Unterrande sich vereinigt. Die Auftreibung selbst hat ganz die Form und Grösse des Körpers der Gyge, letztere ist ohne Ausnahme darin so gelegen, dass die schildförmig ahgeflachte Rïrkenfläche dem Kïrper der Hippolyte anliegt, während die stark gewölbte Bauchseite mit den Fïssen und Mundtheilen der Haut des Riickenpanzers sich dicht anschmiegt. Da eine Veränderung der Lage des Thieres in seinem Aufenthaltsort nicht wohl möglich ist, kann man somit auch nicht amnehmen, dass dieser Parasit seine Nahrung aus den Kiemen der Hippolyte ziehe, wiewol er stets einem 'Theile derselben unmittelbar mit der Riickenfläche aufliegt und diese Stelle etwas eingedrüickt erscheint, sondern

tice paullo attennatum; segmentis dorso valde convexis, praesertim postice linea mediana dorsi fere carinae rotundatae instar prominente. Corporis superficies ubique granulosa, segmentis dorsi quatuor anterioribus lina impressa transversa semilumari, segmentis omnibus linea prominente transversa margini posteriori parallela.

Antennae superiores ad medium articulum tertium basalem antennarum inferiorum porrectae, inferioris corporis dimidiam longitudinem aequantes.

Abdomen triangulare, dorso valde convexo rotundato-anguloso, apice incisura sat profunda rotundata in medio emarginatum. Abdominis segmenta excepto primo in latere incisuram parvam dentiformem formante, omnino coalita.

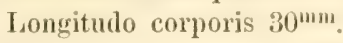

Hab.: Spitzhergen, Storfjord. 
es ist wol wahrscheinlich, dass die im Riickenpanzer circulirende Plutflüssigkeit von demselben anfgesogen wird.

Das kleinste Stück der Hippolyte, welche den Schmarotzer erkemnen liess, war $27^{\mathrm{mm}}$ lang, und die daran befindliche Auftreibung betrug $4^{\mathrm{mm}}$. Doch dïrfte die Anwesenheit der jüngsten Radien schwierig zu constatiren sein. Die grössten Auftreibungen an erwachsenen Rücken der Hippolyte waren $10^{\mathrm{mm}}$ lang, ein hieraus genommenes Thier zeigte sich etwas grösser, fast $11^{\mathrm{mm}}$ lang, sodass dasselbe ein wenig zusammengekrimmt an seinem Aufenthaltsort gelegen erscheint.

Nur etwa bei der Hälfte der befallenen Stiicke waren die Parasiten noch rorhanden, und nur bei dem grössern $11^{\mathrm{mm}}$ langen, frisch herausgenommenen weiblichen Thier fand sich ein 2mm langes Männchen unterhalb eines der hintern Kiemenanhänge vor; während bei einigen kleinen Weibchen von $3-7^{\mathrm{mm}}$ keine Männchen sich fanden.

Die Formen beider Geschlechter sind von den citirten Beobachtern himreichend beschrieben worden.

Nur bei einer einzigen Hippolyte und zwar einer ziemlich kleinen, fanden sich gleichzeitig zwei Gyge vor, welche auf der rechten und linken Seite an der betreffenden Stelle ihren Sitz hatten, sonst nur stets eine einzelne, welche bald auf der rechten, bald auf der linken Seite des Körpers befinlich erschien.

\section{1) Phryxus abdominalis Kiröyer.}

Bopyrus abdominalis Kröyer, Naturhistorisk 'lidskrift, III, 205, tab. I.

Ders., Monographisk Fremstilling af Slægten Hippolytes Nordiske Arter, p. 55. Phryxus Hippolytes Rathke, Nova Acta Acal. Nat. Cur., XX, 40.

Diese von den angefuihrten Forschern sehr genau beschriebene Art scheint vorziiglich häutig bei Hippolyte Gaimardi rorzukommen, indessen gibt bereits hröyer an, sie einigemale bei Ilippolyte tmingida angetroffen zu haben.

Nur ein einziges $g^{m m}$ langes Exemplar dieser Art war bei einer Ilippolyte turgida, in der gewöhnlichen Weise unterhalb des Abdomens. befestigt, in Dr. Pansch's Sammlungen enthalten. Dasselbe trug ein Männchen bei sich.

Leptophryxus Buchholz, Gen. nov.

Genus Bopyridarum Phryxo valde affine.

Es wird das Vorkommen ron Bopyriden bei Mysis allerdings in dem Werke von Spence Bate und Westwood kurz Erwähnung gethan, ohne dass indessen angegeben wird, von welchem Beobachter und bei welcher Mysisart dasselbe heschrieben worden. Da es mir leider nicht 
möglich war wegen des dringend nöthigen baldigen Abrchlusses der Arbeit etwas Näheres hieruiber zu ermitteln, und eine genauere Be-

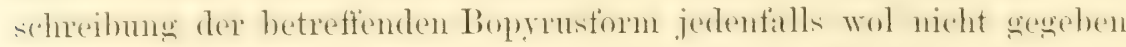
worken ist, so erscheint es mir gerechtfertigt, das vorliegende grönlïndische Exemplar als Typus einer eigenen Gattung in dieser Familie anzusehen.

16. 1) Leptopheryxus Mysidtis Buchholz, nov. sp. 'Taf. II, Fig. 2.

Diagnosis. Femina adulta segmentis corporis in medio dorso tantum conspicuis corporis partibus lateralibus valde inflatis segmentis coalitis. Caput a thorace haud discretum, Antemnis rudimentariis, externis triarticulatis perbrevibus.

Quinque pertum thoracicorum paria, capiti proxima in thoracis parte anteriore tertia sita. Segmenta thoracis duo ultima laminis ovigeris magnis obtecta pedibus carentes. Abdomen parrum conicum superne segmentorum lineis 5 ad 6 conspicuis, quorum primum laminis quadrangularibus, illis segmentorum thoracis ultimorum minoribus, instructum.

Mas a maribus Phryxorum vix diversus, capite oblongo sat elongato oculis haud conspicuis, antennis superioribus perbrevibus, inferioribus longioribus flagello septem-articulato. Pedem paria thoracis septem subcheliformia, ejusdem fere longitudinis. Abdomen conicum tertiam fere corporis partem aequans, segmentis vel appendicibus mullis.

Habit. in Myside oculati.

Leider war von dieser interessanten Bopyride nur ein einziges Stiick vorhanden, welches von Dr. Pansch auf Mysis oculate an der Sabine-Insel gesammelt worden war. Dasselbe war seinem Wohnthier entnommen, ohne dass iiber die Art der Befestigung an demselben etwas nitheres angegeben wird. Es ist ein erwachsenes Weibchen, welches sowol reife Brut als auch ein Männchen bei sich trug.

Der Körper des Weibchen ('laf. II, Fig. $2 \mathrm{a}$ und 2b) ist $4^{\mathrm{mm}}$ lang, länglichrund, fast herzförmig, vorn breit und am rordern Rande riemlich tief ausgebuchtet, die Seitenränder verlaufen schwach convex nach hinten his dicht vor das von dem sehr kleinen Abdomen gebildete, verschmälerte und etwas zugespitzt vorragende hintere Körperende.

Die Unterseite ist sehr stark concav und zeigt ein länglichrundes, nur mässig gewölbtes Mittelfeld, welches rom quer abgeschnitten erscheint und daselbst den Kopf, sowie fünf dicht an denselben herangerïckte sehr kleme Fusspare erkennen lässt, welche indessen nur 
den vordersten Abschnitt desselben eimnehmen, der grösste Theil wird von den sehr grossen blattförmigen Anhängen der beiden letzten Thoraxsegmente, sowie von demjenigen des ersten Abdominalsonmentes bedeckt. Dieses Mittelfeld ist durch eine Furche von den sehr gewölbten, den Seitentheilen des Thorax entsprechenden Körperseiten getrennt, welche ziemlich steil abschiissig nach aussen abfallen.

Der Rücken ist nur in den Seitenhälften etwas gewölbt, während die Nitte desselben ron einer ziemlich schmalen, eine Art Längsrime bildenden Vertiefung eingenommen wird, in welcher sich deutlich die Grenzen der Thoraxsegmente erkennen lassen, während die gewölbten Seitentheile, welche durch die Anhäufung der sehr zahlreichen Eier in dieser Weise stark ausgedehnt erscheinen, keine Spur einer Segmentirung mehr erkennen lassen. Ich war anfangs zweifelhaft, ob die Querfurchen, welche die Nitte des Riückens erkennen lïsst, wirklich auf Segmentgrenzen zu beziehen seien, da indessen ihre Zahl mit der Anzahl der Körpersegmente in Einklang ist, so lässt sich nicht wohl daran zweifeln. Die vier vordern Segmente sind sehr kurz, viel breiter als lang; vor denselben liisst sich vom Rïcken her nur' ein kleiner Theil des Kopfsegmentes erkennen, dessen grösster Theil auf der Unterseite des Kopfes gelegen ist. Nach den Seiten werden die vordersten Segmente und der Kopf von den zipfelartig hervorragenden Thoraxseiten ïberragt, auf welchen einige Querfalten sichtbar sind, die mir indessen kaum als Segmentgrenzen eine Deutung zuliessen.

Das fünfte Segment ist fast quadratisch, die beiden letzten dagegen stark verlängert; hinter ihnen befindet sich noch das vorderste Abdominalsegment von den Thoraxseiten eingefasst, während der übrige 'Theil des Abdomens als ein conischer kurzer Fortsatz, von welchem man vier oder fünf Segmente unterscheiden kann, frei nach linten hervorragt.

Der Kopf des Thieres bildet eine breite, sehr kurze, nach abwärts geneigte, etwas gewölbte Platte, deren vorderer auf der' Unterseite befindlicher Stirnrand in der Medianlinie in Form eines sehr kleinen, abgerundet dreieckigen Vorsprunges hervorragt, während die Seitenhälften schwach Sförmig geschwungen verlaufen. Von Augen ist keine Spur zu erkennen, anch wollte es mir nicht gelingen die Form der Anhänge des Kopfes deutlich zu erkennen. Jederseits neben dem mittlern Stirnvorsprung lief eine kleine dreieckige Platte (Taf.' II, Fig. 2e), welche ihrer Lage zufolge keine andere Bedeutung besitzen kamn, als dass man sie für das. Basalglied der innern Antennen anzusehen hat, welches auch beim Männchen ähnlich geformt erscheint. 
Nach aussen daron glaubte ich ein cylindrisches Basalglied der äussern Fühler zu gewahren, anch konnte ich ron der Geissel bei sehr guinstiger Belenchtung erkennen, dass sie klein und fadenförmig schlank ist, so lang wie das Basalglied. Sie schien mir dreigliedrig zu sein. 'Zwischen die imnern Fïhler schiebt sich ein kleiner' conischer, nach rorn gegen den mittlem Stirnfortsatz gerichteter 'Theil ein, der wol als der Saugriissel mit Sicherheit anzunehmen ist, dessen Beschaffenheit ich indessen nicht näher untersuchen konnte.

Die fünf sehr kleinen 'Thoraxfusspare sind sehr dicht aneinander an den Seiten des Körpers inserirt und unmittelbar hinter dem Kopfe befindlich. Sie hahen die gewöhnliche bei den Bopyriden rorkommende Form und sind sämmtlich dreigliedrige, mit einem scheerenartigen Endgliede versehene Klammerfüsse. Thre Form schien ganz mit denjengen des Männchen übereinzustimmen. Die Füsse sind unter sich ziemlich gleich gross, oder die beiden hintern Paare vielleicht nur um ein ganz Geringes länger als die vordern. Sie sind mit linglich elliptischen, ziemlich schmilen und ahgerundet zngespitzt endenden Brutbliittern versehen, die sich zum grossen 'Theil gegenseitig rerdecken, aber, soviel ich sehen komnte, unter sich riemlich sleich gross und gleich gestaltet erschienen.

Der eigenthiimliche Mangel der beiden letzten Thoraxfusspare mnterscheidet die Art ron den sonst nahestehenden Phryxus-Arten, ich konnte keine Spur derselben an den beiden hintern Thoraxsegmenten crkennen; es ist auch nicht denkbar, dass sie von den grossen brutbättern dieser Segmente hätten rerdeckt sein kömnen, da dieselben nach imnen von den Fïssen inserirt sind. Letztere sind ron rechteckiger Form und sehr gross, sie bedecken die Ventralseite der betreffenden Segmente rollkommen, indem ihre Ränder sich dachziegelförmig decken.

Von den Abdominalsegmenten besitzt nur das erste ein Parr grosse blattförmige Anhänge, welche von ähnlicher Form als die vorangehenden, aber beträchtlich weniger gross erscheinen. Zwischen denselben fand sich wie bereits bemerkt das Männchen, und zwar mit dem Vorderende eingeschlossen, während das Schwanzende frei uiber das Abdomen des Weibchens herrorragte. An den beiden folgenden Abdominalsegmenten findet sich jederseits nur ein kleiner Höcker anstatt des blattförmigen Anhanges, während die beiden letaten ohne dieselben erscheinen. Das Endsegment ist ziemlich tief in der Nitte ausgebuchtet, die beiden seitlichen Zipfel desselben in eine kleine conische, dümn zulaufende Spitze verlängert.

Die Färbung ist durchaus gleichmässig weisslich-gelb. 
Das Männchen (Taf. II, Fig. 2e) ist ganz in seiner Form mit demjenigen der verwandten Phryxus-Arten iibereinstimmend. Wie bei jenen ist der Körper schmal langgestreckt und zeigt sieben völlig gut gesonderte, mit ebensoviel gleichartigen Klammerfiissen versehene Thoraxsegmente, sowie ein einfaches ungegliedertes Abdomen.

Dasselbe ist $1,8^{\mathrm{mm}}$ lang und besitat eine etwas zusammengekrümmte Haltung, welche sich auch durch gelinden Druck nicht beseitigen lässt.

Der. Kopf ('Taf. II, Fig. 2f) ist ganz charakteristisch für die Art und bei weitem länger, als nach den Darstellungen von Bate bei den Phryxusmänmchen sonst der Fall ist. Derselbe erscheint ziemlich so lang wie die drei ersten Thoraxsegmente zusammengenommen, und ist etwas länger als breit; von der Fläche gesehen ist seine Form fast rechteckig mit leicht geschwungenen Seitenrïndern und etwas convexem in der Mitte in eine kleine spitze Ecke vortretendem Endrande. Von der Seite gesehen erscheint er von langgestreckt conischer, zugespitzter Form und erkennt man unterhalb des spitzen Kopfendes den conischen, etwas über das Kopfende nach vorn hervortretenden Saugrïssel.

Von den Augen komnte ich keine Spur erkennen, möglich dass sie fehlen, wiewol sonst die Mảnnchen der Bopyriden damit versehen zu sein pflegen.

Die Mundtheile bilden ('Taf. II, Fig. 2 fR) einen riemlich umfangreichen, cylindrisch-konischen Riüssel, der von der Unterseite betrachtet mit seiner Spitze ein wenig uiber den rordern Kopfrand hervorragt, während seine Basis in der Mitte der Unterseite des Kopfes befindlich ist. Aus welchen Theilen diese Rüsselscheide gebildet wird, vermochte ich nicht deutlich zu erkennen, von Tastern oder anderweitigen Mundtheilen rermochte ich wenigstens keine Andeutung zu erkennen, während doch bei andern Bopyriden blattförmige Maxillarfüisse nach den Angaben der genamnten Forscher vorhanden sein sollen. Es is aber ohne Zerlegung kaum möglich, hierüber sichern Aufschluss zu erhalten.

Innerhalb der Rï̈sselscheide sind ein Paar stiletförmig gestalteter Mandibeln dentlich sichtbar, deren Spitze etwas über das Rüsselende hervorragt.

Zu beiden Seiten des Riüssels sind die beiden Antennenpare inserirt, welche weit entfernt rom vordern Kopfrande, neben der Wurzel desselben, in der Mitte der Unterseite des Kopfes, hintereinander inserirt sind.

Die vordern Antennen (Taf. II, Fig. $2 \mathrm{f}^{1}$ ) sind äusserst rudi- 
mentär, sie bestehen nur aus einem Basalgliede ron länglich dreieckiger Form, welches rom und nach aussen in je eine kleine mit kurzen Börstchen beset»te Ecke ausgezogen ist. Unterhalb des äussern dieser Vorsprünge ist ein äusserst kleines kurzes zweites Glied befindlich, welches gleichfalls am Ende mit einigen sehr kurzen Borsten besetzit ist.

Die untern Fiihler ('Taf. II, Fig. $2 \mathrm{f} \mathrm{A}^{2}$ ) sind ehenfalls auf einer dreieckigen Platte inserirt, welche unmittelbar neben der Wurzel des liuissels befindlich ist. Sie sind siebengliedrig, fadenförmig, etwas länger als der Kopf, und reichen nach hinten ausgestreckt zum Ende des zweiten Thoraxsegmentes; die Glieder sind schlank und gegen das Ende hin stark verdiunnt, das Endglied riemlich lang und am Ende mit einigen kurzen Börstehen versehen.

Die sieben Thoraxsegmente sind im Ganzen ziemlich gleichartig gebildet, die hintern nur mbedeutend breiter und etwas länger als die vordern. Sie sind sehr flach im liiicken gewölbt, sodass der Körper im Ganzen etwas niedergedrüickt erscheint, ihre Seitenränder sind convex. Die Fusspare (Taf. II, Fig. $2 \mathrm{~g}$ ) sämmtlich gleich gestaltet, die hintern kaum merklich an Länge etwas zunchmend, dreigliederig, die beiden ersten Glieder cylindrisch, ziemlich gleich lang; das Endglied articulirt mit dem zweiten durch ein kurzes Zwischenglied; es ist von ovaler Form, am Endrande mit einem schräigen Ausschnitt für die starke etwas gekrümmte Kralle, welche halb so lang als das Glied. An der hintern Ecke des Krallenausschnittes zwei nach vorn gerichtete kurze Stacheldornen. Im iibrigen die Fïsse kahl.

Das Abdomen ist von eylindrisch-conischer Form, fast ein Drittel so lang als der Körper und völlig ungegliedert und ohne Anhänge. das Hinterleibsende erscheint conisch zugespitzt, ohne Spur ron Fortsätzen.

Die Larve habe ich ('laf. II, Fig. 2d) dargestellt, wie sie unmittelbar nach dem Ausschlüpten ans dem Ei erscheint. Die Eier sellost, welche rollkommen ausgebildete Larven enthalten, sind kugelig und haben einen Durchmesser von $0,27-0,3^{\mathrm{mm}}$. Die soeben ausgeschliipfte Larve misst $0,36-0,4^{\mathrm{mm}}$ ohne die Hinterleibsanhänge. Sie gleicht durchaus den sonst beschriebenen Bopyridenlarven.

Der Körper ist lïnglichrund, der Längsdurchmesser anderthalbmal so gross als die lireite, das vordere Körperende breit, am rordern Endrande leicht ausgebuchtet.

Der Kopf der Larve ist rerhältnissmässig sehr breit und kur\% mond sehr undeutlich ron dem Körper gesondert, doch ist seine Lünge

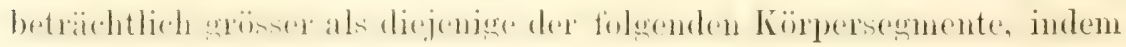


sie derjenigen der drei vordersten Thoraxsegmente gleichkommt. Auf den Kopf folgen sechs Thoraxsegmente mit ehenso viel ziemlich plump geformten Krallenfüssen, deren Grenzen allerdings äusserst schwierig zu erkennen sind, während sie von den Seitenrändern des Körpers durch sehr deutliche Einschnitte abgetrennt sind, und ihre Seitenränder nach hinten zu in zahnartig vorspringende Ecken verlingert erscheinen.

Auf den T'horax folgt alsdam als letzter Körperabschnitt das Abdomen, welches gleichfalls aus Segmenten gebildet wird, die mit ebenso vielen zweï̈stigen Fussparren versehen sind. Es ist gleichfalls mit dem übrigen Körper zu einer gemeinsamen Masse verschmolzen und nimmt an Länge diss hintere Drittel desselben ein. Vor'n mit dem Thorax dieselbe Breite darbietend, verjüngt es sich

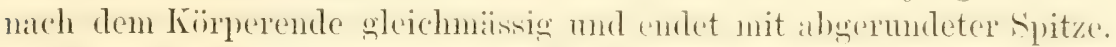
Eigenthümlich erscheinen an den fünf vordern Abdominalsegmenten, an den Seitenrändern derselben inserirte, eigenthümlich blattartige, lamellöse Anhünge, von sehr durchsichtiger zarter Beschaffenheit, welche die Basalglieder der betreffenden Fussparare nach Art von Epimeren bedecken. Sie sind von lïnglich rechteckiger Form und decken einander theilweise dachziegelförmig, dex äussere liand bildet nach hinten eine spitze zahmartige Ecke, während darüber, am Ende des Vorderrandes, eine zweite kleinere zahmartige Ecke befindlich ist. Sie sind nur dann deutlicher zu sehen, wenn die Fusspanre des Abdomen nach dem Körper zuriickgeschlagen sind, ich habe deshalb auf der linken Seite die letztern in dieser Haltung dargestellt.

Ich finde nicht, dass einer der angeführten Beobachter diese Bildung bei einer andern Bopyridenlarve bemerkt hätte, indessen dïrfte sich dieselbe, da sie ziemlich schwierig deutlich zu erkennen ist, leicht der Beobachtung entzogen haben können.

Am Kopfe vermochte ich von den Augen und Mundtheilen nichts mit Sicherheit zu erkemnen, woran indessen die durch die Conservirung etwas schwierige Untersuchung des äusserst zarten Thierchens Schuld tragen mochte.

Die imnern Antemen sind ganz rudimentär, sie bestehen nur aus einem dicht unterhalb des vordern Stirnrandes befindlichen kleinen, rundlichen Höcker, welcher eine längere stärkere gekrümmte Borste, sowie zwei kleinere Nebenborsten trägt.

Die äussern Antennen sind ziemlich gross und zweigliederig. Das erste Glied ist cylindrisch, ziemlich dick, und nach aussen und etwas mehr nach hinten als der Höcker der imnern Antemen inserirt, es ist etwas kürzer als das Kopfsegment. Das zweite Glied ist beden- 


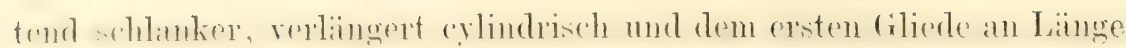
gleich. Dasselbe trägt am Ende zwei ziemlich starke, etwas gekrimmte Endborsten, von denen die längern imnern so lang als die beiden Antennenglieder zusammengenommen.

Die sechs Fussparare des Thorax sind cylindrische, plump geformte Krallenfuisse, an welchen man kaum deutlich drei Glieder erkennen kann. Das Endglied ist noch einfach eylindrisch und num an den beiden vordern Paaren ein wenig verdickt. Im iibrigen sind sie alle von ziemlich gleicher Länge und form.

Die an dem Abdomen befindlichon zweiästigen Schwimmfïsse haben mit Ausnahme des abweichend gestalteten am sechsten Segment befindlichen Paares der Endanhänge, sämmtlich dieselbe Bildung. Sie bestehen aus einem cylindrischen diinnen Basalglied, welches, wie bereits erwähnt, unterhalb des blattförmigen Seitenanhanges am Seitenrande inserint ist und etwas kürzer als letzterer erscheint. Dasselbe trïgt zwei gleichfalls cylindrische Endäste von gleicher Lünge, die ein wenig kürzer sind als das Basalglied und am Ende mit je zwei schr lamgen einfachen Borsten besetzt erscheinen.

Das hinterste Fusspaar ist beträchtlich stïrker und von dem rorangehenden abweichend gestaltet. Es besteht aus einem dicken cylindrischen Basalglied, welches zwei sehr ungleiche Aeste trägt: der äussere lïngere ist ziemlich so lang als das erste Glied, aber sehr vicl schlanker, mit zwei starken langen Endborsten, ron denen die iussere nur halb so lang als die imnere. Der innere Ast ist dagegen äusserst kurz und gleichfalls mit zwei starken langen Endborsten rersehen.

\section{A M P H I P O D A.}

Die nordischen und insbesondere die arktischen Crustaceen dieser Ordnung sind seit Kröyer's bahmbrechenden Arbeiten in neverer Zeit

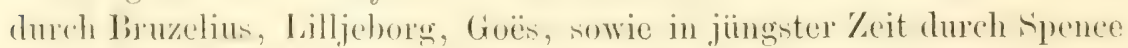
Bate, Westwood und A. Boeek so oftmals zum Gegenstande grösserer liearheitungen gemacht worden, dats ich mich auf das Yothwendigsto beschräinken darf.

Ebenso ausführlich ist der Körperbau der Amphipoden namentlich durch Bruzelius, sowie in den Werken von Spence Bate und Westwood behandelt worden. Es wird daher genïgen, hier nur einzelne Punkte hervorzuheben. 
Die specitischen Anhänge, welche an den mämnlichen Fühlern bei der Mehrzahl der Amphipoden vorhanden sind, scheinen mir eine besondere Beachtung zu verdienen.

Zunächst ist herrorzuheben, dass es allerdings der überwiegend grossen Mehrzahl nach die Mämnchen sind, welche mit diesen Bildungen versehen sind. Indessen fand ich doch bei manchen Arten, welche mir reichlicher vorlagen, dass neben gewöhnlichen Weibchen auch andere, gleichfalls mit völlig ausgebildeten Brutblättern versehene Individuen vorkommen, welche mit völlig wie bei den mïmlichen Thieren gebildeten Fühleranhängen versehen sind. Nit gefuilltem Brutraum habe ich freilich keines derselben getroffen, doch ist an der weiblichen Natur dieser Individuen wol nicht zu zweifeh. Ich wurde zuerst bei Amathilla Sabini darauf aufmerksam, wo mir ein Brutlamellen besitzendes Individum begegnete, welches mämnliche Fühler darbot, da indessen die ïbrigen, mit mämnlichen Antennen versehenen Stiicke alle olne die Brutlamellen waren, so war ich geneigt, dieses für ein mit accessorischen Organen versehenes Mimmchen anzusehen, bis später bei Amphithonotus aculcatus und Gammarus locustu das unzweifelhafte Vorhandensein von specifischen Fühleranhängen bei einer grossen Anzahl weiblicher 'Thiere mich ron dem Gegentheil uiberzeugte. Es ist, wie ich finde, das Vorkommen dieser Bildungen bei weiblichen 'Thieren bei Amphithonotus bereits ron Kröyer als ein eigenthümlicher Ausnahmefall angegeben worden, was indessen wie es scheint unbeachtet geblieben ist.

Sind num diese eigenthümlichen Bildungen atuch nicht mehr wie früher als ein sicheres Kenuzeichen der mämnlichen Thiere anzusehen, so bleibt es doch nicht minder yon Interesse, ihre Form und Anordnung bei den einzelnen Arten näher zu untersuchen, was bisher, soviel mir bekannt, noch so gut wie gar nicht geschehen ist. Dieses erscheint um so mehr wünschenswerth, als dieselben trotz des im Ganzen durchaus ïbereinstimmenden Plans, nach welchem sie gestaltet sind, eine ausserordentliche Mannichfaltigkeit der Form und eine sehr constante Bildung bei den einzelnen Arten darbieten:

Was num den allgemeinen Bildungsplan betrifft, der sich bei allen diesen so verschiedenartig erscheinenden Anhängen exkennen lässt, so bestehen dieselhen durchgïngig aus einem napflörmign ausgehöhiten. mehr oder weniger deutlich stets in drei Abschnitte getheilten Endtheile, welcher auf einem kürzern oder längern Stiele, der sich an das erste Glied des Endtheiles befestigt, der Antenne aufsitzt. Was die Abschnitte des Endtheiles betrifft, so wïsste ich die eigenthiimliche Art und Weise ihrer Verbindung nicht besser auszudrïicken, als 
wenn man sich drei flach schiisselförmige Gebilde in der Weise excentrisch übereinander gesetzt denkt, dass nur ein grösserer oder geringerer Theil des folgenden dem darunter befindlichen aufliegt.

Das Vorhandensein dieser drei Hauptabtheilungen fand ich durchgängig ohne Ansnahme, wiewol es oftmals einiger Aufmerksankeit bedurfte, um sie deutlich unterscheiden zu können. Ueberdies erscheint mitunter der zweite, durchgängig aber der dritte dieser $A b-$ schnitte durch eigenthïmliche, in der Membran auftretende Falten in eine grössere oder geringere Zahl concentrischer Abschnitte eingetheilt; in der Regel sind auch an der Oberseite bei allen Abschnitten radiäre feinere oder gröbere Streifungen vorhanden, welche gleichfalls als der Ausdruck äusserst feiner Faltenbildungen wie ich glaube anzusehen sein dürften.

Nur in einem einzigen Falle, bei Amphithonotus aculcatus, befinden sich eigenthümliche Chitinanhänge, welche einen zierlichen Fächer bilden, an dem Endtheile, welche an der Verbindungsstelle des ersten mit dem zweiten Gliede inserirt erscheinen.

Es fragt sich nun, welcher Function die Fühleranhänge zu dienen bestimmt sein dürften. Der zunächst liegende Gedanke, dass sie eine besondere Sinnesempfindung vermitteln, hat wie ich glaube, die Ansichten der meisten Beobachter für sich gehabt. Auch ich theilte diese Anschaung, bis sie mir späterhin wegen der ausserordentlichen Variation in der Form dieser Bildungen, sowie ihr häufiges Fehlen bei ganzen Familien, mehr und mehr unwahrscheinlich wurde. Handelte es sich um eine wesentliche Sinnesfunction, so würde ein solches Verhalten zum mindesten schwierig zu erklären sein, und in der That finden wir die unzweifelhaft einer solchen Function dienenden Riechborsten ganz ausnahmslos vor und in der Form äusserst wenig variabel. Ich habe rüicksichtlich dieser zu bemerken, dass sie ausschliesslich auf' der Geissel der obern Fühler, hier indessen ausnahmslos vorhanden sind. Ich habe sie nie weder auf den Basalgliedern der obern Fïhler oder auf der Nebengeissel, noch auf den untern Antenien angetroffen. In der liegel stehen sic in kleinen Gruppen oder einzeln am Ende der einzelnen Geisselglieder, dagegen ist für die Lysiannassiden die büschelförmige Gruppirung auf dem ersten Geisselgliede besonders charakteristisch.

Dar nun die oben ausgesprochene Ansicht über die specifischen Fïhleranhänge sehr unwahrsehemich geworden, so fragt es sich weiter, welche andere Function sie etwa erfuillen diurften. Ich muss bemerken, dass mir, seitdem ich die eigenthümlichen, oft mit sehr sonderhar geformten Iautsüumen versehenen IIaftborsten an den Fïhlern 
und Füssen mancher Copepoden ans eigener. Inschaunng kennen lernte. die Vermuthung, dass es sich um eigenthümliche Haftapparate handelt, als die wahrscheinlichste erscheint. Freilich darf die mitunter napförmige Form der betreffenden Bildungen nicht dazu verleiten sie als Saugnäpfe zu betrachten, was sowol der Beschaffenheit des Randes, als auch der Abwesenheit von Muskelfasern imerhalb derselben zufolge durchaus ummöglich ist.

Dass hingegen die Antennen der Amphipoden in mamnichfacher Weise als Greifwerkzenge verwandt werden ist bekannt, und diirften somit diese eigenthïmlichen Cuticularbildungen an denselben eine solche Function unterstiitzen.

Riucksichtlich der Augen ist zu bemerken, dass die Form und Stellung derselben sehr constante und für die einzelnen Formen oft sehr charakteristische Merkmale darbietet. Freilich ist diese Form bei den jüngern 'Thieren oft abweichend von derjenigen bei den erwachsenen. Die bei einigen Gattungen (Amphithonotus, Pleustes u. a.) in hohem Grade hervortretende Prominenz der Augen, welche einen Uebergang zu der Bildung von gestielten Augen anzudeuten scheint, ist indessen keine isolirt auftretende Erscheinung, dir fast bei allen Amphipoden bei genauerer Beobachtung die Cornea mehr oder minder gewölbt hervortritt.

Die Mundtheile sind seit den vorzüglichen Arbeiten von Kröyer und Bruzelius in neuester Zeit von A. Boeck wieder mit besondlerer Sorgfalt bei einer sehr grossen Anzahl von Formen untersucht worden.

Die Gesammtform des Körpers erscheint mir ron besonderer Wichtigkeit, da sie in den einzelnen Gruppen mehr oder weniger charakteristisch erscheint. Ich habe daher, um den darauf beziiglichen Angaben einige Bestimmtheit zu verleihen, einige Maassangaben gemacht, die eine kurze Erörter'ung erfordern. Von besonderer Wichtigkeit für den Habitus der Thiere ist der grössere oder geringere Grad der seitlichen Zusammendruickung des Körpers. Ich habe, um diese Verhältnisse bestimmt auszudrïcken, in der Mitte des Körpers (meist in der Gegend des vierten Segments) die Höhe desselben gemessen, indem ich von der Medianlinie des Riuckens bis zur Seitenlinie maass, und gleichzeitig die Dicke des Körpers daselbst in den Seitenlinien gemessen. Durch ersteres Maass erhält man allerdings nicht die Höhe des betreftenden Segments direct, was am unverletzten Thiere iiberhaupt nicht möglich ist, aber doch ein solches, welches vergleichbare Werthe liefert.

liiicksichtlich der Gesammtlïnge des Körpers habe ich bei kleinem 
Rostrum von dem vordern Stirnrande bis zum Ende der. Springfüsse gemessen, da der Candalanhang öfters schwierig als Endpunkt der Nessung zu benutzen sein wiirde.

Zum Schlusse endlich die systematische Eintheilung der Amphipoden und die Anordnung der so iiberaus zahlreichen Formen in natiirliche Familien anlangend, so sind allerdings durch die Arbeiten von Dana, Bruzelius, Lilljeborg, Bate und neuerdings durch A. Boeck sehr wesentliche Fortschritte gemacht worden. Dennoch glaube ich, dass zu einer Erkenntniss der wahrhaft natiirlichen verwandtschaftdichen bezichungen der durch diene Forscher agebildeten birupen noch sehr vieles fehlt, da viele Verhältnisse noch kaum in durchgreifender Weise berüicksichtigt wurden und manche Formen in viel zu spärlichem Material der Untersuchung vorlagen, um mehr als eine sehr fragmentarische Erkemntniss der äussern Gestaltung zuzulassen. Am weitesten in der Tremnung einzelner Gruppen ist in nevester Zeit A. Boeck gegangen und glaube ich, dass man die Mehrzahl der von ihm gebildeten Familien wol als nothwendig begründete wird ancrkemnen müssen. Dagegen erscheint mir die 'Zerspaltung der Gattungen von diesem Forscher mitunter fast etwas zu weit ausgedehnt worden, und habe ich mich daher nicht entschliessen können, dieselben in allen Fällen anzunehmen.

Unter diesen Umständen komnte, zumal bei der Lückenhaftigkeit des mir vorliegenden Materials, in den nachstehenden Mittheilungen rin Versuch einer durchgefuihrten systematischen Lnordnung nicht wohl gemacht werden. Die Familie der Pleustinen glaubte ich neu bilden, die der Epimerinen von $\Lambda$. Boeck dagegen mit den Atylinen wieder vereinigen zu müssen.

Rïcksichtlich der frühesten Jugendstadien sind nur von Bruzelius, sowie von G. O. Sars in seinem schönen Werke über die Süsswasser-Crustaceen von Norwegen nähere Angaben gemacht worden. Ich halte diese Verhältnisse für äusserst wichtig, da sich neben einer gewissen Gleichartigkeit der embryonalen Charaktere, welche allen aus dem Ei geschliipften Amphipoden mehr oder weniger gemeinsam sind, doch mancherlei eigenthïmliche Verschiedenheiten in den einzehnen Gruppen vorhanden sind. Leider bietet sich die Gelegenheit seltener, an conservirten Exemplaren derartige Beobachtungen machen zu kömen, da meist die bruttragenden Weibchen Eier mit weniger entwickelten Embryonen bei sich tragen, oder die junge Brut aus den Bruttaschen herausgefallen oder sonst zerstört ist. Ich labe indessen keine Gelegenheit iiber die Jugendformen etwas zu ermitteln, wie man ersehen wird, voriibergehen lassen. 
An nenen Arten enthält die Sammlung nur zwei: Paramphithoë megalops, sowie Purapleustes gracilis. Herr von Heuglin brachte aus Spitzbergen eine schöne Amathilla-Art heim, die sich ebenfalls als neu erwies.

\section{Lysianassidae, Dama.}

Die Mitglieder dieser sehr natuirlichen Gruppe sind habituell durch den stark gewölbten, gegen die Nitte an Höhe fast stets beträchtlich zunehmenden Körper, die grossen stark entwickelten Epimeren und die verhältnissmässig kurzen Fusspaare charakterisirt. Es kommt dazu die starke Verkürzung der drei letzten Körpersegmente und der Springfuisse, welche ziemlich plump gestaltet sind, sowie die eigenthiimliche Antemenbildung, deren Schaft stets verkiirzt, namentlich aber an den obern äusserst verkiirzt und verdickt erscheint.

Die Mundtheile sind übereinstimmend durch die eigenthümliche Form der Mandibehn, die sehr verlängert und schmal sind und deren Zahhnfortsatz entweder nicht oder doch nur an der Spitze mit sehr stumpfen undeutlichen Zähnen versehen ist. Der Processus accessorius ist in rerkïmmertem Zustande, wie es scheint ziemlich allgemein, doch nur an der linken Mandibel vorhanden, an der rechten stets fehlend, der Kauhöcker klein, ohne Fiederborste, eine sehr rudimentäre Borstenreihe, die auch fehlen kanm.

Die Maxillarfüsse sind durch eine eigenthümliche Eimrichtung des äussern Lappens ausgezeichnet, wodurch derselbe zu einer Art schneidendem Werkzeug vervollkommnet erscheint, und welche in keiner andern Familie derartig wiedererscheint. Der innere freie Rand dieses Lappens erscheint nämlich stark verhornt, sehr zugeschärft und der ganzen Lünge nach mit sägeförmigen Zähnelungen versehen, deren Form sehr an die Säge der Blattwespen erimnert. Der verdickte Hormrand wird von breiten Porenkanälen durchsetzt, welche auf der Spitze der Zähnelungen münden. Der Rand selbst ist stets frei von Borsten oder Stachehn, es finden sich dieselben an der Grenze des Hornsaumes als eine dem Rande paralleler kurzer Borsten oder verschieden gestalteter Stachelborsten vor. Die Oberlippe verhält sich gleichfalls sehr eigenthümlich; sie wird bei den von mir untersuchten Arten von einer kleinen Hornplatte gebildet, welche mit einem stark rorspringenden mittlern Gesichtskiel, dessen unteres Ende sie bildet, unbeweglich verwachsen ist.

Ein eigenthïmlicher Charakter, der allen Lysianassinen gemeinsam zu sein scheint, liegt in der eigenthümlichen Anordnung der Iiechborsten, welche auf dem stets stark vergrösserten ersten Geissel- 


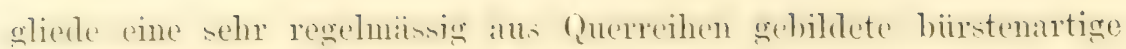

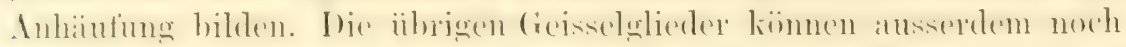
einzelne Riechborsten besitzen, wie z. B. bei Anonyx lagenu, bei andern Arten fehlen sie dagegen hier ganz und sind auf die erwähnte Stelle beschränkt.

Die Nebengeissel ist stets vorhanden und mehrgliederig.

Die Geschlechtsunterschiede sind nur in den Fühler'n ausgeprägt, welche in der Mehrzahl der Fälle bei den männlichen Thieren ein

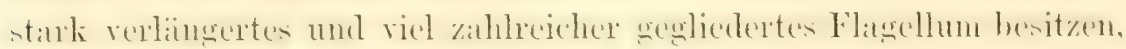
doch ist dics nicht ausnahmslos, wie z. B. bei Anomyx plautus, bei welcher Art die Männchen ebenso kurze Fühler wie die weiblichen Thiere besitzen. Stets scheinen bei ersteren specifische Fiihleranhïnge vorhanden zu sein, welche ich bei den mir vorliegenden drei Arten gleichmässig nur auf den Geisselgliedern beider Fühlerpare intraf.

Kröyer's sehr artemreiche Gattung Anomyx, welche die grösste Mehrzahl der arktischen Formen einschliesst, ist neuerdings von 1. Bereck in eine beträthtliche Anzahl ron Gattungen atufgelist worden. Es scheint mir ron Seiten dieses Forscher's fast etwas zu weit gegannen, wiewol ziemlich ausgeprägte Verschiedenheiten in der Bildung der Nundtheile bestehen. Da dats an Arten auftällig spärliche Iaterial, welches mir zur Bearbeitung vorlag, mir kein Urtheil hieriiher ermöglicht, so lasse ich die wenigen in Ostgrönland gesammelten unter dem ältern Gattungsnamen hier folgen.

17. 1) Anomyx lagena Kröyer.

Cancer ampulla Phipps, Voyage towards the North Pole, 1763, p. 191. tab. XII, fig. 2.

Gammarus muax Sabine, Supplem. to the Append. of Parry's voyage, p. 229. - Owen, Appendix to the second Voyage of Capt. lioss, 1. 87.

Anomyx lagena Kröyer, Grönlands Amfipoder, p. 9, tab. X, fig. 1, 2.

Anomyx ampulla Kröyer, Naturhist. 'Tilskr. anden Række, I, 578. maridea, 1. 39 .

- Bruzelius, Bidrag til Kümnedomen om Skandinaviens Amphipoda Gam-

Lysianassa lagena Goës, Crustacea Amphip. maris Spetsberg. alluent., p. 518 .

Anonyx ampulle Spence Bate and Westwood, Ilistory of British Sessile-Eyed Crustacea, I, 116.

Anomyx legena A. Boeck, Crustacea Amphipoda Borealis et Arctica, 1. 28.

Die Fïrbung ist gleichmässig gelbröthlich.

Die Grösse der erwachsenen Individuen scheint auch bei dieser Art ziemlich beträichtlichen Schwankungen zu unterliegen, wiewol mit Brut versehene weihliche stiicke sche spärlich vorhathlen waren, mëchte ich doch iiber $25^{m m}$ grosse für allsgebildet ansehen. Die grössten 
Individuen maassen $40^{\mathrm{mm}}$ in der Totallänge; die beiden Männchen 26 und $30^{\mathrm{mm}}$. Auffällig ist die Spärlichkeit der Männchen, da die Anzahl der von Dr. Pansch gesammelten Exemplare eine sehr beträchtliche ist, und ich darunter nach sorgfältiger Durchsicht nur zwei männliche Exemplare antraf.

Jugendform. Es gelang mir nicht ausgeschlüpfte Junge noch in der Bruttasche des Weibchens zu finden, doch fand ich zwischen kleinern Exemplaren auch ein ganz junges dieser Art angehöriges Thier, welches nur :3,2mm T'otallïnge besass, also wol erst kürzlich ausgeschlüpft sein konnte. Es liess sich daran constatiren, dass eine irgend beträichtliche Metamorphose bei dieser Art nicht stattfindet, namentlich erschien, wie ich kaum erwartet hätte, die eigenthümlich kurze verdickte Form des obern Antennenschaftes, sowie die Grösse der Epimeren bereits völlig wie bei den Erwachsenen. Die Gesammtform wich überhaupt nicht merklich von jenen ab. Die Augen erschienen noch gelblich ohne schwarzes Pigment, die Form liess sich unter dem Mikroskop deutlich erkennen und erschien langgestreckt senkrecht, aber noch ohne die charakteristische Flaschenform. Obere Antemnen kurz, die Basis sehr stark verdickt, fast noch stärker als beim Erwachsenen, auch hier die beiden letaten Glieder sehr verkürzt. Die kurze Geissel siebengliederig, das erste Glied etwas verlängert und immer mit einem dichten Riechborstenbuischel besetzt. Nebengeissel dreigliederig, Endglied sehr klein. Untere Antenne kaum lünger als die obere.

Die drei hintern Thoraxfusspare haben verhältnissmässig grosse Coxalglieder, welche so lang sind als die vier tibrigen Gliedler zusammengenommen, letztere sehr kurz und dick.

Epimeren der vordern Segmente wie beim Erwachsenen, an dem Abdominalsegment erscheint die dritte hinten mit einer rechtwinkeligen Ecke und ohne den nach aufwärts gerichteten Zahn.

Caudalanhang und Springfüsse nicht merklich abweichend.

liei cinem $9^{\mathrm{mm}}$ langen Exemplar fand ich die Antennen noch ziemlich kurz, die Geissel der obern achtgliederig, Nebengeissel fünfgliederig, der Zahn an der letzten Epimere wie beim Erwachsenen, das tünfte bis siebente Fusspar noch sehr kurz, die vier Endglieder kaum länger als die Coxen.

Verbreitung sehr häufig und allgemein an der ostgrönländischen Kïste: Sabine-Insel 10-20 Faden sehr reichlich, sehr grosse Exemplare; Sabine-Insel 5 Faden; Germaniahafen 3 Faden; Jackson-Insel 24 Faden. 
18. 2) Anonyx Tittoratis Kröyer.

Kröyer, Naturhist. Tidskrift, 2 Rakke, I, 621.

Ders., Voyages en Skandinavie, pl. 13, fig. 1.

Bruzelins, Bidrag til Kïnnedomen om Skandinaviens Amphip. Gammaridea, p. 46. Goës, Crustacea Amphipoda maris Spetsbergiam alluent., p. 521.

Onisimus littoralis $\Lambda$. Beeck, Crustacea Amphipoda borealis et aretica, 1. 32.

Yon dieser im höchsten Norden sehr verbreiteten Art lag auch in Dr. Pansch's Sammlungen ein ziemlich reichliches Material vor.

Die Färbung des lebenden 'Thieres ist hellweisslich durchsichtig mit einem blassrosa Anfluge, der stellenweise am Riiicken etwas stärker hervortritt, ohne indessen deutlich begrenzte Flecken zu bilden.

Grösse. Die Grösse der Erwachsenen beträgt zwischen 15 und $1 \mathrm{~g}^{\mathrm{mm}}$; grössere sind mir nicht vorgekommen. Die jüngsten, welche ich sah, besassen eine Grösse ron $5^{\mathrm{mm}}$, sie waren den Erwachsenen bereits völlig gleich.

Die zwischen dem Packeise gefangenen waren durchschnittlich grosse Exemplare, doch sind auch stellenweise juingere in allen Wachsthumsstadion daselbst reichlich anzutreffen.

Bei einem Weibchen von $18^{\mathrm{mm}}$ 'Totallïnge:

Ohere Anteme. . . . . . . . . $5,5^{\mathrm{mm}}$
Untere Antenne . . . . . . .
Körperhöhe bis zur Seitenlinie (4. Segment) $3,5^{\mathrm{mm}}$
Körperhöhe mit Einschluss der Epimere. .
Querdurchmesser (in der Mitte) des Körpers
Hinterste Springfïsse. . . . . . . . . $1,5^{\mathrm{mm}}$

Verbreitung. Diese an den arktischen Küsten fast überall beobachtete Art ist durch ihr massenhaftes pelagisches Auftreten sehr weit vom Lande sehr bemerkenswerth, wo sie neben Anomyx plautus und den ïbrigen pelagisch auftretenden Arten ziemlich allgemein zwischen dem Packeise an der Oberfläche des Meeres, ja selbst noch eine Strecke weit ausserhalb der Eisgrenze im offenen Meere angetroffen wird. In der Sammlung des Dr. Pansch findet sich eine reichliche Anzahl von Exemplaren, welche am 12. Juli 1869 an der Meeresoberfläche gesammelt wurden, also zwei Tage ehe die Eisgrenze erreicht wurde; ich selbst bemerkte sie zuerst am 14. Juli, gleichfalls mehrere Meilen von der Lisgrenze entfernt. Das Meer besitzt dort eine 'liefe, welche mit 940 Faden durch das Loth nicht ergründet werden konnte.

An der Lisgrenze selbst, sowie zwischen dem Packeise ist sie allenthalben anzutreffen, in oftmals betrïchtlicher Individuenmasse, doch steht sie bei Weitem hinter der Massenhaftigkeit dex Individuen 
des Gammarus locuste zuriek. Kröyer fand die ersten Exemplare auf Spitzbergen im Belsund auf dem Strande selbst, sodass sie rom Ufer aufgesammelt werden konnten, und wurde dadurch zu der Artbenennung veranlasst.

Auch bei dieser Art sind die Männchen viel spärlicher als die weiblichen Thicre; die meisten Gläser enthielten nur Weibchen, nur die bei Kap Wym enthielten unter 14 Exemplaren sechs Männchen.

Die Fundorte an der ostgrönländischen Küiste sind: Ḱap Wym 5 Farden, November 1869; Germaniahafen 3 Faden; an beiden Stellen reichlich.

\section{3) Anomyx plautus Kröyer.}

Kröyer, Naturhistorisk 'Tilskr., 2 Rrekke, I, 629.

Ders., Voyage en Skandinavie, taf. 15, fig. 2.

Spence Bate and Vestwood, Hist. of the Brit. Sessil-Eyed Crust., I, 111.

Lysianassa plauta Goës, Crustac. Amphipod. maris Spetsherg. alluent., p. 521.

Onisimus plantus A. Boek, Crustac. Amphipod. borealis et aretica, p. 32.

Diese Art steht der vorangehenden sehr nahe und theilt mit ihr' dasselbe Vorkommen.

Färbung. Diese Art ist im lebenden Zustande ziemlich intensir röthlichgelh gefärbt und so bereits leicht von Anomyx littoralis zu unterscheiden, die Färbung ist gleichmässig iiber den ganzen Körper verbreitet, doch am Riucken etwas dunkler.

Grösse. Sie ist von merklich geringerer Grösse als die vorige. Die grösten Exemplare, welche mir vorlagen, besitzen nur $13^{\mathrm{mm}}$ 'Totallänge; die juingsten von $4^{\mathrm{mm}}$ Länge gleichen den Erwachsenen sonst bereits völlig, nur ist die Geissel viel kiirzer, 6-7gliedrig, kïrzer als der Schaft und viel plumper, Nebengeissel dreigliederig.

Männchen anch hier viel spärlicher, nur einige wenige unter der ganzen Anzahl vorhanden.

Die Verbreitung dieser Art stimmt im Wesentlichen mit der rorigen ganz iiberein; zusammen mit derselben findet sie sich ebenfalls allenthalben pelagisch zwischen dem Packeise, doch beträchtlich spärlicher an Individuenzahl vor. In Dr. Pansch's Sammlung sind allerdings keine Exemplare vorhanden, welche zwischen dem Packeise gefangen worden wären. Ich erinnere mich, sie fast überall zusammen mit Anonyx littoralis daselbst beobachtet zu haben. Auch von der ostgrönländischen Küiste waren Exemplare derselben zusammen mit der vorigen gesammelt worilen, bei Kap Wynn 3 Faden, wenige; Germaniahafen 3 Faden, ziemlich reichlich; Sabine-Insel 10 Faden, zwei Exemplare. 
Nach Suiden ist sie weiter beobachtet worden als Anomyx littoralis, da nach Spence Bate ein Exemplar von der schottischen Küste erhalten wurde, und nach $\Lambda$. Boeck dieselbe auch weiter siidlich an der norwegischen Kiiste beobachtet worden ist.

Unter den von H. von Heuglin bei Spitzbergen gesammelten Crustaceen befanden sich mehrere Exemplare dieser Art, welche durch eine weit beträchtlichere Grösse von den grönländischen verschieden sind.

Die grössern Exemplare messen bis zu $24^{\mathrm{mm}}$, sind also grösser als selbst die ron Grönland mir vorliegenden Stïcke ron Anomyx littoralis. Im Uebrigen sind sie von den grönländischen nicht abweichend.

\section{Syrrhoinae, A. Boeck.}

Diese kleine Familie nähert sich in mancher Beziehung den Oedicerinen, welches sich nicht allein in der Gesammtform des Körpers, sondern anch in der Bildung der Nundtheile ausspricht, die im Wesentlichen sehr ähnlich wie bei jener Gruppe geformt sind. Doch sind die Mandibehn beiderseits ungleich, nur die linke mit einem processus accessorius rersehen, was bei den Oedicerinen nicht der Fall ist. Auch die Kopfform und die hochstehenden, oder selbst auf der Stirn verschmolzenen Augen erimnern an jene Gruppe, doch ist das Rostrum nie so beträchtlich entwickelt. Die obern Antennen besitzen eine Nebengeissel, welche den Oedicerinen fehlt. Ob die Antemnen bei den männlichen 'Thieren mit specifischen Anhïngen versehen sind, vermag ich bei dem geringen Material, welches mir vorlag nicht zu entscheiden, doch ist es nach Analogie mit den Oedicerinen eher wahrscheinlich dass sie fehlen.

Die Fusspare des Thorax sind betrïchtlich schlank, die beiden vordem namentlich mit sehr schwachen schmalen Scheerengliedern, das siebente Paar nicht aussergewöhnlich verlängert.

Die Springfüsse stimmen dagegen sehr mit denjenigen der Oedicenerinen iiberein.

20. 1) Syrrhö̈ cremulata Goës.

Goës, Crustac. Amphipoul. maris Spetsbergiam alluentis, p. 527, fig. 25.

A. Boeck, Crustacea Amphipoda horealia et aretica, 1) 67.

Diese durch die schwedischen Expeditionen bei Spitzbergen entdeckte Art lag in einigen Exemplaren anch von der ostgrönländischen Iiiiste ror.

Die Färbung des 'Thieres ist gleichmässig gelblich, ohne Pig- 
mentirung, es scheint im lebenden Zustande ziemlich farblos durchsichtig zu sein.

Die Grösse betreffend, so besass das einzige grössere mir rorliegende Exemplar eine Totallänge von $12^{\mathrm{mm}}$. An demselben fand ich:

Entere Antenne . . . . . . . . . . . . . $4^{\mathrm{mm}}$

Körperhöhe im dritten Segment, ainschliesslich der Epimere $2 \frac{1}{\mathrm{~mm}}$

Querdurchmesser des Kïrpers daselbst . . . . . . $21 / 2^{\mathrm{mm}}$

IInterste Springfüsse . . . . . . . . . . . . . 2)mm

An trei kleinern 4-6 $6^{\mathrm{mm}}$ langen Exemplaren find ich sonst keine Abweichungen, ausser dass die Geissel der untern Antennen nur siebengliederig erschien.

Verbreitung. Sie scheint ziemlich selten an den Küsten ron Ostgrönland, da im Ganzen nur fünf Exemplare vorhanden waren: Sabine-Insel 10 Faden (ein grosses Exemplar); Sabine-Insel 5-10 Faden, mehrere kleinere.

Pardaliseinae, A. Bøck.

Diese kleine Gr'uppe scheint zu den Syrrhoinen in verwandtschaftlicher Beziehung zu stehen, doch bietet die Bildung der Mundtheile, sowie der beiden vordern Fusspare charakteristische Eigenthïmlichkeiten. Die Körperform ist gestreckt, die Segmente im Verhältniss zum Querdurchmesser niedrig, im Rüicken breit gewöllbt, die Epimeren sehr klein. Die Segmente in der Mitte des Körper's sind kaum höher als vorn, sowie auch der Querdurchmesser des Körpers sich ziemlich gleich bleibt.

Die Mundtheile bieten mancherlei Eigenthümliches. Die Mandibehn sind beiderseits ungleich, indem nicht allein der Zahnfortsatz beiderseits abweichend geformt, sondern auch der processus accessorius sehr verschieden ist; links ist er ziemlich rudimentiir in Form eines schmalen hakenformigen Fortsatzes, rechts wiederholt er die Form des Zahnfortsatzes und ist mit demselben verwachsen. Borstenreihe rudimentär; Kauhöcker fehlt.

Die Naxillarfüsse sind durch die eigenthïmliche Form der beiden imnern Lappen ausgezeichnet: der basale völlig rudimentär, der äussere schmal rechtedkig mit dem betreftenden Gliede in seiner ganzen Länge verwachsen.

Die Antennen schlank und dünn, mit verhältnissmässig kurzem Schaft, im Ganzen nicht von besonderer Länge; die obern mit wohlentwickelter Nebengeissel. Ob sexuelle Differenzen an denselben rorhanden sind, geht weder aus den bisher gemachten Angaben 
hervor, noch konnte ich bei dem geringen Material dariber ins Kilare kommen.

Augen getremnt, seitlich.

Thoraxfüsse schlank, die drei hintern ziemlich stark verlängert, mit kleinen schmalen Coxalgliedern.

Die beiden vordersten Paare bei Purdalisca sehr abweichend mit zweigliederiger gezähnter Kralle, welche nicht gegen das letzte liussglied zurïckgelegt werden kann; bei Nicippe, welche ich nicht aus eigener Anschaumg kenne, scheinen sie von der gewöhnlichen Bildung.

Springfüsse schlank, ziemlich lang.

21. 1) Pardatisca cuspidata Kröyer. 'Tab. I, fig. 3 et tab II, fig. 1.

lỉröyer, Naturh. Tidskr., förste Række, IV, 153.

Bruzelius, Bidr. til Kämedomen om Skand. Amphip. Gammaridea, p. 101.

Goës, Crustac. Amphip. maris Spetsberg. alluent., p. 529.

Bœeck, Crustacea Amphip, borealia et arctica, p. 71.

Von dieser, wie es scheint an der ostgrönländischen Küste ziemlich selten vorkommenden Art lagen mir nur drei daselbst gesammelte Stiicke vor.

Der Körper zeichnet sich im Allgemeinen durch seine gestreckte und schmächtige Form aus, indem die Epimeren sehr klein und niedrig sind und die Höhe des Körpers infolge dessen geringer erscheint. Im Uebrigen erscheint derselbe im Rüicken gewölbt und abgerundet, sein Querdurchmesser in der Mitte ist wenig geringer als die Höhe bis zur Seitenlinie, derselbe erscheint daher im Ganzen wenig seitlich zusammengedrückt. Derselloe ist in der Gegend der mittlern Segmente kaum merklich breiter als nach vorn und hinten zu, sodass die Seitenränder bei der Ansicht von oben fast parallel erscheinen.

Der Kopf ist ziemlich gross, fast so lang als dic beiden ersten Segmente zusammen genommen, und nach vorn in ein kurzes, zugespitztes Rostrum verlängert. Das Auge ist zinnoberroth, welche Färbumg sich indessen nur bei einem der Exemplare erhalten hatte, während sie bei den iibrigen sich in eine gelbliche Färbung umgewandelt hatte. Es ist sehr lang und schmal, linear, an beiden Enden, namentlich dem untern etwas verbreitert, sein Lïngendurchmessẹ senkrecht. Letzterer ist riemlich ron der halben Lünge des Kopfes.

Die Antemen (Taf. II, Fig. 1h) fand ich kaum merklich an Lïnge verschieden, die obern fast ummerklich länger als die mitern. Sie sind verhältnissmässig lang und diun, mit langer zahlreich-gliederiger Geissel. Sie sind etwas kïrzer als die halbe Gesammtlänge des Thieres betrïgt. 
Die obern Antennen besitzen eine verhältnissmässig sehr kurze Basis, welche kaum die Länge des Kopfes besitzt, das zweite und dritte Glied sind zusammen etwas kürzer als das erste. An dem Flagellum zählte ich gegen 50 (ilieder; die Nebengeissel ist fünfgliederig und von der Länge des zweiten Basalgliedes. Die Basalglieder sowol als die Geissel sind nur mit sehr schwachen Börstchen besetzt.

An den untern Antennen fällt vorzüglich die grösste Kürze des vorletzten Basalgliedes auf, welches kaum länger erscheint als die vorhergehenden, und nur wenig über das vordere Ende des ersten Basalgliedes der obern Antennen vorragt. Dagegen erscheint das letzte Basalglied sehr stark verlängert, schlank und langgestreckt, und reichlich dreimal so lang als die vier ersten Basalglieder zusammen genommen. Der Basaltheil zusammen genommen ist nahezu drei Viertel so lang als die Geissel, welche gegen 40 Glieder zeigt.

An keinem der drei untersuchten Exemplare konnte ich knöpfchenförmige Anhänge oder etwas dem Aehnliches auffinden; an den obern Antennen befanden sich auf den Geisselgliedern je zwei bis drei der wie gewöhnlich gebildeten Riechborsten, welche gegen das Ende hin fehlen. Leider ist das mir zu Gebote stehende Naterial zu gering, um zu entscheiden, ob in dieser Familie die männlichen Fühleranhänge fehlen.

Mundtheile. Die Mandibeln sind, wie im Allgemeinen von den frühern Beobachtern richtig hervorgehoben wird, durch eine sehr bemerkenswerthe Ungleichheit der beiden Körperseiten ansgezeichnet, doch finde ich nur von Bruzelius die Bildung derselben in zutreffender Weise angegeben. Während $\Lambda$. Bøek den mocessus accessorius nur an der linken Mandibel vorhanden sein lässt', hat Bruzelius die eigenthümliche Bildung desselben im Ganzen gut erkannt. Die Mandibeln sind im Ganzen schwach, der an der linken Mandibel ziemlich lange und zugespitzte Zahnfortsatz erscheint an der rechten weit küryer und wesentlich anders geformt. Während der obere Rand bei jener durch ziemlich spitzige Einschnitte in vier grosse spitzige, verhältnissmässig breite, dreieckige Zähne getheilt erscheint, findet sich an der rechten Mandibel derselbe nur mit zwei viel kïrzern und durch eine runde Ausbuchtung verbundenen Zähnen versehen, von welchen der auf der Spitze stehende breit abgestumpft, der andere dagegen zugespitzt erscheint; dahinter erscheint der Rand nur mit

${ }^{1}$ Die Angabe bezieht sich allerdings auf die Familie der Pardaliscinen, da für Pardatisca cuspidata eine nähere Angabe fehlt. 
äusserst schwach ausgeprägten unregelmässigen Crenelirungen versehen, die nur bei starken Vergrösserungen deutlich sichtbar sind.

Die linke Mandibel (Taf. II, Fig. 1a) besitzt einen sehr rudimentïren processus accessorius in Form eines gekrümmten hakenförmigen, gelenkig-mit derselben verbundenen dïnnen Fortsatzes, welcher nur bei der Besichtigung derselben von der imnern Seite her sichthar ist und mit einem einfach zugespitzten Ende versehen ist. ohne Andeutung von Zähmen. Dicht an der Wurzel desselben befindet sich eine einzelne ziemlich kurze Fiederborste, welche als der verkiimmerte Ueberrest der gewöhnlich von dem processus accessovius hinzichenden liorstenreihe anzusehen ist. Ganz eigenthümlich verhält sich dagegen der processus ciccessorius an der rechten Mandibel (Taf. II, Fig. 1b), woselbst derselbe, wie Bruzelius sehr treffend bemerkt, eine ziemlich genane Wiederholung des Zahnfortsatzes selbst bildet und einen ziemlich breiten, mit seinem obern Ende verbreiterten und dem Zahmrande des Kiefers selbst gleichgeformten Fortsatz darstellt. Doch ist die Zähnelung des hintern Randabschnittes hier etwas stärker und deutlicher. Uebrigens erscheint dieser Fortsat\% nicht gelenkig mit dem Kiefer verbunden, wie Bruzelius angibt, sondern mit demselben unbeweglich verwachsen. Dass es sich hier übrigens nicht um einen imnerhalb der Mandibel liegenden, durch eine neve Häutung bedingten, sondern um einen wirklich äusserlich herrorragenden 'Theil handelt, davon habe ich mich deutlich ïberzengt, zumal man die eingeschachtelten, für die Häutung vorgebildeten Wiederholungen beider Theile im Innern der Mandibel ausserdem leicht wahrnehmen kann. Auch hier finden sich an der Wurzel des mocessus accessorins zwei sehr kurże Börstchen als Andeutung der Borstenreihe. Von dem Kauhöcker ist an beiden Mandibeln keine Spur vorhanden.

Der Mandibulartaster ist sehr schlank und dünn, vori mässiger Länge, ein und ein halb mal so lang als die Mandibeln; das zweite schwach gebogene sehr schlanke Glied ist bei weitem das längste, indem das Lndglied nur halb so lang ist.

Die Maxillen des ersten Paares (Taf. II, Fig. 1c) sind mit einem ziemlich stark verlängerten Basaltheil versehen, sodass der sehr verkiimmerte basale imnere Lappen durch einen beträchtlichen Zwischenraum von dem Ursprunge des Krautheils getrennt erscheint. Der 'Taster besitzt ein am Ende ziemlich stark verbreitertes, keulenförmig gestaltetes Endglied, dessen Rand mit einer Reihe kurzer Stacheln, zwischen denen einige kurze Borsten stehen, besetzt ist. Der Kautheil ist ziemlich klein, ragt kaum über das erste Glied des Taster's 
hervor und ist auf dem schräg alogeschnittenen Endrande mit zwei stärkern gekrümmten Stacheln versehen, von welchen der auf der äusseru Spitze befindliche beträichtlich länger und stïrker und beinahe so lang als der Kautheil selbst erscheint; der untere dagegen ist kamm halb so gross. Ich konnte keine Zähnelung an demselben erkennen. Unter diesen beiden Stachehn stehen am Endrande alsdann noch mehrere einfach zugespitzte Borsten und am innern Ende desselben eine etwas längere Fiederborste.

Der sehr verkümmerte Basallappen bildet einen sehr kleinen. wenig hervorragenden, abgerundeten und auf der Spitze mit zwei kurzen Borsten besetzten Lappen.

Die hintern Naxillen ('Taf. II, Fig. 1d) sind durch die betrïchtliche Lünge und die grosse Schlankheit der beiden Aeste ausgezeichnet. Der imnere Lappen ist ein wenig länger und breiter als der iussere, indessen gleichfalls linear langgestreckt, nach der Spitze verschmälert und längs des grössten Theils des imnern Randes mit langen und langgefiederten Borsten besetzt. Der äussere Lappen erscheint dagegen äusserst schmal langgestreckt, fast gleich breit bis zur Spitze und nur auf dieser mit drei langen Fiederborsten besetzt.

Die Maxillarfüsse ('Taf'. II, Fig. 1e) sind bemerkenswerth durch die fast vollkommene Verkiimmerung des untern inmern, sowie durch die eigenthümlich rechteckige Form des obern imnern Lappens. Ersterer fehlt nicht ganz, wie A. Bøeck angibt, sondern ist, allerdings nur in der Form eines sehr kleinen conischen, anf der Spitze mit einer einzelnen Borste besetzten, am untern innern Rande des Basaltheils befindlichen Fortsatzes vorhanden. Letzterer ist im grössten Theile seiner Länge mit dem Basaltheil rerwachsen rechteckig, am obern Ende quer abgeschnitten, und ragt nur bis zum Ende des ersten Tastergliedes nach vorn hervor. Der obere Rand ist mit mässig langen einfachen Borsten besetzt, welche am innern Rande sich in eine Reihe sehr kurzer Borsten fortsetzen. Der 'Taster ist ziemlich lang und schlank, länger als der Basaltheil bis zum vordern Ende des obern Lappens und mit einer zweigliederigen Kralle versehen, welche halb so lang als das Endglied ist.

Die beiden vordern Fussparre haben eine sehr eigenthümliche Form. Sie scheinen, da die Kralle aus zwei Gliedern besteht, welche eine aussergewöhnliche Grösse und Entwickelung besitzen, ein Glied mehr als gewöhnlich zu haben. Die Form derselben ist an beiden ganz iibereinstimmend, doch erscheint das zweite merklich länger als das erste.

Während bei den meisten Amphipoden die beiden vordern Fuss- 
paare fünfgliederig sind (mit Ausschluss der Kralle) scheinen dieselben bei Pardalisce sechs Glieder zu haben. Bruzelins und Bock denten das der stark geziihnten Kralle voranfgehende schlanke dilied als fünftes oder Scheerenglied, was indessen irrthümlich ist, da von denselben die sehr kurzen und schwach entwickelten zweiten und dritten Glieder der betreftenden Fusspatare als ein einziges angesehen worden sind. Dits eigentliche fünfte oder Scheerenglied ist viehmehr das stark verlïngerte und verbreiterte Glied, welches jenen voraufgeht und schon durch diese beträchthiche Grössenentwickelung dem betreftenden Giliede hei der Mehrzilhl der Amphipoden entsprechend sich verhält.

Nimmt man die soeben dargelegte Deutung der Glieder als die richtige an, so verhalten sich dieselben folgendermaassen. Das erste Glied, das Coxalglied, ist von der gewöhnlichen stark verlängerten Form, die beiden folgenden sehr kurz und nicht sehr deutlich getrennt, das vierte Glied, welches sonst dem Scheerengliede an Umfang riemlich gleichzukommen pflegt, erscheint ebenfalls sehr klein und kaum grösser als die beiden vorangehenden. Das hierauf folgende eigentliche Scheerenglied kommt dem Coxalgliede an Länge gleich und erscheint merklich breiter als die iibrigen Fussglieder, doch von der Basis nach der Spitze hin etwas verschmälert. Die Kralle kann nicht gegen dasselbe zurückgelegt werden, wesshalb ein besonder's abgesonderter Krallenrand an demselben nicht vorhanden ist; der untere Rand erseheint viehnehr ziemlich gleiehnïissig mit abwechselnet kürzern und längern Borsten besetzt.

Die verhältnissmässig sehr lange zweigliederige Kralle (Taf. II, Fig. 1f) ist von verhältnissmässig sehr beträchtlicher Länge und kommt dem Scheerengliede an Länge fast gleich. Das erste Glied derselben ist schlank cylindrisch, am untern Rande mit dichtstehenden kurzen Borsten besetzt und etwa halb so lang als das Scheerenglied. Das zweite Krallenglied ist an der Wurzel verhältnissmässig breit, gegen das Ende zugespitzt, leicht gekrimmt und kommt dem crsten Gliede der Kralle an Länge ziemlich gleich. Dasselbe ist am ganzen untern Rande fast bis zur Spitze mit eincr Reihe dichtstchender langer und zugespitzter Kammzühme besetzt.

Das dritte und vierte Fusspaar ist von ziemlich gleicher Lïnge mit dem vorhergehenden, schlank und ron der gewöhnlichen Bildung, die Krallen derselben sind einfitch und ohne Zähnelung. Die Glieder sind an dem untern Rande mit kurzen Borsten besetzt und ohne Stacheln. Die drei hintern Thoraxfïsse sind ziemlich stark verlïngert, ron sehr schlanker Form und unter sich an Länge wenig ver- 
schieden. Das fünfte Fusspaar ist um die Länge seines Endgliedes länger als das vorangehende; die beiden hintern nur sehr wenig länger als dieses und unter sich nicht an Länge verschieden. Die Coxalglieder derselben sind sehr schwach erweitert, schmal, oblong viereckig und an Grösse kaum verschieden. Die Glieder sind schmächtig und mit der gewöhnlichen Bestnchehung versehen, die Krallen einfach.

Die Epimeren der 'I'horaxsegmente sind durch ihre sehr geringe Grössenentwickelung ausgezeichnet; diejenigen der vier vordern Segmente sind klein und fast quadratisch, mit winkeligen Ecken, die vierte ist kaum grösser als die vorangehenden und am Hinterrande ohne einen Ausschnitt, indem derselbe von der Lpimere des folgenden Segments unbedeckt gelassen wird. Die Epimeren der drei hintern Thoraxsegmente sind im Verhältniss zu ihrer Breite äusserst niedrig, am meisten die letzte, welche fast linear erscheint; sie sind am untern Rande ziemlich stark ausgerandet.

Von den Segmenten des Abdomen ist das dritte und vierte an der Dorsalseite neben der Medianlinie am Hinterrande mit je zwei etwas divergirenden, leicht nach aussen gekrümmten, spitzigen Zähnen versehen, das fünfte in der Medimlinie mit einem gerade nach hinten gerichteten, sonst ebenso gestalteten Zahne, während die übrigen unbewehrt sind. Die Epimeren der drei vordern Abdominalsegmente hesitzen ziemlich zugespitzte zahnartige hintere Lcken, welche namentlich an dem dritten in Form eines deutlich abgesetzten zugespitzten Zahnes erscheint.

Der Caudalanhang bildet eine riemlich stark verlïngerte, fast rechteckige Platte, welche ein und ein halb mal so lang als breit und gegen das Ende unbedeutend verschmälert erscheint. Derselbe ist durch einen sehr tiefen, fast bis zum Basalrande reichenden mittlem Einschnitt in zwei Hälften getheilt. Die mittlere Incisur ist in dem grössten Theile ihrer Länge sehr schmal mit geradlinigen dicht aneinanderliegenden Rändern, während sie im letzten Drittel gegen das Ende zu sich plötzlich erweitert, indem ihre liänder in einem spitzen Winkel divergiren, und der Endtheil der beiden Seitenhälften daher beträchtlich verschmälert erscheint. Diese verschmälerte Spitze derselben erscheint durch einen mässig tiefen Einschnitt zweizähnig. Auf dem Caudalanhang befinden sich zwei Paar Stachelborsten, welche nahe dem äussern Rande auf dem Basaltheil der beiden Seitenlappen befindlich sind. Auf der Spitze bemerkte ich keine Stacheln, wie sie Bruzelius angibt. Die Spitze des Caudalanhanges ragt nur um wenig über das Ende des Basalgliedes des letzten Fusspares hervor. 
Die drei letzten Fusspare des Abdomen erscheinen im Ganzen ron mässiger Länge, die beiden vordern sind etwas kïrzer als das letzte. Letzteres zeigt ein Paar gleich lange, blattförmig zusammengedriickte Endäste, velche fast nur die Hälfte länger als das Basalglied und an dem verschmälerten Ende nicht spitz zuliufen, sondern quer abgeschnitten sind. Der innere Rand ist gegen das Ende mit sehr feinen Stacheln, dariber mit einigen längern oder kürzern Borsten besetzt; den äussern Rand finde ich an dem untersuchten Exemplar unbewehrt.

Das vorletzte Paar der Springfuisse (Taf. II, Fig. $1 \mathrm{~g}$ ) besitzt sehr schlanke Endäste von wenig verschiedener Länge, von welchen der längere innere fast ein Drittel länger als das Basalglied, der äussere kaum länger als dieses erscheint. Sie sind am innern liande mit abwechselnd länger'n und kiirzern Stacheln und am Lnde mit einer einfachen geraden Kralle versehen.

Das vorderste Paar besitzt fast gleichlange Endäste, welche kuirzer sind als das Basalglied, und ist im Uebrigen von iibereinstimmender Bildung.

Dimensionen. Das grösste Exemplar besass eine Totallänge von $28^{\mathrm{mm}}$.

Bei dem kleinern wohlerhaltenen, $19^{\mathrm{mm}}$ langen fand ich folgende Maasse:

Höhe des Körpers (viertes Segment) bis zur Seitenlinie. . 3 3m Höhe d. Körpers (viertes Segm.) mit Einschluss der Epimere $3,5^{\mathrm{mm}}$ Querdurchmesser des Körpers daselbst . . . . . 2, 2,5m Antemnen . . . . . . . . . . . $8^{\text {mm }}$

Hinterstes Paar der Abrominalfüisse . . . . . . . $3^{\mathrm{mm}}$

Färbung, soweit sie kenntlich geblieben, gleichmässig blass gelbröthlich.

Verbreitung: Nord-Shannon, in 30 Faden Tiefe.

\section{Leucothoinae, Dana.}

Ich muss gestehen, dass mir diese Familie in dem von A. Bock angenommenen Umfinge zu viel heterogene Elemente zu enthalten scheint, um als eine besonders natürliche angesehen werden zu kömmen. Ich verzichte daher darauf, eine Charakteristik derselben zu versuchen, da ich glaube, dass dieselbe später doch in verschiedene Gruppen wird zerlegt werden müssen. 
22. 1) Eusirus cuspidatus Kröyer. Taf. III, Fig. 2.

Kröyer, Naturhist. Tidskr., 2 Række, I, 501.

Bruzelius, Bidr. til Kännedomen om Skand. Amplip. Gammaridea, p. 63.

Goës, Crust. Amphip. maris Spetsberg. alluent., p. 529.

Bock, Crustacea Amphipoda borealia et arctica, p. 76.

Nur zwei Exemplare dieser, wie es scheint iiberall selten vorkommenden, Art lagen von Ostgrönland vor, ein erwachsenes grosses nnd ein kleineres.

Der Körper ist ziemlich stark seitlich zusammengedriickt, die Höhe bis zur Seitenlinic im vierten Segment ziemlich ebenso gross als der Querdurchmesser des Körpers daselbst, die Segmente nehmen vom ersten bis zur Mitte sehr mässig an Höhe zu, der Rücken in der Medianlinie daher mässig gewölbt, dagegen im Querdurchschnitt mit hoher Wölbung in die Körperseiten steil abfallend. Die vier vordersten Segmente ungekielt, vom fünften Segment bis zum vierten Abdominalsegment ein Mittelkiel, die beiden letzten Kïrpersegmente ungekielt. Der Mittelkiel ist am fünften Thoraxsegment sehr schwach angedeutet; an den beiden letzten, sowie an den zwei ersten Abdominalsegmenten erhebt er sich stärker und erscheint am hintern Segmentrande in eine zahnartige gerade nach hinten gerichtete Spitze verlängert, welche an den drei letztern erwähnten Segmenten beträchtlich entwickelt ist und ein Drittel der Länge der betreffenden Segmente besitzt. Der Kiel selbst nimmt die ganze Länge der betreffenden Segmente ein.

Am dritten und vierten Abdominalsegment ist der Kiel gleichfalls ziemlich hoch und nimmt die ganze Länge derselben ein, ohne indessen hinten zahnartig über den hintern Segmentrand hervorzuragen.

Der Kopf ist ziemlich klein, wenig länger als das erste Segment, der Scheitelrand sehr wenig gewölbt, fast gerade nach vorn verlaufend; Rostrum klein, dreieckig zugespitzt. Der untere Theil des Kopfes, sowie die Mundtheile fast völlig von der vordersten Epimere bedeckt.

Die Augen sind bei den aufbewahrten Exemplaren gelblich abgeblichen, ziemlich schwierig zu erkennen; bei dem grössern war anfangs noch eine röthliche Fürbung daran theilweise kemntlich, welche aber späterhin ebenfalls verschwand. Nach Holböll's Angabe sind sie beim lebenden Thiere zinnoberroth. Dieselben sind senkrecht, schmal, fast linear-nierenförmig, der längere Durchmesser fast so lang als der obere Kopfrand, das untere Ende etwas erweitert; sie sind dem vorder'n Gesichtsrand ausserordentlich stark genähert. 
Die Antennen sind mässig lang, die obern betrïchtlich länger als die untern, sie waren bei dem grössern Exemplar nicht ganz vollkommen, bei dem kleinern die obern von halber Körperlänge, die untern zwei Drittel so lang als diese.

An den obern Antemnen (Taf. III, Fig. 2 b) der Schaft ziemlich verlängert, das erste Basalglied so lang als der Kopf, das zweite Glied schlanker und ein wenig länger als das erste, ist am Endrande cigenthümlich gebildet, indem der-elbe schnäg al)geschnitten erscheint und daselbst jederseits mit drei sehr langen spitzigen, leicht gebogenen Zühnen versehen ist, von denen der mittlere am grössten und unterhalb der Spitze noch mit einem accessorischen kleinen 'Zahn versehen ist. Das dritte Basalglied klein und sehr kurz, kaum länger als breit und kaum ein Viertel so lang als das zweite, am untern Ende des Endrandes in eine etwas vorspringende zahnartige Ecke ausgezogen. Nebengeissel rudimentär eingliedrig, so lang als das erste Geisselglied. Geissel doppelt so lang als der Schaft mit sehr zahlreichen Gliedern, die mit ein bis zwei Riechborsten versehen sind, welche indessen nur auf den alternirenden Gliedern vorhanden sind.

Die untern Antennen mit stark verlängertem Schaft, das dritte Glied bis etwas iiber die Mitte des ersten Basalgliedes der obern Antemnen reichend, am Ende oben ebenso wie das zweite mit zwei kurzen Zähnen, sowie am untern Ende gleichfalls mit einer kleinen zahnartigen Spitze jederseits, das vierte Glied, bis zum Ende des obern Fühlerschaftes reichend, stark verlängert, am Endrande mit einer zalnurtigen Leke jederseits, das fünfte Glied unbedentend kiurzer als das vierte, am Endrande einfach. Die Geissel sehr kurz, beträchtlich kïrzer als die beiden letzten Gilieder des Schaftes, mit zahlreichen sehr kurzen Gliedern. Beide vorliegende Exemplare weiblich, das grössere mit grossen, wie gewöhnlich geformten Brutb]ättern, ohne Spur specifischer Anhänge der Fühler.

Die Nundtheile konnte ich nicht untersuchen.

Die beiden vordersten Fuspare sind ron beträchtlicher Länge und mit sehr entwickelten, sehr eigenthümlich geformten Scheerengliedern versehen; sie sind unter sich gleich lang und ziemlich ebenso lang als die beiden folgenden Paare. Das vorletzte Glied - sehr schmal, am Ende nicht verbreitert, etwas gebogen und am untern Rande ganz nahe der Basis mit einem langen, etwas gekrümmten, am Ende verschmälert-abgerundeten und beborsteten Fortsatz versehen, welcher mit dem davorliegenden 'Theile des untern Randes 
einen Ausschnitt zur Aufnahme des hintern Theils des Scheerengliedes bildet.

Letzteres erscheint dadurch ganz auffällig abweichend gebildet, dass es nach hinten zu ausserordentlich erweitert und verbreitert erseheint, indem der untere Rand von der Insertion des vorletzten Gliedes gerade nach hinten verläuft und so den obern Rand der Scheere fortzusetzen scheint; der nach hinten gerichtete erweiterte $\Lambda$ bschnitt des Scheerengliedes ist ebenso lang als der vordere Abschnitt, aber beträichtlich breiter, der. Winkel, welchen der untere Rand hinten bildet, bogenförmig abgerundet. Der Krallenrand ist sehr lang und beträchtlich länger als der Oberrand und mit feinen Borsten dicht besetzt; an seinem hintern Ende eine höckerartig vorragende Ecke, auf welcher eine kurze Stachelborste.

Es ist demnach nicht ganz richtig ausgedrückt, wemn Bœck bemerkt: der Carpus sei mit dem Scheerengliede in der Mitte des vordern Randes verbunden.

Die Kralle sehr lang und schlank, länger als der obere Scheerenrand, einfach, ungezïhnelt.

Das fünfte bis siebente Fusspar mässig verlängert, das fünfte ein wenig länger als das vorhergehende, die beiden letzten etwas länger, unter sich kaum an Länge verschieden. Die Coxalglieder mässig erweitert, oblong, nach dem äussern Ende verschmälert, die lintere untere Ecke wenig vorragend. Ihr hinterer Rand äusserst fein gezïhnelt. Die Lünge der Coxalglieder erreicht nicht ganz diejenige der zwei folgenden Glieder zusammen genommen. Letztere schlank, sehr fein bestachelt, das dritte an der untern Ecke hinten etwas zahnartig ausgezogen.

Die vier vordern Epimeren ziemlich gross, etwas niedriger als die betreffenden Segmente, mit convex gerundeten untern Rändern, die vierte verbreitert und hinten in der obern Hälfte seicht ausgeschnitten.

Ton den Epimeren der drei vordern Abdominalsegmente bildet die vorderste eine stumpfe Ecke, die zweite und dritte eine wenig vorragende spitze zahnartige Ecke. Der Hinterrand ist an der dritten ziemlich stark regelmïssig gesägt-gezähnt, an den zwei vordern dagegen feiner und undeutlich gezähnelt.

Die drei hintersten Körpersegmente ziemlich verlängert, mit langen schlanken, sehr verlängerten Springfüssen.

Die drei Paare der letztern ragen gleichweit nach hinten herror, das dritte besitzt zwei ziemlich gleichlange, fast cylindrische, nur schwach zusammengedrüickte, zugespitzt endende Endäste, welche etwa 
doppelt so lang als das Basalglied sind; der : inssere Ast ein wenig kiirzer als der innere, die Seitenränder mit zahlreichen kurzen Stachelborsten.

An dem mittlern Parre der äussere Ast ein Viertel küirzer als der innere, am vordersten der Unterschied sehr unbedentend, an beiden Paaren die Endäste am Ende zugespitzt, hakenförmig gekrümmt, ohne Endkrallen, an den Seitenrändern mit zahlreichen Stachelborsten besetzt.

Der Caudalanhang sehr stark verlängert, sehr schmal linear, fast drei mal so lang als breit, fast so lang als die Springfïisse, am Ende ctwas verschmiilert und durch spaltfömmigen mittlern dusschnitt fast bis zur Mitte gespalten; die Seitenhälften am Ende schräg abgeschnitten, aussen stark zahnartig vorspringend, neben der Mittellinie eine sehr viel kleinere, spitze, zahnartige Ecke bildend.

Färbung ganz gleichmässig gelblich ohne Pigmentirungen.

Die Grösse des grössern beträgt im Ganzen $39^{m m}$.

Obere Antenne. . . . . . . . . . $16^{\mathrm{mm}}$

Körperhöhe bis zur Seitenlinie (viertes Segment) $5,5^{\mathrm{mm}}$

Höhe der vierten Epimere . . . . . 4,5m

Querdurchmesser des Körpers daselbst . . . $6^{\mathrm{mm}}$

Caudalanhang . . . . . . . . . 4,5

Hinterste springfïisse . . . . . . . . $5^{\mathrm{mm}}$

Erstes Fusspatr . . . . . . . . . . $10^{\mathrm{mm}}$

Das kleinere Exemplar Totallänge $18^{\mathrm{mm}}$.

Obere Antenne $9,5^{\mathrm{mm}}$

Untere Antenne $6,5 \mathrm{~mm}$.

Vorkommen. Das grössere Exemplar: Sabine-Insel (20110 Faden; das kleinere sonderbarer Weise ausserhalb der Packeisgrenze an der Oberfläche des Meeres am 13. Juli von Dr. Pansch gefangen.

23. 1) Amplithonotus aculeutus (Lepechin). 'Taf. IV.

Oniscus uculeatus Lepechin, Act. Petropolit., 1778, I, 247, tab. 8, fig. 1.

Talitrus Edwardsii Sabine, Supplem. to the Append. of Parry's first Voyage, p. 233, tab. II, fig. 1-4. - J. C. Ross, Append. to Parry's fourth Voyage, 1). 205.

Amplithoë Edwardsii Owen, Append. to J. lioss sec. Voyage, p. 90.

Kröyer, Naturhist. 'lidskrift. Ny liække, II, 76.

Ders., Voyages en Scandinavic, tab. X, fig. 1.

Amphithonotus aculeatus Goës, Crustac. Amphip. maris Spetsb. alluent., p. 526.

Tritropus aculeata Bock, Crustac. Amphip. borealia et arctica, 1) 78.

Tritropis Ilelleri Boek, ebend., p. 79. 
Diese schöne durch ihre Grösse und charakterischen Formen bemerkenswerthe Art ist $z u$ den ausschliesslich arktischen zu rechnen, da sie bisher nur an den eigentlich arktischen Küisten getroffen worden ist, woselbst sie freilich vom arktischen Amerika bis zum weissen Heere ziemlich gleichformig verbreitet ist, wenngleich auch nirgends gerade häufig. In Südgrönland scheint sie zu den seltenen Erscheinungen zu gehören, da Kröyer bemerkt von dorther keine Exemplare gesehen zu haben, wiewol Goës angibt, dass sie durch Amondsen bei Julianshaab gesammelt sei. An den isländischen Küisten ist sie noch nicht aufgefunden, dagegen in Spitzbergen, wie es scheint an einigen Stellen ziemlich häufig.

An den skandinavischen Küsten ist sie bisher nur im äussersten Norden in Finmarken nach $\Lambda$. Bock's Angabe in neuerer Zeit aufgefunden. " Was das Vorkommen der betreffenden Art in Ostgrönland betrifft, so gehört sie daselbst jedenfalls nicht zu den häufigern Erscheinungen, da die Sammlungen der Expedition nur zwei erwachsene und ein ganz junges Exemplar enthielten. Die beiden erstern, von denen jedoch nur eins gut erhalten war, waren bei Nordshannon in 30 Faden 'liefe, das letztere zusammen mit Amathilla pinguis bei Kap Wynn in 3 Faden Tiefe gefunden worden. Alle Exemplare, welche Dr. Pansch sammelte, stammen somit aus geringer 'Tiefe, womit auch Goës' Angaben iibereinstimmen. Dass sie aber auch in beträichtliche Meerestiefe heralogeht und daselbst eine bedentende Grösse erreicht, hatte ich selbst wahrzunehmen Gelegenheit, demn es war diese Art, von welcher zwei ausnehmend grosse Exemplare bei 125 Faden auf Shannon-Bank, gegen 10 dentsche Meilen von der Küste entfernt, am 16. August aufgebracht wurden. Dieselben steckten in den Höhlungen eines grossen Schwammes, welcher mir den Renieren anzugehören schien.

Die vorliegende, bereits auf den ersten englischen Nordpol-Expeditionen aufgefundene Art ist durch Kröyer später so vorzïglich beschrieben worden, dass dessen Angaben in den meisten Punkten kaum etwas Wesentliches hinzuzufïgen ist.

Grösse. Nur an einem der beiden erwachsenen Exemplare konnte die Grösse gemessen werden, doch erschien mir das zweite in dieser Hinsicht ziemlich gleiche Verhältnisse darzubieten. Die Totallänge bei dem gemessenen betrug $44^{m m}$ (einschliesslich des Rostrum).

1 Loc, cit, p. 79. 
Rostrum

Letzte Abdominalfüsse.

Obere Antenne

Lintere Anteme

Körperhöhe bis zur Seitenlinie (viertes Segment)

Querdurchmesser daselbst .

Die von mir in 125 Faden 'Tiefe gesammelten Exemplare besassen jerlenfalls eine viel beträchtlichere frö̈se und es gehört somit die betreffende $\Lambda \mathrm{rt}$ zu den ansehnlichsten lormen unter den Amphipoden.

Jugendform. Das kleinere von mir untersuchte Exemplar, welches eine T'otallänge ron $17^{\mathrm{mm}}$ besass, zeigte, trotzdem dasselbe seit dem Ausschlüpfen bereits beträchtlich gewachsen sein musste, doch noch beträchtliche Abweichungen von der erwachsenen Form.

Die Antennen sind auffällig lang, die untern $13^{\mathrm{mm}}$, die obern mochten $7,5^{\mathrm{mm}}$ betragen, sie haben bereits die schlanke sehr vielgliederige Form der erwachsenen 'Thiere angenommen. An der obern Antenne ist der Unterschied zwischen dem zweiten und dritten Basalglied viel geringer als bei der erwachsenen Form, letzteres ist fast halb so lang als das zweite. Am Kopfe ist das Rostrum auffüllig kurz und so steil nach abwärts gebogen, dass es zwischen den Basalgliedern der obern Antennen gänzlich verborgen ist, es ist etwa halb so lang als jene. Das Auge ist nur sehr schwach hervorgequollen, der Höcker und Mittelkiel fehlt ganz. Von dem Mittelkiel ist auf den sechs ersten Segmenten noch keine Andeutung vorhanden, an dem siebenten ist in der Nitte des Hinterrandes eine sehr kleme zahnförmige Spitze entwickelt. An den folgenden drei $\Lambda$ bdominalsegmenten ist der Kiel deutlich, die Mittelzähne länger und spitzig, aber im Verhältniss zu der erwachsenen form noch viel geringer entwickelt, vor ihnen fehlt der bei den Erwachsenen daselbst befindliche klemere Zahn noch völlig. I as vierte Abdominalsegment besitzt einen dentlichen Nittelkiel, ohne aber hier an IInterrande zahmartig verlïngert zu sein.

Die Seitenkiele sind nur vom achten Segment an deutlich, im iibrigen etwas schwächer, aber von derselben Form als bei den Erwathenen, die von denselben gebildeten Seitenzähne sind verhältnissmässig noch schwach entwickelt.

Die Limeren haben ganz die Formen als im ausgebildeten Zustande bereits angenommen, der Hinterrand der beiden letzten des Abdomen exscheint ziemlich grob crenulirt.

Die beiden vordern Fusspare weichen von denen der Erwachse- 
nen nicht merklich ab, an dem fünften bis siebenten Fusspaar sind dagegen die Coxalglieder etwas anders; sie erscheinen hier verhältnissmässig breiter und stärker erweitert, auch sind sie im Verhältniss zum dritten Gliede beträchtlich länger als bei der erwachsenen Form, woselbst sie, wie bereits Kröyer richtig hervorhebt, auffällig klein erscheinen. Der zahnartige Fortsatz und darunter liegende Ausschmitt fehlen an dem Hinterrande gänzlich, derselbe erscheint einfach abgerundet.

Der Caudalanhang und die hintern Abdominalfuisse zeigten sich im Wesentlichen bereits ganz mit der erwachsenen Form iibereinstimmend.

Wie aus dem Voranstehenden ersichtlich ist, stimmt somit der Jugendzustand dieser Art vollkommen mit der von $\Lambda$. Bock beschriebenen neuen Art, welche im Christiania- und Bukefjord angefroffen worden ist, überein, und da die Abweichungen beider Formen vorzugsweise diejenigen Theile hetreffen, welche während des Wachsthums vorzugsweise sich verändern, wie z. B. der Rïckenkiel, das liostrum, welche in den jüngsten Stadien fast immer noch weniger entwickelt sind, so kann ich keinen Anstand nehmen, die Identität derselben als gesichert anzusehen.

Färbung. Die Fïrbung des erwachsenen Stiickes liess sich noch deutlich erkennen und stimmte mit den Angaben, welche Kröyer an lebenden Exemplaren von Spitzbergen gegeben hat und wie ich selber dieselben im Gedächtniss hatte, überein. Danach ist die Grundfïrbung blass gelbröthlich, auf dem ganzen Körper zeigen sich ziemlich unregelmässig verwischt erscheinende hellroth gefürbte Flecke und Wische, welche namentlich an den Riickenstachehn und an den Seitentheilen der Abdominalsegmente stärker markirt erscheinen, sowie auch auf dem Basaltheile der Antennen in Form von rothen Querbändern auftreten.

\section{Gen. Tritropis, Bœek.}

Diese Gattung behalte ich für die von A. Boek mit Amplithonotus aculeatus unter derselben generisch vereinigte Tritropis fragitis bei, welche doch im Bau der Mundtheile, dem völligen Mangel des Rostrum und der sehr abweichenden Augenbildung halber sich zu weit von der vorangehenden Art entfernt, um eine solche Vereinigung gerechtfertigt erscheinen zu lassen. Im Allgemeinen nähert sich die Art, obwol im IIabitus sehr an Amplithonotus erinnernd, doch in vielen Beziehungen sehr an die Atylinen und zwar an die Gattung I'aramphithor. So durch die gleichartige Bildung der Nandibehn, 
sowie die sehr verlängerten und diinnen Antennen und die Bildung der beiden vordern Fusspaare, welche nicht die den Leucothoinen sonst eigenthimliche starke Entwickelung der Scheerenglieder besitzen.

Die sehr beträchtliche Verlängerung der drei letaten Thoraxfusspare ist wie bei Amptithonotus.

Die Springfüsse sind viel mehr der Bildung bei Paramphithoë als derjenigen von Amphithonothus übereinstimmend gebildet, diejenigen des letzten Paares besitzen stark comprimirte, lanzettförmig zugespitzte Endäste, die vordern Paare sind mit starken Endlkrallen versehen.

Es erscheint mir daher fraglich, ob die Vereinigung dieser Gattung mit den Lencothoinen überhaupt am Orte ist.

\section{1) Tritropis franitis (Goës). Taf. III, Fig. 1.}

Paramplithoë fragilis Goës, Crustac. Amphip. maris Spetsb. alluentis, p. 524 . Tritropis fragilis Boeck, Crustacea Amphipoda borealia et arctica, p. 80.

Von dieser Art lag ein im Ganzen sehr spärliches Material von der ostgrönländischen Küiste ror, zumal die Mehrzahl der wenigen Exemplare mehr oder weniger wegen der sehr zarten Beschaffenheit des Thieres beschädigt war.

Der Körper schlank, sehr gestreckt, niedrig, im Rücken breit gewölbt, der Rïcken an den Abdominalsegmenten winkelig in die Seitenflächen übergehend und hier an den drei crsten derselben einen schwach hervortretenden Kiel bildend. Die Höhe der Segmente sehr viel geringer als der Querdurchmesser des Körpers, letzterer ebenso gross als die gesammte Höhe einschliesslich der Epimeren und in der Mitte des Körpers nicht zumehmend.

Der Kopf gross, so lang als die drei vordersten Segmente zusammengenommen, der Scheitel vom hintern Kopfrande an leicht gewöllbt, mit sanfter Krïmmung in die etwas schräg abfallende Stirn iibergehend, Rostrum nur sehr schwach angedeutet durch eine kleine spitze Herrorragung zwischen der Wurzel der obern Antennen.

Das sehr grosse, sehr dunkelschwarze Auge ist quer und ron ziemlich gerundet viereckiger Form. Der grösste Durchmesser ron vorn nach hinten und etwas nach oben gerichtet ist etwas beträchtlicher als der senkrechte, der hintere Rand stark convex, der untere concar, die untere vordere Ecke etwas ausgezogen, im übrigen die Ecken gerundet. Der längere Durchmesser etwa ein halb so lang als der obere Kopfrand.

Der vordere Gesichtsrand tritt unterhall, der Wurzel der obern Fühler stark nach abwärts und rorn vor und bildet unterhalb der 
untern Antennenwurzel eine stark zugespitzte Ecke, er ist bis zu derselben hin mit zahlreichen spitzen Zähnen versehen.

Die schlanken, sehr verlängerten, mit sehr langer fadenförmiger Geissel versehenen Antennen besitzen grosse Aehnlichkeit in den Verhältnissen mit den Paramphithö̈-Arten, die untern sind fast doppelt so lang als die obern und ziemlich der Gesammtlänge des Körpers gleichkommend.

An den obern ist der Schaft verhältnissmässig kurz, den vierten 'Theil der ganzen Anteme bildend, mit schlanken Gliedern, das erste etwas kürzer als der obere Kopfrand, das zweite ein wenig mehr als halb so lang als dieses und das dritte nur zwei Drittel so lang als das zweite.

An allen ist der Endrand mit spitzen stachelartigen Zähnen rersehen, am ersten und dritten ein solcher Zahn an der untern Seite, am zweiten sind zwei derartige Zähne vorhanden, überdies an den beiden ersten neben den Zähnen einige Stachelborsten. Die Glieder der Geissel sind kurz und sehr zahlreich, von einer Nebengeissel keine Andeutung. Riechborsten scheinen zu ein bis zwei auf den Gliedern der Geissel vorhanden zu sein.

Die untern Antennen besitzen einen etwas längern Schaft als die obern, der aber gleichfalls im Verhältuiss zur Geissel sehr kurz ist und kaum ein Viertel der ganzen Antennenlänge beträgt. Das dritte Glied bis zum Ende des ersten Basalgliedes der obern Antennen reichend, am Endrande unten mit drei spitzen, eine vorragende Ecke bildenden Zähnen, darunter einige Stachelborsten; das vierte Glied reicht etwas iiber das Ende des obern Fühlerschaftes ror, das fünfte ebenso lang als dieses und etwas schlanker; ersteres an der untern Seite des Endrandes ebenfalls mit einem längern spitzen Zahn.

Die Mundtheile sind ron der vordersten Epimere unbedeckt und ziemlich stark vorragend.

Die Mandibeln (Taf. III, Fig. 1e und 1f) breit und kräftig, mit ziemlich grossem, starke Zahnleisten besitzendem Kauhöcker rersehen, jederseits gleich gebildet. Der Taster breit und kräftig, ziemlich kurz, die beiden ersten Glieder etwas kürzer als die Nandibel, das dritte um ein Viertel kuirzer als das zweite, nach der Spitze verschmälert, mit leicht gekrümmtem ziemlich kurz beborstetem Innenrande. Der Zahnfortsatz ist schlank, ziemlich stark gezähnt, die beiden Endzähne am grössten, dahinter noch drei kleinere am innern Rande.

Der processus accessorins zeigt beiderseits kaum merkliche $\mathrm{Ab}$ weichungen; er ist etwas kürzer als der Zahnfortsatz, schlank mit 
drei bis vier stumpfen oder etwas spitzern Zähnen rersehen. Die Borstenreihe aus acht bis zehn ziemlich starken kurz seirulirten Borsten bestehend, welche mit sehr dümen fein zerschlissenen alterniren. Der breite stark rorragende Kauhöcker steht riemlich tief, sein oberes Wurzelende etwas unterhalb der Insertion des Tasters, eine Fiederborste ron mässiger Länge an seiner Wurzel vorhanden.

Die rordern Maxillen (Taf. III, Fig. 1b) besitzen einen ziemlich kurzen breiten Taster, dessen Endglied etwas keulig erweitert ist. Auf dem Endland desselben eine Reihe ron sieben bis acht Stacheldornen, welche beiderseits etwas verschieden sind: auf der rechten Seite sind sie sehr kurz und dornartig, auf der linken dagegen längere Stachelborsten. Hinter denselben eine Reihe einfacher Borsten. Der Kanfortsatz ziemlich schlank, der schmale Endrand mit fünf Paar Kauborsten, welche éin bis drei ziemlich lange Seitenzähne besitzen, darunter an der innern Ecke eine kurze Fiederborste.

Basallappen klein, lïnglichund, am Ende mit drei Fiederborsten.

Die Maxillen des zweiten Paares mit gleich langen Lappen, von denen der äussere etwas breiter, am Endrande mit dichtstehenden einfachen, leicht gekrümmten Borsten besetzt; unter denen am innern Ast am imnern Rande zwei lïngere Fiederborsten.

Maxillarfüsse (Taf. III, Fig. 1d). Taster breit, von der Länge des Basaltheils. Endglied kurz und breit, die Endkralle etwas kïrzer, aus zwei sehr ungleichen Gliedern bestehend; das basale verhältnissmässig dick, sehr stark von dem sehr dünnen Endgliede abgesetzt.

Der obere innere Lappen gross, fast bis zum Endrande des zweiten Tastergliedes reichend, am Endrande nit einer Reihe längerer Fiederborsten, welche continuirlich in eine ebensolche, parallel dem innern Rande, etwas entfernt von demselben stehende Reihe kiirzerer Borsten sich fortsetzt.

Der basale Lappen gross, rechteckig, bis zur Mitte des obern Lappens reichend, am Endrande mit dichtstehenden Fiederborsten, welche sich in eine Reihe ebensolcher nach abwärts an Lünge zunehmender. am innern Rande fortsetzen. Die Basalglieder, sowie das erste Tasterglied an den äussern Ecken mit mehrern Stacheldornen besetyt.

Die Fusspare des Thorax sämmtlich sehr schlank und schmächtig. Die beiden vordersten ('Taf. III, Fig. $1 \mathrm{~h}$ ) mit sehr schmalen verlängerten, rechteckigen Scheerengliedern, die zwei ein halb mal so lang als breit, nach dem Ende etwas breiter als an der Basis, Endrand etwas schräge, den Krallemand bildend, mit sehr feinen Stachel- 
spitzen, ein Drittel so lang als der Unterrand und mit einer etwas stumpf abgerundeten Ecke in denselben übergehend, auf welcher zwei Paar Stachelborsten. Kralle wenig gekrümmt, so lang als der Krallenrand, am Innenrande fein gezähnelt. Das vorletzte Glied so lang als das Scheerenglied, nach dem Ende zu etwas verbreitert, dort so breit als letzteres. Das fünfte bis siebente Fusspaar stark verlängert, namentlich die beiden letatern ungewöhnlich stark, das siebente Paar etwas iiber halb so lang als die Gesammtlänge des Thieres. Die Coxalglieder derselben mässig erweitert, oblong, nach dem Ende zu verjüngt, mit ziemlich geradem, stark gezähntem Hinterrande, so lang als die beiden folgenden Glieder. Die Glieder sehr verlängert, mit zahlreichen Stacheln besetzt. Kralle sehr lang und schlank, halb so lang als das Endglied.

Die vier vordern Epimeren klein, beträchtlich niedriger als die betreffenden Segmente und wie diese an Höhe gleich bleibend. Unterrand bei allen fein gekerbt gezähnt.

Die vorderste vorn in eine spitze Ecke verlängert, die vierte kaum breiter als die vorangehende, am hintern Rande ausgeschnitten, mit convexem unterm Rande.

Die fünfte bis siebente Epimere am hintern Rande stark gesägtgezähnt.

Die Epimeren der drei ersten Abdominalsegmente besitzen sehr stark gesägt-gezähnte hintere Ränder, die erste ist abgerundet, die beiden hintern mit ziemlich rechtwinkeligen hintern Ecken. An der Verbindungsitelle des Epimerenrandes mit dem hintern Segmentrande ein Ausschnitt, an welchen der Seitenkiel herantritt. Ein Mittelkiel ist auf den betreffenden drei Segmenten sehr schwach angedeutet.

Die drei letzten Körpersegmente stark verlängert schlank, von der Länge der beiden vorhergehenden zusammengenommen. Die Hinterränder der beiden erstern derselben jederseits nach aussen hin gezähnt, am vierten Abdominalsegment mit acht bis zehn, am fünften mit sechs spitzigen Zähnen jederseits versehen, am letzten Körpersegment der Hinterrand einfach.

Die Springfïsse des letzten Paares sind beträchtlich länger als die vorhergehenden, mit ziemlich verlängertem Basalglied, welches so lang als der Caudalanhang, und zwei ziemlich gleich langen langgestreckt lanzettförmigen, zugespitzten Endïsten, welche ziemlich ein und ein halb mal so lang als das Basalglied und an den Rändern sehr stark bestachelt sind. Der äussere Ast erscheint nur unbedentend kürzer als der imnere.

Diejenigen des mittlern Paares reichen mit dem längern Endaste 
nur wenig uiber das Basalglied des letzten Paares hinaus, die Endäste sehr schlank cylindrisch, der äussere nur halb so lang als der innere, an Ende mit sehr langer schlanker Endkralle, das erste Paar ebenso, doch die Endäste weniger an Länge verschieden, der längere bis zur Mitte der Endaiste des letzten Paares reichend.

Der Caudalanhang (Taf. III, Fig. $1 \mathrm{~g}$ ) ist verlängert, um die Hälfte länger als breit, gegen das Ende ein wenig verschmälert und abgerundet, mit einem etwa ein Viertel seiner Länge einnehmenden schmalen spaltförmigen mittlern Ausichnitt, die Seitenrïnder und der Endrand gesägt-gezïhnt.

Die Färbung ist gleichmässig blassröthlich-gelb mit einigen schwach angedenteten röthlichen Zeichnungen an dem IIinterrande der Dorsalsegmente, sowie auf den Seiten des Riückens.

Die Grösse betruğ bei dem grössten mir vorliegenden Stiick im Ganzen $17^{\mathrm{mm}}$; bei diesem:

Obere Antenne

Körperhöhe einschliessl. der Epimere (viertes Segm.) $3^{\mathrm{mm}}$

Querdurchmesser des Körpers daselbst . . . $3^{\mathrm{mm}}$

Siebentes Thoraxfusspar . . . . . . . $10^{\mathrm{mm}}$

Bei einem $12^{\mathrm{mm}}$ langen:

Untere Antenne circa. . . . . . . . . . . $11^{\mathrm{mm}}$

Verbreitung. Sie scheint im Ganzen spärlich an der ostgrönlïndischen Kïiste; Sabine-Insel 10 Farden, ein grosses Exemplar; Kap Wynm :3 Faden, särlich; einige meist stark beschädigte Exemplare.

Familie 0edicerinae, Lilljeborg.

Der Habitus dieser Gruppe wird bedingt durch den im Ganzen gestreckten niedrigen, in der Medianlinie des Rïckens nicht gewölhten, etwas niedergedriickten, nach den Seiten zu flachgewölbten Körper. Der Kopf ist gross mit einem durchgehends grossen, an der Wurzel sehr breiten und dachförmig die Wurzel der obern Antennen bedeckenden Rostrum versehen, die Augen hoch an die Oberseite des Scheitels geriickt und meist verschmolzen. Die Antennen kurz, die obern ohne Nebengeissel und bei dem Männchen ohne specifische Anhänge.

Die Fusspare des Thorax sind durch die betrïchtliche Entwickelung der Scheerenglieder der zwei vordersten Paare, sowie die ungewöhnlich starke Vorlängerung des siehenten Paares ansgezeichnet; die Springfüsse schlank und verlängert.

Die Mundtheile sind gleichfalls durch die Kürze und Breite der Mandibeln, welche beiderseits wie es scheint durchgehends gleich- 
gestaltet und mit einem processus accessorius beiderseits versehen sind, sowie durch den kleinen Kauhöcker ausgezeichnet.

Die Maxillarfüsse besitzer einen durch die Breite der Glieder ausgezeichneten 'Taster, die imnern Lappen verhïltnissmïssig klein, der obere am innern Rande mit Borsten besetzt.

\section{Gen. 0ediceros, Kröyer.}

Die geringen Verschiedenheiten in der Bildung der beiden vordern Fusspaare, welche Bock dazu veranlasst haben, diese Gattung in einige andere aufzulösen, scheinen mir nicht wohl zureichend, eine solche 'Trennung der Arten durchzufiihren, weshalb ich die beiden nachfolgenden unter der urspringlichen Gattungsberzeichnung aufführe.

\section{1) Oediceros boreatis (A. Boek). Taf. V.}

Oediceros affinis Goës, Crust. Amph. maris Spetsberg. alluent., p. 527, fig. 21. Monoculodes borealis A. Bøek, Crustacea Amphip. borealia et arctica, p. 88.

Der Körper ist wie bei den verwandten Arten gestreckt, kaum seitlich zusimmengedrückt, die Rückensegmente nehmen von rorn bis zur Mitte des Körper's sehr wenig an Höhe zu, Rücken daher von voru nach hinten fast gerade. Rücken überall breit abgerundet, mit ziemlich Hacher Wölbung in den Körperseiten übergehend, nirgends eine Indeutung eines Kieles. Die Höhe der Segmente bis zur Seitenlinie ist ungefähr nur zwei Drittel so gross als der Querdurchmesser des Körper's, sie erscheinen daher leicht niedergedruickt. Der Kiopf ist gross, etwas länger als die drei vordersten Rückensegmente, der Scheitel verliuft in zwei Drittel der Kopflïnge fast gerade nach vorn, woselbst er mit starker Wölbung in die nach abwärts gerichtete Stirn und das sehr grosse Rostrum übergeht. Es wirl dieser ganze kappenförmig über der Basis der obern Antennen hervorragende Theil gewöbnlich als Rostrum bezeichnet, da indessen das Auge auf demselben befindlich ist, ist er jedenfalls als eine Vereinigung beider letztern 'Theile anzusehen.

Das Rostrum selbst, welches bei den erwachsenen Individuen fast senkrecht oder etwas schräg nach vorn und abwärts gerichtet ist, ist breit, dreieckig, zugespitzt endend, schnbblartig vorragend und reicht etwas bis über das Ende des ersten Basalgliedes der obern Antennen vor.

Bei jüngern Exemplaren ist Stirn und Rostrum anders geformt, die knieförmige Umbiegung der Stirn ist hier nicht vorhanden, die Stirn und das Rostrum verlaufen ziemlich gerade nach vorn in derselben Richtung mit dem Scheitel und das Rostrum erscheint schmaler 
und stärker zugespitzt, ragt aber gleichfalls bis zum Ende des ersten Basalgliedes der Antennen vor.

Das verhältnissmässig kleine, gänzlich verschmolzene Stirnage steht gerade auf der knieförmigen Wölbung der Stirn, welche sie in ihrer ganzen Länge einnmmt. Ls ist lïnglichrund, der lïngere Durhmesser nimmt die Medianlinie der Stirn ein und ist ein und ein halb mal so gross als der Querdurchmesser. Die Form ist elliptisch rund, die Färbung bei allen conservirten Exemplaren in gelblich verblichen, es ist keine Andeutung einer Trennung in zwei seitliche Hälften vorhanden. Der Längsdurchmesser fast ein Drittel so lang als die Kopflänge.

Der vordere Seitenrand des Kopfes bildet, von der Basis des Rostrum nach abwärts, einen ziemlich grossen bogenförmigen Ausschnitt, welcher mit einer ziemlich spitzen, etwas vor'springenden Ecke in den gerade nach hinten verlaufenden untern Gesichtsrand ïbergeht. Letzterer, sowie die Mundtheile beinahe ganz von der vordern Epimere bedeckt.

Die Antenneu sind sehr ungleich an Länge, die obern kaum mehr als halb so lang als die untern. Letztere zwei Fünftel so lang als die Gesammtlänge des Körpers.

Die obern Antemnen (Taf. V, Ḧig. $1 \mathrm{~m}$ ) besitzen einen mässig langen Schaft, welcher ziemlich die Hälfte der Länge der ganzen Antenne besitzt, das erste Glied cylindrisch, ziemlich halb so lang als der Kopf, das zweite kaum zwei Drittel so lang, beträchtlich schlanker, das dritte kaum halb so lang als das zweite. Die Glieder sind an der obern und untern Seite mit vereinzelten, namentlich am Ende stehenden, längern, an der Endhälfte lang gefiederten Borsten versehen, ohne Stachehn. Die Geissel unbedeutend lïnger als der Schaft, bei den erwachsenen Exemplaren 16-17 gliederig; die Gliedler zunächst der Basis sehr kurz, weiterhin gestreckt, länger als breit. Das erste Glied verlängert, von der Länge des dritten Basalgliedes. Die Glieder der Geissel sind mit kurzen Börstchen, sowie an der obern Seite am Ende mit ein bis zwei blassen Riechborsten versehen, welche ron der Länge der Glieder sind.

An den untern Antemen ist der Schaft ziemlich stark verlängert, fast bis zum Ende der obern Antennen reichend, wenig kürzer als die Geissel. Die drei ersten Glieder kurz, das dritte bis zur Mitte des ersten Basalgliedes der obern Antennen reichend, das rierte und fïnfte ist etwas kürzer als dieses und beträchtlich schlanker. Anch hier sind die Basalglierler mit längern dïnen borsten weitläufig besetzt, von welchen einige an der obern Seite, an den Enden der Glieder 
befindliche, in derselben Weise gefiedert sind wie an den obern Fïhlern, während die ïbrigen, namentlich die an der Unterseite befindlichen einfach sind. Die Geissel ist fadenförmig, nach der Spitze sehr allmählich verdïnnt und besteht aus sehr zahlreichen kurzen Gliedern. Geschlechtsunterschiede komnte ich an den Fïhlern nirgends bemerken, und waren eigenthïmliche fiuhleranhïnge an keinem der Exemplare rorhanden.

Mundtheile. Die Mandibeln (Taf. V, Fig. 1b und 1c) sind beiderseits gleich, ziemlich kurz und vou sehr gedrungener Form, wenig lïnger als breit. Der Taster ziemlich lang und schlank, fast doppelt so lang als die Mandibel, das Endglied sehr schlank und diinn, an der Spitze und der innem Seite mit langen Borsten besetzt.

Zahnfortsatz stark, an der Spitze und dem untern Rande stark gezahnt; an der Spitze ein grösserer spitzer Zahn, dahinter sechs bis sieben ebenfalls kräftige, ziemlich spitze Zähne. Der processus accessorius ziemlich ebenso lang als der Zahnfortsatz, stark, am Ende in einen langen gekrümmten sehr spitzen Zahn ausgehend, dahinter mit vier bis fünf ebenfalls spitzen Zähnen am untern Rande. Borstenreihe aus $6-8$ starken zugespitzten einfachen Borsten bestehend, bis zux Wurzel des Kauhöckers reichend. Der Kauhöcker ist klein, in der Mitte des Innenrandes befindlich, seine Wurzel beträidhtlich unterhalb der Insertion des Tasters befindlich. Er ragt ziemlich stark vor, die Endfläche ist klein und mit wenigen Zahnleisten versehen.

Vordere Maxillen (Taf. V, Fig. 1d). Taster beträchtlich länger als der kleine Kaufortsatz; Findglied cylindrisch, am Fnde verschmälert, unterhalb der Spitze mit einigen kurzen Borsten am Innenrande, sowie mit einigen einfachen längern auf der Spitze, darunter am äussern Rande zwei Paar ebenfalls längere Borsten. Kaufortsatz klein schlank, wenig über das erste Tasterglied vorragend, auf der sehr schmalen Endfläche mit fünf I'atr einfachen schwachen ungezähnten Kauborsten. Basallappen klein, rundlich, mit drei sehr kurzen Börstchen auf der Spitze versehen.

Hintere Maxillen (Taf. V, Fig. 1e). Die beiden Lappen kurz und breit, nicht länger als breit, an der Spitze nicht verschmälert, abgerundet, am Endrande mit kurzen Borsten dicht besetzt. Der innere Lappen sehr unbedeutend kürzer als der äussere.

Naxillarfüsse (Taf. V, Fig. 1f). Taster gross, etwas länger als der Basaltheil, einschliesslich des obern Lappens, die Glieder sehr breit. Das Endglied ist sehr kurz, halb so lang als das zweite, rundlich, am Ende verbreitert und abgerundet, nicht länger als breit. Kralle lang und stark, reichlich so lang als das Endglied, leicht ge- 
kriimmt und zugespitzt. Das zweite Glied lang und auffällig verbreitert. Die beiden innern Lappen sind klein, der untere nur bis zur Basis des obern reichend, am Lind- und Innenrande, sowie auf der Fläche mit ziemlich kurzen Borsten besetzt. Der obere innere Lappen reicht nur bis zur Mitte des zweiten 'Tastergliedes, er ist am innern Rande mit einer dichten Reihe einfacher, ziemlich starker Borsten besetzt.

Die beiden vordern Fusspare ('Taf. V, Fig. 1 h und 1i) beträchtlich gross und stark, mit sehr stark entwickelten grossen Scheeren. Das erste etwas länger als das dritte, das zweite sehr beträchtlich, ziemlich um den Betrag des sehr vergrösserten Scheerengliedes länger als das erste. Am ersten Fusspar das Scheerenglied doppelt so lang als breit, etwas gebogen, ziemlich rechterkig mit schräg abgerundeter vordern untern Ecke, der leicht convexe Krallenrand länger als der hintere Abschnitt, auf der Grenze beider eine Stachelborste, der Krallenrand selbst mit kurzen Börstchen und feinen Stachelspitzen besetzt. Kralle schlank, ziemlich gekrümmt, hall so lang als das Scheerenglied, einfach, ohne Zähnelungen. Das vierte Fussglied kürzer als das Scheerenglied, kaum zwei Drittel so lang, am Ende stark verbreitert und daselbst an der untern Ecke in einen ziemlich breiten, abgerundeten, an Grösse etwas variabeln Fortsatz verlängert. Bei den grossen Exemplaren fand ich ihn etwas grösser und stärker entwickelt als bei den jüngern, indessen hier auch nur höchstens ein Drittel so lang als das Scheerenglied, bis zur Verbindung des Krallenrandes mit dem Unterrande reichend. Er ist auf der Spitze mit längern steifen Borsten besetzt, sowie auch am untern Rande des ciliedes mehreve (iruppen derselben befindlich sind. Auch das dritte Glied ist an der untern Ecke in einen kleinen Fortsatz verlängert, welcher mit Borsten besetzt ist.

Am zweiten Fusparr ist das Scheerenglied sehr beträchtlich verlängert und, bei gleicher Breite mit derjenigen des ersten Fusspaares, etwas ïber drei mal so lang als breit. Der Krallenrand ist daher verhältnissmässig viel kürzer und nimmt nur ein Drittel des ganzen Untermandes ein, uibrigens ist seine Bildung dieselbe, Kralle etwas weniger als halb so lang als das Scheerenglied, einfach. Das vierte Glied ist nur ein Drittel so lang als das Scheerenglied und am ïussern Ende unten in einen nach vorn gerichteten cylindrischen, schmalen und sehr langen Fortsatz verlängert, der bei grossen Exemplaren ebenfalls stärker entwickelt ist und hier zwei Drittel so lang als das Scheerenglied, mit der Spitze bis zum Ende des Krallenrandes reicht. 
Das dritte (Taf. V, Fig. 1j) und vierte Fusspatr sind kurz und ziemlich stark mit breiten gedrungenen Gliedern. Die Krallen gross, so lang als das letzte Glied und eigenthümlich blattartig verbreitert.

Das fünfte bis siebente Fusspaar besitzen kleine und verhältnissmässig wenig verbreiterte Coxalglieder, welche etwas kürzer als die zwei folgenden Glieder sind. Das fünfte Paar kurz, kaum länger als die vorangehenden und diesen an Form sehr ähnlich, das sechste Fusspaar (Taf. V, Fig. 1k) ist etwas länger, das siebente schlank und ausserordentlich verlïngert.

Die Coxalglieder an Grösse zunehmend, namentlich dasjenige des siebenten Fusspatres bedeutend grösser als die vorhergehenden, nach dem untern Ende beträchtlich verschmälert, der hintere Rand fein crenulirt, ungezähnt, ebenso wie der obere Liand mit kurzen Börstchen besetzt.

Am fünften und sechsten Paar die Kralle gross, wenig kürzer als das Endglied und wie an den vorhergehenden Fuspataren an der Basis blattartig verbreitert. Das siebente Fusspaar halb so lang als die Gesammtlänge des Körpers; das dritte bis fünfte Glied sehr verlängert schlank, der Reihe nach an Länge etwas zunehmend, die Kralle sehr lang. und düm, gerade, sehr wenig kürzer als das letzte Fussglied.

Die vier vordern Epimeren schmal, oblong, etwas niedriger als die Segmente, die vierte abwärts unbedeutend verbreitert, hinten sehr leicht ausgerandet. Die untern Ränder derselben sind mit ziemlich langen Borsten besetzt.

Die fünfte bis siebente Epimere ziemlich quadratisch, unten seicht ansgeschnitten, mit abgerundeten hintern Ecken. IDie Epimeren der drei vordern Abdominalsegmente niedrig, sämmtlich mit stark convexen abgerundeten mutern Rändern, welche bogenförmig in den Hinterrand übergehen, und mit langen Borsten besetzt.

Von den drei letzten Segmenten des Körpers erscheint das erste ziemlich lang, wenig kürzer als das dritte Abdominalsegment, die beiden letzten dagegen ïusserst verkürzt, so dass sie zusammen nur die Länge jenes Segments besitzen.

Die Springfüise (Taf. V, Fig. 11) sind lang und schlank; das hinterste Paar soweit als die beiden vordern nach hinten vorragend. Dasselbe besitzt ein stark verlängertes Basalglied, die Endiste sind cylindrisch schlank, ann Ende zugespitzt auslaufend, sehr wenig an Länge verschieden; der äussere Ast ein wenig kürzer, von der Länge des 
Basalgliedes, oder selbst ein wenig kürzer, nur mit wenigen kurzen Stachelborsten an den Seiten.

Die beiden vordern Paare fast ebenso gestaltet, die Endäste cybyndrich, an Ende zugespitzt leicht hackenfömigg gebogen, ohne Endkralle, die beiden Endäste an beiden Paren fast von gleicher Länge, der iusnere Lst gamz unherleutend kiirzer. gleichfills ziemlich schwach bestachelt.

Caudalanhang ('Taf. V, Fig. 11) kurz, kaum lünger als breit, kaum halb so lang als das Basalglied der hintern Springfüsse, nach dem Ende kaum verschmälert mit einer breiten, seichten Ausrandung in der Mitte und abgerundeten Seitenecken, auf welchen jederseits ein kurzes Börstchen.

Die Färbung ist bei den erwachsenen Individuen ziemlich dunkel, mit dunkehn schwarzhräinlichen, ins Violette zichenden P'igmentirungen der Haut, welche ziemlich regelmässige, scharf begrenzte Zeichnungen und Streifen auf der Oberfläche des Körpers bilden. Die dunkeln Zeichnungen sind vorzugsweise an der Dorsalseite des Körpers ausgebildet, während die untern und seitlichen Gegenden und Extremitäten eine hellere gelbliche Grundfarbe besitzen. Am Kopfe ist die Dorsilseite von einem eigenthiimlichen Netzwerk von Pigmentstreifen eingenommen, welche kleine hellere Felder einfassen. Ein breiter Querstreifen zieht dicht hinter dem Auge an der Basis des Rostrum quer über die Stirn, von welchem mehrere dunkle ziemlich breite Lüngsstreifen, welche mehrfach durch quere Anastomosen verbunden sind, bis zum hintern Kopfrande verlaufen.

Auf den Körpersegmenten bildet das dunkle Hautpigment in der Medianlinie seln breite dunkle Riickenflecken an allen Segmenten bis zum dritten Abdominalsegment, von welchem schmale dunkle Querbänder an den Hinterränder'n der Segmente bis zur Seitenlinie herabziehen, welche an den drei ersten Abdominalsegmenten mit breiten, auf der Grenze der Epimere und der Segmente befindlichen dunkeln Längstreifen verbunden ersheinen, in welchen gleichfalls netzfömige dunklere Streifen anftreten. Auf' den Epimeren und Extremitäten fehlt das dunklere Pigment auch an denjenigen Stiicken, an welchen die Fïrbung sich gut erhalten hatte.

Grösse. Das grösste der mir vorliegenden Exemplare aus Ostgrönland besass eine Totallänge von $15^{\mathrm{mm}}$; bei diesen betrug:

Obere Antenne. . . . . . . . . . . . . $6^{\mathrm{mm}}$

Lintere Intenme $3,4^{\mathrm{mm}}$

Letztes Paar Springfiisse . . . . . . . . $2,5^{\mathrm{mm}}$

Höhe bis zur Seitenlinie (viertes Segment). . $2^{\mathrm{mm}}$ 
Höhe bis zur Seitenlinie mit Einschluss der Epimere $3^{\mathrm{mm}}$ Querdurchmesser des Körpers . . . . . . $3^{\mathrm{mm}}$

Die jüngsten Individuen dieser Art, welche die Sammlungen enthielten, waren $6-7^{\mathrm{mm}}$ lang. Bei diesen fand ich sonst keine merklichen Abweichungen in der Form, bis auf das sehr abweichend gebildete Rostrum. Letzteres ist bei denselben nicht knieförmig gebogen, die Stirnwölbung schwach angedeutet, Riostrum schmal, zugespitzt, fast gerade nach vorn, sehr wenig abwärts gerichtet, etwas über das Ende des ersten Basalgliedes der obern Antenne vorragend. Die Antennen kürzer, die obere nur 10 gliederig; die beiden vordersten Fusspaare haben im Ganzen völlig die Form der Erwachsenen, nur die Fortsätze des vorletzten Gliedes etwas kürzer.

Verbreitung. Im Ganzen, obwol die häufigste der bei Ostgrönland rorkommenden Arten, scheint sie daselbst doch ziemlich spärlich vorzukommen; Sabine-Insel 10 Faden, mehrere kleinere und mittlere; Germania-Hafen.

26. 2) Oediceros lynceus Sar's. Taf. VII, Fig. 2.

Oediceros lynceus Sars, Översigt over de Norsk-Arctiske Krebsdyr. Vidensk. Selskabs Forhandlinger, Christiania 1858, p. 143.

Oediceros propinquus Goës, Crustacea Amphipoda maris Spetsbergiam alluent, p. 526 , fig. 19.

Oediceros lynceus Bœeck, Crustacea Amphipoda borealia et arctica, p. 82.

Diese Art, welche der vorigen in Rïcksicht der allgemeinen Form und Grösse sehr nahe steht, ist ebenfalls an den ostgrönländischen Küsten nicht ganz selten, wenn auch etwas minder häufig als die vorige.

Die allgemeine Form des Körpers ganz mit der vorigen übereinstimmend.

Das Rostrum (Taf. VII, Fig. 2a) ist sehr abweichend von dem der vorigen Art und sehr charakteristisch. Dasselbe ist gerade, breit, nach vorn hin kaum verschmälert und an der Spitze breit abgestumpft und von ziemlicher Grösse, halb so lang als der Kopf überhaupt und nach vorn etwas über das Ende des ersten Basalgliedes der obern Antennen hervorragend. Das Auge, welches wie bei der vorigen geformt und gleichfalls gelblich verblichen ist, befindet sich beträchtlich vor der Nitte des Rostrum, ganz dicht vor der Spitze desselben.

Antemmen viel kürzer, die obern nur so lang als der Schaft der untern, die untern auch bei den grössern Exemplaren kaum ein Drittel so lang als die Gesammtlänge. Das erste Basalglied der obern An- 
temnen ('in I)rittel so lang als der Kopf', einschliesslich des Rostrum, das zweite (ilied zwei Inittel so ling als dieses, beträchtlich schlanker, das dritte kaum halb so lang als das zweite. Die Glieder des Schaftes mit chensolchen an der Spitze gefiederten langen Borsten am Ende versehen, als die vorigen. Die Geissel sieben- bis achtgliederig, ctwas kïrzer als der Schaft und nur mit dem Endgliede iiber den Schaft der untern Fühler vorragend.

An den untern Antennen das dritte Glied wenig verlängert, fast bis zum Ende des ersten Basalgliedes der obern Antenne reichend, das vierte bis zum Lnde des Schaftes derselben, das fünfte ein wenig kürzer und schlanker. Geissel kurz, kaum so lang als die beiden letzten (iliculer des Schaftes, 10-12gliederig, Glieder ziemlich rerlängert.

Inndtheile wie bei der vorigen Art.

Die beiden ersten Fusspare sind kaum an Länge verschieden, mit gleich grossen, sehr entwickelten, ziemlich gleichgebildeten Scheeren versehen.

Am ersten Fusspaar (Taf. VII, Fig. 2b) das Scheerenglied stark verlängert, zwei ein halb mal länger als breit, von der Basis nach der Nitte etwas verbreitert, elliptisch, der Krallenrand ziemlich stark convex, durch eine sehr schwach angedeutete Ecke von dem hintern Abschnitt des untern Randes abgesetzt, auf derselben eine Stachelborste, der Krallenrand selbst mit sehr feinen, kleinen, dichtstehenden Stachelspitzen und dazwischen mit kurzen Borsten besetzt; derselbe nimmt etwas mehr als die Hälfte des untern Randes ein. Kralle schlank, zwei Drittel so lang als das Scheerenglied, gekrümmt, einfach. Das vorletzte Glied ist durch seine sehr geringe Grösse und das gänzliche Fehlen eines Fortsatzes an der vordern untern Ecke bemerkenswerth, es ist nur ein Fünftel so lang als das Scheerenglied.

An dem zweiten Fusspare (Taf. VII, Fig. 2c) das Scheerenglied ziemlich ebenso gross als an dem vorhergehenden, eher ein wenig kürzer und an der Basis etwas breiter. Krallenrand etwas länger, zwei Drittel so lang als der Unterrand und mit einer stärker vorspringenden Ecke an hintern Ende, auf welcher eine Statchelhorste, im übrigen ebenso wie die Kralle gebildet als am ersten Fusspare.

Das vorletzte Glied ein Viertel so lang als das Scheerenglied, am Ende stiirker verbreitert und unten in einen ziemlich grossen Fortsatz verlängert, weldher ein Drittel so lingr ats das Scheerenglied und bis zum hintern Ende des Krallenrandes reicht.

Die hintern lusspatare, sowie die Epimeren bieten im Wesentlichen dieselben Verhältnisse als bei der vorigen Art, ebenso die 
Springfüsse. Der Caudalanhang kaum länger als breit, nach dem Ende etwas verschmälert und quer abgeschnitten, ohne mittlere Ausrandung, am Endrande mit einigen kurzen Börstchen.

Die Färbung ist, soweit ich aus den vorliegenden Exemplaren henrtheilen konnte, völlig iibereinstimmend mit derjenigen ron Ocdiceros boreatis, doch war sie etwas weniger deutlich erhalten.

Die Grösse scheint gleichfalls im Ganzen mit der vorigen iibereinzustimmen, dloch scheint sie etwas kleiner zu bleiben. Das grösste Exemplar besass $12^{\mathrm{mm}}$ Körperlänge, an demselben:

\section{Untere Antemen . . $3, \mathrm{~s}^{\mathrm{mm}}$ \\ Letztes Paar Springfuisse $2^{\mathrm{mm}}$}

Mehrere kleine Stiicke lagen vor. Das jüngste Individuum von $4^{1 / 2}{ }^{\mathrm{mm}}$ besass bereits alle wesentlichen Artcharaktere, die Form des Rostrum und die beiden vordersten Fusspaare, die Antennen waren nicht erhalten.

Verbreitung mit der vorigen zusammen: Sabine-Insel 10 Faden, zwei mittlere Exemplare; (iermania-Hafen, zwei grössere Exemplare; Ebendas. 3 Faden, ein ganz junges Exemplar.

\section{Pleustinae.}

Für die Mitglieder dieser kleinen Gruppe glaube ich aus mehrfachen Griinden eine besondere Familie bilden zu müssen. Von A. Bock wurden sie unter der Gattung Paramphithoë zu den Oedicerinen gestellt, indessen wird von ihm selbst bemerkt, dass diese Vereinigung kaum eine natürliche sei. Mir erschien es passender, die Gattungsbezeichnung Paramphithö: für die typischen Formen der Atylinen beizubehalten, da diese den Stamm der ursprïnglich ron Bruzelius aufgestellten Gattung gebildet hatten, zumal da ron Spence Bate bereits das. Genus Pleustes für die betreffenden Formen geschaffen worden war.

Die habituellen Charaktere der Pleustinen bestehen in einem im (ianzen gestreckten, in der Medianlinie wenig gewölbten, vorn durch die beträchtliche Entwickelung der vordern Epimeren sehr hoch erscheinenden Körper, der häufig gekielt erscheint.

Der Kopf ist klein, das Rostrum verschieden stark entwickelt, bei Plenstes an die dachförmige Bildung der Oedicerinen erimnernd, doch weit weniger umfangreich, die Augen klein und seitlich.

Die Antennen ziemlich kurz, die untern kürzer als die obern, ob sie sexuelle Verschierdenheiten darbieten, kamn ich nicht entscheiden.

Die Nundtheile sind durch das gänzliche Fehlen des Kauhïckers der Matudibeln, sowie durch die breite beilfömige destalt des Zahm- 
fortsatzes ausgezeichnet, sie sind bei Pleustes sehr ungleich, bei $P a-$ rapleustes dagegen auf beiden Seiten kaum rerschieden.

Die beiden vordern Fusspare sehr gross, mit sehr beträchtlich entwickelten Scheerengliedern versehen; die drei hintern 'Thoraxfusspaare wenig verlängert, das siebente nicht besonders verlängert.

Springfüisse schlank, ziemlich stark verlängert.

\section{Pleustes, Spence Bate.}

Körper vorn sehr hoch, mit ausserordentlich hohen vordern Epimeren, die vierte sehr gross stark verbreitert. Derselbe gekielt, ausser dem Mittelkiel mit Seitenkielen rersehen, die Körperbedeckungen sehr dick und rigide. Augen klein, stark prominirend. Rostrum gross, dachförmig.

27. 1) Pleustes panoplus (Kröyer). Taf. VII.

Amplithoë panopla Kröyer, Grönlands Amfipoder, p. 42, tab. II, fig. 9. Ders., Voyage en Scandinavie, pl. II, fig. 2.

Paramphithoë panople Bruzelius, Skandinaviens Amphipoda Gammaridea, p. 69. - Goës, Crustacea Amphipoda Maris Spetsbergiam alluentis, p. 523.

Plenstes tuberculates Spence Bate, Catalogue of Amphipod. in the British Mus., p. 62 , taf. 9 , fig. 8 .

Parcomphithoë panopla A. Bœek, Crustacea Amphipoda borealia et arctica, p. 96.

Die Körpergestaltung dieser Art ist durch die enorme Entwickelung der vier vordern Epimeren besonders ausgezeichnet, der Körper erscheint daher vorn sehr hoch, während er hinten in dem Abdominaltheil schlank und gestreckt bleibt. Die Körpersegmente nehmen von vor'n zur Mitte sehr beträchtlich an Höhe zu, der Rücken daher von vorn nach hinten stark gekrümmt.

Die Dicke des Körpers ist sehr beträchtlich, in der Mitte ist der Querdurchmesser in der Seitenlinie betrïchtlich grösser als die Töhe der Segmente. Der Riicken kaum gewölbt, rom Mittelkiele dachförmig in die Seitenflächen fast gerade sich fortsetzend, die Seitentliivhen sind nur an den Abdominalsegmenten winkelig von dem Riicken abgesetat. An den Segmenten des T'horax bilden die Seitenhälften des Rïickens einen sehr stumpfen Winkel in der Medianlinie.

Nirgends fanden sich specifische Anhänge an den lühhlern oder Abweichungen, welche auf sexuelle Unterschiede zu beziehen wären.

Iund theile. Nandibeln kräftig mit stark gezahntem Zahnfortsatz und langem starken 'Taster. Letzterer bedeutend länger als die Mandibel, die beiden ersten Glieder so lang wie diese, das dritte Glied stark verlïngert, cylindrisch gerade, am Ende nicht verschmälert, abgerundet, etwas länger als das zweite Glied; es ist auf der 
Spitze mit einigen wenigen kurzen Borsten besetzt, die ein Drittel so lang als das Glied am innern Rande; eine weitlüufige Reihe kürzerer, sowie an der Basis eine Querreihe längerer Borsten. Das zweite Glied gerade, wenig stïrker als das Endglied.

Beide Mandibehn differiren nicht allein durch das Fehlen des processus accessorius an der rechten, sondern auch durch die Bildung des Zahnfortsatzes. An der linken (Taf. VI, Fig. 1c) ist derselbe mit vier grossen spitzen, dreieckigen Zähnen versehen, welche ziemlich gleich gross sind und den ganzen obern Rand des Zahufortsatzes eimnehmen, der an der Spitze stehende ist etwas schmäler und spitzer. Der Zahnfortsatz im Ganzen breit und kurz, ziemlich beilförmig. Der processus accessorins hat im Ganzen dieselbe Form wie der Zahnfortsatz, ist breit und kurz, etwas kuirzer und kleiner als dieser, und am obern Rande mit sechs bis sieben spitzen, gleich grossen Zähnen versehen, der Endzahn etwas grösser und lïnger.

An der Mandibel ('Taf. VI, Fig. 1b) ist keine Spur des processus accessorius vorhanden. Der Zahnfortsatz hat im Ganzen dieselbe Form. die vier grossen Zähne des Oberrandes sind aber ein jeder gekerbt und zweitheilig, sodass doppelt so viele kleinere Zähne als an der linken Mandibel vorhanden sind.

Die Borstenreihe besteht aus acht bis zehn ziemlich kurzen, wenig verdickten gekrimmten Borsten, welche bis zur Wurzel des sehr verkiimmerten Kauhöckers reichen. Letzterer ist sehr rudimentär und bildet einen sehr kleinen conischen Höcker, der in einen schmalen weichhäutigen zipfelartigen Fortsatz verlängert ist, der am Ende mit einigen zugespitzten warzenartigen Hervorragungen besetzt ist, aber weder hornig ist noch eine Spur von Zahnleisten besitzt. Fiederborste fehlt.

Vordere Maxillen (Taf. VI, Fig. 1d). Taster schlank, Endglied schmal, cylindrisch, um die Hälfte länger als der Kaufortsatz, am Ende mit vier bis fünf kurzen zugespitzten Stachelborsten, Kaufortsatz schmal, schlank, Endfläche sehr schmal, mit vier Paar ziemlich starker am innern Rande sehr fein und kurz gezähnter Kauborsten. Basallappen sehr klein, rundlich, auf dem Ende mit einer einzelnen liingern Borste.

Hintere Maxillen (Taf. VI, Fig. 1 e). Die beiden Lappen breit nach der Spitze nicht verschmälert, der innere sehr wenig kürzer, auf der Spitze dicht beborstet.

Maxillarfüsse (Taf. VI, Fig. 1f). Taster stark verlängert, länger als der Basaltheil; Glieder ziemlich schlank. Endglied ziemlich von der Länge des zweiten Tastergliedes, schlank, am Ende nicht 
verbreitert, daselbst neben einfachen gewöhnlichen mit eigenthümlichen sägezïhnigen Borsten besetzt. Letztere bilden eine Gruppe von acht bis zehn am äussern Ende des Endgliedes, an der innern Seite neben der Kralle, sie sind ziemlich kurz und dick eylindrisch, bis zum Lnde breit und an beiden Rändern mit kurzen und breiten, abgerundeten, zahnartigen Fortsïtzen, mit Ausnahme des basalen $\mathrm{Ab}$ schnittes dicht besetzt. Kralle schlank, fast gerade, undeutlich zweigliederig, drei Viertel so lang als das Endglied, fein behaart. Die beiden ersten Glieder des Tasters sind schlank und ziemlich stark verlüngert, das zweite Glied dicht und lang beborstet.

Die beiden imnern Lappen sind kurz und klein. Der basale Lappen rechteckig klein, am Endrande mit einfachen steifen Borsten dicht besetzt, der obere imnere Lappen kurz schmal, nur bis zum Ende des ersten Tastergliedes reichend, oblong rechteckig am Endrande, sowie am imnern Rande mit einer dichten Reihe einfacher mässig langer Borsten dicht besetzt, sowie mit einer Reihe ebensolcher, etwas entfernt vom immern Rande stehender und mit denselben paralleler Borsten.

Oberlippe ('Taf. VI, Fig. $1 \mathrm{~g}$ ) kurz, viel breiter als lang, am Endrande in der Mitte ziemlich tief ausgerandet, mit einem schmalen verlängerten Zipfel nach aufwärts versehen.

Färbung. Die Körperbedeckungen sind sehr dick und starr, undurchsichtig, mit Ausnahme der drei letzten Epimeren, welche etwas durchsichtig sind, allenthalben durch Porenkanäle fein getiipfelt. Fïrong gleichmäsisg gelblich, nit spuren röthlicher fleckenartiger Zeithnungen, die am Riïckenkiel, anf dem Riïcken und Hinterrändern der Segmente, an den aufgeworfenen Rändern der Seitenlinie, sowie an den vordern und untern Rändern der vordern Epimeren bei einigen Lxemplaren besonders deutlich sind, an einigen sogar die untern Ränder dieser Epimeren intensiv roth gefärbt.

Die nicht sehr zahlreichen Exemplare, welche mir vorlagen, waren wenig an Grösse rerschieden. Die Totallänge betrug zwischen 16 und $18^{\mathrm{mm}}$.

Bei einem $18^{\mathrm{mm}}$ langen Exemplai:

Körperhöhe bis zur Seitenlinie (viertes Segment)

Ganze Höhe daselbst

Querdurchmesser daselbst.

Rostrum .

Obere Anteme

IIinterste Springfiisse

Yerbreitung. An den Küsten des nordöstlichen Grönland nicht 
gerade selten, doch ziemlich spärlich: Sabine-Insel 27 Faden, 29. October 1869, sechs Exemplare; Sabine-Insel 20-110 Faden, ein Exemplar.

2) Parapleustes Buchholz, nov. Gen.

Corpus epimeris quatuor anterioribus mediocribus, dorso rotundato epidermide tenui. Rostrum exiguum. Antennae breves, inferiores superiores breviores. Mandibulae processu dentali brevi, lato cum processu accessorio coalito, tuberculo molari nullo. Labium superius breve et latum, profunde emarginatum.

Ceterum generi Pleustes valde affinis.

Die Abweichungen im Bau der Nundtheile, sowie der Mangel eines Riickenkieles und des sehr schwach entwickelten Rostrum, scheinen mir wesentlich genug, um die nachstehende Art von der vorhergehenden Gattung, welcher sie übrigens ziemlich nahe steht, zu tremnen.

28. 1) Parapleustes glacilis Buchholz, nov. spec. Taf. VII, Fig. 1.

? An:Amphithopsis glaber Bøek, Forhandl. ved de Skand. Naturf., 8. Möde, 1860, p. 662.

? Paramphithoë exigua Goës, Crustacea Amphip. maris Spetsbergiam alluent., p. 523, fig. 12 .

? Paramphithoë glabra Boeck, Crustacea Amphipoda borealia et arctica, p. 95.

Ich muss gestehen, dass es mir etwas zweifelhaft bleibt, ob die nachstehend beschriebene kleine Art von Ostgrönland mit den angeführten Synonymen identisch ist, da die sehr kurzen Angaben von Bœck und Goës hieriiber beträchtliche Zweifel bestehen lassen. Ich ziehe daher vor, sie als neue Art zu beschreiben und glaube sie mit der vorigen, wegen der ziemlich beträchtlichen $A$ bweichungen in der Bildung der Mandibehn und Körperformen, nicht in derselben Gattung vereinigen zu können. Dass sie eine unausgebildete Jugendform, wie ich erst glaubte, sei, ist mir späterhin wegen der vollständig ausgebildeten grossen Brutblïtter, womit die meisten Individuen versehen sind, ganz unwahrscheinlich geworden.

Der Körper ist im Ganzen gestreckt, die Segmente mässig nach der Nitte an Höhe zunehmend, der Rücken von vorn nach hinten schwach, von der Mitte nach den Seiten iiberall stark gewölbt und abgerundet, nirgends weder winkelig noch mit der Andeutung eines Kieles, was nach Goës' Angabe bei Parapleustes exigua der Fall zu sein scheint. Die Höhe des Körpers nimmt bis zum vierten Segment ziemlich beträichtlich zu, da auch die Epimeren beträchtlich an Höhe zunehmen, sie ist daselbst am grössten, aber bei weitem nicht so beträchtlich als bei Parapleustes panoplus, und die Epimeren viel we- 
niger gross als bei jener Art. Der Querdurchmesser des Körpers ist etwas grösser als die Höhe der Segmente bis zur Seitenlinie, der Körper erscheint daher kaum seitlich zusammengedrickt.

Der Kopf ist klein, wenig länger als das vorderste Körpersegment, der Scheitel gerade nach rorn verlaufend und ebenso in der stirn mit dem kleinern nath vorn gerichteten Rostrum sich fortsetzent. Letzteres kaum ein Viertel so lang als das Basalglied der obern Antemen, dreieckig, zugespitzt.

Der' untere Theil des Kopfes mit den Mundtheilen völlig von der vordersten Epimere verdeckt, doch ist die Basis der untern Antennen sichtbar. Der vordere Gesichtsrand bildet unterhalb der Basis der obern Antemen eine sehr spitze Lcke.

Das Auge ist dunkelschwarz, länglichrund, dem vordern Gesichtsrande etwas mehr als dem hintern Kopfrande genähert, senkrecht, der längere Durchmesser ziemlich halb so lang als der Kopf, der Querdurchmesser nur wenig kleiner. Es erscheint ohne Untersuchung durch das Mikioskop viel kleiner, da das schwarze Pigment nur in der Mitte vorhanden ist, und diese dunkelschwarze Augenmitte von einem Kreise mmpigmentirter Krystallkörper rings eingefasst wird. 1)iese eigenthiimliche Bildung fand ich bei allen Exemplaren in gleicher Weise vor: Eine ,fast nierenförmige" Form, wie Bœck von Parapleustes glabra angibt, hat dasselbe durchaus nicht, der vordere und hintere Rand sind vielmehr beide convex.

Antennen kurz, die obern zwei Fünftel so lang als die Gesammtlïnge, die untern fast un ein Viertel kürzer als jene.

An den obern Antennen der Schaft ziemlich verlängert, halb so lang als dieselben, das erste Basalglied von der Länge des Kopfes, cylindrisch, am kndrande unten mit einem luurzen spitzen zahnartigen Stachel, das zweite Glied unbeträchtlich küizer, schlanker, am Endrande einfach, das dritte Glied halb so lang als dieses. Die Glieder nur mit kurzen Börstchen besetzt. Geissel von der Länge des Schaftes, 15-16gliederig, die Glieder langgestreckt, mit ein bis zwei beträchtlich grossen Riechborsten versehen, von welchen einige fast doppelt so lang als die Glieder sind.

Untere Antemen: Schaft etwas länger als derjenige der obern Antemnen, viel liinger als die Geissel, das dritte Glied his zur Mitte des ersten Basalgliedes der obern Fühler reichend, der processus auditorius des zweiten Giliedes ungewöhnlich lang, etwas iiloer das Ende des zweiten Gliedes nach vorn vorragend, gerade nach vorn gerichtet. Die beiden lezten Glieder: des Schaftes verlängert, das vierte fast bis

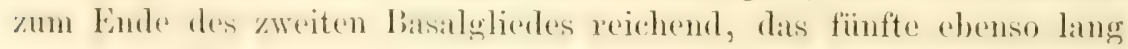


als dieses, etwas schlanker bis zum Ende des dritten Geisselgliedes reichend. Geissel ein und ein halb mal so lang als das fünfte Basalglied, 6-7gliederig.

An keinem der Exemplare fand ich specifische Fiihleranhänge orler merklich ausgeprägte sexuelle Differenzen der Fühler.

Mundtheile.

Mandibeln (Taf. VII, Fig. $1 \mathrm{~b}$ und $1 \mathrm{c}$ ) breit und kräftig, ein und ein halb mal länger als dicht unterhalb des Zahnfortsatzes, breit, beiderseits gleichgebildet, vïlig ohne spur eines Kanhöckers. 'Taster lang schlank, die beiden ersten Glieder fast von der Länge der Mandibel, das zweite etwas gebogen, das dritte ebenso lang als das zweite, kaum dïnner, gerade, cylindrisch, am Ende mit einigen kurzen Borsten, am Innenrande sehr spärlich mit einzelnen kurzen Borsten, die keine zusammenhängende Reihe bilden. Die Insertion des Tasters hoch, in einer Linie mit dem obern Rande des Zahnfortsatzes. Letzterer eigenthümlich gebildet breit und sehr kurz, am obern Rande mit vier bis fünf groben, ziemlich spitzen Zähnen. Was die Bildung desselben ganz eigenthümlich erscheinen lässt, ist die Verwachsung mit dem processus, welcher, an der Basis mit demselben völlig verschmolzen, mit seinem freien Rande eine dem Zahnende parallele, scharfe, stark gezähnte Leiste bildet; die Zähne derselben sind viel spitzer und etwas zahlreicher als diejenigen des obern Randes des Zahnfortsatzes, es sind sieben bis acht schmale stark zugespitzte Zähme an demselben rorhanden (Taf. VII, Fig. 1 b p. a.). Es wäre möglich, dass dies Verhalten von Boek und Goës nicht richtig erkannt worden, letzterer bildet den Kiefer aber auch insofern abweichend ab, als ein Kauhöcker an demselben dargestellt wird, der bei der vorliegenden Art, wie ich bei mehrern Exemplaren fand, durchaus fehlt. Die Borstenreihe besteht aus acht bis zehn kurgefiederten zugespitzten Borsten.

Vordere Maxillen (Taf. VII, Fig. 1d). Taster ziemlich kurz schlank, am Ende kaum verbreitert, um die Hälfte des Endgliedes länger als der Kaufortsatz; dieses am Ende mit einigen kurzen Stachelborsten und dazwischen einigen länger'n einfachen Borsten. Kaufortsatz lang schlank, Endrand schmal, Kauborsten nach dem inmern Ende an Länge abnehmend, am innern Rande sehr fein gezähnelt. Basallapper klein rundlich mit einigen sehr kurzen Börstchen besetzt.

Hintere Maxillen (Taf. VII, Fig. 1e). Die beiden Lappen gleich lang, aber von sehr ungleicher Breite, der äussere sehr schmal, am Ende dicht mit kurzen Borsten besetzt, der innere beträchtlich 
breiter, abgerundet, mit weitläuftigen kürzern Borsten spärlich besetzt.

Maxillarfüsse (Taf. VII, Fig. 1f). Sie sind ähnlich in der Form wie bei Pleustes, der Taster lang und ziemlich schlank. Das Endglied so lang als das zweite, am Ende nicht verbreitert, Kralle gross, schlank, fast so lang als das Endglied, nicht deutlich zweigliederig. Die beiden innern Lappen kurz und ziemlich klein, der basale viereckig, am Endrande mit einfachen kurzen Borsten besetzt, der obere bis zur Nitte des zweiten Tastergliedes reichend, am innern Rande mit einer Reihe einfacher Borsten besetzt.

Oberlippe (Taf. VII, Fig. 1j) sehr kurz und breit, doppelt so breit als lang, in der Mitte mit einer sehr tiefen ausgerundeten Ausrandung.

Die beiden vordersten Fusspaare von beträchtlicher Grösse und mit betrïchtlich entwickelten Scheeren versehen. Sie sind ziemlich gleicher Länge und wenig kürzer als die beiden folgenden.

Die Scheerenglieder sind äusserst ähnlich wie bei Pleustes panoylus geformt, diejenigen des ersten Fusspares merklich grösser als die des zweiten, welche letztere ich bei mehrern übereinstimmend nur drei Viertel so lang finde, als die des vordersten Paares. Beide sind gleichgeformt, verlängert, am Ende rom Beginn des Krallenrandes an stark verschmälert, letzterer wie der ganze untere Rand stark convex gekrümmt, mit einer Reihe kurzer Börstchen oberhalb des Randes, sonst einfach ohne Zähnelung, an seinem hintern Ende zwei durch einen Ausschnitt getrente Gruppen ron Stachelborsten. Kralle schlank, einfach, halb so lang als das Scheerenglied. Das vorletzte Glied ist an beiden Fusspaaren sehr klein, namentlich am r'sten Paare kaum ein Drittel so lang als das Scheerenglied, am Ende unten nicht in einen Fortsatz verlängert, mit einer stumpf abgerundeten, mit einfachen Borsten besetzten Ecke. Das vierte Glied am Ende unten in eine spitzige Stachelspitze endend.

Das dritte und vierte Fusspanr (Taf. VII, Fig. 11) ziemlich kräftig und lang, wenig länger als die vorigen.

Das fünfte bis siebente Fusspaar sind verhältnissmässig kurz und rom ziemlich gedrungener Form. Das fünfte besitzt die Länge der vorausgehenden; die beiden folgenden wenig länger als dieses, unter sich gleich lang. Coxalglieder stark verbreitert, mit stark convexen vordern und hintern Rïndern, wenig lïnger als breit, an Länge gleich den beiden folgenden (iliedern zusammen, der hintere Rand ziemlich fein kerbzähnig mit spitzen, ziemlich kleinen, zahlreichen Zähnen. Glieder wenig an Iänge verschieden, Endglied etwas lïnger als die 
übrigen, stark bestachelt, das dritte Glied am Ende hinten in eine stark vorspringende Ecke ausgezogen. Krallen gross einfach.

Die vier vordern Epimeren sind höher als die zugehörigen Segmente und nehmen so beträchtlich an Höhe zu, dass die vierte fast doppelt so hoch ist als die erste. Die drei ersten sind oblong, ziemlich rechteckig mit abgerundeten Winkeh, am hinter'n Rande mit drei nach abwärts gerichteten spitzen Zähnen, von welchen der unterste ziemlich an der untern Ecke selbst befindlich ist. Bock's Angabe': ,Epimera tria anteriora in angulo inferiore postico hamulis singulis armata" könnte sich hierauf beziehen, doch ist nur der unterste Zahn auf der untern Ecke befindlich.

Die vierte Epimere ist stark verbreitert, etwas breiter als die beiden vorhergehenden zusammen, der untere Rand stark convex, der hintere Rand in der vordern Hälfte ziemlich tief ausgeschnitten.

Die fünfte bis siebente Epimere an Grösse etwas, indessen nicht beträchtlich abnehmend, mit alggerundeten hintern Ecken, menten nicht ansgerandet, sondern ziemlich stark convex über die Insertion der Coxalglieder hervorspringend.

Die Epimeren der drei vordern Abdominalsegmente ziemlich rechteckig, die hintern Winkel nicht zahnartig vorragend, die hintern Ränder einfach. Eine Reihe kurzer Stachelborsten etwas oberhalb des untern Randes.

Die drei letzten Körpersegmente ziemlich kurz, kaum länger als das dritte Abdominalsegment; Springfüsse (Taf. VII, Fig. $1 \mathrm{~g}, 1 \mathrm{~h}$ und 1i) schlank, ziemlich verlängert, sehr ähnlich denjenigen von Parapleustes panoplus gebildet. Das hinterste Paar etwas kürzer als die vordern, Endäste cylindrisch zugespitzt, der äussere Ast zwei Drittel so lang als der innere, an den Seiten bestachelt, Basalglied kurz und dick, kürzer als der äussere Ast.

Die beiden vordern Paare ein wenig weiter nach hinten vorragend, am mittlern der äussere Ast zwei Drittel so lang als der innere, ziemlich so lang als das Basalglied, sie enden mit einer ziemlich langen Endkralle. Das vorderste Paar sonst gleichgebildet, doch die Endäste fast gleich lang.

Caudalanhang (Taf. VII, Fig. $1 \mathrm{~m}$ ) kurz, so lang als breit, am Ende nicht verschmälert und abgerundet, in der Mitte ein wenig vorspringend, mit einigen sehr kleinen Börstchen besetzt.

Die Färbung ist gleichmässig gelbröthlich, ohne irgendwelche dunkeln Zeichnungen.

${ }^{1}$ Crustacea Amphipoda borealia et arctica, p. 95. 
Die Grösse war an den mir vorliegenden Exemplaren sehr wenig verschieden, sie betrug zwischen $4-5^{\mathrm{mm}}$ in der 'Totallänge des Körpers, ich möchte dieses für die Grösse der erwachsenen Individuen ansehen, obwol mir bruttragende Weibchen nicht vorlagen.

Bei einem $5^{\text {mm }}$ langen Exemplar:

Obere Antennen . . . . . . . . $2^{\mathrm{mm}}$

Körperhöhe bis zur Seitenlinie (viertes Segment) $0,7^{\mathrm{mm}}$

Körperhöhe (ganze Höhe) daselbst . . . 1,5 $1,5^{\mathrm{mm}}$

Querdurchmesser des, Körper's . . . . 1, 1,2

Vorkommen. Ich fand im Gauzen neun Exemplare dieser kleinen Art zwischen andern Amphipoden. Von Sabine-Insel, 10 Faden.

Familie Iphimediuae, A. Boek.

\section{1) Vertumme servatus ( $\mathrm{F}_{\text {. }}$.}

Oniscus serratus Fabricius, Fauna grœnlandica, 1780, p. 262.

Amphithoё scrru Kröyer', Grönland's Amphipoder, p. 266, tab. II, fig. 8.

deconthonotus serra Milne Liwards, Hist. natur. des Crustac., III, 25.

Vertummes serratus Goës, Crustac. Amphip. maris Spetsberg. alluent., p. 522.

- Boek, Crustacea Amphipoda borealia et arctica, p. 100.

Nur ein einziges Lxemplar von Ostgrönland, ohne Antennen.

Nordshamon :30 Faden.

Dasselbe $7^{\text {mm }}$ lang. Körper sehr stark seitlich zusammengedrückt, stark gekielt, der Kiel bildet am fünften bis siebenten 'Thoraxsegment schr grosse nach rïckwärts gerichtete, gegen das Ende leicht hakenförmig nach abwärts umgebogene sehr spitze Zähne, deren Wurzel aus der ganzen Lüinge der betreffenden Segmente sich erhebt. Am dritten Abdominalsegment endet der sehr hohe Kiel in einen abger'undeten Vorsprung. Die drei letzten Körpersegmente äusserst verkiirzt ohne Kiel.

Auge klein, schwarz, fast dreieckig rundlich, senkrecht etwas verliingert, unten etwas erweitert, dem vorderm Gesichtsrande sehr genähert.

Die eigenthïmlich tiefe Ausbuchtung des Hinterrandes der Epimere des dritten $\Lambda$ bdominalsegments wie sie Bœek beschreibt.

\section{Gammar inae, Dana.}

Der Köper ist in dieser Gruppe im Ganzen gestreckt, wenig seitlich comprimirt und nicht besonder's hoch, im Rïicken stark gewölbt und mit mässig grossen Gimeren versehen. Sie kamn durch das Lbenmaass der' Theile gewissermaassen als die typisch am vollkommensten entwickelte unter den Amphipoden angesehen werden. 
Der Kopf ist von mittlerer Grösse mit durchschnittlich sehr kleinem, schwach angedeutetem Rostrum, seitlichen senkrechten Augen, die Antennen von mittlerer Länge, kürzer als der Körper, mit Nebengeissel der obern Antemen, sowie wie es scheint durchgehend specifische Fühleranhänge bei den Männchen vorkommen.

Auch in den Mundtheilen spricht sich eine sehr regelmässige Bildung ans, die Mandibehn meist anf beiden Seiten sleichgebildet, oder wie bei Gummarus mit geringer Formverschiedenheit des processus accessorius, mit stark entwickeltem und sehr vorragendem Kauhöcker und langem kräftig entwickeltem 'Taster versehen.

Die Maxillarfüsse sind mit sehr regelmässig entwickelten Theilen versehen und bieten nichts Besonderes.

Die Fusspaare des Thorax sind kräftig und gedrungen, die beiden ersten Paare mit ziemlich stark ausgebildeten Scheerengliedern, die drei hintern wenig verlängert.

Die Springfüsse sind ziemlich verschieden, durchgehend ziemlich verlängert, das letzte Paar bald mit lamellär zusammengedrückten, bald mit cylindrischen Endästen versehen, sowie auch die Form des Caudalanhanges sehr variirt.

Ga mm a r us, Fabricius.

Diese Gattiung ist durch den gestreckten, etwas seitlich comprimirten Körper, die eigenthïmliche Formverschiedenheit des processus accessorius beiderseits, sowie die eigenthimliche Beschränkung der specifischen Fühleranhänge auf die Geissel der unter'n Antennen, die allen Arten zukommen zu scheint, charakterisirt; überdiess ist die verhältnissmässig geringe Entwickelung der Coxalglieder der drei hintern Fussparre des Thorax, die Bestachelung der Ietzten Abdominalsegmente, sowie die tief zweitheilige Form des Caudalanhanges eigenthiimlich bezeichmend.

30. 1) Gummanelocusta (L.).

Gammarus areticus Scoresby, An Account of the Arctic Regions, I, 541, II, tab. 16, fig. 14.

Gammarus borens Sabine, Suppl. to the Append. of Parry's first Voyage, p. 229.

Gammanus sitchensis Brandt, Niddendorft's Sibirische Reise, I, 133.

Diese Art, welche unter allen arktischen Formen den weitaus grössten Verbreitungsbezirk besitzt, erscheint auch im hohen Norden Ostgrönlands nicht nur an Individuenmasse weit vorherrschend, sondern wird anch in der Allgemeinheit der örtlichen Verbreitung kaum von einer andern erreicht. 
Es erschien mir bei den so ausserordentlich verschiedenen Lebensbedingungen, unter welchen sie im Eismeer namentlich als pelagische Thierfor'm auftritt, zum mindesten wahrscheinlich, dass sich zwischen den Individuen beträchtliche locale Abänderungen der Form ergeben wïrden, indessen hat eine sehr sorgfältige, auf alle Theile ausgedehnte Vergleichung zwischen der Ostsceform und Exemplaren verschiedener Loralitïten ron Ostgrönland und aus dem Eismeer kaum bemerkbare, oder wenigstens nicht mit Sicherheit als constant anzusehende $\mathrm{Abänderungen} \mathrm{ergeben,} \mathrm{sodass} \mathrm{anzunehmen} \mathrm{ist,} \mathrm{dass} \mathrm{die} \mathrm{Art}$ in dem ganzen ungehenern Vorhreitungshezirk, welehen sie eimnimmt, ihre Charaktere fast röllig unverändert bewahrt.

Die Abweichungen eben ausgeschlüpfter junger Individuen von der Erwachsenen Form sind von Bruzelius bereits richtig hervorgehoben worden. Ausser der geringern Gliederzahl der Antennen und der ovalen Form des Auges, finde ich bei $3^{\mathrm{mm}}$ langen Jungen die hintersten Abdominalfuisse etwas abweichend, der innere Ast kaun ein Drittel so lang als der äussere conisch zugespitzte, auf der Spitze mit einer langen Borste. Die Dorsalstacheln der drei letaten Segmente bereits wie beim Erwachsenen.

Färbung. Die Färbung des Thieres bietet röthliche Zeichnungen, welche kaum deutlich auf dem Rïcken und den Hinterrändern der Segmente, an den Antemnen und Extremitäten in Form röthlicher Querbänder deutlich hervortritt. Es ist dies namentlich an den grössern arktischen Exemplaren durchgehends der Fall, während bei den jüngern und den Ostsee-Exemplaren kaum Spuren davon vorhanden sind. Sehr eigenthïmlich sind die hellzinnoberrothen Flecke an den Seiten der drei ersten Abdominalsegmente, welche auch bei zahlreichen Exemplaren von der grönländischen Küste deutlich vorhanden waren, und welche bei den Individuen von der Ostsee fast immer vorhanden sind. Bei den im Eismeer lebenden sind sie jedoch wie es scheint in der Regel nicht rorhanden, wenigstens erimere ich mich bestimmit, sie hier an den sehr massenhaft gefangenen Thieren nicht wahrgenommen zu haben.

Grösse. Gammarus locusta erreicht im arktischen Meere eine so bedeutende Grösse, dass er zu den ansehnlichsten Amphipoden zu rechmen ist. Die grössten Exemplare von Ostgrönland sind $40^{\mathrm{mm}}$ lang, die Grösse der Erwachsenen scheint zwischen $25-40^{\mathrm{mm}}$ schwanken zu kömnen. Die sehr weit von der Küste im Eismeer pelagisch lebenden besitzen dieselben Grössenverhältnisse wie diejenigen ron der Küste. Bei der Ostseeform ist die Grösse ausgewachsener Thiere durchschnittlich $10-15^{\mathrm{mm}}$, sie diirfte wol kaum $20^{\mathrm{mm}}$ erreichen. 
Die Verbreitung bietet insoferm ein ganz besonderes Interesse, als die Art sich den allerverschiedenartigsten Lebensbedingungen anzupassen vermag. An den ostgrönländischen Küsten ist sie so allgemein und massenhaft verbreitet, dass sie als die häufigste Art daselbst anzusehen ist.

Sabine-Insel 10-20 Faden, sehr massenhaft; Germania-Hafen 3 Faden.

Im Polarmeere begegnet man, wie ich schon früher ${ }^{1}$ hervorgehoben habe, dieser Art so allgemein und in so grosser Individuenzahl als keiner andern. Ich bemerkte sie bereits sehr weit von der Packeisgrenze, bald nachdem wir die Insel Jan-Meyen passirt hatten. Zwischen dem Eise selbst ist sie allenthalben überaus massenhaft anzutreffen.

\section{Gen. Amathilla, Spence Bate und Westwood. (Amathic H. Rathke.)}

Die Arten dieser Gattung ${ }^{2}$ sind habituell von den eigentlichen Gammarus-Arten verschieden durch den weniger schmächtigen und zusammengedrǘcken, im Riïcken stark gewöl,ten und breiten Körper, die rerkürzten obern Antemen, welche durchgängig kürzer als die

1 Erlebnisse der Mannschaft des Schiffes Hansa (Königsberg 1871), S. 4.

2 Amathilla Heuglini (Buchh.), nov. spec.

Diese bisher, soweit ich ersehen kann, noch nicht beschriebene Art lag mir nur in einem einzigen durch Herrn von Heuglin bei Spitzbergen gesammelten erwachsenen Exemplare zur Untersuchung vor. Da dieselbe zu den ansehnlichern Formen der Grösse nach gehört, ist sie wol äusserst selten daselbst anzutreffen und bildet eine interessante und charakteristische Bereicherumg der dortigen, bereits so vielfach durchforschten Crustaceen-Arten.

Da ich dies Stück natürlich nicht zergliedern konnte, kann ich dasselbe nach sorgfältiger Prüfung der äussern Charaktere nur als mit höchster Wahrscheinlichkeit dem Genus Amathilla zugehörig anführen, und erscheint sie namentlich der Amathilla pinguis im ganzen Habitus der Theile am nächsten stehend.

Diagnosis spec.: Corpus sat altum, magnum, epidermide crassa, quasi loricatum, dorso rotundato lato, medio tumidum. Oculi nigri, mediocres, reniformes. Antennae superiores inferioribus paullo breviores tertiam fere corporis longitudinem aequantes; flagello accessorio mediocri quatuor articulos praebente.

Epimera anteriora mediocria, quartum multo latius, postice in spinam validissimam acutam horizontalem productum. Epimera segmentorum abdominalium: secundum et tertium angulo posteriore in dentem acutum producta, primum rotundatum, tertium praeterea in margine posteriore in dentem acutum sursum spectantem productum. Appendix caudalis elongata indivisa, apice incisura media perparva emarginatum. Pedes saltatorii tertii paris, ramis aequalibus compressis, anterioribus non longiores.

Color pallide flavus. Long. total. $36^{\mathrm{mm}}$. 
untern sind, die stärker erweiterten Coxalglieder der drei hintern Fusspare und die Form des Caudalanhanges. Die Mundtheile sind schr ähnlich denen von Gammarus gebildet, nur mangelt die eigenthïmliche Formverschiedenheit des processus accessorius der Mandibeln. Die specifischen Anhänge sind zahlreich, auf beiden Fühlerparen, sowol auf der Geissel als dem Schafte vorhanden, und wie es scheint durchgehend von eigenthümlich verlängerter Form.

31. 1) Amathilla Sabini (Leach).

Tat. V1II, Tig. 1, 2 und 'Tit'. IX, Fig. 1.

Gammarus Subini Leach, Ross Voyage of Discovery ete., Append., 1819, p. 178.

- Sabine, 1 Supplement to the Append. of Capt. Parry's first Voyage, 1824, p. 232 , tab. I, fig. $8-11$.

- Kröyer, Grönlands Amphipoder, p. 16, tab. I, fig. 3.

- Bruzelius, Bidr. til Kännedomen om Skand. Amphip. Ganmaridea, p. 50.

Amathia Sabini Goès, Crustac. Amphip. maris Spetsberg. alluentis, p. 531.

- Spence Bate, Catal. of Amphip. in Brit. Mus., p. 197, pl. XXXV, fig. 9.

Amathilla Sabini Spence Bate and Westwood, Histor. of British Sessil Eyed Crustacea, I, 361, 1863.

- A. Beck, Crustacea Amphipoda borealia et arctica, Vidensk. Selsk. Forhandl., 1870, p. 136 .

Kopf von mässiger Länge, etwas länger als das erste Thoraxsegment, mit Einschluss der Mundtheile, welche unterhalb der vordersten Lpimere stark hervoragen, doppelt so hoch als lang. Derselbe ist mit einem zugespitzten Rostrum versehen, welches kaum bis zu ein Drittel der Länge des Basalgliedes der obern Antennen vorragt. Jie Oberseite des Kopfes zeigt eine schwache Andentung des Mittelkieles, welche sich nach vor'u zu, wo sie auf das Rostrum ibbergeht, stiriker erhebt.

Das Auge ist schwar\%, nierentörmig ovalpund, sein längster Durchmesser etwas schräge von unten und vorn nach oben und hinten gerichtet, halb so lang als die Lïnge des Koptes, der vordere Riund concar, der hintere Riund convex abgerundet, sein Lïngsdurchmesser doppelt so gross als die Breite.

Die obern Antennen ('laf. VII, Fig. 1b) sind ein wenig kiuzer als die untern, letztere von nahezu halber Körperiange. Das Basalglied der obern Intemen so lang als der Kopt, die beiden folgenden successiv etwas kiirzer und schmächtiger als das Basalglied, zusammen sind dieselben so langr als zwei Drittel des Flagellum.

Nebengeissel schlank, sechsgliedrig, drei Viertel so liung als das dritte basalglied, das letzte Glied sehr klem rudinentïr, conisch, atu ler Spitze mit enem Biischel sehr kurzer Börstehen versehen. Die 
ïbrigen Glieder schlank, langgestreckt cylindrisch, vom ersten ab etwas an Länge und Dicke abnehmend, an der Spitze mit einer Querreihe sehr kurzer einfacher Börstchen besetzt.

Die untern Antennen überragen mit ihrem Basaltheil die Spitze des dritten Basalgliedes der obern um ein weniges, sie sind ziemlich um die Länge des dritten Basalgliedes dieser letztern länger als dieselben. Das letzte ziemlich schlanke Basalglied kömmt den vier ersten an Länge nahezu gleich.

Bau der männlichen Antennen. Da mir von dieser Art ein reichliches Material aus allen Stadien zur Verfügung stand, konnte ich das Verhalten der betreffenden Theile genauer untersuchen. Die Fühler bieten bei beiden Geschlechtern die nämlichen Grössenverhältnisse und äussere Gestaltung dar, dagegen sind sie bei den männlichen Individuen mit einer sehr beträchtlichen Anzahl sehr charakteristischer Anhangsgebilde versehen.

Was zunächst die Anordnung und Anzahl der eigenthümlichen knöpfchenförmigen Anhänge betrifft, so ist letztere beträchtlicher als bei den meisten übrigen von mir darauf untersuchten Arten, indem sowol die Basalglieder als auch die Geisselglieder beider Antennenpaare äusserst reichlich mit derselben besetzt erscheinen. Charakteristisch erscheint die Anordnung derselben in regelmässige Querreihen, welche nicht nur auf den Geisselgliedern beider Antennenpare, sondern auch an der Basis der obern Antemnen auftritt.

An der obern Antenne befindet sich am ersten Basalgliede an der untern äussern Ecke eine kleine Gruppe dieser Bildungen, während an den beiden letzten Basalgliedern die ganze untere Fläche damit besetzt erscheint. Am zweiten Basalgliede bilden sie acht bis zehn mehr oder weniger deutlich ausgeprägte Querreihen, sowie anch am dritten Gliede cirea acht eben solche aus ziemlich zahlreich aneinandergereihten Anhängen bestehende schräg verlaufende Querreihen.

An dem Flagellum derselben bilden sie am Endrande jedes einzelnen Gliedes einen um den grössten Theil des Umfangs herumlanfenden, aus einer einfachen Querreihe gebildeten Ring, welcher nur an dem obern Umfange wnterbrochen erscheint, woselbst eine Gruppe von sechs bis acht kurzen Riechborsten befindlich ist. Die Anzahl derselben in diesen Querringen beträgt $8-12$, gegen das Ende der Geissel sind sie etwas weniger zahlreich, fehlen aber nur den letzten drei bis vier Gliederu gamz.

An der untern Antenne sind die drei letzten Batsalglieder an ihrer obern Fliche zicmlich dicht mit denselben besetzt, ohne dass 
sie hier indessen eine regelmässige Gruppirung darbieten. . An den (inisselgliedern dagegen sind sie sehr zierlich in dicht stehender einfacher Querreihe an dem Endrande der Glieder, in Form eines ringförmig denselhen umgebenden Kranzes angeordnet, in welchem ich :n jedem einzelnen Gliede gegen 30 zählte. Die Riechborsten fehlen hier, sodass der Kranz ununterbrochen erscheint. Gegen das Ende werden sie weniger zahlreich und fehlen den letzten fünf oder sechs Gliedern gïnzlich.

Nicht minder eigenthümlich als die soeben geschilderte Anordnung ist ferner die Form, welche die Anhänge bei der vorliegenden Art darbieten. Sie sind (Taf. VIII, Fig. 1e) zunächst auffällig lang gestielt, indem der dünne lange Stiel, auf welchem der verbreiterte Endtheil aufsitzt, beträchtlich länger erscheint als der letztere. Bei keiner andern von mir untersuchten Art besteht ein derartiges Verhältniss, indem regelmässig sonst der Stiel, auf welchem diese Bildungen aufsitzen, beträchtlich an Länge gegen den Endtheil zurücksteht. Letzterer selbst erscheint wie gewöhnlich aus drei Gliedern zusammengesetzt, bietet aber, namentlich durch die starke V'erlängerung des zweiten Gliedes, dine eigenthümlich langgestreckte Form dar, welche ich am liurzesten mit der Form einer Zipfelmuitze vergleichen möchte. Das erste Glied stellt wie gewöhnlich eine napfförmige Ausbreitung des Stielendes dar, das zweite Glied ist ungewöhnlich verlïngert und gegen das Ende hin, woselbst das Endglied sich mit demselben verbindet, merklich verschmälert. An demselben konnte ich keine Spur einer radiären Streifung oder fächerförmiger Chitinstäbchen erkemmen. Das Endglied ist von länglich ovaler Form und durch drei scharf markirte Furchen in vier Segmente abgetheilt, von denen die drei crsten concentrisch aneinander gereihten Halbringen gleichen, das letzte die Form eines länglichen Ovales darbietet. Der Längendurchmesser des gesammten Endtheils beträgt $0,060^{\mathrm{mm}}$, die grösste Breite an der Basis $0,024^{\mathrm{mm}}$; wie ich aus einer Messung zahlreicher einzelner Anhänge ersehe, scheint ihre Grösse an den verschiedenen Stellen der Fïhler kaum merklichen Schwankungen unterworfen zil sein. ${ }^{1}$

Il und theile.

Die Mandibeln (Taf. VIII, Fig. 1d) sind kräftig entwickelt, der

1 Wie ich bei dieser Art beobachtete, sind die Anhänge der mämlichen Fühler hier bereits bei den kürzlich aus dem Ei geschlüpften Jungen vorhanden, wenngleich, wie bei der Beschreibung dieses Stadiums ausführlicher dargethan werden wird, in Form und Anordnung von der erwachsenen Form abweichend. 
Zahnfortsatz zeigt zwei grössere zugespitzte Endzähne und davor vier kleinere, gegen die Basis an Grösse abnehmende, am obern Rande; der kräftig gebildete, dem Zahnfortsatz an Länge gleichkommende processus accessorius zeigt fünf bis sechs spitze Zähne. Der Kauhöcker ist gross, zeigt stark entwickelte Zahnleisten und ist dazwischen mit kurzen Härchen dicht besetzt, die Fiederborste an demselben ist vorhanden und von mässiger Länge. Der Mandibularpalpus länger als die Mandibel selbst, die beiden ersten Glieder zusammen von der Länge des letztern. Die Glieder verhältnissmässig dick, das zweite Glied etwas länger als das Endglied und leicht gekrümmt, mit der Concavität nach Aussen, die, convexe Innenseite ziemlich dicht mit ziemlich kurzen Borsten besetzt, welche wenig länger sind als das Glied breit ist. Das Endglied schlanker als das vorangehende, im entgegengesetzten Sinne leicht gekrümmt als dieses, trägt auf der Spitze einige längere Borsten, welche kiirzer als die Hiilfte des Gliedes selbst sind, der Innenrand ist mit noch kiurern Borsten dicht besetzt, eine Gruppe ähnlicher kurzer Borsten steht dicht über der Basis am Ausseniande.

Maxillarfüsse (Taf. VIII, Fig. 1c). Der untere innere Lappen kurz und breit, am Endrande mit drei starken zugespitzten dornartigen Stacheln bewehrt, ausserdem der Rand, sowie die Fläche mit ziemlich kurzen Borsten besetzt. Der obere innere Lappen am innern Rande mit mehrern Reihen dichtstehender, mässig langer Borsten besetzt, die einseitig sehr kurz gefiedert sind, ohne Bewehrung mit Stacheln oder Zähnen. Der Palpus verhältnissmässig kurz und plump gestaltet, mit Ausschluss der Kralle so lang als der Basaltheil bis zur Spitze des obern Lappens. Die Kralle selbst deutlich zweigliederig schlank, zwei Drittel so lang als das Endglied.

Färbung. Die Färbung hatte sich an manchen Exemplaren so gut erhalten, dass sie noch deutlich in allen 'Theilen erkembar erschien.

Die ganze Oberfläche des Körpers erscheint bei erwachsenen Thieren ziemlich stark mit lebhaft hellorangeröthlichen Marmorirungen gezeichnet, welche besonders an den Seitentheilen des Körpers in der Gegend der hintern 'Thorax- und vordern Abdominalsegmente, sowie an den Hinterrändern der Segmente und an den obern Rändern der Zïhne des Rïckenkieles stärker ausgeprägte Striemen und Flecken bilden. Auch an den Antennen tritt diese röthliche Zeichnung in Form von Querbändern deutlicher hervor.

Jugendform ('Iaf. VIII, Fig. 2). Wie bereits Bruzelius ${ }^{1}$ richtig

1 Bruzelius, Bidrag til Kännedomen om Skandinav. Amphip. Gammaridea, p. 51. 
hervorhebt, sind die $\Lambda$ bweichungen, welche die aus dem Ei herrorgehenden Jungen bei dieser Art von der erwachsenen Form darbieten, scher betriachtlich; sie betreffen nicht allein die mollstïndigere Gliederzahl der Antennen und den Mangel des Rückenkieles, sondern die hintern Abdominalfuisse zeigen selbst eine sehr abweichende Gestaltung, sodass man, wie jener Forscher richtig bemerkt, auf den ersten Blick geneigt ist, sie fuir eine besondere Art anzusehen. Ich hatte Gelegenheit eine ziemliche Anzahl aus diesem frühesten Stadium zi mntersuchen, wiewol ich sie nicht mehr in dem Brutraum des erwachsenen Thieres antraf. Doch befanden sie sich in denselben Gefässen mit Erwachsenen zusammen und waren wol, wie ich vermuthe, noch im Brutraum derselben befindlich gewesen. Die Länge der Jungen beträgt zu dieser Zeit 5 und $6^{\mathrm{mm}}$.

Die Antennen sind verhältnissmässig sehr viel kürzer als bei den Erwachsenen und verhältnissmässig dick und plump geformt. Sie sind fast von gleicher Länge, doch ist auch hier die untere constant etwas länger als die obere, erstere ist kaum ein Drittel so lang als die Totallänge des Thieres beträgt. Bei einem $5^{\mathrm{mm}}$ langen Exemplare waren die untern Antennen nur 1,5 $5^{\mathrm{mm}}$, bei einem von $6^{\mathrm{mm}}$ Länge, 2.mm lang.

Die Geissel der obern Antemnen besteht nur aus fuinf bis sieben ziemlich dicken und kurzen Gliedern, diejenige der untern ist sechs- bis achtgliederig. Die Nebengeissel der erstern ist zweigliederig und ron der Länge des ersten Geisselgliedes.

Sehr bemerkenswerth ist der Umstand, dass bereits in diesem friihesten Stadium die Geschlechter deutlich durch das Vorhandensein der Anhänge an den männlichen Antennen erkennbar erscheinen. Letztere sind sehr klein und konnte ich sie nur auf der obern Antenne zu dieser Zeit auffinden. Sie haben einen Längsdurchmesser von $0,020^{\mathrm{mm}}$, sind verhältnissmässig kurz gestielt und zeichnen sich in noch stärkerm Grade als bei der erwachsenen Form durch eine eigenthïmliche langgestreckte Form aus. Namentlich erscheint der Endtheil in form eines langen zugespitzten Zipfels ausgezogen und mit zahlheichern Querringehn rersehen als dort, während das mittlere cilied, welches an der ausgebildeten Antenne den Hauptantheil an der Verlängerung nimmt, noch kaum deutlich gesondert erscheint.

1/u dieser \%eit finde ich die Knöpfehen nur in ziemlich geringer Anzahl an der obern Anteme des Nännchen, und zwar zu je zweien am bude des dritten basalgliedes, sowie der Geisselglieder mit Ausnahme des letzten. Die liechborsten sind gleichfalls bereits vorhan- 
den, aber erst in der Zahl von zwei bis drei auf denselben Gliedern der obern Antenne befindlich.

Die Mundtheile zeigen nur geringe Abweichungen ron der Bildung bei den Erwachsenen. Die Mandibel besitzt einen verhältnissmässig ebenfalls noch sehr kurzen und plump gestalteten Taster, welcher kürzer ist als dieselbe; in Uebrigen sind die Theile derselben bereits im Ganzen wie bei der ausgebildeten Form.

An der vordern Maxille (Taf. IX, Fig. 1b) sind die beiden Endglieder des 'Tasters noch weniger an Grösse verschieden und man bemerkt noch ein drittes Basalglied, welches später mit dem Basalstick verwächst. Der Kanfortsatz erscheint schmächtiger und schlanker und zeigt bereits die kammartig gezähnten Borsten auf seinem Endrande.

An dem zweiten Maxillenpaar (Taf. IX, Fig. 1c) zeigt sich der innere Lappen merklich kürzer als der äussere, auch erscheinen dieselben gegen die Spitze zu etwas verschmälert und weniger breit im Verhältniss zu den Erwachsenen.

Die Maxillarfüsse (Taf. IX, Fig. 1d) sind ron ziemlich derselben Form; die einzige Abweichung, welche ich gewahren konnte, besteht in der Bewehrung des freien Endrandes des basalen innern Lappens, an welchem statt der drei stärkern Danspitzen bei den Erwachsenen, eine grössere Anzahl derartiger Dornen an dem ganzen Rande befindlich ist.

Der Körper selbst ist bei diesen noch ganz jnngen Thieren noch ohne die geringste Andentung des Kieles und erscheint infolge dessen stïker am Rücken gerundet. Die Gliedmaassen sind kürzer und gleichfalls gerlungener und haben verhältnissmässig kiurzere Glieder, welche im Uebrigen indessen keine wesentlichen Abweichungen bieten.

Un so beträchtlicher erscheinen dagegen die Formverschiedenheiten der drei letzten Fusspaare des Abdomen. Das letzte Paar derselben zeigt die beiden Endäste von sehr verschiedener Grösse, sie sind noch nicht ron der blattartig zusammengedrickten Form, sondern cylindrisch rund und gegen das Ende conisch zugespitzt. Der innere Ast ist fast nur ein Drittel so lang als der äussere und trägt auf der Spitze eine einfache dümne Borste, der äussere ist an der Spitze mit drei mässig langen einfachen Borsten und gegen die Basis noch mit einigen andern kïrzern Borsten besetzt. Die beiden vordern Paare ragen nach hinten mit ihren längern imnern Aesten ebenso weit ror als das letzte, die äussern Aeste sind etwa um ein Drittel kürzer als jene. An der Spitze sind sie sämmtlich mit einer verhältnissmässig sehr langen schlanken, etwas gekriimmten Stachel- 
borste versehen, deren Länge der Hälfte des innern Astes gleichkommt. Im Uebrigen erscheinen die Seitenränder nicht bestachelt, sondern mit ein bis zwei kürzern gewöhnlichen Borsten besetzt.

Der Caudalanhang (Taf. VIII, Fig. 2d) ist verhältnissmässig etwas kiirzer und am Endrande in der Mitte ziemlich seicht abgerundet ausgerandet, und mit vier sehr kurzen Börstchen besetzt.

Was die weitern Wachsthumsveränderungen betrifft, so fand ich bei einem jungen Thiere ron $8^{\text {mm }}$ Länge den Beginn des Kieles auf den drei ersten Abdominalsegmenten bereits schwach angedeutet, doch noch ohne zahnartige Torsprünge, die Geissel der obern Antennen war zehngliederig, die Nebengeissel aber noch zweigliederig und die letzten Abdominalfüsse hatten noch völlig die embryonale Form. Bei (mnem $11^{\mathrm{mm}}$ langen Individunm find ich dagegen den Riickenkiel schon in der ganzen Länge deutlich entwickelt und auch an den vordern Abdominalsegmenten bereits deutlich zahnatig vorspringend. Die obern Antemnen bereits mit 15 gliederigem Flagellum und dreigliedriger Nebengeissel, die letzten Abdominalfüsse haben bereits die Form der ausgebildeten Theile im Grossen und Ganzen angenommen, doch besteht immer noch eine ziemlich starke Ungleichheit in der Länge der beiden Endäste.

Die Grösse der Erwachsenen schwankt zwischen 30 und $44^{\mathrm{mm}}$ Totallïnge, die grössten Exemplare ron ()stgrönland, welche ich maass, waren $44^{\mathrm{mm}}$, darunter befanden sich männliche Individuen, welche dieses Maass erreichten, und welche also hinter den weiblichen nicht zurückbleiben. Bei $17^{\mathrm{mm}}$ langen Individuen fand ich bereits eine völlige Uebereinstimmung der Form mit den Erwachsenen, doch nehmen die Zähne des Rüickenkieles noch etwas an Grösse bei den ganz grossen Individuen zu.

Bei einem der grössten männlichen Exemplare ron $44^{\mathrm{mm}}$.betrugen:

Die letaten Abdominalfuisse

Obere Antenne . . . . . . . . . . . . $18^{\mathrm{mm}}$

Untere Antenne . . . . . . . . . . . . . $20^{\mathrm{mm}}$

Körperhöhe bis zur Seitenlinie (4. Segment) olme den Kiel $7^{\mathrm{mm}}$

Körperhöhe bis zum untern Rande der Epimere . . . $11^{\mathrm{mm}}$

Transversaler Durchmesser in der Seitenlinie des 4. Segm. $9^{\mathrm{mm}}$

Verbreitung. Diese Art gehört zu den weitverbreitetsten Formen im nordatlantischen Gebiet, da sie nicht allein längs der ganzen norwe gischen und schwedischen Nordseckiisten herabgeht, sondern selbst noch in dex Ostsee bei Kiel angetroffen wird, wie Herr Professor K. Möbius mir mittheilte, und, wie wenige der eigentlich arktischen 
Formen, längs der ganzen englischen Küisten beobachtet worden ist, wie aus den Angaben von Spence Bate (British sessil eyed Crustac, l. c.) hervorgeht.

In den von der Deutschen Expedition berïhrten Theilen Ostgrönlands gehört diese Art zu dẹ am häufigsten und zahlreichsten vorkommenden, und ist daher von einer grössern Zahl von Fundorten in den Sammlungen vertreten: Sabine-Insel 20-110 Faden, an mehrern Stellen; ebend. 10-20 Faden, an mehrern Stellen; GermaniaHafen.

32. 2) Amathilla pinguis Kröyer. 'Taf. IX, Fig. 2.

Gammarus pinguis Kröyer, Grönlands Amphip., 1838, p. 24, tab. I, fig. 5.

- Goës, Crustacea Amphipoda maris Spetsbergiam alluentis, p. 531.

Amathilla pinguis A. Boek, Crustac. Amphipod. borealia et arctica, Vidensk. Selsk. Forhandl., 1870, p. 138.

Diese von Kröyer begründete Art ist neuerdings von A. Bœek, wie es scheint mit grossem Rechte von Gammarus abgetrennt und mit Gammarus Sabini in dem Genus Amathilla vereinigt worden. Mir stand ein ziemlich reichliches Material von derselben zu Gebot, sodass ich einige Bemerkungen hinzufïgen kann.

Ton den beiden Antennenparen sind die obern beträchtlich kïrzer als die untern und ein Drittel so lang als die Körperlänge. Ich finde sie bei den von mir untersuchten Exemplaren nicht ganz zwei Drittel so lang als die untern, während Goës den Unterschied geringer angibt. Die beiden ersten Basalglieder derselben sind ziemlich gleich lang, zusammen von der Länge des Kopfes. Das dritte Basalglied ist beträchtlich kürzer und schmiichtiger, katum halb so lang als das vorangehende.

Das Flagellum ist länger als die Basis der Antenne, welche letztere zusammen etwa zwei Drittel der Geissel beträgt. Die Geissel besteht aus circa 24 Gliedern. Die Nebengeissel ist ziemlich kurz, von der Länge des dritten Basalgliedes und besteht aus drei successiv an Lünge abnehmenden Gliedern, das Endglied ist auf der Spitze mit einigen sehr kurzen Börstchen besetzt.

Die untere Antenne ist amähernd halb so lang als der Körper (in der Regel ein wenig dariber); die beiden letzten Basalglieder ziemlich verlïngert, das letzte derselben reicht bis zum ersten Drittel des Flagellum der obern Antennen. Die Geissel besteht aus einigen 30 Gliedern.

Bildung der Fühler des Männchen.

Auch bei dieser Art sind die Geschlechtsunterschiede nur in dem Zweite Deutsche Nordpolfahrt. II. 
Vorhandensein der Anhänge an den Fühlern ansgepräigt, im Tebrigen finde ich sie bei beiden Geschlechtern gleichgestaltet.

Die Knöpfchen sind auch hier wie bei Amathilla Sabini auf beiden Antemenparen vorhanden und durch eine eigenthümliche Form ausgezeichnet (Taf. IX, Fig. 2i).

Was die Anzahl und Anordnung derselben auf den Antennen anbetrifft, so sind sie beträchtlich weniger zahlreich als bei $A$. Sabini. Anstatt der Querreihen, in welcher sie bei jener Art auf den Geisselund Basalgliedern stehen, findet sich hier nur eine einfache Reihe derselben.

An der untern Antenne fehlen die Knöpfchen an den Basalgliedern ganz und sind auch hier bis zur Nitte der Geissel an den einzelnen Gliedern an der obern Ecke in einfacher Zahl vorhanden, während die Riechborsten fehlen.

Mundtheile.

Mandibeln (Taf. IX, Fig. $2 \mathrm{j}$ ) wie bei Amathilla Sabini ziemlich kräftig gebildet, mit rerhältnissmässig kurzem gedrungenen Taster. Der Zahnfortsat\% rerhält sich sehr eigenthïmlich bei dieser Art, indem an demselhen die Zähne vollständig fehlen. Derselhe endet mit einer ziemlich breiten abgerundeten Spitze, sein oberer Rand, welcher sonst immer gezahnt ist, ist rollkommen ohne dieselben, wie ich mich durch Zergliederung mehrerer Exemplare bestimmt ïherzeugte. Von keinem der frïhern Beobachter ist dieses eigenthïmliche Verhalten bemerkt worden.

Die Maxillen des ersten Paares (Taf. IX, Fig. 2d) haben einen ziemlich liurzen Taster, das Endglied ist gerade, am Ende ziemlich breit abgerundet, ron keulenförmiger Gestalt und überragt um die Hälfte seiner Länge den Kautheil. Auf seiner Spitze eine Reihe sehr kurzer kleiner Stacheln, welche nach abwärts in eine Reihe rom innern Rande etwas entfernt stehender ziemlich kurzer Borsten sich fortsetzen.

Der Katheil ist rerhïlnissmäsisig schlank und langgestreckt, auf der schräg alogeschnittenen Spitze ist die gewöhnliche Anzahl kammz:ihniger Kauborsten hetindlich, welche mit drei bis vier ziemlich langen zugespitzten Kammz:ihnen versehen sind. Die äussern derselben sind durch eine eigenthümlich hreit abgerundete spitze und weniger starker Zïhne otwats abweichend von den ibrigen. Der Basallappen ist von dreieckiger, gegen die Spitze stark verschmälerter und zugespitzter Form.

Das zweite Maxillenpaar ('Taf. IX, Fig. 2e) zeigt nichts Bemerkenswerthes; die beiden Lappen sind von gleicher Länge, der innere 
etwas schlanker mol ausser den Randborsten mit einer fast iiber die ganze Fläche fortziehenden schrägen Borstenreihe.

Die Maxillarfüsse (Taf. IX, Fig. 2h) sind mit rerhältnissmässig noch kürzer verstärktem Taster versehen als bei Amathitla Sabimi. Die drei Glieder des Tasters zusammen mit Ausschluss der Kralle sind kürzer als der Basaltheil bis zur Spitze des obern Lappens.

Die Oberlippe (Taf. IX, Fig. 2g) ist am Endrande in der Mitte ziemlich stark abwärts in Form einer stark rorspringenden conisch abgerundeten Spitze verlängert.

Die beiden vordersten (Taf. IX, Fig. 2c) Fusspaare sind schlank gleichgestaltet, mit wenig ausgehildeten schwachen scheeren, wenig kuirzer als die beiden folgenden.

Das Scheerenglied ist langgestreckt linear, dreimal so lang als breit, die beiden Ränder laufen im basalen Abschnitt, welcher die Hälfte bildet, parallel, der Endtheil erscheint durch den Krallenausschinitt, welcher geradlinig ist und mit dem basalen Theil des Randes in stumpfem Winkel zusammentrifft, etwas rerschmälert und nach der Spitze hin rerjüngt. An der Ecke, welche der Krallenausschnitt mit dem untern Rande bildet, stehen drei bis vier kurze Stacheln und darïber noch vier in einer Reihe hintereinander angeordnete kurze Stacheldornen.

In der Form und Grösse der Scheeren findet kein Unterschied an den beiden rordersten Fusspaaren statt; ebenso wenig als ein solcher zwischen beiden Geschlechtern zu beobachten ist.

Die drei hintern Fusspare des Thorax nehmen der Reihe nach an Länge zu, das erste ron ziemlich der Länge der vorangehenden, die beiden folgenden etwas länger; doch ist die Differenz zwischen dem fünften und siebenten Paar geringer als die Länge des Endgliedes des letztern, während das letztere der vorhandenen Paare nur sehr unmerklich an Länge verschieden ist.

Von den drei hintern Abdominalfussparen ist das letzte ron mässiger Länge und etwas kürzer als das vorletzte.

Das erste der drei Springfusspaare (Taf. IX, Fig. 2 b) besitzt gleich lange Endäste und ist mit dem vorangehenden von gleicher Länge.

Caudalanhang (Taf. IX, Fig. 2f) verlängert, ein und ein halb mal so lang als breit, nach dem Ende zu mässig verschmälert und quer abgeschnitten, der Endrand ist durch zwei sehr seichte Einschnitte in drei ahgermulete Lappen getheilt, zwischen denen zwei sehr feine Börstchen stehen.

Die Fä rbung ist bei den Weingeistexemplaren ziemlich gleichförmig gelbröthlich, ohne besonders herrortretende Flecken oder Zeichnungen. 
Ueber die Abreichungen der Jugendformen hatte ich nicht Gelegrenheit etwas zn ermitteln, dat die kleinsten mir vorliegenden Exemplare bereits die Bildung der Erwachsenen hatten.

Die Grösse bei dem grössten ron mir gemessenen Exemplare $2 t^{\text {mm }}$, die durchschnittliche Cröisse erwatchsener Individuen 20 -2:2nm; bei einem $17^{\mathrm{mm}}$ langen Individum fand ich indessen schon die Bruttasche mit Eiern gefüllt. Auch hiex finde ich die Männchen nicht kleiner als die weiblichen 'Thiere.

Bei einem Exemplar von 22mm 'Totallänge betrugen:

Obere Anteme . . . . . . . . . . . . $7,5^{\mathrm{mm}}$

Untere Anteune . . . . . . . . . . . . . . . $12^{\mathrm{mm}}$

Letztes Paar der Abdominalfüsse . . . . . . . . $3^{\mathrm{mm}}$

Höhe les Körper's bis zur Seitenlinie (viertes Segment) . $t^{\text {mm }}$

Höhe des Körper's bis zum untern Riande der vierten Epimere ¿, $55^{\text {mm }}$

Transversaler Durchmesser (viertes Segment) . . . . $5^{\text {mm }}$

Verbreitung. Die vorliegende Art scheint im nordüstlichen Grönland zu den verbreitetern Formen zu gehören, da sie an verschiedenen Stellen in ziemlich zahlreichen Exemplaren atufgefunden ist: SalbineInsel 10 Faden; Kap Wyun 3 Faden, 3. November 1869 reichlich; Furd-Shamnon 30 Faden, Angust 1560; Germania-Hafen 3 Faden (11. October 1869 mit Anomyx lagena).

Im Uebrigen ist dieselbe als eine ausschliesslich arktische Form anzusehen, da sie ausser den Küsten von Grönland und Spitzbergen bisher noch nirgend angetroffen worden ist. In Allgemeinen scheint sie, wie aus Dr. Pansch's Angaben hervorgeht, vorzugsweise in geringerer Tiefe bis 30 Faden zu leben, woselbst sie in grösster Zahl angetroffen wurde.

\section{Atylina e, Lilljeborg.}

Die Mitglieder dieser Familie wïrden in der Begrenzung, wie sie derselben von A. Back gegeben wird, eine sehr natiirliche Gruppe bilden, wenn nicht diejenigen Arten, welche dieser Autor unter der Gattung Atylus vereinigt hat, in mancherlei P'unkten ron dem Typus derselben sich stark entfernten. Dagegen bietet der grösste Theil der Arten, welcher die Gattung Paramphithoë, wie ich sie begrenze, bilden, sowie die zunächst stehenden Formen ansserordentlich grosse Uebereinstimmung dar. I ie ron A. Back errichtete (iruppe der Epimerinen schliesst sich in allen wesentlichen Punkten so vollkommen an diese letztern in, dass es mir nicht wohl gerechtfertigt erscheint, dieselbe als besondere Familie aufrecht zu erhalten, die einzigen ('hatraktere, welche die Gattungen Acunthorone und Eprimeria, welche 
letztere ich freilich nicht aus eigener Anschauung kenne, von den $P(t-$ ramphithö̈-Arten trennen, bestehen in einer bedeutenden Festigkeit und Rigidität des Hautpanzers und einer an denselben auftretenden eigenthïmlichen Stachelbekleidung.

Atylus Leach.

Atylus A. Bœck, 1. c., p. 109, Char. Emendat.

Diese Gattung ist in den Sammlungen von Ostgrönland durch nachstehende zwei Arten vertreten.

\section{1) Atylus carinatus (F.) Taf. X.}

Gammarus carinatus F., Entom. system., II, 515.

Atylus carinatus Leach, 'Transact. of the Linn. Society, XI, 357.

Amphithoë carinata Kröyer, Grönlands Amphipoder, p. 28, tab. II, fig. 6.

Paramplithoё carinata Goës, Crust. Amphip. maris Spetsberg. alluent., p. 523. Atylus carinatus A. Bock, Crustacea Amphip. borealia et arctica, p. 110.

Diese öfters beschriebene Art lag sehr reichlich zur Untersuchung vor, wodurch ich hinreichenden Aufschluss über die äussern Formverhältnisse erlangen konnte.

Als ein auffälliger Umstand in der Bildung der Antennen muss die völlige Abwesenheit der eigenthïmlichen knöpfchenförmigen Hautanhïnge bei beiden Geschlechtern angesehen werden, da diese Bildungen sonst ganz allgemein bei den Atylinen und den iibrigen verwandten Gruppen angetroffen werden. Ton dieser Abwesenheit konnte ich mich bei der vorliegenden Art mit voller Sicherheit ïberzengen, da mir ein sehr reichliches Material an Individuen aller Grössen zur Verfügung stand, und von mir grösstentheils mikroskopisch in dieser Hinsicht geprïft wurde. Ob Atylus Smittii sich ebenso verhält, kanm ich nicht entscheiden.

Was die vorliegende Art betrifft, so prägen sich die sexuellen Differenzen nur in ziemlich wenig hervortretenden Formverschiedenheiten aus. Bei den männlichen Thieren, welche sich unter den erwachsenen Stiicken durch das Fehlen der Brutblïtter documentiren, zeigen die beiden vordersten Fusspaare etwas stärker entwickelte Scheeren, die merklich breiter und grösser sind als bei den Weibchen, im Uebrigen aber dieselbe Gestalt besitzen. In Betreff der Antennen fund ich in der äussern Form keine merklichen Verschiedenheiten; diejenigen der männlichen Thiere mochten um ein ganz Geringes lïnger sein, doch war der Lnterschied nicht merklich genug, un aus der Breite individueller Abweichungen herauszutreten. Dagegen erschienen die Fühler rïcksichtlich der Beborstung bei beiden 
Geschlechtern mach einem etwas abweichenden Typus gebildet, was sich mir bei einer Vergleichung einer Anzahl von Exemplaren als ein constantes Merkmal herausstellte.

Bei den weiblichen Thieren (Taf. X, Fig. $1 \mathrm{~g}$ ) fand ich stets die cinander zugewandten Flichen der beiden Antennenpare mit rerhältnismörsig sehr langen, lang gefiederten Fiederborsten beretat, wolche in regelmässigen $\Lambda$ bständen voneinander stehen und neben welchen eine kleine Gruppe kürzerer Borsten rorhanden ist. Auch die einzelnen Glieder der Geissel, sowol der obern als auch der unteru Antemen ersehienen mit je einer derartigen langen Fiederborste versehen.

Dagegen erschienen bei den Mämnchen (Taf. X, Fig. 1f) an den entsprechenden Flidenen der Batsalglieder beider Antennenpatare eigenthïmlich gekriimmte Büschel kurzer gekrümmter Härchen, wodurch die Oberfläche der Antennen ein eigenthïmlich zottiges Ansehen erhält, während die langen Fiederborsten sowol hier als auch auf den Geisselgliedern fehlen und nur durch eine viel kürzere einfache Borste an den Basalgliedern vertreten werden. Von eigenthümlichen knopfförmigen Anhängen, wenn auch in verkiimmertem Zustande war niemals eine Andeutung vorhanden.

Mund theile. Die Mandibeln (Taf. X, Fig. 1b) sind wie bei den Atylinen riemlich kräftig, anf heiden Seiten gleichgebildet und mit stark gezahntem processus accessorius, sowie mit stark vorragendem und viereckigen, mit starken Zahnleisten versehenem Kanhö̈ker ausgestattet. Der Taster ist ziemlich lang und schlank, lïnger als die Mandibel selbst; das schlanke eylindrische Endglied kaum kürzer als das vorhergehende, sowie dieses am innern Rande mit ziemlich langen Fiederborsten besetzt. Die Insertion des Tasters ist wie bei den rerwandten Itylinen beträchtlich oberhalb des Kauhöckers gelegen. An der Wurzel des Kauhöckers ist an der innern Seite eine ziemlich lange Fiederborste vorhanden.

Der processus accessorius, welcher an beiden Kiefern gleichgestaltet ist, ragt ebenso weit ror als der Zahnfortsatz und ist wie dieser mit fünf bis sechs kräftigen Zähnen versehen.

Die vordern Maxillen (Taf. X, Fig. $1 \mathrm{~h}$ ) besitzen einen ziemlich kurzen Taster, welcher nur wenig über den Kautheil hervorragt und dessen riemlich hreites, leicht gekriimmtes Endglied an der abgerundeten Spitze mit einigen kurzen einfachen Borsten besetzt erscheint. Der Kaufortsatz ist ziemlich lang und schlank, auf der Spitze mit fünf Paar gezühnten Borsten versehen, von welchen die äussersten in eigenthïmlicher Weise an der spitze geweihartig gezïhnt erscheinen. 
Der Basallappen ist dreieckig zugespitzt und ragt kaum iiber die Basis des Kautheiles nach vorn.

Die hintern Maxillen bieten nichts Besonderes, der innere Lappen erscheint ein wenig kürzer als der äussere.

Die Maxillarfüsse (Taf. X, Fig. 1c) zeigen einen mässig langen, ziemlich schlanken Taster, dessen Länge dem Basaltheil bis zur Spitze des obern Lappens gleichkommt. Das zweite Tasterglied ist stark verlängert, schlank und ragt kaum über die Spitze des obern Lappens hervor, das dritte Glied ist beträchtlich kürzer als dieses und mit einer zweigliedrigen ziemlich schlanken Kralle rersehen, welche etwas mehr als halb so lang als das Endglied ist.

Die Oberlippe (Taf. X, Fig. 1i) ist ziemlich quadratisch, am Endrande sehr schwach ausgerandet und an der Basis nach beiden Seiten in einen kurzen seitlichen, alogerundeten Fortsatz verlängert.

Die Springfüsse sind mässig stark verlängert und ziemlich schlank geformt. Das hinterste Paar derselben (Taf. X, Fig. 1j) besitzt zwei stark verlïngerte, gleich lange, schlanke, cylindrische Endäste, welche beinahe vier mal so lang sind als das sehr kurze Basalglied. Sie sind am Lnde mit zwei hakenförmig gekrümmten, kurzen starken Endkrallen rersehen, ïber denen noch mehrere Paare gleich geformter Stacheln befindlich sind, die Seitenrïnder sind mit lïngern Borsten bewimpert, zwischen denen am innern Rande nach oben zu noch vier kurze, ziemlich starke Stacheln stehen.

Das vorletzte Paar der Springfiisse ('Taf. X, Fig. 1e) ist beträchtlich kürzer als die vorigen und reicht nur etwa bis zur Mitte der Endïste desselben nach hinten vor. Die Endïste desselhen sind wenig an Länge verschieden, der äussere kaum um ein Viertel kürzer als der innere, beide cylindrisch, am Ende zugespitzt und in eine ziemlich starke einfache, ziemlich gerade Endkralle ausgehend; der äussere Ast von der Länge des Basalgliedes.

Das vorderste Paar der Springfüisse (Taf. X, Fig. 1d) ist beträchtlich länger und ragt nach hinten ebenso weit als das letzte Paar vor. Seine Endäste sind von gleicher Länge, mit einer langen starken Endkralle versehen und gleich lang mit dem Basalgliede, sie sind an den Seitenrändern, so wie die des zweiten Paares mit ziemlich starken Stacheln versehen.

Der Caudalanhang (Taf. X, Fig. 1j) ist halb elliptisch, ein und ein halb mal so lang als breit und durch einen tiefen mittlern Einschnitt in drei Viertel seiner Länge getheilt. Letzterer ist in der Hälfte seiner Länge sehr schmal spaltförmig, verbreitert sich aber in der Endhälfte, sodass die beiden Seitenhälften des Anhanges an 
der Spitze zipfelurtig verschmälert erscheinen, sie sind auf dem zugespitzten Ende mit einer kurzen Stachel und einer kurzen Borste versehen.

Grösse. Die vorliegende Art gehört zu den ansehnlichern unter den arktischen Imphipoden, die Grösise der erwitchsenen Exemplare schwankt im Allgemeinen zwischen $30-35^{\mathrm{mm}}$. Das grösste von mir gemessene Stiick war $: 36^{\mathrm{mm}}$ lang. Die mämnlichen Exemplare stehen den Weibchen an Grösse nicht nach.

Bei einem Individum von $27^{\mathrm{mm}}$ Totallinge fand ich:

Länge der Antennen . . . . . $11^{\mathrm{mm}}$

Höhe des Körpers bis zur Seitenlinie $4^{\mathrm{mm}}$

Querdurchmesser (viertes Segment) . $3^{\mathrm{mm}}$

Jugendformen. Obwol ich mehrere erwachsene Weibchen mit Eiern in der Bruttasche antraf, hatte ich doch nicht cielegenheit die Gen ansgeschliupften Jungen noch in dem Brutraum selbst zu beohachten. Indessen traf ich ein ganz junges 'Thier, welches nur vor kurzem atus dem Li geschlïpft sein komnte und mir über die friiheste Form bei dieser Art Aufschluss gewïhrte.

Dasselbe mass nur im Ganzen 4,5 $5^{\mathrm{mm}}$. Die ebenfalls gleich langen Antemnen $1,5^{\mathrm{mm}}$, also kürzè als bei den Erwachsenen. Der Körper ist im Grossen und Ganzen wie bei diesen, doch ist derselbe noch nicht ganz so stark comprimirt, auf dem Rücken in dem vordern Theile abgerundet, und der Kiel ist nur an den vier ersten Abdominalsegmenten ziemlich schwach angedeutet und mit sehr kurzen zilhnartigen Spitzon verschen, welche an den beiden letzten der betreffenden Segmente etwas stärker hervorragen.

Der Kopf ist gross, das Auge klein kreisrund und schwarz, es nimmt dieselbe Stellung ein wie beim Erwathsenen. Das Rostrum ist noch sehr kurz, cin Viertel so lang als dias crste Basalglied, breit und rorn abgerundet. Die Antemnen sind plumper und rerhältnissmässig viel dicker als bei der ausgebildeten Form, sie bestehen aus vicl weniger zahlleichen Gliedern. Die Basalglieder der obern Antenne sind wenig an Länge vershieden, die heiden ersten gleich gross, das dritte, zwei Drittel so lang als das rorangehende, trägt ein kurzes cingliedriges lindiment der Nebengeissel, welehes ganz wie beim Frwachsenen gestaltet ist. I) Cieissel ist kiirzer als der Basaltheil und besteht nur aus fünf ziemlich kurzen und dicken Gliedern.

An den untern Antennen ist der Basaltheil etwas dicker und kiirzer als heim Erwachsenen, die Geissel sehr viel kïrzer als jener, nicht länger als das letzte Basalglied und besteht nur aus vier Gliedern. 
Die vordern Epimeren sind im Ganzen ganz wie beim Erwachsenen, die der drei ersten Abdominalsegmente sind rechtwinklig und tragen jede auf der hintern Ecke einen starken Stachel, der hintere Rand ist ganzrandig.

Die Springfuisse sind verhältnissmässig viel kiirzer und plumper geformt als bei den Erwachsenen und mit kurzen dicken Endästen versehen, deren Bestachelung im Ganzen wie beim Erwachsenen sich verhält, das mittlere Paar derselben ist nur wenig kürzer als die beiden ïbrigen. Der ('audalanhang ist im (ranzen nicht abweichend gebildet.

Die Färbung war bei allen Stücken gleichmässig gelblich, nur bei einzelnen erschienen in der Mitte der Seitentheile der vier ersten Abdominalsegmente undentlich ausgeprägte Jängswische, welche die Gegend des Seitenkiels der betreffenden Segmente einnehmen.

Verbreitung. Diese Art, welche zu den eigentlich hocharktischen gehört, ist an den Küsten des nordöstlichen Grönlands eine der häufigsten, da sie an der Mehrzahl der Fundorte und meist zahlreich gesammelt wurde: Sabine-Insel 10 Faden und 20-110 Faden; Germania-Hafen 3 Faden, October 1869, sowie ron einigen andern nicht näher bezeichneten Stellen.

\section{2) Atylus Smittii (Goës).}

Paramphithoë Smittii Goës, Crustacea Amphipoda maris Spetsbergiam alluent., p. 524, fig. 14 .

Atylus Smitii A. Boek, Crustacea Amphipoda borealia et arctica, p. 110.

Nur ein einziges Exemplar von Ostgrönland; Nord-Shamnon 30 Faden.

Dasselbe ist $16^{\mathrm{mm}}$ lang. Untere Antennen etwas länger als die obern, $10^{\mathrm{mm}}$.

Acanthozoue, A. Boek.

Acanthosoma Owen.

Die Gattung schliesst sich, wie oben bereits bemerkt, in dem gesammten Habitus des Körpers, sowie der Bildung der Fühler und Fuisse durchaus an Paramphithoë an. Die vorliegenden sehr wenigen Exemplare der einzigen bekannten Art sind insofern ron hesonderm Interesse, als zwei derselben einen Ausbildungsgrad zeigen, der, soviel ich ersehen kann, noch nicht beschrieben worden ist. Es zeigt sich auch hier, dass die Stachelbekleidung, welche bei dem eben ansgeschlïpften Thiere rermuthlich kaum entwickelt ist, in erwachsenen Zustande mit dem Alter sich in höherm Grade ausbildet. 


\section{1) Acanthozonc hystrix Owen. 'I'af. XI.}

Oniscus cuspitatus Lepechin, Acta Petropolitana, 1778, p. 247, tab. VIII, fig. 3. Acanthosoma hystrix Owen, Append. to Ross second Voy., p. 91, tab. B, fig. 4. Amphithö̈ hystrix Kröyer, Grönlands Amphipoder, p. 31, tab. II, fig. 7.

Paramphithoë hystrix Bruzelius, Scandinaviens Amphip. Gammaridea, p. 71.

- Goës, Crustacea Amphip. maris Spetsbergiam alluent., p. 525.

Acanthozone cuspidata Bøck, Crustacea Amphip. borealia et aretica, p. 104.

Diese Art, welche durch die seltsam ausgebildete Stachelbekleidung des Körpers zu den bezeichnendsten Formen unter den arktischen Amphipoden gehört, ist an den Kïisten des nordöstlichen Grönland wie es scheint ziemlich selten, sowie sie überhaupt allenthalben nur selten vorzukommen scheint. Ich fand nur zwei Exemplare unter den von Dr. Pansch gesammelten Crustaceen vor, von welchen das grössere ziemlich erwachsen war, das kleinere dagegen, ein ziemlich junges Exemplar, leider in sehr defectem Zustande sich befand.

Ich habe den eimmal allgemein gebräuchlich gewordenen Artnamen Owen's für dieselbe beibehalten, wiewol die erste Beschreibung des Thieres bereits frïher von Lepechin gegeben wurde. Da die mir bekamnten friihern Mhbildungen den Habitus des Thieres etwas mrollkommen wiedergeben, so habe ich nochmals eine Zeichmung von demselben entworfen.

Irund theile.

Die Oberlippe ('Taf. XI, Fig. 1j) ist verlängert, länger als breit, am Ende abgerundet und in der Mitte in eine etwas verschmälerte aldgerundete Spitze verlingert, welche mit feinen Hïrehen besetzt ist.

Der Basalrand ist an den Seiten in zwei kurze abgerundete Vorspriinge erweitert, der nach aufwärts gerichtete zwischen den Antennen gelegene Fortsat/ ist kurz und von conischer Form.

Die Mandibeln ('Taf. XI, Fig. 1b) sind auf beiden Seiten gleichgebildet. Der 'Taster ist verhältnissmässig kurz, von der Länge der Mandibel; das Endglied ein wenig kürzer als das zweite und auf der Spitze und am innern Rande mit ziemlich kurzen Borsten besetzt. Der /ahnfortsatz ist mit sechs bis sieben ziemlich kuxzen und kräftigen Zähmen versehen, der processus accessorius ist kräftig, mit fünf starken Zähnen versehen und ragt beinahe ebenso viel nach Aussen als der Zahnfortsatz. Die Borstenreihe besteht aus gegen 15 ziemlich starken gekrimmten Borsten. Der Kauhöcker ist von mässiger Grösse, ragt stark hervor und ist mit starken Zahuleisten auf der hreiten viereckigen Endtiache versehen; die lïngere Fiederborste an der Wurzel desselben ist vorhanden. Die Insertion des Kauhöckers 
ist nicht so tief als bei vielen Atylinen, der obere Rand desselben ist kaum tiefer als die Insertion des 'Tasters.

Das erste Maxillenparr (Taf. XI, Fig. 1e) zeigt einen ziemlich grossen Taster, dessen am Ende koulenförmig verbreitertes Endglied den Kiatheil beträichtlich ïberragt. Ier abgerundete Endrand desselben ist mit einer Reihe von acht zugespitzten Stachelborsten besetzt, welche von Aussen nach Innen gleichmässig an Länge zunehmen. Der ziemlich schlanke Kaufortsatz ist an dem schräg abgeschnittenon Fndrande mit der gewöhnlichon Inppelreihe gezähnter Kauborsten rersehen, die in der Mitte mit zwei kurzen spitzen Kammzähnen besetzt sind. Der Basallappen ist ziemlich gross, von vier'eckiger Form und ragt bis zum innern Ende des Kaufortsatzes nach vor'n vor, er ist mit sieben bis acht mässig langen langgefiederten Borsten am Endrande besetzt.

Das zweite Maxillenparr (Taf. XI, Fig. 1f) ist von der gewöhnlichen Form, die beiden Lappen sind gleich lang, der innere etwas breiter als der äussere, beide auf der abgerundeten Spitze mit mässig langen einfachen Borsten dicht besetzt.

Die Maxillarfüsse (Taf. XI, Fig. 1d) besitzen einen mässig langen Taster, dessen Länge dem Basaltheil mit Einschluss des vordern Lappens gleichkommt. Das Endglied ist etwas kürzel als das zweite, am Ende etwas verbreitert und mit einer zweigliederigen, ziemlich schlanken Kralle versehen. Der untere innere Lappen ist am obern Rande mit fünf ziemlich starken, kurzen Dornen bewehrt, darunter steht eine einfache Reihe längerer Borsten. Der obere innere Lappen ist oval, ziemlich kurz, reicht nach vorn bis zur Mitte des zweiten Tastergliedes und ist am obern Ende mit einigen längern einfachen Borsten, darunter am Innenrande mit einer einfachen Reihe sehr kurzer Börstchen besetzt, welche vom Rande selbst etwas entfernt stehen.

Die beiden vordersten Fusspare (Taf. XI, Fig. $1 \mathrm{~g}$ ) sind schlank geformt, sie sind wenig an Länge verschieden, aber beträchtlich kürzer als die beiden folgenden.

Das fuinfte bis siebente Fusspaar (Taf. XI, Fig. 1h) sind schlank und ziemlich verlängert, die beiden ersten sind unbedentend an Länge verschieden und wenig lïnger als die vorangehenden. Das siebente ist dagegen ziemlich betrïchtlich verlängert und mit etwas stïrkern, langgestreckten Gljedern versehen.

Von den Springfiissen (Taf. XI, Fig. 1i) zeigt das vorletzte Paar ein sehr kurzes dickes Basalglied, welches nur halb. so lang ist als der Caudalanhang. Dasselbe trägt zwei gleich grosse und gleichge- 
staltete Endäste, welche reichlich drei mal so lang sind als es selber, sehr rhlank und lamellïr zusammengedrückt erscheinen; sie sind gegen das Ende zu gleichmässig verjüngt und zugespitzt, sowie an den beiden scharfen Seitenrändern mit einer lieihe sehr kurzer kleiner Dornen besetzt, neben welchen vereinzelt sehr kurze Börstchen stehen.

Das vorletzte Paar ist beträchtlich länger und ragt nach hinten nur bis zur Mitte der Endäste des letzten Paares vor. Seine Endäste sind ungleich, der äussere um ein Viertel kürzer als der innere, sie sind schlank cylindrisch, am Ende mit einer ziemlich langen schlanken geraden Endkralle versehen und an den seiten bestachelt.

Das vorderste Paar ist beträchtlich länger, ragt nach hinten so weit vor als das letzte, die Endäste sind nahebei gleich lang, im Uebrigen wie die des mittlern Paares gestaltet.

Der Caudalanhang (Taf. XI, Fig. 1 c) ist von mässiger Länge, etwas länger als an der Basis breit, nach der Spitze zu etwas verschmälert und durch einen kurzen spitzen mittlern Einschnitt an Endrande in zwei spitze dreieckige Seitenlappen getheilt. Im Uebrigen ist derselbe ohne Stacheln oder Borsten.

Die Färbung ist gleichmässig blass gelbröthlich.

Die Grösse betrug bei dem grössern erwachsenen Stücke $22,5^{\mathrm{mm}}$ vom vordern Stirnrande bis zum Ende der Springfüsse, an denselben fand ich:

Untere Antenne . . . . . . . . . . . $23^{\mathrm{mm}}$

Körperhöhe bis zur Seitenlinie (viertes Segment) $4^{\mathrm{mm}}$

Ganze Höhe daselbst . . . . . . . 5, $5,5^{\mathrm{mm}}$

Querdurchmesser daselbst . . . . . $5^{\mathrm{mm}}$

Hinterste Springfüisse . . . . . . . $4^{\mathrm{mm}}$

Das kleinere Exemplar maass nur $8^{\mathrm{mm}}$. Die Bestachelung an demselben zeigte einige Abweichungen von der ausgebildeten Form.

Die Stirn war bei dem letztern vom Beginn des Kopfes an ziemlich stark nach abwärts gebogen, der mittlere Frontalstachel viel kleiner und schwach entwickelt; an ersten Basalglied der obern Antenne ein ziemlich langer schlanker, am äussern obern Ende befindlicher Stachel, die Stachehn des untern Gesichtsrandes kiirzer und schwächer. Der vordere Dorsalstachel des ersten Segments stärker nach worn serichtet. im Uebrigen die Dorsalstacheln ïhereinstimmend mit dem erwachsenen.

An den Abdominalsegmenten zeigen die Hinterränder weniger Seitenstacheln, an den beiden ersten vier, am dritten nur zwei, 
ebenso sind die Coxen der drei letzten Fusspaare des Thorax nur mit zwei Stacheln am Hinterrande versehen und schmaler.

Aus den Angaben von Kröyer, Bruzelius und A. Bøek geht, was die Bestachelung betrifft, demnach hervor, dass sie nur jüngere Exemplare vor sich gehabt haben, was auch durch die von beiden Erstern gemachten Grössenangaben bestätigt wird. Ein ebensolches unausgewachsenes Exemplar hat auch der a. a. O. citirten Abbildung Owen's zu Grunde gelegen.

Verbreitung. Die beiden einzigen Exemplare waren von Nordshannou 30 Faden tief zusammen mit Amphithonotus aculcatus gesammelt worden. Ausserdem ein grosses sehr beschädigtes von unbestimmtem Fundort, welches ich noch am Schlusse der Arbeit in einem Glase mit Balanus porcatus von der ostgrönländischen Küste auffand, und welches ganz die Ausbildung des oben beschriebenen grössern Stückes besass.

\section{Gen. Paramphith oë, Bruzelius.}

Diese Gattung, wie sie von Bruzelius ${ }^{1}$ begrïndet und späterhin von Goës mit mehrern andern neuen Arten bereichert wurde, umfasste ziemlich heterogene Formen, welche durch $A$. Bøck bereits in verschiedene Gattungen abgetrennt worden sind. So wurden die Pleustinen, für welche dieser Autor den Bruzelius'schen Gattungsnamen beibehielt, den Oedicerinen zugefügt, während die der Gruppe der Paramphithö̈ carinata angehörigen unter dem Genus Atylus mit grossem Rechte zusammengefasst wurden. Dagegen wurden die den Stanm des Bruzelius'schen Genus bildenden kleinen Arten, wie mir scheint in etwas zu weitgehender Weise, von diesem Forscher in eine Anzahl nener Gattungen: Pontogeneia, Halicrates und mehrere andere gespalten, die doch nur auf sehr unbedeutende Abweichungen begründet sind.

Ich ziehe daher vor, fuir die nachfolgenden drei ostgrö̈nlïndischen Arten die Bruzelius'sche Gattungsbezeichnung beizubehalten und wïrde sich die Gattung in dem Simne, wie ich sie begrenze, in folgender Weise charakterisiren:

Kleine zarte, mit sehr dünnen Hautbedecknngen versehene Atylinen von schlankem lö̈perbau, mit sehr verlüngerten falenfömigen Fühlern und schlanken, stark verlängerten Füssen, die beiden rordern mit linearen schwach entwickelten Scheeren. Rücken abgerundet, Körper krumm zusammengedrickt, Rostrum sehr klein. Spring-

1 Skandinaviens Amphipoda Gammaridea, p. 68. 
füsse sehr schlank, rerlängert, das letzte Paar mit lanzettförmigen zusammengedrüickten Endästen.

Die Männchen besitzen stets zahlreiche specifische Anhänge der Fühler, deren Anordnung und Form freilich bei den einzelnen Arten anffillig grosse Verschiedenheiten darhietet, im iibrigen keine ̈̈ussern sexuellen Charaktere.

Uebrigens ist die Gattung durch die ausserordentliche Individuenzahl, wodurch Paramphithoë incrmis und fulvocincta an der ostgrönlïndischen Küste mit zu den dominirenden Arten gehören, für die dortige Littoralfauna besonders bezeichnend.

\section{1) Paramphithoë incrmis Kröyer.}

Amphithoë inermis Kröyer, Grönl. Amphipoder, p. 47, tab. III, fig. 11.

Amphithoë cremulata Kröyer, ebend., p. 50, tab. III, fig. 12, mas.

Atylus inermis Spence Bate, Catalogue of Amphip. in the Brit. Mus., p. 138, 1). XXVI, fig. 5 .

Atylus crenulatus Spence Bate, ebend., p. 139, pl. XXVI, fig. 6.

Paramphithoë inermis Goës, Crustac. Amphip. maris Spetsb. alluentis, p. 524.

Pontogeneia inermis Beek, Crustacea Amphipoda borealia et aretica, p. 114.

Diese Art, welche der Massenhaftigkeit der Individuen nach zu den vorherrschenden im nordöstlichen Grönland gehört, lag mir in sehr reichlicher Weise in allen Zuständen zur Untersuchung ror.

Die Färbung bei lebenden Thieren ist röllig durchsichtig, farblos, bei Weingeistexemplaren gleichmässig gelblich.

Grösse. Bei dieser Art, sowie der nahestehenden Paramphithö̈ fulvocinctu ist die beträehtliche Grössenversehiedenheit bei ausgehildeten Thieren ron demselben Fundort auffïllig. Im Allgemeinen gehört sie zu den kleinern Formen.

Die Länge der erwachsenen Stiicke beträgt in der Regel zwischen $8-12^{\mathrm{mm}} ; 9^{\mathrm{mm}}$ grosse weibliche Thiere fand ich bereits mit gefülltem Brutraum an. Daneben fanden sich indessen grössere Indiriduen, welche dies Maass beträchtlich überschritten, bis zu $15^{\mathrm{mm}}$ long. tot. Lis schienen dies vorzugsweise Weibchen zu sein, wenigstens fand ich keine mit Fühleranhängen dazwischen, auch trugen sie meistens Brut bei sich.

Jugendform. Ich untersuchte kürzlich aus dem Ei geschlïpfte junge Thiere von cirea 2mm Totallänge, welche die gewöhnlichen embryonalen Charaktere darboten. Antennen viel kiirzer als beim Erwachsenen, die untern um ein Drittel länger als die obern, sind selber nur ein Drittel so lang als der Körper. Obere Antennen mit kurzen dicken Basalgliederm, die gleichmässig in die rerhältnissmässig grossen (icisselglieder ïbergehen, das dritte basalglied ohne den zahnförmi- 
gen Vorsprung des Erwachsenen, Geissel viergliederig. Untere Antennen mit sechsgliederiger Geissel.

Rostrum im Verhältniss wie beim Erwachsenen und vorf derselben Form.

Im Uebrigen in allen Theilen die Formen des Erwachsenen, Füsse etwas plumper und kiirzer, ('audalanhang wie beim Erwachsenen, die Springfüsse ron ziemlich ühereinstimmender Bildung, die Endliste des letzten Paares ohne Fiederborsten, und so wie diejenigen der beiden vordern Paare, an den Seitenrändern ohne Stacheln.

Verbreitung. Paramphithoë inermis gehört zu den gewöhnlichsten und in grösster Massenhaftigkeit rorkommenden Formen an den Küisten Nordostgrönlands. I)r. Pansch's Sammlungen enthielten dieselbe mehr oder minder reichlich ron der Mehrzahl aller Fundorte.

So Sabine-Insel 10-120 Faden, an zahlreichen Stellen sehr reichlich; Kap Wynn 3 Faden; Germania-Hafen 3 Faden; so an mehrern andern Stellen.

Ueberdies glaube ich bestimmt angeben zu können, dass diese Art auch weit vom Lande entfernt zwischen dem Eise auf der Oberfläche des Meeres angetroffen wird; ich habe damals diese Art und die ziemlich ähnliche Puramphithö fulvociurta allerdings nicht unterschieden, doch glaube ich sicher, dass sie beide daselbst nebst Anomyx litioralis und plautus nicht ganz selten von mir gesehen wurden. Dr. Pansch's Sammlung enthält keine der beiden Arten mit der Angabe, dass sie an der Oberflïche des Meeres gesammelt worden wïre, doch legte derselbe die Reise nach der Küiste in rerhältnissmä̈sig kurzer Zeit zurück und hatte daher wol nicht so oft Gelegenheit zwischen dem Eise zu fischen.

Bei diesem massenhaften Vorkommen ron Paramphithoë inermis an den Küsten Grönlands muss es auffällig erscheinen, dass sie bei Spitzbergen noch nicht beobachtet ist, sie war bisher nur aus dem Westen und Siiden Grönlands bekannt.

\section{2) Paramphithoë fulvocincta (Sars).}

Amphithoë fulvocincta Sars, Oversigt over de norsk-Arktiske Krebsdyr. Forhandl. i Vidensk. Selsk. i Christiania, 1854, p. 141.

Pherusa tricuspis Stimpson, Proceedings of the Acad. of Science of Philadelphia, 1863, p. 138 .

Paramphithoë fulvocincta Goës, Crustacea Amphipoda maris Spetsb. alluent., p. 525 , fig. 15 .

Halirages fulvocinctus Bœck, Crustac. Amphip. borealia et arctica, p. 116.

Diese Art, welche in der äussern Erscheinung der Paramphithö̈ inermis sehr nahe steht, unterscheidet sich schon bei oberflichlicher 
Betrachtung leicht durch die am siebenten bis neunten liörpersegment in der Mittellinie des Riückens befindlichen spitzen Zïhne, sowie durch die grössere Länge der Fühler. Yon der nächstrerwandten Purumphithoë tridentutu Bruzelius, welche die norwegischen Küsten bewohnt, und die gleichfalls diese Zähne besitzt, ist sie sicher verschieden. Ihr Vorkommen an den von der Deutschen Nordpolar-Expedition berïhrten Küisten Ostgrönlands ist ein ebenso allgemein rerbreitetes und häufiges als dasjenige ron Paramplhithoë incrmis, sie gehört mit zu den an Individuenzahl am meisten vorherrschenden Arten.

Die Färbung erscheint bei lebenden 'Thieren ziemlich farblos durchsichtig, mit bräunlich-schwarzen Augen und bräunlich queren Pigmentstreifen, sowie an den drei ersten Abdominalsegmenten auf der Dorsalseite derselben, jederseits neben der Mittellinie zwei Querreihen dunklerer bräunlicher Riiickenflecke bilden. An Weingeistexemplaren ist die Färbung gleichmäsig gelblich, die Augen wie bei Paramphithoë inermis gelblich rerblasst und die Rïckenflecke undeutlich, nur seltener ist die Andeutung derselben deutlich erhalten.

Grösse. Diese Art steht der Paramphithoë inermis hinsichtlich der Grösse sehr nahe, doch besitzt sie durchschnittlich etwas grössere Dimensionen. Die durchschnittliche Grösse erwachsener Individuen beträgt $10-15^{\mathrm{mm}}$ Totallänge, toch fand ich auch hier grössere Exemplare, welche ansehnlichere (irösse erreichen als die gewöhnliche Form. Die grössten unter denselben waren bis zu $20^{\mathrm{mm}}$ lang, ich fand hier rorzugsweise mämnliche Exemplare unter diesen grössten Stiicken ror.

Bei einem Exemplar von 13,5 long. tot. fand ich:

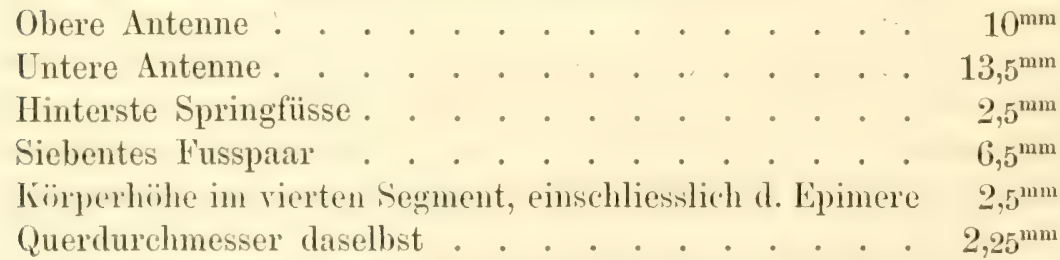

Verbreitung. IDe rorliegende Art gehört an den nördlichen Kïisten Ostgrönlands zu den an häufigsten und massenhaftesten auftretenden; in 101. I'ansch's Summlungen ist sie neben P'tramphithoë inrmis von der grössten Alehrzahl der Fundorte und noch reichlicher an Individuenzahl als jene rorhanden.

So Sabine-Insel an zahlreichen Fundorten 4-110 Faden, äusserst reichlich; (iermania-Uaten; Kap, Wynn 3 Faden; Shamnon, October 1869.

Wie bereits erwähnt, traf ich diese Art auch ziemlich weit entfernt von der Küste auf der Oberfläche des Meeres zwischen Packeis- 
schollen nicht ganz selten an. Wie ich aus meinem Tagebuche ersehe, fischte ich dieselbe zum ersten male am 26. Juli 1869 hei $73^{\circ} 7^{\prime}$ nördl. Br., $16^{\circ} 24^{\prime}$ westl. L., also sehr weit rom Lande entfernt; späterhin bemerkte ich sie noch oftmals, wenn auch spärlicher als Anomyx littoratis und die iibrigen pelagisch anftretenden Arten zwischen dem Eise.

Im sïdwestlichen Grönland ist sie nach Goës' Angabe durch Torell gefunden und in Spitzbergen ziemlich verbreitet, doch wie es scheint nicht so massenhaft, auch in Fimmarken wurke sie noch aufgefunden.

Die jüngste eben ausgeschlüpfte Form dieser Art gleicht völlig derjenigen ron Paramphithö̈ incrmis, von welcher sie nur durch die Form des Caudalanhangs unterschieden werden kann.

\section{S. 3) Paramphithoë megalops Buchholz, spec. nov. Taf. XII.}

Die nachstehend beschriebene kleine $\Lambda \mathrm{r}$, welche den beiden roranstehenden in der Bildung ziemlich nahesteht, ist von allen bisher beschiebenen Arten verschieden; ich habe der grossen dunkelschwarzen Augen wegen ihr den obigen Artnamen beigelegt. Sie kommt, wenngleich viel spärlicher, doch ziemlich verbreitet neben den zwei rorigen Arten in Nordostgrönland ror und war in ziemlich zahlreicher Anzahl von Exemplaren in Dr. Pansch's Sammlungen vorhanden, sodass mir ein völlig ausreichendes Material zur Untersuchung vorlag.

Diagnosis: Corpus parvum gracile, tenerum, dorso rotundato ubique inermi, oculis permagnis nigris, transversis, ovali-reniformibus, antennis perlongis, subaequalibus, longitudine totius animalis paullo brevioribus, pedum anteriorum manibus parvis ovatis; epimeris quatuor anterioribus parris, illis segmentorum trium abdominalium primoxum margine postico fortiter serrato dentatis; pedibus saltatorius elongatis gracilibus. Longit. tot. ad $7^{\mathrm{mm}}$.

Der Körper ist wie bei den verwandten Arten schlank und langgestreckt, die vordern Epimeren klein und niedrig, die Füsse schlank und verlängert.

Der Kopf ist rerhältnissmässig gross, so lang als die drei vordersten Segmente zusammengenommen, sein senkrechter Durchmesser ist grösser als die Länge, die Mundtheile, welche gänzlich ron der rordersten Epimere mberleckt bleiben, ragen nach abwärts stark hervor. Der Stimrand verlinuft ziemlich gerade nach vorn und erscheint schwach convex gekrïmmt, vom Scheitel schwach gegen den rordern Rand abfallend. Derselbe setzt sich in ein verhältnissmässig grosses Rostrum fort, welches ziemlich halb so lang als der Kopf ist, und nach vorn bis zum Ende des ersten Basalgliedes vorragt. Das- 
selbe erscheint schmal, ron den Seiten her senkrecht zusammengedrückt und schwach nach abwärts in der Richtung der Verlängerung des Stimrandes gebogen; es endet zugespitzt.

Das verhältnissmässig sehr grosse schmarze Auge ist mit seinem längern Durchmesser, der halb so lang als der Kopf ist, ziemlich quer gestellt, derselbe verläuft schräg ron vorn nach hinten und aufwärts. Es besitzt eine ziemlich orale oder genaner abgerundet trapezoide Form, der obere Rand ist ziemlich gerade, der untere, viel kürzere geht mit abgerundeten Ecken in den rordern und hintern Rand über. Die vordere und hintere Ecke sind ziemlich gleich weit rom rordern Kopfrande sowie rom Hinterrande desselben entferut. Die dunkelschwarze lärbung des lugenpigments erscheint nirgends durch die Aufbewahrung in Weingeist rerändert.

I) Antemnen ('Tat'. XII, Fig. 1(') sind stark rerlängert, sehr' schlank farlenförmig. waren aber bei der grössten Mehrahl der Exemplare wegen der grossen Zartheit der Theile nur unvollständig erhalten. An den wenigen Exemplaren, welche mit rollständigen Fühlern rersehen waren, fand ich sie an Länge sehr unbedeutend rerschieden, die obern sehr wenig kiirzer als die untern. Die Länge der untern beträgt fünf Sechstel der Gesammtlänge des Thieres.

Die obern Antennen sind wie bei den rerwandten Arten durch die sehr grosse Kiirze des. Schaftes ansgezeichnet; derselbe ist wenig

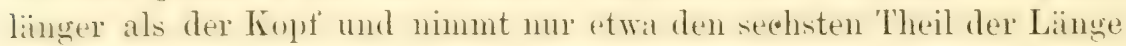
der ganzen Antenne ein. Das erste Glied ziemlich halb so lang als der Kopf, schlank cylindrisch, erscheint nur gegen das Ende mit einigen kurzen Börstchen besetzt und am Endrande unten mit zwei zahnartigen spitzen Eden rersehen. Dats zweite Glied ist kaum kiurzex als das erste, schlanker und am äussern Endrande unten ebenso wie das erste Glied mit zwei spitzen Zähnen versehen. Das dritte Glied ist halb so lang als das vorhergehende, es fehlen hier am Endrande die Zähne, derselbe erscheint quer abgeschnitten und nicht wie bei beiden vorigen Arten in einen zahnartigen Vorsprung verlängert. Von einer Nebengeissel ist keine Andeutung rorhanden. Die Geissel besteht aus sehr zahlreichen Gliedern, deren an völlig erhaltenen Fühlern einige 30 zu zählen sind, sie erscheinen ziemlich schlank und langgestreckt.

Die untern Antennen besitzen gleichfalls einen kurzen Schaft, welcher indessen etwas länger als derjenige der obern Antemen ist. Die drei ersten Glieder sind sehr kurz, die beiden letzten rerlängert und ziemlich gleich lang. Das vierte Glied reicht nach vor'n bis zum Ende des dritten Basalgliedes der obern Antennen, es ist am End- 
rande mit einem spitzen Zahn rersehen, sowie auch das rorhergehende Glied des Schaftes mit mehrern solchen Zähnen versehen erscheint. Das Endglied ist schlanker und sehr unbedeutend kürzer und am Endrande einfach quer abgeschnitten. Die Geissel besteht aus ziemlich ebenso zahlreichen Gliedern als diejenige der obern Antennen.

Was die Anhänge der Fühler bei den Männchen anbetrifft, so sind sie wie bei Paramphithoë fulvocincta äusserst klein und in ähnlicher Weise angeordnet, indessen im Ganzen viel spärlicher als bei jener Art. Sie finden sich ebenfalls auf den beiden letzten Basalgliedern beider Antennenpare, sowie auf den Gliedern des Flagellum. An den obern Antennen sind sie ron der Unterseite der beiden letzten Basalglieder nur in einfacher Längsreihe rorhanden und wenim zahlreich, am zweiten vier bis fünf, am dritten Basalgliede nur drei. Auf den Gliedern der Geissel stehen sie einzeln an der gewöhnlichen Stelle, sind aber nur im basalen Abschnitt derselben vorhanden, während sie im grössten Theile in etwa drei Viertel der ganzen Länge fehlen. An der untern Antenne findet sich auf der Oberseite des vierten Basalgliedes eine etwas grössere Anzahl von gegen 10, welche ziemlich unregelmäsig in zwei Reihen stehen, anf dem letzten Gliede des Schaftes stehen sie dagegen in einfacher Lüngsreihe zu fünf angeordnet. Die Geissel ist ebenso wie an der obern Antenne, nur in ihrem Anfangstheile mit einzelnen Anhängen besetz. Die Form und Grösse der Anhänge ist riemlich vollstïndig übereinstimmend mit denjenigen ron Parrmpllithö̈ fulvocincta, ich fand den Längendurchmesier des Endtheils wie dort $0,025^{\mathrm{mm}}$ im Durchschnitt gross, und die Form der einzelnen Abschnitte gänzlich übereinstimmend.

II und theile.

Die Mandibeln (Taf. XII, Fig. 1 e) sind ganz wie bei den nächstverwandten Arten, doch zeigt der Taster in der Kürze des Endgliedes sich abweichend gebildet. Der Taster ist im Ganzen kurz, unbedeutend lïnger als die Nandibel. und das Endglied kaum hall, so lang als das zweite. Letzteres ist kaum merklich gebogen, das Endglied anm Ende imnen schrïg abgeschnitten und hier neben einigen lïngern auf der Spitze stehenden Borsten mit einer Reihe ziemlich kurzer Borsten versehen.

Der Zahnfortsatz ist wie bei den verwandten am Ende mit zwei grössern und dahinter mit vier bis fünf an Grösse abnehmenden stumpfern Zähnen versehen. Der processus accessorius zeigt auf beiden Seiten dieselbe Ungleichheit wie bei den zwei voranstehenden Arten, an der ersten Nandibel gleicht er dem Zahnfortsatz selber, 
ist wenig kürzer und am obern Rande in gleicher Weise gezühnt. An der linken Mandibel ist er dagegen ganz wie bei Paramphithoë incrmis, viel kürzer und kleiner quer abgeschnitten und am Ende mit drei dïnnen, lang zugespitzten Vähnen rersehen. I) zum Kinhï̈ker verlaufende Borstenreihe besteht ans fünf bis sechs dicken gekrïmmten, am obern Rande spitz gezähnten Borsten. Der Kauhöcker wie bei den vorigen Arten, die lïngere Fiederborste ist an demselben vorhanden.

Die vordern Maxillen (Taf. XII, Fig. $1 \mathrm{~g}$ ) finde ich im Uebrigen ganz wie bei Paramphithoë inermis, nur sind die auf dem Kaufortsatz befindlichen Kauborsten mit nur ein his drei langen und spitzigen Seitenzähnen versehen. Der Basallappen ist klein viereckig und am obern Rande mit einer Reihe ziemlich kurzer dicker Fiederborsten versehen; seine Spitze ragt bis zur Insertion des Tasters nach rorn ror.

Die hintern Maxillen bieten nichts besonderes, die beiden Lappen sind gleich lang, der innere beträchtlich schmäler als der äussere.

Die Maxillarfüsse (Taf. XII, Fig. 1f) bieten einige Besonderheiten dar. Der 'Taster ist merklich kuirzer als der Basaltheil mit Einschluss des obern Lappens; das dritte Glied desselben etwas kürzer als das zweite, ist schlank cylindrisch und am äussern Ende, über dem Lrsprunge der Kiralle, nur wenig verlingert. Die zweigliederige Kralle ist halb so lang als das dritte Glied und zeigt gleichfalls ein grosses ziemlich dickes Wurzelglied, welehes mehr das Ansehen eines kleinen 'Tastergliedes darbietet, und ein von demselben sehr stark abgesetztes, sehr dünnes und viel kürzeres, hakig gebogenes kndglied. Die beiden innern Lappen sind gross und breit, der basale am obern Rande mit drei kurzen, sehr starken Dornen bewehrt, der obere reicht bis zum Ende des zweiten Tastergliedes und geht am obern Ende in eine verschmälerte, abgerundete Spitze aus. Der innere, etwas concare Rand ist ohne Stachelborsten, es findet sich etwas entfernt von dem Rande selbst eine mit demselben parallele Reihe paarig stehender kurzer einfacher Borsten vor, welche nur wenig iiber den Rand hervorragen. Der äussere, stark convexe Rand ist mit längern Fiederborsten an der Spitzenhälfte besetzt.

Die Oberlippe ganz wie bei Paramphithoë inermis.

Die beiden vordern Fusspare (Taf. XII, Fig. 1b) sind schlank, das zweite etwas länger und in allen Theilen etwas grösser als das erste. Sie sind mit ziemlich schwachen Scheeren versehen, das Scheerenglied, kaum verbreitert, ist von länglich abgerundeter Form. Es 
ist etwas kürzer als das rorangehende Glied, etwas mehr als doppelt so lang als breit, und am Ende durch den Krallenrand schräg abgeschnitten; der Krallenrand ist leicht concar ausgeschnitten, mit äusserst feinen kerbartigen Zähnelungen rersehen; er nimmt etwa die IIiilfte des montern Randes des Scheerengliedes ein und geht in stumpfem abgerundeten Winkel in den hinterm Aloschnitt des letztern iiber, und ist an dieser Stelle mit mehrem starken Stachelborsten versehen. Sonst erscheint das Scheerenglied oberhalb des untern Rimdes mit zahlreichen Querreihen von Borsten, sowie am obern Rande mit vereinzelten einfachen Borsten besetzt. Die Kralle ist kräftig, ziemlich breit und gekrimmt scharf zugespitzt und halb so lang als das Scheerenglied, sie ist lïngs des innern Randes bis nahe zur Spitze mit feinen spitzen Stachelzähnen versehen.

Das dritte und vierte Fusspanr ist sehr schlank und ziemlich verlängert und die Länge des Endgliedes länger als das zweite. Die Krallen sind ein Drittel so lang als das Endglied, schlank und schwach gekrümmt.

Das fünfte bis siebente Fusspaar länger als die vorhergehenden und gleichfalls sehr schlank geformt, sie nehmen der Reihe nach an Länge zu, so dass das siebente um den Betrag des Endgliedes das fünfte ïbertrifft, letzteres kaum länger als das vierte. Die Coxalglieder sind mässig erweitert, oblong viereckig, mit abgerundetem convexem Hinterrande, gegen das untere Ende etwas verschmälert und quer abgeschnitten, sie sind so lang als die beiden folgenden Glieder. Der Hinterrand derselben ist mit ziemlich starken spitzigen Sägezähnen rersehen. I) schlanken Glieder sind in der gewöhnlichen Weise mit schlanken Stachelborsten an den Seitenrändern bewehrt, die Kralle ein Drittel so lang als das Endglied einfach.

Die vordern Epimeren bieten nichts besonderes; sie sind klein, am untern Rande quer abgeschnitten und niedriger als die zugehörigen Segmente. Die vierte Epimere ist nicht rergrössert und am untersten Theile des Hinterrandes mit drei bis vier Sägezähnen versehen. Die zweite und dritte bilden an dem Zusammentreffen des hintern und untern Randes einen spitzen Zahn, oberhalb dessen der Hinterrand mit einer Reihe ziemlich ebenso grosser Zïhne versehen erscheint, an der zweiten sind es vier bis fünf, an der dritten acht bis zehn, welche an letzterer den ganzen Hinterrand der Epimere bis zum Uebergang in den Dorsalrand einnehmen. Ausserdem sind die nutern Liänder der betreffenden drei Epimeren mit einer Reihe parweise gestellter kleiner Stachelborsten versehen, welche etwas ober- 
halb des freien Randes auf der Fläche derselben stehen, wie dies auch bei den beiden vorangehenden Arten der Fall ist.

Die drei hintersten Körpersegmente sind ziemlich langgestreckt, zusammen wenig kiirzer als die beiden vorangehenden Segmente.

Das letzte Paar der Springfiisse (Taf. XII, Fig. 1d) ragt nach linten weiter hervor als die beiden vorangehenden und erscheint schlank und ziemlich verlängert; das Basalglied ziemlich schlank, etwats lïnger als der (andalanhang, die Endäste sind etwas über doppelt so lang als das Basalglied. Letztere erscheinen schmal linear zusimmengedruickt, spit\% zulaufend, gleich lang, an beiden Seitenräindern mit zahlreichen in einficher Reihe stehenden, ziemlich starken Stachelborsten versehen. Zwischen diesen befinden sich an den innern Rïndern heider Endäste eine Reihe kleiner dichtstehender feiner Stachelspitzen, die nur bei stärkerer Vergrösserung sichtbar sind.

Das mittlere Paar der Springfüsse (Taf. XII, Fig. 1d) ist am kiirzesten, die Endïste von ungleicher Lü̈nge, der lïngere innere Ast reicht kaum bis zu ein Drittel der Endäste des letzten Paares und ist nur halb so lang als dieser. Sie sind am Ende mit einer längern stiirkern ziemlich gerarlen Endkralle und daneben mit zwei kürzern Stachelborsten versehen, sowie an den Seitenrändern in der gewöhnlichen Weise weitläufig bestachelt.

Das vorderste Paar der Springfüsse ist etwas länger, der längere Endast dewelben ragt etwas über die Mitte der Endïste des hintersten Paares nach hinten vor, die beiden Endäste sind wenig ungleich, indem der äussere nur um etwa ein Fünftel kürzer als der innere erscheint.

Der Caudalanhang (Taf. XII, Fig. 1d) ist ziemlich dreieckig geformt, nach der Spitze gleichmässig verschmälert und quer ahgeschnitten; der Fndrand erscheint nur sehr seicht ausgerandet, mit abgerundeten Ecken und nur mit zwei sehr kleinen Börstchen daselbst versehen.

Die Färbung des Thierchens ist vermuthlich ganz durchsichtig farblos, da sich keine Spur von dunklerm IIautpigment vorfindet, nur das dunkelschwarze grosse Auge erscheint pigmentirt.

Die Grösse der vorliegenden Art ist beträchtlich geringer als diejenige der beiden voranstehend beschriebenen. Diejenige der erwachsenen Exemplare beträgt zwischen 5 und $7^{\mathrm{mm}}$ in der Gesammtlänge, grö̈sere Individuen wurden unter einem ziemlich reichhaltigen Material nicht angetroffen.

Unter den Erwachsenen fanden sich ziemlich zahlreiche mit ge- 
fïlter Bruttasche versehene Weibchen, indessen waren die Embryonen noch nicht ausgeschlüpft und konnte ich daher über die erste Jugendform bei dieser Art nichts Näheres beobachten.

Es scheint daher eine sehr beträchtliche Schwankung in der Grösse der erwachsenen 'Thiere wie bei Paramphithö̈ incrmis und fulvocincta hier nicht vorzukommen.

Verbreitung. Sie scheint an den Küsten von Nordostgrönland nicht selten und ziemlich verbreitet vorzukommen, in Gemeinschaft der beiden roranstehenden Arten, da von einem der Fundorte eine ziemlich reichliche Menge gesammelt worken war; indessen ist sie doch weit spärlicher an Individuenzahl vertreten als die beiden vorigen.

Sabine-Insel 10 Faden, sehr reichlich; Germania-Hafen, mehrere; Shannon, September 186 ! mit P'urumphithö fulvocinct zusammen.

Alle von D1. Pansch gesammelten Exemplare stammen somit aus geringerer Tiefe.

\section{Ampeliscinae, Spence Bate.}

Für diese Gruppe ist im Wesentlichen die selir ungewöhnliche Augenbildung bereits hinreichend charakteristisch, da einfache Augen sonst bei Amphipoden nicht vorkommen. Habituell wird sie durch den ziemlich stark seitlich zusammengedriickten, in der Medianlinie von vorn nach hinten ziemlich stark gewölbten hohen Körper, der mit hohen vordern Epimeren versehen ist, den gewöhnlich sehr stark verlängerten grossen Kopf, der ohne Rostrum mit schmaler, quer abgeschnittener Stirn endet, die schlanken mässig lingen Fühler, sowie die eigenthïmliche Fussbildung bezeichnet. Letztere sind ziemlich kurz, besonders die drei hintern Pare, die beiden vordern sind einfache Krallenfüsse, ohne zurücklegbare Kralle, das fünfte bis siebente Paar sind ungewöhnlich kurz und mit verhältnissmässig sehr grossen, sehr stark erweiterten Coxalgliedern versehen.

Die drei hintersten Segmente ziemlich stark verkürt, eine Verwachsung der beiden letzten, wie Bock angibt, kamn ich bei Ampelisce Eschrichtii nicht constatiren.

Die Mundtheile konnte ich nicht untersuchen, sie sind, nach den Angaben der erwähnten Beobachter, ziemlich regelmäsig gebildet.

Ueber die sexuellen Differenzen in dieser Gruppe ist nichts bekannt.

39. 1) Ampelisca Eschrichtii Kröyer. Taf. XIII, Fig. 1.

Kröyer, Naturhist. Tidskr., IV, 155.

Ampetisca ingens Stimps, Spence Bate, Catal. of Amphip. of Brit. Mus., p. 92. 
Ampetisca Eschrichtii Goës, Crust. Amph. maris Spetsberg. alluent., p. 529.

- Beck, Crustacea Amphipoda borealia et arctica, p. 1.4.

Von dieser zuerst durch Kröyer von Grönland beschriebenen Art lag mir nur ein grösseres und zwei ganz kleine Exemplare zur Untersuchung ror.

Die beiden vordern Fusspaare ('Taf. XIII, Fig. 1c) sind einfache Krallenfiisse, etwas kiirzer als die folgenden, schlank und ohne ausgebildete Scheeren; die Kralle selbst ist ziemlich lang und deutlich zweigliederig, kam aber nicht gegen das letzte Glied zuriekgelegt werden.

Das dritte und rierte Fussparr sind durch die eigenthimlichen Verhältnisse der Glieder, sowie die sehr langen und zugespitzten Krallen ausgezeichnet.

Die drei hintern Fussparare des Thorax sind auffillig kurz und stehen den beiden vorangehenden Paaren merklich an Länge nach. Das fünfte reicht etwa bis zur Mitte des Lndgliedes des vierten, das sechste ist ein wenig länger, das siebente dagegen merklich kïrzer als dieses.

An dem fünften und sechsten Patr (Taf. XIII, Fig. 1 b) erscheinen die vier Endglieder schlank und länger als das Coxalglied, das vierte Glied ist an der untern hintern Leke etwas ausgezogen, und auf der rorspringenden Ecke mit einigen stark verdickten, ziemlich langen Borsten, zwischen denen einige kürzere dornartige Stachelborsten stehen, besetzt. Das Endglied trägt an Ende zwei sehr lange ziemlich dicke Borsten von der Lünge des Gliedes selbst; die Kralle ist klein, eigenthümlich hakig gebogen und auf der Umbiegungsstelle mit drei kurzen Stacheldornen in der Mitte des convexen liandes versehen.

An dem siebenten Fusspar sind die vier Endglieder eigenthiumlich verkiirzt und rerdickt, sodass sie zusammengenommen nur dem Coxalgliede an Länge gleichkommen.

Das hinterste Paar (Taf. XIII, Fig. 1 d) der Springfüsse, welches ziemlich um dic Länge seiner Endäste weiter nach hinten vorragt als die vorangehenden, ist mit zwei lanzettförmigen, blattartig zusammengedrückten Endiisten ron gleicher Länge rersehen. Sie sind fast doppelt so lang als das Basalglied, und am äussern Rande mit mässig langen Fiederborsten besetzt, wïhrend der imnere nur einzelne sehr kurze Börstchen zeigt.

Das vorletzte l'ar Springfüsse (Taf. XIII, Fig. 1e) zeigt zwei cylindrische schlanke lindäste, von denen der äussere nur um ein wenig kürzer als der imnere und oberhalb der kurzen Lndkralle mit einel eigenthiimlich verdickten. zugespitaten starken borste versehen 
ist, welche dem innern Aste fehlt. Beide sind am inrern Rande mit einer Reihe kurzer Stacheldornen bewehrt.

Das vorderste Paar der Springfüsse sind im Ganzen ebenso gebildet wie die vorigen und ragen ebenso viel nach hinten vor, doch sind die beiden Endäste hier ziemlich gleich lang, am Ende hakenförmig zugespitzt, die verdickte Borste am äussern Rande scheint hier zu fehlen.

Der Caudalanhang (Taf. XIII, Fig. 1d) ist verlängert, halb elliptisch, gegen zwei Drittel so breit als lang, am etwas verschmälerten Ende quer abgeschnitten; die Seitenränder sind leicht convex. Von der Mitte des Endrandes geht ein sehr tiefer schmaler, spaltförmiger mittlerer Einschnitt aus, durch welchen der Caudalanhang in beinahe drei Viertel seiner Länge gespalten erscheint.

Färbung. Ausser dem lebhaft rothen Auge erschien der ganze Körper bei den vorliegenden Exemplaren gleichmänig hochgelblich und ziemlich durchsichtig.

Grösse. Das grösste der Exemplare bot folgende Maasse:

Totallïinge . . . . . . . . . . 16,5 $5^{\mathrm{mm}}$

Obere Antenne . . . . . . . . . $5^{\mathrm{mm}}$

Untere Antenne . . . . . . . . . . . $9^{\mathrm{mm}}$

Höhe des Körpers (4. Segm.) bis zur Seitenlinie 2,2 $2^{\mathrm{mm}}$

Höhe der vierten Epimere . . . . . . 2, 2, $8^{\mathrm{mm}}$

Querdurchmesser des Körpers daselbst . . 2,25 $5^{\mathrm{mm}}$

Letztes Parr des Abdominalfüisse . . . . $2^{\mathrm{mm}}$

Zwei kleine Individuen besassen $8^{\mathrm{mm}}$ Länge, sie waren bereits völlig übereinstimmend mit dem Erwachsenen gebildet.

Verbreitung. Ampelisca Eschrichtii scheint im nordöstlichen Grönland ziemlich spärlich vorzukommen; es waren nur drei Individuen gesammelt, zwei im Germania-Hafen, ein kleineres von SabineInsel 10 Faden; also alle in geringer 'Tiefe.

Sollte Ampetisca macrocephula Lilljeborg nicht, wie mir wahrscheinlich ist, bloss eine locale Abart sein, so würde die vorliegende Art nu auf den höchsten Norden beschränkt, woselbst sie von Grönland, Island, Spitzbergen und Finmarken angegeben wird.

\section{Podlocerinae, $\Lambda$. Bock.}

Diese Gruppe steht den Corophinen in der Gesammtbildung des Körpers, sowie der wesentlichen 'Theile sehr nahe, von welcher sie mur durch einige Verschiedenheiten in der Antennenform, sowie der Bildung des letzten Paares der Springfüsse, welche zweiästig sind, abweicht. 
Die Geschlechtsverschiedenheiten sind an den Antennen kaum anwepriint. sperifische luhinge an demselben fehlen durchans, sowie anch sonst die Fïhler des Mïnnchen höchst unbedentend verlängert sind, dagegen sind die beiden vordersten Fuspatre beim Männchen bei weitem grösser und mit viel stärkern Scheeren versehen.

40. 1) Podocerus anguipes (Kröyer). Taf. XIII, Fig. 2 u. Taf. XIV.

Ischyrocerus anguipes Kröyer, Grönlands Amfipoder, 1. 55 , tab. III, fig. 14. Ders., Naturhist. 'lidskr., IV, 162.

Gammarus Zebra Rathke, Acta Leopold., XX, 74, tab. III, fig. 4.

Podocerus anguipes Bruzelius, Bidrag til Kännedomen om Skandinaviens Amphipoda Gammaridea, 1. 21.

- Goës, Crustacea Amphipoda maris Spetsbergiam alluentis.

- Bøck, Crustacea Amphipoda borealia et arctica, p. 167.

Diese im Norden ziemlich verbreitete Art ist im nordöstlichen Grönland ziemlich hïufig und lag ein ziemlich reichliches Material von derselben in Dr. Pansch's Sammlungen vor.

Der Körper ist langgestreekt schmächtig, kaum seitlich zusammengedrïckt, der liücken sehr flach gewïlht, gleichmässig in ziemlich flachem Bogen über die Seitentheile übergehend. Die Höhe des Körpers ist in der Gegend des vierten Segments einschliesslich der Epimere kaum grösser als der Querdurchmesser daselbst.

Der Kopf ist ziemlich gross, so lang als die beiden ersten Körpersegmente, seine Höhe ist ziemlich ebenso gross als die Länge. Die Stirn verliuft geradlinig nach vorn und ist am Ende zwischen den obern Antennen mit einem sehr kleinen zugespitzten Rostrum versehen. Die Augen sind klein dunkelschwarz, ziemlich rund, doch im senkrechten Durchmesser ein wenig lïnger, ihr längerer Durchmesser beträgt etwa ein Sechstel der Kopflänge. Sie sind dem vordern Kopfrande sehr genähert und mit dem vordern Rande kaum von ihrem Durehmesser davon entfernt. Der vordere Kopfrand verläuft rom Ende der Stirn bis zum untern Ende der Insertion der obern Antemen senkrecht nach abwïrts und bildet hier eine ziemlich spitze, fast zahnartig ausgezogene Ecke, um unterhalb derselben ziemlich stark schräg nach hinten und abwärts bis zur Insertion der Mundtheile zu verlaufen, sodass die untern Antemen merklich weiter nach hinten inserirt sind als die obern.

Die Antennen sind bei beiden Geschlechtern nur wenig verschieden, indem bei den erwachsenen Mämchen die untern merklich länger als die obern erscheinen, während bei den Weibchen, sowie bei den jüngern Exemplaren der Untersehied kaum vorhanden ist. An 
beiden erscheint der Schaft sehr viel verlängert und sehr viel länger als die kurze weniggliederige Geissel.

Die obern Antennen ('Taf. XIV, Fig. 1b) sind durehschnittlich halb so lang als die Gesammtlänge des Thieres beträgt, oder bei den Männchen nur sehr wenig dariiber; der sehr verlängerte Schaft nimmt zwei Drittel ihrer ganzen Lünge ein. Das erste Basalglied ist am kürzesten, zwei Drittel so lang als der Kopf und schlank cylindrisch, das zweite und dritte Glied sehr verlängert, das zweite reichlich doppelt so lang als jenes, das dritte nur unmerklich kiurzer als das zweite. Dasselbe ist am Ende quer abgeschnitten und mit einer sehr kleinen rudimentïren Nebengeissel versehen, welche kürzer als das erste Geisselglied ist und bei stärkerer Vergrösserung zweigliedrig erseheint; das erste ist langgestreckt cylindrisch und mit einem äusserst kleinen, auf der Spitze mit mehrern kurzen Borsten versehenen Endgliede versehen. Sämmtliche Glieder des Schaftes sind auf beiden Seiten nur mit einfachen Borsten ziemlich reichlich besetzt, neben diesen kürzern Borsten ist die Unterseite des zweiten und dritten Basalgliedes mit einer Reihe sehr viel lïngerer, pararweise gestellter, kurz gefiederter Borsten besetzt. Die Geissel erscheint nur wenig länger als das dritte Basalglied und besteht aus acht bis neun ziemlich verlängerten Gliedern. Das erste Glied ist beträchtlich grösser und länger als die folgenden, welche successiv an Länge und Breitendurchmesser abnehmen. Auch die Glieder der Geissel tragen ausser den kürzern Borsten an der untern Seite ein bis zwei längere Fiederborsten und daneben bei beiden Geschlechtern ein bis zwei blassrandige Riechborsten.

Die untern Antennen sind bei den Weibchen kaum merklich, bei den Männchen durchgehends länger als die obern, bei letztern zuweilen zwei Drittel so lang als das ganze Thier. Doch scheinen hier individuelle Abweichungen häufig zu sein, da ich sie mitunter auch bei ausgebildeten Männchen wenig länger als die untern fand. Der Schaft ist an denselben noch stärker verlängert und nimmt den bei Weitem grössten Theil der ganzen Antenne ein, bei den Männchen reicht derselbe fort bis zum Ende der obern Fühler. Das dritte Glied ist kurz, wenig länger als breit und reicht nach vorn bis zu zwei Drittel des ersten Basalgliedes der obern Antennen, das vierte und fünfte Glied sind sehr verlingert, ersteres reicht etwas üher das Ende des zweiten Basalgliedes der obern Antenne. Das fünfte ist etwas länger als dieses. Auch hier erscheinen die beiden letzten Gilieder des Schaftes an der Unterseite mit längern, paraweise gestellten, zahlreichen Borsten in regelmässigen Zwischenräumen besetzt. 
Die Geissel ist etwas kuirzer als das letzte Glied des Schaftes, besteht bei den Erwachsenen aus sieben Gliedern, von welchen das erste beträchtlich länger und grösser als die übrigen, das Endglied dagegen schr kurz erscheint. Sie ist ebenso wie die Glieder des Schaftes dicker als die betreffenden Theile der obern Antemnen; ihre Glieder sind nur mit kurzen Börstchen besetzt, ohne dass Riechborsten daselbst vorhanden sind.

Von Fühleranhingen liens sich hei dieser Art nirgends eine Spur erkennen.

Inud theile.

Oberlippe (Taf. XIV, Fig. 1h) kurz, fast doppelt so breit als lang, am Endrande quer abgeschnitten, in der Mitte sehr seicht ausgerandet. Sie ist nach aufwärts in einen auffällig stark verlängerten, sehr schmalen und lang zugespitzten zipfelförmigen Fortsatz ausgezogen, welcher sich zwischen die Insertion der untern Fühler erstreckt.

Die Mandibeln (Taf. XIV, Fig. 1e und 1d) sind beiderseits gleich gestaltet, mit sehr langem und kräftigem Taster versehen. Letzterer ist beträchtlich lïnger als die Mandibel, seine beiden ersten Glieder etwas länger als diese, breit und kräftig, das Endglied etwas kuirzer als das zweite, am Ende breit keulig rerdickt und daselbst am Endrande sehr dicht mit zahlreichen, sehr langen Borsten besetzt, welche fast doppelt so lang als das Endglied selbst sind.

Der Zahnfortsat\% am Ende mit vier ziemlich grossen etwas stumpfen Zähnen versehen; der processus accessorius ziemlich breit, am Ende mit zwei längern spitzen Zähnen, davor am obern Rande zwei bis drei kürzere stumpfe und breite Zühne.

Die zum Kauhöcker gehende Borstenreihe verhält sich eigenthümlich durch die sonderbar verbreiterte Form der Borsten. Letztere sind sehr wenig zahlreich zu zwei bis drei vorhanden, stark abgeplattet und verbreitert und an den Rändern, besonders dem obern, in spitze zahmartige Fortsätze zerschlitzt.

Der Kauhöcker ist ron mässiger Grösse und nicht besonders stark hervorragend, er ist tiefer als der Taster inserirt. Die Kaufläche ist ziemlich klein, mit starken Zahnleisten versehen und zeigt an dem obern Ende noch einen besondern kleinern viereckigen, am Ende gleichfalls mit Zühmen besetzten, accessorischen Fortsatz, den ich sonst nirgends bei andern Arten angetroffen habe. Auf dem obern Rande des Wurzeltheils ist eine Reihe lïngerer langgefiederter Borsten befindlich; die gewöhnliche, an der Aussenseite desselben stehende Fiederborste ist vorhanden und ziemlich lang.

Das vordere Maxillenpar. (T'af. XIV, Fig. 1e) bietet wenig 
Besonderes. Der 'Taster ist ron gewöhnlicher Bildung, das Endglied fast um die Hälfte länger als der Kaufortsatz, am Ende schwach rerbreitert und mit einer Reihe kurzer zugespitzter Borsten versehen. Der Kaufortsatz ist ziemlich verlängert und schlank, am Ende mit der gewöhnlichen Doppelreihe stärkerer Kauborsten, welche nur ein bis zwei Zähne besitzen; der Basallappen klein dreieckig zugespitzt, am obern Rande mit einigen kurzen Börstchen.

Die hintern Maxillen (Taf. XIV, Fig. 1f) bestehen aus zwei ziemlich gleich grossen Lappen, der innere ist unmerklich kürzer, beide auf der Spitze mit diehtstehenden, mässig langen Borsten besetzt.

Maxillarfüsse (Taf. XIV, Fig. $1 \mathrm{~g}$ ). Taster ziemlich lang, so lang als der Basaltheil mit Einschluss des obern Lappens, das zweite Glied am längsten, das Endglied riemlich kurz, halb so lang als das zweite und gegen das Ende keulig verbreitert. Die Bildung der Kralle ist eigenthümlich, es ist mur das erste Glied derselben vor'handen, welches ron cylindrisch conischer Form ist und am Ende mit einem Büschel ziemlich langer Borsten besetzt erscheint, ohne dass ich eine Spur der eigentlichen Kralle gewahren konnte. Der obere innere Lappen ist ziemlich so lang als das zweite Tasterglied, nach dem obern Ende verschmälert und am innern Rande mit einer am Rande selbst stehenden Reihe ziemlich starker, gekrïmmter Stachelborsten besetzt.

Der untere Lappen reicht bis zur Hälfte des vorigen, ist länglich viereckig, am Endrande mit ziemlich starken Borsten und dazwischen mit drei kurzen Dornen versehen.

Die beiden rordern Fusspaare sind bei beiden Geschlechtern ziemlich gross und mit stark entwickelten Scheeren versehen, das zweite ist beträchtlich länger als das erstere und bei den männlichen Exemplaren mit einem abweichend geformten sehr vergrösserten Scheerengliede versehen. An dem vordersten Pare ist das Scheerenglied länglich oval, beträchtlich länger als das kurze, am Linde stark verbreiterte vorletzte Glied. Es ist etwa doppelt so lang als breit, der obere Rand gerade, der untere ziemlich stark convex, der Krallenrand schräg, nimmt über die Hälfte des untern Randes ein und ist sehr fein gezilhnelt; sein hinterstes Ende bildet eine abgerundete Ecke, auf welcher einige starke Stachelborsten stehen, sowie auch dahinter einige kürzere Stacheln am untern Rande befindlich sind. Die Kralle stark, schwach gekrümmt, am innern Rande fein spitzig gezähnt. Bei den Weibchen und den jüngern Thieren ist das zweite Fusspaar (Taf. XIII, Fig. 2a) mit einem ebenso gestalteten Scheerengliede versehen, nur ist dasselbe ein und ein halb mal länger. Bei den er- 
wachsenen Männchen besitzt dagegen das Scheerenglied eine unverhäiltnissmässige Grösse, ist länger als das erste Fussglied, ïber drei mal so lang als breit, der Länge nach leicht gebogen mit gekriimmtem obem Rande und diesem parallel concar gebogen, am Ende an der Wurzel der Kralle quer abgeschnitten. Der Krallenrand ist nicht deutlich abgesetzt, der ganze Unterrand ist gleichmässig mit lïngern Borsten gewimpert und bildet am Ende, da, wo er in den Endrand ïhergeht, einen ziemlich starken, stumpfen Hïcker. Ausserdem befindet sich ein kleiner spitziger Höcker an demselben auf der Grenze des vordern und mittlern Drittels desselben, welcher mit einem stumpfen Höcker an der Kralle selbst, der an denselben angelegt wird, correspondirt.

Die Kralle selbst ist sehr gross und stark, zwei Drittel sa lang als das Scheerenglied, mïssig gekrümmt, am immern Rande glatt und ganz ohme Zähnelung, dagegen hier in der Mitte mit einer abgerundeten, höckerförmigen Verdickung, zwischen welcher und der dicken Wurzel der innere Rand tief ausgebuchtet erscheint.

Die beiden folgenden Fusspare sind ziemlich kurz, kaum so lang als das zweite Fusspaar bei den Weibchen und beträchtlich kürzer als die drei hintersten.

Das fünfte bis siebente Fusspaar stark verlängert und der Reihe nach ziemlich gleichmässig an Länge zunehmend. Sie besitzen ziemlich schmale kleine Coxalglieder, welche in demselben Verhältniss an Grösse zunehmen. Letztere sind von länglich rechteckiger l'orm, kürzer als das zweite und dritte Fussglied zusammengenommen und etwa doppelt so lang als breit. Der vordere und hintere Rand derselben ist parallel geradlinig, der hintere einfach und ungekerbt, die hintere Ecke unten rechtwinkelig alogerundet. Die Fussglieder sind schlink und stark verlängert und in der gewöhnlichen Weise bestachelt; die Krallen kräftig und am imnern Rande in zwei Drittel ihrer Länge sehr fein gezähnelt.

Die vier vordern Epimeren sind klein und ziemlich von derselben Höhe wie die betreffenden Segmente, ron ziemlich achteckiger Form mit stark gerundeten Winkeln. Die vierte ist nicht rerbreitert und am Hinterrande ohne Ausschnitt, von derselben Form als die vorheragehende.

Die Epimeren der drei letzten Thoraxsegmente sind sehr niedrig, die letate derselben ist etwas abweichend geformt, schmaler als die beiden vordern, von abgerundeter form und ohe Ausrandung am untern Rande.

Die Epimeren der drei ersten Abdominalsegmente sind verhält- 
nissmässig sehr klein und wenig nach abwärts hervortretend, sie sind nicht ganz so hoch als diejenigen des dritten und vierten Segments. Sie sind von rechteckiger Form mit abgerundeten Winkeh, die Hinterränder einfach.

Die drei letzten Körpersegmente sind ziemlich verlängert, zusammen etwas länger als die zwei vorhergehenden Abdominalsegmente.

Die Springfïsse sind ziemlich lang und schlank, alle drei Paar ragen nach hinten gleich weit ror. Das hinterste Paar (Taf. XIII, Fig. 2d) ist ausgezeichnet durch die starke Verlängerung des Basalgliedes und die verhältnissmässig sehr kleinen Endiaste. Das Basalglied ist eylindrisch sehr viel linger als der ('audalanhang und nach dem Ende hin gleichmässig verjuingt, es ist nur mit sehr kleinen Stachelborsten an beiden Seitenränlern spärlich besetzt, an seinem Endrande befindet sich eine Querreihe längerer verdickter Borsten. Die beiden Endäste sind gleich lang und nur ein Viertel so lang als das Basalglied und ron cylindrisch runder Form; sie sind nach dem Ende ebenfalls gleichmässig rerjüngt und rugespitzt. Der äussere Endast ist auf der Spitze mit einer starken, stark hakenförmig gekrümmten Endkralle versehen, oberhalb deren an äussern Rande noch vier etwas kürzere, ebenfalls ziemlich starke, gerade nach aussen gerichtete dornartige Stachehn befindlich sind, welche das miterste Yiertel des äussern Randes eimmehmen. Daribber erscheint derselbe mit mehrern Reihen sehr feiner Stacheln dicht besetzt.

Der innere Endast trägt nur an der Spitze eine gerade Endkralle, welche aber kürzer und schwächer als diejenige des äussern Astes ist, neben welcher noch zwei kiirzere Nebenstacheln sich befinden. Im Lebrigen erscheinen die Seitenrïnder desselhen ginzlich einfach und ohne Stacheln oder Borsten.

Die beiden ersten Pare der Springfïsse (Taf. XIII, Fig. 2 b und 2e) sind im Ganzen von der gewöhulichen Form; das mittlere Paar besitzt ziemlich ungleiche Endiiste, von welchen der kiirzere äussere zwei Drittel so lang als der innere ist und der Länge des Basalgliedes gleich liommt. Das Basalglied ist am untern Ende mit einem zwischen der Basis der beiden Endïste hervorragenden, zugespitzten stachelartigen Fortsatz versehen, welcher halb so lang als der äussere Ast ist. Die Endäste sind cylindrisch, schlank, am Ende verjüngt und daselbst mit einer längern, fast geraden Endkralle und drei bis vier Nebenstachehr versehen, im Uebrigen von den Seitenrảndern in gewöhnlicher Weise bestachelt.

Das vorderste Paar besitzt weniger ungleiche Endäste, welche nur um ein Fïnftel an Länge rerschieden sind, es ist im Uebrigen. 
dem vorigen gleichgestaltet und ragt ebenso riel nach hinten ror. Das Basalglied ist mit einem ähnlichen, aber etwas kïrzern stachelartigen Fortsatz am untern Ende rersehen.

Der Caudalanhang (Taf. XIII, Fig. 2e) ist kurz, dreieckig, ebenso lang als breit und nach dem Ende verjiingt und in der Mitte zugespitrt. Die Seitenränder sind stark convex gekrümmt. In der Witte desselben befinden sich jederseits nahe der Mitte des Seitenrandes drei stärkere, zugespitzte Stachelborsten, ron welchen die ïussere am längsten ist.

Färbung. Die ganze Oberfläche des Körpers erscheint iiberall ziemlich dicht und fein schwärzlichbråun punktirt und gesprenkelt, besonders dicht auf dem Riücken der Dorsalsegmente.

Grösse. Die grössten der mir vorliegenden Exemplare von Ostgrönland waren Männchen, die Totallänge betrug bei dem grössten derselben $13^{\mathrm{mm}}$. Die Grösse erwachsener, mit gefüllter Bruttasche versehener Weibchen schwankte zwischen $7-11^{\mathrm{mm}}$.

Leider konnte ich keine kiirzlich ausgeschliipften ganz jungen Thiere untersuchen, doch fand ich ganz kleine $3^{\mathrm{mm}}$ lange Individuen in allen 'Theilen bereits den Erwachsenen gleich.

Bei einem Männchen von $13^{\mathrm{mm}}$ Totallänge fand ich:

Körperhöhe mit Einschl. der 3. Epimere (4. Segm.) $2^{\mathrm{mm}}$

Querdurchmesser daselbst . . . . . . 1, $1, \mathrm{~s}^{\mathrm{mm}}$

Obere Antenne. . . . . . . . . . . . $6,5^{\mathrm{mm}}$

Untere Antenne . . . . . . . . . . $7^{\mathrm{mm}}$

Kweites Fusmaar . . . . . . . . . . 5.5m

Hinterste Springfüsse . . . . . . . . . $1^{\text {mm }}$

Bei einem Weibchen von $11^{\mathrm{mm}}$ :

Antennen $\cdot \cdot 5^{\mathrm{mm}}$
Zweites Fusspaar $3^{\mathrm{mm}}$

Verbreitung. Das Vorkommen der Art an den Küisten des nordöstlichen Grönland ist ein sehr häufiges und scheint sie daselbst ziemlich allenthalben rerbreitet, an einigen Stellen war sie ziemlich massenhaft gesammelt; so: Sabine-Insel 10 Faden, sehr reichlich; ebend. 20 -110 Faden; Germania-Hafen sowie vereinzelt an mehrern andern Stellen.

\section{Familie Corophinae, Dana.}

Von dieser Familie wurde nur die nachstehende Art an der grönländischen Kïiste aufgefunden, welche auch nur sehr spärlich angetroffen wurde. 
41. 1) Glauconome leucopis Kröyer.

Kröyer, Naturhistorisk Tidskrift. Anden Räkke, I, 491, tab. VII, fig. 2. Goës, Crustac. Amphipod. maris Spetsbergiam alluentis, p. 533.

A. Boek, Crustacea Amphipoda borealia et arctica, 1) 179.

Nur zwei Exemplare dieser Art von Ostgrönland lagen mir ror, welche nicht besonders erhalten waren.

Färbung gleichmässig hellgelblich, ohne Spur von Zeichnungen.

Grösse. Das grösste Exemplar besass eine Totallänge ron $12^{\mathrm{mm}}$, das kleinere, welchem die Fühler fehlten, $10^{\mathrm{mm}}$.

Verbreitung. Scheint bei Ostgrönland selten. Das grössere Exemplar zwischen zahlreichen andern Amphipoden ron Nordshannon 30 Faden, das kleinere Germania-Hafen.

\section{Hyperidae, Dana. \\ Themisto Guerin.}

Die gestreckte schlanke Form des Körper's, welcher mehr oder weniger seitlich zusanmengedriickt und sellsst gekielt erscheint. die eigenthümliche Form der beiden ersten Fusspare und die starke Verlïngerung der hintern Thoraxtuspare und der Springfïsse simb für diese Gattung, ausser der Bildung der Mundtheile, bezeichnend.

Es sind durchaus pelagische Thierformen, welche einen sehr ausgedehnten Verbreitungsberirk einzunchmen scheinen. Die Gesehlechter sind durch eine verschiedene Antennenbildung, wie es scheint, unterschieden, doch beruht dieses nur auf Vermuthung, wenigstens gelang es mir nicht, bruttragende Weibchen zu finden und konnte ich auch keine Brutbliitter ron den Thoraxsegmenten auffinden. Es scheint daher, dass die Eier und Jungen nur kurze Zeit von den Thieren getragen werden.

\section{1) Themisto libellule (Mandt). Taf. XV, Fig. 1.}

Gammarus libellula Mandt, Observat. in Itinere grœnlandico factae, 1822, Diss., p. 32.

Themisto arctica Kröyer, Grönlands Amphipoder, p. 63, fig. 16.

Themisto crassicornis Kröyer, loc. cit., p. 67, fig. 17. $\mathrm{I}, 522$.

- Spence Bate and Westwood, History of British Sessile-Eyed Crustacea,

Themisto libellula Goës, Crustacea Amphipoda maris Spetsbergiam alluentis, p. 533 , fig. 33.

- Bœek, Crustacea Amphipoda borealia et arctica, p. 8.

Diese Art, welche in ungehenerer Individuenzahl überall im grönläpdischen Eismeer an der Oberfläche des Meeres angetroffen wird, arscheint in mehrern durch den Alterszustand bedingten Abänderungen. 
Es sind vorzugsweise die kleinen Jugendzustände dieser Art, welche in dieser Weise an der Meeresoberflïche angetroffen werden, während völlig ansgebildete erwachsene 'Thiere nur sehr vereinzelt daselbst vorzukommen scheinen. Letztere findet man dagegen häufig noch sehr wohl erhalten in grosser Menge im Magen der Phoce granlandica mil von Wasservögehn, und sind alle der erwachsenen Form angehörigen Exemplare in Dr. Pansch's Sammlung anf diese Weise erhalten worden.

Die Mundtheile sind bereits mehrfach genauer beschrieben, sodass ich nur wenig hinzufügen kann.

Die Mandibeln (Taf. XV, Fig. 1 b und 1 c) sind, wie sonderbarer Weise anch von Bœck nicht angegeben wird, beiderseits unsleich, indem nur die linke den processus accessorius besitzt, welcher der ersten völlig fehlt. Der Kauhöcker steht sehr hoch und hat eine ungewöhnliche, sehr strrk zusammengedrüickte Form, ist ron der Wurzel gegen das Ende etwas verbreitert, trapezoïdisch, und auf der sehr schmalen schrren Endfäche mit sehr zahlreichen queren Zahnleisten versehen, die im Profil als kileine spitzige Zähne hervortreten.

Das Fehlen des processus accessorius an der rechten Mandibel wurde bei mebrern Individuen, sowol der erwachsenen als der Jugendform constant getroffen.

Die Bildung der Fusspaare bei der erwachsenen Form ist bereits himreichend genau von den früher n Bcobachtern erörtert worden; die von Goës angegebene, von der typischen Form abweichende Varietät von Jan Mayen ist nichts ande'es als die Jugendform.

Färbung. Der in Taf. XV, Fig. 1) mitgetheilten Abbildung ist eine von Dr. Pansch nach dem lebenden Thiere gemachte Skizze zu Grunde gelegt. auch hatte sich die Färbung bei manchen Stïcken recht gut erhalten. Die Augen sind tief dunkelviolettschwarz. Der Körper ist überall auf dem Riücken der Segmente mit grossen dunkelvioletten, meist sternförmigen Pigmentflecken gezeichnet, welche bei den jüngern 'Thieren häufig in Form runder unverzweigter Flecke erscheinen, ebenso die Springfüsse und der Caudalanhang sehr stark violett gefürbt, wäbrend die übrigen Extremitäten blassröthlich erscheinen.

Die Grösse der mir vorliegenden erwachsenen 'Thiere beträgt zwischen $25-37^{\mathrm{mm}}$ 'lotalliinge. Bei einem $30^{\mathrm{mm}}$ langen:

Körperhöhe mit Linschl. der Epimere (4. Segm.) 4,8mm

Querdurchmesser des Körpers daselbst . . . $4^{\mathrm{mm}}$

.. lopples. . . . . 4.5 $45^{\mathrm{mm}}$

(1)eres Anteme. 
Bei einem ebenso langen Stücke mit verlängerten Fühlern:

$$
\begin{aligned}
& \text { Obere Antenne } 6,5^{\mathrm{mm}} \\
& \text { Untere Antenne } 8^{\mathrm{mm}}
\end{aligned}
$$

Die betreffenden Exemplare waren sämmtlich aus dem Mageninhalt einer Phoea (vermuthlich granlandica) von Dr. Pansch Ende Juli 1869 gesammelt. Ich selbst fing nur ein einziges mal ein völlig erwachsenes 'Thier an der Neeresoberfliche zwischen dem Packeise, nahe der Eisgrenze, fand dagegen gleichfalls mehrmals den Magen der genannten liobbe vollkommen damit angefüllt.

Zwei halberwachsene Stücke, welche ron Dr. Pansch dicht an der Fisgrenze am 13. Juli 1869 an der Oberfläche gesammelt wurden, sind $15^{\mathrm{mm}}$ lang und besitzen im Ganzen bereits völlig die ausgebilileten Formen.

Jugendform. Diese sehr massenhaft rorliegenden, von der Oberfliche gesammelten jüngern Stadien sind von $3^{m m}$ an in sehr verschiedenen Grössen bis zu $8^{\mathrm{mm}}$ anzutreften. Die Abweichungen, welche diese jüngsten Stadien von der erwachsenen Form darbieten, sind besonders in den Antemen und hintern 'Thoraxfussparen ausgeprägt. Die Antennen sind äusserst kurz, mamentlich die Geissel, an den obern die kurze dicke und zugespitzte Geissel nur so lang als der Schaft, sie besteht nur aus dem basalen ungegliederten Abschnitt und ist auch bis zur Spitze mit Riechborsten besetzt, während der gegliederte Endabschnitt fehlt. Auch die mutern Fiihler ebenfalls mit kurzer ungegliederter Geissel, die nur wenig länger ist als der Schaft.

Die Mandibeh besitzen emen sehr viel kürzern Taster, der die Länge der Mandibel selbst nicht übertrifft, die Glieder ziemlich gleich gross.

Im Uebrigen sind die Mundtheile wie bei der erwachsenen Form.

Die beiden ersten Fusspara im Wesentlichen iibereinstimmend, doch ist am zweiten der Fortsatz des vierten Gliedes kürzer und dicker, sowie auch das fünfte Glied kürzer erscheint. Am dritten und vierten ist das vierte Glied weit weniger stark erweitert und kleiner, das fünfte Fussparr besitzt noch nicht die ungewöhnliche Verlängerung, sondern ist bei den jüngsten Exemplaren von derselben Länge mit den folgenden, bei etwas grössern nur umbedentend länger.

Die drei hintersten Körpersegmente mit ihren Anhängen wie bei der erwachsenen Form.

Verbreitung allenthalben im grönländischen Eismeer an der Oberfliche in erstaunlichen Massen. Sie wird bereits weit ausserhalb der Packeisgrenze angetroflen mol ist zwischen dem Fise selhst allenthalben verbreitet. Sie ist wol auch ausserhalb des Eises in edm 
ganzen Polarmeer häufig, da sie ebenso sehr frïhzeitig mit Cetochilus septentrionalis zusammen zwischen Jan Mayen und der Eisgrenze bemerkt wurde.

\section{Caprellinae, Leach.}

Ls liegt nur eine einzige Art dieser Gruppe sowol von Ostgrönland als von Spitzbergen vor.

43. 1) Aegina spinifera (Bell).

Caprelle spiniferc Bell, App. to Belchers last of the Arctic Voyages, p. 407, tab. 35 , fig. 2 .

- Goës, Crustacea Amphipoda maris Spetsbergiam alluent., p. 535.

Aeginella echinata Bœck, Crustacea Amphipoda borealia et arctica, 1. 191.

Ich habe zwei Exemplare von Ostgrönland und zwei sehr wohl conservirte von Spitzbergen ror mir und zweifle nicht, dass die arktische Form mit der von Bœek von der norwegischen Küste identisch ist, da seine Beschreibung genau auf das weibliche Thier passt. Unter den rorliegenden befindet sich nur ein weibliches. Bei den Nännchen sind nicht nur die Fühler sehr viel länger, sondern das zweite Fusspaar beträchtlich länger und mit stärker entwickelten Scheeren versehen, sowie die Stacheln, welche den Rüicken bedecken, lïnger und zahlreicher sind.

Die beiden grössten Exemplare von Grönland 29mm , und das spitzbergische $31^{\mathrm{mm}}$ Länge waren Männchen, das Weibchen nur $25^{\mathrm{mm}}$.

\section{P H Y L L 0 P 0 D A.}

\section{Nebaliadae, Baird.}

\section{1) Nebatia bipes (O. F.).}

Cancer bipes Fabricius, Fauna gronlandica, Nr. 223.

Nebatia Ilerbstii Leach, Zool. Miscellan., I, 100, tab. 44.

- Milne Edwards, Hist. naturelle des Crustacées, III, 356.

Nebalia bipes Kŕröyer, Naturhist. Tidskr., Ny Rakke, II, 436.

? Nebatia Geoffroyi, Milne Edwards, Histoire natur. des Crustacées, III, 35.

Obwol die Art an der ostgrönländischen Küste ziemlich allgemein verbreitet zu sein scheint, so liegen doch nur sieben Exemplare in Dr. Pansch's Sammlung von verschiedenen Stellen vor, sodass sie im Ganzen doch dort ziemlich vereinzelt aufzutreten scheint. 
Obschon die grönländische Art bereits im vorigen Jahrhundert in Fabricius' grönländischer Fauna aufgeführt worden ist, und als die am längsten bekannte Art der Gattung anzusehen ist, ist dennoch ihr Verhältniss zu den im südlichen atlantischen Gebiet vorkommenden Formen wie ich glaube noch keineswegs genïgend sicher gestellt.

Da ich Gelegenheit hatte, die grönländischen Exemplare mit einer ziemlichen Anzahl solcher vergleichen zu können, die von mir in friiherer Zeit bei Neapel gesammelt wurden, und sich hierbei mit einziger Ausnahme der beträchtlichern Grösse der grönländischen Form eine völlige Uebereinstimmung bis ins geringste Detail der Theile herausstellte, so erscheint es mir jedenfalls im höchsten Grade unwahrscheinlich, dass die an der Küste der Bretagne von Milne Edwards angetroffene und in Cuvier's Règne Animal abgebildete Nebalia Greoffroyi einer andern Art angehören sollte. Kröyer, welcher (a. a. O.) die genamesten Angaben über die grönländische Nebalia bipes gemacht hat, bemerkt freilich, dass dieselbe sich leicht von Nebalia Geoffroyi unterscheiden lasse, im Falle die citirte Abbildung genau sei. Da indessen die Details derselben keineswegs genau sind, so scheint mir auf die betreffenden Abweichungen kaum ein erhebliches Gewicht zu legen zu sein.

Vorkommen. Germania-Hafen 3 Faden; Sabine-Insel; JacksonInsel, in geringerer Tiefe. Sie scheint ausserdem auch die geringern Tiefen zu bewohnen, da ich mich erinnere sie auf Shannon-Bank bei 150 Faden, ebenfalls vereinzelt, gesammelt zu haben.

\section{O P E P O D A.}

Von dieser Abtheilung war ausser einer sehr reichlichen Anzahl von Calaniden, welche grösstentheils an der Meeresoberfläche gefischt waren, in Dr. Pansch's Sammlungen nichts vorhanden. Indessen gelang es mir doch aus den Rückständen verschiedener Gläser mit andern Crustaceen, welche ich genauer mit der Lupe durchmusterte, cine ziemliche Anzahl der mikroskopisch kleinen littoralen (opepodenformen herauszusuchen. Das Resultat der etwas muihseligen Arbeit erschien im Ganzen ziemlich lohnend, indem sich bei genauerer Durchsicht des auf diese Weise gesammelten Materials herausstellte, dass sechs verschiedene Arten aus den Familien der Harpactiden, Peltididen und Cyclopiden an der grönländischen Küste verbreitet sind, 
von denen freilich keine einzige derselben eigenthïmlich ist, indem sie sämmtlich an den deutschen, englischen oder norwegischen Küsten der Nordsee vorkommen. Immerhin ist es indessen ron Interesse, dass der Verbreitungshezirk dieser kleinen Crustaceen nach dem höchsten Norden hin ein so ausgedehnter ist, dass die Nordseefauna fast nur als Bezirk ihres Verbreitungskreises erscheincu dürfte, während in den ïbrigen Abtheilungen doch eine beträchtliche Anzahl dem arktischen Gebiete eigenthimlicher Arten auftritt.

Die Aceresoberflaiche sellsst scheint dagegen innerhalb des Polarmeeres, in grösserer Lntfernung von den Kï̈sten, ausschliessend von Cetochilus-Arten bevölkert zu werden, wie ich bereits an einem frïhern Orte bemerkte, da weder von mir jemals im Auftriebe des feinen Netzes anderweitige Gattungen bemerkt wurden, noch auch in Dr. Pansch's Sammlungen sich eine Spur solcher antreffen liess.

\section{Calanidae.}

Gen. Cetochitus Roussel de Vauzème. Claus.

(Calanus auctor.)

Die Trennung der Cotochitus-Arten von dem Genus Calams, wie sie von Claus ${ }^{1}$ auf Grund der Bildung des letzten Fussparres angegeben werden, wird allerdings von neuern Autoren nicht allgemein angenommen, scheint aber doch hinreichend wichtig, um die 'Trennung der Gattungen aufrecht zu erhalten.

Was die in den arktischen Meeren in so ungehenerer Massenhaftigkeit rerbreiteten hierher gehörigen kleinen Crustaceen anbetrift't, so liegt allerdings in Dr. Pansch's Sammlungen eine höchst betríchtliche Individuenzahl vor, welche ich auf den von Goodsir und später von Baird genauer beschriebenen Cetochilus septentrionalis glaube beziehen zu müissen. Es sind allerdings von Kröyer ${ }^{2}$ nicht weniger als sechs verschiedene Arten aus dem arktischen Gebiete beschrieben worden, indessen da von diesem Forscher die sexuellen Differenzen nicht erkannt worken, und iiberdies mehrere Arten auf sehr unsichere Merkmale gestiitat worden sind, bleibt es unsicher, ob dieselben nicht vielmehr in den Formenkreis einer einzigen Art gehören dürften.

Ich halte es nicht für mmöglich, dass mehrere wirklich differente Arten dieser Gattung im arktischen Gebiet rorkommen, doch habe

1 Die fiei lebenden Copepoden (186:3), S. 169.

${ }^{2}$ II. Tŕröyer, Carcinologislie Bidrag. Naturhist. 'Tiılskrift, 1848, Ny Räkke, T. II. Om Sliegten Calanus, 1) 527 sq. 
ich nach genanerer Durchsicht des vorliegenden Materials, trotz der Reichlichkeit desselben, die Ueberzeugung gewonnen, dass dasselbe zur Entscheidung dieser Frage nicht genügt. Um einige Sicherheit hieriiber zu erhalten, mïsste man bei den sehr geringfügigen Artunterschieden eine Reihe rollkommen erhaltener Individuen beiderlei Geschlechts zu untersuchen Gelegenheit haben. Es sind aber an den in Alkohol conservirten Exemplaren dieser äusserst zarten Thierchen leider gerade sehr wesentliche Theile, wie die Borsten der Furca, die Spitzen der obern Antennen und die letzten Glieder der Füsse so allgemein zerstört, dass es mir nicht gelang unter einer ïusserst grossen Anzahl untersuchter Exemplare auch nur eins aufzufinden, an welchem diese Theile völlig erhalten sich gezeigt hätten. Unter diesen Umständen musste ich es für einen völlig aussichtslosen Versuch ansehen, ein genügendes Material zur Aufklïrnng der schwebenden Fragen daraus zu gewinnen.

45. 1) Cetochilus septentrionalis Goodsir. 'Taf. XV, Fig. 2.

Goodsir, New Edinburg. Phil. Journ., XXXV, 339.

Baird, Natural History of the British Entomostraca, 1850, p. 235.

Calames hyperboreus Kröyer, Om Slægten Calanus. Naturhistorisk Tidskrift, II Räkke, II, 542.

?Calanus spitzbergensis, affinis, minutus, quinqueanulatus Kröyer, 1. c., 1. $531-545$.

Ich halte es für nicht unmöglich, dass auch Cetochitus helgolandicus Claus, sowie die damit identische Calanus finmarchicus Gunnerus nach A. Bock's Angaben mit dieser Art zusammenfallen. Ich finde wenigstens ausser den sehr geringen Grössen kein Merkmal in den Angaben dieser Beobachter, welches dagegen spräche.

Die Mämnchen scheinen sehr spärlich, wenigstens suchte ich zwischen einer grossen Menge der kleinern form, sowie bei allen den grossen vergeblich danach; freilich waren zu viel beschädigt, als dass sie sich nicht hätten der Wahrnehmung entziehen kömnen.

Verbreitung. Die enorme Massenhaftigkeit, mit welcher diese kleinen Crustaceen in den nordischen Meeren auftreten, wird von mehrern der erwähnten Beobachter bereits hervorgehoben. So von Baird und Kröyer, auch von Scoresby wird (An account of the Arctic Regions) dieser'Form Erwähnung gethan und ihre ungemeine Nenge im Eismeer hervorgehoben. Man findet sie bereits weit ausserhalb des Eises und sehr weit rom Lande pelagisch, wie es scheint im ganzen Polarmeer verbreitet. In Dr. Pansch's Sammlung befindet sie sich schon vom 10. Juli 1869 an der Oberfläche gefangen. 'Zwischen dem Packeise ist sie allenthalben sehr häufig. 
In einem Glase befindet sich überdies eine Anzahl namentlich grösserer Exemplare, welche im Netz von 175 Faden heraufgezogen wurden. Es finden sich hier auch der Grösse nach Abstufungen zu der kleinern Form. Es scheint somit, dass, wie bei Themisto, die grossen röllig ausgebildeten Thiere vorzugsweise in tiefern Wasserschichten anzutreffen sind.

46. 2) Diaptomus castor Jurine.

Cyclopsine castor Milne Edwards.

Leider war in der Sammlung ron Herrn Dr. Pansch nur ein einziges Exemplar in einem Glïschen mit der Angabe, dass es am 22. Februar 1870 am Fluthloch beim Schiffe gefunden sei, sowie auch einige Skizzen von Dr. Pansch, welche sich auf dieselbe Thierform beziehen, und gleichfalls im Februar entworfen wurden. Es wird dabei bemerkt, dass das Thier geleuchtet habe, was meines Wissens ron dieser Art nicht bekannt ist, wenigstens finde ich bei Baird und Claus nichts dariiber angemerkt.

Wiewol es mir daher leider nicht möglich war an dem vorliegenden, sonst ziemlich gut conservirten Exemplar mir über die Identität eine volliw sichere (iewisheit zu rerchatfen und die Skizzen Dr. Panseh's hierzu nicht ausreichen, so kann ich doch nicht wohl daran zweifeln, obgleich Diaptomus castor eigentlich eine Suisswasserform ist und mich das Vorkommen daher etwas iiberraschte.

Das Exemplar ist weiblich, $5,8^{\mathrm{mm}}$ lang ohne die Schwanzborsten, das dreigliedrige Abdomen nimmt daron $2,8^{\mathrm{mm}}$ ein. Diese Grösse ist ansehnlich beträchtlicher, als die Angaben der citirten Beobachter besagen.

Die 25gliedrigen imnern Antennen etwas lïnger als der 'Thorax, die Furcaglieder so lang als das dritte Abdominalsegment, die Endborsten ron der Länge des Gliedes. Das fünfte Fusspaar mit dreigliedrigem Lndast; es wollte mir nicht ganz gelingen sicher zu erkennen, ob dasselbe wirklich wie es schien einïstig ist. Ein Rostrum nicht zu bemerken.

\section{Il arpactidae, Clans.}

47. 1) Harpacticus chelifor (O. F'. Miiller).

Cyclops chelifer Müller, Zool. Danic. Prodromus, Nr. 2413.

IIarpucticus chelifer Milne Edwards, Hist. nat. des Crustacées, III, 430.

- Lilljeborg, Crustacea ex ordinib. Clatocera etc. in Scania occurentes, tab.XXII, fig. $2-11$. 
Harpactidus chetifer Claus, Die freilebenden Copepoden, S. 135. 1864, p. 37.

A. Beck, Översigt over de ved Norges kyst jagttague Copepoder,

Diese an den nordischen Küsten weit verbreitete $\Lambda$ rt fand ich zwischen Amphipoden und Crustaceen anderer Art, welche an der Sabine-Insel in geringerer 'Tiefe an mehrern Stellen gesammelt waren. in mehrern Gläsern ziemlich reichlich; besonders von Sabine-Insel 10 Faden tief.

Die vorliegenden Exemplare von Ostgrönland stimmen im Ganzen vollkommen mit den Angaben von Baird, Claus und A. Bøek überein, nur dass sie eine etwas beträichtlichere Grösse darbieten, ich finde sie ohne die Schwanzborsten bis zu $2,5^{\mathrm{mm}}$ lang.

48. 1) Tisbe furcata (Baird).

Canthocampus furcatus Baird, British Entomostraca, p. 210.

Tisbe furcata Claus, Die freilebenden Copepoden, S. 116, Taf. XV, Fig. 1-12.

Idya furcata Boek, Översigt over de ved Norges liyst jagttagne Copepoder, p. 34 .

Auch diese an den englischen und nor'wegischen Küsten sowie bei Helgoland häufig beobachtete Art ist an den Küsten Ostgrönlands wie es scheint sehr häufig, ich fand eine ziemlich reichliche Menge von Individuen in verschiedenen Gläsern von Amphipoden, besonder's auch von Sabine-Insel 10 Faden. Die Uebereinstimmung mit Claus' Angaben und Zeichnungen ist vollständig, auch die Grösse bis zu $1,5^{\mathrm{mm}}$.

49. 2) Cleta minuticomis Miiller. Taf. XV, Fig. 3.

Cyclops minuticornis Müller, Entomostraca, p. 117, tab. 19, fig. 14, 15.

Canthocamptus minuticomis Baird, The Natural History of the British Entomostraca (London 1850), 8vo.

Schon von Claus wird diese an der englischen Küste aufgefundene Art vermuthungsweise zu dieser Gattung gestellt, wiewol sie ron Baird sehr ungenau beschrieben ist.

Ich entdeckte nur sehr wenige Exemplare dieses äusserst zierlichen Thierchens zwischen den andern vorhergehenden kleinen Copepoden und kanm bestätigen, dass sie in allen wesentlichen Charakteren mit den übrigen Cleta-Arten übereinstimmt.

\section{Peltididae, Claus.}

50. 1) Zaus spinosus Claus.

Zaus spinatus Goodsir? 
Zaus spinosus Claus, die freilebenden Copepoden, S. 146.

- Bock, Översigt over de ved Norges kyst jagttagne Copepoder, p. 10.

Diese ron Claus bei Helgoland und von A. Boek an der West-

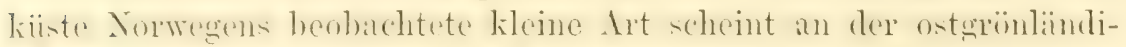
schen Küiste nicht selten. Ich fischte eine ziemliche Zahl wohlerhaltener Exemplare aus rerschiedenen Gliisern, welche andere Krebsthiere enthielten, heraus und fand sie, sowie Harpacticus chelifer von verschiedenen Stellen, meist wie es scheint aus geringer T'iefe vor, besonders in einem Glase von Sabine-Insel 10 Faden, welches sehr zahlreiche Amphipoden enthielt.

Ueber die Identitït mit der citirten Art kamn nach den Angaben der angefiihrten Beobachter liein Zweifel bestehen, ich finde alle Merkmale röllig mit der Nordseeform iibereinstimmend.

\section{2) Zaus ovalis (Goodsir').}

Sterope ovalis Goodsir.

Sterope armatus Goodsir.

Zus ovatis Clans, Die freilebenden Copepoden, S. 146, 'Taf. XIII, Fig. 11-18.

Diese ron Goodsir entdeckte, damn ron Claus von Ilelgoland näher beschriebene Art fand sich nur in drei Exemplaren ron Ostgrönland, gleichfalls wie die übrigen kleinen Copepoden zwischen andern Krebsthieren zwischen der rorigen Art ror.

Sie ist ansehnlich grösser als die rorige, die vorliegende bis zu $2^{m m}$, ohme die Schwanzborsten; der Körper viel mehr lang gestreckt als bei jener, die Formen ganz mit Claus' Angaben und Zeichnungen iibereinstimmend. Das Rostrum finde ich aber nicht so breit abgeschnitten, wie Clans angibt, sondern dreieckig zugespitzt. Die Borsten an dem Ende der Aeste des ersten Fussparres wie sie von Claus angegeben werden. Die Aussenrïnder an den Aesten der Schwimmfüsse zwischen den grössern Stacheln mit ziemlich starken Stacheldornen bewehrt, ebenso der Aussen- und Endrand des blattartigen Fusspares. Ebenso die äussern liänder der Abdominalsegmente mit noch stïrkern dichtstehenden und mohrere Reihen bildenden Stachelzähnen besetzt, sowie auch die Furca am Endrande zwischen den Schwanzborsten mit solchen Stachelzïhnen hewehrt ist, welche auch an der Wurzel der Fureaglieder eine Querreihe bilden. Die Schwanzborsten waren nicht erhalten.

An der norwegischen Küste ist sie, wie es scheint nicht beobachtet worden, wenigstens wird sie von $\mathrm{A}$. Bock nicht angegeben.

Goodsir's Beschreibung ist mir nur durch Claus' Citat bekamnt und komite daher nieht reroglichen werden. 


\section{Cyclopidae, Dana. \\ Thorellice Bock.}

Diese von $\Lambda$. Bøek an der norwegischen Küste beobachtete Gattung steht den Suisswasserarten sowol in der gesammten Form und Gliederung des Körpers als auch namentlich in der Bildung der Mundtheile äusserst nahe. Ich hatte nur sehr wenige Exemplare vor mir, von denen ich nicht bezweifeln kann, dass sie mit der norwegischen Art identisch sind.

52. 1) Thorellia brumea Bœck.

Bock, Översigt over de ved Norges kyster jagttagne Copepoder etc. Clristiania Vidensk. Selsk. Forhandling. for 1864, p. 26.

Die sehr wenigen Exemplare won Ostgrönland fand ich zwischen den übrigen kleinen Copepoden sehr vereinzelt vor. Ich kamn nicht genau angeben, in welchen Gläsern sie enthalten waren, doch waren einige bestimmt von der Sabine-Insel aus 10 Faden Tiefe.

Die Grösse ist etwas beträchtlicher als die von Bœck angegebene; ich fand die Länge bis zum Ende der Furca, ohne die Borsten derselben bis zu $1,8^{\mathrm{mm}}$, während Bøck sie nur zu $1^{\mathrm{mm}}$ angibt.

Die von Bock angegebene charakteristische Fürbung war an den vorliegenden Exemplaren nicht wahrzunehmen, ich bemerkte nur die bräunlich durchschimmernden Leberschläuche, deren Form aber nicht mit auf die von Bœek angegebenen brïmnlichen Zeichnungen bezogen werden kann.

\section{COPEPODA PARASITA.}

Caligidae, Milne Edwards.

53. 1) Lepeophtheives Hippoglossi Kröyer.

Lepeophtheirus Itippoglossi Krröyer, Naturhist. Tidskr., I, 625, tab. VI, fig. 3. - Baird, British Entomostraca, p. 276, tab. XXXII, fig. 12.

Mehrere Individuen dieser Art wurden von Dr. Pansch auf der Fahrt durch die Nordsee auf den Kiemen von Pleuronectes Rhombus und Hippoglossus gesammelt. Das grösste bis $13^{\mathrm{mm}}$ lang, olne die Eisïcke. Auch ich sammelte sie damals reichlich von denselben Fischen.

\section{Lernaeopodidae.}

54. 1) Brachiclla rostrata Kröyer.

Brachiella rostrata Kröyer, Naturhist. Tidskrift, I, 207, tab. II, fig. 1.

Zusammen mit Lepeophtheirus Hippoglossi von Dr. Pansch auf denselben Fischen in der Nordsee in drei Exemplaren gesammelt. Das 
๓rösste $13^{\mathrm{mm}} \operatorname{lang}$, die Eisäcke $9^{\mathrm{mm}}$, das kleinste $9^{\mathrm{mm}}$, gleichfalls mit Eisäcken versehen. Ich erimnere mich ebenfalls sie damals bei der sclben Gelegenheit gesammelt zu haben.

\section{I R R H I P E D I A.}

\section{5ั5. Butamus porcutus Da Costa.}

Da Costa, Histor. Natur. Testac. Brit, , p. 249 (1779).

Darwin, A Monograph of the Subclass Cirrhipedia (1854), p. 256.

Die enzige Art, welche an der ostgrönländischen Küste gesammelt wurde. Der Fundort ist leider nicht genauer bezeichnet. Die wenigen vorliegenden Exemplare meistentheils von cylindrisch röhriger, verlängerter Form, bis zu $22^{\mathrm{mm}}$ lang. Die Schaale ist gelblich, an dem Schmabel des Tergum keine purpurrothe Fïrbung sichtbar. Die Lüngsrippen auf den Schaalenstücken stark ausgeprägt, die Zwischenräume zwischen denselben bei den meisten glatt, nur bei einem Exemplar mit Querfurchen versehen.

\section{11 h a $11 \mathrm{~g}$.}

Obwol die folgende Gruppe nicht zu den Crustaceen zu rechnen ist, füge ich die wenigen Arten, welche beobachtet wurden, denselben dennoch bei, da sie gemeinsam mit denselben bearbeitet wurden und ihre Verbreitung sie den Crustaceen zunächst anreiht. Durch Herrn von Ifenglin wurde Nymphon longiturse Kröyer auf Spitzhergen (Storfjord) gesammelt.

\section{Pycuogonida.}

Diese Gruppe ist in den Sammlungen von Ostgrönland nur sehr spärlich durch einige wenige Stiicke vertreten. Ich befolge die von II. Kröyer ${ }^{1}$ in seiner vorzüglichen Arbeit über die nordischen Formen gegebene Arteintheilung, worin sïmmtliche vorliegenden Stiicke eine Stelle finden.

1) Nymplion grossipes O. F.

Nymplion grossipes Kröyer, loc. cit., p. 109.

Ein $5^{\mathrm{mm}}$ langes Exemplar ron Nordshannon, welches mit den

ग) H. Kröyer, Bidrag til Kundskab on Pycnogoniderne eller Söspindlerne. Natur. hist. Tidskrift, II Raikke, II, $90 \mathrm{fg}$. 
Kröyer'schen Angaben sonst völlig iibereinstimmt, doch finde ich den Körper mit sehr feinen Härchen besetzt; die Nebenkralle viel kiirzer, nur ein Drittel so lang als die Kralle.

Zweites Fusspar 22mm. 'Trotz der geringen Grösse sind die Maxillarfüsse mit einem Eierhaufen besetzt.

2) Nymphon mixtum Kröyer.

Nymphon mixtum Kröyer, loc. cit., p. 110.

Zwei Stücke, das eine von Ostgrönland $7^{\mathrm{mm}}$ lang, das andere $9^{\mathrm{mm}}$ von Spitzbergen aus dem Storfjord trugen die von Kröyer angegebenen Merkmale dieser Art an sich. Doch muss ich dahingestellt sein lassen, ob die von Kröyer angegebenen auf dem Verhältniss der Länge des Tarsus zum Endglied beruhende Artunterscheidung ausreichend ist, 1 m diese Art von der vorigen zu trennen.

Auch hier finde ich die Nebenkrallen sehr viel kiurzer als Kröyer angibt, bei dem spitzbergischen Exemplar sogar kaum ein $\Lambda$ chtel so lang als die Kralle selbst. Die Länge des zweiten Fussparares bei letzterm $30^{\mathrm{mm}}$.

3) Nymphon hivtum O. F.

Nymphon hirtum Kröyer, 1. c., 1) 113.

Ein kleines Exemplar dieser Art von $5^{\mathrm{mm}}$ von Ostgrönland (Nordshannon), sowie zwei sehr grosse von $H$. von Heuglin in Storfjord gesammelte, $14^{\mathrm{mm}}$ lange, von denen das eine ein mit Eiern versehenes weibliches, das andere ein männliches Exemplar; bei letzterm sind die vierten Glieder an allen Fusspaaren beträchtlich dicker als bei ersterm.

\section{Erklärung der Abbildungen.}

Tafel I.

Fig. 1. Hippolyte Panschii, nov. spec., Weibchen. b. Endrand des Caudalanhanges.

Fig. 2. Pasiphä̈ glacialis, nov. spec. b. vorderer Kopfrand mit dem erhaltenen Theile der Antenne; $c$. letztes Körpersegment mit den mittlern und seitlichen Caudalanhängen; $d$. erstes $-e$. drittes $-f$. funftes Thoraxfusspaar g. Endglied der iussern Maxillarfüsse.

Fig. 3. Pardalisca cuspidata.

Tafel II.

Fig. 1. Pardalisca enspidata. a. linke $-b$. rechte Mandibel; $c$. vordere $-d$. hintere Maxille; e. Maxillarfuss; $f$. erstes 'Thoraxfusspaar; $g$. zweites Paar Springfüsse; $h$. obere Antenne. 
Fig. ‥ a. Leptophryxus Aysidis, nov. spec. Weibchen von unten, sechs mal vergrössert, mit dem Münnchen in Situ; $b$. dasselbe von ler Rüickseite; $c$. Männchen stärker vergrössert; $d$. die soeben ausgeschlüpfte Larve stark vergrössert; $e$. Kopf und vordere 'Thoraxgegend des Weibchens von der Unterseite stärker vergrössert; $f$. Kopf des Nünnchens von unten starki rergrössert: $R$ Saugrüssel, $A^{1}$ obere $-A^{2}$ untere Antenne; $g$. siebentes 'I'horaxfusspaar des Mïmohens.

\section{Tafel III.}

Fig. 1. Tritropis fragitis. b. vordere - c. hintere Maxille; d. Maxillarfuss; c. rechte - $f$. linke Mandibel; g. letztes Körpersegment mit Caudalanhang; $h$. zweites Thoraxfusspaar; $i$. Oberlippe.

Fig. ‥ ILusines cuspitatus. Z. obere Anteme.

\section{Tafel IV.}

Fig. 1. Amphithonotus aculeatus. b. vordere $-e$. hintere Maxille; d. Maxillarfuss; c. zweites Paar Springfüsse; f. rechte Mandibel; g. Oherlippe; $h$. Unterlippe; $i$. specifische Fühleranhänge en face; $j$ obere Antenne.

\section{Tafel V.}

Fig. 1. Oediceros borealis. $b$, rechte $-c$. linke Mandibel; $d$. vordere $-e$. hintere Naxille; $f$. Maxillarfuss; $g$. Stirn und Rostrum eines jungern Exemplars; $h$. erstes $-i$. zweites $-j$. drittes $-k$. sechstes Thoraxfusspaar; l. letztes Körpersegment mit Caudalanhang und hintersten Springfüssen; m. obere Antenne.

\section{Tafel VI.}

Fiø. I. Pleustes panoplus. $b$. rechte $-c$. linke Mandibel; $d$. vordere $-\epsilon$. hintere Maxille; $f$. Maxillarfuss; g. Oberlippe.

Tafel VII.

Fiy. 1. Parapleustes gracitis, nov. spec. b. rechte - c. linke Mandibel; d. vordere - e. hintere Maxille; $f$. Maxillarfuss; $y$. erstes - h. zweites $i$. drittes Paar Springfüsse; $j$. Oberlippe; $k$. Unterlippe; 7. viertes 'Thoraxfusspaar; m. Caudalankang des letzten Körpersegments.

Fig. 2. Ocdiceros tynceus. a. Stim und Rostrum; b. erstes - c. zweites Thoraxfusspaar.

\section{Tafel VIII.}

Fïg. 1. Amathilla Sabini. b. obere Antenne; c. Maxillarfuss; d. linke Mandibel; e. specifische Fühleranhänge.

F'ig. ‥ Junges Exemplar derselben Species; b. Oberlippe; c. Unterlippe; d. letztes Körpersegment mit Caudalanhang.

\section{Tafel IX.}

Fig. 1. Amathilla Sabini juv. a. erstes Thoraxfusspaar; $b$. vordere - c. hintere Maxille; d. Maxillarfuss; e. linke Mandibel.

Fig. 2. Amathilla pinguis. b. zweites Paar Springfüsse; c. crstes Thoraxfusspaar; $d$. vordere - e. hintere Maxille; $f$. letztes Körpersegment mit Caudalanhang und hintersten Springfiissen; g. Oberlippe; h. Maxillarfuss; $i$. specifische Fühleranhänge; $j$. linke Mandibel.

\section{Tafel $\mathrm{X}$.}

Fig. 1. Atylus carinatus. b. rechte Mandibel; c. Maxillarfuss; $l$. crstes - c. zweites Par Springfiisse; f. obcre Antenne rom Männchen, \% rom Weih- 
Z00L0GLE, 8. Crustaceen 'T'af.I.

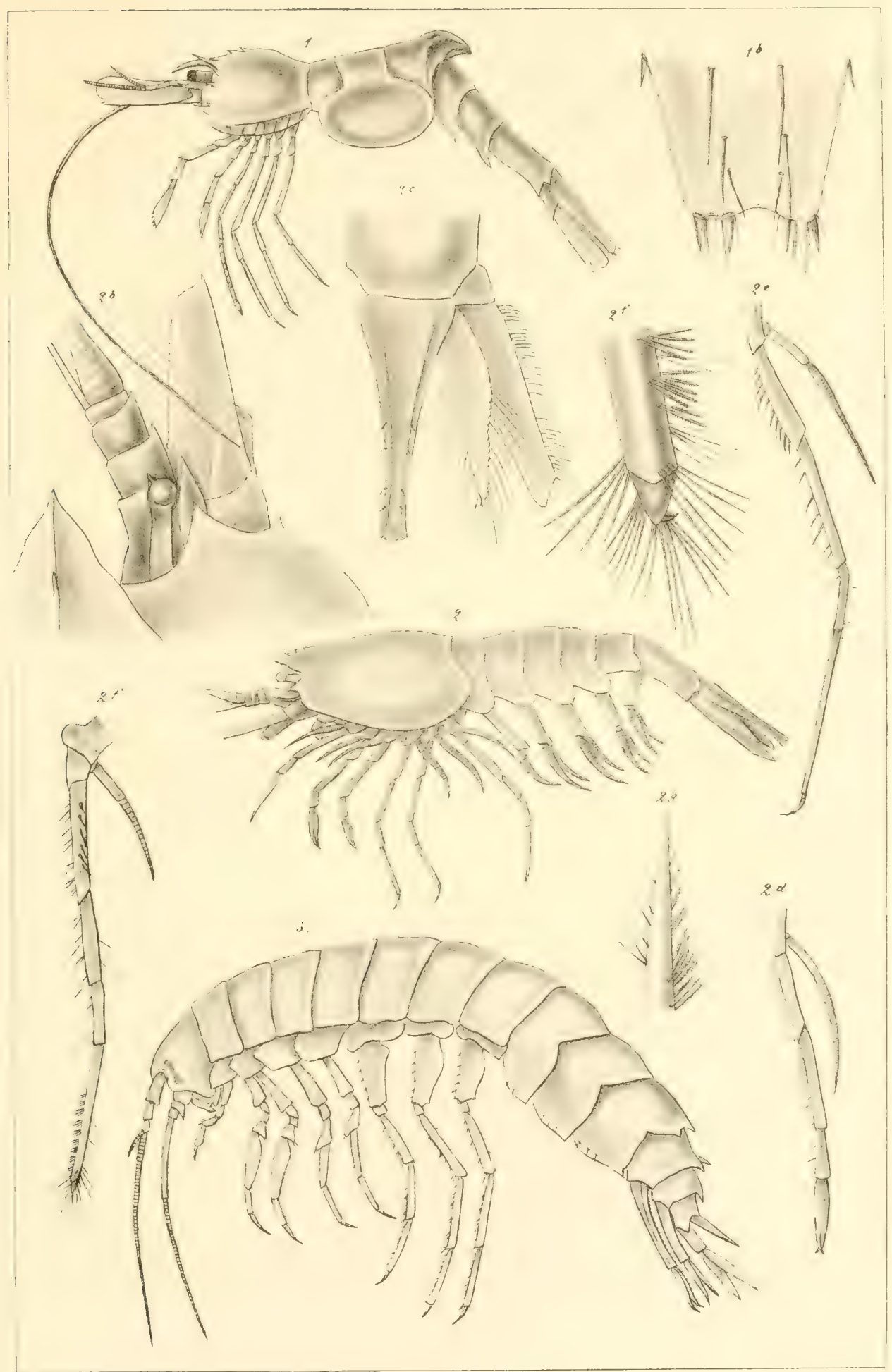

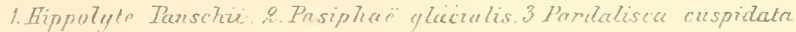




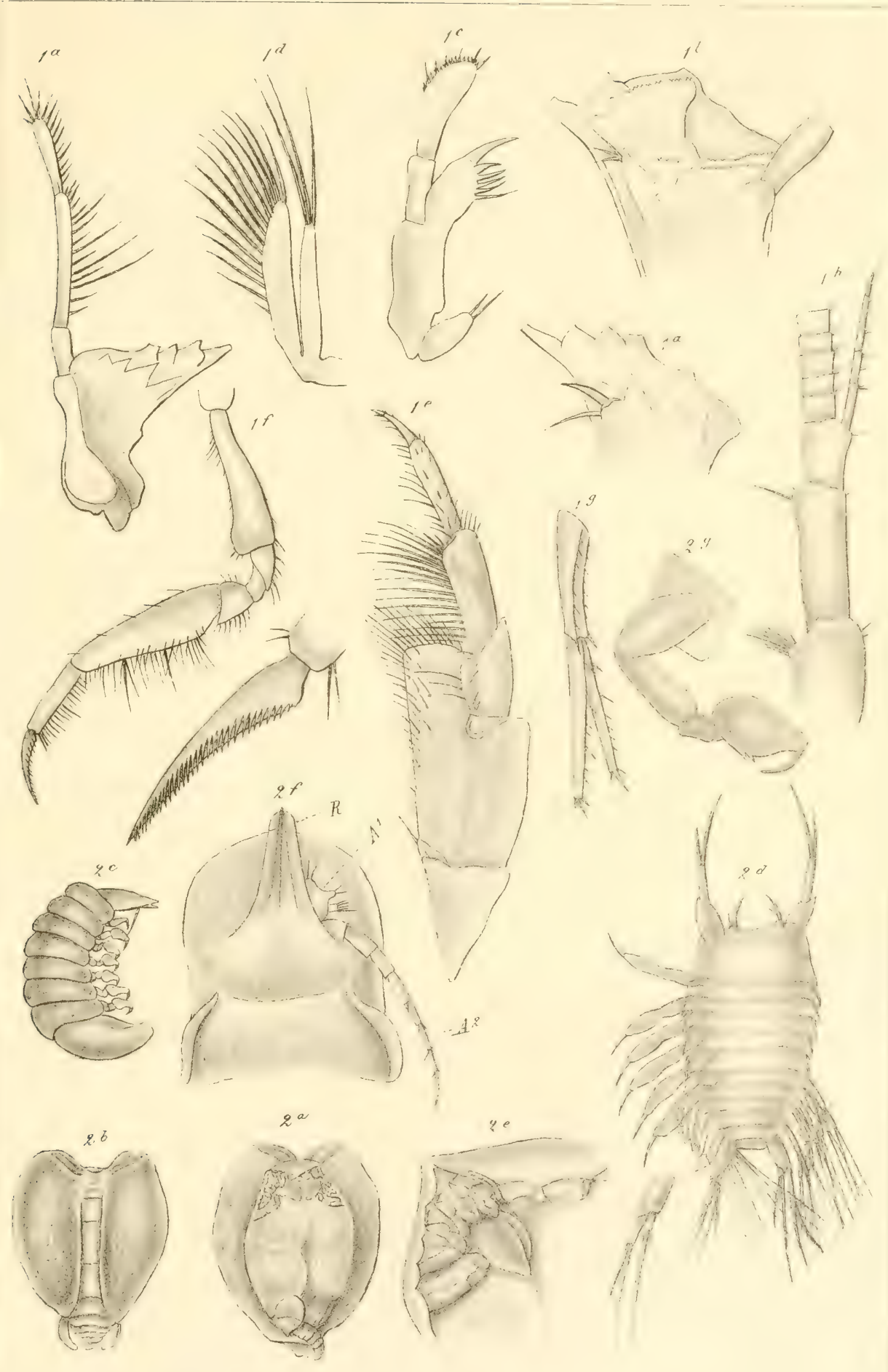


ZootoGle, 8. Crustaceen 'T'a P'. IIL.

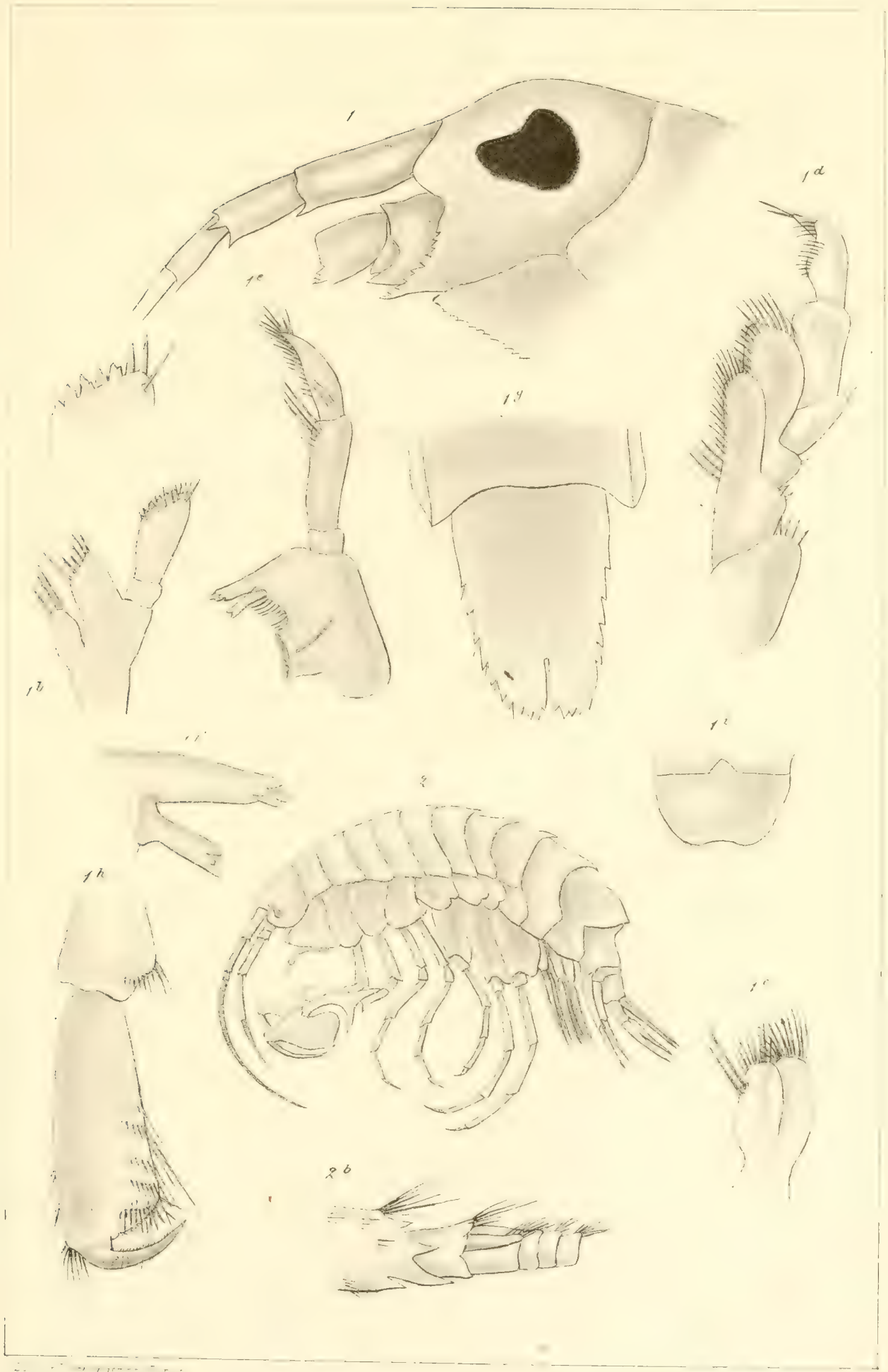

1 Tinuropis fragilis. ‥ Furesirnes cuspidatus 


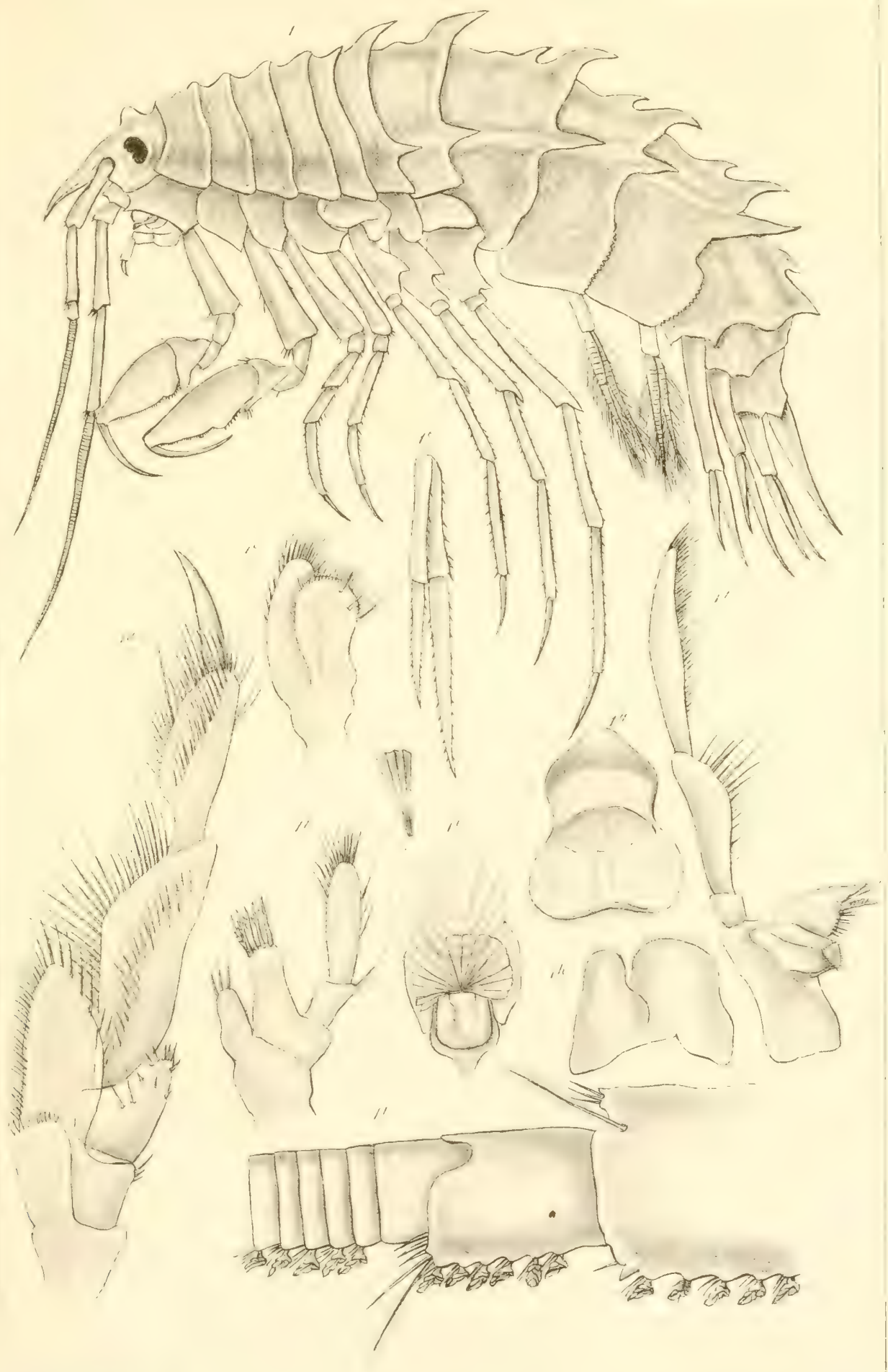




$$
\text { - }
$$




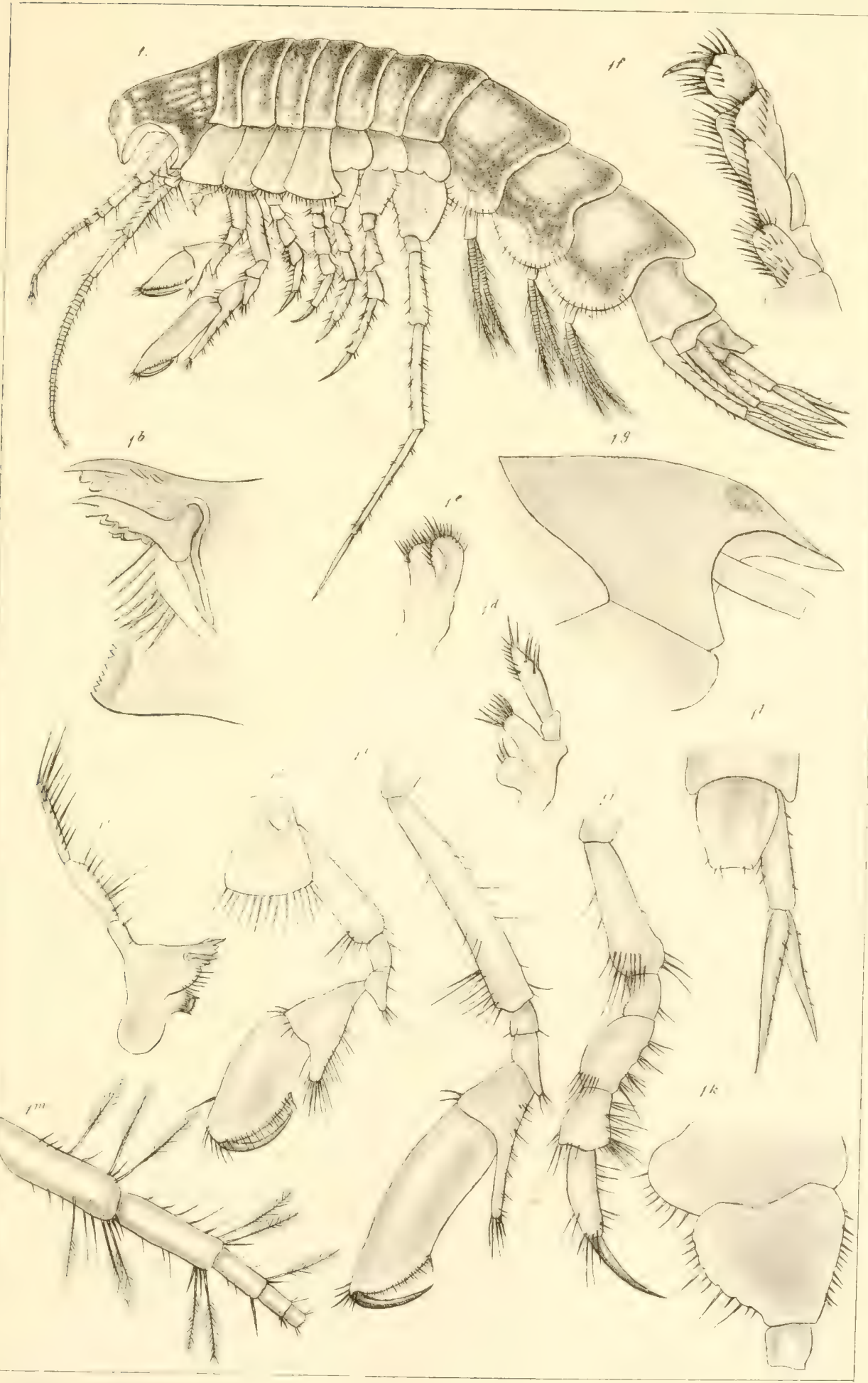





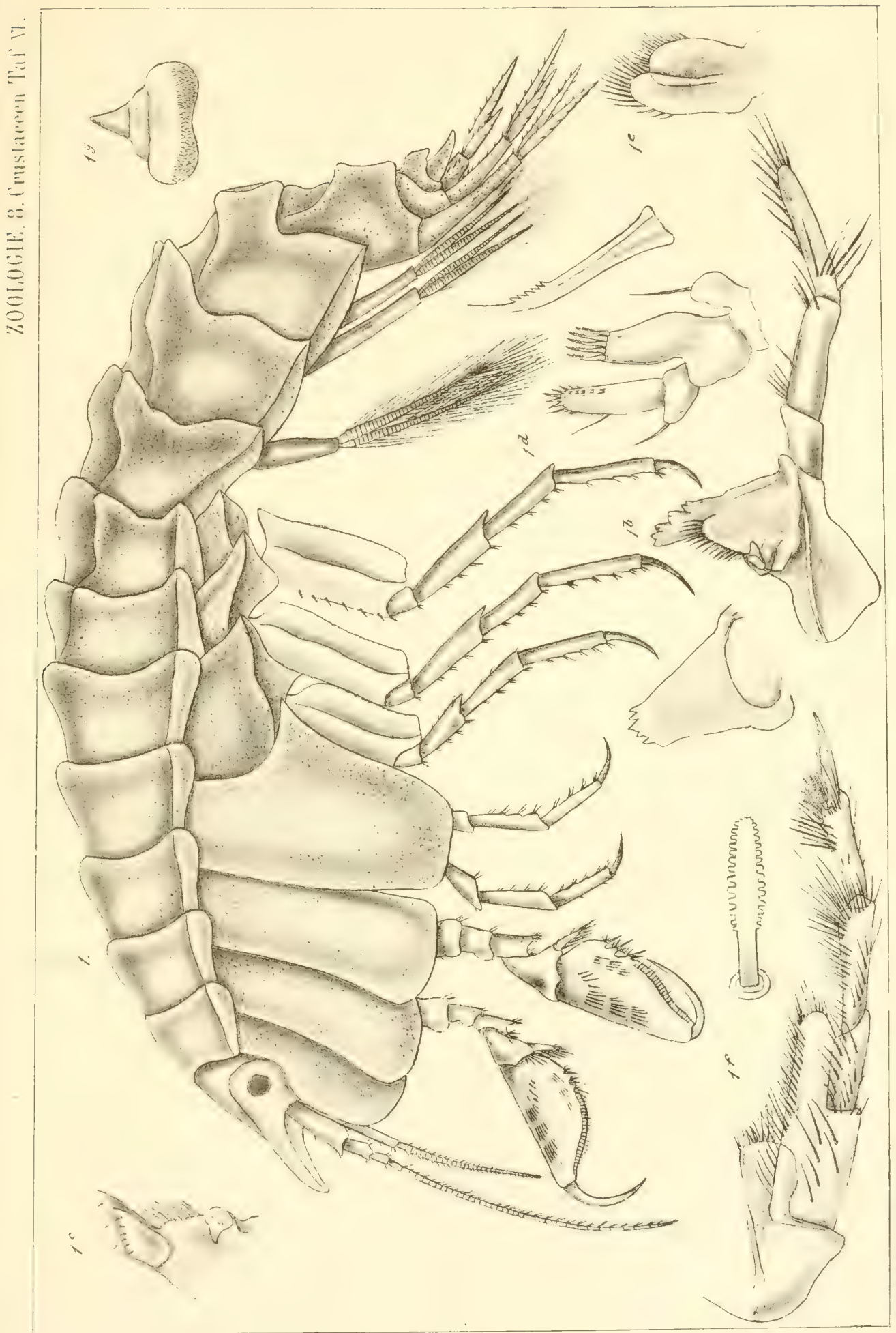





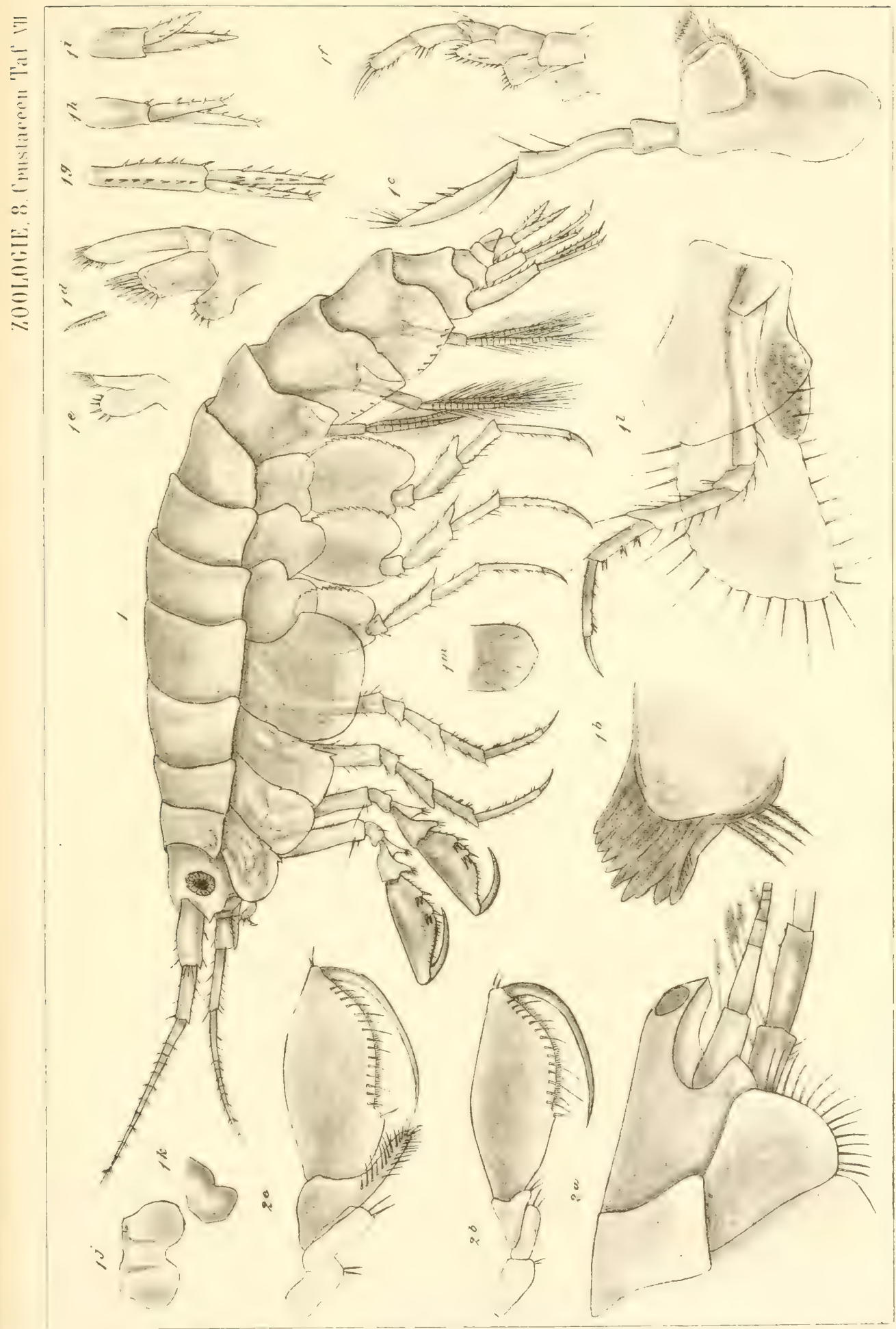




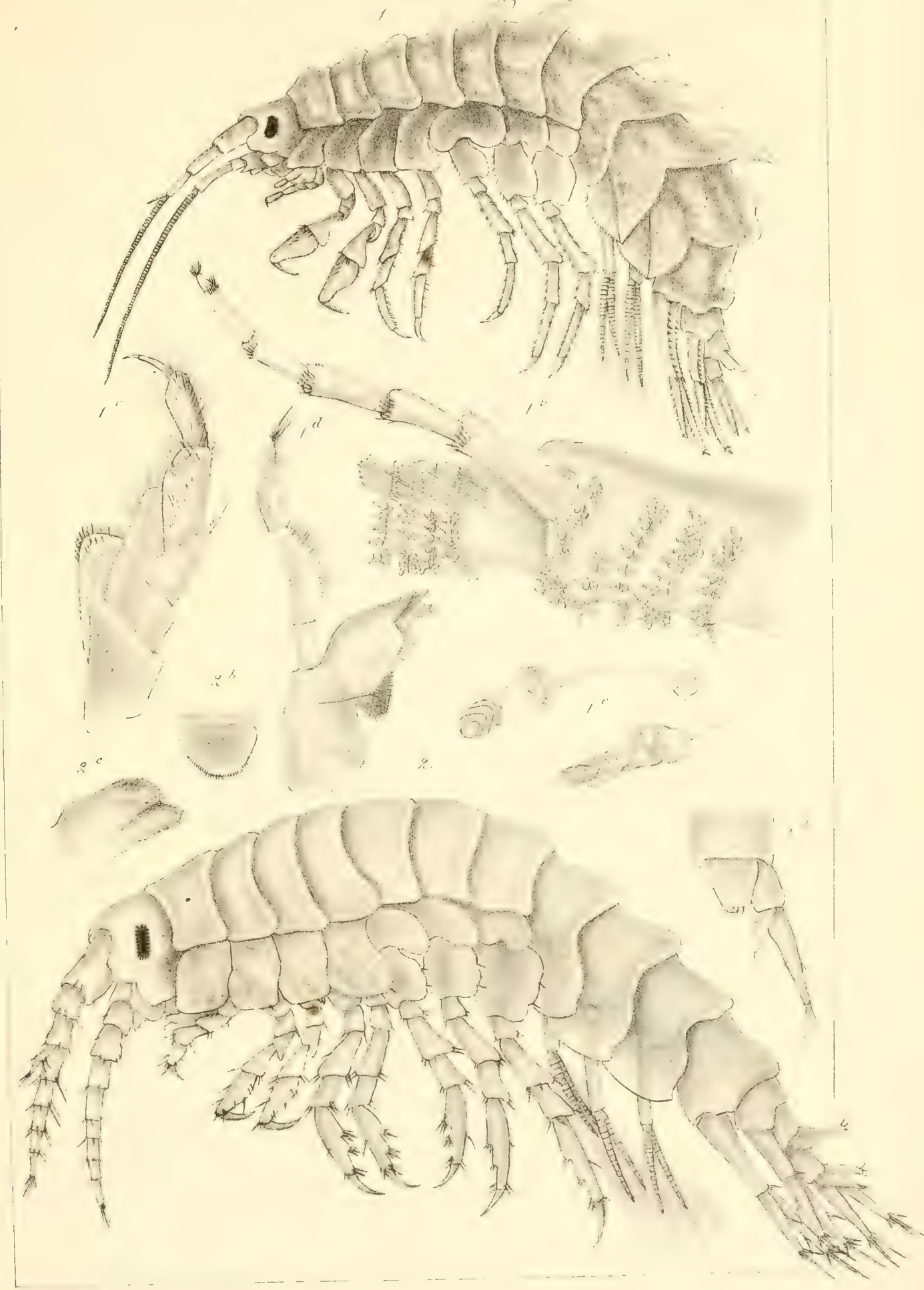




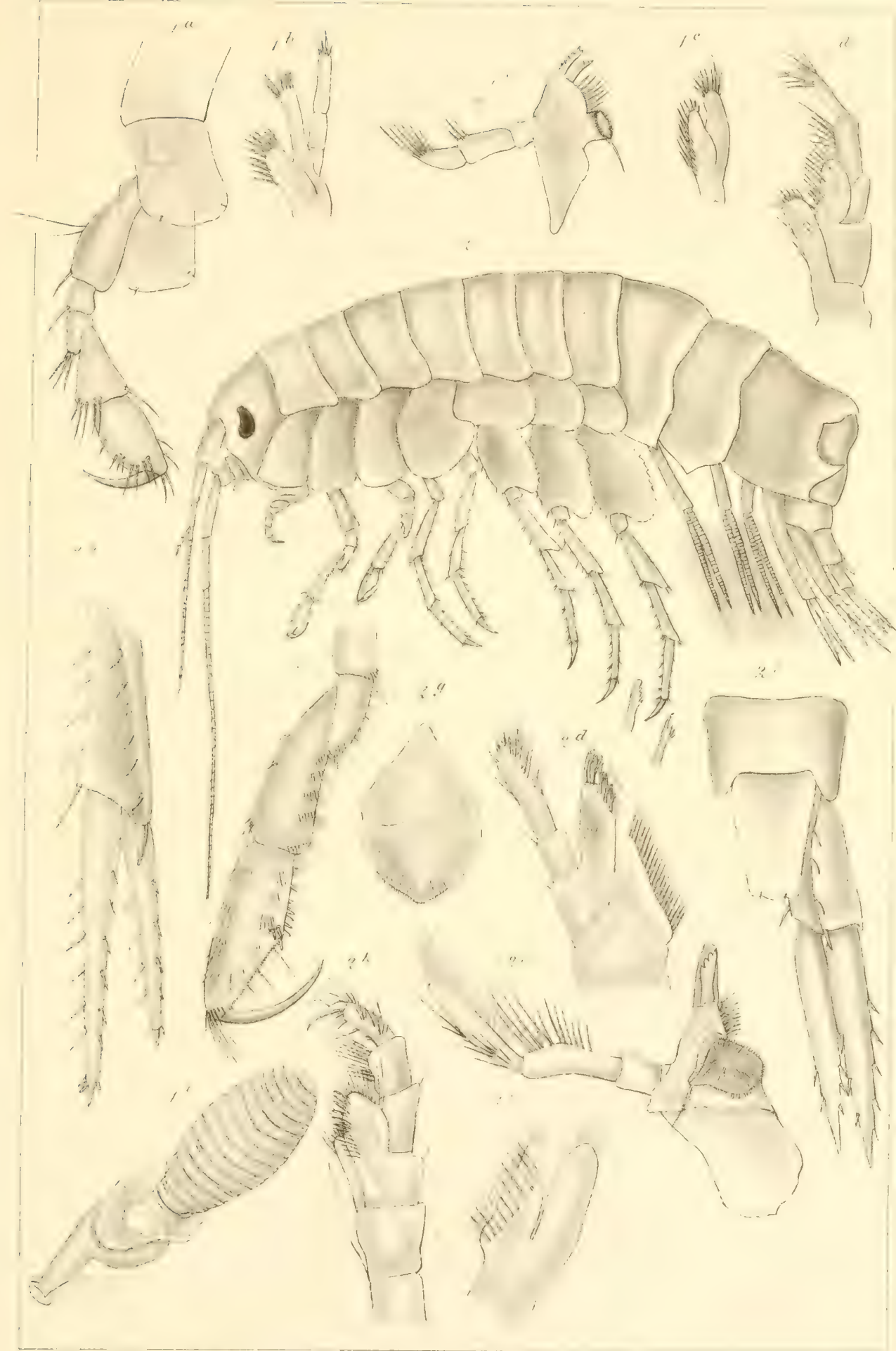





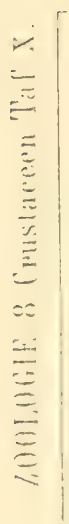
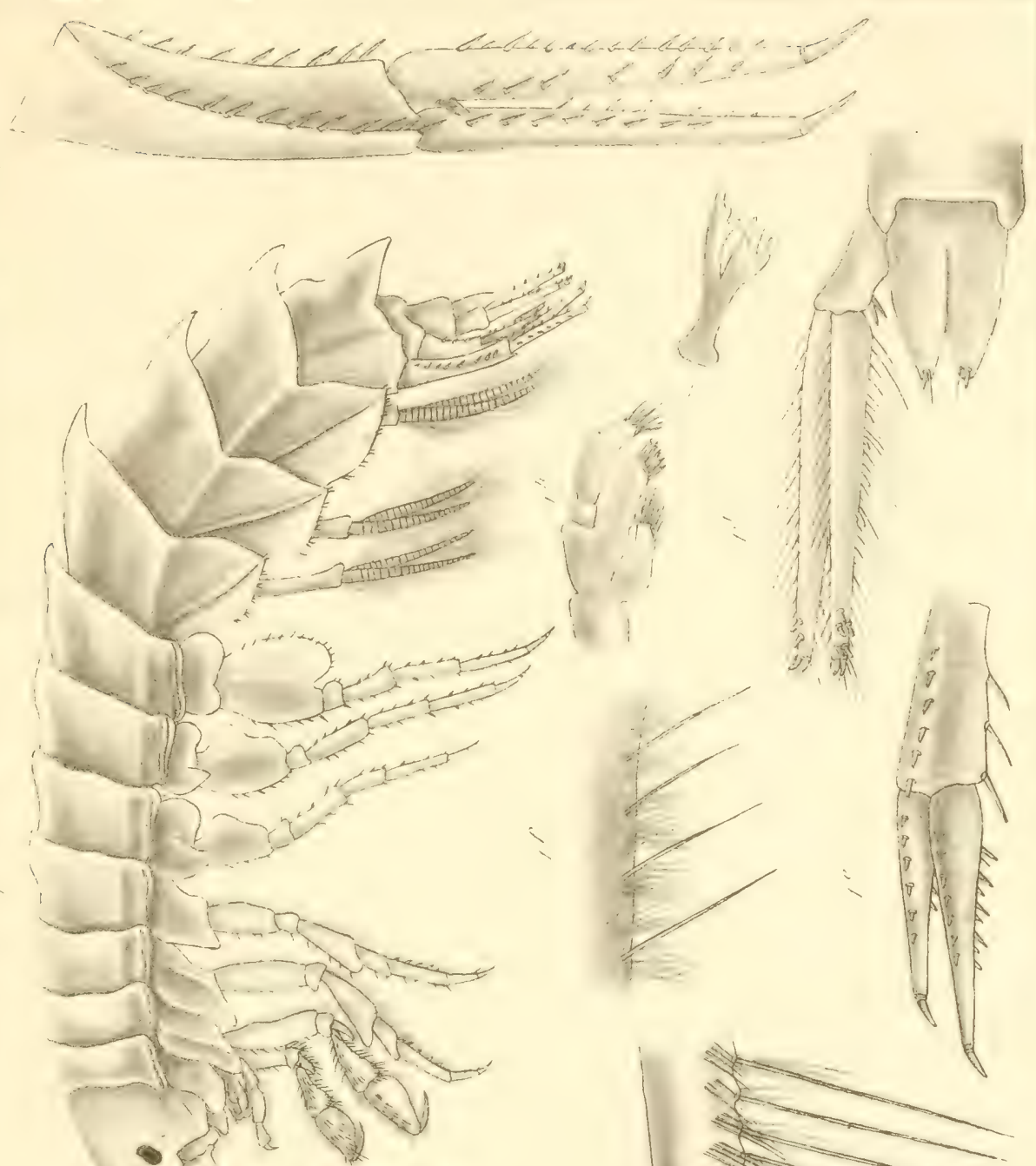

- ma na

(1)
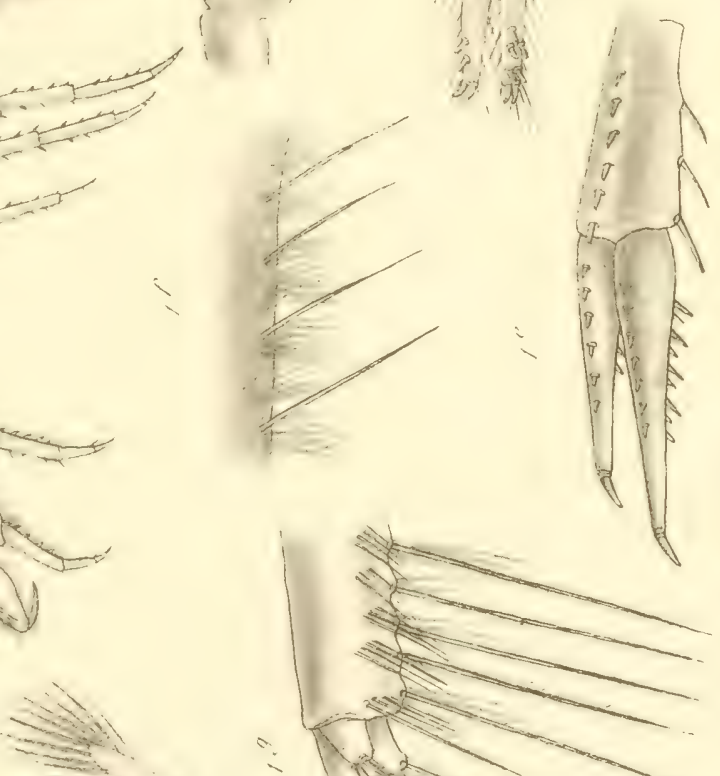



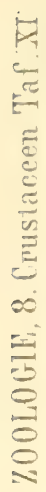
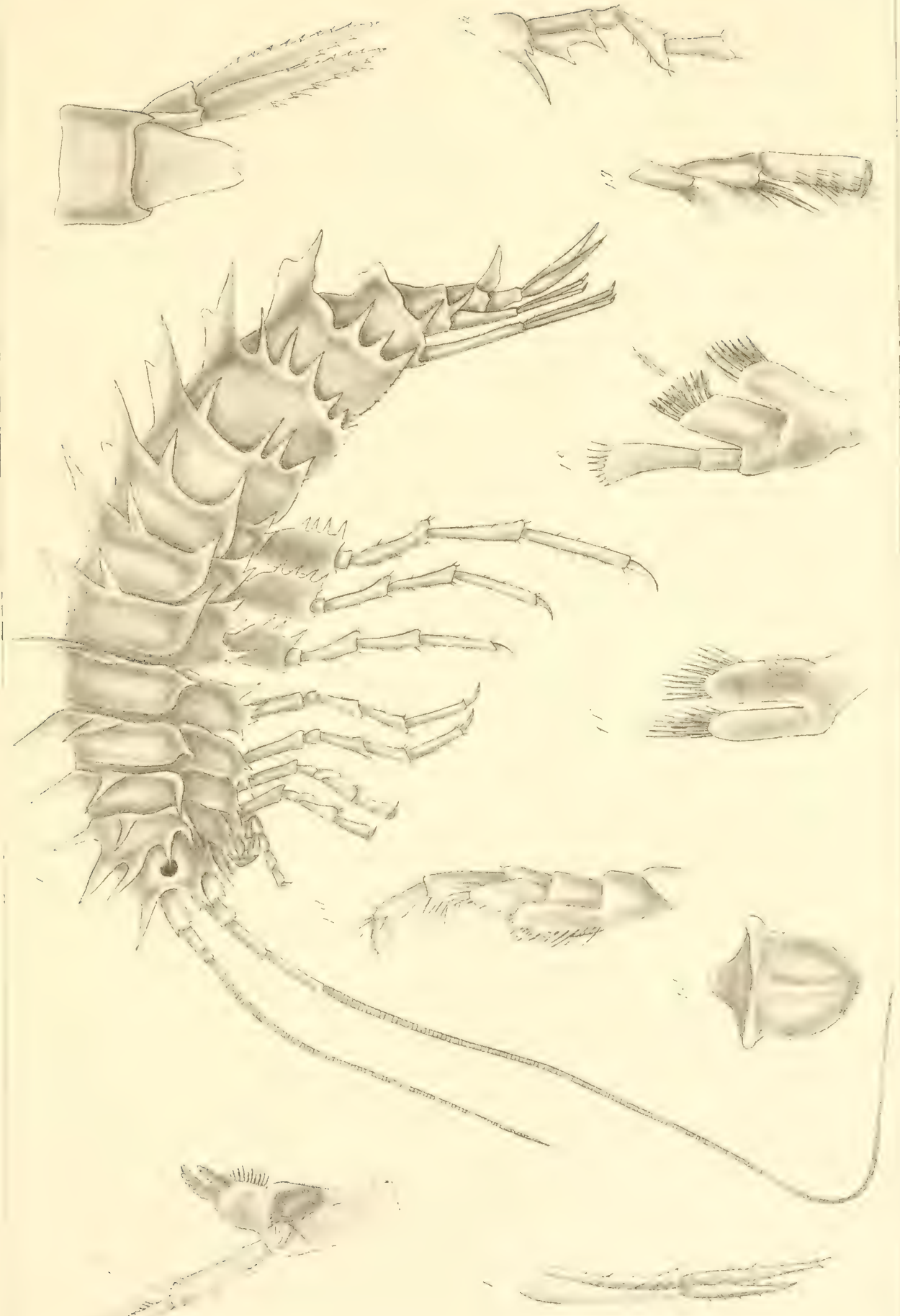



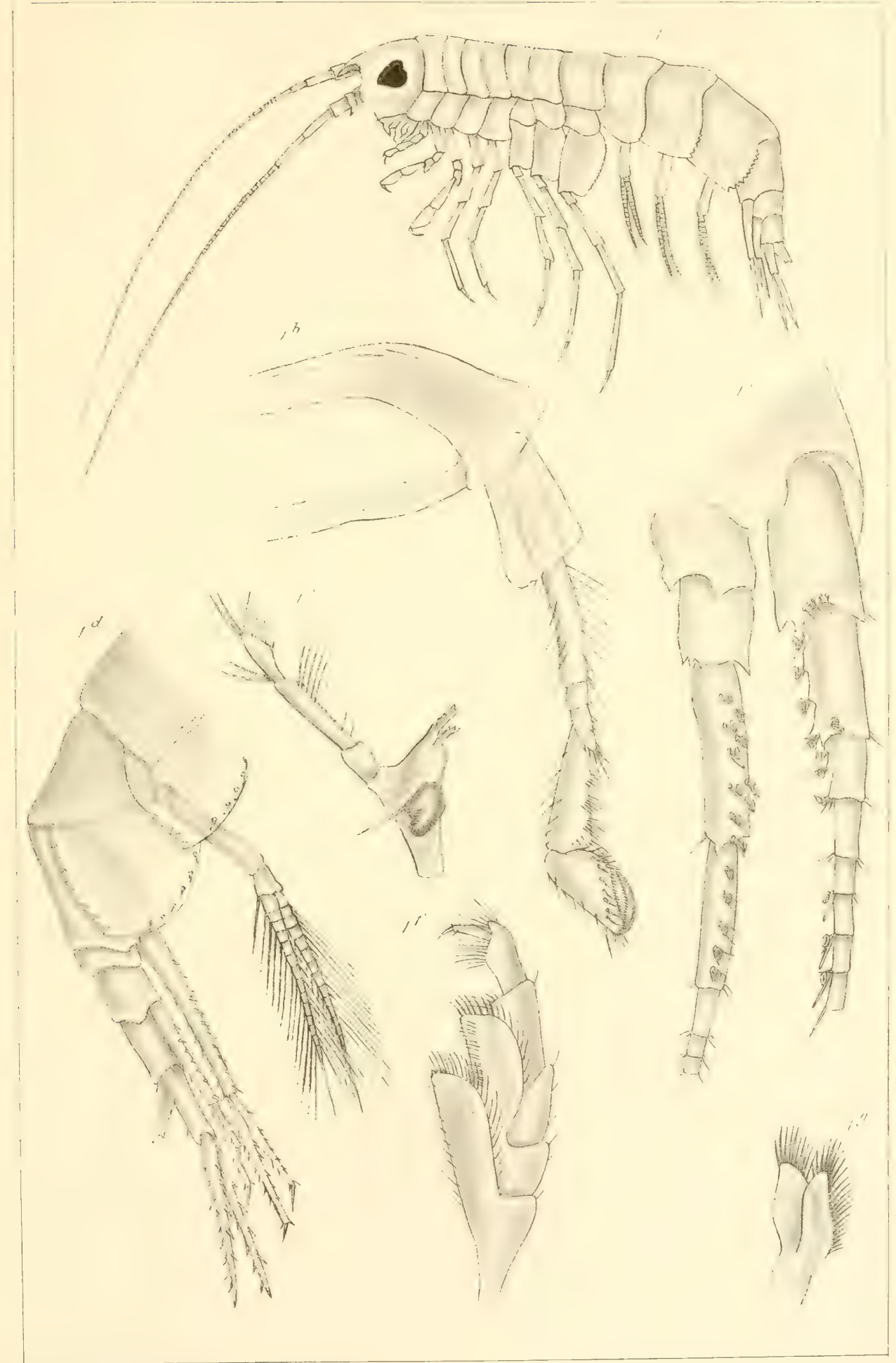





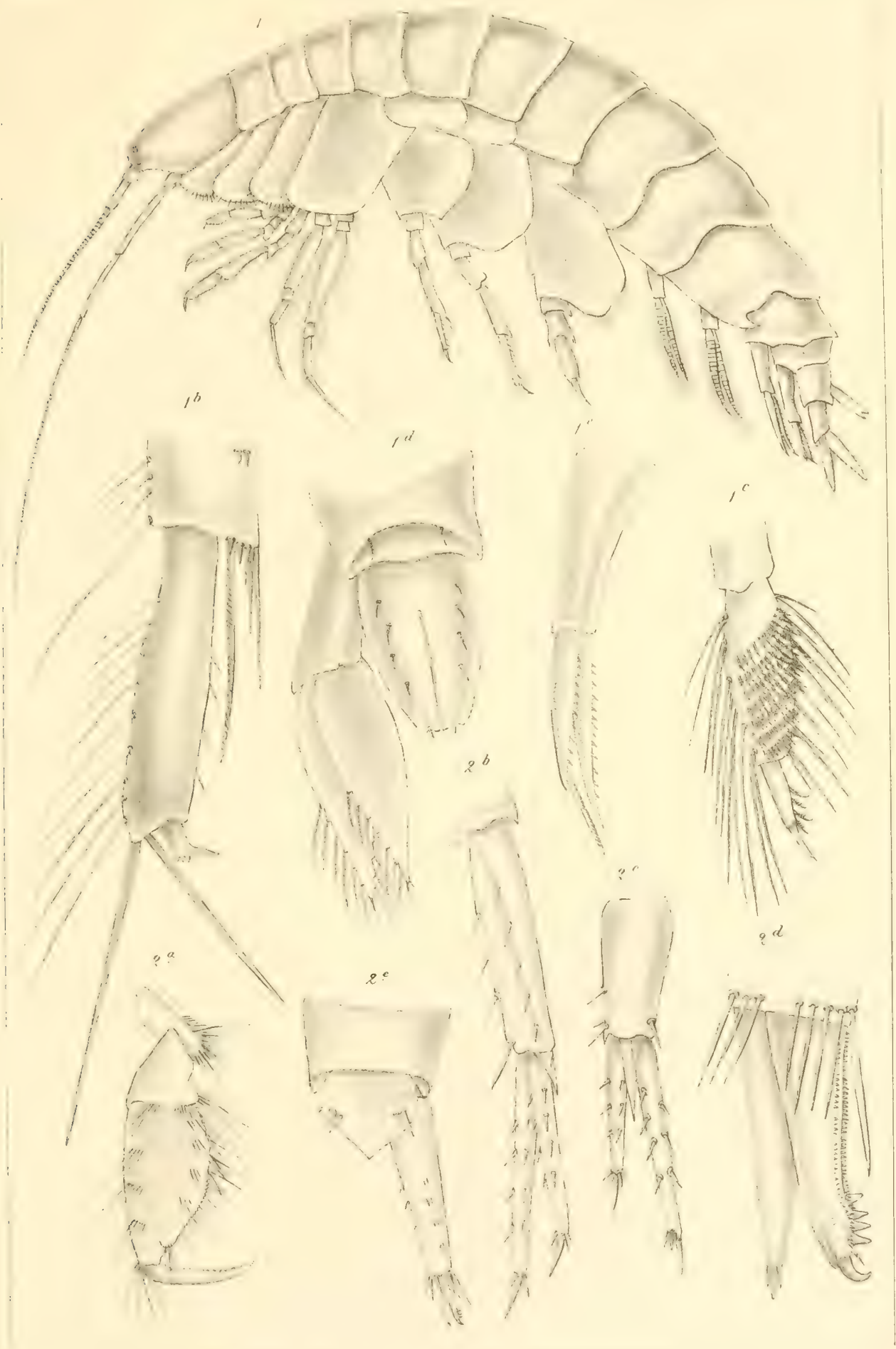





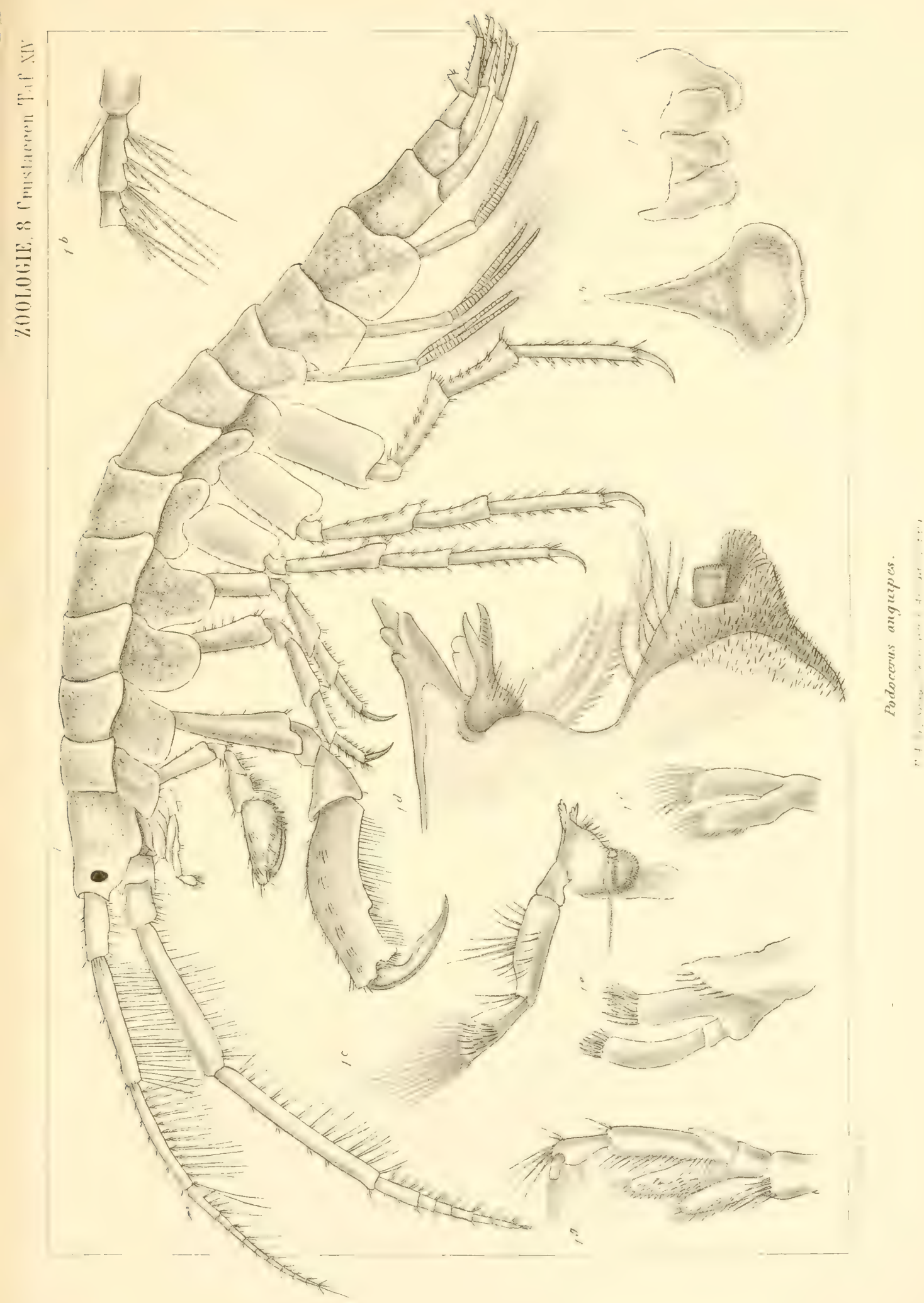





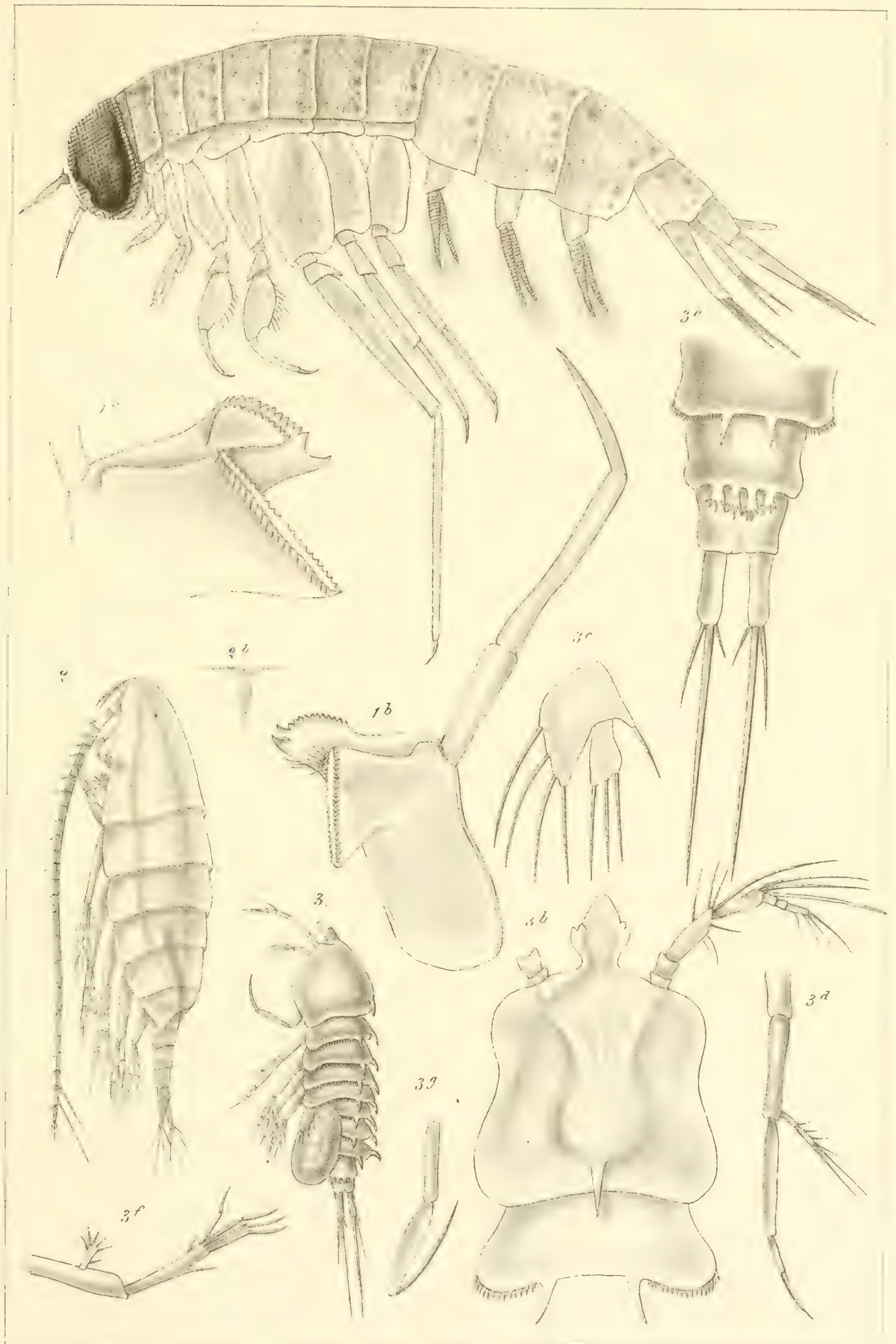



chen; h. vordere Maxille; $i$. Oberlippe; $j$. letztes Körpersegment mit Candalanhang und hinterste Springfüsse.

\section{Tafel XI.}

Fig. 1. Accuthozone hystrix. b. linke Mandibel; c. letztes Körpersegment mit Caudalanhang und letzten Springfüsen; $d$. Maxillarfuss; $e$. vordere $-f$. hintere Naxille; $g$. erstes - $h$. siebentes Thoraxfusspaar; $i$. zweites Paar Springfüsse; $j$. Oberlippe.

\section{Tafel XII.}

Fì. 1. Paramplithoë megatops, nor. spec. b. erstes Thoraxfusspar; c. Antenne; $\boldsymbol{d}$. letztes Körpersegment mit Caudalanhang und hintersten Springfüssen; e. linke Mandibel; $f$. Maxillarfuss; $g$. vordere Maxille.

\section{Tafel XIII.}

Fig. 1. Ampelisca Eschrichtii. b. sechstes - c. erstes Thoraxfusspaar; d. letztes Körpersegment mit Caudalanhang und hintersten Springfüssen; $e$. zweites Paar Springfüsse.

Fig. 2. Podocerus anguipes. a. zweites Thoraxfusspaar des Treibchens; $b$. crstes c. zweites - d. drittes Paar Springfüsse; e. letztes Körpersegment mit Caudalanhang.

\section{Tatiel XIV.}

Fïg. 1. Podocerus anguipes. b. obere Antenne; c. Mandibel; d. linke Mandibel; e. vordere - $f$. hintere Maxille; $g$. Maxillarfuss; 7 . Oberlippe; $i$. Unterlippe.

\section{Tafel XV.}

Fig. 1. Themisto Tibellula. $b$. rechte $-c$. linke Mandibel.

Fig. 2. Cetochitus septentrionatis. (Nach einer Farbenskizze des Dr. Pansch.) b. das Thier in natürlicher Grösse.

Fï. :3. Cleta mimuticomis. b. Cephalothorax und erstes Thoraxsegment von der Dorsalseite; $c$. fünftes - $d$. erstes Fusspaar; $e$. die drei letzten Abdominalsegmente; $f$. untere Antenne; $g$. Maxillarfuss. 
9.

\title{
I l a c ll $l ı$ i d e n.
}

\author{
Bearbeitet von \\ L. $\mathrm{K} \circ \mathrm{ch}$ \\ in Nürnberg. \\ Mit einer Tafel in Kupferstich.
}

Wenn in unsern Gegenden der Schnee schmilat und allmählich an somnigen Anhängen oder um die Wurzeln mächtiger Bäume kleine Oasen brauner Lrde sichtbar werden, dam kommen bei hellem Sonnenlichte auch gleich die immer beweglichen Lycosiden, Wolfsspinnen, zum Vorschein, auch dicht am Rand der Gletscher treiben sie sich herum. Eben weil der grösste Theil der zu dieser Familie gehörenden Arten sommeliebend ist, scheint sie auch die Kälte nicht zurïckzuschrecken, wenn nur der klare Somnenschein nicht fehlt. So ist es denn auch sehr erklärlich, dass im höchsten Norden, wo vielleicht mur wenige andere Spinnen mehr ihr Dasein fristen können, noch die muntern Iycosen, gleich ihren hochlebenden Verwanten in der Alpenwelt, in grösserer Anzahl existiren können. Die aus Nordostgrönland mitgebrachten Thiere repräsentiren nur eine Species, dieselbe ist noch nicht bekannt und soll daher nun ausführlich beschrieben werden.

Lycosa aquil outris, nov. sp. 'Taf. I.

Femina.

Cephatothorax braun, zwischen den Augen ins Schwarzbrame rerdunkelt; parallel mit dem Seitemande verläuft ein braungelbes, feingezacktes Längsband bis zu den Vorderrandswinkeln; vom Hinterrande zieht ein Lïngsstreifen, ebenfalls ron braungelber l'arbe, bis zum vordern Ende der Mittelritze, längs derselben breiter und durch diese gabelig getheilt; der äusserste Rand der seitlichen Abdachung, 
die beiden Längsbänder und der Mittelstreifen mit reinweissen Härchen bedeckt; die anliegende Beharrung der übrigen Fläche braungelb, die abstehenden Haare schwarz. Die Mandibeln braun, der Innenrand der untern Hälfte und cin von der Basis bis zur Mitte reichender Längsflecken an der Vorderseite braungelb. Das Sternum tiefschwarz, grauweiss behart. Das Abrlomen schwarzhram, bräunlichgelb behart, ein ron der Basis bis zur Mitte reichender, hinten spitz zulaufender Längsstreifen und eine Tieihe von feinen Bogenlinien hinter demselben reinweiss behart. Die Unterseite mit grangelben Haaren bedeckt; die Epigyne röthlich bram, von gelblichweissen Härchen umgeben. Die Palpen braungelb; das Femoralglied an der Aussen- und Innenseite schwarz gefleckt; das Patellarghed oben mit drei undeutlichen schwarzen Längsstreifen, zwei seitlichen und einem mittlem; die Behaarung graubram. Die Schenkel bramgelb, unten und an beiden Seiten bram gefleckt, oben mit drei schwarzen Lïngsstreifen, welche in der Mitte durch einen schwarzen Querflecken miteinander verbunden sind; die Patellen und Tibien bramgelb, oben mit drei schwarzen Längsstreifen; die Metatarsen und 'Tarsen röthlichbraun. Die Behaarung der Beine bräunlichgelb, die Stacheln schwar\%.

Mas.

Das Mämnchen ist wie das Weibchen gefürot mol gezeichnet, die Decke der Copulationsorgane ist schwarzbraun und schwarz behaart, das 'Tibialglied der Palpen ebenfalls schwarz behaart; die Beharung der Unterseite des Abdomen ist nicht graugelb, sondern grauweiss.

liemina.

Der Cephalothorax kiurzer als die Patella und 'Tibia eines Beines des vierten Paares, nicht so breit als 'libia IV lang, vorn nur' halb breit als in der Linie zwischen dem zweiten Beimpare, nach hinten steiler als in den Seiten abgedacht, oben gerade, dem Umisse nach eiförmig, mit anliegenden Hïrchen diinn berleckt, am Kopftheil oben, vorn und seitlich mit langen, abstelıenden Haren reichlich bewachsen. Der Kopftheil oben zwischen den Augen etwas gewölbt, in die Seiten fast senkrecht abfallend.

Die vorderste Augenreihe durch Tieferstehen der Seitenaugen etwas gebogen; die Augen gleich gross; die Mittelaugen an einer schwachen Hervorwölbung, von einander weiter als von den Seitenaugen entfernt, letztere rom Kopfende ungefïhr im Durchmesser eines Auges der zweiten Reihe entfernt. Dic Augen der zweiten Reihe circa anderthalb mal soweit von einander als ihr Durchmesser beträgt, ron jenen der dritten Reihe aber merklich weiter entfernt; sie uiberragen 
mit ihrer :inssern Hälfte die vordern Seitenaugen. Die Augen der dritten Reihe kleiner als jene der zweiten und grösser als die Augen der ersten Reihe.

Die Mandibeln vorn herab leicht gewölbt, so lang als die vordersten Patellen, nicht so dick als die Vorderschenkel, etwas glänzend, der Quere nach fein gerunzelt, mit langen abstehenden Haaren reichlich besetzt; am vordern und hintern lílanenfalzrande je drei Zähnchen, von welchen der mittlere lïnger ist.

Die Maxillen gewölbt, über die Lippe geneigt, vorn gerundet; die Lippe kaum halb so lang als die Maxillen, aus breiter Basis rerschmälert zulaufend, vorn gerade abgestutat.

Das Sternum glanzlos, herzförmig, wenig gewölbt, mit anliegenden kürzern Härchen dicht bedeckt und reichlich mit langen abstehenden Haaren bewachsen.

Das Abdomen (vor dem Eierlegen) dem Umrisse nach ron riemlich elliptischer Form; bei ältern Exemplaren ist dasselbe hinten breiter als rom, es ist dicht mit anliegenden, seidenglinzenden Härchen bedeckt und mit langen, abstehenden Haaren oben und in den Seiten reichlich besetzt; die Unterseite ist mit kurzen, anliegenden Härchen dicht bedeckt.

Die Palpen diinngliederig, das Femoralglied unten mit langen Haaren bewachsen, das Tarsalglied mit Ausnahme einiger langen Borsten gleichmässig kuxz behaart.

Die Schenkel der Beine aus dicker Basis verschmälert zulaufend, unten etwas gewölbt und lang behart; jene des ersten Paares vorn an der Spitze mit zwei Stacheln besetzt; an den T'arsen der beiden Vorderpare unten eine düme Scopula.

Länge des Cephalothorax: $0^{\mathrm{m}} 004$, des Abdomen: $0^{\mathrm{m}} 00 \breve{5}$, eines Beines des ersten, zweiten oder dritten Paares: $0^{\mathrm{m}}$ 009, des vierten: $0^{\mathrm{m}}$ 0125. Die linsenförnigen Eiersäcke haben einen Durchmesser von $0^{\mathrm{m}} 004$.

\section{Mas.}

Unter den mämmlichen Exemplaren fand sich nur ein entwickeltes Thierchen; der Cephalothorax und das Abdomen desselben sind kürzer, die Beine aber länger als bei den Weibchen. Der Brusttheil des Cephalothorax ist in den Seiten etwas steiler abgedacht; die Mandibehn sind kürzer und fallen vom Kopfende senkrecht ab; das Abdomen ist nicht länger als der Cephalothorax und schmäler als dieser, die Schenkel sind ebenso lang, aber dichter behart. Das 'libialglied der Palpen ist lang behant; die Decke der Copulationsorgane etwas glinzend, ans breiter, germuleter Basis in einen largen, am Gnde 
Z,OOLOGIE, 9. Arachniden. Taf. 1.

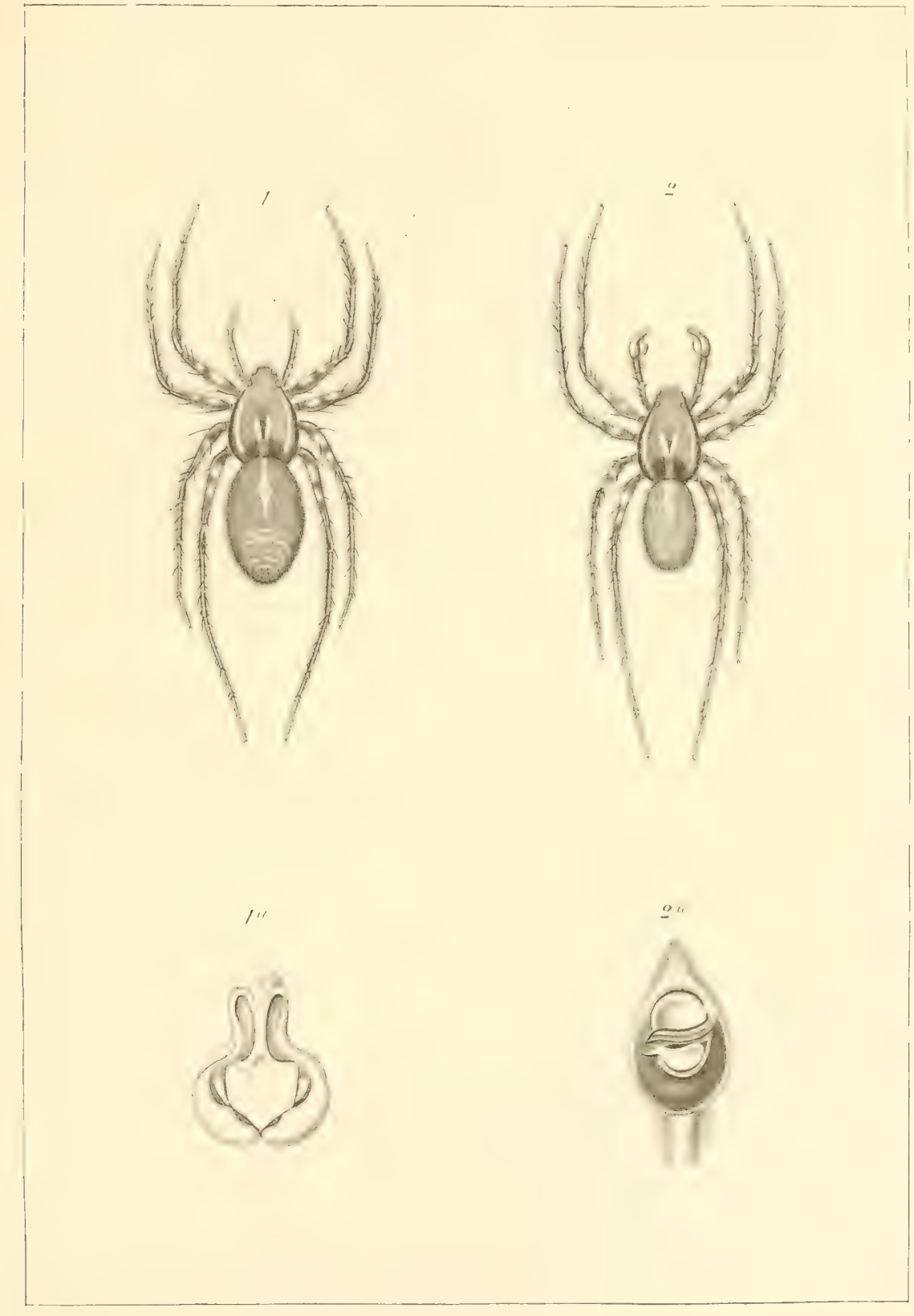

I. Fock ge:

Lycose aquitonaris, Hoch

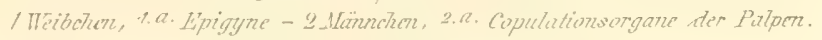

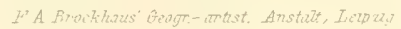



etwas aufwärts gebogenen Schnabel verlïngert, gleichmässig kurz behaart, nur die Unterseite der schmabelartigen Verlüngerung ist mit lïngern Haaren besetzt. Im Uebrigen stimmen beide Geschlechter iiberein.

Länge des Cephalothorax: $0^{\mathrm{m}}$ 0035, das Abdomen ebenso lang; Liinge eines Beines des ersten Pares: $0^{\mathrm{m}} 01$, des zweiten oder dritten: $0^{\mathrm{m}} 0095$, des vierten: 0$)^{\mathrm{m}} 0125$.

Ls scheint diese Art mit weiss und messinggelb gemischter Behaalung zu variiren; unter der rorhandenen Anzahl fanden sich zwei so gefübte Lxemplare, ein entwickeltes und ein junges Weibchen.

Lycosa aquilomaris ist der von C. Koch aufgestellten Untergattung der Leimonien beizuzählen. Mit Lycosa septontrionalis Westring (Aranex Snecica, p. 469), welche bis jetzt nur in Norwegen gefunden wurde, hat sie bezüglich der Farbe und Zeichmung des Cephalothorax und Abdomen grosse Aehnlichkeit, weicht jedoch in wesentlichen Merkmalen von derselben ab; namentlich fehlt unserer Species die auffallende kleine Wulstung am Cephalothorax unterhall, der hintersten Augen und die Epigyne ist ganz anders gestaltet; statt der drei schwarzen Längsstreifen an den Schenkeln, Patellen und 'Vibien aller Beine hat Lycosa septentrionalis schwach dunkel geringelte Beine.

Im verflossenen Jahre hat 'Thorell unter' dem 'Titel: ,Om några Arachnider från Grönland" (Öfrersigt af konl. Vetenskaps-Akad. Förhandlingar, Nr. 2, Stockholm) eine Schrift über grönländische Spinnen veröffentlicht und darin eine Lycosa, welche mit den vorliegenden grosse Aehnlichkeit besitzt, aufgeführt; diese Art, von Fabricius (Famna gronlandica, p. 228) 1780 als Lycosa sociatu beschrieben, weicht jedoch ausser der Färbung der Beharung, dem Fehlen des hellen Fleckens an den Mandibeln besonders in den Formen der von Thorell aufs Sorgfältigste dargestellten Sexualorgane beider Geschlechter so sehr ab, dass die Verschiedenheit beider Species kaum bezreifelt werden kann. 
10.

\title{
Hymenopteren und Iipteren.
}

\author{
Bearbeitet ron \\ A. Gerstäcker \\ in Berlin. \\ Mit Noten von Adolf Pansch \\ in Tiel.
}

\section{HYMENOPTERA.}

1) Bombus pratorum L.

Fauna Suec., No. 1711. - Kirby, Monogr. Apmn. Angl., II, 360, No. 103 (mas: Apis Burrellana Kirby, ebend., p. 358, No. 101).

Von dieser über das ganze nördliche und mittlere Europa verbreiteten Art liegen zwei männliche Exemplare vor.

[Hummeln beobachteten wir mehrmals, sowol fliegend als auf dem Erdboden kriechend, indess nie zahlreich. Ganze Schwärme oder Bienenstöcke, von denen Scoresby spricht, sind uns nicht vorgekommen. - P.]

2) Cryptus sponsor Fab.

Syst. Piezat, p. 83, No. 50. - Gravenhorst, Ichneumonol. Europ., II, 554, No. 93.

Ein. Weibchen dieser Art wurde bei Kap Broer Ruys an der Erde auf dem Grase kriechend gefunden.

3) Limneria difformis Gravenhorst.

Ichneumon. Europ., III, 458, No. 1 (Campoplex).

Ratzeburg, Ichneum. der Forst-Insecten, I, 92, No. 1.

Holmgren, Monogr. Ophionid. Suec., 1. 58, No. 8.

Ein Weibchen, auf Shamnon (Kap Börgen) auf der Erde kriechend gefunden. 


\section{I P T E R A.}

1) Tipula truncorum Meig. No. 10.

Europ. zweifl. Insecten, VI, 247, No. 46. - Zetterstedt, Dipt. Scand., X, 3926,

Ein weibliches Exemplar, ohne Angabe der Localität.

[Wir trafen diese Schnacke an warmen Tagen längs der ganzen Küste. - P.]

2) Echinomyia anea Streger.

Zetterstedt, Dipt. Scand., VIII, 3217, No. 6-7.

Ein einzelnes Exemplar, ohne nähere Angabe des Fundorts. Da dasselbe nur vier Linien in der Länge misst und den in der Streger"schen Beschreibung hervorgehobenen Metallglanz wenigstens nicht deutlich erkennen lässt, könnte die Richtigkeit der Bestimmung in Zweifel gezogen werden. Der durch längeres Liegen in Weingeist hervorgebrachte mangelhafte Zustand würde indess selbst für den Fall einer specifischen Verschiedenheit keine genügende Charakteristik ermöglichen.

3) Cynomyia alpina Zetterstedt.

Dipt. Scand., IV, 130t, No. 26.

Ein männliches Exemplar von der Sabine-Insel mit goldig-grïnem Hinterleib, von Cynomyia mortuonm L. indessen durch die Färbung der Fühler unterschieden. Ob die Art nicht trotzdem nur auf kleinere Exemplare der Cynomyic mortuonm gegründet ist, erscheint zum mindesten zweifelhaft.

4) Calliphora grenlandica Zetterstedt.

Dipt. Scand., IV, 1330, No. 3.

In einem kleinern Exemplare von Nordshannon und einer Anzahl grösserer beiderlei Geschlechts, welche Ende Mai 1870 bei $0,8-0,9^{\circ} \mathrm{R}$. auf Deck gefangen wurden, vorliegend.

[Fliegen wurden noch im Herbst 1869 häufig von uns gesehen, verschwanden aber mit den ersten Frösten im September. Im folgenden Jahre zeigte sich die erste einer grossen, schillernden Art am 26. Mai, an welchem Tage sich die Temperatur zum ersten male iiber den Gefrierpunkt erhob (max. $+0,8^{\circ}$; min. $-4,3^{\circ}$ R.). 
Als am andern Tage das Thermometer bis $+4,9^{\circ} \mathrm{R}$. stieg, waren die Tliegen, wie mit einem Schlage, in Unmasse vorhanden und paarten sich. Es war meist die grosse blanschillernde Art (Calliphor granlandica), aber auch die kleinere stahlblaue zeigte sich nicht selten. Wir trafen sie sowol auf dem Schiffe als am Lande überall häufig an, selbst auf hohen bergen.

An 7. Juni fand ich die ersten Eier und um Mitte Juni wimmelte gefundenes Aas von Maden. - 1'.] 


\title{
11. \\ Lepid op teren.
}

\author{
Bearbeitet voll \\ Alexander von Homeyer \\ in sohweidnitz.
}

Iie Schmetterlinge der zweiten Deutschen Nordpolexpedition wurden dem Entomologen Herrn Dr. Herrich-Schäffer zur wissenschaftlichen Bestimmung ïberschickt, während die im lebenden Zustande mitgebrachten Raupen dem Lepidopterologen Herm Iwan Tesch in Bremen zur Pflege iibergeben wurden.

Später erhielt ich durch persönliche Freundschaft des Herrn Dr. Finsch die Schmetterlinge nebst Notizen Herrich's und Tesch's zur Bearbeitung. Um ganz sicher zu gehen, conferirte ich mit meinem ebenso liebenswiirdigen, wie hochberihmten Lehrer, dem IIerrn Dr. Wocke, und stellte derselbe, nachdem er die Nordostgrönländer mit Exemplaren seiner Sammlung aus Labrador und Lappland verglichen, mir ausführliche Notizen ebenfalls zur Verfügung.

Dr. Herrich-Schäffer schreibt bereits December 1870:

„, Die wenigen Schmetterlinge waren offenbar schon beim Einsammeln verflogen und zerrissen, doch können unzweifelhaft bestimmt werden:

1) Argymis polaris Boisd., 1 ô.

2) Argymis chariclea Schnd., 1 t, 2 .

3) Colias hecla Lef, 2 o, 1 o.

4) Larentia polata Hübner (Zutr. Fig. 805-806), 5 o."

Mit Beriicksichtigung dieser Bestimmung Herrich's dürften betreffs der Verbreitung dieser Arten nach Dr. Staudinger's und Dr. Wocke's Katalog, folgende Bemerkungen nicht iiberflïssig sein:

1) Argynnis polaris Boisd. Vaterland bis jetzt mit Bestimmtheit 
nur Iabrador, wïhrend das nördliche Lappland und das nördliche Ostsibirien in Frage gestellt werden (s. Dr. Staudinger's und Wocke's Katalog, 1871, S. 20). Demmach wäre diese Art für Grönland neu.

Ich nehme hier gleich die brieflichen Nittheilungen des Dr. Wocke dazu; dieselben lauten:

"Argmmis polaris (Boisd). ot gar nicht abweichend ron meinen Exemplaren aus Labrador, ausser in der Fïrbung, welche der des Labradorweibchens gleicht, während die Nännchen ein lebhafteres liothgelb führen."

2) Argymis chericlea Schnd. Nach Staudinger's Katalog (1871, p. 20) ist das Vaterland nicht nur Grönland, sondern auch Labrador und sogar das bergige nördliche Lappland. Wocke schreibt briefllich: „Drei gespannte und fünf ungespiesste Exemplare der Argymis chariclea. 'Wwei der gespannten sind auf der Oberseite sehr dunkel bestäubt, im Uebrigen von den anderi nicht abweichend. Alle gleichen ganz meinen von mir selbst in Fimmarken gefangenen Stïcken, wogegen meine vier Lxemplare aus Labrador ein lebhafteres Colorit haben."

3) Colias hecla Lef. Nach Staudinger (Kat., 1871, p. 6) ist das Vaterland Grönland und das nördliche Lappland. Dr. Wocke schreibt brieflich:

"Zwei ô, ein $q$ und ein ungespiesstes ô der Colias hech Lef. Die of sind auf der Oberseite bei gleicher Zeichung nur wenig bleicher als meine lappländischen Exemplare, am Vorderrande die Vorderfliigel etwas breiter schwefelgelb. Die Unterseite ist durch schwärzliche Bestiubung aller viex Fligel stark verdunkelt, wie bei keinem meiner europaiischen Stücke. Bei dem o ist die dunkle Bestäubung noch auffallender. Meine lappläindischen Weibehen sind auf den Vorderflügehn gegen die Wurzel cher heller gefïrbt als auf der Flïgelmitte, die Hinterfliggel nur wenig schwärzlich bestäubt und daher der Mittelfleck wenig hervortretend. Bei diesem o aber. ist der Wurzeltheil der Vorderfliigel bis dicht vor dem grossen Mittelfleck schwärzlich, ehenso die Flügehrippen; die Hinterflügel sind fast ganz schwarz mit nur schwacher gelber liestaubung. Ton den Randflecken fehlt auf den Vorderflïgeln de in \%elle vier, auf den Ilinterflügeln sind die Riandflecke gan\% verschwunden, wogegen der gelbrothe Mittelfleck rein und grell hervortritt. Die Unterseite ist noch etwas disterer, als bei den Mämnern und anch auf den Vorderflügehn die gelbe Grundfarbe nur an der Inmenrandhälfte sichthar."

4) Larentia polate Itiibn., von Staudinger zu Cidaria gestellt. Dieser Spanmer ist ebenfalls für Grönland nicht neu, und auch seine fernere Verbreitung im nördlichen Lappland und Labrador bekannt. 
Dr. Wocke schreibt brieflich: "Cidaria Polatu Hb. (Brullei Lef.) fünf Exemplare, wie es scheint alles ô, stark abgegriffen, nur bei dem einen Stück ist die Zeichnung dentlich. Diese Exemplare weichen von den lappländischen und Labradorern durch bedentend dunklere Färbung ab, sonst finde ich keinen Unterschied.“"

5) Gcometra sp.?

Line Raupe auf der Sabine-Insel, unter lockern Kräuterwurzeln kriechend gefunden.

6) Dasychira grenlandica Wocke, nov. spec.

Dr. Herrich-Schäffer fährt in seiner brieflichen Mittheilung weiter fort:

„Lin spinnerartiges 'Thier ist an den Hinterflïgeln so verkriippelt und verletzt und die Beine sind so defect, dass hieraus die Gattung nicht festzustellen wäre, wenn nicht die in mehrem Exemplaren mitgeschickte Raupe, theils getrocknet, theils in Weingeist, durch ihre gleichmässig vertheilte lange dichte Beharung auf eine Arctia deuten wïrde."

Ich erlaube mir hier dirauf aufmerksam zu machen, dass also Herrich den nun beschreibenden Schmetterling der Raupe halber für einen Bär "Arctia" hält, trotzdem der Schmetterling selbst ihn nur an eine Dasychira erimnert. Herrich fährt nämlich fort: „Der' Schmetterling hat ganz die Gestalt und Grösse einer männlichen Dasychira fascelina, nur sind die Vorderftigel etwas schmaler. Auch die Flïgelrippen, soweit sie untersucht werden können, stimmen damit überein; ebenso das mit Haaren vermengte, nicht sehr compacte, auch micht coconartig geformte Gespinnst und die glänzend schwarze, auf dem Riicken mit langen Haaren besetzte Puppe. - Von diesen Raupen sollen einige Stück lebend mitgebracht worden sein, ohne Futter genommen zu haben, noch jetzt (December 1870) leben. Sie uiberwintern in ihrem Vaterlande wahrscheinlich zwei mal, wie auch auf den Hochalpen manche dictinen-Raupen."

So weit Herrich-Schäffer.

Ich habe den Spinner auch untersucht und musste ihn zweifelsohne für eine ächte Dasychira und zwar für die in Labrador vorkommende Dasychira Rossii (Curt., Deser. App. Narr., p. 70, pl. A 10; Möschler, Stett. Z., 1870, S. 252) halten.

Freund Wocke schreibt mir darüber:

„Eine sichere Dasychira, zur Aufstellung einer neuen Art kaum brauchbar.

„Dasychira grantandica nov. spec. ö; der Dasychira Rossii sehr 
nahe verwandt und vielleicht nur eine zufïllige schwarze Aberration derselben. Fliigelspamnung $37^{\mathrm{mm}}$; Vorderflügelbreite $71 / 2^{\mathrm{mm}}$; Fiihler $6^{m m}$ lang, bis zur Spitze beiderseits stark gebräunt, Kammzähne schwarz, Schatt oben weisslich, mit einer in der Mitte verlaufenden Längsseihe schwärzlicher Flecken, unten schwarz. Palpen schwär\%lich, durch zottige Beharung versteckt. Kopf und Thorax schwarzgrau behart; der Hinterleib scheint gleiche Behaarung getragen zu haben. Beine heller grau, dicht behaart, Tarsen bräunlichgrau mit weisslichen Enden. Vorderflügel grob und diunn beschuppt, mit den Franzen russig schwarbraun, längs des Vorderrandes und gegen die Wurzel mit eingemengten hellern bräimlichen Schuppen. Von Zeichnungen bemerke ich nur eine auf der Querrippe befindliche dichtere Schuppenanhäufung, welche einen undentlichen Mondfleck darstellt und bald hinter diesem an Vorderrand eine schwïchere Verdunkelung. Die verkriippelten und defecten Ilinterffïgel sind licht gelbgrau, sehr diun mit feinen schwarzen Haarschuppen bekleidet. Auf der Unterseite sind die Vorderflügel einfarbig braungrau, der Vorderrand und alle Rippen mit Ausnahme der (kuerrippen gelblichbraun beschuppt, letatere schwïzlich.

"Die beisteckende Raupe halte ich nicht für eine Arctia, sondern ebenfalls für eine Dasychira und höchst wahrscheinlich für die eben beschriebene Art. Ich sehe die den Riicken und das Endghied der Dasychira-Raupen auszeichnenden Haarbüschel ganz deutlich, und durch ihre schwarze Farbe von der ïbrigen sehr dichten und langen rothbramen Beharrung abstechen. Im Uebrigen halte ich das vorliegende Lxemplar nicht zu einer genanen Beschreibung geeignet."

So weit Wocke. Was nun die lebenden Raupen anbetrifft, so gingen dieselben nach Ablauf des Winter's zu Grunde. Herr Iwan T'esch hat sich viele Miihe mit der P'flege gegeben, und trotz mannichfaltiger Futterpflanzen kein Glïek gehabt, indem die Thiere das Futter nicht anrihrten, wie dies ja bei vielen Spinnerraupen keine Seltenheit ist. Ich glaube, dass man gut gethan hätte, die Raupen zwischen Doppelfenstern mit Laub leise zu uiberschütten, dazu einige Futterptlanzen zu stellen und num die Thiere sich selbst zu iiberlassen; so würde wahrscheinlich ein regelrechter, wemn anch verkürzter Winterschlat eingetreten sein, wozu es im vorstehenden Fall nicht gekommen zu sein scheint. Störung in Winterschlaf ist aber fast immer todbringend. 


\title{
12. \\ Hydroiden und Bryozoën.
}

\author{
Bearbeitet von \\ $\mathrm{K}$ i r c h e n p a u e $\mathrm{r}$ \\ in Hamburg.
}

Die Ausbeute an Bryozoën sowol als an Hydroiden ist von geringer Bedeutung.

Unter den sehr wenigen Hydroiden-Arten, welche sich dabei befinden, ist nur eine (Lafoxa fruticosa) durch zahlreiche Exemplare vertreten; die uibrigen finden sich nur vereinzelt, fast nur in liragmenten, wie unabsichtlich mit den gesammelten Bryozoën in die Glasgefässe gebracht. Nach meiner Neinung sind es nur vier Species, darunter drei die schon früher in Grönland gefunden sind; die vierte dürfte überhaupt neu sein, das Fragment ist aber zu klein um bestimmt werden zu kömnen.

Zahlreicher sind die Bryozoën. Bei Weitem überwiegend sind unter diesen nach der Zahl der Exemplare die Horneren. Nach den Bestimmungen in den sehr sorgfältigen Arbeiten von Smitt (Kritisk Förteckning öfver Skandinaviens Hafs-Bryozoër, in den Verhandlungen der Stockholmer Akademie, 1864-67) müssen sie aber sïmmtlich zu einer einzigen Species (Homera lichenoides) gerechnet werden. Gleichwol lassen sich vier distincte Formen unterscheiden, die ich anch in verschiedene Gläser vertheilt habe. Diese für vier gerechnet betrïgt die Zahl der untersuchten Bryozoënspecies im Ganzen 29; darunter sind keine neuen Arten, auch keine die nicht schon von Grönland her bekannt wïren; von den bei Smitt (Bryozoa marina in regionibus arcticis et borealibus inventa, in den Verhandlungen der 
Stockholmer Akademie, 1868) als in Grönland vorkommende Species aufgeführten 75 fehlen hier also bei Weitem die meisten. Während Smitt in seinem Verzeichniss bei jeder Species angibt, ob sie der Strandfauna oder der Tiefe, oder der zwischen beiden liegenden mittlern Region angehört, ist hier bei keiner Art über den Standort etwas bemerkt.

Die sämmtlichen Gegenstïnde waren in Spiritus aufbewahrt, was bei diesen Thierklassen in der Regel wenig zur Conservirung der Organismen beiträgt und also in den meisten Fällon nichts nützt, in allen aber die Untersuchung sehr erschwert. Gleichwol habe ich geglaubt das Eintrocknen vermeiden zu'müssen, namentlich wenn auch nur eine Spur der organisehen Theile zu erkennen war.

IBei der Bestimmung und Benennung der Bryozoën habe ich hinsichtlich der Cyclostomata und der Ctenostomata die schon erwähnten Abhandlungen ron Smitt, hinsichtlich der Chcilostomata den Katalog von Busk (Catalogue of marine Polyzoa in the Collection of the Brit. Museum, 185̃2-54) zu Grunde gelegt, ohne jedoch die spätern Beschreibungen neuer Species in den Ammales des Sciences naturelles, dem Quarterly Journal for mikroscopical Science und den Annals and Magazine of natural history, ferner Heller's Bryozoën des Adriatischen Neeres, oder auch dic älteren Werke ron Lamarek, Lamouroux, Audouin, Savigny, Blainville, Johnston u. s. w. unberiicksichtigt zu lassen. Allerdings ist für alle drei Ordnungen von Bryozoën der nordischen Meere die mehrerwähnte Smitt'sche Arbeit das classische Hauptwerk, aber die Benutaung desselben wird, abgesehen von der mir nicht gelüufigen schwedischen Sprache, besonders dadurch erschwert, dass die Benennungen der Genera und Species fast sïmmtlich ron den allgemeiner üblichen abweichen.

Was bei Busk, Johnston, Hincks, Norman, Milne-Ewards, Heller u. A. verschiedene Arten sind, verbindet Smitt oft als verschiedene Formen einer Art, und umgekehrt, was bei jenen zu derselben Gattumg gehört, bildet bei diesem verschiedene Genera. Besonders gilt dies von der Johnston'schen Gattung Lepratia, welche, wie überhaupt in den nordischen und wahrscheinlich in allen (nicht australischen) Heeren, so auch in der vorliegenden kleinen Sammlung bei Weitem die zahlreichste ist. Smitt vertheilt die Lepralien in ganz verschiedene Genera, fur welche er theils den alten Namen Mollia, theils die d'Orbigny'schen und Gray'schen Benemungen benutzt. Hierbei mögen dem, so reichlich und sorgfïltig auch bei Smitt die Beschreibungen der andern Autoren citirt sind, doch immer noch gar manche Synonyma übersehen und andere irrig angegeben sein. Eine selbstän- 
dige Controle iiber die durchgängige Richtigkeit dieser Angahen wiirde, selbst wenn ich mich derselben gewachsen fühlte, allzu viel Zeit in Anspruch genommen haben. Auch wïrde das Resultat dem erforderlichen Aufwand am Zeit und Mühe kaum entsprechend gewesen sein, am allerwenigsten bei der Gattung Lepratia. Die Mannichfaltigkeit des (mikroskopischen) iussern Anblicks bei den verschiedenen Arten, die ungefähr wie bei den Kieselschalen der Diatomen nur etwa den Eindruck einer verschiedenen Ornamentirung macht, scheint fast ins Endlose zu gehen. Die verschiedenen an der Aussenseite der Zoazien befindlichen Merkmale, die man zur Bestimmung der Arten benutzt hat: die Avicular - und Vibracularorgane, die Dornen und Zähnchen, die Warzen und Poren, die Löcher und Griibchen, die Ritzen, Spalten, Streifen, Zacken u. s. w. bieten alle den Uebelstand, dass sie an vielen Exemplaren eimer Species, fü welche sie charakteristisch sein sollen, sehr häufig fehlen, sei es infolge äusserer, mechanischer Einwirkungen, sei es nach dem Entwickelungsstadium der Colonie, sei es wegen Verkalkung der äussern Hülle, sei es aus innern mit der Abstammung und Vererbung zusammenhängenden Gründen. Hiex wird es immer zweifelhaft bleiben, was man als Varietiten, Formen u. s. W. derselben Species, und was als verschiedene Species anzusehen hat und ob die ron dem einen Autor mit gewissen Merkmalen beobachtete und abgebildete Art wirklich mit der gerade rorliegenden identisch ist, welcher alle diese Merkmale fehlen. Gilt das eben Gesagte ganz besonders von den Lepralien und iiberhaupt von den Eschariden und Celleporiden, so gilt es ferner, wenn auch in geringerm Maasse, auch von Homera und andern 'Tubuliporiden.

Dieser Hindernisse ungeachtet habe ich gleichwol den eben deswegen nur ungenügend ausgefallenen Versuch gemacht, in der folgenden Aufzeichnung bei jeder Species unter dem gewählten Namen 1) die von Smitt, Busk u. A. aufgefühten Synonymen, soweit sie mir unzweifelhaft schienen, 2) die rorhandenen Abbildungen, soweit sie wirklich mit den vorliegenden Exemplaren übereinstimmten, 3) den Fundort dieser Exemplare, soweit er ron dem Sammler angegeben war, und 4) die Verbreitung der Species aufzuführen, wobei denn allerdings die Richtigkeit der letztern Angaben wesentlich davon abhängt, ob die Synonyme richtig sind (wie z. B. das Vorkommen der nordischen Escharella Legentitii Smitt im rothen Meere nur dam sich behaupten liesse, wemn sie wirklich mit der Flustra Legentilii Audouin identisch wäre, was ich bezweifle). Ueberhaupt aber darf den Angaben ïber die Verbreitung der Bryozoënspecies noch kein grosser Werth beigelegt werden, weil nur erst wenige Meere. in dieser Be- 
ziehung durchforscht sind. Ausser den europäischen Küsten, namentlich denen der Britischen Inseln (Ellis, Fleming, Couch, Allman, Alder, Busk, Norman, Hinks u. A.), Frankreichs (Lamarck, Lamouroux, d'Orbigny, Nihe Edwards), der Niederlande und Belgiens (Pallas, van Beneden), ausser dem rothen Meere (Savigny und Lhrenberg), ferner dem mittelländischen und adriatischen Meere (costal, Meneghini, Iteller) und neverdings den arktischen und nordischen Meeren ([Fabricius, Miüler], Sars, Smitt) haben eigentlich nur die Westküste von Südamerika (d'Orbigny) und besonders Südaustralien (M[ Gillivray, Busk, Gray u. A.) ein nemnenswerthes Contingent zu den bis jetzt bekannten Arten von Bryozoën geliefert, wïhrend kein Grund zu der Annahme ist, dass nicht die andern Kíistenstriche der südlichen Meere ebenso reich an Bryozoën sein sollten wie die meisten der ebengenannten - wie die meisten, nicht wie alle, denn die Bass-Strasse (zwischen Neuholland und Van Diemensland) diurfte wol immer die Hauptbrutstätte der Bryozoën bleiben; ihr Artenreichthum ${ }^{1}$ scheint dort mit der massenhaften Menge der Individuen gleichen Schritt zu halten. Fast scheint es, als ob in Grönland von beidem das Gegentheil der Fall wäre, doch werden daruiber die fernern Entdeckungsreisen weitern Aufschluss geben.

1) Von Grörlands Westküste kennen wir schon seit bald einem Jahrhundert die Bryozoën (Fabricius, Fauna gronlandica, 1780), von Australien seit kaum 20 Jahren (Voyage of the Rattlesnake, 1852); gleichwol zählt von Cheilostomen Smitt (1. c., 1868) für Grönland nur 58 Arten auf, MI* Gillivray ('T'ransactions Roy. Society of Victoria, Melbourne 1869) für die Südküste von Australien schon 140 Arten (Ieller nennt im adriatischen Heere 75). 


\section{Systematisches Verzeichniss}

der in Ostgrönland gesammelten Hydroiden und Bryozoën.

Class. Coelenterata. Subcl. Hydrozoa.

Fam. Campanularida.

\section{Ordo HYDROIDA.}

Suborlo Tecaphora.

1) Lafoa fruticosa Sars.

2) Campanularia sp.?

Fam. Sertularide.

3) Sertularella tricuspintata Hincks.

4) Sertularia sp. not ? ?

Class. Malacazoa.' Subcl. Acephala."

Ordo BRYOZOA.

Fam. Cellulariadx.

\section{Subordo Cheilostomata.}

1) Menipea arctica Busk.

2) " Smittii Norman.

3) Scrupocellaria inermis Norman.

Fam. Membraniporida.

4) Mcmbranipora Flemingii Busk,

5) " minax Busk.

6) " lineata Busk.

7) Lepratia hyatina Thoms.

8) "Landsborowii Johnst.

9) "Smittii.

10) " Peachii Johnst.

11) " simeosa Busk.

12) " pertusa Busk.

13) Hemeschara(?) contorta Kirch.

Fam. Celliporidse.

14) Celleporella Tepratioides Norm.

15) Cellepora scabra Fabr.

16) " incrassata Lam.

17) " Slienei Johnst.

Fam. Escharidse.

18) Eschara cervicomis Lam.

Fam. Iloprueridie.

\section{Subordo Cyclostomata.}

19) Honera lichenoides Sm.

Fam. Diastoporida.

20) Diastopora hyatina Sm.

I Vielleicht richtiger: Class. Vermes. Subcl. Gephyrea. 
Fam. Tubuliporidae.

21) Idmonea atlantica Sm.

22) Phalangella flabellavis Sm.

Fam. Lichenoporidse.

23) Discoporella vernucaria Sm.

24) " hispida Sm.

Fam. Haleyonellea.

\section{Subordo Ctenostomata.}

25) Alcyonidium hirsutum f. membranacea Sm.

26) "gelatinosum Sm.

\section{H Y D R O I D A.}

1) Lafoe fruticosa Sars (Norske Hydr. Videnskab. Verh., 1862).

Calicella fruticosa Hincks, Ann. and Magaz., VIII, 293.

Campanularia gracillima Alder (fide Hincks).

Campanularia fruticosa Sars, Reise i Lofoden. Ngt. Mag., 1851.

Abbildung. Hincks, Brit. Hydr. Zooph., tab. XLI, fig. 2.

Fundort. Nordshannon (10b, 11, 15, 26).

Verbreitung. Island, 'Tromse, Nordkap, Bergen; nach Hincks identisch mit Campamilaria gracillima Alder aus Shetland und Northumberland, auch mit einer in Busk's Sammlung befindlichen Lafoea aus der Bass-Strasse (Australien). - Die arktische Form unterscheidet sich von der britischen Campanularia gracillima durch die viel längeru, geringelten Sticle der Kelche, welche bei der britischen kurz und gewunden sind. Diese lebt im tiefen Wasser, jene immer in starker Strömung.

2) Campanularia sp.? Unkenntliches Fragment.

Fundort. Nordshamnon (13a).

3) Sertularella tricuspidata Ilineks (Brit. Hydr. Kooph.).

Sertutaria ericoides Pallas, Elench. Zooph.

Sertularia polyzonias Fabricius, Fauna grøenlandica.

Sertularia trieuspidata Alder, Catal. Northumberl. Zooph. (non Murray).

Cotulina polyzonias Agassiz, Nat. hist of U. St.

Abbildung. Esper, Pflanzenth. Sert., XII, 1, 2. Nlder in Ann. Mağ., 1856, pl. XIII, fig. 1, 2. Hincks, l. c., XLVII, 1.

Fundort. Ostgrönland (49; nur ein einziges defectes Exemplar).

Verbreitung. Die Gattung wurde durch Gray von Sertularia, die Species durch Alder von Serhularia polyzonias getrennt; die letz- 
tere scheint durch alle Meere rerbreitet; die Sertularella tricuspidatu gehört vorzugsweise dem hohen Norden an, namentlich Grönland und Spitzbergen; ich habe auch Exemplare von Vardo im Eismeer und rom Nordkap. Hincks gibt an: Reikiavik in Island und Strasse ron Belle-Isle in 40 Faden Tiefe; und Alder: , an andern Zoophyten ron den Tiefwasserböten, welche den Markt von Newcastle im Frühling mit Fischen versorgen." Das vorliegende grönlïndische Exemplar ist iibrigens der neuseelïndischen Scrtularella Jolmstoni von Gray überaus ähnlich und von Vardœe besitze ich Exemplare der nordischen Art, die ganz regelmässig gefiedert und in dieser Form wiederum nicht zu unterscheiden sind ron Exemplaren, die das Museum Godeffroy aus der Bass-Strasse in Australien erhielt.

4) Sertularia Spec. (nova?)

Fundort. Nordshannon (Nr. 85), nur ein kleines Fragment, nicht genau zu bestimmen. Soweit rorhanden ist es Sertularia fitiformis, ramosa, hydrothecis distantibus, alternis, tubutosis, adpressis, ore integro.

\section{B R Y O Z 0 A,}

\section{Cheilostomata.}

1) Menipea aretica Busk (Journ. Microscop. Se., 1855, April).

Cellularia ternata (Sol.), 3. forma gracitis Smitt, Vendensk. Akad. Förhandl., 1867, No. 5.

Sertularia reptans Fabricius, Fauna gronlandica, p. 445.

?Cellarina gracilis Van Beneden, Bull. Brux., T. XV., I, 73, II, 645, fide Smitt.

Abbildung. Busk, l. c., tab. I, fig. 1-6. Smitt, 1. c., tab. XVI, fig. $15-24$.

Fundort. Nordshannon (Nr. 16).

Verbreitung. Westgrönland, Assistance Bay (Dr. Sunderland fide Busk). Andere Exemplare aus Grönland im Hamburger und im Dresdener Museum. Nach Smitt in den arktischen Meeren überhaupt in mittlerer 'Tiefe bis 200 Faden sehr häufig an Sertularien u. s. w. Wenn die Van Beneden'sche Species identisch ist, auch noch in Belgien. Die von Smitt gleichfalls mit einem ? unter den Synonymen angeführte Crisia pilosa Aud. (Savigny, Egypte, Polypes, tab. XII, fig. 1) aus dem rothen Neere gehört wohl nicht hierher; sie hat lange

Zweite Deutsche NordpoIfahrt. II. 
Vibracula, drei bis vier Dornen auf dem Aricularium, grosse Opercula vor der Zellemmïndung und Grüibchen auf den Eierkapseln, welches Alles der Mcnipea arctica fehlt.

2) Memipea Smittii. Norman (Journ. Microsc. Sc., 1868, October). Cellutaria ternata, forma duplex Smitt, 1. c.

Abbildung. Smitt, 1. c., tab. XVI, fig. 25, 26.

Fundort. Nordshanmon (21), Grönland (10a).

Verbreitung. Spitzbergen 50 Faden Tiefe (Norman); Smitt nennt gleichfalls nur Spitzbergen und zwar in der Littoralzone. Smitt fasst diese und die vorige Art nebst einer dritten und der Menipea ternata Busk als eine Species unter dem Namen Cellularia ternata zusammen, was wenigstens insofern bedenklich ist, als die Menipen (Cellaria, Cellularia, Crisia, Tricellaria) ternata Auct. sich gerade durch die kurzen keulenförmigen, nur drei Zellen (Zoøcien) enthaltenden Glieder des Stockes sehr charakteristisch auszeichnet, während die hier erwähnte Form ganz anders gestaltete, lange, schlanke Glieder mit mehr als vier Zellen hat, die in zwei parallelen Reihen neben einander stehen.

3) Scrupocellavia inermis Norman, 1. c.

Cellularia scabra, forma elongata Snitt, 1. c., XVII, fig. 35, 36.

Abbildung. Norman im Journ. microse. Se., 1868, October, $\mathrm{V}, 1-3$.

Fundort. Ostgrönland (66).

Verbreitung. Die vorliegende Species scheint mir die ron Norman, 1. c., gemeinte zu sein, welche nach seiner Angabe 1863 und 1866 in Shetland in tiefem Wasser gefunden wurde; ein Beispiel mehr fiir die häutiger vorkommende Cebereinstimmmong gönländischer brynzoёn mit Tiefenhewohnern der See bei den Shetland-Inseln. Smitt in seinen Schriften von 1866 und 1867 konnte die spätere Norman'sche Species noch nicht citiren, deswegen findet sich dieser Name auch nicht in seinem Verzeichniss der grönländischen Bryozoën, aber die vorliegenden Exemplare stimmen, wenn auch nicht mit Smitt's Beschreibung seiner Cellularia scabra, so doch mit der oben angeführten Smitt'schen Abbildung der Cellularia scubra forma elongata, die auch in dem grönländischen Verzeichniss genannt ist; für diese werden auch Spitzbergen und die arktischen Neere iiberhaupt als Fundorte angegeben. 
4) Membranipora Flemingii Busk, Brit. Mus. Cat.

Flustra unicornis Flem.

Membranipora unicornis Blainville.

Membranipora membranacea Jolnst., Br. Zooph.

Membranipora Flemingii, forma trifolium Smitt (verschiedene andere Synononyma bei Smitt, die aber wenigstens zu den vorliegenden Exemplaren nicht passen).

Abbildung. Busk, Cat, tab. LXXXIV, fig. 3-5. Smitt, 1. c., tab. XX, fig. $37-42$.

Fundort. Ostgrönland (Nr. 111).

Verbreitung. Smitt führt Spitzbergen und die skandinavischen Meere, Heller das adriatische -, Busk die emropäischen Neere an; Letzterer auch Australion mit einem?.

5) ITembranipora minax Busk, Journ. microc. Sc., 1860, Januar.

Membranipora Flemingii, forma minax Smitt.

MLembranipora sacculate Norm., Amn, and Mag., 186t, Januar, pl. XI, fig. 3. Membranipora comigere Busk, 1. c., pl. XXV, fig. 2.

Abbildung. Busk, l. c., pl. XXV, fig. 1 (als Membramipora rhynchota). Smitt, XX, 43.

Fundort. Ostgrönland (Nr. 119).

Verbreitung. Shetland-Inseln Busk. Membranipora comigera und Mtombranipora sacoulata, welche mir beide mit der vorliegenden Art identisch scheinen, stammen gleichfalls von den Shetland-Insehn.

6) Membranipore lineate Busk, Brit. Mus. Cat.

Fhestra Tineata $\mathrm{L}$.

Flustra hirta Lrx.

Callopora lineata Gray.

Flustra spinifera Johnst.

Membranipora lineata, forma lineata Smitt.

? Membranipora spinifera Smitt.

Abbildung. Busk, Cat., tab. LXI, fig. 1. Smitt, l. c. (als Mcmbranipore spinifora), tab. XX, fig. 12.

Fundort. Sabine-Insel (Nr. 87).

Verbreitung. Die Autoren geben die emropäischen Meere und schon Lamouroux auch Grönland an.

Smitt erwähnt anch eines bei Spitzbergen gefundenen Exemplars seiner Membranipora lineata, welche er von seiner dort häutig vorkommenden MLmbranipora spinifera unterscheidet; die Avicularien, deren Stellung und Form nach ihm beide Arten unterscheiden wïrde, fehlen an dem vorliegenden Exemplar, welches übrigens mehr der 
Smitt'schen Abbildung von Membramipora spinifera als ron lineatu entspricht; bei Busk hat die letatere keine Aricularien.

7) Lepratia Tyatina W. Thomson.

Cellepora hyalina L.

Cellepora nitida Fabricins, Fanna grœnlandica.

Escharina personata Lmek., Am. s. vert.

Lepratia cylindrica IIass, Amm. and Mag. Nat. Hist.

Moblia leyalina, forma hyalina Smitt.

Abbildung. Johnst., Brit. Kooph., tab. LIV, fig. 1. Hass., l. c.. tab. IX, fig. 6. Busk, Br. Mus. Cut., LXXXII, 1, 2. Smitt, 1. c.. XXY, 84.

Fundort. Sabine-Insel an Fucus (Nr. 22).

Verbreitung. Grönland, Spitzbergen, Skandinavien, Helgoland,

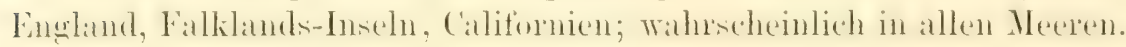

S) Lepratia Landsborowii Johnst.

Escharella Landsborowii Smitt, 1. c., p. 13.

Abbildung. Busk, Brit. Mus. Cat., pl. LXXXVI, fig. 1; CII, 1. Smitt, l. c., tab. XXIV, fig. 60.

Fundort. Nordshamnon an einer Homera (Nr. 110) und mit Cellepora lepralioides (120).

Verbreitung. Grönland, Spitzbergen, Nortregen; ïberall nicht häufig, selten auch an der englischen Kïiste. (An dem vorliegenden Exemplar sind die Wände der meisten Zoocien nur an ihren Ründern durchlöchert, in der Mitte mehr mit Warzen bedeckt; doch sind zuweilen auch diese durchbohrt.)

9) Lepralia Smittii (nom. nor.).

Escharelle Legentitii, forma prototypa Smitt, 1. c.

Abbildung. Smitt, l. c., tab. XXIV, fig. 47-52.

F'undort. Nordshamnon an Algen (Nr. 18).

Verbreitung. Die Smitt'sche Art, über deren Identität nach den vortrefflichen Abbildungen kein '/weifel sein kamn, findet sich bei Spitzbergen und Norwegen. Ausserdem aber gibt Smitt fuir seine Art noch folgende Symonyma an:

Flustra Legentilii Aud. zu Savigny, Eg., tab. IX, fig. 2.

Flustra Montferrandi Aud., ibid., tab. IX, fig. 14.

Escharina rimulata d'Orb., Amer., pl. VII, 1-4.

Lepretia reticulate $\mathrm{II}^{\mathrm{c}}$ Gillivray, Ann. and Mag. Nat. hist, Vol. IX; Busk, Catal., tab. XC, fig. 1, tab. XCIII, fig. 1, 2.

Deren Fundorte sind: Die britischen Kïisten; das ägeische Meer, 
die Falklands-Inseln, Neuseeland. Vergleicht man indessen diese Ab-. bildungen, so wird deren Uebereinstimmung mit der vorliegenden Art sehr zweifelhaft; jedenfalls wird man nicht ohne viele Conjecturen sie herstellen kömnen, und da dieser Zweifel ganz besonders von der Flustra Legentilii Aud. gilt, von welcher Smitt den Speciesnamen entlehnte, so glaube ich diesen Namen nicht beibehalten zu diufen; deswegen der vorgeschlagene andere.

10) Lepratia Peachii Johnst., Brit. Zooph. etc., 2.

Berenicea immersa Flem., Brit. anim.

Escharella immersa Gray, Brit. Red.

Lepralia immersa Johnst., Brit. Zooph.

Discopora coccinea, forma Peachii Smitt.

Abbildung. Johnst., Brit Kooph., tab. LIV, fig. 5, 6 (Lepratia Peachii) und tab. LVII, fig. S (Lepratia immersa). Busk, Brit. Mus. Cat., tab. XCVII. Smitt, 1. c., tab. XXVII, fig. 160-166.

Fundort. Sabine-Insel, auf einem Stein mit Lepratia simusa (N1. 82).

Verbreitung. Spitzbergen, Norwegen, Britische Inseln, im tiefen Wasser.

11) Lepratia simuosa Busk.

Discopore coccinea, forma ovalis Smitt, tab. XXVIL, 175.

Abbildung. Journ. microse. Sc., 1860, Janual. 'Loophytology tab. XXIT, tig. -2.

Fundort. Sabine-Insel, an einem Stein mit Lepratia Peachii (Nr. 82) und Ostgrönland (ohme nähere Angabe) an Proboscina incrassutu (Nr. 10).

Verbreitung. Shetland-Inseln auf Muschelschalen. - Busk (Brit. Mus. Cat, pl. LXXXIII, fig. 3, 4) gibt noch eine Lepralia areolata aus der Magellanstrasse, welche ich mit dieser fiu identisch halten wïrde, wenn nicht Busk selbst beide getrennt hätte.

Uebrigens fasst Smitt die drei Species der englischen Autoren: Lepratia ventricosa, Lepratia Peachii und Lepratia simosa als verschiedene Formen einer und derselben Species zusammen, die er Discopora coccincu nemnt; letztere jedenfalls nicht zu verwechseln mit Lepratia coccinea Busk.

12) Lepralia pertusa Busk.

Cellepora pertusa Esper, Pflanzenth. Celleporen, Taf. X, 2.

Escharina pertusa et Escharina perlacea Lamarck, Ans. Vert. ed. M. Edwards. Cellepora perlacea W. Thomson, Ann. and Mag., Bd. X. 
Abbildung. Busk, Cat. Mar. polyz., pl. LXXIX, fig. 2.

Fundort. Ostgrönland (Nr. 108).

Terbreitung. Ein einziges kleines Exemplar, welches unzweifelhaft mit der Beschreibung von Busk und mit der einen oben citirten Abbildung (nicht aber mit den iibrigen Abbildungen) ïbereinstimmt. Die Bemerkung yon Norman (Journ. microse. Sc., 1868, October), dass die Busk'schen Abbildungen nicht zu Lepralia pertusa, sondern zu IIomeschara sunguincu gehören, wird sich wahrscheinlich anf die übrigen Abbildungen beziehen; doch bleibt die ganze Species immer problematisch, um so mehr als Busk der Aricularien nicht erwähnt, die sich an vorliegendem Exemplar bei einigen \%owcien zu beiden Sciten der Mündung finden. Die Identität vorausgesetzt scheint die Verbreitung von Lepralic pertusa eine allgemeine. Busk und Johnston führen die Orkneys und verschiedene Plätze an der Westkiiste der Britischen Inseln, Lamarck die europäi-

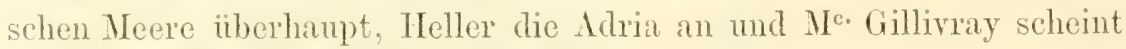
sie in Australien gefunden zu haben.

\section{3) Hemeschara(?) contorta mihi.}

? Escherelle porifore, forma cancellate smitt, 1. c., 1.9.

Charakter. Colonia lamellosa, contorta. Zoweia et Oœcia tuberculata, tuberculis sepe perforatis, Koøcii apertura magna semicircularis, margine proximali sape in processum labire-formem producto.

Fundort. Nordshamon (Nr. 12).

Die beiden Exemplare sind blattförmige, theilweise zusammengerollte Conoecien, gewissen Eschara-Arten ähnlich, bestehen aber nur aus einer Schicht von Zowcien und entsprechen deswegen der Norman'schen Gattung Hemeschara, am meisten der Hemeschara sunguineu Norm. (Journ. microse. Sc., 1868, October, pl. VII, fig. 9, 10, 11), von der ihr jedoch die tiefrothe Farbe und die mehrfachen Lünschnitte in der Unterlippe der Zocecienöfthung fehlen. Die Zoœcien selbst stimmen einigermaassen iiberein mit den Abbildungen der Lepratia pertusu Busk (Brit. Mus. Cat., pl. LXXIX), von denen Norman sagt, dass sie seine Homesclura sanguinea bezeichnen, nicht aber mit der Lepratia pertusa selbst, deren Wände mit durchlöcherten Grübchen bedeckt sind. Bei der vorliegenden Species sind die Wände mit kleinen umregehäissigen, durchsichtigen Bliischen besetzt, die zwar meistentheils, aber keineswegs immer ein kleines rundes Loch haben. Uebrigens bleibt es zweifolhaft, ob wirklich eine Hemeschara vorliegt, denn beide Exemplare lassen sich auch als incrustirende Lepralien ansehen, deren Substrat rerwittert oder in sonst einer Weise entfernt 
worden wäre. Aber anch unter den zahllosen Lepralien finde ich keine der vorliegenden ganz entsprechende Species, es wäre denn die oben citirte Smitt'sche arktische Species (ohne Avicularien), deren Oœcien aber weder warzig noch durchlöchert sind. Lepratia bellis Busk (Journ. microse. Sc., 1860, pl. XXYII, fig. 2, 3) aus den Shetland-Inseln wäre :̈hnlich, hat aber einen ganz ander's geformten Mund.

NB. Auf der Riickseite des einen Exemplars hat sich eine Tubulipora (Phalangella) flabellaris ausgebreitet.

\section{4) Celleporella Tepralioides Norman.}

Abbildung. Norman, Brit. Polyz, in Journ. microse. Sc., 1865, October, pl. VII, fig. 4, 5 .

Fundort. Ostgrönland an Homera lichenoides ( $\mathrm{N}_{1}$. 109).

Verbreitung. Die Norman'schen Exemplare wurden bei den Shetland-Inseln in 90-100 Faden Tiefe mit dem Schleppnetz gefischt. Bei Smitt finde ich diese Species nicht, wenigstens nicht in dieser Form, wenn sie nicht etwa auch eine Form vou Cellepora seabra Fabr. ist, mit der sie zusammen vorkommt.

15) Cellepora scubra (Fabr.).

Smitt, 1. c., p. 30 führt unter diesem Namen drei Formen anf, nämlich Cellepora scabra Sm., Cellepora plicata Sm. und Cellepora ovata Sm., von denen nicht zu ersehen ist, ob er sie als besondere Species betrachtet. Die hier rorliegenden gehören zu der zweiten und dritten, und stehen neben und zwischen einander, sodass sie ein einziges Conøcium zu bilden scheinen. Bei einigen Zoøcien ist aber die Unterlippe auffallend weit vorgestreckt, viel stärker als auf den Smitt'schen Abbildungen, fast wie bei der Celleporc Lancretii And. (zu Savigny, Egypte, pl. VII, fig. 2) aus dem rothen Neere, oder wie bei Cellepora labiata Lix. (Polyp. flex., tab. I, fig. 2) aus Australien. Ob letztere mit der vorliegenden Art identisch, ist bei Lamouroux' schlechter Abbildung und ungenïgender Beschreibung nicht zu ermitteln.

Abbildung. Smitt, l. c., tab. XXVIII, tig. 189-197.

Fundort. Sabine-Insel (Nr. 81) und ohne nähere Angabe (Nr. 97).

Verbreitung. Die Smitt'schen Arten in der Nordsee und dem Eismeer.

16) Cellepore incrassata Lmek.

Cellepora pumicosa Sars, Mag. f. Naturw., VI, 127.

Cellepora cervicomis Busk, Anu. and Mag. nat. hist., 1856, July, pl. I, fig. 1.

Celleporaria incrassata Smitt, 1 c., p. 33. 
Abbildung. Busk, 1. c. Smitt, tab. XYVIII, fig. 212-216.

Fundort. Ostgrönland (Nr.9 und 102). (Zahlreiche Exemplare, aber grösstentheils stark verkalkt und mit andern Zoophyten besetzt; einzehne Stuicke, an welchen die Parasiten kenntlich waren, habe ich besonders gelegt.)

Terbreitung. Nach Smitt bei Spitzbergen und Grönland, weniger häufig bei Finmarken, von wo her die von Busk beschriebenen Exemplare stammen.

17) Cellepora Skenei Johnst.

Bitlepora Sliemei Eillis et Solander.

Cellepora palmate Flem.

Discopore Skenei Smitt.

Abbildung. Johnst., Brit. Zooph., tah. LII, fig. 6, 8. Busk, Bi. MI. Cat., tab. CXXII. Smitt, tab. XXVII, fig. 182.

Fundort. Ostgrönland (Nr. 106).

Verbreitung. Spitzbergen, Norwegen, Britische Inseln.

18) Eschara cervicomis Lamarek.

Porus cervinus Borlase, Nat. hist. Coruw.

IItlepora alcicomis Ésper, Milleporen, V, 7.

Mitlepora compressa Sow., Brit. Miscell.

Cellepora cervicornis Couch., Zooph. Cornw.

Porella corvicomis Gray, Brit. Mus.

A bbildung. Johnston, Brit. Zooph., LIII, fig. 2-5 (nicht 1). Busk, Brit. Nus. Cat., CIX, 7 (nicht CXIX, 1). Smitt, 1. c., XXVI, 138 (nicht 136, 137). M. Edwards, Ann. des Sc. nat., Tome VI, pl. 182.

Fundort. Ostgrönland ohne nïhere Angabe (Nr. 101).

Verbreitung. Die iussere Form der Zowcien ist je nach dem. Alter sohr verschieden, daher auch die meisten vorhandenen Abbildungen nicht miteinander, und nur einige derselben mit den hier vorliegenden Excmplaren stimmen; auch sind wol zuweilen nicht zusammengehörige Arten von den Schriftstellerm verbunden worden. Der Porus cervinus von Inperato und von Marsigli aus dem mittelländischen Neere kamn, der Abbildung nach, ebensogut irgendeine andere Eschara oder Cellepora sein. Die Eschara cervicornis von Forbes aus dem ägeischen Mecre (Journ. misrose. Sc.) scheint eine andere Species, stimmt aber übrigens mit der Millepora cervicomis von Ellis und Solander, die nach Couch keine Eschara cervicornis ist. Für die rorliegende Species sind Grönland und Spitzbergen, Finmarken und Norwegen sichere Standorte, ebenso die Shetland-Inseln, Schottland 
und Nordengland. Heller führt Eschara corvicornis auch aus der Adria an.

\section{Cyelostomata.}

19) Hornere lichenoides Smitt, 1. c., p. 409.

Millepora lichenoides Lim.

Millepora tubipora Ellis et Sol.

Homera frondiculeta Lamarck.

Hornera serrata et Hornera tubulosa Menighini (fide Heller).

Hornera borealis Busk.

Abbildung. Smitt, 1. c., tah. VI, fig. 10; VII, 1-14. Busk, Ann. et Mag., 185̃6, pl. I, fig. 7 (frondiculuta). Busk, Microse. Journ., 1864, pl. V, fig. 1-7 (borealis).

Fundort und

Verbreitung. Unter den recht zahhreichen, aber meistentheils schlecht erhaltenen Exemplaren, welche mit Eschara cervicomis, Cellepora incrassata vermengt in einem grossen Glasgefäss (ohne Bezeichnung des Fundorts) lagen, waren nach Aussonderung jener andern Gattungen noch drei oder vier Formen (zwischen denen aber vielfache Uebergänge stattfinden und die wol alle zusammengehören) mehr oder weniger deutlich zu unterscheiden. Ich habe sie getrennt und in verschiedene Gläser gelegt, auch vorläufig benannt: forma borecelis, forma flabellaris, forma frondiculate und forma veticulata. Es sind folgende:

a) Eine robuste Form, ziemlich stark, theilweis etwas abgeplattet, weniger verïstelt als die übrigen; entsprechend der Abbildung bei Smitt (tab. VII, fig. 3) und auch der von Busk (Journ. microse. Sc., 1864, April, pl. V, fig. 1-7) nach Exemplaren aus Shetland abgebildeten und beschriebenen Homera borealis B. Dies ist die vorherrschende Form (Nr. 100, Nr. 24).

b) Eine andere mit ebenso dicken Aesten, die sich aber dadurch auszeichmen, dass sie fast alle von der. Wurzel auf dicht neben- und miteinander fast parallel, alle in einer Fläche aufwachsen, sodass ein mehr fächerförmiges Gebilde entsteht (forma flabellaris, Nr. 90), von welcher ich keine zutreftende Abbildung finde; erwähnt scheint sic bei Smitt, 1. c., p. 470 unter 8.

c) Eine zartere feinere Form, stïrker verästelt, mit dünnern Zweigen und weiter vorragenden Zoøcien ( $\mathrm{Nr}_{1} .47$ ), entsprechend der von Busk (Amn. et Mag., 1856, July, pl. I, fig. 7), nach Exemplaren aus Fimmarken abgebildeten und beschriebenen Horner a frondiculata Lrx., und der Abbildung bei Smitt, tab. VII, fig. 1, 2, 
theilweise anch der Menighini'schen Homer serratu, die nach Heller ein Jugendzustand der Homera frondiculata ist.

Dass diese drei formen, ebenso wie eine vierte von M. Edwards, Ann. Sc. nat., Zool., 1838, pl. IX, fig. 1 als Hornera frondiculata abgebildete, zwischen welchen allen auch Uebergänge stattfinden, sämmtlich zu derselben von Smitt als Homera lichenoides bezeichneten (tab. VII, fig. 4-14 abgebildeten) Species gehören, scheint mir unzweifelhaft; anch der von Busk hervorgehobene Unterschied zwischen seiner Hornera frondiculate und Hornera borealis, welcher in der Beschaffenheit der beiderseitigen Fruchtkapseln liegen soll, war nicht zu ermitteln; die Unterschiede scheinen vielmehr nur in dem durch verschiedenes Alter oder durch äussere Umstände veranlassten Habitus zu liegen. Ist dem aber so, dann kann man, was die Verbreitung anlangt, diese Species als eine kosmopolitische bezeichnen. Doch muss erwähnt werden, dass Busk in dem Aufsatz ron 185̃6, 1. e., die Meinung ausspricht, die nordische Form sei von derjenigen des indischen und stillen Oceans specifisch verschieden und einc dritte Species sei diejenige des mittellïndischen Meeres.

d) Eine vierte Form endlich, die ich nirgends beschrieben finde und deren specifische Identität mir viel zweifelhafter scheint, zeichnet sich durch ihren Habitus sehr auffallend aus. Die Zweige liegen mit ihrer schr dünnen Rïickseite meistens zu mehrern in einer Fliche, als wären sie mit derselben an einem glatten Stein hinaufgewachsen; die Vorderseite aber ist nicht bloss wie bei andern IIorneren in die Ilöhe gewachsen, sondern häufig auch nach vorn, sodass sie damn nicht wie sonst eine schmale, gewölbte Fläche, sondern eine senkrecht auf der Achse des Zweiges stehende $L a$ mina bildet; diese Lamina ist ganz düm, ron sehr verschiedener Breite und auf beiden Seiten mit den Mïndungen der Zoocien besetzt. Diese Varietiat fand sich in ziemlich vielen Exemplaren (Nr. 107). Vielleieht ist es die ron Smitt neben verschiedenen Tubuliporiden (tab. X, unter A. B. C.) abgebildete Reticulipor nummulitorum, von der aber keine Beschreibung zu finden und die mir gänzlich unbekannt (vielleicht fossil) ist.

\section{0) Diastopora hyalina Smitt.}

Berenicec prominens Isx., Exp. method.

Berenicea hyalina Ileming, Brit. Anim.

Tubulipora Obelia Conch., Cornw. Launa.

Diastopora Obetia Johnst., Brit. Zooph. 
Abbildung. Smitt, I. c., tab. VIII, fig. 9-12. Johnst., I. c., tab. XLVII, fig. 7-8.

Fundort. Sabine-Insel, Nr. 86; Nordshannon, Nr. 83 (Fragm.). Verbreitung. Arktischer und atlantischer Ocean, mittelländisches und adriatisches Neer.

21) Idmonea atlentica Smitt.

Abbildung. Smitt, l. c., tab. IV, fig. 3.

Fundort. Nordshannon, ein ganz kleines, wenig bemerkbares Fragment.

Verbreitung. Atlantischer Ocean, Eismeer.

\section{2) Phalengella flebelleris Smitt.}

Tubipora flabellaris Fabricius, Fauna gronlandica.

Tubutipora verrucosa M. Edw., Ann. des Se. nat., Ser. 2, Vol. VIII, tab. XII. Tubulipora verrucarice Hassal, Ann. et Mag., Vol. VII, tab. VI, fig. 3, 4.

Tubulipora phalangea Johnst., Brit. Zooph., tab. XVI, fig. 1.

Phalangella phalangea Gray, Cat. Brit. Mus.

Abbildung. Smitt. l. c.. tah. IX, tig. li-s.

Fundort. Nordshannon, auf' der Rïckseite von Hemeschara contorta $m$. ausgebreitet ( $\mathrm{Nr}$. 12).

Verbreitung. Grönland, Spitzbergen, Norwegen, britische und französische Küste; auch Adria (Heller).

23) Discoporella verrucaria Smitt.

Madreporce verncarice Lin., S. N.

Tubulipore orbiculus Lam., An. s. Vert.

Tubutipora hispida var. $\beta$ Jolnst., Brit. Zooph.

Unicavea convexa d'Orb., Pal. Franc.

Discoporella flosculus Hincks, South. Devon. Zooph.

Abbildung. Smitt, l. c., talb. XI, fig. 1-6.

Fundort. Sabine-Insel an Algen (Nr.23).

Verbreitung. Nordsee und Eismeer, atlantischer Ocean.

24) Discoporelle hispida Smitt.

Discopora hispida Flemg., Brit. Amim.

Tubulipora hispida Johnst., Brit. Zooph.

Heteroporella hispida Hincks, South. Devon. Zooph.

Melobesia radiata Aud. zu Savigny, tab. VI, tig. 13.

Lichenopora mediterranea Blainville, Actinologie.

Discocavea aculeata d'Orb., Paleontologie franc.

Heteroporella radiata Busk., Crag. Polyzoa.

Discosparsa hispida Heller, Bryozoën des adriatischen Meeres.

Abbildung. Smitt, 1. c., tab. XI, fig. 7-9. Johnston, 1. c., tab. XLVII, fig. $9-11$. 
Fundort. Ostgrönland (Nr. 105) an Homera.

Verbreitung. Im Eismeer und der Nordsee, an den britischen und französischen Küsten, im mittelländischen und adriatischen Meere und, wenn alle oben (grösstentheils nach Smitt) angegebenen Synonyma richtig sind, auch jm rothen und stillen Meere; jedenfalls kommen in den siidlichen Heeren sehr ähnliche Formen vor.

\section{clemostomata.}

25) Alcyonitium hirsutum, forma mombranacea Smitt.

Alcyonidium mamillatum, Alder, Catal.

Abbildung. Smitt, tab. XII, fig. 6.

Fundort. Nordshannon an Horneren (Nr.24).

Verbreitung. Arktische, nordische, europäische Neere.

26) Aleyonidium gelatinosum. Smitt (?).

Ein einzelnes kleines Exemplar an einer Hornera von Nordshannon (Nr. 25), welches ohne zerstört zu werden nicht untersucht werden konnte. Die Bestimmung desselben ist deswegen zweifelhaft. Ls ist von fast kugeliger Gestalt, wie sie nirgends abgebildet ist. Ich habe deswegen von den zahlreichen Abbildungen und den Synonymen des bekannten Alcyonidium (Alcyonium L.) gelatinosum keine eitirt. 


\title{
13. \\ Ki es elspongien.
}

\author{
Bearbeitet von \\ Oscar Sehmidt \\ in Strassburg. \\ Mit einer Tafel in Kupferstich.
}

Die Expedition der Germania hat ein nicht umbedentendes Contingent an Kieselschwämmen geliefert. Zu den zehn in meiner „Spongien-Fauna“ 1870 beschriebenen Gattungen, resp. Species der westgrönländischen Küste kommen nunmehr acht Arten von Ostgrönland, alle bei Nordshamnon gesammelt. Von bekannten Species sind darunter Isodictya infundibuliformis Bwbnk. und Thecophore semisubevites Silt. Unentschieden muss es bleiben, ob sich nicht auch unter den übrigen Arten schon von Bowerbank in seiner Monographie der britischen Spongien beschriebene Formen befinden.

Da die westgrönländischen Spongien gar nichts Fremdartiges und Eigenthïmliches gezeigt haben, indem selbst Thecophora nach den Funden der englischen Tiefseeuntersuchungen viel weiter östlich und südlich vorkommt, da auch die ostgrönländischen sich in den schon gezeichneten Rahmen vollständig einfügen, da endlich unter den von der Expedition zur Erforschung der deutschen Meere, 1871, bei Arendal gesammelten Spongien sich Chalinula ovulum Sit. (Ostgrönland), Desmacidon anceps n. sp. (Westgrönland) und Suberites Lütkenii Sdt, (Dänemark und Westgrönland) finden, so erscheint auch jetzt noch die gesammte grönländische Spongienfauna als ein integrirender Bestandtheil des grossen atlantischen Gebietes.

Folgende Formen haben sich mehr oder minder feststellen lassen. 
1) Cacospongia Schmidt sp.

Zwei Exemplare von Hasehnussgrösse, rundlich, mit ebener Oberflïche und einem Osculum. Die Hornfasern sind gänzlich ohne Einschliisse, ron mngleicher Stärke und feiner, sehr auffällig welliger Schichtung. Man kann, wie bei den meisten Hornschwämmen, radiäre und quere Fasern unterscheiden und ist das Skelet zart und weich.

Der Fund ist wegen der Seltenheit der reinen Hornschwämme im Norden interessant. 'Zu erinnern ist dabei an Spongionella pulchra Bbnk. und Cacospongia mollion Sit.

\section{2) Chatinula Silt. sp.}

Nicht näher zu charakterisirendes Bruchstiick mit einspitzigen Nadeln ron $0,21448^{\mathrm{mm}}$.

3) Reniera Sdt. sp.

Nadeln von $0,1915^{\mathrm{mm}}$ Länge.

4) Isodictya infundibuliformis Bbnk.

5) Thecophora semisuberites Solt.

(6) Desmacidon anceps n. sp.

Ich habe in meinen letzten Arbeiten die proteusartige Gattung Desmacidon einigermaassen zu begrenzen versucht, jedoch mit dem Zugeständniss, dass sie nur ganz künstlich gegen die ältere Gattung Esperia abgesperrt werden kann. Wenn in den Arten mit den symmetrischen Doppelhaken nie die unsymmetrischen Ankerzähne rorkämen und umgekehrt, so würde damit eine Grenze gegeben sein. Es gibt allerdings viele Species, d. h. Formen oder Vorkommnisse von Desmacidinen bloss mit dem symmetrischen Doppelhaken, und diese könnte man Desmacidon s. s. nennen, wie Esperia s. s. jene, wo die Ankerzähne allein rorhanden. Sobald man aber diese Gruppen erustlich meint, so hat man zwischen sie wenigstens noch zwei bis drei Gattungen einzuschieben, welche die Combinationen der vermeintlich charakteristischen Kieseltheile und ihrer sich mehrenden Uebergangsformen enthalten miissten. Wollte man aber dies Princip durchführen und natiirlich auch auf die Species iibertragen, so wird sich jeder der den Versuch macht, iiberzeugen, dass fast jedes Stiick oder Exemplar mit einem Speciesnamen zu belegen wäre. So wenig als sich die Stadien der bei der Familie vorkommenden bald glatten, bald knotigen, spitzen, stumpfen, stecknadelförmigen Nadeln auf bestimmte Species fixiren lassen, ebenso wenig ist dies der Fall mit 
den Doppelhaken und den ankerzahnförmigen Kieselkörpern nebst den Spangen, von denen ich zeigen zu können glaubte, dass sie einen einzigen grossen Varietätenkreis innerhalb der einaxigen Kieselkörper bilden.

An einer bei Arendal vorkommenten Esperia habe ich num die sehr interessante Entdeckung gemacht, dass sowol die Spangen als die Haken aus einem Vexkieselungsprocess ron Zellmembranen oder wenigstens der membranähnlichen Oberflächenschicht von echten Zellen hervorgehen. Die speciellern Mittheilungen hierïber gehören nicht hierher. Diese Beobachtungen, welche an lebendem und gutconservirtem Material ergänzt werden müssen, führen möglicherweise und wahrscheinlich zu einer andern Auffassung des Verhältnisses dieser für die Desmacidinen charakteristischen Bestandtheile zu den einaxigen Nadeln, als ich es in der atlantischen Spongienfauna darstellte, sie sprechen aber wenigstens für den engern Kusammenhang dieser Hakengebilde unteremander. Thre Veränderlichkeit und Substitutionsfähigkeit bleiben dieselbe und in unserm Urtheil ibber die Tariabilität der Desmacidinen wird nichts geändert.

Von Nordshannon liegen eine Reihe von Spongienexemplaren vor, theils incrustirend und rom Habitus, den ich früher Myxilla genamnt, theils massiv, theils ästig, mit oder ohme deutliche Oberhant, aber wegen der Kieselformen ganz untrembar. Nicht alle Arten dieser letztern finden sich in jedem Exemplar; aber wenn sie in dem einen massenhaft vorkommen, so sind sie in dem andern wenigstens einzeln zu haben und zeigen die Möglichkeit des allmählichen Versehwindens oder des Anwachsens und Torherrschens. Es stimmt also kaum ein Exemplar ganz mit dem andern und es ist das wieder einer jener colatanten Fälle, wo man entweder jedes Stück als eigene Species beschreiben oder eine Species ohme Begrindung anfstellen muss.

Wer sich die Nühe nimmt, meine verschiedenen Mittheilungen ïber Desmacidinen zu recapitulixen und zu erwägen, dass, wie ich gezeigt, fast der dritte 'Theil der ron Bowerbank beschriebenen britischen Kieselschwämme Desmacidinen sind (etwa 56 von 180), wird also in der Creirung von Gattungen und Species imnerhalb dieses Itreises nichts anderes erblicken als willkiurliches Zusammenfassen von Varietäten. Solche Varietätenkreise, wie wir einen solchen als Desmacidon anceps bezeichnen, sind nicht einmal localer Natur, da er in unserm Falle von Ostgrönland nach der norwegischen Küste von Arendal überspringt. Es ist nicht zu zweifeln, dass unter den britischen sogenannten Arten sich der vollkommene Anschluss ergeben wird.

Nach diesen Bemerkmngen erübrigt nur, die Kieselkörper und 
den Umfang ihrer $\Lambda$ bänderungen anzugeben. Ganz allgemein kommen die stumpf-spitzen Knotenuadeln vor. Meist sind sie ganz mit Knötchen bedeckt, nicht selten nur am stumpfen Lnde. Es ist damit der Uebergang zu solchen Lxemplaren gegeben, wo die Knotennadeln nur cinzehn vorhanden und ihre Massenvertretung von glatten Nadeln übernommen ist. Sie sind in unregelmässigen Zügen gelagert. Zwischen ihnen, namentlich aber in der Oberflächenschicht und in der bei manchen Stiicken rorhandenen Oberhaut liegt eine sehr charakteristische schlanke Nadelart (Fig. 1 und 2), welche an beiden Enden zu einem Köpfehen anschwillt. Die letztern tragen, auch wenn sie sonst ganz glatt sind, fast immer eine kleine Endpapille. Es kommen jedoch auch Exemplare vor, wo nur einzelne der doppelköpfigen Nadeln die Endwärzchen besitzen. Bei den Varietäten von Arendal sind die Köpfchen ganz mit Knötchen bedeckt. Eins dieser Exemplare hatte viele schlanke und sehr feine Nadeln mit perlschnurförmigen Einschnürungen (Fig. 3). So runsinnig es wäre, auf dieses letzte Vorkommen und auf die Varietäten der doppelköpfigen Nadeln Species zu begründen, ebenso wenig Anspruch auf eine solche Verwerthung hat eine, bei mehrern grönländischen Exemplaren gefundene ganz nene Kieselform (Fig. 4), eine durchschnittlich etwas über $0,05^{\mathrm{mm}}$ lange Klammer. Das Ende des einen Schenkels ist oft etwas angeschwollen; die ganze Oberfläche trägt feine Knötchen. Schon der Unterschied in den Dimensionen verbietet, diese Form etwa für eine monströs gebogene Knotennadel anzusehen; Vorkommen und Lagerung verweisen sie vielmehr in das Bereich der aus Zellen hervorgehenden Spangen und Haken.

Die Grösse der Spange hält sich zwischen 0,038 und $0,15^{\mathrm{mm}}$. Diese Schwankungen kommen in einem und demselben Exemplare vor, während man in andern eine grössere Constanz wahrnimmt. Von den symmetrischen, d. h. an beiden Enden gleichmässig ausgebildeten IIaken zeigen Fig. 5, 6 und 8 zwei Varietäten. Line bisher noch

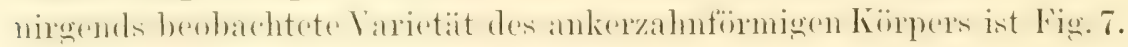
Die Eigenthïmlichkeit besteht in der Zuspitzung des Schaftes. Lünge fast $0,03^{\mathrm{mm}}$. Wenn dieser Haken in Gemeinschaft mit der Klammer, Fig. 9, bei einer lieihe auch sonst zusammenstimmender Exemplare unzertrennlich rorkäme, so könnte man dies Verhältniss als ein befestigtes msehen und darauf hin eine Species creiren. Allein dem ist nicht so; die Klammer bedarf des Hakens nicht, und unter einem reichlichern Material wïrde man zuversichtlich auch Stücke olme die Klammer, aber mit der nenen Varietät des Ankerzahmes entdecken.

Die einzige Einwendung, welche die conservativen Freunde der 
Z00L0GIE, 13 Fieselspongien Taf. I

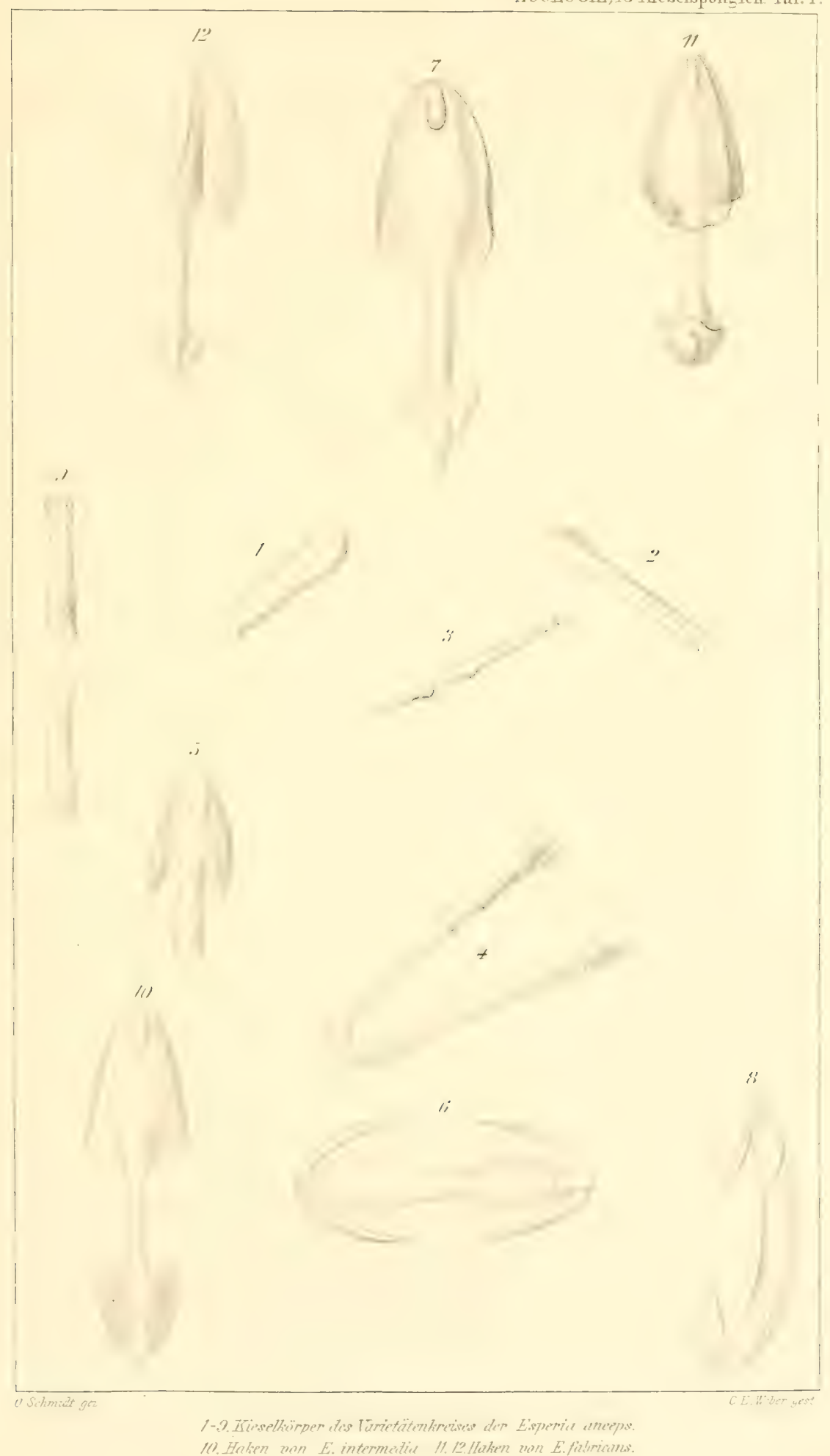



wohlumschriebenen, wenn auch ins Unendliche rermehrten Species gegen meine Auffissung machen kïmten, wäre die zu geringe Berücksichtigung der äussern Form dieser Spongien. Auch sie weise ich mit der blossen Hindeutung auf meine friihern Lntersuchungen iiber Desmacidinen und andere Gattungen und Arten, z. B. Siphonochatina papyracea, zurïck, und ich kann hinzufügen, dass neve Beobachtungen iiber die Variabilität des Habitus neuholländischer Spongien dasselbe Resultat gegeben haben.

7) Esperia intermedia n. sp.

Ein unbedeutendes Bruchstiick hat als Skelettheile unspitzige Narleln in Züigen und zwei Sorten von Ankerzähnen. Die kleinere misst 0,0224, die grössere (Fig. 10) 0,0605 $\mathrm{mm}$. Aus der Abbildung geht die unbedeutende, sich dem symmetrischen Haken nähernde Abweichung hervor.

8) Esperia fabricans n. sp.

Die Nadeln sind spitz. Von symmetrischen Haken mehrere Varietäten, eine mit kürzern stumpfen Zähnen, wie Fig. 8, die andere mit spitzen. Der Ankerzahn zeichnet sich durch die weiter als gewöhnlich vorstehende Mittelplatte aus (Fig. 11 und 12). 


\section{4. \\ Kalk- nnil fallertspongien.}

Bearbeitet von

F. II a e c k l

in .Jens.

\section{1) Ascattis Lamarchii Ireckel.}

E. Ireckel, Nonogr. der Kalkschwämme, S. 60, Taf. 9, Fig. 5; Taf. 10, Fig. 4.

Dieser Kalkschwamm gehört zu der Familie der Ascanen oder Microporeuten ron Hreckel, welche im Ganzen den Grantien ron Lieberkühn und den Leucosolenien ron Bowerbank entsprechen und dureh die einfachen veränderlichen Hautporen ihrer diinnen Magenwand charakterisirt sind. Die sämmtlichen Exemplare, welche Dr. Pansch bei der Insel Norelshannon, an der Ostküste von Grönland gesammelt hat, sind mundlose Stöcke und stimmen wesentlich mit denjenigen überein, welche Alexander Agassiz von der Kíuste von Florida mitgebracht hat. Auch die mundlosen Stöcke dieser Art, welche Hrekel in der Strasse ron Gibraltar und an der Kïiste ron Marokkn (bei Mogador) gesammelt hat, sind wenig verschieden. Es scheint demnach diese Art weit iiber den nordatlantischen Ocean rerbreitet zil sein.

Der Körper stellt bei allen Exemplaren ein sehr dichtes Geflecht von sehr feinen Röhren dar. Die äussere Gesammtform ist sehr unregehässig und weehsehnd, meistens ein länglichrunder Kilumpen ron $5-20^{\mathrm{mm}}$ Durchmesser, der auf Algen, Bryozoënstöcken u. dgl. festgewachsen ist. Der Durchschnitt eines solchen Klumpens zeigt dasselbe Aussehen wie die äussere Oberfläche. Ueberall zeigen sich sehr dicht nebeneinander zahlreiche feine Löcher ron 0,2-0, smm Durchmesser, getrennt durch feine hohle ' $/$ wischenbalken ron $0,1-0,3^{\mathrm{mm}}$ Dicke. Diese Zwischenbalken sind die einzehnen Personen des Schwam- 
mes; ihre Höhlung ist die Nagenhöhle, welche von einer sehr dünnen, von mikroskopischen Poren durchsetzten Wand umschlossen ist. Eine Mundöftinung oder ein Osenlum existirt nirgends. Vielmehr bilden die communicirenden Magenhöhlen der zahlreichen anastomosirenden Personen ein geschlossenes Kanalsystem, in welches das Wasser blos durch die mikroskopischen Magenporen ein- und ausströmt. Die mit hlossem Auge sichtbaren feinen Löcher zwischen den anastomosirenden liöhren sind nichts weiter als Zwischenräume, welche durch deren Verästelung und Verbindung entstanden sind.

Das Skelet der Ascaltis Lamarckii besteht nur aus drei-und vierstrahligen Kalknadeh, welche sämmtlich gleichwinkelig und gleichschenkelig sind. Die Schenkel sind ganz gerade, schlank cylindrisch, scharf konisch zugespitzt. Die Schenkel der grössten Dreistrahler sind 2-3 mal so lang und dick als die Schenkel der grössten Vierstrahler. Ein Schenkel der Vierstrahler springt frei in das Lumen der Röhren (in die Magenhöhle) vor. Die drei andern Schenkel liegen gleich den Schenkeln aller Dreistrahler in der Fläche der dünnen Tïhrenwand.

2) Sycultis glucialis Hreckel.

E. Hæckel, Monographic der Kalkschwämme, S. 269, Taf, 45, Fig. 4-7.

Dieser Kalkschwamm gehört zu der Familie der Syconen ron Lieberkühn, welche den Grantien von Bowerbank und den Orthoporeuten von Hrekel entsprechen, und durch die unverästelten, regelmïssig radial gestellten, geraden Kanäle (Radial-Tuben) ihrer Nagenwand charakterisirt sind. Die beiden Exemplare der Sycaltis glaciatis, welche Pansch bei der Insel Nordshannon, an der Ostkïste ron Grönland gesammelt hat, stimmen ganz mit denjenigen uiberein, welche Bessels ron der Küste von Spitzbergen mitgebracht hat. Alle Exemplare sind einfache P'ersonen mit einer nackten Mundöffinung, welche weder rüsselartig vorlüngert, noch mit einem Nadelkranz umgeben ist.

Der Körper ist cylindrisch, gerade oder etwas verbogen, nach der Basis hin verdiinnt, 20-30 $\mathrm{mm}$ lang und $4-6^{\mathrm{mm}}$ dick. Die Körperwand ist sehr düm, nur $0,6-0,8^{\mathrm{mm}}$ dick. Ihre äussere Oberfläche (Dermalfäche) ist ganz eben und glatt, fein porös. Die inmere Höhlung (Magenhöhle) ist ganz geräumig, von derselben Gestalt wie der Körper. da die Wand ailserall gleichmässig dick ist. Thre imnere Oberflïche (Gastraltlaiche) ist feinstachelig. Die Wand ist iberall von den Radial-Tuben durchsetat, welche dicht aneinander und senkrecht auf ler Fläche stehen. Sie sind prismatisch, mit ihren Seitenflichen völlig rerwachsen $0,5-0,7^{\mathrm{mm}}$ lang, $0,2^{\mathrm{mm}}$ dick. Inwendig auf der gastralen 
und auswendig anf der dermalen Flidche mïndet jeder Rarlial-Tubus durch eine rundliche Oeffrnung ron $0,1-0,15^{\mathrm{mm}}$ Durchmesser. Die

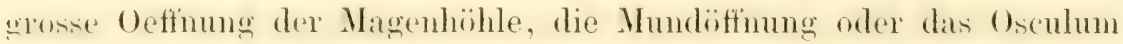
ist ein einfaches kreisrundes Loch von $2-3^{\mathrm{mm}}$ Durchmesser.

Das Skelet der Sycaltis glacialis besteht nur aus drei- und rierstrahligen Kalknadeln. Einfache Nadeln sind nicht vorhanden. Die Wreistrahler sind sämmtlich patrschenkelig und paarwinkelig, inden der eine Schenkel grösser als die beiden andern und ebenso der ersterm gegenüberliegende Winkel grösser als die beiden andern ist. Die äussere (dermale) Oberfläche ist von einer einfachen Schicht solcher Dreistrahler bededt, deren lïngerer Schenkel parallel der Lüngisaxe des Körpers nach abwärts gegen dessen Basis gerichtet ist. Das Gerüst der Radial-Tuben wird durch zwei Schichten von Dreistrahler'n gebildet. Der längere Strahl der äussern Schicht ist radial nach innen, der längere Strahl der innern Schicht ist radial nach aussen gerichtet. Die beiden kiirzern Strahlen der äussern Schicht liegen unter der äussern (dermalen) Fläche. Die beiden kürzern Strahlen der imern Schicht liegen unter der immern (gastralen) Flïche. Die letatere selbst ist mit einer Schicht ron Vierstrahlern belegt. Drei Strahlen jedes Vierstrahlers liegen in der Nagenfläche und der längere von diesen drei Strahlen ist parallel der Lüngsaxe des Körpers nach abwärts gerichtet. Der vierte Strahl ist stark gekrummt und springt frei in die Magenhöhle vor.

Hatisarca Dujardinii Johnst., welche Pansch bei Ostgrönland sammelte, gleicht den bei Norwegen vorkommenden Formen und ist in keiner Beziehung verschieden. 
15.

\section{Das unsichtbar wirkende Leben der Nordpolarzone}

am Lande und in den Meerestiefgründen bei 300 mal verstärkter Sehkraft, nach Materialien der Germania erläutert

voll

C. G. Ehrenberg in Berlin.

Nit vier Tafeln in Kupferstich.

Die Lebensbilder eines, dem natürlichen Auge gar nicht zugänglichen, terrestrischen und unterseeischen, erst $300 \mathrm{mal}$ zu vergrössernden Naturverhältnisses möchte wol noch lange Zeit hindurch das allgemeine Interesse wenig bewegen. Selbst die, welche an der grossen sichtbaren schönen Natur lebhaften Antheil nehmen, sich in derselben zu erholen, zu erfreuen und geistig zu erheben vermögen, ermüden schmell bei mikroskopischen Bildern, und es wird noch manche frische Kraft zum Anbahmen fester Wertheindrücke verwendet werden müssen. Die 300 mal verstärkte Sehkraft, bei welcher ein fünf Fuss hoher Mensch 1500 Fuss gross erscheint, ist bei weitem nicht die grösste schon jetzt erreichbare Verstärkung des Gesichtssinnes, welche bis auf mehrere 1000 mal im Durchmesser anwendbar ist; allein die 300 malige ist diejenige Vergrösserung, bei welcher reichere, unter sich vergleichbare Einzelheiten und auch noch ihre Organisation in Lebersicht zu bringen und in mässigem Raume abzubilden sind. So ist denn diese angewendete kleinere Vergrösserung nur eine nothwendige Finthaltsamkeit der weit grösseren zu Gebote stehenden, aher nur für Einzelheiten nutzbaren Kraft.

Hiernächst möge noch eine andere kurze Betrachtung einleitend 
sich anreihen, welche die Berechtigung vor Augen stellt, aus den so kleinen unsichtharen Verhältnissen auf grössere zu schliessen, deren gesichertes Dasein muleugbar von so grossem Einfluss ist, dass die so gewomnenen Anschaumgen grosser 'Theilnahne werth sind.

Wie sich aus den feinen Wassertheilchen der Nebel und Wolken unscheinbare, aber höchst einflussreiche belebende 'Tropten als liegen und Schnee, aus diesen aber sich Bäche, Ströne und Seen gestalten, so ist anch der unscheinbare, oft laistige Luftstaub, die Wassertriibung und der Schlamm der Flüsse die Veranlassung des herrlichsten Naturlebens mit all seinem, die Existenz der Völker bedingenden Ackerhumus und den reichen Culturlindern der Flussdeltas, unter denen das alte Aegypten eine so hohe Stelle eimahm. Diese Humusdeltas der Flussmiundungen bedecken oft in ansehnlicher messbatrer Mächtionkeit den Fand der Meereskïste mul bilden mit ähnlichen Hummiagen die terrestrischen Oberflichen aller Länder bis zur Polarzone.

Noch viel wichtiger ist der Meeresschlamm der Tiefgriunde. Freilich ist die geringe mit dem 'Talgloth, mit der Federspule oder' auch mit dem schleppnetz heraufgezogene Menge unbedentend und der Lnvorsichtige mag es oft Schmuz oder Abfall nennen, selbst wenn einige Muscheln oder Seeigel mit hervorgehoben sind. Hierzu kommt, dass

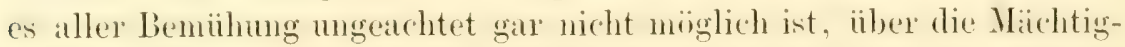
keit des Meeresgrundes direct Aufschluss zu erhalten, so etwa wie am Delta der Flïsse die Mächtigkeit ihrer Dammerde oft stark in die Augen faillt. Im Meeresgrunde bleiben die Senkapparate schon in fusstiefem Schlamme stecken und, sind sie nicht nach Brooke's Methode ablösbar, so reisst gewöhulich die Sehnur heim Herautziehern. ()) der beribhte selhlammige Tieforund 1 Fuss, 10 Fuss oder 1000 Fuss mächtig ist, lïsst sich niemals, auch mit dem Schleppapparat nicht, bestimmen.

Da tritt nun eine andere Betrachtung in ihr Gewicht ein. Eine aufimerksame geologische Beobachtung der (Obertlichen der Frole hat lïngst erkennen lassen, dass ganze grosse Länderstrecken und hohe Berge, besonders auch in ihren Abstiirzen und Schluchten, sich durch ihre gan\%e Mächtigkeit als chemaliger Meeroboden zu erkennen geben. welchen vulkanische Kräfte seit alter Zeit iiber das Meer gehoben haben und der mit Meeresorganismen reich erfullt ist, ja ganz aus ihnen besteht. Ein solches Meeresproduct ist die Schreibkreide der Secundärzeit und die Polythalamien- und Nummulitenkalke der 'Tertiäzeit. Beide sind angenscheinlich als alter Meeresboden oft ganz aus feinsten Meeresorganismen und seltener cingestreuten grössern

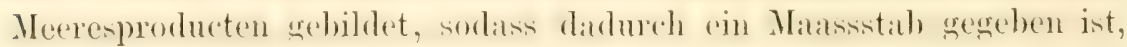


dass der schlammige Meeresgrund zuweilen sicher und öfter wahrscheinlich die Maichtigkeit der Schreibkreide haben muisse. Diese Mächtigkeit beträgt aber $800-1000$ Fuss.

So mögen dem die gehobenen T'iefgrundproben nicht selten die obern Schichten von 1000 Fuss mächtigen Schlammablagerungen sein, welche zwar, der Kreide gleich, fast ganz aus unsichtbaren feinen Lebensformen bestehen, die aber wegen ihrer reichen Mischung mit kieselschatigen Bacillarieen nicht der Kreidebildung zugeschrieben werden kömen, sondern als nenere Mergelschichten den Nummulitenkalken der 'Tertiürzeit näher stehen und jedenfalls der neuesten Bildungsperiode angehören müssen. Nächtige Schreibkreiden bilden übrigens den boden der am meisten gesegneten Länder civilisirter Nationen in England, Frankreich, Deutschland, Russland und am ausgedehntesten am Mississippi in Nordamerila.

Die im Jahre 1854 gegebenen Lebensbilder dieser Art in der Vikrogeologie entbehrten noch der Darstellungen aus der Polarzone, welche jetat erst durch diese deutschen Polarfahrten in reichem Maassstabe zur Anschaumug gelangen.

\section{Erste Deutsche Polarfahrt 1867.}

Als sich im Jahre 1867 die erste Deutsche Nordpolexpedition unter Kapitiin Koldewey mit dem Segelschiff Germania zu wissenschaftlichen Zwecken vorbereitete, fand ich mich veranlasst, demselben einige meiner wissenschaftlichen Wünsche zu gelegentlicher Berïcksichtigung zu empfehlen. Es schien damals nicht nöthig auf den räthselhaften Reichthum des Eismeeres an grossen und werthvollen Thieren, die kein Schiffer unbeachtet lassen kann, aufmerksam zu machen. Wohl aber erschien es mancher Miihe werth, auf die verborgenen Grïnde die Aufmerksamkeit zu lenken, welche einen solchen Reichthum an grossen Lebensformen, scheinbar ohne alle Mittel zu ihrer Ernährung, daselbst möglich machten. Es war dies um so wichtiger, je mehr ein ausgezeichneter englischer Naturforscher, Edw. Forbes, 14 Jahre früher als Resultat seiner grossen und sehr verdicnten Bemïhumgen im Mittelländischen Meere die Abnahme der zu’ Nahrung grösserer Thiere dienenden kleinen Thiere und Pflanzen nach der Tiefe hin festgestellt zu haben glaubte, und iiber die von ihm angezeigte Grenze hinaus nur todten kalkigen, scheinbar der Kreide ähnlichen Schlamm angezeigt hatte. Da dieser geniale Naturforscher mich unaufgefordert mit Zusendung der von ihm gehobenen 
Tiefgrundproben erfeut hatte, so komnte im Jahre 1854 die Mitheilung von mir gemacht werden, dass jene anscheinend todten Tiefgrundproben noch reich an lebensfïhigen, jedenfalls mikroskopischen Gestaltungen seien.

Später hatten die Ĺntersuchungen zu unterseeischen Telegraphenlinien im Atlantischen Ocean, besonders iiber Island bis zur Davisstrasse und an andern oceanischen Punkten immer mehr die Vorstellung hefestigt, datss die obere Schicht des Tiefgrundes der Meere keine todte, sondern eine lebende sei. War dies num auch in der Polarzone festzustellen, so komnte es nicht an Nahrung selbst für zalhllosse Robben und Walfische fehlen, indem das mikroskopische Leben der Tiefgründe der Brut der Fische, und die zahllosen kleinen I"ische und kleinen Krebse und Mollusken immer grössern Thieren zu vollstïndig ausreichender und überreicher Nahrung dienen mussten.

Diese Naturansichten waren von mir in einer akademischen Instruction für das preussische Kriegsschiff Nymphe im Jahre 1865 zusammengestellt worden, und der die Lebensformen betreffende Theil dieser Instruction wurde im Jahre 1867 in der Berliner geographischen Zeitschrift alogedruckt und dem Schiffe Germania mit Zusätzen zur Verfïigung gestellt. Die noch hier und da auftanchenden, den urweltlichen ähnlichen ()rganismen, sowie das Neereslenchten bis zu den Tiefgrinden, waren der Beachtung empfohlene Gegenstiinde. So sind dem auf der ersten Reise 39 Grundproben von der Germania gehoben worden, welche sämmtlich aus der Polarzone von $73^{\circ} 17^{\prime}$ bis $80^{\circ} 39^{\prime}$ nördl. Br. stammen. Die tiefste Probe ist aus $250 \mathrm{Fa}$ $d e n=1500$ Fuss entnommen. Von diesen 39 Proben sind 22 Schl:mmmproben, die iibrigen 17 bestanden nur aus gröbern steinigen Elementen ohme Schlammanhang. Da diese P'roben mit 'Talgloth gehoben waren, so bedurfte es der lieinigung derselben von dem liett, um sie mikroskopisch im Wasser verwerthbar zu machen, was Herr Professor Rammelsberg durch einen seiner Assistenten des chemischen Laboratoriums der Gewerbeakademie ausfuihren liess.

Zunïchst ging aus diesen Sand- und Schlammproben die für die dortigen Neeresströmungen wichtige 'Thatsache hervor, dass an den 17 Oertlichkeiten des Tiefigrundes ohne Schlamm sich die Anwesenheit von Meeresströmungen scharf erkennen liess, welche von dem groben Sande allen feinen Mulm wergefegt habe, der sich nothwendig sonst aus dem obern Meere abgelagert haben müsste. Auch liess sich durch die (irösse der groben Kalk- und Kieselsandtheile nachweisbar finden, dass die dortige Grundströmung überall nur eine mässig beschleuniste sein kam, dex diese gröbern Rollsteinchen noch 
zu widerstehen vermögen. Andererseits beweisen die 22 gehobenen Schlammproben, diss an all diesen Oertlichkeiten eine Grundströmung des Meeres nicht existire, weil anch jede schwache fortgesetzte Bewegung des Wassers die gehobenen feinen Schlammtheilchen fortgefegt haben wiirde.

Die 39 zur Untersuchung gelangten Proben geben nach der wachsenden geographischen Breite geordnet folgende Uebersicht:

\begin{tabular}{|c|c|c|c|c|c|c|}
\hline $\begin{array}{l}\text { Laufende } \\
\text { Nummer. }\end{array}$ & $\begin{array}{l}\text { Datum de } \\
\text { Lothung. }\end{array}$ & & Schiftsbreite. & Schiffslänge. & & efe. \\
\hline 24 & August & 5 & $73^{\circ} 23^{\prime} \mathrm{N}$ & $17^{\circ} 22^{\prime} \mathrm{V}$ & 140 & Faden. \\
\hline 23 & & 3 & $73^{\circ} 17^{\prime}$ & $17^{\circ} 40^{\prime}$ & 250 & n \\
\hline 25 & & 5 & $73^{\circ} 25^{\prime}$ & $17^{\circ} 22^{\prime}$ & 170 & $"$ \\
\hline$* 1$ & Juni & 27 & $75^{\circ} 15^{\prime}$ & $12^{\circ} 30^{\prime}$ & 240 & $n$ \\
\hline$* 19$ & Juli & 6 & $75^{\circ} 20^{\prime}$ & $21^{\circ} 13^{\prime} 0$ & 25 & $"$ \\
\hline 18 & $n$ & 6 & $75^{\circ} 32^{\prime}$ & $22^{\circ} 26^{\prime}$ & 31 & ) \\
\hline 21 & ” & 7 & $75^{\circ} 33^{\prime}$ & $19^{\circ} 2^{\prime}$ & 45 & $"$ \\
\hline 17 & » & 6 & $75^{\circ} 38^{\prime}$ & $23^{\circ} 24^{\prime}$ & 30 & 11 \\
\hline 20 & ” & 7 & $75^{\circ} 39^{\prime}$ & $19^{\circ} 48^{\prime}$ & 40 & $"$ \\
\hline$* 14$ & " & $\tilde{5}$ & $75^{\circ} 40^{\prime} \prime$ & $22^{\circ} 59^{\prime} \prime$ & 30 & $n$ \\
\hline$* 13$ & " & 5 & $75^{\circ} 42^{\prime}$ & $22^{\circ} 29^{\prime}$ & 26 & $n$ \\
\hline$* 12$ & " & 5 & $\left.75^{\circ} 43^{\prime}\right)$ & $21^{\circ} 59^{\prime}$ & 25 & $"$ \\
\hline 2 & Juni & 27 & $75^{\circ} 44^{\prime} \prime \prime$ & $12^{\circ} 11^{\prime} \mathrm{W}$. & 135 & $"$ \\
\hline$* 15$ & Juli & 5 & $75^{\circ} 45^{\prime}$ & $22^{\circ} 57^{\prime} 0$. & 25 & $"$ \\
\hline 16 & $"$ & 5 & $75^{\circ} 45^{\prime}$ & $23^{\circ} 24^{\prime}$ » & 45 & " \\
\hline$* 11$ & ” & 5 & $75^{\circ} 46^{\prime}$ & $21^{\circ} 34^{\prime} \prime$ & 22 & " \\
\hline$* 10$ & $"$ & 5 & $75^{\circ} 48^{\prime} \prime$ & $21^{\circ} 9^{\prime} \prime$ & 21 & " \\
\hline$\% 9$ & ” & 5 & $7 j^{\circ} 51^{\prime} \prime$ & $20^{\circ} 25^{\prime}$ & 22 & $"$ \\
\hline 3 & Juni & 27 & $75^{\circ} 52^{\prime}$ & $12^{\circ} 11^{\prime} \mathrm{WV}$ & 150 & ” \\
\hline * 8 & Juli & 4 & $75^{\circ} 58^{\prime}$ & $20^{\circ} 14^{\prime} 0$ & 23 & ” \\
\hline$* 7$ & $n$ & 4 & $75^{\circ} 59^{\prime}$ & $18^{\circ} 55^{\prime}$ & 30 & ” \\
\hline 5 & $"$ & 4 & $76^{\circ} \quad 3^{\prime} »$ & $19^{\circ} 47^{\prime} \prime \prime$ & 85 & ” \\
\hline * 6 & " & 4 & $76^{\circ} \quad 3^{\prime} 川$ & $19^{\circ} 47^{\prime} \Rightarrow$ & 50 & " \\
\hline 4 & " & 3 & $76^{\circ} 36^{\prime}$ & $15^{\circ} 52^{\prime}$ & 300 & $n$ \\
\hline$* 22$ & $"$ & 12 & $77^{\circ} 21^{\prime} \prime$ & $14^{\circ} \quad 4^{\prime}$ & 35 & $"$ \\
\hline$* 26$ & August & 17 & $79^{\circ} 11^{\prime} \prime$ & $10^{\circ} \quad 6^{\prime} n$ & 11 & ” \\
\hline 34 & $"$ & 30 & $79^{\circ} 19^{\prime}$ & $20^{\circ} 52^{\prime} \prime \prime$ & 36 & $\eta$ \\
\hline 35 & 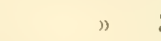 & 30 & $79^{\circ} 19^{\prime}$ & $21^{\circ} 0^{\prime}$ & 31 & $n$ \\
\hline 36 & " & 30 & $79^{\circ} 19^{\prime}$ & $21^{\circ} \quad 6^{\prime}$ & 28 & $"$ \\
\hline$* 27$ & $"$ & 17 & $79^{\circ} 44^{\prime}$ & $10^{\circ} 22^{\prime}$ & 32 & $"$ \\
\hline$* 28$ & $"$ & 17 & $79^{\circ} 52^{\prime}$ & $11^{\circ} 8^{\prime}$ & 7 & $"$ \\
\hline 29 & $"$ & 17 & $79^{\circ} 58^{\prime}$ & $11^{\circ} 46^{\prime}$ & 33 & $»$ \\
\hline 30 & $"$ & 18 & $79^{\circ} 59^{\prime} \quad$ & $11^{\circ} 52^{\prime}$ & 28 & ” \\
\hline 32 & $"$ & 18 & $80^{\circ} \quad 0^{\prime}$ & $13^{\circ} 53^{\prime}$ & 80 & $"$ \\
\hline$* 33$ & $"$ & 18 & $80^{\circ} \quad 0^{\prime} \quad "$ & $14^{\circ} 8^{\prime}$ & 44 & $"$ \\
\hline 31 & $"$ & 18 & $80^{\circ} \quad 0^{\prime} \quad$ & $13^{\circ} 2^{\prime} \prime$ & 80 & $"$ \\
\hline 39 & September & 14 & $80^{\circ} 16^{\prime}$ & $13^{\circ} 37^{\prime}$ & 95 & $"$ \\
\hline 37 & " & 13 & $80^{\circ} 21^{\prime}$ & $15^{\circ} 33^{\prime}$ & 52 & $n$ \\
\hline 38 & $"$ & 13 & $80^{\circ} 39^{\prime}$ & $16^{\circ} 57^{\prime}$ & 55 & $"$ \\
\hline
\end{tabular}


Die vor der Zahlenreihe stehenden : bezeichnen die Oerthichkeiten. welche subberes Geröl ohne f'iefgrundproben ergaben, mithin eine tiete Meeresströmung anzeigen.

Die simmtlichen, 1 ur 21, untersuchten Schlammproben des Meeresgrmudes sind in der Art mikroskopisch gepriilt worden, dass von jeder derselben meist 5 , zuweilen aber 10 Analysen von his $1 / 3$ Kubikline grossen Theilchen bei 300 maliger Linearvergrösserung geprift worden sind. Als Resultat ergab sich zwat nicht ein reines organisches Massenverhältniss, aber doch iberall eine reichliche Mischung in einen morganischen foinen Mulm eingestrenter organischer Formen, (j) Arten, nämlich 21 kieselschatige I'olygaster'n, 15 kalkschatlige Polythalamien, 2 kieselschatige Polycystinen, 19 kieselerdige P'hytolitharien, sammtlich Spongolithe, 2 kieselerdige Geolithien, 5 kalkerdige Zoolitharien und 1 weicher P'lanzentheil. Mls IItuptmasse traten l'olythalamien und śpongolithe hervor, mit nul vereinzelter vingestreuten Polygastern.

Wem man anch aus dem Vorherrschen und allseitigen Vorkommen der Spongolithe zu schliessen berechtigt ist, dass in diesem Theil des Polarmeeres die kieselskelethaltigen Spongien eine grosse Entwickelung haben, so ist doch andererseits die Uebereinstimmung del' meisten erkannten lormen mit den iiberall seln verbreiteten aller Meere auffallig. Demnoch gibt es aber unter diesen Formen einige, welche auf das Vorhandensein bisher mbekannter Schwammarten schliessen lassen: Spongotithis bifrons, Spongotithis Pulsabulum 3. und Spongotithis Clavus 3. b. In den noch etwas speciellern, hier nicht zu wiederholenden Nachrichten in den Monatsberichten der Berliner Akatdemie, 1868 , S. 255, ist daraut hingewiesen, dass nux wenige Schwammformen aus dem Polarmeere durch Limné-Gmélin bekannt waren, Professor Lovèn aber bereits generisch eigenthïmliche Gestaltungen 1868 verzeichnet hat, welche durch Oskar Schmidt 1869 aus den Sammlungen der Germania vermehrt worden sind. Die Lithospharen scheinen der Gattung Geodia der Schwämme anzugehören, welche rou dort noch nicht verzeichnet war. Einige weitere Bemerkungen über die Formenmischungen werden sich bei der tabellarischen Erläuterung der Gesammtmasse in Uebersicht bringen lassen, sodass das in den Monatsberichten der Berliner Akademie von 1869 nach den einzelnen Oertlichkeiten und 'liefen gegebene Verzeichniss der $67 \mathrm{For}$ men dieser ersten Beobachtungsreihe hier zu wiederholen nicht nöthig scheint.

Die grosse Schwierigkeit der mikroskopischen Untersuchung der damals gehobenen Grundproben, welche durch die 'Talgmischung ver- 
anlasst war, weshall, bei der lieinigung viele der interessanten Formen verloren gegangen sein mögen, liess es unrathsam exscheinen mehr als es geschehen, diese Analysen anszudehnen, und die gewonnenen nembaren Formon waren ein schon erfreuliches Ergebniss fiir die Kemntniss der dortigen Naturverhälnisse. Die dimals in den 17 Oertlichkeiten beobachteten Formen sind folgende:

$$
\text { Polygasterin } 21 .
$$

Cocconeis lineuter.

stricete.

Coscinodisens limbatus.

Fragilurie ?

Pimnelevia esperula.

subtilis.

Discoplea levis.

$$
\text { paradoxa. }
$$
junctute.

Dictyocher boreatis.

Diploneis Apis.

$$
\text { glacialis. }
$$

Einotic amplioxys.

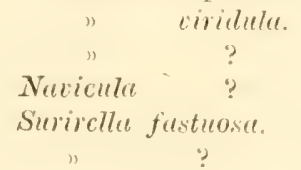

Synceree Utue.

\section{Polythatamien 1 (i).}

Aristerospira adspersel 11. sp. borcalis $11 . \mathrm{sp}$. corticosa 11. su.

Calcurine puradoxa $11 . \mathrm{sp}$.

Dexiopora boreatis 11. sp.

Thegullayse dilatate

Nodosaria bulenarum.

Nonionina Koldeweyi $=$ Dexiospira borealis 1869.

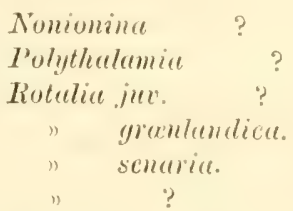

Strophoconus

Textilaria ?

$$
\text { Polycystinen 2. }
$$

Halionma usinem 11. sp. Haliomma radiatum.

\section{Zoolitharien 5.}
Coniodendron dmphidiscus.
Coniasterias Triecros.
Coniadictyzun tubulosum.
Coniorltaphis culcuratu.
1) microporum.

Phytolitharien 19.

Amplitiscus anceps.

Spongolithis acicularis.

aspere.

"var. inflexu.

amblyogongyla.

bifrons n. sp.

calcarata.

canalicularis.

Coput Serpentis.

cenocephala.
Spongolithis Clavus.

Filutis. cfir. Monile

Nais.

P'ulsabulum.

Triceros.

uncinate.

Lithosphera globosa. 


\section{Geolithien 2.}

Dictyolithis megapora.

Dictyotithis micropora.

Weiche Pflanzentheile 1.

Fin weicher Pflanzentheil.

Ausserdem hat das terrestrische kleinste Leben der Insel Spitzberwendurh dieselhe arste deutsche Politufhrt wesentliche Bereicherung erhalten.

\section{Das terrestrische kleinste Leben der Insel Spitzbergen.}

Es war zwar schon in Jahre 1841 durch einen meiner Jugendfreunde, dem ausgezeichneten Reisenden Dr. Thienemann eine Tiefgrundprobe aus der Nahe von Spitzbergen zu meiner Analyse gelangt und in den Abhandlungen der Berliner Akademie der Wissenschaften, 1841, S. 364 mit 9 Formenarten ron zum grössten Theil Meeresorganismen erlïutert worden, allein von der Oberfläche der Insel selbst waren noch keine Kenntnisse zu erlangen gewesen, und die cinzelnen damals mitgehobenen scheinbaren süsswasserformen mögen zи den brakischen, von der Insel alogeschwemmten Gestaltungen gehören.

Durch die von der ersten Expedition herbeigebrachten Moose und monsartigen Pflanzen wurden durch Lebergiessen mit destillirtem und abgekochtem Wasser im Jahre 1869 noch 19 Arten hinzugefüigt, nümlich 14 Polygastern, 2 Nematoiden, 1 ausgebildetes Riiderthier und ein Ei eines andern, sowie ein Acaroid. Da von den 1841 verzeichneten Meeresschlammformen nur Spongolithis acicularis und SyneAru Ulna zu den Süsswasserverhältnissen der Insel gehören könnten, so ist die bekamnte Formenzahl der terrestrischen Oberflächenelemente von Spitzbergen auf 21 gestiegen. Die besondere Methode der Auffindung ist anstithlich in den Monatsherichten der Berliner Akademie der Wissenschaften, 1869, S. 259, geschildert und schliesst sich an die Möglichkeit an, dass in hygroskopischen Substanzen eingehïllte kloinste Lebensformen sich nath sehr langer Zeit durch Befenchten mit Wasser in ein thätiges Leben bis zur Fortpthanzung zuriickführen lassen.

Die aus den Moosen von Spitzbergen in Berlin zu neuer Lebensthätigkeit erweckten Formen waren folgende:

$$
\text { Polygastern. }
$$

Kolpoda cucullus.

Oxytricha pellionella.

Stylonychia pustulate.

Trichodina tentaculata.

Labende Nematoiden.
Anguillute longicaude.

Anguillula brevicuuda. 
Rotatorien.

Callidina atpium.

Ei eines Räderthieres.

Ausserdem fanden sich als leere Schalen dabei:

Difflugia areolata.

Eunotia amphioxys.

Fragilaria striata.

Pinmularia affinis.
Pimmlaria boreatis.

Stanroneis, und cin Acaroid.

Die Diffugiu microstoma genannte Form wird jetzt übergangen, weil sich das zu controlirende Präparat nicht wieder auffinden liess.

Hierzu kommen die 1841 aus dem Meere gehobenen zwei, möglicherweise terrestrischen Formen: Symedra Uma und Spongolithis acimelaris.

\section{Zweite Deutsche Nordpolfahrt 1869 und $18 \%$.}

Auf dieser zweiten Expedition sind ron Kapitän Koldewey mit Vermeidung der Talghothe bt Tieformolproben ansgefïhnt worden, ans Tiefen bis zu 1319 Faden $=7914$ Fuss und überdies sind 26 terrestrische Oberflächenverhïltnisse in Form von Erden und Schlamm gesammelt worden, zusammen 90 Proben. Diese sämmtlichen Materialien sind in Cylindergläsern sauber verpackt an mich gelangt. Das reiche Material hat sich nicht ganz bewältigen lassen, vielmehr musste eine Auswahl des am meisten interessant erscheinenden getroffen werden. Diese Auswahl betrifft 17 Tiefgründe und 11 terrestrische Proben, zusammen 28 Localitäten.

Die 17 analysirten Tiefgrundproben sind aus folgenden Oertlichkeiten:

\begin{tabular}{|c|c|c|c|c|c|}
\hline $\begin{array}{l}\text { Nr. des } \\
\text { Glases. }\end{array}$ & Datum. & Breite. & Länge. & $\begin{array}{l}\text { Tiefe in } \\
\text { Faden. }\end{array}$ & Bemerkungen. \\
\hline 4 & Juli 4 & $63^{\circ} 40^{\prime} \mathrm{N}$ & $5^{\circ} 28^{\prime} 0$ & 569 & Schlick. \\
\hline 5 & ") 26 & $73^{\circ} 16^{\prime} \prime$ & $15^{\circ} 48^{\prime} \mathrm{WV}$ & 1300 & Schlick. \\
\hline 8 & Aug. 1 & $74^{\circ} 11^{\prime}$ & $15^{\circ} 19^{\prime}$ & 224 & Schlick. \\
\hline 14 & $\Rightarrow \quad 5$ & $74^{\circ} 30^{\prime}$ & $18^{\circ} 22^{\prime}$ & 90 & Schlick. \\
\hline 15 & 5 & $74^{\circ} 33^{\prime} »$ & $18^{\circ} 39^{\prime} \%$ & 90 & Schlick. \\
\hline 17 & ) 12 & $\left.75^{\circ} 17^{\prime}\right)$ & $17^{\circ} 22^{\prime}$ & 210 & Schlick. \\
\hline 29 & Juli 22 & $74^{\circ} 34^{\prime}$ & $18^{\circ} 33^{\prime \prime \prime \prime}$ & 78 & Schlick. \\
\hline 30 & - & $\left.74^{\circ} 36^{\prime}\right)$ & $18^{\circ} 30^{\prime}$ & 54 & Schlamm. \\
\hline 33 & " 24 & $74^{\circ} 44^{\prime}$ & $18^{\circ} 6^{\prime}$ & 95 & Bräunlicher Schlick. \\
\hline 42 & » 27 & $\left.75^{\circ} 28^{\prime}\right)$ & $18^{\circ} 1^{\prime}$ & 252 & Schlick. \\
\hline 52 & Aug. 1 & $74^{\circ} 29^{\prime}$ & $18^{\circ} 52^{\prime}$ & 78 & Hamkes-Bay. \\
\hline 55 & ") 1 & $74^{\circ} 15^{\prime}$ & $19^{\circ} 24^{\prime}$ & 13 & Dinkler Schlick. Gale- \\
\hline 57 & 1 & $74^{\circ} 7$, & $19^{\circ} 43^{\prime}$ & 178 & Schlamm. \\
\hline $\left.\begin{array}{l}24 \\
25\end{array}\right\}$ & 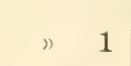 & \multicolumn{2}{|c|}{ Sabine-Insel. } & 3 & $\left\{\begin{array}{l}\text { Schlamm, südl. vom Glet- } \\
\text { scherbach. }\end{array}\right.$ \\
\hline 91 & 1) 25 & $71^{-37^{\prime} \mathrm{N}}$ & $12,23^{\prime} \mathrm{W}$ & 1257 & Schlanım. \\
\hline 92 & "28 & $71^{\circ} 19^{\prime}$ & $11^{\circ} 28^{\prime} \prime \prime$ & 1319 & Schlamm. \\
\hline
\end{tabular}


Diese såmmtlichen 17 untersuchten Oertlichkeiten, mit Ausschluss der ersten aus $63^{\circ} 40^{\prime}$ nördl. Br., lieger innerhalh der Polarzone, und es ist besonders das grössere 'T'iefenverhältniss, welches dic specielle Analyse dieser letztern gleichzeitig reranlasst hat. Die höchste nördliche Breite ist erréicht worden im 77. Grade und die nördlichste hier analysirte Probe ist ans $75^{\circ} 28^{\prime}$ nördl. Br. Die hier mitzutheilenden Analysen schliessen sich unmittelbar an jene der Tiefgründe der Darisstrasse an. welche im Jahre 1861 der Akademie der Wissenschaften zu Berlin rorgetragen worden sind (rgl. Monatsbericht) und werden im Norden durch die grossen Tiefgriinde begrenzt, welche durch die schwedische Expedition gleichzeitig gemessen und deren Schlammproben weiterer Analyse, wie angezeigt ist, zugänglich gemacht worden sind.

So betrifft demn die ganze doppelte Reihe der Koldewey'schen Grundhebungen das zwischen der Davisstrasse und den Tiefgründen nördlich ron Spitzhergen gelegene unterseeische Hochplateau, dem die charaliteristischern Formen jener grö̈sern Tiefuründe fehlen, dessen specieller Charakter aber durch die zur Anschaumg gekommene Formenzahl zur deutlichen Kenntniss gebracht ist. Die Naterialien, welche in der folgenden Tabelle nach den Tiefon anfgezeichnet sind, ordnen sich nach der geographischen Breite wie folgt:

Nr. 4 ist ein hellgraner feiner Schlamm aus 569 Faden 'Tiefe = 3414 F'uss, in $63^{\circ} 40^{\prime}$ nördl. Br. und $5^{\circ} 28^{\prime}$ östl. L. entnommen. Die mikroskopische Untersuchung von 10 Analysen zeigte einen reichen Gehalt an organischen Formen, vorherrschend Coscinodisci. Es wurden im Ganzen 43 Arten beobachtet, darunter 13 Bacillarieen, 2 Polyeystinen, 15 Spongolithe, 12 Polythalamien und 1 Geolithium. Nen sind: Encyrtidium mutans, Rotalia Hegemami, Rotalia microtis und Strophoconus hyperboreus.

$\mathrm{Nr} .5$ ist ein dunkelgraubrauner feiner Schlamm aus 1300 Faden Tiefe $=7800$ luss, in $73^{\circ} 16^{\prime}$ nördl. Br. und $15^{\circ} 48^{\prime}$ westl. L. entnommen. Die mikroskopische Untersuchung ergab in 10 üblichen Analysen einen feinen Mulm mit einzelnen gröbern theilen und sehr vielen kleinen rotalienartigen Polythalamien, wiihrend nur wenig Polygastern und Spongolithe sich zeigten. Die Gesammtsumme der beobachteten organischen Formen beträgt 26, darunter 7 P'olygastern, 11 Spongolithe und \& Polythalamien. Unter den Polygastern ist Difflugia Baileyi $\beta$ polaris bemerkenswerth. Nen ist Planulina profunda und Insitella? temis.

Nr. 8 ist ein graubraumer feiner Schlamm aus 224 Faden Tiefe $=1344$ l'nss, in $74^{\circ} 11^{\prime}$ nördl. Br. nnd $15{ }^{\circ} 19^{\prime}$ westl. I. entnommen. 
Die mikroskopische Untersuchung von 10 Analysen ergab 7 organische Formen, nämlich 2 Polygastern, 3 Spongolithe und 3 Polythalamien, welche in eine gröbere unorganische Masse nur selten eingestrent sind.

Nr. 14 ist ein grauer zusammengetrockneter gröberer Schlamm aus 90 Faden Tiefe $=540$ Fuss, in $74^{\circ} 20^{\prime}$ nördl. Fr. und $18^{\circ} 22^{\prime}$ westl. L. entnommen. In 10 Analysen fanden sich 11 organische Formen: 1 Polygaster, 9 Spongolithe und 1 Polythalamie. Diesen beiden letatern Grundproben scheinen beim Heraufriehen die feinern Theile abgewaschen worden zu sein.

Nr. 15 ist ein grobsandiger Schlamm aus 90 Faden Tiefe = 540 Fuss, in $74^{\circ} 33^{\prime}$ nördl. Br. und $18^{\circ} 39^{\prime}$ westl. L. entnommen. Die mikroskopische Prïfung ergab in 10 Analysen einen gröbern und feinern Sand mit dazwischen liegenden Spongolithen und Coscinodisken, meist in Fragmenten. Die Gesammtsumme ergab 15 Formen: 6 Polygastern, 7 Phytolitharien, meist Spongolithe, und 2 Polythalamien. Nen waren Stauroptera neptunia und Strophocoms arcticus.

Nr. 17 ist ein grauer, beim Trocknen zusammengeballter grober Schlamm aus 210 Faden 'T'iefe $=1260$ Fuss, in $75^{\circ} 17^{\prime}$ nördl. Br. und $17^{\circ} 22^{\prime}$ westl. L. entnommen. Die mikroskopische P'riifung ergab in fünf Analysen nur, in groben Sand eingemischt, 3 Spongolithe, welche ebenfills nur selten beobachtet wurden.

Nr. 29 ist ein feiner graner Sand -aus 78 Faden $=468$ Fuss Tiefe, in $74^{\circ} 34^{\prime}$ nördl. 13r. und $15^{\circ} 33^{\prime}$ westl. L. entnommen. Die mikroskopische Prüfung von fün Analysen ergab einen unorganischen Sand mit selten eingestreuten organischen Elementen. Es wurden im Ganzen 5 Formen beobachtet: 2 Bacillarieen und 3 Spongolithe.

$\mathrm{Nr} .30$ ist wie die vorgehende Probe ein gröberer graufarbiger Sand, aus 54 Faden $=324$ Fuss Tiefe, in $74^{\circ} 36^{\prime}$ nördl. Br. und $18^{\circ} 30^{\prime}$ westl. L. entnommen. Die mikroskopische Priffung zeigte in fünf Analysen einen gröbern Sand mit seltenen organischen Formen, darunter Pimmlaria aspera als Bacillariee und 2 Spongolithe.

$\mathrm{Nr} .33$ ist eine gelblichgraue zusammengebackene Schlammmasse aus 95 Faden $=570$ Fuss Tiefe, in $74^{\circ} 44^{\prime}$ nördl. Br. und $18^{\circ} 30^{\prime}$ westl. L. Die mikroskopische Prïfung ergab in fünf Analysen in einem gröbern Sande 4 organische selten beobachtete Formen, 2 Bacillarieen, 2 Spongolithe.

Nr.42 ist ein dunkelgrauer Schlamm ans 252 Faden $=1512$ Fuss Tiefe in $75^{\circ} 28^{\prime}$ nördl. Br. und $18^{\circ} 1^{\prime}$ westl. L. Die mikroskopische Prüfung ron fünf Analysen ergab eine gröbere unorganische Masse mit schr geringer organischer Beimischung. Es wurden f) Formen 
beobachtet, 1 Bacillariee, Gallionella gramlete als Fragment und 4 Spongolithe. Kieine Polythalamien, wie in den vorhergehenden Nummern.

Nr. 52 ist ein gröberer graufarbiger, in vereinzelte Klumpen zusammengebackener Schlamm aus 78 Faden $=468$ Fuss Tiefe, in $74^{\circ} 29^{\prime}$ nördl. Br. und $18^{\circ} 52^{\prime}$ westl. L. entnommen. Die mikroskopische Prifung ron 10 Analysen ergab viel groben Sand mit selten eingestreuten Spongolithen und sehr wenig Bacillarieen, ohne Kalktheile. Unter den 5 beobachteten Formen ist eine Bacillariee, die ïbrigen 4 sind Spongolithe. Neu ist die Polygasternform Diplonëis mesolia.

Nr. 55 ist ein dunkelgrauer, am Glase angetrockneter Schlamm, aus 13 Faden $=78$ Fuss Tiefe, in $74^{\circ} 15^{\prime}$ nördl. Br. und $19^{\circ} 24^{\prime}$ westl. L. entnommen. Die mikroskopische Prüfung ron fünf Analysen ergab 11 organische Formen: 10 Bacillarieen und 1 Spongolith.

$\mathrm{Nr} .57$ ist eine sehr kleine Probe einer schlammigen lockern Erile aus 178 Faden $=1068$ Fuss 'Tiefe, in $74^{\circ} 7^{\prime}$ nördl. Br. und $19^{\circ} 43^{\prime}$ westl. L. entnommen. Die mikroskopische Prüfung von fünf Analysen ergab eine unorganische sandige Masse mit nu drei selten eingestreuten Spongolithenformen.

Nr. 24 ist ein dunkelbrauner Schlamm aus 3 Faden $=18$ Fuss Tiefe, in der Nïhe der Sabine-Insel entnommen. I Ie mikroskopische l'ruifung ron 10 Analysen ergably eine reiche Mischung von organischen Formen. Es wurden 26 Arten beobachtet, 23 Bacillaricen und 3 Spongolithe. Keine Polythalmien. Unter den Bacillarieen waren als neue Formen: C'ampylodiscus polaris, Campylodiscus Sabinii, Coscinodiscus? IIterostigma, Fragilaria pelagica, Pimmlaria glarial is und Strintella rectica. Lnter den Spongolithen ist als besondere Form Spongolithis septata $\beta$.

Nr. 25 ist ebenfalls ein dunkelbraumer Schlamm aus 3 Faden Thefe $=18$ Fuss, in der Nähe der Sabine-Insel entnommen. In 10 mikroskopisch geprïten Analyen fanden sich 2!) Formen, nämlich 26 lacillarieen, 2. Spongolithe mol 1 Geolithium; keine Polythalamien. Neue Formen sind unter den Polygastern: Cocconëis granlandica, Craspedodiscus? Discoplen, Pimmelevia glacealis, Strietelle arctice und unter den spongolithen: Sipongolithis septete $\beta$ und Actinolithis Tivactis als Geolithium.

Die aus greringer 'Tiefe in der Nähe der Insel entnommene doppelte Schlammprobe enthïlt unter 40 Formen 36 Bacillarieen, 3. Sponfolithe und 1 (ieolithim. Iie grosse Mehrzahl der Formen schliesst sich an die terrestrischen Batcillarieen an. Entschiedene Mecresgebilde 
sind nur Coscinodiscus? Heterostigma, Coscinodiscus al. sp., Diploneis Apis, Diplonëis didyma, Diplonëis Entomon, Odontodiscus eccentricus, Stauroptera aspera, Striatella arctica, vielleicht Pimmlaria glacialis und Fragilarin pelanicu. Ausserdem vielleicht Spangolithis septatu $\rho$ und Actinolithis Triceros. Der Mangel aller Polythalamien zeigt ebenfalls die mehr dem Süsswasser angehörige Beziehung des Schlammes an.

Nr. 91 ist ein dunkelbramer feiner Schlamm aus 1257 Faden = 7542 Fuss Tiefe, in $71^{\circ} 37^{\prime}$ nördl. Br. und $12^{\circ} 23^{\prime}$ westl. L. entnommen. In 10 mikroskopisch geprüften Analysen fand sich ein sehr feiner Mulm mit häufigen kleinen P'olythalamien, seltener Polygastern und Spongolithe. Unter den 14 beobachteten Formen fand sich 1 Bacillariee als Gallionella gramelate, 1 Polycystine als Hatiomma radiatum (vgl. Microgeologie, 'Taf., 19, Fig. 15), :3 Phytolitharien, darunter 1 Lithostylidium, 2 Spongolithe und 9 Polythalamien. Nene l'olythalamienart war: Aristerospire cuculluris.

$\mathrm{Nr} .92$ ist ein feiner, gelblich grauer Schlamm aus 1319 Faden $=7914$ Fuss Tiefe, in $71^{\circ} 19^{\prime}$ nördl. Br. and $11^{\circ} 28^{\prime}$ westl. L. entnommen. In 10 Analysen finden sich in einer feinen mulmartigen unorganischen Masse sehr viele Coscinodisci, besonder's sehr viele kleinere Formen dieser Gattung, weniger Spongolithe.

Unter den 23 beobachteten Formen fanden sich 12 Polygastern, 3 Polycystinen, 6 Spongolithe und 2 Polythalamien. Unter den Polygastern ist Difflugia Baileyi $\beta$ polaris als Arcelline bemerkenswerth, die übrigen sind Bacillarieen. Solenoplea acicularis als Spongolithenform ist von mir aus der Davisstrasse 1361 zuerst verzeichnet worden (rgl. Monatsberichte der Berliner Akademie, 1861, S. 312).

Wemn diese 17 l'roben des oceanischen T'iefgrundschlammes eine sehr ungleiche Erfüllung mit organischen Elementen zu erkemen geben, so ist daraus der Schluss, als sei der 'Tieformun oft nur wenig mit Leben erfüllt, deshalb nicht gerechtfertigt, weil die gुehobenen Substanzen, welche geringere Reichhaltigkeit zeigen, ans einem gröbern Trümmersande bestehen, welcher einerseits von 'T'iefgrundströmungen beeinffusst sein mag und andererseits beim Limporheben den grössten Theil seiner feinen Bestandtheile verloren haben mag. Die Oertlichkeiten mit feinerm Schlammgrunde und mithin ruhigerm Lagerungsverhältniss gleichen sich an grösserm Reichthum der organischen Elemente. Zu entscheidenden Resultaten solcher Untersuchungen bedarf es bestimmter, auf dieselben gerichteter Vorbereitungen, während es hier genügen mag, doch eine grosse Zahl von Localformen 
errungen zu haben, welche ein neues Bild der Polarzone zur Anschaumng bringen.

Nicht ohne Bemerkung darf es bleiben, dass weder die gehobenen Grundproben dieser ersten Polarreise, noch die der zweiten in den sorgfältig untersuchten Materialien jene zähen weissen Schleimverhältnisse haben entdecken lassen, welche zuerst in England den Namen Bathybius Hreckelii erhalten haben und den man, wie ehemals das schillernde Häutchen auf' dem stagnirenden Watsser für die Quelle der generatio spontanea der ganzen Natur anzusehen sich erlaubte. Auch die übrigen von mir nicht analysirten Tiefgrundproben dieser Polarreisen haben nirgends jene weisen schleimverhältnisise gereigt. welche als zäher Kreideschlamm hier und da dem Senkloth sich angchängt haben mögen.

\section{Terrestrische Oberflächen.}

Aus den von der zweiten Expedition gesammelten Materialien sind in fünf verschiedenen Oertlichkeiten der Gehalt der Oberflächen, des Süsswassers und der Gletscher in einer nicht mansehnlichen Zahl ron Formen bestimmbar geworden. Die Qertlichkeiten liegen sämmtlich grösserntheils in den, ummittelbar die Küisten Grönlands einfassenden Inseln oder auf dem Festlande Grönlands selbst, vom 73. Grade bis $75^{\circ} 30^{\prime}$ nördl. Br. Da sich in sechs untersuchten Erdproben nur Truimmersand erkennen liess, so ist die Aufmerksamkeit auf diejenigen intensiver gelenkt worden, deren Substanzen sich mehr oder weniger reich an Lebensformen zeigten. Haben sich auch öfter in den genamiten Oertlichkeiten die Obertlïchen olne Lebensgehalt argeben. so ist dies nicht so zu rerstehen, als ob derselbe da als fehlend anzusehen sei, vielmehr haben meine Kräfte nicht ausgereicht, mich so intensir mit denselben zu beschäftigen und so viel Zeit darauf zu rerwenden als nöthig gewesen sein mag, den Oberflächen-Trümmersand genau genug zu durchschauen, oder es mag auch beim Einsammeln eine leere Oberflächenschicht aufgenommen sein.

Jedenfalls ist hierbei zu erwähnen, dass nach den Erfahrungen der Schiffer auf dieser Expedition selbst in jenen Küustengegenden so gewaltige Sturmorkane von Zeit zu Zeit auftreten, dass sie mit den in den eivilisirten wärmern Gegenden rorkommenden ganz unvergleichbar erschienen und auch verursachten, dass grosse Ebenen im Winter völlig scheelos waren. Wenn demmach der Truimmersand der Oberflaichen von allem Humus und allen feinern Theilen entblösst gefunden wurde, so erinnert das an die, den Meeresströmungen ausgesetzten oceanischen 'Jiefgrïnde und deren Mangel an Schlamm. Daher 
kann es auch nicht Wunder nehmen, wenn ein feines organisches Leben aus oberflichlich abgenommenen Sandproben nicht zu erkemnen ist. Etwas tiefer greifende P'rüfungen der Erdschichten wären liüntiger Forschung vielleicht zu empfehlen.

Da es hauptsächlich auf ein Verzeichniss ankommt ron dem. was iiberhaupt in jenen Gegenden an Lebensformen existint, und welche Gestaltungen sich dort vorherischend zu erhalten und zu vermehren vermögen, so wird immer dieses erste Verzeichniss eine wesentliche Basis für weitere Forschungen und für eine wissenschaftliche Beurtheilung dieser P'olargegend bleiben. Dar aber die Formenzahl doch auf mehr als 60 gestiegen ist und es sehr wahrscheinlich ist, dass die am häufigsten zu verzeichnen gewesenen Formen iiberhapt die häufigern der terrestrischen Polarzone sein mögen, so ist dem Wursche, ein locales Lebensbild dieser Art zu erlangen, einige Genïge geschehen.

Die fünf Oertlichkeiten werden hier in folgender Reihe nach wachsender Breite rerzeichnet.

Probe 85. Erdprobe rom Gletscher der P'ayer-Spitze, 1200 Fuss hoch, aus $73^{\circ} 10^{\prime}$ nördl. Br.

Es ist eine hellgraue feinsandige Erde, welche mit Siure nicht braust und beim Gliihen unverändert bleibt.

Die mikroskopische Analyse von fünf Präparaten zeigte eine sehr durchsichtige klare Masse aus gröbern Theilchen bestehend, mit vereinzelt eingestreuten Bacillarieen, höchstens vier in einem Sehfeld. Es wurden 13 Arten beobachtet. Dieses hohe Gletscherleben verdient eine besondere Beachtung und schliesst sich an die von mir in der Schweiz bereits gemachten Erfahrungen an.

Probe 59 und 60 von der Jackson-Insel, in $73^{\circ} 50^{\prime}$ nördl. Br. in etwa 700 Fuss Höhe entnommen, zeigt eine lockere gelbsandige Erde, deren mikroskopische Analyse in 10 Präparaten einen iberwiegend unorganischen Sand ergab, welcher mit Salzsïure beriihtht nicht branst und durch Gliihen sich dunkler roth färibt. An selten dazwischen liegenden organischen Formen konnten sechs Arten Polygastern, sämmtlich Bacillarieen, bestimmt werden.

Probe 22 enthïlt Schlamm vom Gletscherbach der Clarering-Insel aus $74^{\circ} 12^{\prime}$ nördl. Br.

Es ist eine graubraune, im trockenen Zustande zusammenhanglose lockere Erde, die im feuchten Zustande schlammartig gewesen, mit fast unfühhlbar feinen Bestandtheilchen beim Reiben zwischen den Fingern. Aus der mikroskopischen Untersuchung ergaben sich in 10 Analysen ein Drittel Kubiklinie grosser Theilehen sechs Poly- 
gasternarteh, welche in einen feinen $\mathrm{Mulm}$ sehr rereinzelt cingestreut waren. Beim Glühen nahm diese Erde eine kaum dunklere, aber mehr ins Röthliche ïbergehende Färbung an, wodurch sich ein schwacher Eisengehalt verrieth. Salzsäure ergab kein Brausen. So erscheint die unorganische Masse als ein thonartiger Mulm.

Probe 50 und 51 ist vom Rande der Westendspitze aus 2000 F'uss Höhe von König Wilhelms-Land, der Kulm-Insel gegeniiber, entnommen, in $75^{\circ}$ nördl. Br.

Es ist ein feiner gelblicher Sand, dessen mikroskopische Analyse in 10 Präparaten vorherrschend gröbern Trümmersand ergab, mit sehr vereinzelt eingestreuten fünf Bacillarieen-Formen, einem (irastheil('hen, Lithostylidium vede, und einem weichen I'flanzentheil, zusammen sieben organische Elemente. Durch Salzsäure erfolgte kein Brausen.

Probe 48 enthält Schlamm rom Shannon-Bach, der nördlichen Spitze der Insel entnommen, in $75^{\circ} 30^{\prime}$ nördl. Br.

Fs ist dies ein feiner, etwas scharf sich anfühlender, zusammenklebender Sand von dunkel graubrauner Farbe. Beim Glïhen wurde die Masse zuerst kohlschwarz, dann heller als zuvor und röthlich, zeigt also ebenfalls leichten Eisengehalt an. Die mikroskopische Untersuchung erwies in 10 Analysen die Substanz reich mit Polygatstern erfiillt, 2 Cryptomonadinen, 24 Bacillarieen und 17 Arcellinen. Unter den Bacillarieen zeichnet sich Himantidium Papilio ebenso in Menge aus, wie die Arcellinen auffällig reichhaltig sind, so dass zuweilen auf einem Sehfelde zwei bis drei liegen. Unter den Arcellinen sind viele nete Arten der Gattung Difflugia.

Da das Himantidium Papilio im Passatstaube, niemals aber bisher in Ebenen gefunden ist, so wird es fraglich, ob das aus Guiana stammende früher verzeichnete nicht auch im Abfluss eines hohen Bergwassers zu denken ist.

An diese terrestrischen Oberflïchenverhältnisse schliesst sich noch ein derartiges oceanisches des Eises an, welches ron den Tiefen abzusondern mir rathsam erscheint.

Kapitän Koldewey fand auf einer schwimmenden Eisscholle eine erdige Ablagerung, deren Probe als grünlicher Schlamm erschien. Die von mir davon gemachte Analyse ergab in 10 Präparaten 11 organische Formen und zwar 10 Polygasternarten, darunter 4 entschiedene Meeresformen und 1 Spongolith. Die mikroskopische Prüfung der Substanz zeigte einen feinen Mulm mit vereinzelt eingestreuten organischen Elementen, deren Mehrzahl aus Coscinodiscus minor in oft sehe kleinen kxemplaren und syongolithis acicularis bestand. Mit

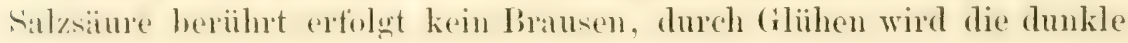


Farbe hell gelbroth. Vielleicht Guano grosser Vögel, die Süsswasserund Seewassergewiirm gefressen haben, wofür auch die grünliche, beim Glïhen zerstörbare Farbe spricht.

Zu den terrestrischen Oberflächenverhältnissen scheint noch eine Reihe von Formen zu gehören, welche bei der Sabine-Insel aus der geringen Mecrestiefe von 18 Fuss mit Schlammgrund gehoben wurden, und die in den Tiefgrundrerhältnissen unter Nr. 24 und 25 speciell verzeichnet worden sind. Diese Tiefgrundproben sind aber ïberwiegend mit organischen Elementen erfuillt, welche den Siisswasserbildungen näher stehen als den Meeresbildungen, und es fehlen derselben Probe die Polythalamien gänzlich, oder sind doch nur sehx schwach vertreten. So würden denn die dort als Grundformen angezeigten Gestaltungen des Sïiswansers zu den Obertlächenbildungen der Sabine-Insel gehören.

Es folgt nun:

\section{Tabellarische Uebersicht der sämmtlichen beobachteten Formen der Nordpolzone.}

Die Gliederung dieser Uebersicht zerfällt in die terrestrischen und oceanischen Lebenselemente. Die oceanischen Tiefgründe der ersten Expedition sind bereits in den Monatsberichten der Berliner Akademie, 1869, ausführlich verzeichnet und werden hier aus ihren 21 Oertlichkeiten in nur einer Columne mit aufgeführt. Die 17 Oertlichkeiten der zweiten Expedition sind nach den wachsenden Tiefen geordnet, um ékennen zu lassen, wie weit ein terrestrischer Einfluss oder ein besonderes Oberflächenverhältniss des Oceans sich auf die Tiefen geltend macht.

Einige auffällige charakteristische Verhältnisse treten in Folgendem hervor:

Die Difflugia Baileyi $\beta$ polaris, welche Bailey aus 16000 Fuss bei Kamtschatka zuerst fand und die in der Davisstrasse in 600?, 9240, 10998 und 12540 Fuss Tiefe 1861 (Monatsbericht der Akademie, S. 280) von mir verzeichnet wurde, ist anch hier nur in der grössten Tiefe von $791 t$ und 7800 Fuss vorgekommen. Nirgends in allen Oertlichkeiten ist ein Vorherrschen polythalamischer Gestaltungen, wie es im Kreidegebirge vorliegt, zum Vorschein gekommen, obschon hier und da zahlreiche Polythalamien nicht nur an Arten, sondern auch an Individuen bemerkbar geworden sind. Das Aufbrausen des Grundschlammes beim Zutritt von Säure ist offenbar iiberall durch solche eingestreute Polythalamien bedingt, während niemals zahlreiche kubische oder rhombische Kalkkrystalle gesehen wurden. 
Ferner sind aus allen Tiefen und Oertlichkeiten Spongolithe zum Vorschein gekommen, wihrend die terrestrischen Lithostylidien und :ihnliche Pliytolitharien als Grastheile meist ganz fehlen. Einige besondere Spongolithe denten auf in den 'T'iefen lebende, aber bisher nur in Fragmenten erkennbare Schwammbildungen hin. Solche Schwammbildungen können auch nicht von der örtlichen Oberfläche des Meeres zur' 'Tiefe gelangt sein, wohl aber' mögen sie in geringern Meerestiefen sich massenhafter entwickeln. Die als Spongolithis uncince und Spongolithis Heteractis rerzeichneten Formen sind von Schneider in sehr ähnlicher Gestaltung, aber ohne Mittelkanal bei Yorwegen aus ciner oceanischen Obertlächenform der Mïller'schen Radiolarien (Physematium) entwickelt worden, und einige der als Geolithien verzeichneten Gestaltungen mögen ebenfalls den zusammengesetzten Polycystinen angehören, welche man als Radiolarien nenerlich bezeichnet hat.

Was die terrestrische Abtheilung anlangt, so wird sie ans den Formen der Oberflächen von Spitzbergen, dem grönländischen Festlande und seinen Inseln gebildet. Sowohl Festlanderden als Schlamm der Süsswasserbäche und der sich auf hohen Gletschern sammehde Staub bilden die zugänglich gewordenen Oberflächen dieser nordischen Festlainder, an welche sich eine einzige Probe von Erden der Oberfliche des oceanischen Eises anschliesst, die aber wegen überwiegender Meerescharaktere in der oceanischen Tabelle rerzeichnet ist. Die gewonnene Gesammtsumme der terrestrischen Formen beträgt 75 Arten. Teriestrische und oceanische Formen zusammen sind hiermit 244 anschaulich geworden, indem in beiden Verzeichnissen nur fünf Formen gleichnamig sind.

Nene Arten sind im Ganzen in beiden Verzeichnissen 55 benannt, darunter 33 Polygastern, 2 Polyeystinen, 14 Polythalamien, 2 Spongolithe, 1 Geolithium, 3 Zoolitharien, deren Diagnosen mit andern zusammengefasst in dem Monatsbericht der Berliner Akademie, 1872, gegeben worden sind.

In der folgenden Tabelle bezeichnen die * das örtliche Vorkommen der einzehnen Formen. 
I.

\section{Verzeichniss der oceanischen Polarformen}

aller 'Tiefgriunde und einer Eisscholle.

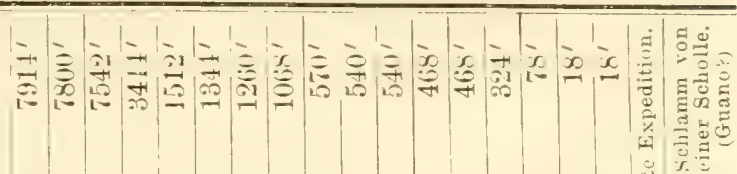

Bezeichnung der Probe. 9259144281757331514522930552425 点

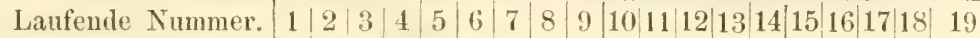

Polygastern \$2.

Actinoptychus senavius...

Amphora angusta.

) libyca

Biblarium Lamina.

Campylodiscus polaris $\mathrm{II}$. sp.

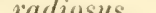

"Sabinii 11. sp.

Cocconëis fimica

gronlandica $1 \mathrm{n}$. sp.

liyperborea

Tineata

Scutellum

striata .....

Cocconema cornutum

cymbiforme

gracile

Leptoceros

Coscinodiscus centralis

eccentricus.

heterostigma n. sp.

isoporus

Timbatus

Tineatus

marginutus

minor .............. $*$ - *

radiatus

radiolatus

subtilis

Craspedodiscus? Discoplea

11. sp. (cfr. Hyalodiscus)

Dictyocha borealis n. sp.

Difflugia Baileyi $\beta$ polaris
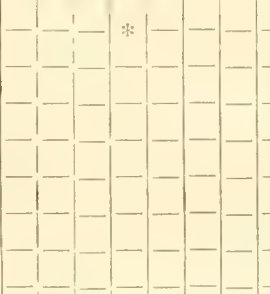


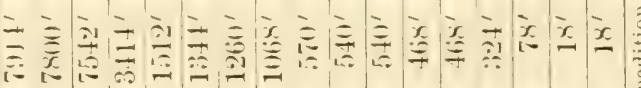

Bezeichnung der Probe. 92 $591+4281757331514522930552425$

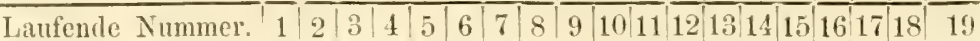

Diplonëis Apis

\section{didyma.}

Entomon

glacialis

mesolia n. sp.

Discopleu levis 11 . sp.

p)aradoxa 11. spe.

Eunotia ampliox

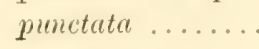

Fragilaria pelagica n. sp.

acute .............

pinnate

Rhubdosoma

Gallionella distans.

gremulata...

nummuloirles

, sulcata

Grammatophora

Insilella? tenuis n. sp.

verticilluta n. sp...

Naricula obtusa

Sigme

Odontodiscus eccentricus

Pinmenaria cqualis

amphyoxis

a.spera

asperula.

glaciatis n. su......

lenceolutu

macilenta.

peregrina.

porrecta

viridula.

Stanoptera aspera

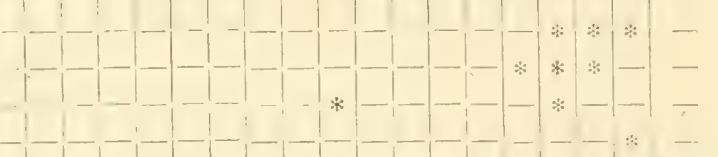




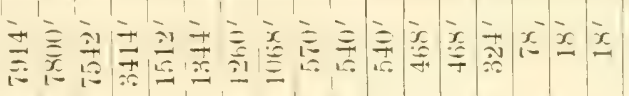

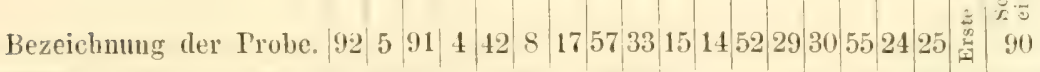

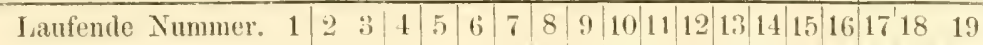

Stephanodiscus lineatus

Striatelle arctica n. sp.

Surirella fastuosa.

Syndendrium tubiferum

spectubitis

Synedra spectubitio

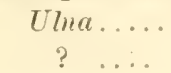

Trachelomonas aspera

Triceratium obtusum

\section{Polyeystimen 6.}

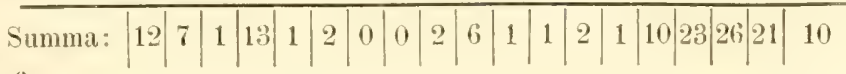

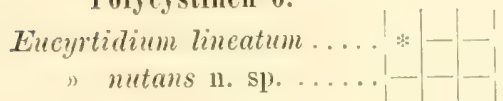

Hatiomma radiatum

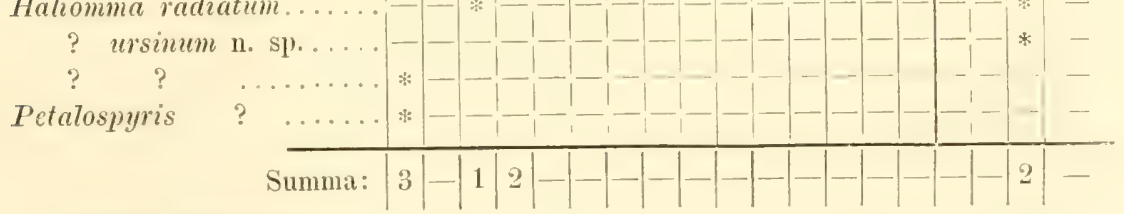

Polythalamien 37.

Summa: $|3|-|1| 2|-|-|-|-|-|-|-|-|-|-|-|-|2|-$

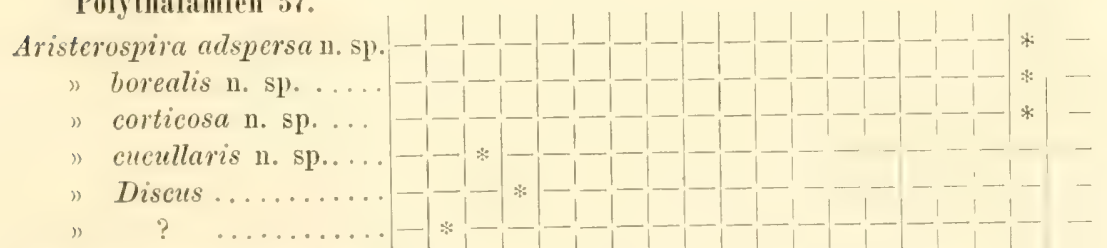

Calcarina paradoxa n. sp.

Dexiopora boreatis $11 . \mathrm{sp}$.

Globigerina Crete.

Megathyra dilatata

"Planularia

Mitiola Ovum

Nodosaria Balenarum 11. sp

Nonionina crystallina.... germanica 


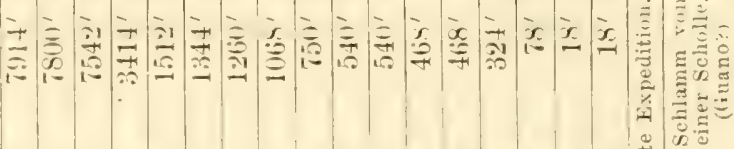

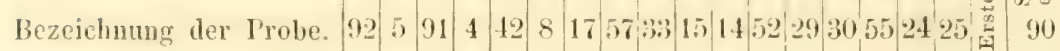

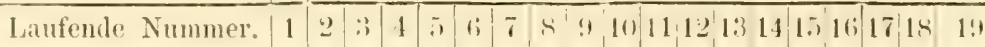

Nonionina hyulina. .

Koldeweyi $=$ Dexio-

spira borealis 186 is

Planulina profunde $11 . \mathrm{sp}$.

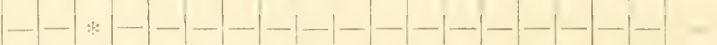

\footnotetext{
$-$
}

Quinqueloculina oblonga

Rolalia aspera

glolumlesal .

"ranlundica $\mathrm{n}$. sp.

Hegemanai $\mathrm{n}$. sp.

Ibex

Microtis $11 . \mathrm{sp}$.

quaternuria

rudis.

semeria

"juv..........

Strophocomes arcticus n. sp.

liyperboreers n. sp).

Textilaria.

Polythalamien-Fragment

l'hytolitharien 35.

Summa: $|2| 8|9| 12|-| 2|-|-|-| 2|1|-|-|-|-|-|15|-$

Ampleidiscus Anceps...

bipileatus.

clavatus.

rerticilletus.

Lithostylidium Clepsummi-

dim .........___

rude ............

Solenoplea acicularis......

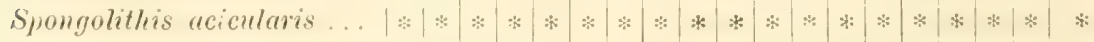

amphioxys....... - * * * -

amblyogong!la ..... 


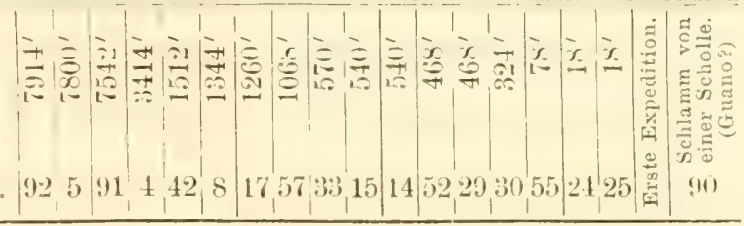

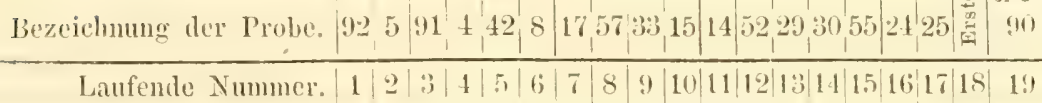

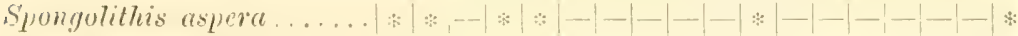

bifrons n. sp.

celcerata.

canalicularis .

Ceput serpentis ...

cenocephale......

Cluvus.

31 , 3

Crmax?

dentuta?

Fustis

Gigas

Hetcractis . .

mesogongylu

Microclëis

cfi. Monite

Nuis.

nodulusen

obtersel....

Prulsabulum

septata?...

Triceros.

meinate.

Lithosplecte globosa

Geolithien 3.

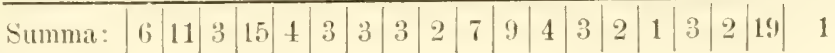

detinotithis Triactis n. sp.

Dictyolithis megapora.

mieropora

Zoolitharien j.

Coniodendron Amphidiscus

Coniodictyum tubulosum...

") microporum...

Coniasterias Triceros

Coniorrhaphis calcarata

Pflanzentheile 1.

Lin weicher Pflanzentheil

Gesammtsumme $169|23| 26|14| 43|5| 7|3| 3|4| 15|11| 5|5| 3|11| 26|29| 65 \mid 11$ 


\section{II.}

\section{Verzeichniss aller terrestrischen Polarformen}

der Landoberflächen und der Siisswässer.

\begin{tabular}{|c|c|c|c|c|c|c|}
\hline Bezeichnung der Probe. & $\begin{array}{c}\text { Clave- } \\
\text { ring- } \\
\text { Insel. } \\
22\end{array}$ & $\begin{array}{c}\text { Shan- } \\
\text { non- } \\
\text { Bach. } \\
48\end{array}$ & $\begin{array}{l}\text { Westend- } \\
\text { spitze } \\
2000^{\prime} \text { hocb. } \\
50 / 51\end{array}$ & $\begin{array}{l}\text { Jackson- } \\
\text { Insel } \\
7100^{\prime} \text { loch. } \\
59 / 60\end{array}$ & $\begin{array}{l}\text { Glet- } \\
\text { scher } \\
1200^{\prime} \\
\text { lroch. } \\
\text { S. }\end{array}$ & $\begin{array}{l}\text { Erste } \\
\text { Exped1- } \\
\text { tion. }\end{array}$ \\
\hline $\begin{array}{l}\text { Polygastern } 68 . \\
\text { Achnanthes }\end{array}$ & & & & & & \\
\hline 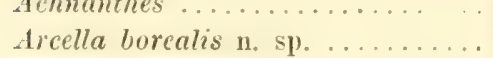 & - & - & - & $\therefore$ & - & - \\
\hline " Disphera . . . . . . & - & * & . & - & & -- \\
\hline "guatimalensis........... & - & $\because$ & - & - & - & - \\
\hline " hyalina... & - & 4 & -- & - & -. & - \\
\hline "laticeps n. sp. ... & - & $:$ & - & - & - & - \\
\hline " Pyrum............... & - & a & - & - & - & $\cdots$ \\
\hline 1) Textile n. sp............ & - & $\therefore$ & - & - & - & - \\
\hline ") $\quad$ ? $\quad \ldots \ldots \ldots \ldots \ldots$ & - & & - & - & - & $*$ \\
\hline Climacidium Monodon ......... & - & $\because$ & - & $\ldots$ & - & - \\
\hline 1) Zygodon .............. & - & $\because$ & - & - & - & -- \\
\hline Difflugia arctica 11. sp.......... & - & $\because$ & 一 & $\ldots$ & - & - \\
\hline " areolate ............... & - & *: & $\ldots$ & - & - & $\because$ \\
\hline " apiculosa $11 . \mathrm{sp}, \ldots . . .$. & - & $\because$ & - & - & & - \\
\hline 1) cellulifera n. sp.......... & - & : & - & - & - & - \\
\hline 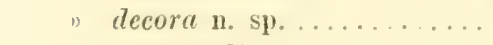 & - & $\therefore$ & - & - & -. & - \\
\hline 1) grontandica n. sp......... & - & $\because$ & - & - & - & - \\
\hline 1. Microstoma $11 . \mathrm{sp} \ldots \ldots .$. & - & $\because$ & - & - & $\ldots$ & - \\
\hline "rectangularis $\beta \ldots \ldots \ldots \ldots$ & - & $\therefore$ & -. & - & 一 & - \\
\hline 1) Shamnoniena 11. sp. ..... & - & $\therefore$ & - & - & -- & - \\
\hline 1) subacuta n. sp. .......... & - & $*$ & 一 & - & -- & - \\
\hline Eunotice amphioxys. ....... & $*$ & -- & - & $*$ & * & $\nLeftarrow$ \\
\hline "Monodon............. & - & -- & * & - & - & - \\
\hline " prarupte ............. & - & $\because$ & - & - & - & - \\
\hline "Zygodon ............. & & $\because$ & $\cdots$ & - & - & - \\
\hline Eragilaria biceps ...... & - & $*$ & - & 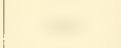 & & - \\
\hline "striatu.......... & - - & - & - & - & - & $\therefore$ \\
\hline "turgens & .. & $*$ & - & - & - & - \\
\hline Gillionella.............. & - & & - & - & * & - \\
\hline Ilimantidium Diodon?....... & - & * & - & - & - & - \\
\hline 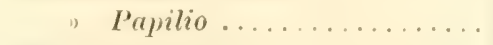 & - & $\therefore$ & - & - & - & 一 \\
\hline Kotpoda cucullus........ & - & - & - & - & - & $*$ \\
\hline
\end{tabular}




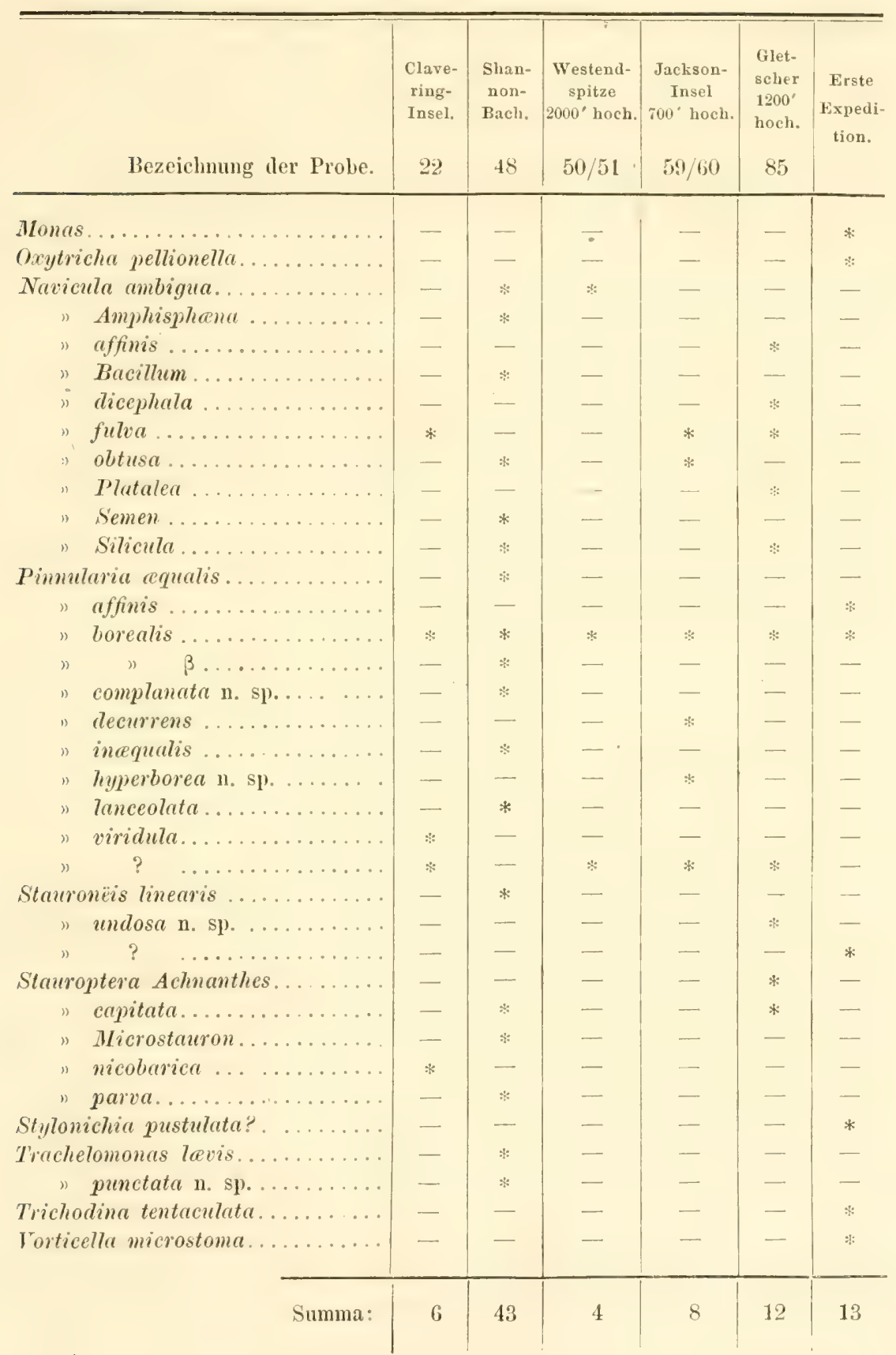




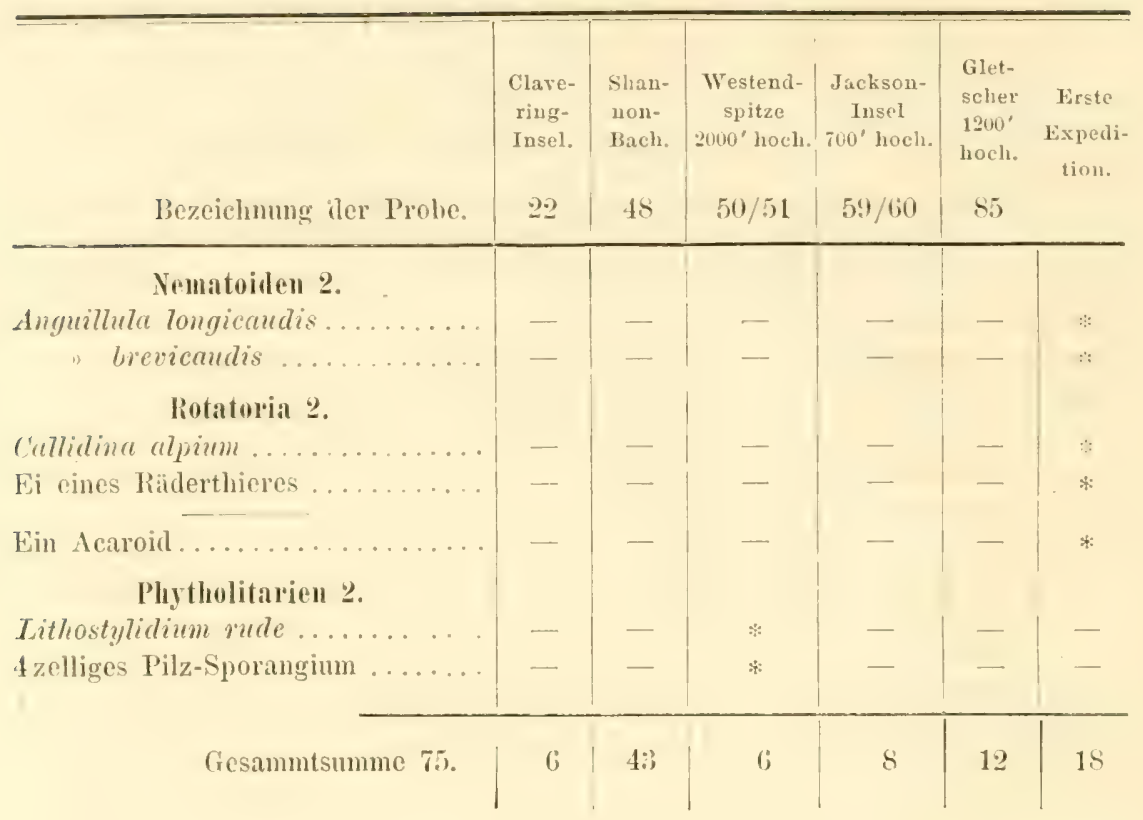

\section{Erklärung der Abbildungen.}

Die vier Tafeln Abbildungen sind dazu bestimmt, die Gestaltungen des mikroskopischen Lebens der Nordpolzone zur Anschaunng zu bringen, von welcher bisher nur sehr geringe Spuren erreichbar gewesen und deren massenhafte oceanische Tiefgrundverhältnisse doch jene überraschenden grossen Wirkungen hervorbringen, welche die reichliche Existenz der Walfische und anderer Formen der grössten und zahlreichsten Wirbelthiere den Menschen zur Benutzung stellt. Yon den 244 durch die beiden Polarexpeditionen zur Kenntniss gekommenen kleinsten Lebensformen bringen die vier 'Tafehn 129 zur Ansehanung und iibergehen die schon mannichfach abgebildeten und einige in dem Verzeichniss mit geringerer Sicherheit aufgestellten formen. I iese sämmtlichen Lebensbilder der Polarzone sind besonders in zwei Richtungen von allgemeinerem Einfluss füi die Naturbetrachtung.

Eine dieser liichtungen besteht darin, dass alle Formen unter sich direkt vergleichbar sind, weil sie bei gleicher Vergrösserung, 
gleichen Methoden und Beurtheilungen in Uebersicht gebracht sind, nicht aber durch verschiedenartige Auffassungen eine gleiche Beurtheilung ausschliessen. Die andere Richtung geht dahin, dass bei den zahlreichen Untersuchungen sowol der terrestrischen Oberflächen, als der oceanischen Tiefgründe sich das Resultat ergeben hat, dass ganz. besonders abweichende Gestaltungen sich ebenso wenig ergeben haben als neue Stoffelemente für das organische Leben. Die in meiner Mikrogeologie, 185̃4, angezeigten sechs Kategorien des allgemeinen Gestaltumgstypus haben sich atuch hier wiederholt als l'olythalamien, Polygastern, Polycystinen, Phytolitharien, Geolithien und Zoolitharien und ebenso sind kohlensaurer Kalls. Kienelsïnre und Fisen, sammt kohlenstoffigen organischen pflanzlichen Fragmenten das allein herrschende geblieben. Weder Talk noch Magnesia, noch auch flusssaurer Kalk und in keinem Falle Thonerde haben sich an den organischen Verhältnissen betheiligt erkennen lassen, ein Verhalten, wie es von allen übrigen Punkten der Erde durch Nachforschungen festgestellt werden konnte, ein Umstand, welcher fiir die Vorstellungen eines Eozoon und den damit verbundenen Talkverhältnissen von Gewicht ist.

Dass die genamnten sechs Abtheilungen, besonders die kieselschaaligen Polygastern und die Polycystinen noch auf mannichfache Weise zerspalten werden kömnen, ist selbstrerständlich und wird nicht ausbleiben, wie denn die Radiolarien ron den Polycystinen nenerlich abgetrennt wurden. Ich habe mich dieser Zersplitterung enthalten zu miissen geglaubt, welche nui mit wachsendem Material berechtigt werden mag. So ist auch über die Natur der Radiolarien der Zweifel ungelöst, ob sie ganz oder zum 'Theil zu den Spongien der Pflanzen oder zu den Thieren zu stellen sind, indem der Nachweis der mir denkbar gewordenen Thierstructur noch fehlt.

Der auf Tafel III beigefügte Maassstab fïr die Vergrösserungen ist derselbe für die Mikrogeologie und in allen frühern und nenern Darstellungen für 300malige Vergrösserung benutzte. Er zeigt auf der untern Linie in zwei Pariser Zoll Länge die einfache Normalvergrösserung an und in der obern Linie die Aberration meines Auges von dieser Norm, welche auch in diesen Zeichnungen gleiche Geltung gewomnen.

\section{Tatel I.}

\section{Kalkschalige Polythalamien der oceanischen Tiefgründe.}

Fig. 1. Aristerospira boreatis n. sp., 1. Exp., aus 510 und $198^{\prime}$ 'Tiefe.

2. Rotalia Hegemami n. sp., 2. Exp., ans 3414 ' 'Tiefe.

$\therefore$ Rotatia Iber, 2. Exp., efr. Microgeologie, 'Taf. XXV II B, Fig. 5, aus 3414 ' 'Tiefe. 
Fig. 4. Nonionina crystallina n. sp., 2. Exp., aus 7542' 'Tiefe.

5. Rotalia microtis 1 . sp., 2. Exp., aus $3414^{\prime}$ Tiefe.

6. Nonionina Koldeweyi n. sp., 1. Exp. = Dexiospiraboreatis n. sp., 1869 , aus 198 und $168^{\prime}$ 'Tiefe.

7. Megathyra dilatuta? 1. Exp., aus $510^{\prime}$ 'Tiefe.

8 und 9. Aristerospira Discus ${ }^{1}$, 2. Exp., aus 3414 ' 'liefe.

10 und 11. " cucullaris 11 . sp., 2. Exp., aus $7542^{\prime}$ 'Tiefe.

12. Strophoconus hyperboreus 11. sp., 2. Exp., aus 3414' 'Tiefe.

13. " arcticus n. sp., 2. Exp., aus 540' 'Tiefe.

14. Aristerospira corticosa 11. sp., 1. Exp., ans 198' Tiefe.

1.5. Rotalia gromtandica n. sp., 1. Exp., aus 450' 'Tiefe.

16. Megathyra Planularia, 2. Exp., aus 540' 'l'iefe.

17 und 15. Plemutina profunda n. sp., 2. Exp., ans 7800' Tiefe.

19. Nodosaria balcenarm n. sp., 1. Exp., aus 168' Tiefe.

Von diesen 19, zи 16 Arten gehörenden Polythalamien sind 12 als nene, nur der Polarzone bisjetzt zugehörige Arten benamnt. Aus iiber 1000 Fuss Tiefe sind folgende acht F'ormen: Rotalia Hegemami, Rotalia Tbex, Nonionina crystallina, Rotalia microtis, Aristerospira Discus, Aristerospire cucullaris, Strophoconus hyperboreus und Plamitina profunda. Nit gelblichen thierischen Weichtheilen erfiillte Formen sind Aristerospira borealis, Nonionina Koldeweyi, Aristerospira corticosa aus 168 - 510 Fuss Tiefe.

\section{Tafel II.}

Fig. 1. Diplonëis mesolia 11. sp., 2. Exp., aus 468' 'Tiefe.

2. "Entomon, 2. Exp., aus 540 und 18 ' 'Tiefe.

3. "Apis, 2. Exp., aus 18 'Tiefe.

"4-6. Himantidium Papitio, 2. Exp., rom Shannon-Bach der Shannon-Insel.

7-8. Eunotia prerupta, 2. Exp., vom Shannon-Bach.

9. Eunotia amphioxys, 2. Exp., vom Gletscher aus 1200' Höhe und rom Gletscherbach der Clavering-Insel.

10. Climacidium Zygodon n. sp., 2. Exp., rom Shamnon-Bach.

"11. "Monodon, 2. Exp., vom Shamnon-Bach.

"12-13. Striatella arcticu n. sp., 2. Exp., aus $18^{\prime}$ Tiefe ron der Sabine-Insel.

14. Amphora libyca, 2. Exp., aus 78 und $18^{\prime}$ 'Tiefe.

15. „ angusta, 2. Exp., aus 18' 'Tiefe, Sabine-Insel.

16. Coscinodiscus subtilis, 2. Exp, aus $7914,7800,3414,1344$ und 540' 'Tiefe.

17. " radiatus, 2. Exp., aus 7914, 7800 und 3414' Tiefe.

18. "eccentricus, 2. Exp., aus 7914 und 3414 'Tiefe.

"19. "Tineatus, 2. Lxp., ans 7914 und $7800^{\prime}$ 'T'iefe.

"20 und 23. Coscinodiscus minor, 2. Lxp., aus 7914, 7800 und 3414' Tiefe.

21. Coscinodiscus marginatus, 2. Exp., aus 7914' Tiefe.

22. "heterostigma n. sp., 2. Exp., aus $18^{\prime}$ Tiefe.

${ }^{1}$ Znerst 1861 in dex Davis-Strasse aus 9240/ 'Tiefe beobachtet (vgl. Monatsber. der Berliner Akademie, 1861, 1) 302). 
Fig. 24. Coscinodiscus centratis, 2. Exp., alls 3414' Tiefe; cfr. Microgeologie, Taf. XVIII, Fig. 39.

2.j. Stephanodiscus lineatus, 2. Exp., aus 7914 und $3414^{\prime}$ Tiefe.

26. Odontodiscus eccentricus, Fragm., 2. Exp., aus $3 \pm 14^{\prime}$ Tiefe.

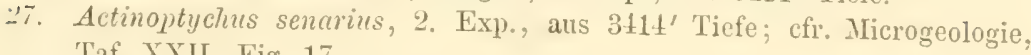
Taf. XXII, Fig. 17.

ㄱ. Craspedodiscus? Discoplea n. sp., 2. Exp., aus $18^{\prime}$ Tiefe, Sabine-Insel.

2!. Gallionella sulcata, 2. Exp., aus 7914 und 3414' Tiefe.

;". Stauronëis linearis, 2. Exp., vom Shannon-Bach.

:1. " undosa n. sp., 2. Exp., vom Gletscher aus $1200^{\prime}$ Höhe.

$\because 2$. Navicula Siticula, 2. Exp., vom Shannon-Bach uud vom Gletscher $1200^{\prime}$ hoch.

:3. Nevicula Amptistena, 2. Exp., rom Shannou-Bach.

"̈t. " ambigua, 2. Exp., rom Shamnon-Bach und aus 2000' Höhe.

3.). "Semen, 2. Exp., rom Shannon-Bach.

$\therefore$ if. " affinis, 2. Exp., rom Gletscher 1200' hoch.

:7. D Platalea juv., 2. Exp., vom Gletscher 1200' hoch.

ㄱ. 1) Bacillum, 2. Exp., rom Shannon-Bach.

3i). " Sigma, 2. Exp., aus $18^{\prime}$ Tiefe, Sabine-Insel.

4'. Stauroptera parta, 2. Exp., Shannon-Bach.

41. "Achnanthes, 2. Exp., Gletscher 1200' hoch.

42 und 43. Stauroptera capitata, 2. Exp., Shannon-Bach und Gletscher $1200^{\prime}$ hoch.

14. Stauroptera microstauron, 2. Exp., Shamnon-Bach.

4.;. " neptunia n. sp., 2. Exp., aus 540' Tiefe.

Hi. "nicobarica? 2. Exp., Gletscherbach auf der Clavering-Insel,

4. Cocconema gracite, 2. Exp., aus 18' Tiefe, Sabine-Insel.

14. "Leptoceros, 2. Exp., aus 18' Tiefe, Sabine-Insel.

4\%. „) comutum, 2. Exp., aus 18' Tiefe, Sabine-Insel.

." und 51. Cocconema cymbiforme, 2. Exp., auf 540 und $18^{\prime}$ Tiefe, SabineInsel.

i2. Pinmularia boreatis, 2. Exp., Shamon-Bach und Gletscherbach der Clavering-Insel.

i:. " boreatis $\beta$, 2. Exp., Shannon-Bach.

i.. " $\quad$ complanata n. sp., 2. Exp., Shannon-Bach.

i.) " aqualis, 2. Exp., aus 18' Tiefe, Sabine-Insel und Shamon-Bach.

if. " inaqualis, 2. Exp., Shannon-Bach.

.T. "glaciatis 11. sp., 2. Exp., aus $18^{\prime}$ Tiefe, Sabine-Insel.

.'s. " aspera, 2. Exp., aus 570, 468, 324 und 18' Tiefe.

i\%. "I Tunceolata, 2. Exp., aus 18' Tiefe und rom Shannon-Bach.

6!!. "viridula-Fragment, 2. Exp., von einer Scholle und von der Clavering-Insel.

61. Pimutaria hypertorea n. sp., 2. Exp., Jackson-Insel $700^{\prime}$ hoch.

1;2. " amphioxys, 2. Exp., 18' Tiefe, Sabine-Insel.

(j:). "macilenta, 2. Exp., 18' Tiefe, Sabine-Insel.

lit. Insilella? verticillata 11. sp., 2. Exp., von einer Scholle.

(ji). „ tenuis n. sp., 2. Exp., ans $7800^{\prime}$ Tiefe.

fif. Syndendrium tubiferum n. sp., 2. Exp., von einer Scholle. 
Diese Tafel und ein Theil der Tafel III umfasst die grosse Masse der Bacillarieen ron den terrestrischen Oberflächen und aus den oceanischen 'Tiefgrïnden ungetrennt.

\section{Tafel III.}

Fig. 1. Cocconëis granlandica 11. sp., 2. Exp., aus 18' Tiefe, Sabine-Insel.

2. " hyperborea, 2. Exp., ans 18' Tiefe, Sabine-Insel.

3. " striata, 2. Exp., aus 18' Tiefe, Sabine-Insel.

4. "Scutellum, 2. Exp., aus 18' Tiefe, Sabine-Insel.

5. Campylodiscus polaris n. sp., 2. Exp., aus $18^{\prime}$ Tiefe, Sabine-Insel.

6. "Sabinii 11, sp., 2. Exp., aus $18^{\prime}$ Tiefe, Sabine-Insel.

7. " radiosus, 2. Exp., aus 18' Tiefe, Sabine-Insel.

8. 1) radiosus-Fragment, 2. Exp., aus 18' Tiefe, Sabine-Insel.

9. Synedra spectabitis, 2. Exp., aus $18^{\prime}$ Tiefe, Sab.-Ins., mit grünem Inhalt.

10 und 11. Fragitaria pelagica n. sp., 2. Exp., aus $18^{\prime}$ Tiefe, Sabine-Insel.

12. Fragitaria acuta, 2. Exp., von einer Eisscholle.

13. " liceps, 2. Exp., rom Shannon-Bach.

" 14. Biblarium Lamina, Fragment, 2. Exp., von einer Eisscholle.

"15. Trachelomonas levis, 2. Exp., Shannon-Bach.

"16. " punctata n. sp., 2. Exp., Shannon-Bach.

" 17. Difflugia apiculosa n. sp., 2. Exp., Shannon-Bach.

18. "Shamoniana n. sp., 2. Exp., Shannon-Bach.

19. " subacuta n. sp., 2. Exp., Shannon-Bach.

20. " rectangularis 3,2 . Exp., Shamnon-Bach.

21. " microstoma, n. sp., 2. Exp., Shannon-Bach.

"22. "grontandica n. sp., 2. Exp., Shannon-Bach.

"23. " areolata, 2. Exp., Shannon-Bach.

"24. " cellutifera n. sp., 2. Exp., Shannon-Bach.

25. "Baiteyi $\beta$ polaris, Fragment, 2. Exp., aus 7914' Tiefe.

26. "Baiteyi $\beta$ polaris, 2. Exp., aus $7800^{\prime}$ Tiefe.

"27. "decora n. sp., 2. Exp., Shamnon-Bach.

28. " arctica n. sp., 2. Exp., Shannon-Bach.

29. Arcella boreatis n. sp., 2. Exp., Shannon-Bach.

"30. "laticeps n. sp., 2. Exp., Shannon-Bach.

31. " Textrix n. sp., 2. Exp., Shamnon-Bach.

32. " hyatina, 2. Exp., Shannon-Bach.

33. "Disphera? 2. Exp., Shanuon-Bach.

34. " Pyrum, 2. Exp., Shannon-Bach.

35. "gratimalensis, 2. Exp., Shannon-Bach.

\section{Tafel IV.}

\section{Polycystinen.}

Fig. 1. Eucyrtidium mutans n. sp., 2. Exp., aus 3414' 'Tiefe.

2 und 3. Eucyrtidium lineatum, 2. Exp., aus 3414' 'Tiefe.

4. Petalospyris?-Fragment, 2. Exp., aus 7914' Tiefe.

"5. Hatiomma? ursinum n. sp., 1. Exp., aus $312^{\prime}$ 'Tiefe. 
Phytolitharien.

Fig. 1;. Amplidiscus verticillatus, 2. Exp., aus 1512' Tiefe.

7. " bipileatus, 2. Exp., aus 3414' Tiefe.

$\therefore$ " $\quad$ anceps, 1. Exp., aus 1020' Tiefe.

$\therefore$ Spongotithis uncinata, 1. Exp., aus $1500^{\prime}$ 'Tiefe.

"11. "Heteractis, 2. Exp., aus 3414' 'Tiefe.

. 11. "PulsabuTum $\beta, 1$. Exp., aus $570^{\prime}$ Ticfe.

"12. "Pulsabutum, 2. Exp., aus 540' Tiefe.

"1.;. "Fustis, 2. Exp., aus 540' Tiefe.

"14. Solenoplea acicularis, 2. Exp., aus 7914' Tiefe.

1.j. Spongolithis obtusa, 2. Exp., aus 540' Tiefe.

16. "dentata, 2. Exp., aus $7800^{\prime}$ Tiefe.

17. "Caput serpentis, 2. Exp., aus 7800' Tiefe.

11. ") cenocephaĩa, 2. Exp., aus 3414' Tiefe.

19. "Clavus, 1. Exp., aus 1020' Tiefe.

"). " septata? 2. Exp., aus 18' Tiefe, Sabine-Insel.

1. " bifrons n. sp., 1. Exp., aus $270^{\prime}$ Tiefe.

22 und 23. Spongotithis aspera, 2. Exp., aus 3414 und 540' Tiefe.

\section{Geolithien.}

Fig. 24. Actinolithis Triactis n. sp., 2. Exp., aus $18^{\prime}$ Tiefe, Sabine-Insel.

Zoolitharien.

Fig. 25 und 26. Coniodendron Amphidiscus n. sp., 1. Exp., aus 270' Tiefe. 



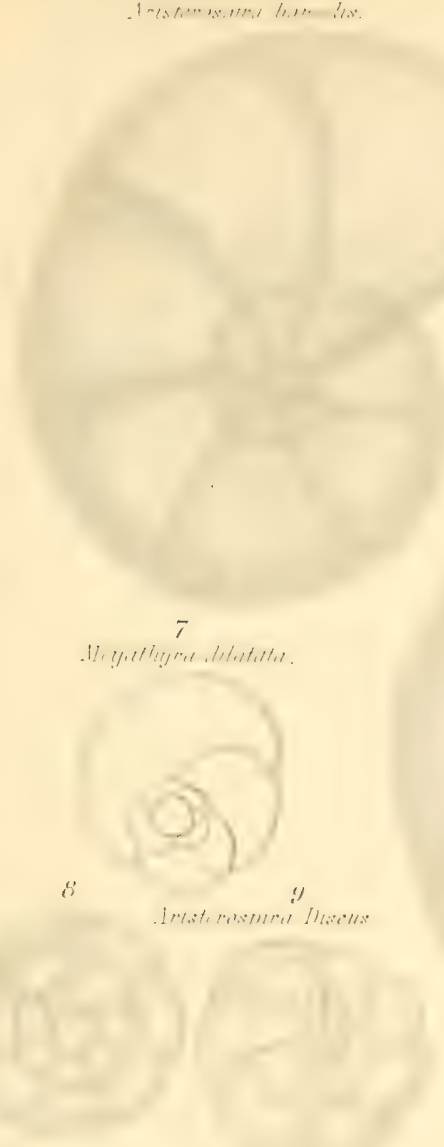

1.5

Ristuliue tremlandlint

16

Alegathyra Plamularia

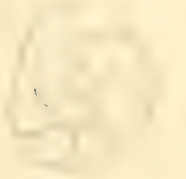

$17 \quad 18$

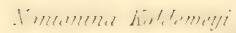

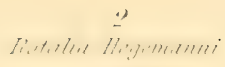

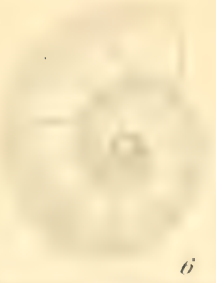

$i$

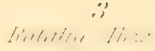

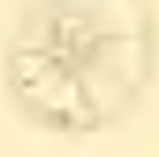

lamianiun inyshallinu.

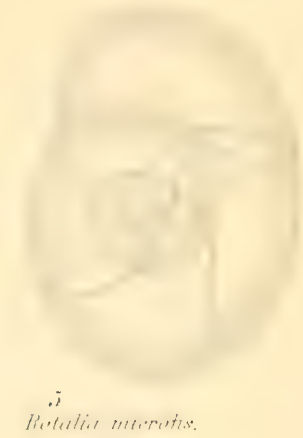

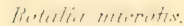

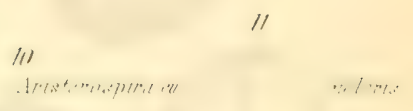

II)

Strophocomes

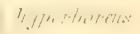

1:3 Siropherimus areticus.

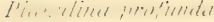

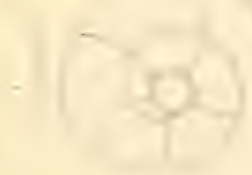

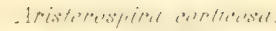

$\therefore$

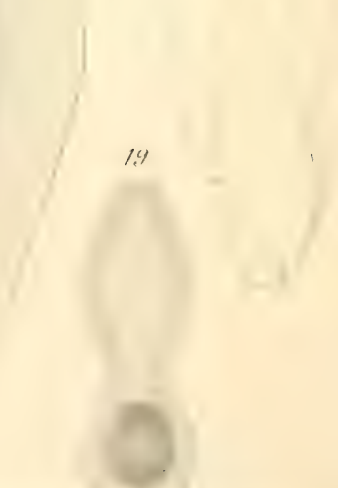


, 
ZO0L,0GJL, 15. Bacillaricen 'TiL' II
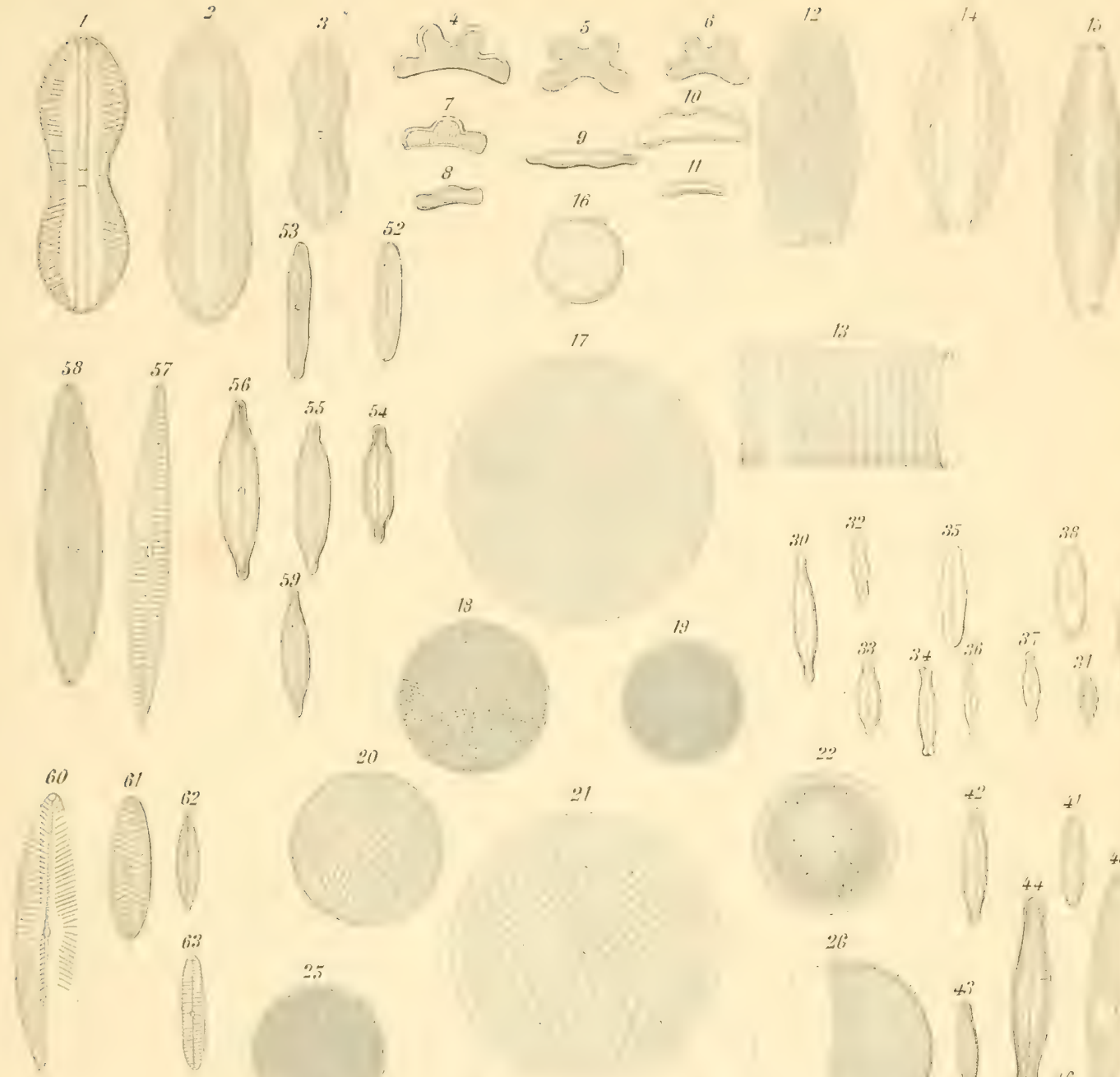

20
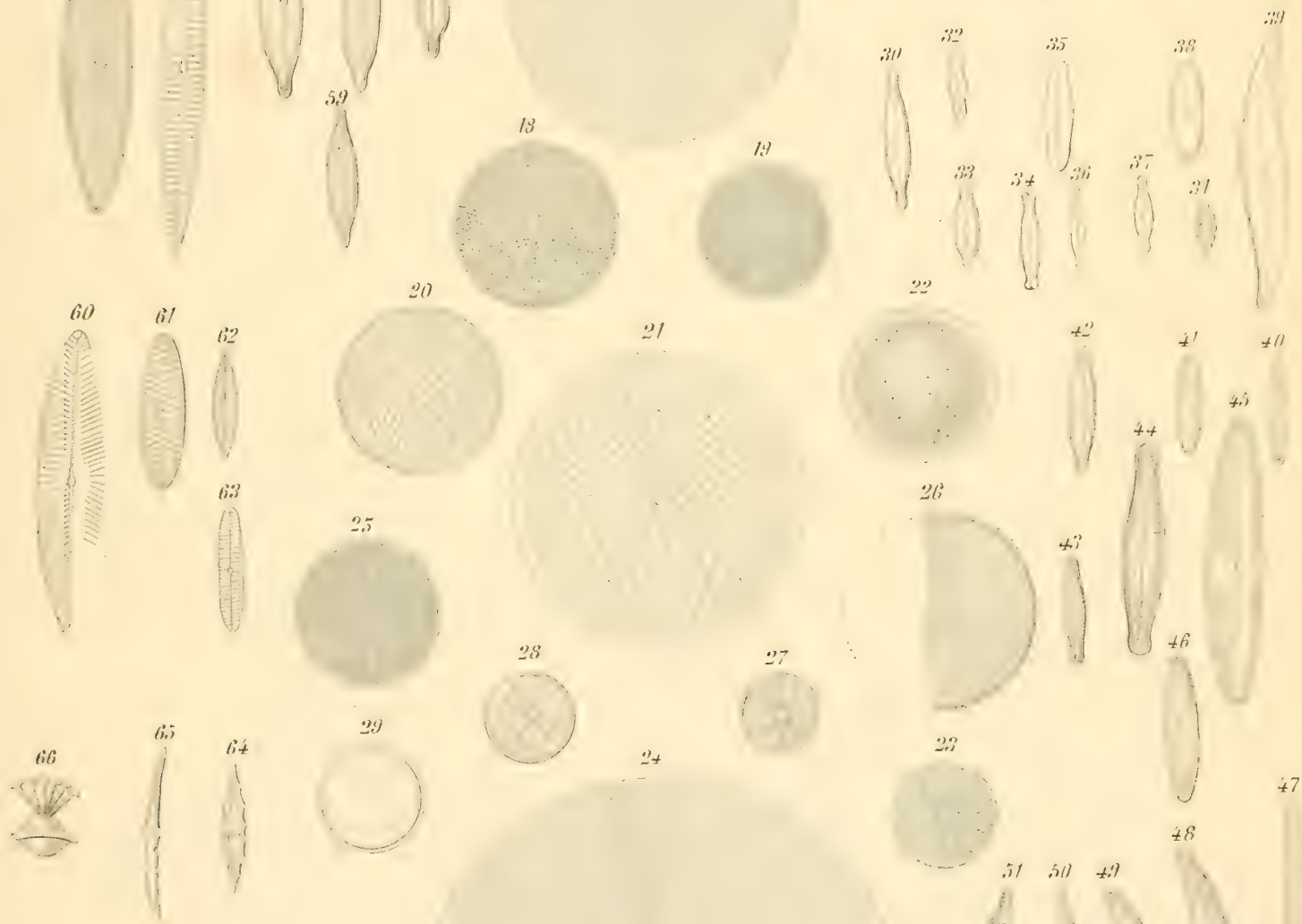

29
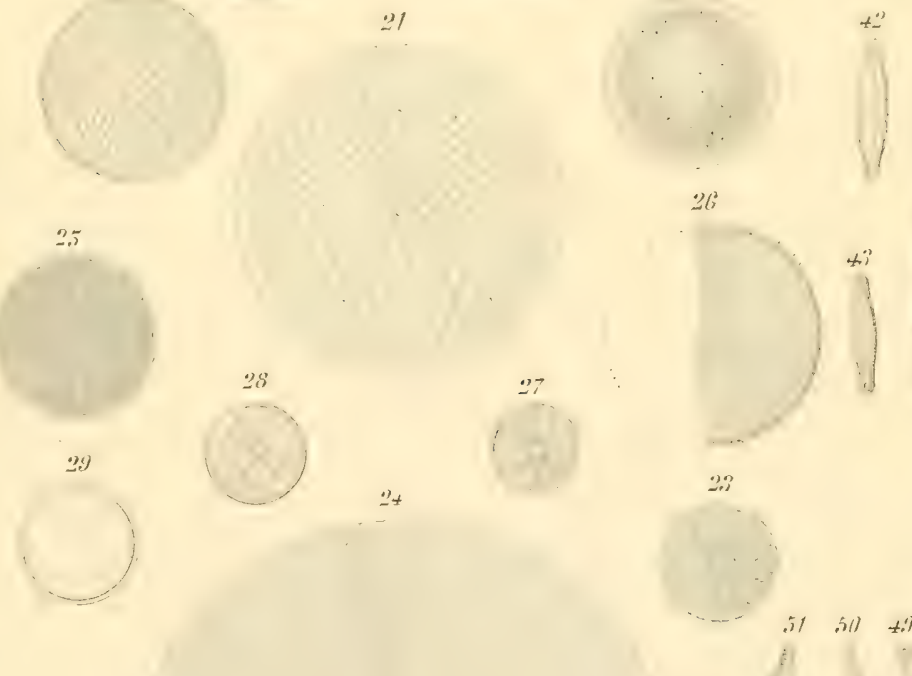

$26^{2}$
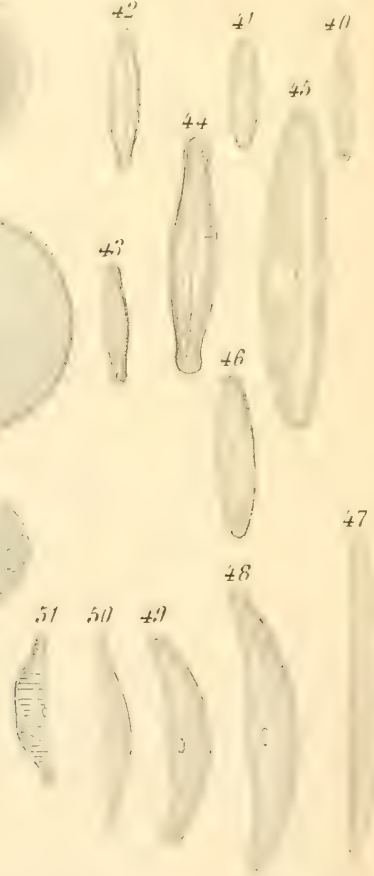

1-3.Diplonëts. 4-ti. Himuntutium.

7-2. Eunatia. 10-11. Climacidium.

12-13. Striatella 14-15. Amplinora.

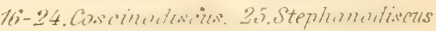

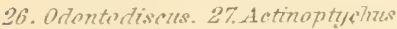

30-31 staumonizs. "32-39. Taviculn.

28. Craspedadiscus. 29. (ratlionella.

52-6i3 piñzlaria 64-6.5. Insitella

$40-46$. Stazropteriz, 47-.51. cocconema.

bifi. Sizndendrium. 

Bacillaricen.

Cryptomonadinèn.

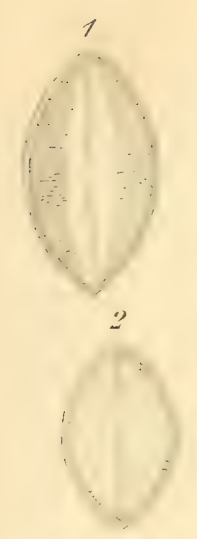

17
5
5
5
5
5
5
5
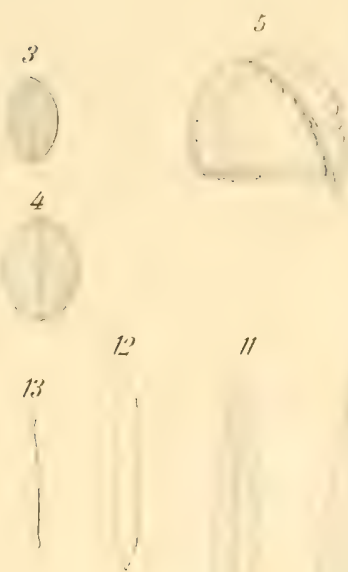

13

13

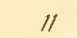

(I)

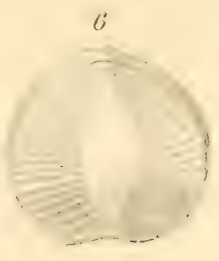

Areellinen.
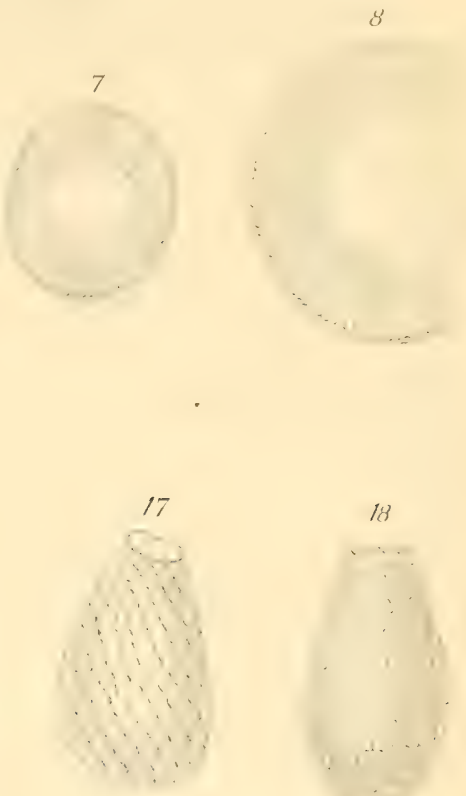

18

?
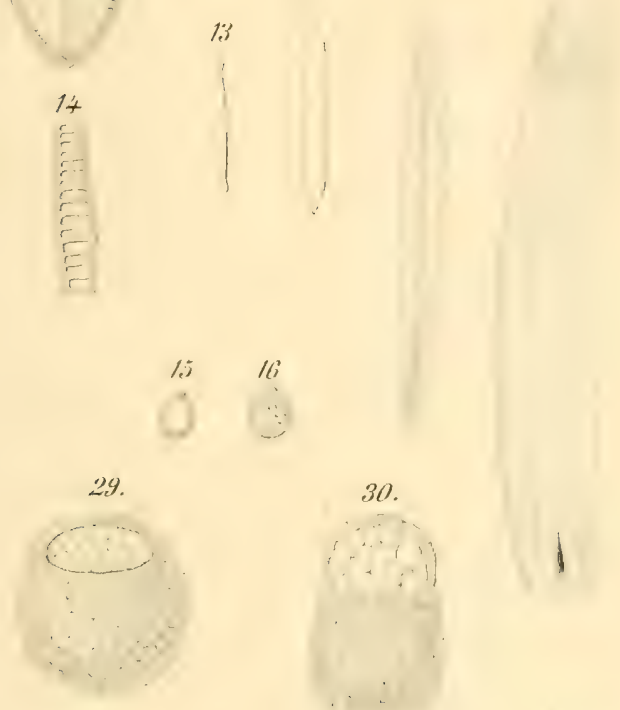

30.

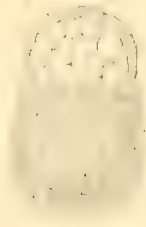

1
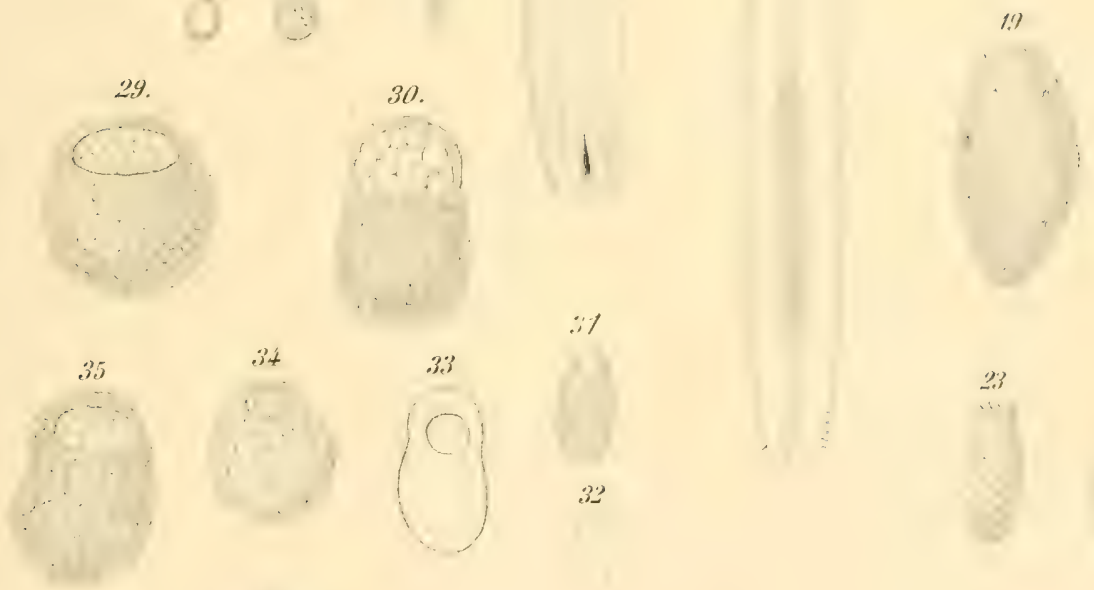

20

28
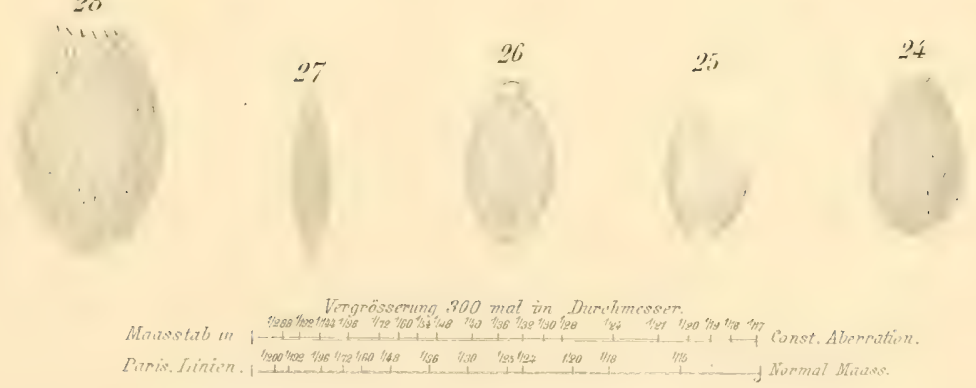

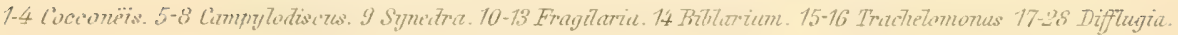
$29-35$-Arcella. 

Z00L00IF.,15.Geoliflien Taf.IV.

Polycystinen. Spongolithe. Geolithien. Coniolithe.

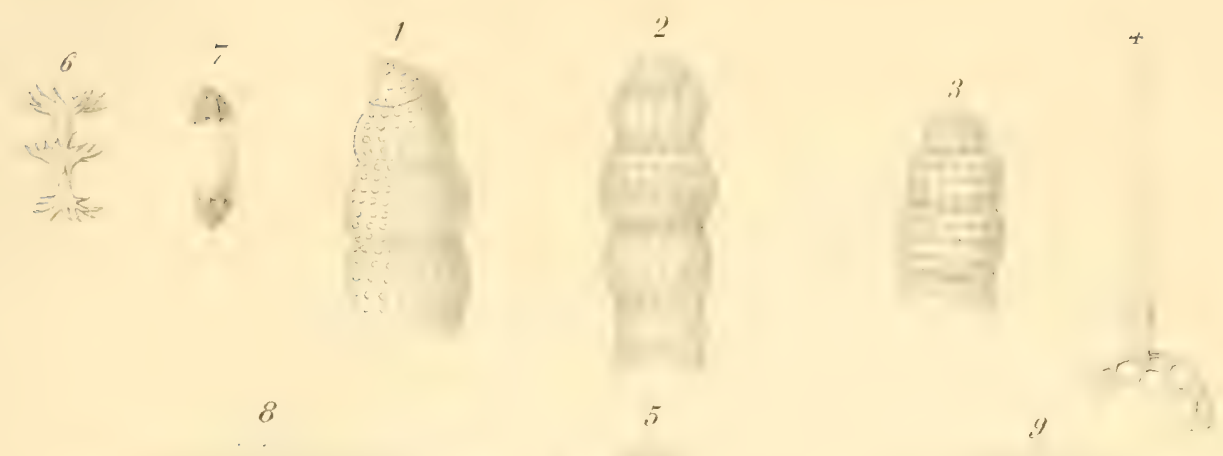

13

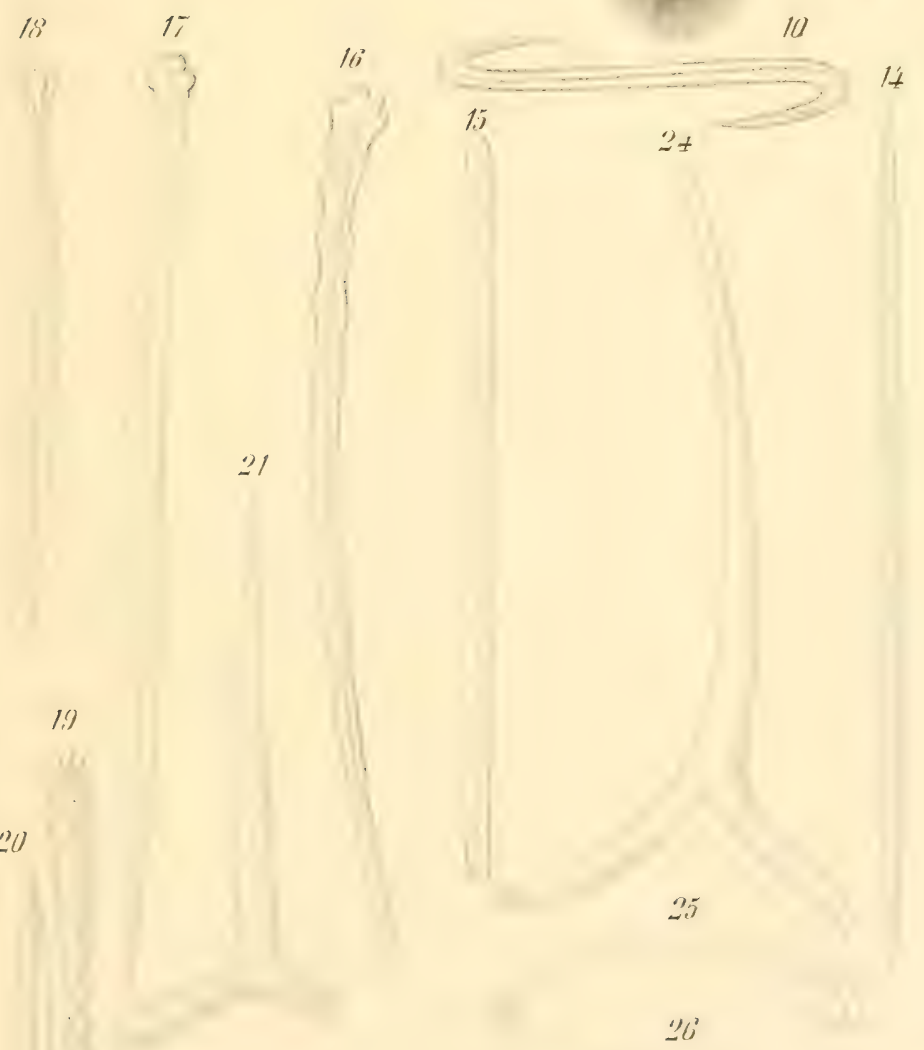





\title{
DIE ZWEITE
}

\section{DEUTSCHE NORDPOLARFAHRT}

\author{
IN IDEN JAHREN 1869 UND $180^{\circ}$
}

UNTER FÜHRUYG DES KAPITÄN KARL KOLDEWEY.

\author{
HERAUSGEGEBEN
}

VON DEM

VEREIN FÜR DIE DEUTSCHE NORDPOLARFAHRT IN BREMEN.

ZWEITER BAND.

WISSENSCHAFTLICHE ERGEBNISSE.

MIT 31 TAFELN IN LITHOGRAPHIE UND KUPEERS'ICH

UNI) : LITHOGRAPHIRTEN KAR'TEN.

ERSTE ABTHEILUNG.

LEIPZIG :

F. A. BRO C K H A US. 


\section{Inhalt der ersten Abtheilung.}

I. Botanik.

Torwort

Seite

Vorbemerkung

1. Ḱlima und PHanzenleben auf Ostgrönland. Bearbeitet von Dr. AdowF PANscir in Kiel

2. Gefässpflanzen. Bearbeitet von Professor Dr. Franz Buchexau und Dr. Wilfelas Olbers Focke in Bremen .......................... 12

3. Laubmoose. Bearbeitet von Professor Dr. Kard Mülder in Halle a. d. S. 62

4. Flechten. Bearbeitet von Professor Dr. G. W. Köpber in Breslau ...... 75

5. Algen. Bearbeitet von Oberfinanzrath G. ZELLER in Stuttgart .......... 83

6. Pilze. a) Fleischpilze. Bearbeitet ron Regimentsarzt Dr. H. F. Boxorden in Herford.

b) Endophytische Pilze. Bearbeitet von L. Fuckes in Oestrich (Rheingau).

7. Treibhölzer. Bearbeitet von Professor Dr. Gregor Kraus in Erlangen...

S. Einige Bemerkungen ïher Alter und Wachsthumsverhïltnisse ostgrönlänclicher IIolzgewächse. Bearheitet ron Professor Dr. Gregor línal's in Erlangen.

\section{Zoologie.}

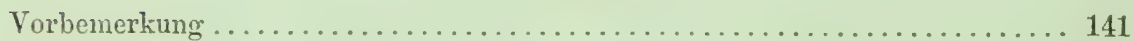

1. Anthropologie. Bearbeitet von Dr. Adolf PANsci in Kiel ............. 144

2. Sïugethiere und Fische. Bearbeitet von Professor D1. W. Peters in Berlin. 157

ஆ. Bemerkungen über die Schädel der Eskimohunde. Bearbeitet von Henus

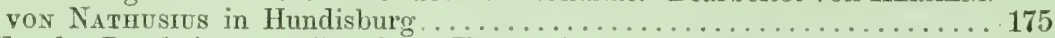

4. Vögel. Bearbeitet von Dr. Oтто Finscr in Bremen. Mit Noten von Dr. Adolf Pansch in Kiel

5 . Fier. Bearbeitet von Professor Dr. Alprop Nes

6. Tunicat Bearbeitet

7. Mollusken, Würmer, Echinodermen und Coelenteraten. Bearbeitet von

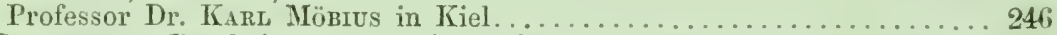

8. Crustaceen. Bearbeitet von Professor Dr. R. Bucriouz in Greifswald ... 262

9. Arachniden. Bearbeitet von Dr. L. KocH in Nürnberg.............. 400

10. Hymenopteren und Dipteren. Bearbeitet von Dr. A. Gerstäcken in Berlin. Mit Noten von Dr. Adolf Pansch in Kiel ...................... 404

11. Lepidopteren. Bearbeitet von Hauptmam Alexanden von Honerer in

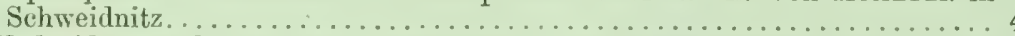

12. Hydroiden und Bryozoën. Bearbeitet von Bürgermeister Dr. G. H. Kirchenpauer in Hamburg . . . . . . . . . . . . . . . . . . . 411

13. Kieselspongien. Bearbeitet von Professor Dr. OsKar Scmind in Strassburg. 429

14. Kalk - und Gallertspongien. Bearbeitet von Professor Dr. E. Haecked

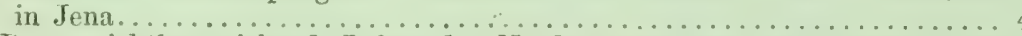

15. Das unsichtbar wirkende Leben der Nordpolorzone am Lande und in den Meerestiefgründen bei $300 \mathrm{mal}$ verstärkter Sehkraft, nach Materialien der Germania erlïutert von Geheimrath Professor Dr. C. G. Linnenetior in Berlin.

\section{Abbildungen.}

\begin{tabular}{l|l} 
Lithographien. Seite & Kupferstiche. Seite
\end{tabular}

Botanik 6. Pilze 'Taf. I. ....... 96 Zoologie 7. Mollusken etc. Taf. I. 260

Zoologie 2. Siugethiere und Fische Taf. I. .

Säugethice und Fische

Taf. II. ........... 174

" 8. Crustaceen Taf. $\mathrm{I}-\mathrm{XV}$.

9. Arachniden » I. . 402

13. Kieselopongien " I.. 432

15. Polythalamien » I. 468

15. Bacillarieen " II. . 468

15. Polygastern "III. . 468

15. Geolithien "IV. 468 


\section{Zur Nachricht.}

Die zweite Abtheilung (Schluss) dieses zweiten Bandes hefindet sich bereits unter der P'resse und wird der vorliegenden ersten Abtheilung bald folgen. Sie enthält:

\section{Geologie.}

Vorwort von Professor D1: F'erdinand vox Hocusteter in Wien.

1. Geologie Ostgrönlands zwischen dem 73- $\mathbf{7 6 ^ { 0 }}$ nördl. Br. (Mit einer geologischen Kartenskizze.)

a) Allgemeine Uebersicht der geologischen Beschaffenheit Ostgrönlands. Bearbeitet von Dr. Franz 'Toula in Wien.

b) Specielle Darstellung der geologischen Verhältnisse Ostgrönlands. Bearbeitet ron Dr. O. LENz in Wien.

2. Beschreibung mesozoischer Versteinerungen von der Kuhn-Insel. Bearbeitet von Dr. I'ranz 'Toula in Wien. (Mit 2 lithographirten 'Tafeln.)

3. Analysen einiger Gesteine aus Ostgrönland. Aus dem Laboratorium des Professor A. BAUER am k. $k$. polytechnischen Institute in Wien.

4. Pflanzenversteinerungen. Bearbeitet von Professor Dr. Oswald Heer in Zürich. (Mit 1 lithographirten Tafel.)

\section{Meteorologie und Hydrographie.}

Vorwort von W. von FreEden, Director der Deutschien Seewarte in Hamburg.

1. Einleitung. Von Dr. C. Börgen in Leipzig und Dr. Ralph Copeland in Parsonstown.

2. Lufttemperaturen. Von Kapitän Kard Koldewey in Hamburg.

3. Winde und Wetter. Von Demselben.

4. Luftdruck. Von Demselben.

5. MTeerestemperaturen und Strömungen. Von Demselben.

6. Ebbe - und Flutbeobachtungen. Von Demselben.

7. Aräometerbeobachtungen. Yon Dr. C. BörGEN in Leipzig.

Karte zur Uebersicht der Reisen des Expeditions-Schiffs Germania in den Jahren 1869 und 1870, mach den Aufnahmen derselben und mit Benutzung der ältern Quellen entworfen und gezeichnet auf der norddeutschen Seewarte. Massstab $1: 500000$.

\section{Astronomie, Geodaesie und Erdmagnetismus.}

Vortwort von Dr. Börgen und Dr. Copeland.

1. Geographische Ortsbestimmungen, von Dr. Börgen und Dr. Coperand.

2. Recognoscirung für eine Gradmessung in Ostgrönland, von Dr. BörGex und Dr. Copeland. (Mit 1 Karte.)

3. Magnetische Beobachtungen, von Dr. Börgex. (Mit 3 Tafeln.)

Die zweite Abtheilung (Schluss) des ersten Bandes liam erst nach der vorliegenden ersten Abtheilung des zweiten Bandes erscheinen, wird aber voraussichtlich schon im Februar 1874 atusgegeben werden können. 

. 


